


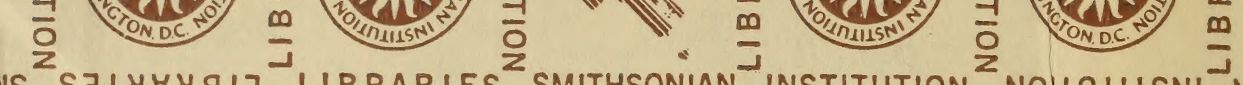

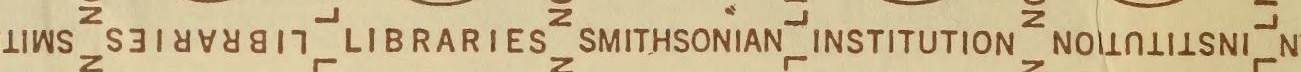
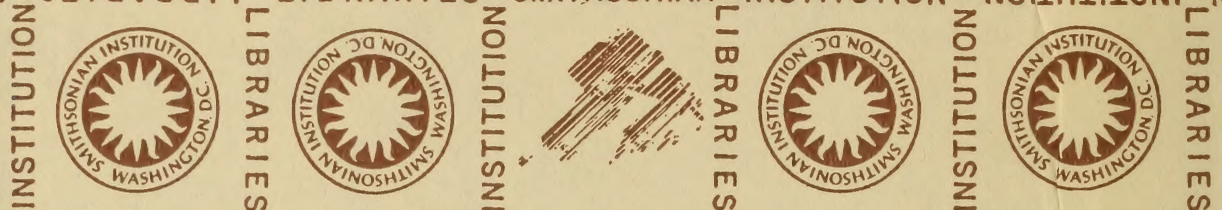

NIAN INSTITUTION NOILNIIISNI
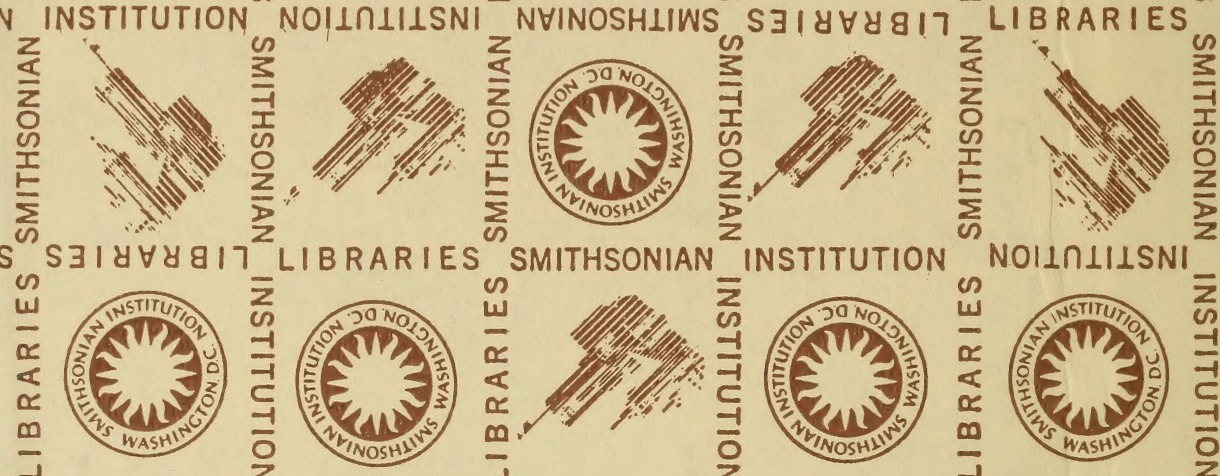

SMITHSONIAN

INSTITUTION

NOILIIISNI

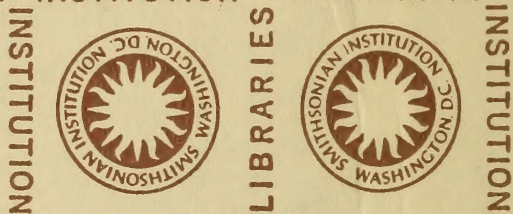

INIAN INSTITUTION NOILIIILSNI NHINOSHLIWS
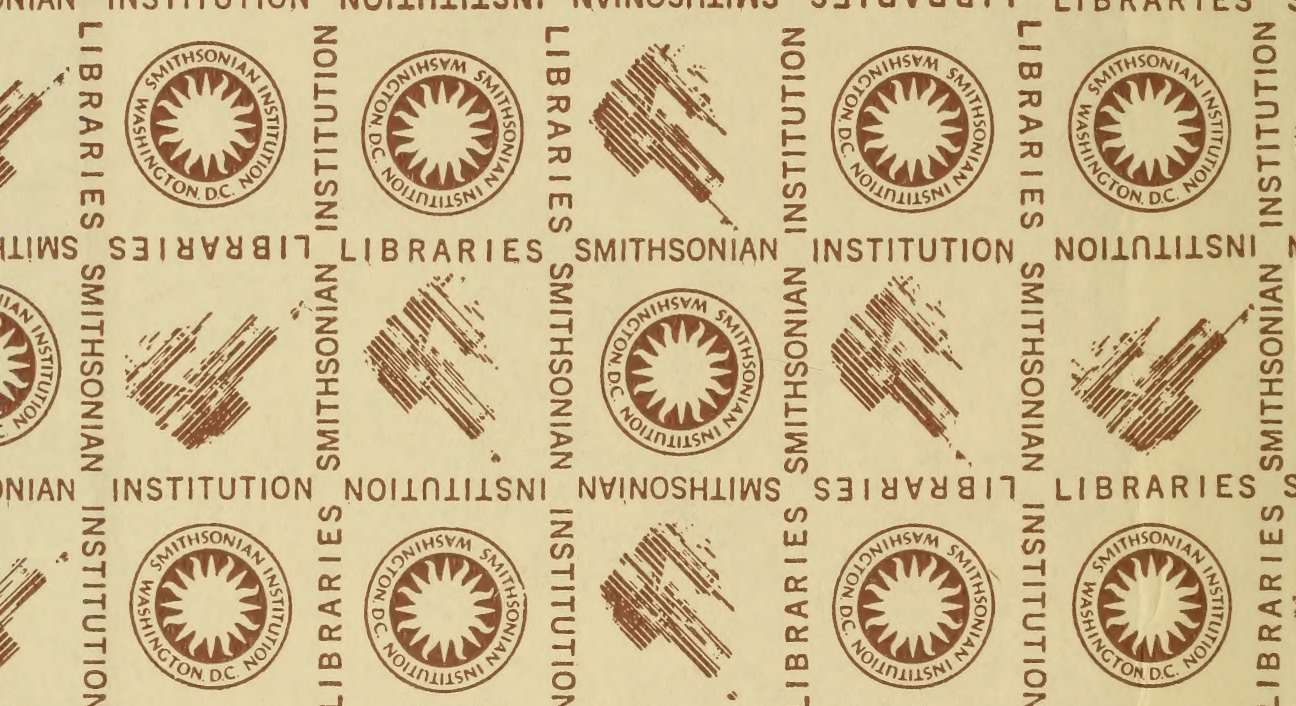

,
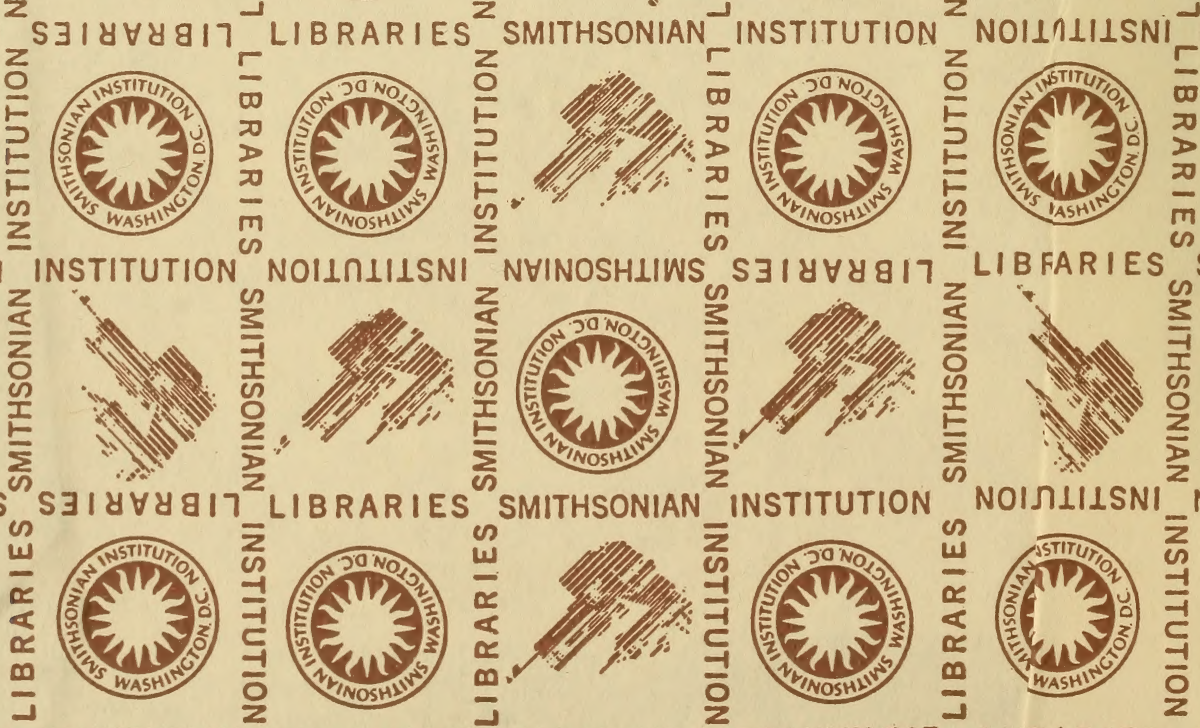


\section{-7 \\ — \\ (ivis) \\ 夏

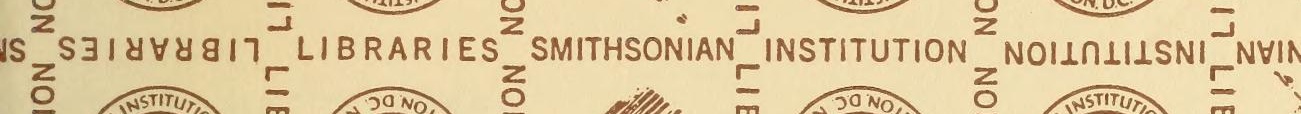
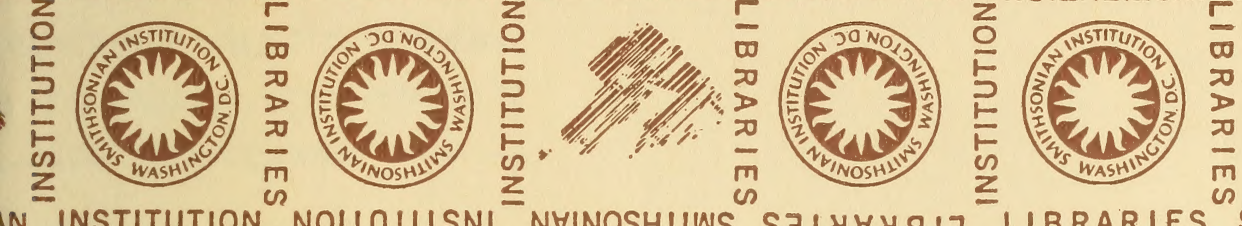
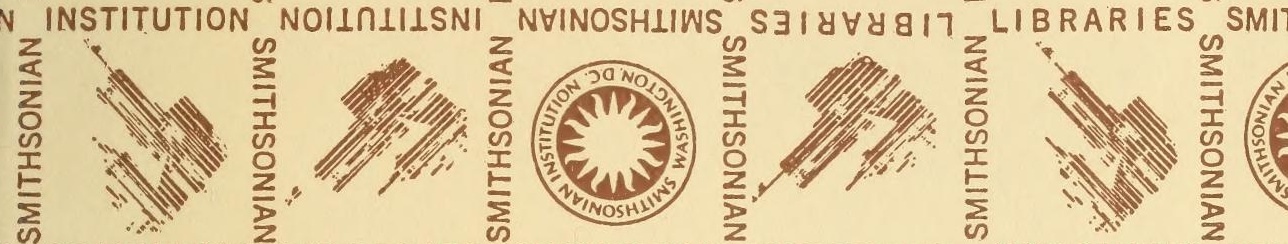

IS S 31 Y $84917^{2}$ LIBRARIES SMITHSONIAN
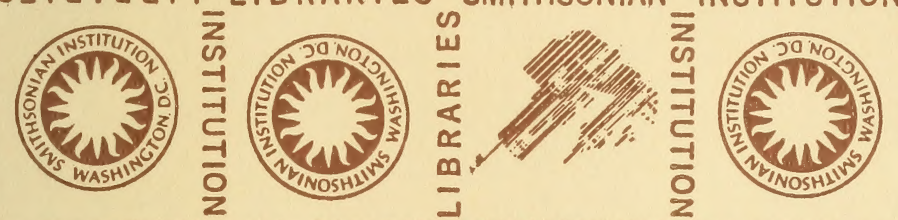

NOILNIIISNI NHII
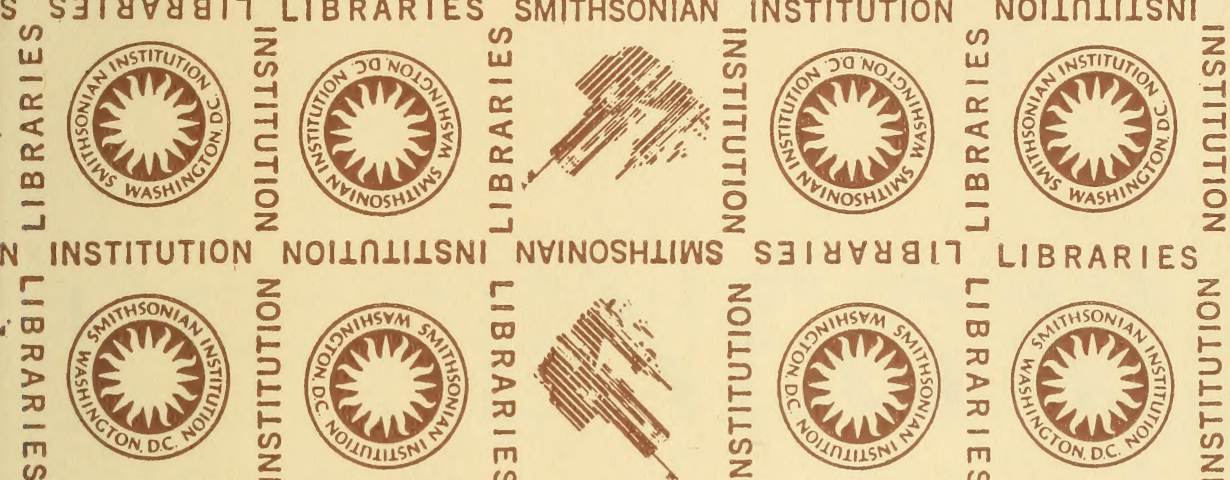

NYINOSHLIWS
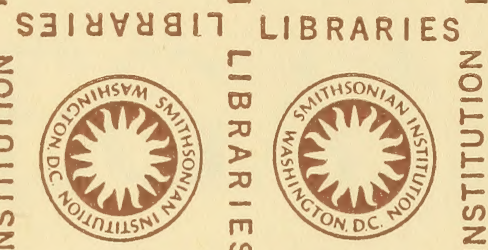

SMI
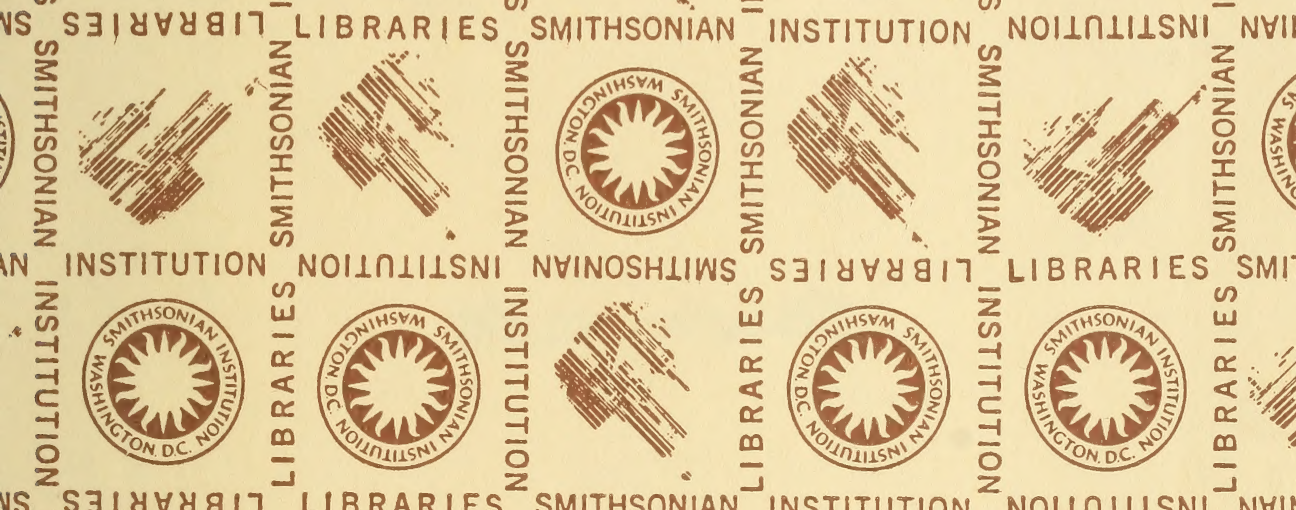

LIBRARIES SMIT
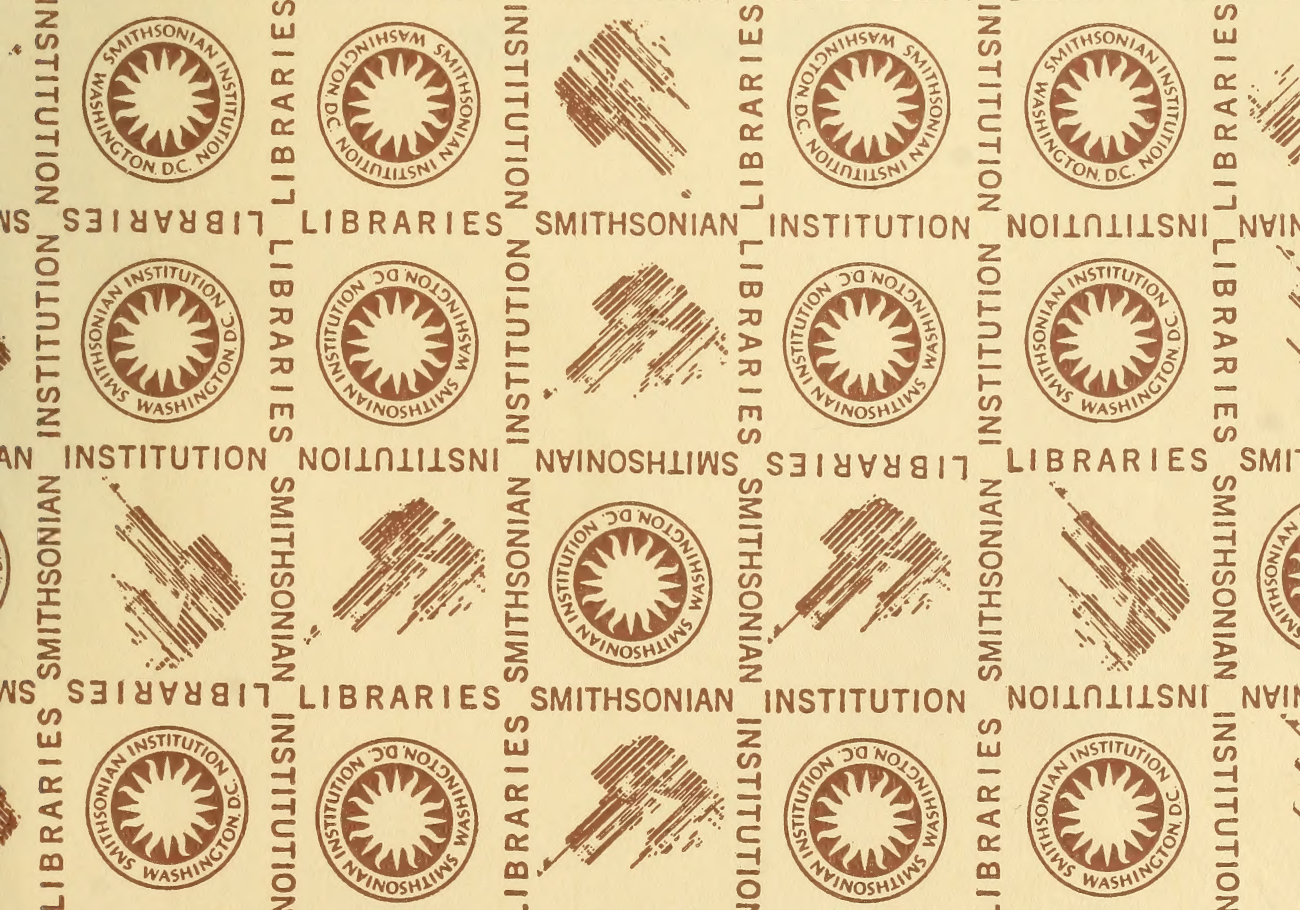

NOILIIISNI NHII

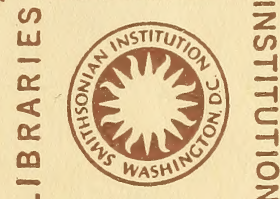



ПUVERNEMENT GÉNÉRAL

L'AFRIQUE OCCIDENTALE FRANÇAISE
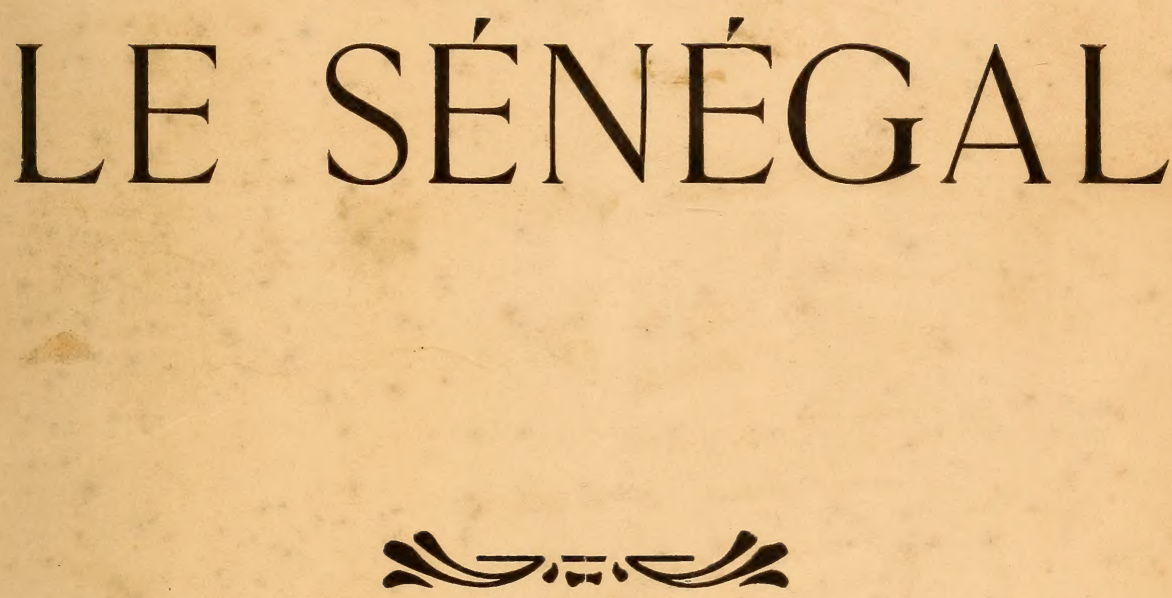


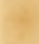

춯

al

× as.

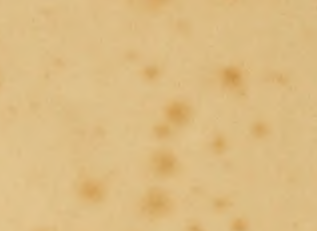

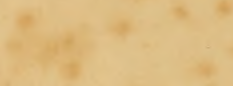

3

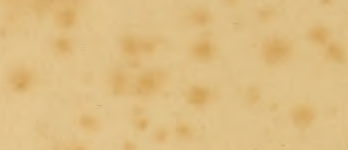

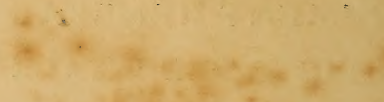

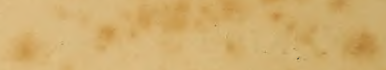

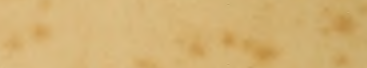
20

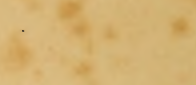

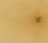
$x^{2}$ thes

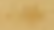
ie $\rightarrow z$

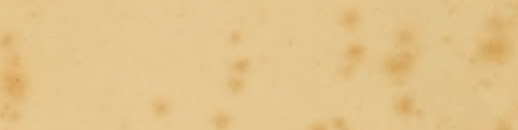

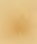

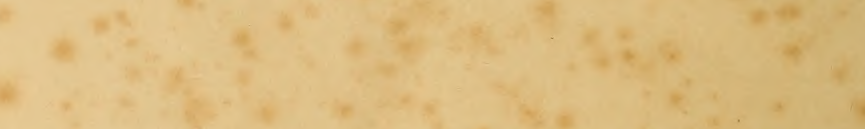
$x^{2}+2 x+3$

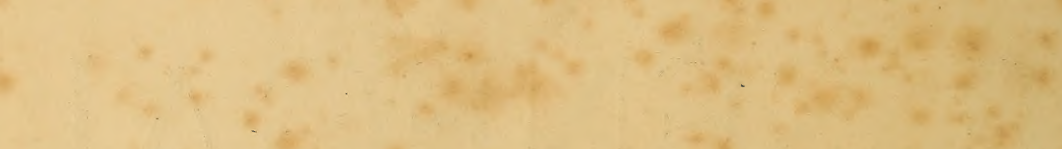

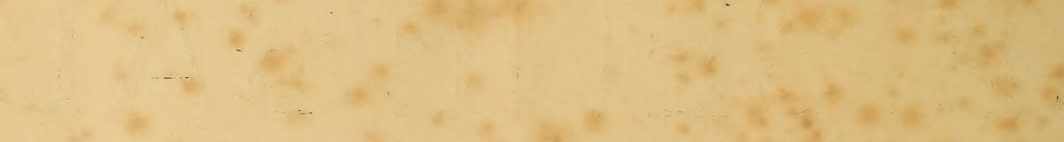

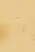

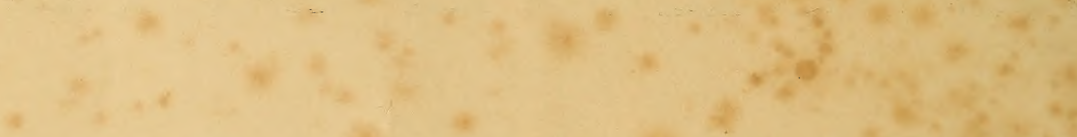

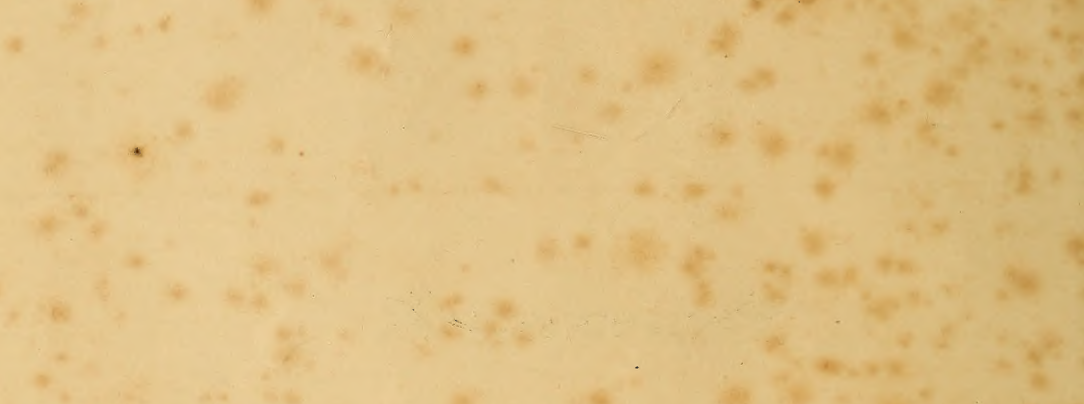

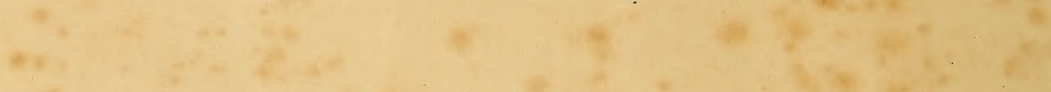

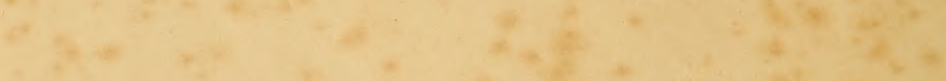

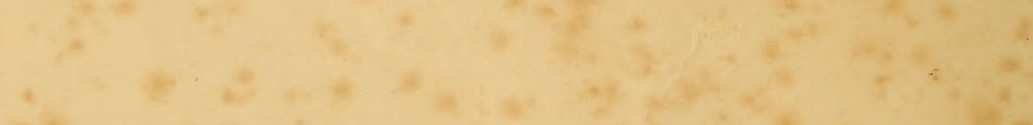

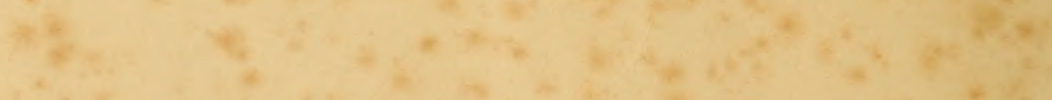

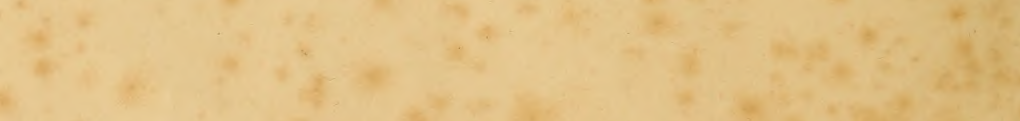

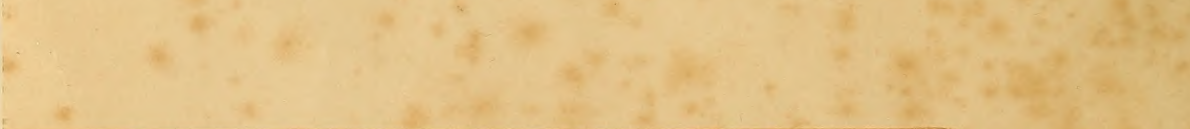



$+2$

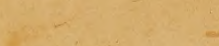

$-$

vills

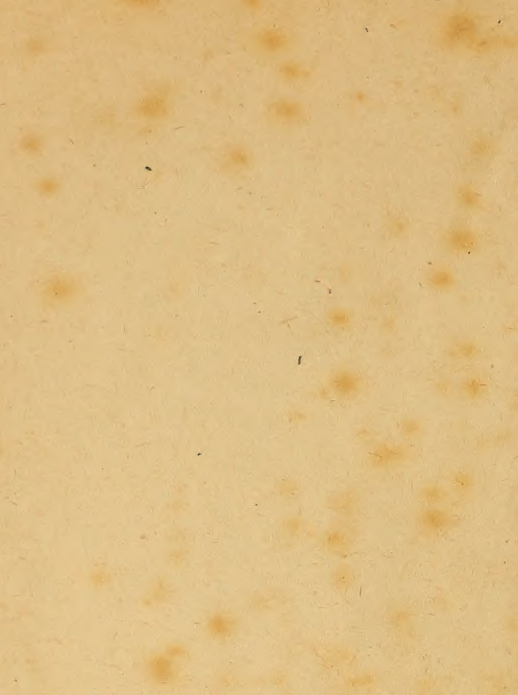

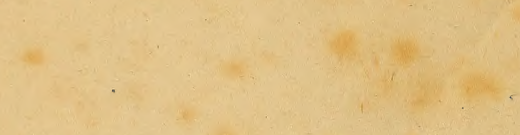

(1)

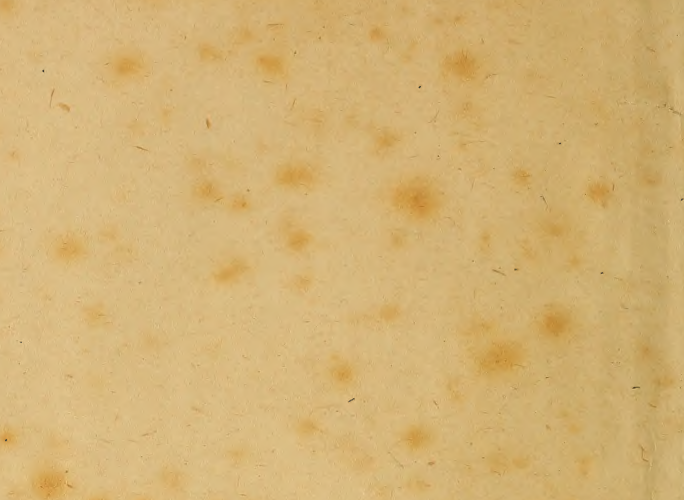

$\sqrt{3} \cdot 1-$

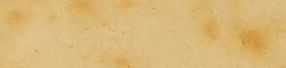

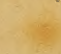

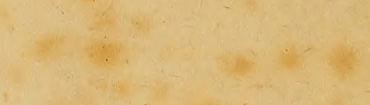

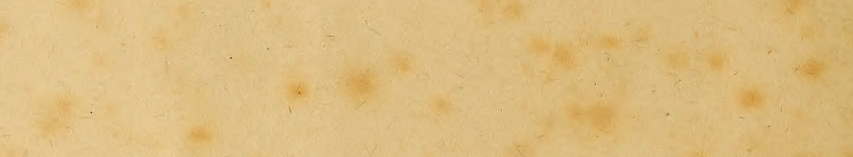

(20)

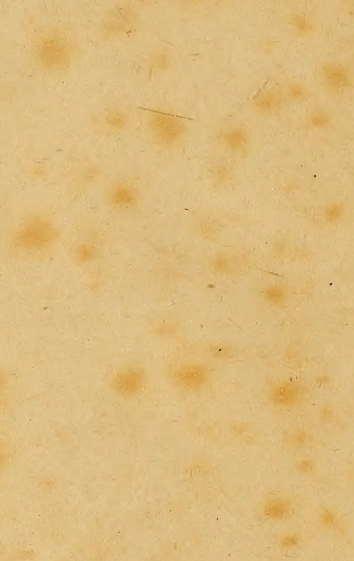

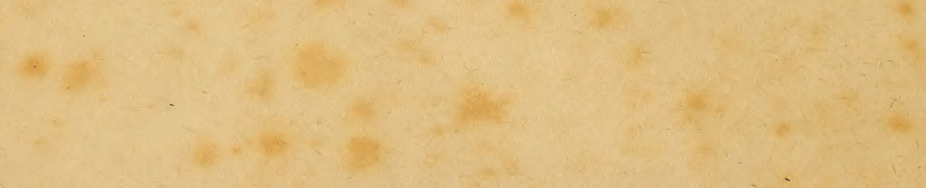

$-1$
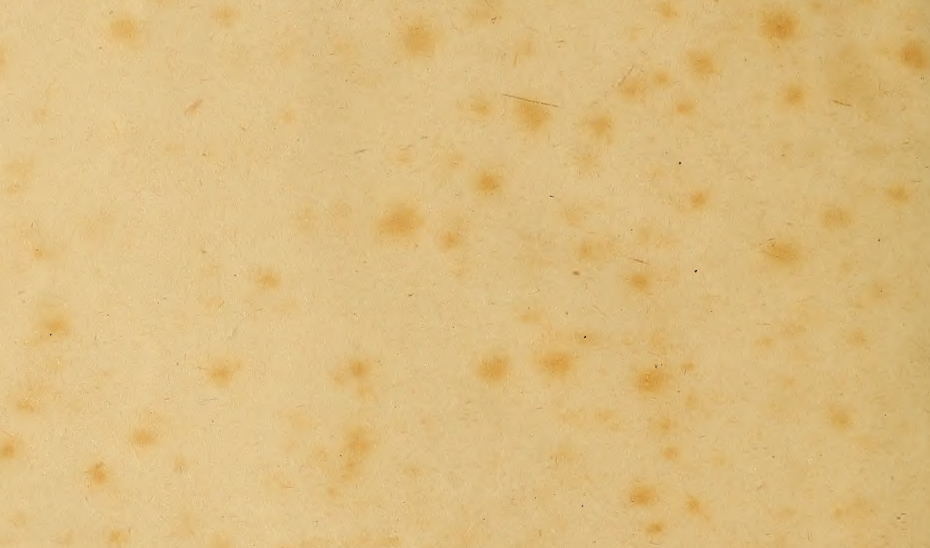

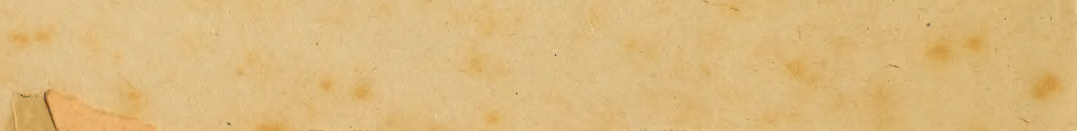

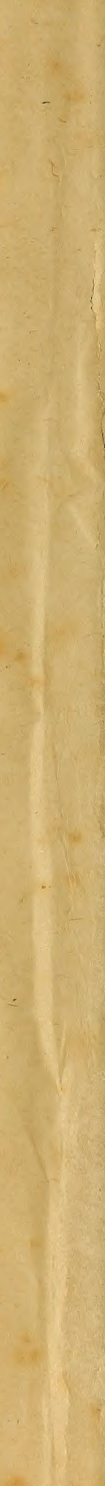




\section{LE SÉNÉGAL}




\section{A LA MÊME LIBRAIRIE}

\section{NOTICES}

\section{Publiées}

par le Gouvernement Général de l'A frique occidentale française à l'occasion de l'Exposition coloniale de Marseille.

La Guinée, par M. F. Rouget . . . . . . . . . . 7.50

Le Haut-Sénégal et Niger . . . . . . . . . . 7.50

Les chemins de fer en Afrique occidentale française :

I. - Dakar à Saint-Louis . . . . . . . . . 3.50

II. - Haut-Sénégal. - De Kayes au Niger. . . . . . 3.50

III. - Guinée, Côte d'Ivoire, Dahomey . . . . . . 3.50

La Côte d'Ivoire . . . . . . . . . . . . . 7.50

Le Dahomey. . . . . . . . . . . . . . . . . . 7.50

Les Postes et Télégraphes . . . . . . . . . . . . . . . . 3.50

L'Enseignement, par M. Lemée. . . . . . . . . . 2 ”

Service médical au Haut.Sénégal et Niger . . . . . . . 1 ”

Service météorologique . . . . . . . . . . . 1 ”

Le Sénégal, par M. M. Olivier . . . . . . . . . . 7.50

L'Afrique occidentale française, par M. G. François . . . 7.50

Toutes ces notices (format in- $8^{0}$ raisin) sont accompagnées de nombreuses reproductions photographiques. 
GOUVERNEMENT GÉNÉRAL DE L'AFRIQUE OCCIDENTALE FRANÇAISE AT

\section{NOTICES}

PUBLIÉES PAR LE GOUVERNEMENT GÉNÉRAL

A L'OCCASION

de l'Exposition Coloniale de Marseille
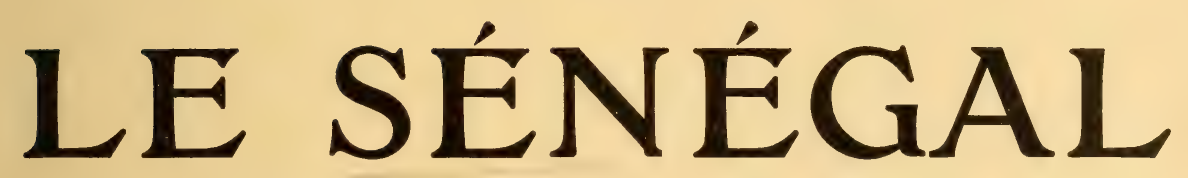

P A R

\section{Marcel OLIVIER}

Rédacteur au Ministère des Colonies

PAR IS

ÉMILE LAROSE, LIBRAIRE-ÉDITEUR

11, RUE VICTOR COUSIN 



\section{PREMIËRE PARTIE}

\section{L'EXPANSION COLONIALE FRANCGASE AU SÉNÉGAL}





\section{CHAPITRE PREMIER}

LA PRise de pOSSESSion ET L'OCCupation côttière (1626-1848)

Premières expéditions au Sénégal. - Si les Français ne s'établirent d'une manière définitive au Sénégal que dans le courant du xvi ${ }^{\mathrm{e}}$ siècle, cette partie de la côte occidentale d'Afrique avait particulièrementattiré les négociants de Dieppe et de Rouen, qui dès la fin du $\mathrm{xvi}^{\mathrm{e}}$ siècle, $\mathrm{y}$ faisaient un commerce assez suivi : aussi bien s'y étaient-ils portés surtout depuis que les Portugais les avaient chassés de leurs établissements de la Guinée.

Est-il besoin de rappeler les explorations que firent déjà au XIve siècle sur la côte occidentale d'Afrique les marins dieppois et rouennais, atteignant, après avoir - et non sans difficulté franchi le Cap Noun aux abords dangereux, le Cap Vert. et mouillant devant Rio Fresco, dans une baie qui portait encore le nom de baie deFrance, lorsque Villault de Bellefond y passa en 1666 ? Pendant le règne de Charles $\mathrm{V}$, les documents historiques ne mentionnent-ils point l'annuelle expédition entreprise vers les côtes de Guinée, et l'établissement des loges, appelées à faciliter les relations avec les indigènes?

La guerre civile devait à partir de $\mathbf{1 4 1 0}$ arrêter l'essor du commerce, et il paraît certain que jusqu'après $\mathbf{1 4 3 0}$ les Normands n'ont plus tenté aucune expédition maritime sur la côte d'Afrique. Tandis que les Portugais, entrainés dans ce mouvement par Henri le Navigateur, fondaient au début $d u x^{e}$ siècle de nombreux établissements, les Français ne recommencèrent à fréquener les côtes de Guinée que sous Henri II et l'expédition de Jean 
de Béthencourt allait réveiller chez nous le goût des lointaines aventures.

Nos marins avaient certainement recommencé à commercer au $\mathrm{xvI}^{\mathrm{e}}$ siècle sur les côtes occidentales d'Afrique, car à cette époque Coligny avait demandé qu'on les protégeât contre les Portugais et plusieurs d'entre eux prirent part à l'expédition dirigée contre Madère par Peyrot de Montluc.

Les Compagnies de commerce. - A partir de 1626, le Sénégal peut être considéré comme une véritable colonie. De cette année date, en effet, la Compagnie normande, formée par des marchands de Dieppe et de Rouen, à laquelle on doit la création, dans une île de l'embouchure du Sénégal, de l'établissement qui fut l'origine de la ville de Saint-Louis.

L'importance de ce comptoir s'accrut rapidement, mais les Hollandais, dont la puissance maritime était considérable, surveillaient l'embouchure du Sénégal, établis solidement à Arguin, Gorée et Rufisque.

En 1664, la Compagnie normande vendit ses établissements à la Compagnie des Indes occidentales, à laquelle Colbert avait fait donner le privilège exclusif de faire le commerce sur les côtes de l'Atlantique, du Canada au cap de Bonne-Espérance.

Mais cette dernière fut bientôt déchue de son privilège en 1672 et ses droits passèrent à la Compagnie du Sénégal. Entre temps, les Français s'étaient emparés d'Arguin, Portudal, Rufisque, Gorée et Joal, dont la possession leur fut confirmée en 1678 par le traité de Nimègue.

La Compagnie du Sénégal eut à lutter bientôt contre les Hollandais et les Anglais qui possédaient aussi des comptoirs sur la côte ; elle fit place, en 1696, à la Compagnie royale du Sénégal, cap Nord et côte d'A frique qui eut pour directeur André Bruë.

Arrivé à Saint-Louis en août 1697, Bruë fit entrer la colonie dans une ère nouvelle de prospérité et d'accroissement. Il explora le pays afin d'y ouvrir de nouveaux débouchés pour notre commerce. Il visita le Cayor, remonta le Sénégal jusqu'au delà de Bakel, ainsi que la Falémé, et dépassa les chutes du Filon. Il parcourut la Gambie et descendit jusqu'aux rivières du Sud et fit explorer par Compagnon le Bambouk et la Falémé ; 
il noua des relations avec les chefs de l'intérieur, notamment avec les Maures Braknas et les indigènes du Dimar et du Toro et fit enfin lever la première carte du Sénégal. Revenu en France en $\mathbf{1 7 2 0}$, il retourna au Sénégal en $\mathbf{1 7 2 3}$ pour régler les intérêts de la Compagnie. Ce fut son dernier voyage : ses successeurs n'eurent qu'à suivre la voie qu'il avait tracée pour maintenir la prospérité de la colonie (1).

Malheureusement pendant la guerre de Sept ans, Saint-Louis et Gorée tombèrent aux mains des Anglais et une Compagnie royale d'Afrique reprit tout le commerce de la région. A la paix, Gorée nous fut rendue, mais Saint-Louis resta aux mains des Anglais jusqu'au moment où le duc de Lauzun s'en empara pendant la guerre de 1779.

Gorée et Saint-Louis furent encore repris par les Anglais au cours des guerres de l'Empire. Enfin le traité de Paris de $\mathbf{1 8 1 4}$ nous restitua ces deux établissements auxquels se limitèrent long temps nos possessions du Sénégal.

La situation en 1814. - Il y avait à ce moment-là quelque mérite à ne point désespérer, à envisager les chances d'une reconstitution de notre domaine colonial, pour des hommes qui avaient connu les obstacles mis par un adversaire implacable, à la plus légitime des reprises de possession. Notre spoliation était commencée depuis 1814, et pourtant que d'épreuves humiliantes nous furent imposées par surcroît quand l'heure arriva de nous rendre les débris de notre bien. Lorsque nos officiers réclamèrent sur place l'exécution du traité spécial du 20 novembre 1814 ils se trouvèrent en présence d'une série de procédés dilatoires dont l'inspiration n'avait rien de commun avec le droit des gens, et au Sénégal, le colonel Schmaltz allait se voir en butte à une odieuse persécution.

Le colonel Schmaltz. - Celui-ci avait été chargé de la direction des établissements du Sénégal avec le titre nouveau de

(1) Toir l'ouvrage de Berliouz. Andrè Bruë ou origine de la colonie du Sénégal. Paris, 1874,1 vol. in $\cdot 8^{\circ}$. 
" commandant et administrateur pour le Roy " et l'expédition de reprise comprenait un personnel civil et militaire et une mission d'une trentaine de personnes, chargées d'étudier un plan de colonisation établi par l'aide de camp du chevalier de Boufflers. La division navale composée de la Méduse, de l'Echo, de la Loire et de l'Argus quitta l'île d'Aix le 17 juin 1816.

Le $\mathbf{2}$ juillet l'inexpérience de M. de Chaumareys, commandant de la Méduse, ancien émigré parvenu à ce commandement en vertu de la fameuse ordonnance du 20 mai 1814, réintégrant avec un grade supérieur les officiers de marine qui n'avaient point servi l'Empire, fit naufrager la frégate sur le banc d'Arguin. Les épisodes de ce naufrage, celui du radeau notamment, sont devenus légendaires (1).

C'est donc en naufragé que le colonel Schmaltz, échappé au danger sur le grand canot du bord, arriva le 9 juillet devant la barre de Saint-Louis. Il allait constater sans retard les dispositions hostiles des Anglais. Brereton, lieutenant-gouverneur de Saint-Louis, répond à la demande de restitution qu'il n'a point reçu d'ordres et qu'il ne dispose d'aucun moyen pour évacuer ses troupes. Schmaltz écrit alors à M. Mac-Carthy, gouverneur des possessions britanniques de l'A frique occidentale à Sierra-Leone. Ce dernier répond que l'évacuation se fera dès l'arrivée des navires nécessaires au transport des troupes et il promet la bienveil. lance des Anglais du Sénégal pour le personnel de l'expédition et pour les malheureux. naufragés qui arrivent successivement. Cette promesse ne fut pas tenue. Le commandant de Gorée s'oppose à l'entrée à l'hôpital des malades les plus atteints; il autorise M. de Foncin, commandant désigné de Gorée, à transformer une maison de la ville en hôpital, mais il est blâmé de sa courtoisie par Mac-Carthy qui lui écrit que " dès que les Français débarqués seront assez rétablis, il conviendra de les éloigner de Gorée " et ces prescriptions sont exécutées ponctuellement. Le colonel Schmaltz se plaint avec vivacité à Brereton et il écrit au ministre :

(1) Un consultera à ce sujet avec profit : Victor Tantet, L'Expédition de la Méduse (Revue hebdomadaire. Avril 1895). 
Les ordres prétendus donnés pour le soulagement de l'expédition, les offres continuelles de service ne sont qu'un échafaudage d'humanité et de bonne volonté dont l'effet est honteusement éludé. Les phrases : On fera tout ce qui pourra être fait; on recevra autant de malades qu'on pourra en admettre dans les hôpitaux ou tout ce qui pourra s'accorder avec mes devoirs, sont autant de subterfuges à l'aide desquels, sous l'apparence de vouloir diminuer les souffrances et les inconvénients de l'expédition, on s'assure les moyens de refuser toute espèce de soulagement.

L'indignation du colonel Schmaltz était d'autant plus explicable que le naufrage de la Méduse le laissait dénué d'argent et qu'il avait dû demander un crédit de 5̋0.000 francs à une maison de commerce française. Il avait cru que la restitution n'eût été qu'une simple formalité et qu'il lui eût suffi de produire la copie de la lettre suivante de lord Bathurst:

\section{Downing-Street, 20 février 1816.}

Monsieur, je vous transmets ci-joint copie de l'ordre donné le 30 juillet 1814 pour la remise des forts et établissements de Gorće et du Sénégal aux commissaires désignés par le gouvernement français pour en prendre possession, et je désire que vous preniez les mesures nécessaires pour mettre à exécution les instructions qui y sont contenues, le. . étant désigné pour cet objet.

De plus l'inscription de rente stipulée par la convention du 20 novembre 1815 comme condition de la rétrocession avait été faite dès la fin de 181 .

Heureusement à la fin du mois de septembre 1816, Ja situation se modifie. Lord Bathurst, mis au courant du conflit, blâme catégoriquement Brereton :

Comme il est très important, lui écrit-il, d'éviter les soupçons que votre refus peut avoir fait naitre sur la bonne foi du gouvernement britannique, je vous enjoins dans le cas où les établissements du Sénégal et de Gorée ne seraient point encore rendus, de les remettre immédiatement après la réception de la présente, à l'officier, quel qu'il soit. de S. M. T. C. qui sera dûment autorisé à les recevoir et qui produira l'ordre donné par S. A. R. le Prince Régent pour leur rétrocession.

Malgré ces ordres impératifs, la remise fut encore ajournée. L'acrimonie du colonel Schmaltz est à son comble, et, daus une 
lettre qu'il adressait à l'intendant du Roi, M. Forestier, il va jusqu’à écrire, en parlant des Anglais : “ N'est-on pas en droit de conclure qu'ils calculent avec une froide barbarie la destruction des sujets de Sa Majesté »?

Cependant, après de nouvelles tergiversations, les Anglais qui occupaient la colonie depuis le 14 juillet 1809 en firent remise aux autorités françaises le 25 janvier 1817 , et dès le 8 juillet 1818, un personnel et un matériel déjà important étaient envoyés de France pour faire dans la colonie des essais de cultures indigènes.

Traité de Nguio (8 mai 1819). - Il ne fallut pas plus de deux ans de labeur pour rendre jaloux de nos progrès d'expansion et de mise en valeur nos maitres de la veille, et le 8 mai 1819 le colonel Schmaltz ouvrit à la colonisation le territoire de Oualo par un traité conclu à Nguio avec Amar Boye, brack du Oualo et ses principaux chefs. La lecture de ce seul document prouvera combien l'officier énergique qui reprit possession du Sénégal était soucieux de développer pacifiquement les richesses du sol et de donner essor au commerce.

Aux termes de ce document:

Art. 1 ${ }^{\text {er. }}$ - Le roi Amar Boye, Brack du pays de Wallo, les chefs ci-dessus dénommés et tous autres invitent le commandant, pour le roi et administrateur du Sénégal et dépendances, à diriger les sujets de S.M.T.C. sur les terres du pays de Wallo pour y former, conjointement et avec le secours des habitants indigènes, des établissements de culture dans toutes les positions qui lui paraitront les plus avantageuses.

Arт. 2. - En conséquence de l'article ci-dessus et pour son exécution, le roi Amar Boye, Brack du pays de Wallo, les chefs dénommés ci-dessus et tous autres sobligent et promettent de céder, remettre et transporter à S. M. le roi de France, en toute propriété et pour toujours, les îles et toutes autres portions en terre ferme du royaume de Wallo qui paraitront convenables, au commandant pour le roi et administrateur du Sénégal et dépendances pour la formation de tous établisse ments de culture qu'il jugera à propos d'entreprendre dès à présent et par la suite Lesdites cessions faites en retour des redevances ou coutumes annuelles qui seront déterminées ci-après et en considération du désir qu'ils ont d'augmenter la prospérité de leur pays par sa mise en valeur et le commerce, et des secours qu'ils trouveront dans une alliance avec le gouvernement français. 


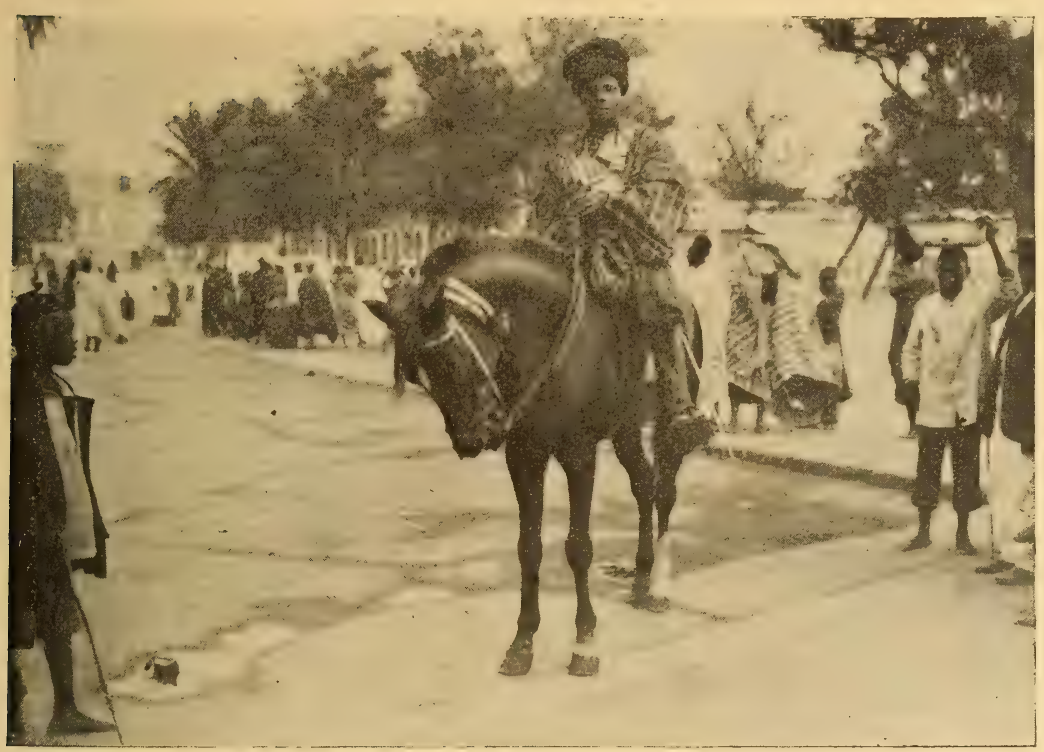

Fig. 1. - Griot toucouleur.

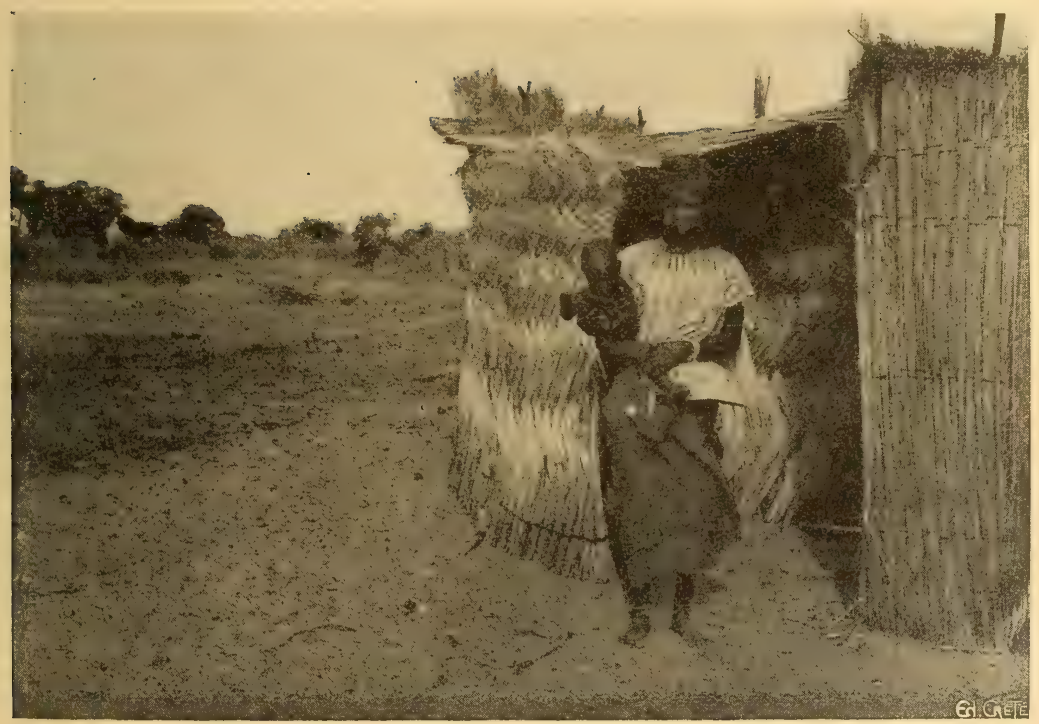

Fig. 2. - Femme Peuhle. 

Arr. 3. - La tranquillité du pays de Wallo et la sùreté des établissements de culture qui y seront entrepris, nécessitant des mesures de protection suffisantes pour mettre les personnes et les propriétés à l'abri de toutes incursions de la part des peuples voisins, Amar Boye, Brack du pays de Wallo, les chefs ci-dessus dénommés et tous autres demandent qu'il soit construit par le gouvernement français un fort au village de Dagana, situé sur sa frontière avec le pays de Toro, et des postes moins considérables dans les autres parties du royaume, partout où ils seront jugés nécessaires par le commandant pour le roi et administrateur du Sénégal et dépendances, et qu'il y soit placé les garnisons qu'exigera leur défense.

ArT. 9. - Il ne sera rien changé aux lois et usages actuels du royaume de Wallo en ce qui concerne les rapports maintenant existants entre le roi, les principaux chefs et sujets ou subordonnés; ils conserveront, comme par le passé. l'entier exercice de leurs droits et de leur police sur les indigènes qui ne seront point employés dans les établissements de culture formés par les habitants français.

Anт. 10. - En retour des dispositions ci-dessus et de l'empressement avec lequel les habitants du royaume de Wallo ont recherché l'alliance du gouvernement français et se sont prêtés à ses vues, le commandant pour le roi, au nom du roi de France, s'engage et promet de traiter toujours le roi Amar Boye, Brack du pays de Wallo, comme un ami distingué, et les chefs ci-dessus dénommés et tous autres avec la considération propre à leur assurer le respect et l'obéissance de leurs subordonnés; denvoyer former dans leur pays des établissements de culture; de faire payer, par les propriétaires aux chefs de village qui fourniront des cultivateurs et rempliront les conditions présentes, l'allocation annuelle de quatre barres par chaque tête d'individu dont l'engagement aura été complètement rempli ; de faire rendre exactement justice aux contractants ; de construire à Dagana le fort demandé et des postes armés dans tous autres lieux où il jugera nécessaire d'en établir pour assurer la conservation des propriétés et la tranquillité du pays; de placer dans lesdits forts et postes des garnisons suffisantes pour les défendre; enfin, de protéger les habitants du royaume de Wallo contre toutes incursions de la part de leurs voisins (1)

Traités arec les chefs Maures. - Ce même génie colonial, passionné pour lagriculture a laquelle il doit tant, et désireux d'en faire bénéficier nos nouveaux sujets, se retrouve dans l'histoire de nos relations avec les chefs Maures : divers traités furent,

(1) M Dubois et Terrier, Un siecle d'expansion coloniale. Paris, 1900, in-8, pp. 133-134. 
en effet, passés pour étendre les opérations du commerce des gommes.

Notre mouvement de colonisation fut un instant entravé par l'hostilité des Maures Trarzas qui, prétendant avoir des droits sur le Oualo, se liguèrent avec les Braknas et le Damel du Cayor contra les Français et attaquèrent en aoùt 1819 deux bateaux français qui remontaient le fleuve. Le 7 juin 1821, Amar Moktar, chef des Trarzas, vaincu par une colonne française, traitait avec le capitaine de vaisseau Lecoupé :

Ant. $1^{\mathrm{er}}$. - La mésintelligence qui existait entre la tribu des Trarzas et les Français cesse à compter de ce jour; les escales seront rouvertes et les anciennes relations rétablies à dater du moment de la signature du présent traité.

Arт. 2. - Le roi et les princes Trarzas prétendent avoir des droits sur les terres du pays de Wallo que les Français ont achetées à Brack. Le gouverneur croit que ces droits sont réels, mais prétend alors leur acheter la faculté d'y faire des établissements, moyennant une nouvelle coutume qui sera stipulée plus bas.

Аrт. 3. - Le roi Amar-Moktar et les princes Trarzas consentent à céder aux Français, moyennant cette coutume, tous leurs droits sur le Wallo ; ils s'engagent non seulement à respecter tous les établissements qu'il plairait aux Français de former sur la rive gauche, mais encore à les défendre, les conserver et les protéger et à contribuer de tous leurs moyens à leur prospérité.

An T. 4. - Le roi Amar Moktar et les princes Trarzas engagent le gouvernement français à s'établir dans leur pays sur la rive droite; ils lui concèdent à cet effet tous les terrains où il jugerait convenable d'élever des habitations et de faire des lougans, lui promettant d'y contribuer eux-mêmes de tout leur pouvoir, de les défendre, respecter et faire respecter, etc. Ils verront avec plaisir les Français bâtir chez eux des cases et des maisons et fonder des établissements.

Arт. 10. - Le roi et les princes Trarzas s'engagent à favoriser de tous leurs moyens toute espèce de culture et particulièrement celle du coton, soit dans le Wallo, soit sur la rive droite, à déterminer et pousser les habitants des deux rives à en venir vendre aux bâtiments qui vont traiter, et, dans le cas où quelques nègres des habitations établies viendraient à déserter, ils promettent et s'engagent à les ramener à leurs propriétaires gratuitement.

Arт. 17. - Il est entendu entre le gouverneur du Sénégal et le roi et les princes Trarzas que les Français ne prétendent s'immiscer en rien dans les affaires du pays des Trarzas, soit entre eux et leurs sujets et 
qu'ils n'ont aucune prétention de souveraineté dans le pays des Trarzas, hors leurs établissements de culture.

Le 25 juin, un traité identique était signé avec Hamet-Dou, chef des Braknas :

Ant. ${ }^{{ }^{\circ} \text { r. }}$ - Hamet-Dou, roi de la tribu des Braknas, promet et s'engage de favoriser par tous les moyens qui seront en son pouvoir la traite de gomme qui se fait à son escale et tout autre commerce qui pourrait s'ouvrir parla suite entre les sujets du roi de France et les siens dans toute l'étendue du pays.

Авт. 7 . - Le roi Hamet-Dou promet et s'engage de respecter et faire respecter par tous ses sujets les terres et habitants du pays de Wallo, les regardant comme faisant partie de l'ile et habitants de Saint Louis. Il reconnait et garantit en outre au commandant pour le roi et administrateur du Sénégal et dépendances tous les arrangements qu'il a faits avec les chefs de ce pays et toutes les concessions stipulées par eux et le gouvernement français.

Arт. 8. - Le roi Hamet-Dou engage le commandant pour le roi et administrateur du Sénégal et dépendances, à faire dans son pays des établissements de culture; il lui concède à cet effet tous les terrains où il. jugerait convenable d'élever des habitations et de faire des lougans, lui promettant d'y contribuer lui-même de tout son pouvoir, de les défendre et faire respecter. Il permet en outre au gouvernement français d'élever des forts ou batteries pour la défense et protection des habitations et lougans qui pourront se former par la suite.

Art. 9. - Le roi Hamet. Dou s'engage à favoriser de tout son pouvoir toutes espèces de culture, et particulièrement celle du coton sur les terres qui sont sous sa domination; il promet, en outre, d'engager et de porter ses sujets à en cultiver et à en vendre aux bâtiments qui vont traiter (1).

Les deux caractères de l'expansion sénégalaise apparaissaient nettement dans ces traités qui répondaient surtout à des préoccupations d'ordre agricole et commercial et stipulation de " coutumes ", c'est-à-dire de redevances annuelles, en faveur des chefs maures.

Construction du poste de Bakel. - Le 7 février 1821, Moktar, prince des Dorviches, s'était engagé à établir, moyennant une " coutume ", une escale sur le fleuve à Bakel, à y envoyer toutes

(1) Ibid., p. 137. 
les gommes recueillies dans son pays et à protéger le commerce. On commença, le 3 juillet, afin de donner à cette stipulation plus d'efficacité, à construire à Bakel un poste fortifié, et dès lors la traite de la gomme eut un regain d'activité.

Nouvelles difficultés arec les Maures. - Mais de nouvelles difficultés s'élevèrent avec les Maures, et, à la voix d'un de ces faux prophètes, comme il en surgira en Afrique occidentale jusqu'à la fin du siècle, Mohamed Amar, les Trarzas envahirent le Oualo. Le capitaine de vaisseau Bron réprima sévèrement ce mouvement; Mohamed Amar fut pendu et le 15 avril 1829, le gouverneur ratifiait le traité qui mettait fin provisoirement aux hostilités.

" Le traité conclu le 7 juin 1821 entre M. Lecoupé, commandant et administrateur du Sénégal et dépendances, et Amar-Ould-Mokhtar, roi des Trarzas, dont l'effet avait été momentanémnet atténué reprend toute sa force à partir de ce jour. Les deux parties contractantes s'en confirment réciproquement les articles et jurent d'y adhérer en tous points.

Les tribus maures qui sont actuellement dans le Walo seront libres d'y demeurer ou de passer sur la rive droite. Au cas où il resterait dans le Walo des Maures tributaires des princes Trarzas, ceux-ci pourront, comme autrefois, exiger les redevances dues par ces tributaires, mais, en cas de difficulté, ils s'abstiendront d'employer envers eux aucun moyen de rigueur avant d'avoir prévenu le gouverneur du Sénégal ou ses agents en rivières afin qu'ils puissent intervenir pour arranger les différends à l’amiable ».

Par mesure de sécurité, le gouverneur traitait le 25 avril avec les Maures Dakhelifas qui s'engageaient à coopérer avec lui pour repousser toute agression étrangère contre les établissements français du Oualo, à l'informer des événements de leur région et à employer leur influence auprès des Trarzas et auprès des Oualos en faveur des Français.

Les Anglais n'étaient point sans suivre avec intérêt nos efforts de colonisation au Sénégal. Ils les redoutaient même et James Grey Jackson, chargé de missions diplomatique et commerciale au Maroc, ne cachait point en 1820 ses inquiétudes (1) :

1. J. Grey Jackson. An account of Timbucloo and Housa. Londres, 1820, in-8. 
“ Les Français, écrivait-il, si nous continuons à ne pas nous préoccuper de leurs importants essais agricoles en Afrique, seront, d'ici quelques années, capables de nous supplanter sur le marché européen, dans le commerce des denrées d'Amérique.

En effet, au Sénégal, la main-d'œuvre des nègres affranchis étant peu coûteuse, les Français peuvent cultiver à un prix de revient très inférieur à celui de nos possessions des Antilles. La distance est inférieure de moitié et il faut prévoir que d'ici peu de temps le marché européen s'approvisionnera de denrées coloniales au Sénégal, l’importation de ces denrées en Europe coûtant moitié moins cher que si on les importait de nos possessions des Antilles.

La Grande Bretagne sera ainsi évincée du marché des produits coloniaux, sauf ou à peu près, en ce qui regarde sa propre consommation.

Les Français commencent à recueillir les fruits de ce plan à la réalisation duquel ils travaillent depuis que nous leur avons laissé prendre pied sur les rives du Sénégal. Leur ex empereur, Bonaparte, se complaisait dans cette idée que le malin génie de Talleyrand lui avait suggérée pour compenser la perte de Saint-Domingue.

En outre, les Français qui défrichent avec une ardeur infatigable le sol du Sénégal seront, d’ici quelque temps. non seulement en mesure de fournir tous les marchés d'Europe de produits coloniaux, mais encore, puisqu'ils seront devenus les maitres de l'Afrique, ils pourront établir un nouveau Ceuta sur le promontoire du Cap Vert et au cas d'une guerre, porter un préjudice considérable à notre commerce des Indes.

D'autre part ils sont susceptibles de former au Cap-Vert avec le concours des Américains toujours disposés à les aider, un entrepôt des plus précieux produits des Indes et les introduire de là en Afrique et en France, à l'exclusion presque totale de l'Angleterre.

Si nous voulons bien penser à empêcher ces événements de s'accomplir, nous pouvons nous approprier plusieurs de leurs mesures. Les temps ont bien changé et en ce qui regarde les affaires africaines nous devons nous montrer plus vigilants, plus actifs, plus énergiques que jamais.

Nous espérons que ces réflexions attireront l'attention des ministres de Sa Majesté. Qu'ils surveillent avec l'œil de l'aigle et la prudence du serpent les empiètements sans cesse grandissants des Français sur nos marchés coloniaux ».

Il faut reconnaitre cependant que si l'initiative privée préparait seule nos progrès vers le haut fleuve et vers le Soudan par les explorations du commis de marine Mollien en Gambie, de l'enseigne de vaisseau de Beaufort au Bambouk et au Kaarta et par la prodigieuse traversée continentale de René Caillié, nos 
établissements se bornaient encore en 1830 à l'ilôt de Gorée, à Saint-Louis, et aux trois postes de Richard-Toll, Dagana et Bakel.

Désormais, en une nouvelle période, l'action des gouverneurs qui se succédèrent au Sénégal allait être marquée par des efforts en vue de la mise en valeur des anciens territoires de la colonie et aussi de son expansion le long du fleuve ou sur les côtes voisines.

L'ordonnance du 7 septembre 1840. - La mesure qui encouragea nos gouverneurs du Sénégal à entreprendre cette double œuvre fut l'ordonnance du $\mathbf{7}$ septembre $\mathbf{1 8 4 0}$, organisant le gouvernement de la colonie du Sénégal à laquelle n'était point applicable la loi du 24 avril 1833.

Art. $1^{\mathrm{e}}$. - Le commandement et la haute administration de la colonie du Sénégal et de ses dépendances sont confiés à un gouverneur résidant à Saint-Louis .

Аrт. 2. - Un commissaire de la marine et le chef du service judiciaire dirigent, sous les ordres du gouverneur, les différentes parties du service.

Авт. 3. - Un inspecteur colonial veille à la régularité du service administratif et requiert, à cet effet, l'exécution des lois, ordonnances et règlements.

Ant. 4. - Un conseil d'administration, placé près du gouverneur, éclaire ses décisions et statue, en certains cas, comme conseil du conten. tieux administratif.

Art. ๖. - Un conseil général séant à Saint-Louis et un conseil d'arrondissement séant à Gorée, donnent annuellement leur avis sur les affaires qui leur sont communiquées et font connaitre les besoins et les vœux de la colonie.

Le gouverneur exerce les pouvoirs administratifs, militaires et civils qui ont été conférés aux gouverneurs des autres colonies par la loi de 1833. Il lui est particulièrement recommandé de s'attacher au développement du commerce : " le gouverneur, spécifie l'article 20, suit les mouvements du commerce et prend les mesures qui sont en son pouvoir pour en encourager les opérations et favoriser les progrès. Bien plus, la métropole, crai- 
gnant que cette recommandation ne fut insuffisante, prit le 20 janvier 1842 une ordonnance spéciale prescrivant au gouverneur de régler le mode, les conditions et la durée des opérations commerciales avec les peuples de l'intérieur de l'Afrique et de déterminer les localités, où les échanges sont permis ».

Aussi bien, les conditions d'exploitation du Sénégal s'étaientelles modifiées, et peu à peu le commerce remplaçait l'agriculture : " $\mathbf{A}$ un engouement des plus vifs pour l'exploitation agricole, écrivait Raffenel en 1843, succéda bientôt l'indifférence, puis le dégoût; la mauvaise foi de plusieurs des nouveaux colons vint, en outre, augmenter l'embarras des gouverneurs qui se virent forcés à prendre un parti extrême; ils abandonnèrent les cultures qui ne s'étaient élevées que sous la protection et à l'aide des subventions du gouvernement. Tout à coup privées de cette immense ressource, elles tombèrent, et avec elle s'évanouit l'espoir conçu par des hommes à grands desseins d'assurer un avenir prospère au Sénégal " (1).

Nouveau traité avec les Maures. - Cependant, le commerce, vers lequel se portait toute l'activité de la colonie, rencontrait sans cesse l'opposition des tribus Maures, dont l'hostilité ne cessait d'entraver les relations commerciales que la Compagnie de Galam, notamment, entretenait avec les escales du fleuve, et que les " coutumes " étaient insuffisantes à maintenir. Raffenel ne signale-t-il point que " les Trarzas et les Bracknas qui sont avec nous dans de continuelles relations de commerce nous placent très fréquemment dans des situations fâcheuses " ".

Il ne fallut que l'exécution du chef Trarza, Moctar, fusillé le 19 décembre 1832 à Saint-Louis, à la suite d'une révolte, pour provoquer un nouveau soulèvement que les Maures crurent devoir rendre plus efficace, en provoquant le mariage de leur chef Mohamed-el-Habib avec " la princesse Guimbotte ", reine du Oualo.

Une expédition fut organisée contre eux : le Oualo fut conquis et bientôt les Maures demandèrent la paix. Le roi des Trarzas

(1) Anne Raffenel. Voyage dans l'Afrique Occidentale exécuté en 1843-1844. Paris, 1846, in-8. 
" renonça formellement, pour lui personnellement, ses descendants et successeurs à toutes prétentions directes ou indirectes sur la couronne du Pays de Walo et notamment pour les enfants qui pourraient naitre de son mariage avec la princesse Guimbotte ". Au reste, si celle-ci demeurait princesse du Oualo, le gouverneur Pujol prit soin d'y installer un nouveau chef par le traité du 4 septembre $\mathbf{1 8 3 5}$.

“ Le Brack Fara Pinda et les principaux chefs du Oualo s'engagent pour eux et tous les gens de leur parti à n'inquiéter ni rechercher soit dans leurs personnes, soit dansleurs propriétés les gens du Wallo qui ont pris parti dans cette dernière guerre pour Kerfi et le Sénégal ; enfin ils promettent un entier oubli des faits accomplis.

Le gouverneur du Sénégal, désirant voir rétablir la paix entre tous les peuples qui ont pris part à la dernière guerre, Fara Pinda et les chefs du Wallo consentent à accepter sa médiation pour terminer leur différends avec Eliman Boubakar.

Aux conditions ci-dessus, le gouverneur du Sénégal reconnaît Fara Pinda pour Brack du Wallo, promet de payer la coutume de cette année ainsi que celle des années suivantes et il autorise les gens du Wallo à rentrer dans leur pays » (1).

C'en était fait désormais de l'opposition des Maures, et c'est en vain qu'en 1840 ils menacèrent le poste de Richard Toll. Nous allions pouvoir porter ailleurs nos efforts les plus énergiques, et si l'exploration de l'intérieur ne fut pas très prospère pendant cette période qui compte seulement deux reconnaissances de Raffenel, l'expansion le long de la côte Occidentale allait être couronnée de succès en C'asamance, en Guinée, à la Côte d'Ivoire, et même au Congo.

L'expansion en Casamance. - Le 24 mars 1837, Dagorne, commandant de Gorée, passait avec Bodian Daja, roi de Boudhie, une convention aux termes de laquelle celui ci " s'engageait à recevoir et protéger les marchandises et commerçants français qui viendront fabriquer dans son pays et à les y mettre à l'abri de toute vexation "; il accorde, en outre, à la France, " un terrain situé au Sud du village de Siguiou et s'étendant le long de la rivière, en la descendant, l'espace de 250 mètres, avec une

(1) M. Dubois et Terrier, op. cit., p. 220. 
profondeur dans l'intérieur de $\mathbf{1 0 0}$ mètres, pour en jouir en toute propriété et sans réserve afin d'y établir un comptoir de commerce $)$.

Le poste de Sedhiou fut immédiatement établi. Le $1^{\text {er }}$ avril, une convention semblable cédait à la France lîle de Dhinbering. Enfin l'Eurèbe concluait en décembre 1839 de nouvelles conventions avec les chefs d'Itou, Dhiogué, Sandiguery Pacao, etc.

Bientôt les perspectives de " grands courants commerciaux " qui avaient engagé le gouvernement impérial, médiocrement dévoué à la cause algérienne, à nouer des relations avec les tribus Sahariennes, devaient lui inspirer le désir de pousser nos lignes de poste et de comptoirs du Sénégal jusqu'au Niger, et la colonie du Sénégal, exclusivement vouée au négoce, intéressant nos grands ports où la doctrine et les pratiques du libre échange étaient très populaires ne pouvait manquer d'éveiller la sympathie privilégiée de l'empereur et de ses ministres. C'est une ère nouvelle qui commence pour notre colonie africaine, et Faidherbe va bientot planter les jalons de notre future expansion. 


\section{CHAPITRE II}

LA FORMATION TERRITORIALE DU SÉNÉGAL

Faidherbe. - La tâche du nouveau gouverneur du Sénégal était difficile ; les incursions périodiques des Maures, la tyrannie des princes indigènes, l'esclavage aboli en principe mais subsistant de fait étaient autant d'obstacles à vaincre. Faidherbe allait consacrer sa vie à cette tâche ardue, et faire " de nos misérables comptoirs du Sénégal une colonie qui devint l'amorce d'un grand empire, dont il put voir avant sa mort s'ébaucher les contours ".

"Tempérament équilibré dans lequel se conciliaient les mérites du savoir et les vertus de l'action, intelligence méthodi. que sans abus d'esprit de système, caractère énergique, mais d'une énergie réfléchie, dont les apparentes boutades et les merveilleuses saillies avaient leur profonde logique, capable de sang-froid ou d'ardeur, suivant les circonstances ou les aptitudes de ses collaborateurs, il fut un des génies les plus complexes et les plus puissants de l'expansion coloniale française. Ses dispositions naturelles s'étaient développées à bonne école : dix années de service actif en Algérie, un séjour de deux ans à la Guadeloupe, une mission en Guinée où il avait très ingénieuse. ment fortifié Dabou près de Grand'Bassam, lui avaient donné une expérience variée de nos colonies. Le maniement des Algériens, dans les dernières années de campagne active, l'avait préparé à comprendre la politique si délicate et en même temps si énergique qu'il convenait d'appliquer aux Maures ; en Guinée, il avait gagné la pratique du gouvernement des sédentaires du 
pays tropical maritime. Son succès est donc une œuvre d'intelligente volonté, de méthodique application; c'est pourquoi à ce mérite d'avoir doté la France d'une voie d'accès vers le Soudan s'ajoute le mérite plus grand encore et plus durable dans ses effets lointains, d’avoir formé à son école la pléiade d'officiers braves, humains dans la mesure des nécessités de la guerre, savants et désintéressés qui ont refait la " plus grande France " sous la troisième république. Il fut un chef et un maître ; il laissa à son pays de vastes territoires, à ses disciples de l'armée une doctrine, une tradition, bien humaine et bien française.

Il n'est pas question ici de sa doctrine générale de colonisation française. A cet égard le grand homme, influencé par les merveilleux succès de son entreprise sénégalaise, peut-être même touché avec excès de ce sentiment si vif d'émulation qui mit longtemps aux prises les colons de l'Algérie et ceux du Sénégal, fermait trop volontiers les yeux au mérite de notre œuvre de peuplement et de culture du Maghreb. " Il parait malheureusement certain " écrivait-il (1), " que nous sommes aujourd'hui peu aptes à fonder descolonies de peuplement. Ainsi en Algérie les deux tiers des colons sont Espagnols ou Italiens etnon Français ". Mais ces maximes d'expansion en Afrique occidentale sont d'une rare justesse et d'une netteté admirables " (2).

Aujourd'hui que la géographie du Sénégal est connue et sa carte levée, nous avons peine à nous représenter exactement ce qu'il fallait d'audace pour concevoir le vaste plan dont Faidherbe assura la rigoureuse exécution. On ne connaissait le régime du fleuve que par les relations des traitants; il s'en fallait de beaucoup que son hydrographie fut achevée complètement. Sil'on commençait à prendre conscience, grâce aux relations des officiers, du caractère des pays Maures de la rive droite, nous étions beaucoup moins nettement renseignés sur la nature des régions de la rive gauche, en particulier des étendues désolées du Ferlo.

Aussi bien, Faidherbe, avec une merveilleuse induction, va-

(1) Général Faidherbe, Le Sénégal, la France dans l'Afrique occidentale. Paris, Hachette, 1889.

(2) M. Dubois et Terrier, op. cit., p. 27 . 
t il rejeter les Maures au delà de nos postes du fleuve, occuper solidement le Cayor pour refouler par l'Ouest comme par le Nord les tribus du Fouta et du Ferlo, et saisir, avec la même promptitude de coup d'œil, le caractère de la domination d'El-hadjOmar, " dégageant la route du fleuve, seule capable d'assurer le ravitaillement de nos colonnes, faisant bonne garde le long de la lisière maritime qui s'étend de Saint-Louis à Gorée pour retirer toute ressource à ses tribus qui voudraient nous harceler sur la rive gauche, puis, grâce à ce déblaiement de la vraie voie de pénétration, arrivant en forces au devant de l'ennemi venu des régions nigériennes ").

Ainsi, en des pages qu'il est intéressant de rappeler, par l'action militaire, bornée aux campagnes indispensables et provoquées du fait des pillards et des fanatiques, par la mise en ouvre de toutes les ressources d'intelligence et de force du Sénégal, Faidherbe allait préparer la marche vers le pays du Niger, au lendemain de la pacification et de l'organisation du Sénégal.

Guerre avec les Maures. - "Nous devons dicter nos volontés aux chefs Maures pour le commerce des gommes. Il faut supprimer les escales en 18004, employer la force si l'on ne peut rien obtenir par la persuasion. Il faut supprimer tout tribut payé par nous aux Etats de fleuve, sauf à donner, quand il nous plaira, quelques preuves de notre munificence aux chefs dont nous serons contents. Nous devons être les suzerains du fleuve. Il faut émanciper complètement le Walo en l'arrachant aux Trarzas et protéger en général les populations agricoles de la rive gauche contre les Maures. Enfin il faut entreprendre l'exécution de ce programme avec conviction et résolution ").

Telles étaient les instructions que donnait au gouverneur Faidherbe le ministre de la marine et des colonies. L'invasion du Oualo par les Trarzas de Mohammed-el-Habib qui se vantait d'aller faire son salam dans l'église de Saint-Louis fut le signal de la reprise des hostilités. Mais grâce à l'énergie de Faidherbe, les Trarzas, puis les Oualos furent défaits, les Trarzas chassés du 
Oualo, la reine du Oualo déchue et le Oualo annexé en décembre 1855 .

Les hostilités reprirent en 1857 et Faidherbe battit complètement les Trarzas le $\mathbf{1 3}$ mai an lac Cayor et le $\mathbf{3 1}$ mai dans le Dimar. Aussi les Trarzas n'inquiétèrent-ils point le gouverneur pendant ses opérations eontre El-Hadj-Omar ; ils finirent mème par demander la paix que sanctionna le traité du 20 mai 1838.

( Le roi des Trarzas reconnaissant en son nom et au nom de ses successeurs que les territoires de Oualo, de Gaë, de Bokol, de Toubé, de Dialakhar, de Gandiole, de Thiong, de Djiaos, de N'diago appartiennent à la France et que tous ceux qui les habitent ou les habiteront plus tard sont soumis au gouvernement français, et par suite ne peuvent être astreints à aucune espèce de redevances ou de dépendance quelconque envers d'autres chefs que ceux que leur donnera le gouverneur du Sénégal.

Le roi des Trarzas reconnaît en son nom et au nom de ses successeurs, que le gouverneur du Sénégal est le protecteur des Etats Ouolof du Dimar, du Djolof, du Ndiambour, et des Trarzas : c'est par l'intermédiaire du gouverneur que les tributs seront perçus et livrés au roi des Trarzas, et c'est par lui que seront levées les difficultés qui pourraient s'élever entre le roi des Trarzas et ces Etats. En conséquence, aucun Maure armé ne traversera le fleuve pour aller dans ces pays, sans le consentement préalable du gouverneur.

Le roi des Trarzas s'engage, en son nom et au nom de ses successeurs, à exercer la plus grande surveillance pour empêcher les courses et pillages de quelques-unes de ses tribus sur la rive gauche du fleuve. Le gouverneur du Sénégal s'engage à aider de tout son pouvoir le roi des Trarzas dans ce but, et à soutenir son autorité contre ceux de ses sujets qui voudraient, malgré lui, revenir à leurs anciennes habitudes.

Les relations commerciales seront immédiatement rétablies entre les Français et les Trarzas. Les Français ne veulent, pour le moment acheter la gommeque dans leurs établissements de Saint-Louis, Dagana, Podor, Saldé, Matam, Bakel et Médine, et veulent l'acheter toute l'année. Le roi des Trarzas ne veut, pour le moment, laisser venir les gommes des Trarzas qu’à Dagana; il en estle maitre. Le roi des Trarzas et le gouverneur prendront, chacun de leur côté et dans la limite de leurs droits, les mesures nécessaires pour faire exécuter leur volonté par leurs sujets et administrés respectifs. Le commerce de tous les autres produits des Trarzas se fera librement et partout, soit à terre, soit à bord des embarcations.

Comme le commerce d'un pays doit rapporter des revenus au gouver- 
nement de ce pays, il est juste que le roi de Trarza tire un profit du commerce des gommes. La perception de cet impôt sur le commerce de ses sujets offrant pour lui des difficultés de plus d'un genre, le gouvernement français, comme preuve de bienveillance envers son allié, veut bien se charger de cette perception. En conséquence, les commerçants qui achèteront la gomme des Trarzas à Dagana, ou peut-être plus tardsur dautres points, sauront que ce produit. est grevé, à sa sortie du pays des Trarzas, d'un droit d'une pièce de Guinée par 500 kilogs de gomme, soit environ $30 / 0$ au profit du roi des Trarza, et qu'ils auront à verser ce droit entre les mains du commandant ou de telle autre personne désignée, qui le livrera au roi des Trarzas quand celui-ci le désirera. La pièce de Guinée par 1000 livres de gomme sera également perçue à Saint-Louis, au profit du roi des Trarzas, quand les caravanes trarzas en apporteront sur ce point avec son autorisation.

Le roi des Trarzas s'engage à protéger, par tous les moyens, en son pouvoir, le commerce des gommes et autres produits contre tous ceux qui voudraient l'empêcher ou le gêner, et à ne jamais intervenir entre les vendeurs et les acheteurs, pas plus que le gouverneur ne le fait : si l'on apprenait que moyennant payement ou gratuitement, il influençât ses sujets pour leur faire vendre de préférence à tel ou tel particulier, on cesserait aussitôt la perception du droit d'une pièce

Le gouverneur permettra, en temps.de paix avec les Trarzas, à leurs caravanes, de traverser les territoires français pour aller faire du commerce sur la rive gauche, mais aucun Maure armé n'accompagnera ces caravanes sans une permission spéciale du gouverneur ou de ses agents autorisés. De leur côté, et en observant les mêmes conditions, les sujets français pourront circuler librement et en toute sécurité sur le territoire du roi des Trarzas.

Les sujets français ne pourront, sans en avoir préalablement obtenu l'autorisation du roi des Trarzas, cultiver ou pêcher, ou en un mot faire aucun acte de propriété sur son territoire. De leur côté, les Trarzas sont soumis aux mèmes conditions vis-à vis des Français ») (1).

\section{Traité avec les Braknas. - Moins redoutables parce que} notre poste de Podor et ses annexes leur barraient le passage vers le Toro et les Douaïch, pillards attitrés du Fouta, les Braknas se soumirent beaucoup plus facilement que leurs congénères de la côte, et un traité semblable à celui des Trarzas fut signé à Podor le 10 juin. Ainsi, en juin 18\%9, les dernières résistances étaient brisées, le Oualo, le Cayor, le Toro, le Fouta et le Damga

(1) M. Dubois et Terrier, op. cit., p..333 


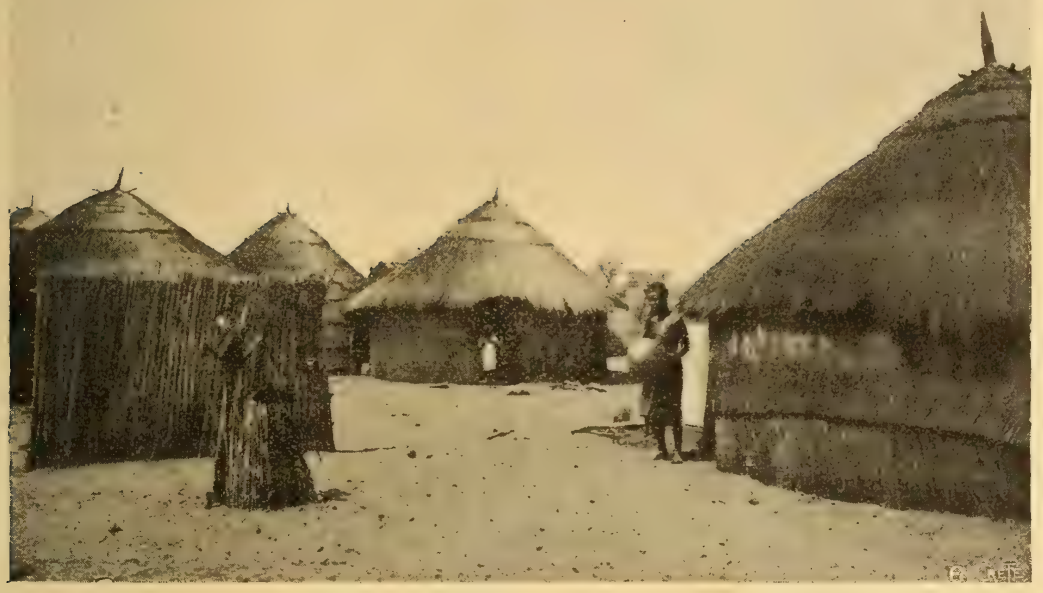

Fig. 3. - Village dans le Sine-Saloum.

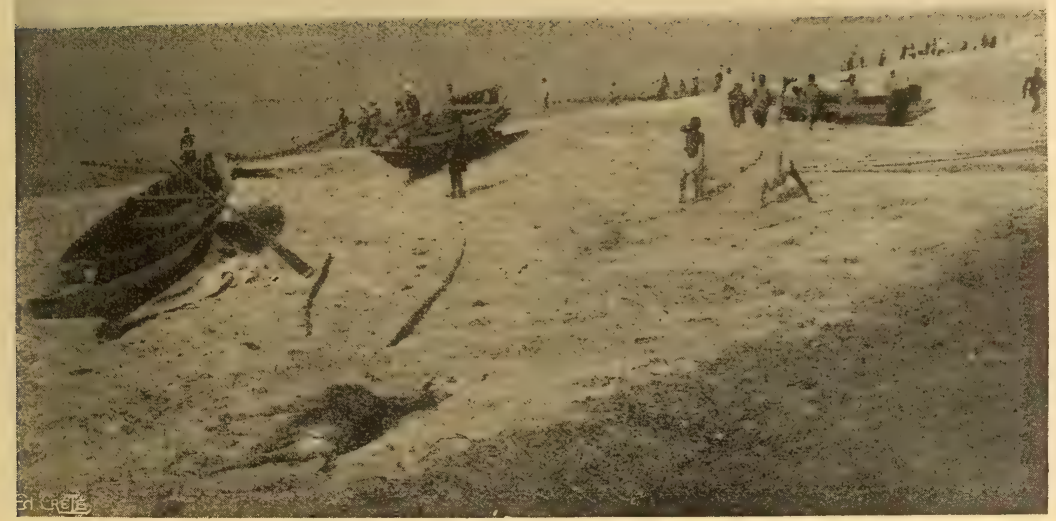

Fig. 4. - Rufisque (La plage). 

étaient réunis à la colonie en dépit des tentatives d'El-Hadj-Omar pour les soulever et Faidherbe pouvait écrire (1) que « grâce à la bonne volonté des chefs et à l'appui que nous leur prêtions, nous étions parvenus à mettre la rive gauche à l'abri des brigandages des Maures, même au-dessus de Podor ».

Guerre avec El-Hadj-Omar. - Mais Faidherbe n'avait point seulement à assurer la pacification des rives du fleuve à bonne distance des escales : il lui fallait mener de front la lutte contre le prophète toucouleur $\mathrm{El}$-Hadj-Omar, aidé par les contingents des régions nigériennes et du Fouta Djallon. Faidherbe aimait à le rappeler : «Ceux qui pendant six ans avec des moyens bornés ont fait face à ces deux besognes, passant la saison sèche à batailler contre les Maures et la saison des hautes eaux à faire des expéditions dans le haut du fleuve, et qui ont malgré cela établi notre domination dans le Sénégal, peuvent avoir la conscience d'avoir rendu un grand service à leur pays ").

La guerre sainte d'El-Hadj-Omar fut, fort heureusement, restreinte aux Toucouleurs et aux Peulhs qui étaient rivaux des Maures dans l'exploitation pillarde des populations du moyen et du bas Sénégal, et l'œuvre de rétablissement d'une vie sédentaire et policée que le gouverneur accomplissait autour de nos escales et dans les pays riverains eut pour effet de rendre difficile le ravitaillement de la grosse armée des fanatiques qui se heurta à des places fortes comme Médine, si vaillamment défendue par Paul Holl en 1857. Holl et ses compagnons résistèrent pendant près de cent jours et allaient succomber faute de vivres, quand la colonne de secours commandée par Faidherbe en personne, vint les débloquer.

El Hadj Omar reprit l'offensive l'année suivante, et tenta d'empêcher Faidherbe d'occuper les mines du Bambouk. Puis il se retira sur Nioro, mais Faidherbe fit enlever par le commandant Faron la garnison qu'il avait laissée à Gueinou. El-Hadj tint encore la campagne pendant plus d'une année, mais il dùt bientôt

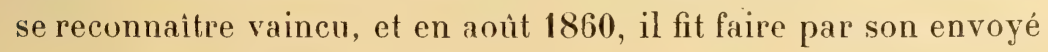

(1) Faidherbe, Le Sénégal, op. cit., p. 1557. 
Tierno-Moussa, des démarches qui aboutirent à la conclusion d'un accord.

En pleine guerre, Faidherbe, qui avait donné, comme officier du geénie, tous ses soins au choix de l'emplacement et à la construction des forts, avait fait élever le poste fortifié de Matam pour tenir le Damga en respect, puis ce fut Saldé, sentinelle surveillaǹt à la fois les Maures et le Fouta, enfin Joal, la citadelle du Sine.

L'expansion française de $1862 \grave{a} 1869$ : le Toro. - Faidherbe se préoccupa d'ailleurs d'assurer l'expansion française chez les peuples ou tribus que l'influence des Maures ou celle d'El-HadjOmar essayaient de soulever contre nous, recourant tantôt à la diplomatie, tantôt à la force.

En 1862-63, en l'absence du gouverneur Faidherbe, le capitaine de vaisseau Jauréguiberry et le colonel Martin des Pallières soumirent définitivement les Toucouleurs du Fouta qui renoncèrent à toute prétention sur le Toro, et, le $1^{\mathrm{er}}$ septembre un traité fut conclu avec le Toro. Les chefs « reconnaissaient de nouveau " l'annexion de leur province à la colonie du Sénégal, annexion solennellement et publiquement prononcée en présence de tous les chefs du pays, notamment des signataires de la présente déclaration à Aéré, le $\mathbf{7}$ septembre $\mathbf{1 8 6 0}$.

Les chefs, en leur nom et au nom des différentes populations du Toro, s'engagent à obéir aux ordres du gouverneur du Sénégal ; ils promettent de vivre en paix les uns avec les autres, et de se secourir mutuellement contre les ennemis étrangers.

De son côté, et dans ces conditions, le gouverneur promet en son nom et au nom de ses successeurs de faire tous ses efforts pour protéger le Toro contre tout ennemi extérieur et contre les brigandages des Maures.

Dès 1856-18ə8, des campagnes avaient soumis le N'Diambour, le Sine, le Saloum et en 1860, le commandant Pinet-Laprade soumettait les Yolas et les Balantes de la Casamance.

Le Cayor. - La conquête du Cayor donna lieu également à de multiples opérations. Macadou, nommé damel du Cayor en 1860, se révolta contre nous: il nous fallut maintenir par la force le damel élu sous notre influence, Madiodio et nous eùmes 
à vaincre un autre concurrent à la couronne du Cayor, LatDior, qui fut battu à plusieurs reprises, notamment à Loro le 12 janvier 1864.

L'année 1865 fut consacrée à la soumission du Saloum et à la défaite du prophète Maba.

En mars 1869 Lat-Dior reprit l'offensive sous l'inspiration d'Ahmadou Cheikou, chef du Toro, il fut encore battu en diverses rencontres et s'enfuit dans le Rip.

Dans cette dernière campagne se distingua le colonel PinetLaprade, successeur de Faidherbe dans le gouvernement de la colonie à partir de 1863 . L'énergique officier continua la politique d'expansion et procéda, en particulier, à l'occupation et à l'organisation du protectorat des Rivières du Sud.

Bientôt Lat-Dior vint faire sa soumission, et le colonel Vallières le rétablit dans ses fonctions de damel du Cayor par un traité conclu à Saint-Louis le 12 janvier 1871. Le gouvernement de la colonie espérant clore l'ère des hostilités lui rendait le Cayor, sauf les banlieues de Saint-Louis et de Dakar, et la province de Diander.

Cependant déjà le Sénégal à peu près pacifié et organisé, Faidherbe assignait un nouvel objectif à ses inlassables efforts, et, sans partager un enthousiasme qui n'excluait point la logique, se demandait si " cette phrase stéréotypée dans tous les journaux que le Sénégal et l'Algérie doivent se donner la main par dessus le Sahara " avait un sens? Le grand voyage de Mage et de Quintin, achevé en 1866 sous le gouvernement de Pinet-Laprade, allait justifier les desseins de Faidherbe, et donner au Sénégal un franc accès vers les pays baignés par le Niger.

Aussi bien, n'entre-t-il pas dans le cadre de ce travail d'étudier notre expansion territoriale vers ces territoires du Soudan, que devait disloquer entre nos diverses colonies de l'Afrique Occidentale le décret du 17 octobre 1899, et qui, partiellement rattachés au Sénégal, devaient, au cours de l'histoire administrative de cette colonie, en être disjoints pour former tour à tour les 
pays de la Sénégambie et Niger, et actuellement la colonie du Haut Sénégal et Niger?

C'est à l'histoire du haut pays que se réfèrent ces pages glorieuses qu'illustrèrent la marche vers le Niger sous Brière de l'Isle, la mission Gallieni à Segou en 1880-81, les campagnes du général Borgnis Desbordes (1881-83), puis du général Archinard, l'occupation de Tombouctou à la suite de la campagne de 1893-94, et le massacre de la colonne Bonnier, sans parler des nombreuses missions qui s'effectuèrent dans le Niger et de la giorieuse épopée de la mission Joalland Meynier, qui, venant serrer les mains aux bords du Tchad à la mission Foureau Lamy, partie d'Algérie, et à la mission Gentil, partie du Congo, assurait la jonction de nos trois grands groupes de colonies africaines.

L’histoire du Sénégal se résume dès lors en des incidents purement locaux.

Soulèvement du Cayor. - Au Cayor, la construction du chemin de fer de Dakar à Saint-Louis en 1882 souleva de nouvelles difficultés ; Lat-Dior, ayant manifesté des sentiments hostiles, sa déchéance fut proclamée.

Son neveu, Samba Yaye fut installé damel et prit le nom de A hmadi N'Goue Fall.

Quelques mois après l'avènement du nouveau prince, Samba Laobé, héritier naturel par droit de naissance du titre de Damel, se présenta à la tête des captifs de la couronne, et il fallut l'intervention de nos troupes sous les ordres du commandant Dodds pour amener Samba Laobé à faire sa soumission.

Lat-Dior ne manqua point, d'ailleurs, de profiter du mécontentement des habitants du Cayor vis-à-vis d'Ahmadi N'Goue Fall : aidé du Bomba Djoloff, il pénétra dans le pays et le damel prit la fuite, en implorant notre protection.

Le gouverneur Bourbiaux obtint l'abdication d'Ahmadi N'Goué Fall et reconnut comme damel du Cayor, Samba Laobé.

Si les débuts de son règne furent marqués par une politique de pacification qui permit la construction et l'exploitation du chemin de fer de Dakar à Saint-Louis, en mai 1886, sans prendre avis du gouvernement, le damel déclara la guerre à Aly Boury 
Bomba Djoloff et marcha sur Mérinaghen. Il fut battu par Aly Boury qui ne consentit à se retirer que moyennant une indemnité. Le gouverneur Génouille infligea une amende à Samba Laobé : de nouvelles malversations du damel vis-à-vis de nos sujets nécessitèrent une intervention armée et Samba Laobé périt dans un engagement.

Lat-Dior, notre infatigable adversaire, prétendit à sa succession : un détachement de spahis, chargé de surveiller les mouvements du prétendant fut surpris par lui à Dekkilé. Après un combat sanglant, les spahis reconnurent son corps parmi 80 autres cadavres.

Epuisé par tant de luttes, le Cayor entra dès lors dans une période de tranquillité; la région fut divisée en six provinces sous la direction d'un chef énergique et le contrôle de notre protectorat. Les tentatives de quelques prétendants furent vite réprimées.

Baol, Sine et province Sérère - Notre action devait s'exercer non moins efficacement au Baol et dans le Sine.

La déposition du Tègne du Baol Thié Yacine en 1840, le désarmement des Tiédos en 1890 avaient affirmé notre autorité sur ces régions lin 1894, le Baol fut divisé en deux provinces : le Baol occidental et le Baol oriental, ayant à leur tête chacun un chef.

La même organisation fut adoplée en $\mathbf{1 8 9 8}$ pour le Sine et le Saloum.

Enfin, les populations Sérères, soumises seulement à la suite de la persistance qu'avait apporté à les soumettre le colonel Pinet-Laprade, furent réunies en une même province : la province Sérère groupant les districts de M'Badaire, N'Dieghem et Sandog, auxquels fut ajouté en 1891 le pays du Dioba.

Populations de la rive gauche. - Le décret du 18 octobre 1904, en créant la colonie de la Mauritanie, dont la mission Blanchet, et plus récemment les efforts de M. le Commissaire du gouvernement Coppolani, si prématurément enlevé à la noble tàche qu'il s'était assignée, ne constituent point les moins glorieuses fastes, avait enlevé à l'administration du Sénégal le souci 
d'assurer notre autorité parmi les populations établies sur la rive droite du fleuve.

Les efforts de l'administration se concentrèrent donc sur la rive gauche, où la chute de Ségou et de Nioro et l'adaptation d'un régime de protectorat avaient fortifié notre influence.

Dès 1858, le Dimar ạvait été, nous l'avons vu, détaché du Fouta, et quelque temps après le Toro, le Lao et le Damga constituèrent des provinces immédiatement placées sous notre protectorat.

L'expédition dirigée par le colonel Dodds en 1891, et la mort d'Abdul Boubakar en août 1891 assurèrent la pacification de ces régions : le fort de Kaëdi, sur la rive droite du moyen Sénégal, reçut des améliorations en 1894.

Ainsi s'était peu à peu établie notre influence : le nombre des traités passés avec les divers Etats indigènes du Sénégal et dépendances depuis Faidherbe jusqu'à l'époque actuelle et dont le chiffre s'élève à environ 70 , prouve surabondamment l'importance des difficultés que l'administration dut vaincre pour donner un système d'organisation et un caractère d'homogénéité à ce pays, où l'œuvre diplomatique avait été poursuivie concurremment à l'action politique. 


\section{CHAPITRE IV}

L'OEUVRe DIPLOMATIQUE AU SÉNÉGAL

L'œuvre diplomatique devait assurer le règlement des questions de délimitation pendantes avec les puissances qui confinaient à notre colonie du Sénégal : l'Angleterre, dont nous étions les voisins en Gambie, et le Portugal, dont nous cótoyions la colonie de la Guinée portugaise par nos territoires de la Casamance. La convention du 7 mars 1857 et l'accord franco-anglais du 8 avril 1904 réglèrent les relations de frontière avec l'Angleterre. L'arrangement du 12 mai 1886 détermina les confins des possessions françaises et portugaises entre la Casamance et les Rivières-du-Sud.

\section{A. - Délimitation franco-anglaise}

La Gambie. - La rivière de la Gambie constitue une sorte d'anomalie heureuse dans le régime hydrographique du littoral de l'Afrique occidentale. Alors, en effet, que la plupart des cours d'eau y sont presque impraticables une partie de l'année, la Gambie peut, jusqu'à une distance de plus de 300 kilomètres à vol d'oiseau de son embouchure, porter des bateaux de mer. C'est dans cette région une des principales voies de pénétration fluviale; nous en étions exclus jusqu'à présent.

La convention du 7 mars 1857. - L'établissement de l'Angleterre sur la Gambie remonte à l'origine même des entreprises coloniales britanniques à la côte occidentale d'Afrique. Dès 1588 , on voit la reine Elisabeth octroyer une charte commer- 
ciale pour la Gambie à une Compagnie anglaise. Puis vers le milieu du xvis siècle, Fort-James est construit à l'embouchure de la rivière. En 1783, la France reconnaît à l'Angleterre par l'article 10 du traité de Versailles la possession de Fort-James et de la rivière Gambie. En 1816, Sainte-Marie-de-Bathurst est fondée, et dix ans plus tard des arrangements avec des chefs indigènes assurent à l'Angleterre les territoires adjacents au cours du fleuve dans sa partie navigable. Enfin, nous-mêmes, nous cédions le comptoir d'Albréda enclavé, en face de SainteMarie-de-Bathurst, au milieu des territoires anglais et qui constituait le dernier vestige sur ce point des rivalités coloniales des deux nations.

La convention du 7 mars 1857 fixa les frontières de nos possessions, qui ne devaient être délimitées sur le terrain que plus tard, au printemps de 1896.

A cette époque toutefois, et dans les années qui suivirent, on songeait moins à acquérir de territoires en dehors des côtes et l'Angleterre maîtresse du cours navigable de la Gambie, s'occupa uniquement d'exploiter les avantages que lui donnait la possession de cette voie de transit. Mais lorsque, à une époque plus récente, s'annonça le mouvement qui allait diriger vers l'arrièrepays les visées des nations européennes et étendre à l'intérieur des compétitions territoriales jusque-là cantonnées sur le littoral, on vit en 1882 se mettre en marche et monter la vallée de la Gambie une mission anglaise dont le plein succès eût fait de ce qui constitue aujourd'hui la Guinée française, une enclave des possessions britanniques; notre établissement dans le haut bassin du Niger eût été mis en question.

Aujourd'hui c'est la Guinée qui par derrière la Gambie et Sierra-Leone s'est soudée aux autres possessions françaises du Sénégal et du Haut-Sénégal et Niger; c'est la Gambie qui se trouve enserrée dans nos territoires.

L'arrangement de 1889. - Toutefois, comme l'explique M. Delcassé dans le rapport précédant l'arrangement francoanglais du 8 avril 1904 (1), s'il nous fût donné de devancer les 
entreprises étrangères nous ne pûmes pas, lorsque s'ouvrirent en 1889 les négociations pour le règlement des situations territoriales respectives, obtenir un établissement sur la partie navigable du cours de la Gambie. L'arrangement de 1889 assura au gouvernement britannique une zone de dix kilomètres de chaque côté de la rivière entre la côte et le point terminus de la colonie anglaise, qui fut fixé au-dessus de Yarboutenda, en amont des rapides qui nous fermaient absolument le bief navigable.

L'accord du 8 avril 1904. - Lorsque furent reprises les négociations qui devaient amener, au 8 avril 1904, la consécration officielle de " l'entente cordiale », le gouvernement français se préoccupa d'améliorer en Gambie notre situation.

Aux termes de cet accord, la " frontière existant entre la Sénégambie et la colonie anglaise de la Gambie sera modifiée de manière à assurer à la France la possession de Yarboutenda et des terrains et points d'atterrissement, appartenant à cette localité.

$\mathrm{Au}$ cas où la navigation maritime ne pourrait s'exercer jusque-là, un accès sera assuré en aval au gouvernement français sur un point de la rivière Gambie qui sera reconnu d'un commun accord comme étant accessible aux bàtiments marchands se livrant à la navigation maritime.

Les conditions dans lesquelles seront réglés le transit sur la rivière Gambie et ses affluents, ainsi que le mode d'accès au point qui viendrait à être réservé à la France feront l'objet d'arrangement à concerter entre les deux gouvernements.

Il est, dans tous les cas, entendu que ces conditions seront au moins aussi favorables que celles du régime institué par application de l'acte général de la Conférence africaine du 26 février 188 et de la convention franco-anglaise du 14 juin 1898 dans la partie anglaise du bassin du Niger ».

En somme, nous acquerrions environ 20 kilomètres du cours de la rivière dans la partie représentée comme accessible en tout temps aux bâtiments de haute mer; afin de nous mettre à l'abri d'une de ces surprises trop fréquentes dans des régions encore insuffisamment pratiquées, un accès nous était donné 
en un point du fleuve accessible aux bâtiments de haute mer; nous nous assurions sur la Gambie la jouissance du régime prévu par l'acte de Berlin pour garantir sur le Niger la liberté de la navigation et en même temps nous nous ménagions le bénéfice des applications que nous en avons faites d'un commun accord avec l'Angleterre dans la partie anglaise du bassin du Niger par la convention du 14 juin 1898.

Ainsi se trouvait réglée la question des frontières du Sénégal avec l'Angleterre.

\section{B. - Arrangement franco-portugais}

(12 mai 1886)

Au moment où, très habilement d'ailleurs, nos diplomates poursuivaient la tâche difficile de faire consacrer par des traités formels le développement si rapide de l'Afrique occidentale française, la convention franco-portugaise du 12 mai 1886 - au même titre que l'accord franco-allemand du 24 décembre 1885, que les arrangements franco-anglais du 28 juin 1882 et du 10 août 1889 - contribua à libérer notre action dans la Casamance, la Guinée maritime et au Fouta-Djallon.

L'accord du 12 mai 1886. -- Aux termes de cette entente, la frontière suivait " au Nord une ligne qui, partant de Cap Roxo se tiendra, autant que possible, d'après les indications du terrain, à égale distance des rivières Casamance et San-Domingo de Cachen jusqu'à l'intersection du méridien $17^{\circ} 30^{\prime}$ de longitude Ouest de Paris avec le parallèle $12^{\circ} \mathbf{4 0}^{\prime}$ de latitude Nord. Entre ce point et le $16^{\circ}$ de longitude Ouest de Paris, la frontière se confondra avec le parallèle $12^{\circ} 40^{\prime}$ de latitude Nord ").

A l'Est, la frontière suivra le méridien de $16^{\circ}$ Ouest, depuis le parallèle $12^{\circ} 40^{\prime}$ de latitude Nord jusqu’au parallèle $11^{\circ} 40$, de latitude Nord.

Ce même protocole déterminait les confins de la Guinée portugaise et de la Guinée française par une ligne " se tenant autant que possible suivant les indications du terrain, à égale dis. tance de Rio Componi et de Rio Cassini, puis de la branche sep- 
tentrionale du Rio Componi et de la branche méridionale du Rio Conini, d'abord, et du Rio Grande ensuite ", pour venir aboutir au point d'intersection du méridien $16^{\circ}$ de longitude Ouest et du parallèle $11^{\circ} 40^{\prime}$ de latitude Nord.

Appartenaient au Portugal " toutes les iles comprises entre le méridien du Cap Roxo, la côte et la limite Sud formée par une ligne qui suivra le thalweg de la rivière Cajet et se dirigera ensuite au Sud-Ouest à travers la passe des Pilotes pour gagner le parallèle $10^{\circ} 40^{\prime}$ de latitude Nord, avec lequel elle se confondra jusqu'au méridien du Cap Roxo ").

Les opérations de délimitation : la mission Brosselard-Faidherbe (1888). - A la fin de l'année 1887, le gouvernement portugais ayant émis le désir qu'une commission fût chargée de déterminer sur les lieux la position définitive de lignes de démarcation le capitaine Brosselard fut désigné en décembre 1887 comme commissaire du gouvernement français: M. le lieutenant d'infanterie Clere et M. le docteur Noury, médecin de la marine, furent adjoints à cet officier, en tant que membres de la commission. La commission portugaise se composait de M. de Oliveira, premier lieutenant de la marine royale, commissaire du gouvernement portugais, M. de Cabral, ex-secrétaire général de la Guinée, M. Baulan, capitaine de cavalerie, spécialiste topographe.

Les deux commissions se trouvèrent réunies au mois de février 1888 à Kandiafara, et signèrent après avoir procédé de concert aux opérations de reconnaissance et de délimitation de la frontière sud un procès-verbal en date du 2 mai 1888. Il résultait de ce document qu'à partir du méridien $18^{\circ} 40^{\prime}$ de longitude Ouest, jusqu'à la mer, les commissaires étaient en désaccord sur l'interprétation du traité et l'application qui en pouvait être faite: les délégués considérèrent que leur présence sur la côte occidentale d'Afrique n'était plus nécessaire et la commission se sépara.

Les missions Payn. - Il n'en restait pas moins nécessaire de compléter sur les lieux ces opérations par une nouvelle délimitation technique, dans laquelle il s'agirait simplement de rendre manifeste et pratiquement reconnaissable par des signes 
extérieurs la ligne frontière indiquée par le procès-verbal du 2 mai 1888.

Tel fut le but de la mission confiée en 1900 à M. le capitaine Payn, des spahis sénégalais auquel furent adjoints MM. les lieutenants Benoît et Brocard. Dès le début, la commission se heurta à de graves difficultés par suite de la découverte d'erreurs importantes dans la délimitation effectuée en 1888. La suite des travaux topographiques ne fit que confirmer M. le capitaine Payn dans ses vues et qu'établir plus nettement la divergence complète entre la ligne fixée sur le terrain en 1888, par la commission dont faisait partie au nom de la France M. le capitaine Brosselard et le tracé indiqué par le protocole du 12 mai 1886. Les commissaires portugais remarquèrent d'autre part qu'ils étaient là seulement pour opérer sur les lieux une ligne déterminée en 1888 et non pour procéder à une rectification de frontière : les travaux furent donc momentanément suspendus le 21 mars 1900.

Les deux puissances intéressées ayant, d'un commun accord, constaté les inconvénients de ce mode de procéder accordèrent à leurs représentants "pleins pouvoirs pour reconnaitre les superficies gagnées ou perdues, ajourner l'abornement et procéder ensuite au tracé définitif en ayant recours à la voie des cessions réciproques ». Des instructions furent données dans ce sens à M. le capitaine Payn qui fut chargé d'une nouvelle mission.

Mais, malgré l'impossibilité à peu près absolue de suivre le tracé de la commission de 1888, c'est à l'abornement seul que les commissaires portugais se crurent tenus sans admettre la possibilité d'une nouvelle délimitation conforme à l'esprit de la convention de 1886 et sans accepter davantage le système des compensations territoriales. En présence de cette situation, M. le capitaine Payn se borna simplement à un travail d'abornement en commun jusqu'au moment de la mauvaise saison.

En se séparant les deux commissions se donnèrent rendezvous à Mo-Tä̈rou, sans fixer du reste une date pour la reprise des travaux.

Les missions Maclaud (1903-1906). - La situation ne se 
modifia point jusqu'en 1903 , et à cette date, une nouvelle mission fut confiée, pour la France, à M. le $\mathrm{D}^{\mathrm{r}}$ Maclaud, administrateur des colonies : MM. les lieutenants de vaisseau de la marine royale A. Oliveira Muzanty et Jayme Julio de Souza représentaient le Portugal au sein de la commission de délimitation.

Il n'entre pas dans le cadre de cette étude d'indiquer les travaux qui furent accomplis de 1902 à 1904 par la commission mixte de délimitation sur la partie méridionale de la frontière (1). Les travaux de la campagne 1903 avaient été conduits jusqu'aux environs du village de Soukko, sur la frontière de la Casamance: c'est à ce point que les deux missions s'étaient donné rendez-vous pour le 13 janvier 1904: elles s'y rencontrèrent effectivement le $\mathbf{1 7}$ de ce mois.

A Soukko les missions suivirent le parallèle $12^{\circ} \mathbf{4 0}^{\prime}$ et procédèrent à l'abornement de cette ligne sur une longueur de $126 \mathrm{~km}$. jusqu'à son intersection avec le méridien $17^{\circ} 30^{\prime}$.

Il restait aux commissaires, arrivés au point de l'intersection du parallèle $12^{\circ} 40^{\prime}$ avec le méridien $17^{\circ} 30^{\prime}$ à lever le polygone formé par les fleuves Cachéo et Casamance, de manière à déterminer la ligne brisée médiane que l'accord de 1886 précise comme frontière depuis le méridien $17^{\circ} 30^{\prime}$ jusqu'au cap Roxo, enfin à reconnaître sur le terrain cette ligrne et à procéder à son abornement.

Les deux missions eurent à opérer sur un terrain marécageux, difficilement praticable, dans des régions malsaines, imparfaitement connues, et habitées par des populations souvent hostiles : les difficultés qui en résultèrent ne leur permirent pas de mener leur œuvre à terme.

Elles purent néanmoins a près avoir effectué le lever de la rive droite du Cachéo et de la rive gauche de la Casamance regagner le 18 mai le village de Kolibantan, leur point de départ, formant ainsi sans erreur appréciable un polygonedont le développement n'était pas moindre de 366 kilomètres.

La ligne frontière put ainsi être déterminée théoriquementsur

(1) Voir à ce sujet la notice de la Guinée française, par M. F. Rouget (chapitre IV). 
la carte, mais sa reconnaissance sur le terrain et son abornement durentêtre remis à une campagne prochaine. Le 25 mai 1904 fut signé à Manka le procès-verbal de suspension des travaux et rendez-vous fut pris entre les commissaires des deux pays au mê me endroit pour le $\mathbf{1}^{\text {er }}$ décembre suivant.

Cette dernière campagne dura du $1^{\text {er }}$ décembre 1904 au 20 avril 1905, date à laquelle fut élaboré le dernier procès-verbal au poste français d'Oussouye ; après avoir successivement traversé les trois régions que $\mathrm{M}$. le $\mathrm{D}^{\mathrm{r}}$ Maclaud caractérise : région mandingue, région balante et région bagnounk.

"Le grand nombre de marigots navigables qui sillonnent la Basse Casamance, écrit le $\mathbf{D}^{r}$ Maclaud, permet à la fois d'assurer efficacement la sécurité du pays par une surveillance facile et de faire pénétrer jusqu'au dernier village diola les bienfaits de la civilisation. Déjà, dans le cercle d'Oussouy, pacifié depuis deux ans à peine, le commerce se développe, en même temps que les écoles se créent. Le Diola vient au poste du résident demander un jour des médicaments, un autre des semences. Les commerçants européens apprennent le chemin du pays diola et opposent aux vexations des dioulas les procédés d'un trafic honnête et loyal ; des factoreries se fondent, un canot à pétrole circule sur les arroyos d'Elinkine et de Mossor. Encore quelques années, et le pays des fétiches et des "bikinns " sanguinaires deviendra le plus riche des provinces de la Casamance, et l'ancienne escale de Carabane, aujourd'hui presque abandonnée, atteindra une prospérité qu'elle n'a pas encore connu ».

La première partie des travaux de la Commission, relatifs à la frontière méridionale, a reçu l'approbation des deux gouvernements intéressés dès 1904 . En ce qui concerne la frontière de la Casamance, il a été procédé les 6 et 12 juillet 1906 à un échange de notes consacrant l'accord intervenu entre les Commissaires des deux pays par le ministre de Portugal à Paris et le ministre des Affaires Etrangères.

Ainsi se trouve donc définitivement réglée la délimitation des frontières franco-portugaises.

Ainsi, à l'heure présente, les frontières de notre colonie se 


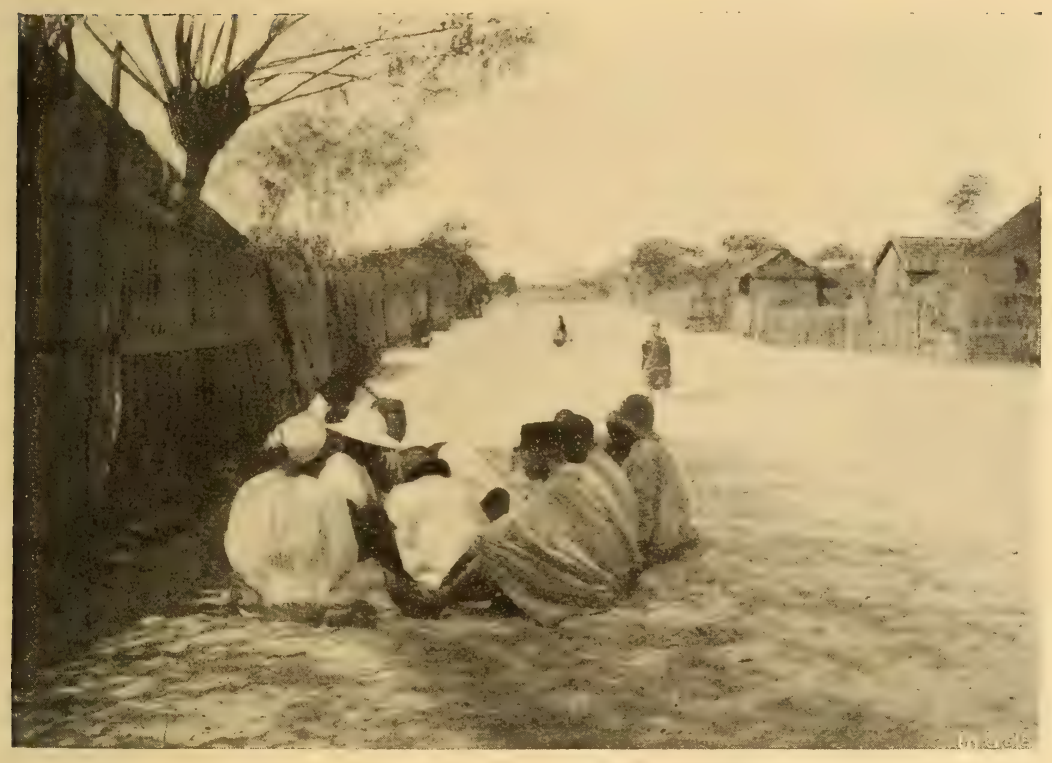

Fig. 5. - Dakar (Le village noir).

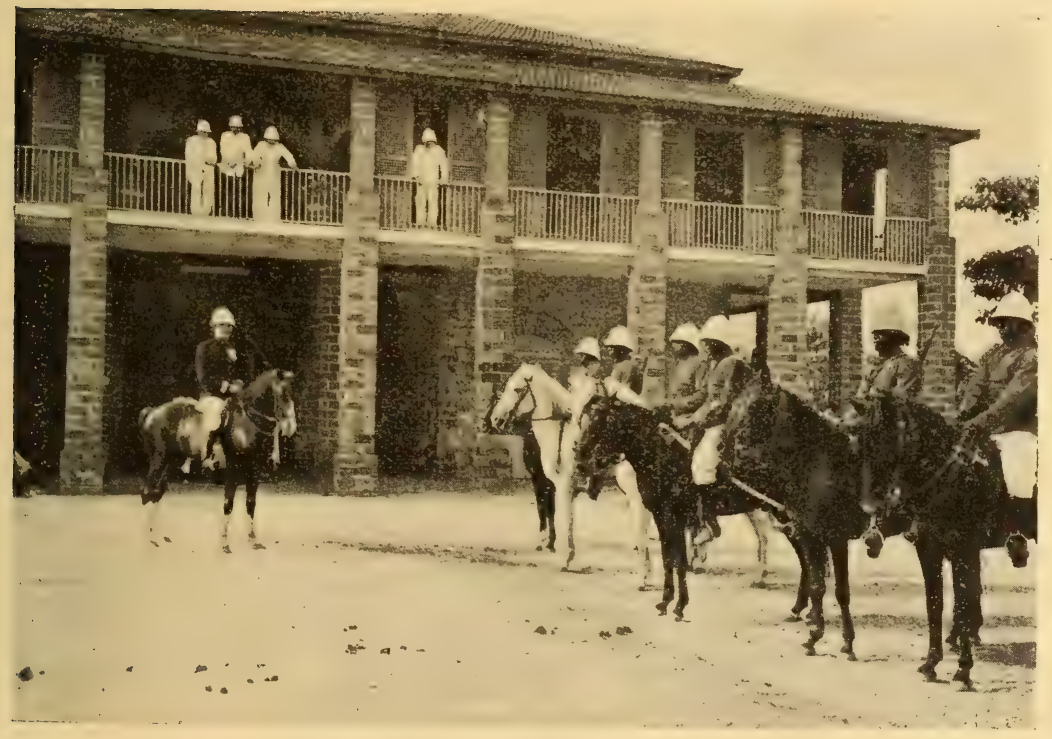

Fig. 6. - La garde régionale à Kaolack. 

trouvent fixées avec ses voisins d'une façon précise, à la réserve des corrections de détail que pourraient rendre nécessaires le progrès de la géographie, ou plus impérieusement encore, les commodités des puissances intéressées.

Aussi bien, convient-il d'étudier maintenant la nature du pays et des habitants avant d'examiner l'organisation administrative, dont la valeur ne saurait être complète que si elle concordait avec les conditions même de la vie sociale. 



\section{DEUXIÈME PARTIE}

LES CONDITIONS DE LA VIE SOCIALE

AU SÉNÉGAL 



\section{CHAPITRE IV}

LE PAYS ET LES GRANDES RÉGiONS NATURELLES

\section{A. - Aperẹu géologique.}

Les divers sondages que l'on a eu l'occasion d'effectuer au Sénégal, soit pour exécuter divers travaux, ou forer des puits, soit dans un but scientifique nous permettent d'avoir une idée assez précise de la constitution géologique de notre colonie.

La surface du sol ne présente guère que du sable, de la latérite et de l'argile. Le long des côtes seulement, on voit apparaître des formations rocheuses.

L'étude de ces affleurements a été faite par différents spécialistes, et en particulier par une mission spéciale de sondages qui partout a trouvé les mêmes terrains.

Les différentes couches se présentent dans l'ordre suivant (1):

$1^{0}$ Sable, ou argile sablonneuse;

$2^{0}$ Latérite;

$3^{0}$ Argile compacte à gros silex ;

$4^{0}$ Calcaire fossilifère, appelé par M. Chautard calcaire de Fandene ;

$5^{\circ}$ Argile magnésienne, appelée par le capitaine Friry marnes feuilletées ;

$6^{0}$ Marnes magnésiennes riches en phosphate et en silex;

$7^{0}$ Calcaires de Rufisque.

(1) D’après les renseignements fournis par M. le capitaine Friry, chef de la mission de sondages. 
Sable. - Le sable est plus ou moins pur et l'épaisseur de la couche est variable : nulle là où la latérite affleure, on en rencontre au contraire des épaisseurs qui vont jusqu’à 40 mètres dans les environs de Louga.

On le trouve souvent aggloméré sous forme de grés tendre dans l'intérieur de la masse et cette formation s'est souvent rencontrée dans certains puits de Louga.

Nulle part on ne trouve de fossiles.

L’argile qui est mélangée au sable, le rend quelquefois imperméable, et de nombreux villages lui doivent les nombreuses céanes qui assurent leur alimentation en eau.

Latérite. - On peut assurer que cette roche n'est pas éruptive. Comment s'est-elle formée? Nous laissons aux spécialistes la résolution de ce problème. On a pu supposer qu'elle était un produit de la décalcification de la roche sous-jacente. Mais cette roche est pétrie de débris fossilifères alors que l'on n'en trouve aucun dans la latérite Cette hypothèse parait donc inexacte.

La plus grande épaisseur constatée de latérite ne dépasse pas 10 mètres. En maints endroits, on n'en rencontre qu'un faible cordon de grains isolés. Sur de vastes espaces, au contraire, elle existe en masse compacte et lorsque l'argile colmate les joints de cette masse et les pores de la roche, des nappes d'eau sont retenues : c'est ce qui s'est passé à Thiès et dans de nombreuses localités du Sénégal.

Argile compacte à silex. - Le banc d'argile n'est pas continu et sa plus grande épaisseur rencontrée à Thiès ne dépasse pas 2 mètres. Cette couche fait d'ailleurs très souvent défaut.

Calcaire fossilifère de Fandène. - Cette roche n'existe pas partout. Aux environs de Thiès, l'épaisseur en est faible; elle semble augmenter au fur et à mesure qu'on se rapproche du fond Toul-Fissel.

Entr'autres fossiles, les puits de Toul et de N'Doukoumane ont donné des oursins. Les nombreux puits qui vont être forés cette année dans cette région permettent d'espérer que l'on recueillera suffisamment de fossiles pour pouvoir déterminer ce terrain.

Argiles magnésiennes ou marnes feuilletées. - Cet étage est 
le plus considérable : il atteint et parfois dépasse l'épaisseur de 50 mètres et se rencontre partout.

La masse est fragmentée en blocs qui, eux-mêmes sont composés de feuillets très minces. La couleur de l'argile est généralement blanche à la partie supérieure, elle devient ensuite d'autant plus foncée que l'on s'approche davantage du fond de la couche.

Comme fossiles, il n'a été trouvé qu'un poisson à la partie inférieure de l'étage, dans le puits de Dieling, près de Soussoune.

Marnes magnésiennes à phosphates. - L'étage précédent repose sur des argiles riches en phosphates de chaux et en silex. Le forage du puits de Dielor a montré que cet étage était parfois assez puissant. La première couche riche en phosphate a 12 mètres d'épaisseur et pendant plus de $\mathbf{2 4}$ mètres, l'on est resté dans le même terrain sans pouvoir le traverser franchement.

Dans les deux puits de Dielor et de Dieling, l'eau a été trouvée dans une couche très riche en silex. Ces deux puits ont donné naissance à une nappe ascendante : ce qui semblerait indiquer que l'on s'est trouvé au-dessus d'un pli du terrain formé par les marnes magnésiennes phosphatées.

Nous ne faisons qu'une hypothèse en admettant que cette couche repose directement sur les calcaires de Rufisque. Cela prouve seulement que l'on n'a pas rencontré de couches intermédiaires, qui peuvent exister malgré cela. Le calcaire de Rufisque étant éminemment perméable, une couche de terrain imperméable doit se trouver au-dessus. Si cetle couche fait défaut, la masse des calcaires de Rufisque, complètement noyée par une nappe d'eau, donnera naissance à des puits de grand débit.

Calcaire de Rufisque. - Ce calcaire représente pour nous le dernier terrain que l'on rencontre; il est très pauvre en fossiles.

Toutes ces formations semblent être tertiaires. Entre ces terrains et ceux qu'on trouve sur la Falémè, y a-t-il des terrains intermédiaires? Jusqu'à présent nos connaissances ne nous permettent pas de répondre.

Quelques échantillons provenant d'un puits du Ferlo semblent nous indiquer que nous aborderons le terrain secondaire.

Un crédit important est affecté cette année à la construction de S. 
puits ; il en sera probablement de même les années suivantes. Tous ces puits seront raccordés par un nivellement au niveau à lunette, on établira avec soin la coupe de chaque puits et l'on arrivera ainsi peu à peu à déterminer la nature géologique des couches supérieures du Sénégal.

\section{B. - Les grandes régions naturelles.}

Relief du sol : la côte subsaharienne. - Le bas Sénégal n'est guère qu'une façade maritime du Sahara. Au Sud des possessions espagnoles, du Rio de Oro, le littoral plat de la Mauritanie, seulement accidenté par quelques dunes de sable qui ne dépassent pas $30 \mathrm{~m}$. d'altitude, est couvert d'une poussière de quartz et bordé le long de la mer par des marigots à salines.

Notre ancien établissement de Portendik, hâvre médiocre où une race foraine faisait jadis quelque trafic de la pomme apportée de l'intérieur par les Maures de l'Adrar, est aujourd hui abandonné.

Vers l'île d'Arguin, la mer est peu active, mais aussi peu hospitalière; le vent alizé du Nord-Est la refoule sans cesse vers le large et lui oppose sur la côte des bourrelets de dunes qui parfois emprisonnent des étangs littoraux. Le relief, bas et monotone, se poursuit sous les eaux peu profondes qui s'étalent audessus du banc d'Arguin.

Ces mêmes caractères se maintiennent dans la colonie du Sénégal au Sud du fleuve Sénégal, et même un peu au-delà du Cap Vert, jusqu'à l'embouchure de la Casamance; le Cayor est plat, les sables et les argiles viennent mourir en lentes ondulations dans la mer, une flèche de sable "la langue de Barbarie " constitue entre les lagunes et la mer la plage de bains de Saint-Louis. Le Cap Vert dresse sur cette vaste plaine des falaises que leur isolement fait paraitre puissantes et que soulignent en mer, les rives basaltiques de l'ilot de Gorée.

En arrière des dunes côtières, une plaine de sables coupée par la vallée du Sénégal, remonte vers le pays tropical, glacis pauvre et desséché des plateaux intérieurs. Du fleuve, on aperçoit par places à l'horizon de vagues amphithéâtres de collines, mais il 
n'existe dans ce pays aucune masse montagneuse proprement dite, aucun centre de condensation et de dispersion des eaux.

Peut-être l'Adrar se distingue-t-il par un relief plus varié, mais la pénétration en est encore si incomplète, que nous devons nous borner ici à des conjectures. Or, on sait que le Sahara forme, au Nord de Tombouctou, un bourrelet contre lequel les eaux d'amont se sont d'abord amassées, formant les lacs Débo et Faguibine qui furent comme le premier delta du Niger. L'Adrar serait alors le bastion le plus occidental de ce redressement, celui dont le voisinage aurait courbé le Sénégal vers l'Atlantique.

La zône de relief subsaharien qui est celle du bas Sénégal se continue vers l'Est, empiétant même sur la bouche du Niger par les steppes du Kaarta et du Macina, et déjà le relief du HautSénégal, où les sources que forment le Niger, le Sénégal, le Falémé, la Gambie, le rio Grande, s'épanouissent en éventail autour du Fouta Djallon, diffère sensiblement de celui du bas pays par son caractère accidenté.

Dans cette partie de la côte sénégalienne, deux régions sont particulièrement intéressantes : le Cayor et le Baol d'une part; la région des Niayes, de l'autre.

" Le Cayor et le Baol constituent une région, dont le soubassement comprenủ des couches très variées, plissées et faillées par les grands mouvements du sol qui ont accompagné l'apparition des volcans du Cap Vert. Il est malheureusement difficile de se faire une idée très exacte de ce sous-sol, car ces régions ne sont entaillées par aucune érosion profonde, et les quelques tranchées nécessitées par l'établissement du chemin de fer de Dakar à Saint-Louis ont traversé des épaisseurs notables de latérite, mais n'ont fait qu'effleurer les calcaires et les marnes sous-jacents. Enfin de fortes épaisseurs de sable et de latérite masquent absolument le sous-sol.

Néanmoins, on a pu recueillir de précieux renseignements, d'une part, grâce aux travaux de forage de puits dans le Baol, d'autre part, grâce à l'examen des falaises qui s étendent depuis les environs de Rufisque jusque vers le Sine-Saloum.

Dans le Baol, lors des forages de certains puits, exécutés par l'administration des Affaires indigènes, l'on a conservé avec soin 
des échantillons des diverses couches traversées, avec l'indication de leurs épaisseurs et de leurs profondeurs. Il serait à souhaiter. dans l'intérêt de l'étude, encore si incomplète, de notre colonie, que cette pratique se généralisât et devînt réglementaire dans tous les travaux entrepris par l'administration.

Voici deux relevés de ces forages :

\section{Puits de Thiès (Baol).}

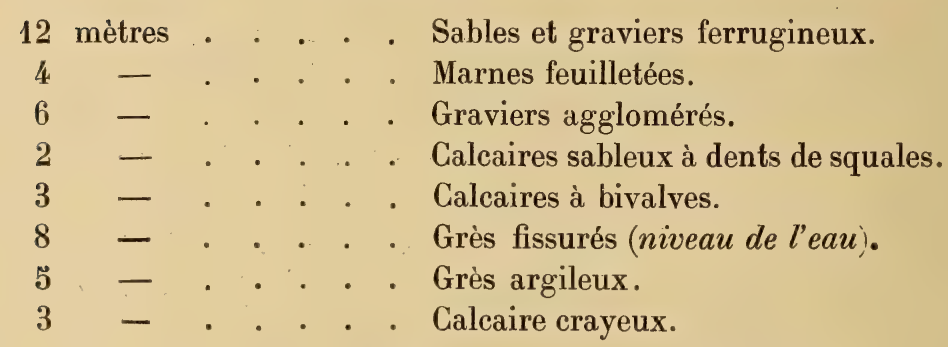

Puits de la ferme-école de M'bambey (Baol).

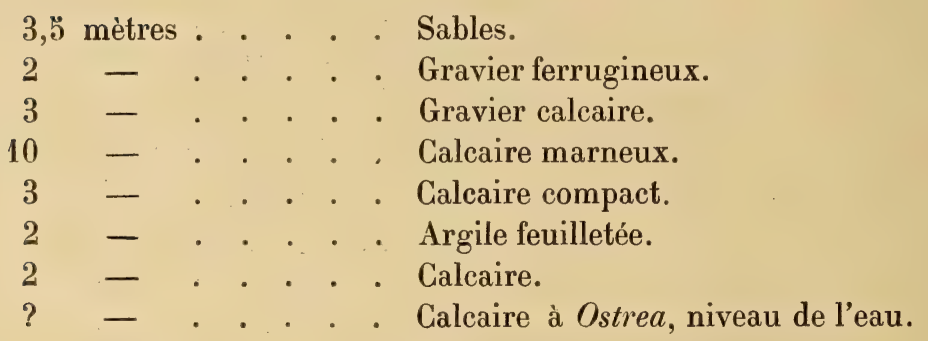

Du cap Rouge au cap de Naze, l'examen des falaises révèle une série de bancs calcaires, quelquefois dolomitiques, plongeant à 10 degrès vers le Sud-Ouest, et dont l'épaisseur totale peut atteindre 45 mètres. Ces calcaires, très remaniés par les pluies tropicles, sont souvent recoupés de filonnets de calcite, d'hématite, etc. Au Sud-Est de Popenguine, au cap de Naze, ces formations calcaires sont remplacées par des épaisseurs de 25 à 30 mètres d'un grès argileux très tendre, jaune, veiné de rouge et de violet par les infiltrations d'hématite. Ces grès reposent sur de puissants bancs de marnes grises et d'argiles bleuâtres, souvent ocreuses, et entrecoupées de petits niveaux de gypse. L'ensemble de ces formations paraîtêtre tertiaire, peut-être avec 
un peu de Crétacé. Certains fossiles, très rares, ressemblent à ceux de l'Éocène français. Des dents de squale paraissent apparlenir à l'Odontaspis cuspidata" (1).

Tout le long de la côte entre Dakar et Saint Louis s'étend la région des Niayes (région des palmiers).

" C'est une plaine sablonneuse, basse, étroite, adossée aux premières hauteurs du Cayor, et séparée de la mer par une chaîne de dunes. C'es dunes d'un sable fin, allant du blanc au rouge brique, atteignent une altitude d'une trentaine de mètres et plus en certains points (Petites Mammelles, au Nord-Est de la baie d'Yof). Ces dunes, interrompues par l'embouchure du Sénégal, se continuent au Nord jusqu’à celles du Sahara. Les unes sont mobiles, les autres fixées par les plantes.

Le fond des Niayes, couvert d'une végétation abondante et touffue, est jalonné par une série d'étangs et de lagunes, les uns d'eau salée, les autres d'eau saumâtre, d'autres enfin, d'eau douce, alimentée par les infiltrations venues de l'intérieur.

La presqu île du Cap Vert, avec les plaines calcaires basses et marécageuses où est construit Rufisque, les hauteurs de Ouakam, les falaises de calcaire altéré, injecté de fer, de Dakar, les basaltes en colonnades de Gorée, du cap Manuel, des îles Madeleines, forme encore une région particulière " (2)

La côte soudanienne. - La côte, monotone et rectiligne au Sud du Cap Vert passe à des conditions nouvelles dès les embouchures des courtes rivières qui précèdent la Gambie; des îles sont détachées du littoral; la mer poussée par le contre-courant équatorial, ne s'épuise plus en vagues molles contre des dunes de sable; des factoreries sont montées sur pilotis dans les alluivons grasses bordant les fleuves qu'elle a creusés; la navigation maritime est ainsi portée par la Casamance et par la Gambie assez avant dans l'intérieur des terres ; c'est la côte du Soudan qui commence, succédant à celle du Sahara; les différences s'accusent de plus en plus nettement jusqu'à notre Guinée par la Guinée portugaise, où l'estuaire du Rio Grande débouche en face de l'archipel des Bissagos.

(1) Cligny, op. cit.

(2) Ibid., p. 332. 


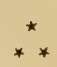

Hydrographie. - Le réseau des eaux courantes comporte principalement le bas Sénégal, qui né dans la zône des pluies tropicales se prolonge comme le Nil à travers le désert, où l'inondation d'amont le soutient en l'absence d'affluents permanents.

La vallée du Sénégal. - La vallée du Sénégal s'étend entre les formations gréseuses du pays des Maures, du Fouta et du Ferlo, aussi désertiques les uns que les autres. Dans la vaste plaine où se creuse son lit, le fleuve s'est livré à des divagations sans nombre; sur ses deux rives s'étend un dédale inextricable de marigots, entre ses bras, de vastes îles autrefois très boisées, maintenant presque entièrement livrées aux cultures sont à chaque crue recouvertes en partie par l'eau, qui chaque fois dépose un limon fertilisant.

En outre, le long des marigots qui avoisinent la mer, l'action des organismes vivants a créé de singulières collines de coquillages, mêlés de sables et de limons, qui peuvent s'élever à 3 mètres, comme celle exploitée pour ballast à Tountoulit. La plupart des mollusques dont les coquilles forment ces accidents appartiennent à des espèces actuellement vivantes dans les eaux saumâtres. Cette formation, bien connue dans les environs de Saint-Louis, se retrouve un peu partout où il existe des lagunes saumâtres. Ainsi, à la Somone, entre Rufisque et Portudal, des acéphales $(A r c a)$, des gastéropodes (Tympanotonus), pêchés comme comestibles par les indigènes, contribuent journellement à angmenter de leurs débris des collines déjà hautes de 8 à 10 mètres.

Cours du Sénégal. - Le bas Sénégal entre dans la colonie à Bakel, pris du confluent de la Falémé.

Le fleuve Sénégal, formé par plusieurs rivières (Bafing, Bakhoy et Baoulé), descendant du Fouta-Djallon, s'étend une longue ur de 1.700 kilomètres et est navigable jusqu'à Kayes. C'est un fleuve à biefs successifs et à crues annuelles importantes.

Le Sénégal n'ayant, ni lui, ni ses affluents, aucun réservoir naturel dans sa partie supérieure, la vague des eaux de la saison des pluies, circulant et s'écoulant sans régulateur, crée des diffé- 
rences de niveau très considérables. Au mois d'avril, les vapeurs ne tirant que 60 centimètres d'eau ne peuvent pas dépasser le seuil de Mafou, à 33 milles (61 kilomètres) de Podor; ils ne peuvent arriver là que parce que la marée s'y fait encore sentir; on est alors obligé de trainer les pirogues et les chalands sur des seuils où il n'y a pas 10 centimètres d'eau. Aux plus hautes eaux, de juillet à octobre, des vapeurs de 1.000 tonneaux peuvent aller directement de Bordeaux à Kayes. A Bakel, la crue est de 15 mètres; à Dagana, elle atteint encore 4 mètres.

Le fleuve, dont le courant est presque insensible au mois de janvier, ronge aux hautes eaux les parties concaves de ses rives, de manière à mettre en danger certains postes, Dagana par exemple, à faire disparaittre deux sur trois des rangées de magnifiques caïlcédrats bordant les quais de Podor, et à nécessiter des travaux de défense assez sérieux pour garantircertaines localités contre l'envahissement de l'eau.

De temps en temps (tous les quatre ans, disent les indigènes), des crues d'une ampleur exceptionnelle inondent la vallée sur une largeur qui atteint $\mathbf{3 0}$ kilomètres, transformant certains postes en îles, et fertilisant tout le fond de la vallée par le dépôt d'un limon sableux analogue à celui qui fait la richesse de l'Egypte.

Les différences de courants et de niveaux ont taillé dans les berges du Sénégal une série de gradins réguliers, qui contribuent à maintenir l'escarpement de ces berges.

Les seuils que le Sénégal est obligé de franchir sont dus à différentes causes : les uns, à la présence des bancs de roches dures, que le fleuve n’a pas encore pu. détruire. D'autres, comme celui de Mafou, paraissent dus surtout à l'accumulation de débris végétaux, peut-être retenus par les aspérités d'unẹ roche dure sous-jacente.

Dans la partie inférieure de son cours, viennent se brancher sur le fleuve un grand nombre de marigots, les uns (marigots de Doué, de Morghen) se comportant comme des bras du fleuve, d'autres se terminant en cul-de-sac, d'autres enfin servant de déversoir à de vastes étendues d'eau (lac Cayar, lac de Guier).

Ce lac de Guier, ou de Merinaghen, ou lac Paniéfoul, pré- 
sente un intérêt particulier. Il occupe une vallée large de 12 kilomètres, longue de 80 , qui se prolonge jusqu'au-delà de YangYang par une autre vallée, plus resserrée, complètement sèche en dehors de l'hivernage, prolongée elle-même vers le Sud-Est par une suite de dépressions.

Le niveau de ce lac est assez variable, en dehors des crues annuelles; alors que, en janvier 1900, il pouvait à peine porter des pirogues jusqu'à Merinaghen, on a pu, en 1891, lors de la campagne contre Ali Boury, ravitailler par chalands le poste de Yang-Yang.

Le lac de Guier communique avec le Sénégal par la rivière Taouey, qui vient déboucher à Richard Toll. Cette rivière tortueuse, aux rives encaissées, d'une largeur qui n'atteint pas 45 mètres a, d'avril à septembre, son courant du Nord au Sud lorsque la crue du Sénégal vient remplị le bassin de Merinaghen; d'octobre à avril, le lac se vide dans le Sénégal, et le courant s'établit du Sud au Nord. C'est au confluent de la Taouey et du Sénégal que le bateau citerne « $A k b a$ » vient chercher une partie de l'eau douce nécessaire aux habitants de Saint-Louis lorsque la baisse des eaux du fleuve permet à la salure de l'Océan de remonter jusqu'à 100 kilomètres dans l'intérieur.

Il serait très facile, en raison de l'étroitesse de la Taouey, de la barrer au moyen d'écluses complétées par quclques digues coupant les plaines basses avoisinantes. On conserverait de la sorte dans le lac de Merinaghen une énorme masse d'eau, capable de servir de voie de pénétration commode jusqu'au cœur du Djoloff.

Dans les environs de Saint-Louis, le marigot de Kassak a été barré pour servir de réservoir d'eau douce. Une usine élévatoire, située à Makhana, envoie cette eau jusqu'à Saint-Louis.

A cinquante kilomètres en amont de Saint-Louis, s'ouvre le marigot des Maringouins, qui se dirige perpendiculairement à la côte. Il parait avoir été un ancien passage du fteuve vers la mer. Il semble aussi que le fleuve ait utilisé autrefois un itinéraire passant par le lac de Guier, et de là par Louga, pour venir déboucher à la mer vers les Nayes; ce qui le donne à penser, c'est, d'une part, dans les environs de Merinaghen, la présence 
d'une série de vallées, actuellement sèches, orientées N.-E. S. -0. et d'autre part la présence sur cet itinéraire, d'un certain nombre de dépôts récents, évidemment d'eau douce. Certains géographes ont cru (mais cette opinion ne parait pas justifiée), que le fleuve, abrité par les dunes du Cayor, suivait la direction du marigot de Bounoun et venait déboucher dans le golle de Rufisque, peut-être à la Somone.

Enfin, une tradition indigène prétend qu'à Benou Boro, près de M'bala (cercle de Tivaouane), il y avait un estuaire où venaient ancrer les vaisseaux des Blancs.

Barre du Sénégal. - A l'heure actuelle, d'ailleurs, l'embouchure du Sénégal est loin d'être fixée; depuis 1850, elle a changé de place, irrégulièrement, sur 23 kilomètres de longueur. Sur ce trajet, le fleuve coule parallèlement à la mer, dont il n'est séparé que par la Langue de Barbarie. C'est une flèche de sable, large de 300 à 400 mètres, si basse que par les gros temps les lames passent par-dessus ; un raz de marée, une tornade, ont bientôt fait de déplacer ces sables mouvants et de créer une brèche qu'agrandit le fleuve et qui devient du jour au lendemain sa nouvelle embouchure. Cette embouchure, d'ail leurs, est obstruée par les sables, qui déterminent la barre du Sénégal; sous l'influence du conflit de la marée, des vents dominants, et du courant fluvial, elle se déplace continuellement et nécessite une surveillance incessante. A la saison sèche, elle n'a souvent pas plus de $\mathbf{2} \mathrm{m}$. $ّ 0 \mathrm{~d}$ eau et oblige les navires à se délester pour passer; à l'hivernage les eaux du fleuve refoulent les eaux de la mer jusqu'à plus de 10 kilomètres au large. M. Bouquet de la Grye, M. Aube, ont proposé de fixer l'embouchure du Sénégal au moyen d'une jetée qui empêcherait les divagations des sables.

Le Sénégal joue, au point de vue économique, un rôle de premier ordre : la vie animale, assourdie sur tous les plateaux voisins par la toute puissance du régime désertique, éclate au contraire et s'épanouit le long du fleuve, et des indigènes sédentaires ont pu, rassurés par la présence des Français, établir des villages sur les points des rives où ne se tenaient autrefois que des marchés temporaires. 
Les Rivières du Sud. - La côte, au Sud de Joal et jusqu'à la colonie anglaise de Sierra-Leone est entamée par une série de vastes et larges vallées-deltas, où, parmi des alluvions récentes sillonnées de nombreux marigots, la mer entre profondément et peut, jusqu'à 150 kilomètres dans l'intérieur des terres, porter des bâtiments d'un certain tonnage. Ce sont les Rivières du Sud : Saloum, Gambie, Casamance, Rio Cacheo, Geba, Mellacorée. Ces curieuses vallées, assez vastes pour contenir un fleuve majestueux, ne servent pourtant de réservoirs qu'à d'assez faibles rivières (Gambie et Rio Grande exceptés). Il faut peut-être y voir d'anciennes vallées, longuement façonnées dans des territoires éloignés de l'Océan, ramenées au niveau de la mer et envahies par ses eaux à la suite d'un de ces effondrements qui ont abaissé le sol africain vers la ligne de fracture jalonnée par les volcans de Madère, des Canaries, de Gorée, des îles du Cap Vert, des îles de Los, de Cameroun et de SaintThomas. Deux larges et vastes vallées, de formation analogue, coupent en deux la presqu'île du Cap.Vert, du Sud au Nord, sur 40 kilomètres de large, et se joignent à la station de Pout par leurs parties amont. C'est la Somone, qui communique avec la mer au Sud, et la Tanma, séparée de la mer au Nord par une ligne de dunes. Le fond de la Somone est occupé par un vaste marigot couvert de palétuviers ; le fond de la Tanma est, pendant la saison sèche, tapissé de vases salées blanchâtres ; pendant la saison humide, rempli d'eau légèrement saumâtre. Ces eaux ne sont alimentées, pendant la saison sèche, que par quelques ruisselets provenant de sources; pendant la saison des pluies, de vastes bassins de réception, découpés dans les assises marneuses et latéritiques du plateau de Thiès, y jettent de puissantes rivières torrentielles.

Mais ces vallées sont trop larges, le seuil qui les sépare trop peu élevé (15 mètres), les hauteurs avoisinantes trop faibles pour qu'elles aient été creusées par les eaux de ruissellement, telles qu'elles peuvent être fournies actuellement. Ce doit être des vallées d'effondrement.

Ainsi, entre le Sénégal et le Niger du Macina, les eaux superficielles sont rares; les colonnes Archinard, à la recherche 
d'Ahmadou dans le Kaarta, durent apporter une provision d'eau potable; les groupements indigènes sont pressés autour des puits, tels ceux d'Ouossiboujou qui furent disputés avec acharnement à nos troupes. Des ravins d'oueds, aux berges abruptes. égratignèrent de raies profondes la surface du plateau. Cette nature est celle du Ferlo, au Sud du Sénégal, région misérable, parce qu'elle manque d'eaux courantes. Dans le Cayor même, le long de la voie ferrée du chemin de fer de Dakar à Saint-Louis, ce sont encore des eaux souterraines qu'il faut amener à la surface pour les besoins de l'homme et de l'agriculture. Mais déjà quelques courtes rivières côtières, le Joal, le Saloum, terminées par de petits estuaires, annoncent l'approche des conditions tropicales.

Le Saloum, n'est autre chose qu'un bras de mer pénétrant très avant dans les terres et se ramifiant en plusieurs dérivations ou marigots qui se détachent du courant principal formé par le flux et le reflux de la marée. Il ne reçoit aucun affluent d'eau douce, sauf au moment des grandes pluies de l'hivernage. Cet estuaire marin et les marigots qui en dérivent baignent de leurs eaux toujours salies les Etats indigènes du Saloum, du Sine, du Niom et du Rip.

A 60 mille marins environ de son embouchure on trouve, sur la rive droite, le poste de Kaolaok que les grands bateaux peuvent atteindre en toute saison.

La Gambie. - Les conditions tropicales se précisent le long de la Gambie et de la Casamance. La Gambie finit en terre anglaise, mais ses sources appartiennent au Fouta Djallon et son cours moyen, jusqu'à Yarboutenda, relève de notre Sénégal.

Avant d'entrer en plaine, elle traverse plusieurs défilés où elle n'est pas navigable; mais les bàtiments de mer peuvent la remonter sur plus de 300 kilomètres, et ses affluents de gauche, Sandougou, Niériko, découpent dans le plateau des brèches par où l'on gagne la Falémé et le Sénégal de Bakel sans sortir de la zône du climat tropical; l'estuaire de la Gambie, dépendance politique de l'Angleterre, appartient économiquement aux maisons bordelaises qui font le commerce du Sénégal.

La Casamance. - La Casamance dont le cours total mesure 
environ 300 kilomètres, finit dans l'Océan par un chenal large de 2 kilomètres et dont les profondeurs seraient au moins $2 \mathrm{~m} .50$ jusqu'à Carabane : de là jusqu'à Sedhiou, de grandes barques de 200 tonnes remontent en toutes saisons; elles font escale au passage à Ziguinchor, poste de la rive gauche. On a songé à pénétrer par la vallée de la Casamance vers celle de la Gambie moyenne : mais le pays intermédiaire, raviné, coupé de petits bois, n'est guère propice à la circulation commerciale. Aussi bien la Casamance est-elle apparue comme un impasse plutôt qu'un corridor d'entrée vers le Soudan occidental. N'en est-il pas de même d'ailleurs du Rio Grande et des petites rivières littorales dont le commandement ne dépasse pas les districts voisins de leurs rives?

Ainsi, le Sénégal apparait au point de vue géographique, comme une colonie de façade, et on ne saurait méconnaitre l'étroite corrélation qui y existe, tant au point de vue du relief que de l'hydrographie, partant de la vie économique, entre nos territoires sénégalais et les pays de l'hinterland, établissant deux régions naturelles distinctes.

Si la zône comprise au Nord du Cap Vert accuse, en effet, un caractère nettement subsaharien, la partie méridionale de la colonie révèle une influence soudanienne, et la Casamance est, dans notre domaine de l'Afrique occidentale, le district le plus septentrional où des expériences d'agriculture tropicale aient été tentées. 


\section{CHAPITRE V \\ LES CONDITIONS DE LA VIE SOCIALE AU SÉNÉGAL \\ (Climat. Flore. Faune).}

\section{A. - Climat.}

La zône subsaharienne à laquelle appartient le Bas-Sénégal est soumise au climat continental, tempéré légèrement sur la côte par le voisinage de la mer.

L'année se divise en saison humide et saison sèche et l'on nomme hivernage au Sénégal, de même qu'aux Antilles, la saison des pluies qui correspond cependant aux mois d'été.

La température moyenne de Saint-Louis est d'environ $20^{\circ}$ centigrades ; elle monte à $27^{\circ}$ pendant l'hivernage de juin à octobre ; l'atmosphère est alors imprégnée d'une humidité chaude, beaucoup plus pénible pour l'Européen que les ardeurs sèches du soleil saharien. C'est le moment où les organismes, débilités par un ralentissement général des combustions, offrent une proie plus facile aux maladies chroniques et épidémiques.

A l'intérieur, la saison pluvieuse est de plus en plus réduite à li précipitation de quelques averses d'été; dans la basse vallée du Sénégal, la chaleur est plus lourde et plus constante qu'à la côte; il y manque, en effet, l'échange quotidien des brises de terre et de mer, et Podor, où se termine la navigation du Sénégal en hiver, est un des " enfers du globe ".

Les plateaux dans lesquels est inséré le fleuve sont balayés par des vents du Nord et Nord-Est qui, s'ils n'apportent pas de fraicheur, renouvellent sans cesse et nettoient l'atmosphère; le 
couloir fluvial échappe à ces influences bienfaisantes, de sorte que la région la plus saine est celle où les eaux superficielles sont plus rares.

La raison de cette salubrité plus grande est dans les excès du climat continental ; l'intensité du rayonnement nocturne est telle que la température oscille, dans les vingt-quatre heures de $25^{\circ}$ à $30^{\circ}$.

11 nous paraît intéressant de donner, à titre d'indications, les tableaux des observations météorologiques qui ont été faites à Saint-Louis et à Dakar pendant l'année 1903 (Voir ces tableaux page 63 et 64 ).

\section{B. -- La flore}

La colonie du Sénégal, que sa situation dans l'hémisphère Nord, met à quelques jours des ports européens, possède de nombreuses sources de prospérité qui se sont déjà partiellement révélées : ses territoires, notamment que l'on représente souvent comme uniformément sableux et arides, présentent au contraire des aspects rariés et sont pour la plupart productifs.

Bien que diminuant d'importance à mesure que l'on s'élève en latitude, les chutes de pluie sont partout assez abondantes pour rendre possibles les cultures et la large vallée du fleuve Sénégal, fertilisée par les inondations annuelles, constitue une région d'avenir.

La véritable limite qui sépare au Nord le Sénégal des régions désertiques est formée par le rebord des plateaux qui marquent, au delà du fleuve, la frontière géologique du Sahara.

Dans son ensemble, la colonie peut être considérée comme un immense plateau pourvu d'une pente à peine sensible de direction Est, Ouest. Les derniers contreforts du massif montagneux du Fouta Djallon s'étendent sur la région Sud-Est qui possède seule un relief notable.

Les terres cultivables sont d'origines et de composition diverses. La vallée du Sénégal souvent fort large, ses îles nombreuses et son vaste delta intérieur sont constitués par des dépôts quaternaires et actuels. Les vallées du Saloum et de la Casa- 


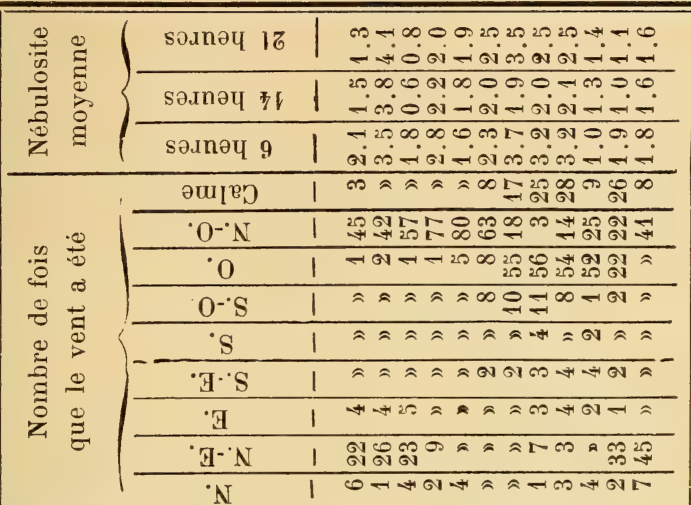

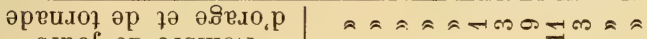
sinol әp aıquoN

\begin{tabular}{|c|c|c|}
\hline \multirow{2}{*}{$\stackrel{\mathscr{\Xi}}{\Xi}$} & $\begin{array}{l}\text { Sunof } ә p \\
\text { әxquioN }\end{array}$ & 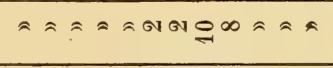 \\
\hline & 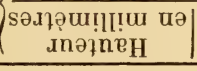 & 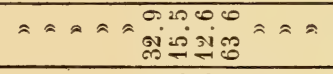 \\
\hline \multirow{3}{*}{ 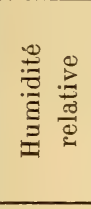 } & $\approx+$ & 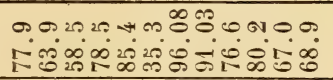 \\
\hline & $\neq 1+$ & 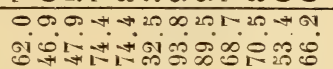 \\
\hline & $\div 1+$ & 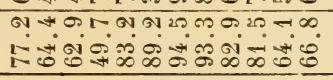 \\
\hline \multirow{7}{*}{ 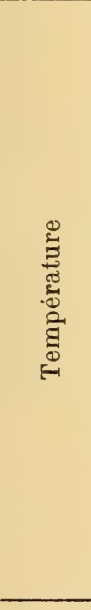 } & 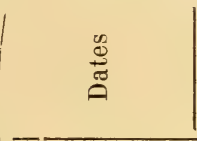 & 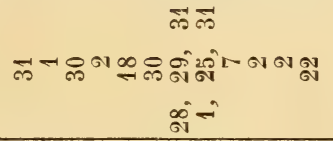 \\
\hline & $\begin{array}{l}\text { nјosqe } \\
\text { eurxen }\end{array}$ & 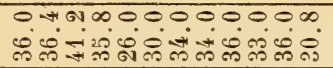 \\
\hline & 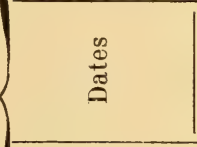 & 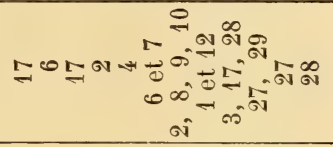 \\
\hline & $\begin{array}{c}\text { njosqe } \\
\text { eurxen }\end{array}$ & 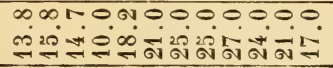 \\
\hline & 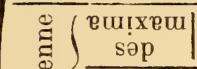 & 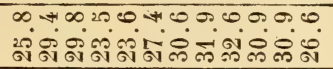 \\
\hline & $\sum_{\sum}^{\infty}\left\{\begin{array}{c}\text { एu!uाuा } \\
\text { sәp }\end{array}\right.$ & 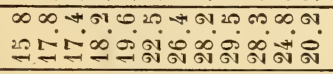 \\
\hline & әчиนว КоW & 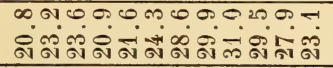 \\
\hline \multirow{2}{*}{\multicolumn{2}{|c|}{ 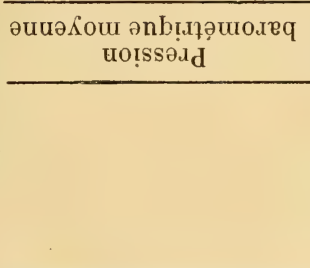 }} & 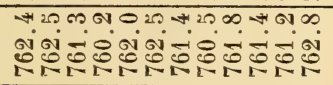 \\
\hline & & 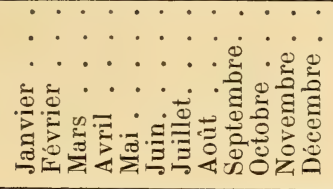 \\
\hline
\end{tabular}




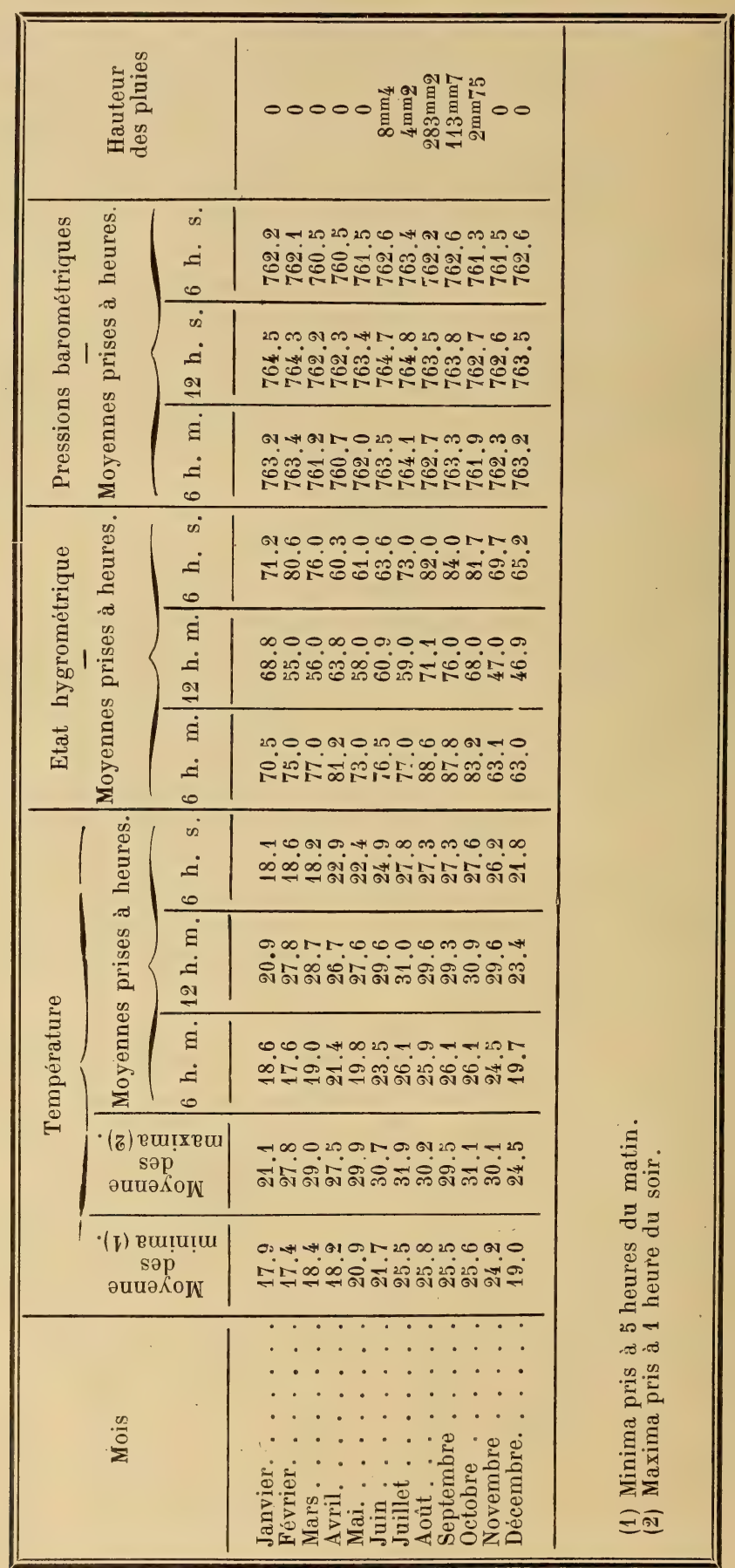


LES CONDITIONS DE LA VIE SOCIALE AU SÉNÉGAL 6 Ð

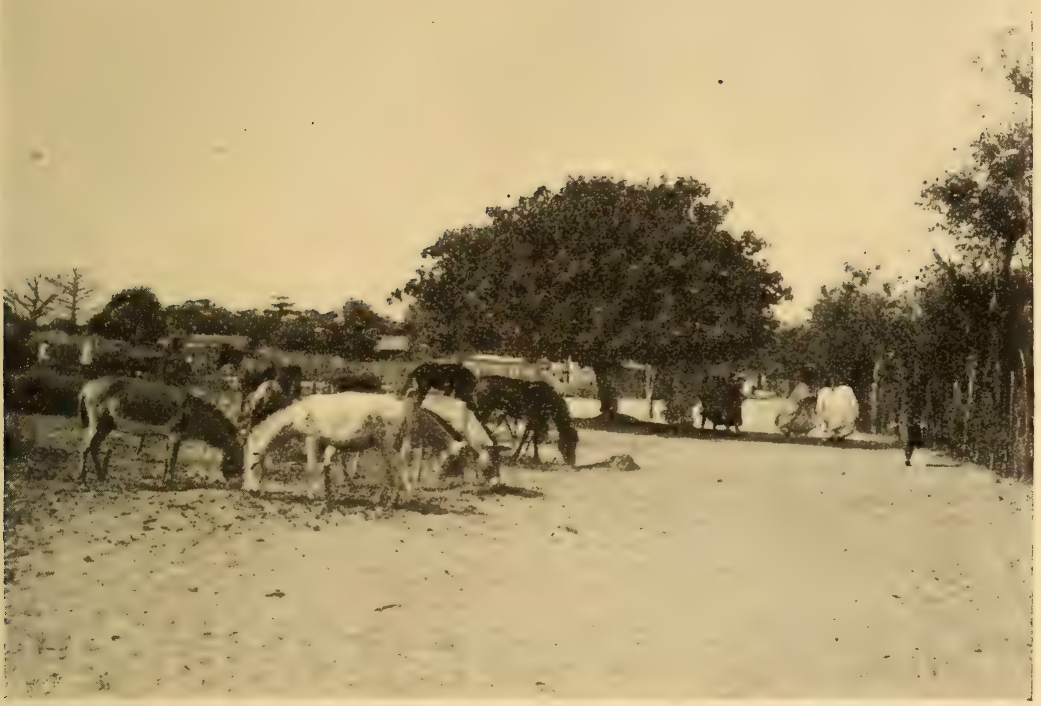

Fig. 7. - Fatick (Marché aux chevaux).

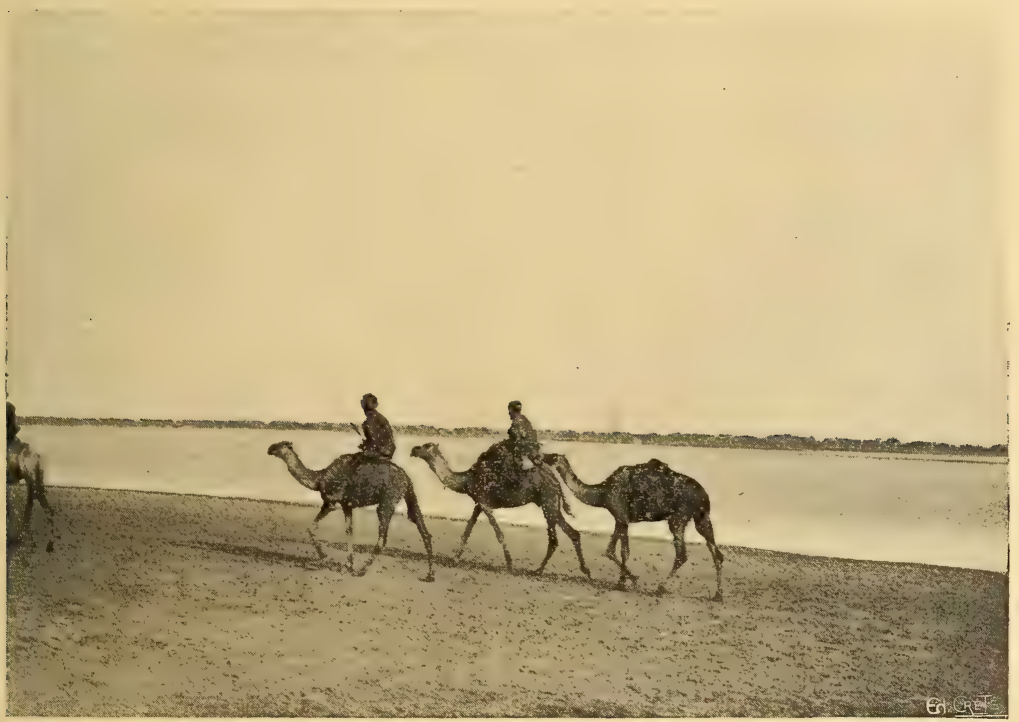

Fig. 8. - Convois de chameaux. 

mance renferment au Sud des terres d'aluvion. Au Sud, dans le Cayor, les terres sont presque uniquement silicieuses et silicocalcaires. Dans le Baol, on rencontre des sols où l'argile est en forte proportion et qui sont parfois recouverts de sable quartzeux chari ié par les vents. Les sols argileux dominent de plus en plus à mesure que l'on s'avance vers le Sud; on n'observe plus le sable qu'en quelques points à N'Danda, à Joal, et, abstraction faite du territoire anglais de la Gambie, sur les plateaux de la Casamance.

Ces terrains variés portent une flore, moins riche que celle des régions équatoriales, mais qui se diversifie beaucoup, principalement selon la latitude.

Les régions botaniques. - Quatre régions botaniques se laissent distinguer, facilement, caractérisées par des espèces particulières et par les cultures qui y sont pratiquées ou qui y sont possibles.

La région du Nord comprend les deux rives du Sénégal et la partie centrale, au Sud du fleuve, appelée Ferlo et Fouta. C'est le pays des accacias à gomme (accacia Sénégal), des arbres et des arbustes épineux à croissance lente et à bois dur On y rencontre le Balamite Egyptiaca, le goniaké et le neb-neb (variétés de l'a. arabica). Hors les forêts de gommiers, les arbres sont geénéralement clairsemés. Dans la région du Ferlo-Fouta la végétation herbacée, composée d'une grande quantité de graminées et de légumineuses, se développe avec vigueur pendant l'hivernage ; des troupeaux nombreux parcourent ce pays que de récentes explorations ont montré jalonné de lignes d'eau et possesseur des ressources encore inutilisées.

La région moyenne est constituée par le Cayor, le Baol, le Sine-Saloum. Les belles espèces d'arbres y sont nombreuses et les individus atteignent souvent une grande taille. Tels sont entr'autres le cnété, le caïlcédra (Kaya Senegalensis) ou acajou du Sénégal, le fromager, le palmier rônier, le cad, le baobab. De larges zônes boisées sont parfois formées d'une seule de ces essences qui constituent parfois des forêts assez denses sur des terrains argileux et latéritiques, notamment dans le cercle de Thiès et les provinces Sérères. Beaucoup d'arbres, dans cette seconde région, produisent des fruits, peu charnus à la vérité et 
souvent âpres, mais estimés par les indigènes et quelques-uns même par les Européens. Ce sont principalement le tamaranier, le détah (detarium Senegalense), le Sapindus-Senegalensis, le poirier et le cerisier du Cayor.

La flore de la troisième zône (Casamance) se rapproche de la flore tropicale; sur les bords du fleuve et de ses nombreuses ramifications les palétuviers végètent puissamment. Dans les forêts, les arbres atteignent de fortes dimensions. On peut citer, parmi les espèces caractéristiques, l'Erytropleum guineense ou tale, le Pentaclethra macrophylla, le Parkia biglobosa, le fromager, le palmier à huile, enfin la liane à caoutchouc est commune surtout dans la Basse-Casamance.

La quatrième et dernière région est constituée par la zône maritime des Niayes. La côte entre l'embouchure du Sénégal et Dakar est bordée de dunes et l'eau qui tombe sur leur versant occidental, arrêtée par le sous-sol argileux, forme des nappes souterraines très rapprochées de la surface des mares. Cette humidité persistante favorise la végétation et lui donne un caractère méridional qui fait contraste avec celui de la seconde région à même latitude. On rencontre là le palmier à huile et le liane à caoutchouc qu'on ne retrouve qu'en Casamance, le palmier nain, le poirier de Sedhiou ou Ndiar. Sur les dunes croissent des cyperacées et des graminées maritimes, quelques arbustes rabougris, le cad, le poirier du Cayor, le tamaria du Sénégal.

Ces provinces botaniques coïncident à peu près avec les zônes de répartition des cultures. Il faut mettre à part la vallée du Sénégal, en raison des conditions particulièrement favorables qu'elle présente pour la culture à cause des terres inondées et des possibilités futures d'irrigation. D’une façon générale les mils, petits et gros, dont il existe de nombreuses variétés, sont cultivés dans la première et seconde région; l'arachide caractérise plus particulièrement cette dernière. Le riz est cultivé en basse et moyenne Casamance ; le cotonnier pourra donner de bons résultats en moyenne et haute Casamance. Enfin la région encore inutilisée des Niayes pourra être plantée en cocotiers, auxquels le climat maritime convient particulièrement. 
Principales espèces (1). - Parmi ces principales espèces, il convient de signaler :

a) Les plantes fournissant des produits industriels ;

b) Les plantes alimentaires;

c) Les plantes utiles diverses.

a) Plantes fournissant des produits industriels. - Parmi les produits industriels, il faut en première ligne citer l'arachide qui est de tous les produits végétaux celui qui est exporté en plus grande quantité. Le palmier à huile, très commun dans toutes les Rivières du Sud, remonte le long de la côte jusqu'au dessus de la presqu'île du Cap Vert. Dans le Haut-Niger, il vient jusqu'aux environs de Siguiri. Le karité est une des essences les plus abondantes etles plus caractéristiques de la flore du Soudan. Le touloukouna roit abondamment le long des cours d'eau et dans les lieux frais de la Casamance, de la Gambie, dans le territoire de la Volta, dans le Sud du cercle de Bougouni.

Le sésame qui existe presque partout dans la boucle du Niger, la haute Gambie et la Casamance, est plus rarement cultivé au Sénégal. Le ricin réussit bien dans les terrains de l'Afrique occidentale et on en rencontre une race à petites graines dans presque tous les villagies du Sénégal.

La gomme du Sénégal est fournie presque toujours par l'acacia Vereck qui est surtout abondant au Sénégal, dans les forêts d'Alfabak et de Lébiar sur la rive droite du Sénégal, la forêt de Bounouni dans le Djolof.

Tout le caoutchouc de l'Afrique occidentale française est fourni par une seule espèce de Landolphia appelé Toll (wolof), folé (mandingue), goïne (bambara) : c'est un des plus beaux arbustes de la flore tropicale, qui, sur les plateaux de latérite, forme souvent des buissons arrondis très touffus, élevés de 3 à 8 mètres. La zône où le Landolphia Hendelotii est plus abondant est comprise entre $9^{\circ} 30$ et $11^{\circ} 30$ de latitude Nord. La liane devient

(1) On consultera avec profit à ce sujet: Aug, Chevalier, Une mission au Sénégal. Paris, 1900 , in- 8 ; on y trouvera une intéressante bibliographie de la flore sénégalienne, p. 258 et sq. 
rare au Nord comme au Sud de ces parallèles : San est sa limite Nord extrême. Dans les points où le Landolphia est le plus abondant comme aux environs de Sindou, de Bobo-Dioulasso, sa densité atteint jusqu'à 500 lianes l'hectare, mais ces taillis où la liane est très répandue ont rarement plus d'un kilomètre de longueur ; on peut ensuite marcher longtemps en ne rencontrant que des pieds isolés.

Il n'existe peut-être pas un village dans tout le Sénégal qui ne cultive au moins quelques pieds de cotonniers. Le coton qu'ils produisent n'est pas de très belle qualité; sa soie est ordinairement courte, souvent tachée de rouille, couverte d'étoiles.

Les indigènes de l'Afrique occidentale ne se contentent pas de lisser des pagnes avec la laine de leurs troupeaux et le coton de leurs cultures, mais ils teignent encore ces étoffes, et même une partie de celles qui leur viennent d'Europe, en couleurs variées et souvent résistantes.

L'indigotier se rencontre dans presque toutes les provinces du Sénégal ; le palétuvier, si commun dans les Rivières du Sud, et en particulier en Casamance, possède une écorce riche en tannin et serait exploitable avec le bon marché du fret.

b) Plantes alimentaires. - Les arbres fruitiers des pays tempérés viennent ordinairement mal au Sénégal ou donnent des fruits peu agréables; tels sont: le pommier, le poirier, l'abricotier, le prunier. La plupart des arbres fruitiers tropicaux ont été introduits dans les jardins européens du Sénégal et y sont producteurs, si on les cultive soigneusement Les plus répandus sont : le papayer, le cocotier, le bananier, le citronnier, l'oranger, le mandarinier, le limonier, le goyavier, l'avocatier, le sapotillier.

Le mil est cultivé avec zèle par toutes les peuplades de nos possessions de l'Afrique occidentale, ainsi que le millet. Le riz se trouve surtout en Casamance, où il présente de nombreuses variétés. Le maïs est cultivé principalement autour des habitations et les Noirs mangent ordinairement ses épis grillés dans le feu ou la graine pilée en couscous.

Le manioc se rencontre en beaucoup de points du Sénégal, où ses tubercules se mangent cuits ou crus et ses feuilles servent 
à confectionner des sauces de couscous. Divers ignames sont cultivés pour leurs gros tubercules en Casamance et, dans les endroits frais de la colonie, spécialement autour des habitations ; ̀̀ proximité des marais ou des cours d'eau, abondent les patates.

Le gingembre est cultivé en petite quantité par quelques Mandingues de Casamance, où il y réussit bien. Les Noirs du Sénégal font usage du poivre africain ou cubèbe, à petits grains noirs, de la grosseur d'un grain de Canis. Le piment noir est produit par un arbre dont il existe quelques représentants au Cap-Vert, mais qui est commun surtout en Gambie et en Casamance.

Le Catjang ou haricot indigène se rencontre dans les champs de l'Afrique occidentale, et les Diolas de Casamance cultivent le haricot d'Afrique qui ressemble un peu à la variété dite de Soissons.

Le papaye est le seul fruit que l'on trouve chez presque tous les indigènes de la colonie ; la noix de Kola doit devenir un des produits d'avenir en Casamance et dans les territoires de nos colonies de l'Afrique occidentale situées au sud du $12^{\circ}$ de latitude nord. En général, on a limité son habitat à la zône comprise entre le $10^{\circ}$ et le $7^{\circ}$.

c) Plantes utiles diverses. - Des forêts assez étendues existent dans la zône guinéenne et la brousse de la zône soudanienne est parfois assez dense pour se prêter à une exploitation régulière et suivie. Le caïlcédrat, appelé encore acajou du Sénégal, doit ce nom à la belle teinte de son bois; les fibres sont fines, mais les rayons médullaires trop apparents. Le Vène possède un beau bois rose très dur. Il faut encore citer le Oitale, au bois d'un rouge noirâtre, le tali, d'une belle couleur foncée, le fok, le dimb, d'un bois jaunâtre facile à travailler.

Le clinting est un bambou bien indigène au Sénégal, qui se rencontre abondamment en Casamance et dans le sud du Soudan à partir de Badourbé ; à proximité de la côte, il s'étend au Nord jusqu'à Thiès.

Les Noirs de toutes les peuplades africaines traitent leurs maladies avec des plantes indigènes et souvent avec succès. Parmi ces plantes, on peut mentionner: l'huile de ricin ou de pignon d'Inde, le thé de Gambie, qui fournit une boisson théiforme 
légèrement sudorifique, l'écorce de Goniaki, réduite en poudre, qui sert à panser la plaie résultant de l'opération de la circoncision, le $\mathrm{Nguer}$, absorbé contre les rhumes et les maux de poitrine.

Certaines plantes sont d'une toxicité extrême et les indigènes. de diverses races les emploient pour empoisonner leurs armes, faire disparaitre leurs ennemis, ou mettre à l'épreuve leurs prétendus sorciers. La plus célèbre est le Tali, un des plus grands et des plus beaux arbres de la Casamance. La fève de Calabar n'existe pas au Sénégal, mais elle est apportée de Guinée jusqu'au marché de Saint-Louis, où on la vend comme grigri. Dans la Haute-Casamance, la Haute-Gambie et sur les bords du Niger et de ses affluents, les pêcheurs cultivent une plante appelée Diefa diaba, dont les feuilles séchées, pilées et jetées dans l'eau font périr le poisson qui reste néanmoins comestible. “D’une façon générale, il est prudent de ne pas toucher les plantes que l'on ne connaît pas et surtout de s'abstenir d'en goûter les. fruits, si beaux qu'ils soient ". C'est ainsi que le Strychnos innocuum n'est pas aussi inoffensif que son nom semblerait l'indiquer, et contient probablement de la strychnine, comme la noix vomique, mais en moins grande quantité.

\section{C. - La faune.}

Dans son Traité de géographie zoologique, Wallace ne consacre que quelques lignes au Sénégal pour signaler la situation mixte de ce pays. Dans la majeure partie de la colonie, le climat, la flore, le sol présentent de grandes analogies avec les caractères correspondants du Sahara et du Soudan : il en résulte tout naturellement une affinité de faunes; le pays relève effectivement de la province éthiopienne et nous en retrouverons les formes caractéristiques: lion, chacal, hyène, chameau, etc. Mais, d'autre part, le voisinage des Rivières du Sud et du FoutaDjallon introduit dans la faune un contingent nouveau, celui

(1) Parmi les travaux qui se rapportent à la faune du Sénégal, nous citerons ceux de M. de Rochebrune et particulièrement sa Faune de la Sénégambie, publiée par la Société Linnéenne de Bordeaux et la remarquable notice de M. Cligny sur Faune du Sénégal de la Casamance (dans Une Mission au Séné. gal. Paris, 1901, in-8), à laquelle nous avons fait de nombreux emprunts. 
des forêts du centre africain (singes, certaines antilopes, etc.). En particulier, le Fouta-Djallon avec ses plateaux plus ou moins élevés, offre une série de stations très distinctes et une série de climats très différents où peuvent coexister des faunes à tendances diverses; la chose doit être surtout sensible pour les animaux domestiques si nombreux dans cette région de pâturages.

a) Animaux domestiques.

Mammifères. - Le Sénégal possède quantité d'animaux domestiques qui méritent de retenir l'attention pour les services qu'ils rendent dès maintenant au pays et pour ceux plus grands encore que l'on peut espérer de l'amélioration des races.

Les chevaux sont très nombreux dans toute la colonie, à l'exception de la Basse-Casamance. Les deux races du pays sont le cheval du fleuve et le M'Bayar, dont le principal centre de production est le canton du Baol oriental.

On trouve également une race de petits ânes très sobres et très résistants, assez vigoureux pour porter une charge de 50 kilogrammes, qui rendent beaucoup de services aux indigènes pour les transports. Leur nomıbre est assez élevé surtout dans le cercle de Podor, qui en fournit du reste au Cayor et au Baol.

Les bœufs constituent de grands troupeaux généralement aux mains des Peulhs; on peut en distinguer trois types : le bœuf à bosse ou bœuf porteur; le grand bœuf sans bosse, dont on rencontre des échantillons superbes dans le Oualo, et surtout dans le Djolof et le Baol oriental ; le petit bœuf, qui est une bonne race de boucherie et la meilleure laitière du Sénégal.

Les chameaux ou plutôt les dromadaires sont assez nombreux dans la colonie, bien que le pays leur convienne imparfaitement ; presque tous appartiennent aux Maures qui pendant l'hivernage les emmènent sur la rive droite du fleuve. Venue la saison sèche, eux ou leurs captifs descendent vers le Sud par Saint-Louis, Dagana ou Podor, et ils échangent les produits de leur pays contre des marchandises de l'escale.

En 1886, on estimait à 15.000 le nombre des moutons; ce 
chiffre est aujourd'hui bien au-dessous de la réalité et il y a peu d'indigènes qui ne possèdent trois ou quatre moutons : on distingue le mouton de Bakel, remarquable par ses pattes très longues, sa tête fortement busquée au chanfrein et le mouton du Fouta-Djallon, possédant des pattes très courtes, des cornes peu enroulées. De même il existe deux races de chèvres, l'une grande, l'autre petite.

Le porc est extrêmement rare dans tout le pays musulman, c'est-à-dire dans la majeure partie du Sénégal; en revanche, il est fort abondant dans la Casamance.

Volailles. - La volaille est représentée au Sénégal par des poules, fort nombreuses et presque partout à bon marché, et des canards, particulièrement abondants en Casamance.

Abeilles. - Le seul insecte domestique du Sénégal estl'abeille, les tentatives d'élevage du ver à soie et de la cochenille ayant chaque fois échoué. Dans le Baol, les provinces sérères et la Casamance, on se livre à une véritable exploitation de cet insecte et les arbres qui avoisinent les villages sont chargés de ruches.

\section{b) Animaux sauvages.}

Le Sénégal est un beau pays de chasse, où l'on rencontre en abondance le gibier le plus varié; mais à mesure que la population augmente, que les cultures s'étendent et avec elles le débroussaillement, les animaux de grande taille s'éloignent chaque jour des escales.

Les singes sont fort nombreux, surtout en Casamance et dans le Fouta-Djallon : le singe rouge très commun le long du fleuve et qui parfois s'aventure jusqu'à Leybar, le golo que beaucoup d'Européens conservent en captivité, le boubou qui ne descend guère en deça de Bakel.

Le lion présente une variété locale dépourvue de crinière, mais qui égale pour la taille et la force les plus beaux lions de l'Atlas; il est remarquable par son pelage jaune clair avec parfois des taches fauves sur les membres; on le rencontre particulièrement sur les deux rives du fleuve en amont de Podor, dans la forêt qui s'étend sur le Oualo, le Djolof et le Diambour, et 
enfin dans tout le Ferlo; pendant la saison sèche, il vient s'abreuver au fleuve ou aux marigots, c'est-à-dire près des lieux habités, et à cette époque, il commet quelques déprédations dans les troupeaux; pendant l'hivernage, au contraire, il s'enfonce dans la grande brousse, et vit presque exclusivement de gibier.

Malgré une croyance très générale, la panthère n'existe pas au Sénégal, et, d'après les travaux de de Rochebrune, le fauve auquel on donne ce nom est un léopard de grande taille avec quelques caractères spéciaux dans le pelage; il est assez rare dans le bas Sénégal, bien qu'il se soit à plusieurs reprises aventuré jusqu'à Richard-Toll ; il est plus fréquent dans le haut fleuve et surtout dans la Casamance et les Rivières du Sud.

Le guépard, plusieurs variétés de chat-ligre, le lynx se rencontrent jusqu à Podor et même plus près de Saint-Louis.

Aux environs de Yang-Yang, on trouve à l'état sauvage un chat gris avec zébrures plus foncées qui parait être le felis Bouvieri de de Rochebrune; cet animal serait un retour du chat domestique à l'état sauvage. La civette se rencontre dans le Cayor et le Oualo; en outre, les indigènes confondent sous le nom de sicor plusieurs espèces de viverridés à odeur nauséabonde, parmi lesquelles la mangouste ou ichneumon d'Egypte grand destructeur d'œufs de serpents et de caïmans.

Les canidés sont représentés par le chien laobé, par des loups, un chacal identique à celui de l'Algérie, des renards de différentes sortes et des hyènes.

Le fleuve et les marigots étaient autrefois peuplés de lamentins dont la peau fort épaisse était utilisée pour faire des cravaches ; ces auimaux sont devenus assez rares.

Si l'éléphant existe encore dans le Sénégal proprement dit, il doit y être également en petit nombre; on en tue encore de loin en loin dans la Haute-Casamance; enfin, il doits'en trouver dans le Fouta, le Ferlo, le Boundou, et d'autant plus qu'on se rapproche davantage de Fouta-Djallon.

Les forêts de l'intérieur possèdent de nombreux troupeaux de biches, gazelles et oryx.

Les rongeur's sont représentés par des lièvres et des lapins qui fréquentent de préférence les endroits sablonneux, plusieurs 
espèces de porc-épic stationnées surtout en Casamance, puis une série d'écureuils.

Les insectivores du pays sont surtout les hérissons dont il existe plusieurs espèces. Les chauves-souris sont très nombreuses et variées, surtout dans la Casamance : le xantarpia straminea ou tınga des Ouolofs est abondant à Saint-Louis et atteint jusqu'à 16 centimètres de long et 603 centimètres d'envergure.

Les édentés du Sénégal trouvent dans le manis ou pangolier remarquable par sa cuirasse cornée et l'orycteropus au corps glabre et au groin allongé deux représentants curieux, grands destructeurs de fournis.

Oiseaux. - Le monde des oiseaux est aussi riche par le nombre et la variété des espèces que par l'éclat et la beauté de certaines d'entre elles. Toutes les nuances les plus vives, les formes les plus gracieuses se rencontrent dans cette classe et de bonne heure, le commerce y a cherché des éléments de parure.

Aussi bien serait-il superflu d'énumérer les représentants des rapaces ou charognards (faucons, éperviers, vautours, etc.), des perroquets, des grimpeurs (pics, coucous, coqs de pagode, couroucous, etc.), des passereaux (volliers ou geais du Cayor, guêpiers rose, vulgaire ou vert, martins-pêcheurs, buceros, tou . cans, huppes, sucriers, hirondelles, martinets, corbeaux, étourneaux, merles métalliques, gonolecks, rossignols de murailles ou rouge-queue, etc.), des gallinacées (pintades, perdrix, cailles, etc.), des échassiers (outardes, vanneaux, grues, hérons, arjettes, etc.), des palmipèdes (oies de Gambie); des coureurs (autruche commune).

Reptiles. - Dans toutes les rivières de l'Afrique occidentale, les caïmans sont fort nombreux; ce sont en réalité des crocodiles et l'on en distingue au moins deux espèces, le crocodilus cataphractus ou caïman noir, le crocodilus vulgaris ou caïman vert; ce dernier a d'ailleurs une aire d'extension considérable puisqu'on le retrouve non seulement dans le Niger, mais encore dans le Nil. Le poisson forme leur nourriture habituelle ; parfois pourtant ils saisissent quelque bœuf ou quelque mouton à l'abreuvoir, mais il est rare que les caïmans s'attaquent à l'homme. Dans la Taouey, les pêcheurs passent leurs journées à 
l'eau, occupés à consolider leurs barrages, à visiter leurs filets, sans être inquiétés le moins du monde par ces animaux qui pullulent dans cette rivière; tout au contraire, le reptile devient leur proie et ils en sont extrêmement friands.

Le Sénégal et les rivières voisines abritent une grande tortue carnivore à carapace molle, le trionyx xgyptiacus; dans les marigots et les terres basses que l'inondation recouvre, on rencontre diverses paludines; enfin dans l'intérieur du pays vivent plusieurs espèces terrestres, la testudo sulcata, dont le plastron est mobile, les pentonyx, remarquables parce qu'elles ont cinq doigts à la patte postérieure comme au membre antérieur.

Parmi les sauriens, nous citerons le varanus niloticus, qui est le tupinambis des voyageurs et que les colons appellent vulgairement gueule-tapée; c'est un grand lézard qui mesure jusqu'à 2 mètres de long et qui présente une coloration gris foncé avec des points d'un jaune vif; il habite de préférence le bord des cours d'eau et sa longue queue comprimée latéralement lui permet de nager très vite; essentiellement carnivore, il se nourrit d'oiseaux, de poissons, mais il est surtout gourmand d'œufs de caïmans, et ne dédaigne pas d'ailleurs les œufs de nos volailles.

Le Sénégal possède des échantillons divers de caméléons et les lézards abondent, tant par la variété des espèces que par le nombre des individus.

Il y a également - et surtout en Casamance - - un contingent nombreux de serpents, qui se montrent peu pendant la saison sèche, mais qui reparaissent volontiers à l'hivernage. L'eryx thebaïcus, le python royal et le python de Seba figurent parmi les espèces non venimeuses; des Solenoglyphes, les vrais serpents venimeux, une seule famille est représentée au Sénégal, qui fournit l'echidna inornala et l'echidna athropos de Casamance, l'echidna mauritanica sur la rive droite du Sénégal.

Anoures, grenouilles et crapauds sont légion au Sénégal et les fleuves et l'Océan fourmillent de poissons aussi remarquables par leur taille que par la finesse de leur chair.

Poissons. - Entre le cap Bogador et le cap Mirik les banes sont visités par les islenos ou pêcheurs canariens qui font là de mer- 
veilleuses récoltes. L'administration étudie d'ailleurs les moyens d'y installer des pêcheries et des sècheries perfectionnées. Les meilleures stations se trouvent au Sud du cap Blanc, sur les hauts fonds sablonneux de la baie du Lévrier et de la baie d'Arguin, c'est-à-dire sur une côte qui nous appartient. Ces bancs sont plus riches, moins éloignés et moins dangereux que ceux de Terre-Neuve. Les espèces dominantes sont des morues, espèces différentes de celles que l'on prend à Terre-Neuve, mais nulle. ment inférieures : serranus papilionaceus, s. fimbriatus, s. fuscus, s. oneus, s. acutirostris, mora mediterranea, phycis limbatus, ph. mediterraneus, toutes espèces de grande taille pesant communément 7,8 et jusqu'à 12 kilogrammes; puis ce sont des labrax ou loups, des mulets, des sargues, des daurades, des trigles, des harengs : bref, une goélette de quarante tonneaux portant seize islenos capture journellement et prépare 3.000 kilogrammes de poissons.

Les pêcheurs de Dakar et de la petite côte sont actifs, et souvent heureux; leurs captures les plus fréquentes sont: des requins, le marteau, le griset, le poisson scie, l'aigle de mer, les labres, le mulct, le splendide chrysophrys, que les indigènes préparent en quantités énormes par une méthode bien rudimentaire, les soles, le turbot, le hareng.

Dans les fleuves et les marigots voisins, nous retrouvons tout d'abord, jusqu'à une grande distance de la côte, certaines espèces de l'Océan, et cela ne peut surprendre si l'on songe qu'à la saison sèche, les eaux de la mer refluent jusqu'à Richard-Toll dans le Sénégal et jusqu'à Sedhiou dans la Casamance ; toute la tribu des requins, les labres et même les maquereaux et les soles pénètrent ainsi dans les rivières. Les eaux douces sont extrêmement peuplées et la pêche est particulièrement active à Podor, sur toute l'étendue du lac de Guier et surtout dans l'émissaire de ce dernier, la Taouey. Ce cours d'eau étroit et profond se trouve barré de place en place par des files de piquets auxquels les indigènes suspendent leurs filets; le roi des eaux douces, c'est le capitaine ou polynemus, superbe poisson aux larges écailles, à la chair fine, qui mesure un mètre et davantage ; il est très abondant sur tous les marchés du fleuve : 
à certaines époques, on a exporté ses écailles et sa vessie natatoire comme colle de poisson. L'hydrocyon forskalii rappelle un peu le brochet par sa tête allongée, par son museau largement fendu, par ses dents redoutables, et les Européens lui donnent souvent ce nom; la chair en est assez fine, mais toute remplie d'arêtes, ce que les Noirs expliquent de la façon suivante : certain jour, le brochet entreprit un long voyage,et chaque poisson de lui donner ses commissions; pour éviter tout oubli,chacun lui confia en même temps une arête; mais le brochet fut fait prisonnier en chemin et toutes les arêtes lui restèrent.

Les marécages, les marigots vaseux et sans courants, abritent une faune très spéciale : ce sont d'abord les periophthalmes ou poissons sauteurs qui fourmillent particulièrement à Sohr et à Leybar; leurs yeux sont très saillants et mobiles, leurs nageoires pectorales affectent l'aspect de pattes et leur permettent de sauter, de ramper voire même de grimper sur les branches obliques des palétuviers. Les Siluridés sont des pois. sons privés d'écailles et pourvus de barbillons autour de la bouche; leur nuque est souvent armée d'un robuste aiguillon; on peut citer dans ce groupe schilbe senegallus, bagrus Adansoni, b. bayad, b. nigrita, b. maurus, pimelodus occidentalis, clarias senegalensis, heterobranchus senegalensis, enfin le mala. pterurus electricus qui produit de violentes commotions électriques. Toujours dans les mêmes marais, on rencontre le protopterus annectans, l'un des trois dipneustes qui sont venus jusqu'à notre époque comme une relique de la faune triasique.

Invertébrés. - Il serait superflu de nous étendre longuement sur les invertébrés et l'A frique occidentale, myriapodes, tels que scolopendres et sentigères, arachnides, comme les scorpions, crustacés, représentés à la cote par les crabes et le homard, insectes parfois très brillants comme le scarabé, élatérides, papillons, assez nombreux pendant l'hivernage, orthoptères, vrais insectes de la brousse qui offrent une forme remarquable de criquets et d'espèces voisines, hyménoptères, représentés par plusieurs espèces d'abeilles dont la seule abeille sérère paraît susceptible de domestication, et surtout une multitude prodigieuse de fourmis. 
La plus grande de toutes mesure près de $\mathbf{2}$ centimètres et se rencontre presque toujours isolée; pourtant elle vit en colonie dans un terrier profond à multiples galeries et parfois elle marche en colonne.

On la rencontre surtout au voisinage des ruches, car elle est très friande de miel et très capable au surplus d'attaquer une abeille; une autre espèce non moins gourmande de miel, mais plus petite, se distingue par son abdomen rayé d'une bande transversale blanc grisâtre; celle-là niche sous l'ćcorce des arbres, et de préférence sur ceux qui portent des essaims. La fourmi la plus redoutée des colons et des indigènes est le magnan, grosse fourmi noire aux mandibules terribles : on la rencontre en colonnes étroites et sərrées qu'il faut enjamber soigneusement; du reste, les Noirs marchant en file indienne ont grand soin de se prévenir de proche en proche quand le sentier coupe une de ces colonnes; si par malheur on y pose le pied, ne fût-ce qu'une seconde, on se trouve envahi par quelques dizaines de ces insectes redoutables dont la morsure fort douloureuse fait poindre une gouttelette de sang; il n'est pas vrai d'ailleurs, comme on le croit souvent, que cette piqûre soit venimeuse et la douleur disparait rapidement quand la fourmi est enlevée; ces fourmis carnivores détruisent en peu de temps les cadavres les plus volumineux; elles ne dédaignent point d'entrer dans les habitations et l'on connaît des cas authentiques où elles ont dévoré des hommes vivants. Leurs colonnes présentent une discipline admirable : sur les deux bords, les guerriers sont rangés immobiles tournant vers l'extérieur leurs fortes mandibules; dans cette haie protectrice roule le torrent rapide des ouvrières; leur capture est d'ailleurs facile car il suffit de plonger dans la colonne un fétu de paille pour quill se garnisse immédiatement de magnans, guerriers et ouvrières qui ne lâchent plus cet engiṇ menaçant.

Nous citerons encore une longue fourmi jaune fauve très grêle qui habite sur les arbres et s'y construit une curieuse demeure en assemblant toutes les feuilles d'un rameau; il en résulte une coque grosse comme les deux poings où s'abritent quelques centaines d'individus; cette fourmi, très agressive, fait une mor- 


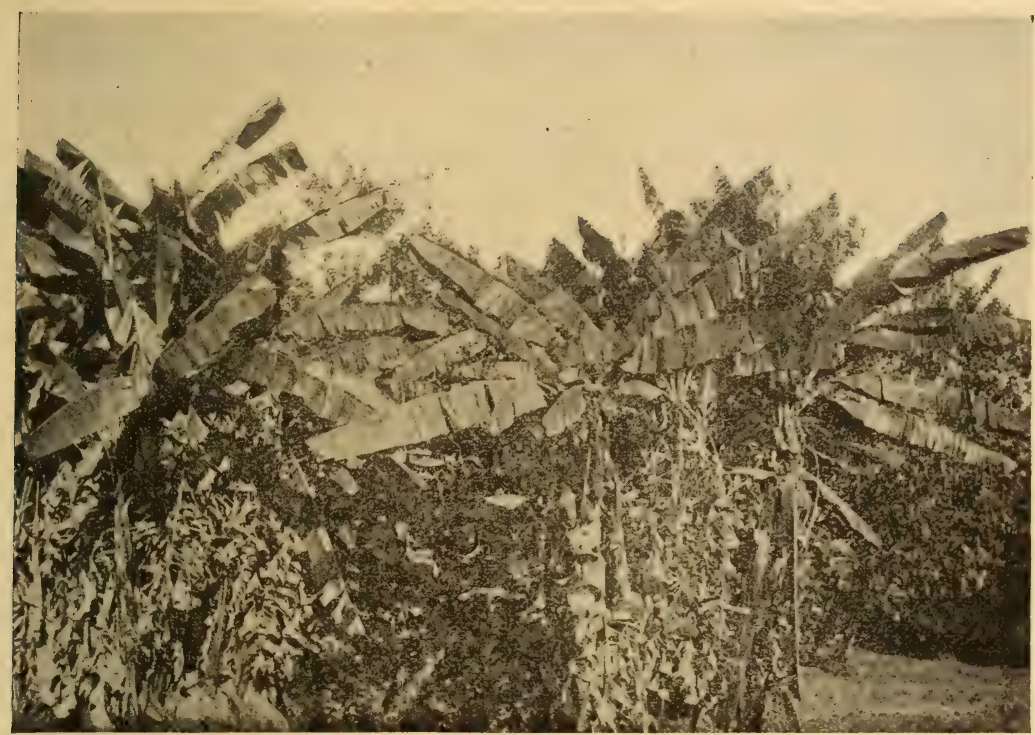

Fig. 9. - Bananiers.

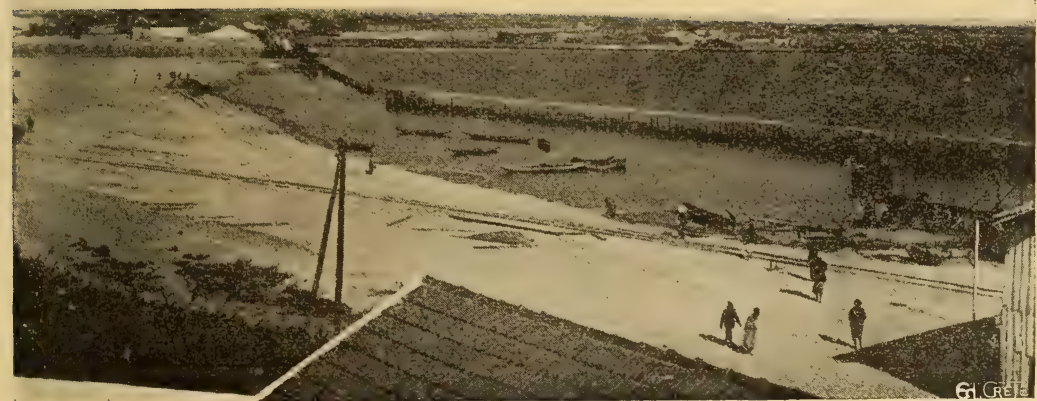

S.

Fig. 10. - Les travaux du port de Dakar. 

sure assez douloureuse. Pourtant elle n'est point carnivore, et se nourrit de fruits

Enfin l'on trouve dans toutes les termitières de nombreuses fourmis appartenant à diverses espèces et qui paraissent faire bon ménage avec les hôtes légitimes de la maison; il semble que ces fourmis commensales n'aient pas d'autre domicile que le logis emprunté, car on y trouve leurs œufs et leurs larves.

Les termites sont des orthoptères pseudo-névroptères qui vivent en colonies nombreuses admirablement policées, et parfaitement organisées pour la division du travail ; ils élèvent des monticules qui penvent atteindre $\mathbf{2}$ mètres de haut et leurs galeries s'enfoncent profondément en terre. En Casamance, on trouve souvent des termitières peu volumineuses ayant la forme d'un champignon.

L'ordre des diptères comprend les moustiques qui pullulent dans la colonie, depuis les maringouins jusqu'aux mout-mouts lilliputiens, abondant autour des fleuves et des marigots, fuyant au contraire les endroits secs, puisque leurs larves sont aquatiques.

Le ver de Médine, dragonneau ou filaire, est un ascaris assez mince, mais dont la longueur peut être considérable et atteindre parfois 1 mètre et davantage.

Le microbe des fièvres paludéennes est un hématozoaire, c'està-dire un être qui vit à l'intérieur des globules rouges du sang. On n’a jamais rencontré cet animal en dehors des êtres vivants ; il semble donc que la maladie exige la présence d'un hôte récepteur et d'un hôte transmetteur; le moustique est ce dernier.

\section{D. - Produits du sous-sol (1).}

Pierres à bâtir. - Les calcaires sont assez fréquents au Sénégal. On exploite à Rufisque des calcaires blancs jaunâtres, d'assez bonne qualité, qui constituent des bancs régulièrement stratifiés, séparés par des lits très minces argilo-calcaires.

(1) Voir : Géologıe et hydrologie de la Sénégambiepar M. Pierre Rirmbaud dans Une mission au Sénégal, op. cit. - Col. Wendling, Etude sur le delta et les marigots du Sénégal (Bull. Soc. Géogr. de Toulon, 1890). - Saint-Meunier. Contribution à la géologie.du Bas-Sénégal (Compte-rendu de l'Académie des Sciences, $1^{\text {er }}$ semestre, 1898). 
Outre ces bancs, la plage de Popenguine est parsemée de très gros blocs qui gardent les traces d'influences atmosphériques longtemps subies et qui appartiennent à divers niveaux. Certains sont dolomitiques, d'autres sont de grès dur à ciment calcaire. tous ont été ramenés par les eaux pluviales et sont traversés par de nombreuses fentes remplies de calcite et d'oxydes de fer.

Des bancs de calcaire coquillier, susceptibles d'un beau poli se rencontrent à Yang-Yang, sur les flanes de la vallée.

Des calcaires plus tendres, mais également utilisables, se rencontrent à 2 kilomètres Est de Mbidjem.

La latérite constitue une pierre de construction convenable ; elle se débite assez facilement en moellons et prend bien le mortier. Sa forte densité constitue un inconvénient pour cerlains travaux. Dakar, Thiès, les bâtiments du haras de Diourbel, Toul, etc., ont été construits en latérite.

Brique. - Une importante briqueterie a été créée à Bop N'dior près de Saint-Louis. Les rives argileuses du fleuve ont permis de fabriquer les briques d'une qualité remarquable dont ont été construits les postes de Podor, les quais de Dagana, etc.

L'argile n'est pas rare dans beaucoup de points. Elle est, avec le sable argileux de termitières, employée par les indigènes pour la construction de leurs cases. Bien protégés par les toits de chaumes et de tuiles, les murs ainsi construits résistent bien aux pluies d'hivernage.

Chaux. - La pierre à chaux est loin de manquer au Sénégal. Dans le Baol, le Cayor, les sondages en révèlent à des profondeurs variables. On en exploite à Rufisque, à Sebikotam. A Thiela, à Yang-Yang, à Merinaghen, on trouve à la surface du sol un calcaire très tendre, contenant parfois un grand nombre de mollusques d'eau douce, remarquablement conservés.

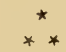

Parmi les météux, le fer est abondant au Sénégal. Il se rencontre généralement sous forme de sesquioxyde anhyllre ou hydraté, quelquefois d'oxyde magnétique ou de carbonate et les indigènes l'exploitent d'une façon primitive.

On n'a reconnu que des traces de carbonate de cuivre, accom- 
pagnant certains grès et certains calcaires. Néanmoins on a vu entre les mains des Maures des disques de cuivre, grossièrement fondus, qui ne paraissaient pas de provenance marocaine. Il se pourrait donc que les Maures eussent dans leur pays du minerai de cuivre.

L'or est abondant dans le Bouré, le Bambouk et le Bonden. Il existe dans des quartz filoniens, dans des schistes anciens métamorphosés ou bien à l'état de paillettes dans certaines alluvions.

Il existe des bancs de lignite dans la Haute Gambie, aux pieds du Fouta-Djallon et peut-être dans le pays des Maures.

Du soufre natif se trouve dans las environs du Cap Blanc : il est assez pur pour brûler sans raffinage ou distillation.

Les basaltes forment l'île de Gorée. Près de Rufisque, à Diokoul se trouve un basalte à apatite, contenant jusqu'à $50 / 0$ de phosphate de chaux.

Le sel est récolté dans le Sahara par les Maures qui l'amènent à Tombouctou : il y a quelques salines rudimentaires sur la côte. 


\section{CHAPITRE VI}

LES POPULATIONS DU SÉNÉGAL

\section{I. - La population du Sénégal (1)}

L'étude des diverses races qui habitent le Sénégal est des plus complexes; en contact avec les races blanches venues les unes des Etats barbaresques à travers le Sahara, les autres du bassin du Nil, en traversant presque tout le continent, le Sénégal offre le contraste des types les plus divers: Maures se rattachant aux Arabes et aux Berbères, Peuhls originaires de la Haute-Egypte, Nigritiens autochtones ou venus du centre de l'Afrique. Cependant depuis quelques années les observations se sont multipliées et ont commencé à faire un peu de jour dans ce fouillis : Binger, en montrant les relations qui existent entre les races nigritiennes du Soudan a créé l'unité ethnique des populations jusqu'alors considérées comme différentes; l'examen de crânes peuhls a permis récemment d'établir leurs rapports avec des crânes fellahs de la vieille Egypte et à à peu près résolu une question depuis longtemps discutée ; trois groupements semblent aujourd'hui nettement établis: les Maures, les Peuhls etles Mandés. Il reste à classer les populations anciennes Ouolofs, Sérères, Diolas, Baniounkas, Balantes qui ont été refoulées vers le littoral et que l'arrivée de

(1) Voir à ce sujet la très intéressante monographie : les Races du Sénégal par le docteur Lasnet dans Une mission au Sénégal (Paris, 1900, in-8²) et celle de M. Zaborowski dans les Colonies françaises (Paris, Larousse, 1900, in- $8^{\circ}$ ) auxquelles nous avons faits de larges emprunts. 
races plus fortes aurait infailliblement fait disparaitre sans notre intervention : quant aux populations fétichistes du bas Sénégal et de la Casamance, elles ont entre elles de nombreux caractères communs que l'on trouve à peu près identiques chez beaucoup d'Achantis et qui peuvent faire supposer une origine commune.

Répartition géographique des racés. - Les Maures habitent la rive droite du Sénégal depuis Bakel jusqu’à la mer ; leur limite est rigoureusement fixée au Sud par le fleuve qu'ils ne doivent pas dépasser (Traité de 18028 avec Faidherbe). Ils sont divisés en un grand nombre de tribus dont les plus importantes sont les Trarzas, les Braknas, les Douaïchs. Les Trarzas occupent un espace d'environ 100 kilomètres sur le bord du Sénégal au-dessus du Oualo et Dagana est l'escale où ils apportent leurs marchandises ; les Braknas s'étendent sur un espace double en longueur au Nord du Dimar et du Fouta, leur escale est Podor; les Douaïchs occupent úne région à peu près aussi étendue au NordEst du Damga et viennent faire leurs échanges à Kaédi. Au Nord de ces trois groupes se trouvent les oasis de l'Adrar et du Tagant, qui entretiennent quelques relations avec le gouvernement du Sénégal et différentes tribus qui viennent rarement aux escales Ouled-Nasser, Ouled-Zaïd, Ouled-Allouch, Ouled-Embareck, Sidi-Mahmoud.

Le chiffre très approximatif de la population maure est de 80.000 , tous musulmans.

Peuhls. - Les Peuhls, Pouls, Fellahs, Foulas, Foulbès, très répandus dans l'Afrique septentrionale, forment une longue traînée depuis le lac Tchad jusqu’au Sénégal; ils sont épars en tribus plus ou moins puissantes depuis le Darfour jusqu'au Fouta, le plus souvent très clairsemés et perdus au milieu des races noires. Au Sénégal, ils constituent la majeure partie de la population de la haute Casamance et de la haute Gambie, sont mèlés aux Toucouleurs dans tout le Fouta et forment de nombreux groupements disséminés en pays ouolof.

Leur population peut être estimée à 110.000 , dont 80.000 musulmans, les autres fétichistes.

Les Laobés inséparables des Peuhls, quoique de race différente, sont par groupes épars au milieu des populations étran- 
gères; environ 10.000 , dont la moitié musulmans, les autres fétichistes.

Toucouleurs. - Les Toucouleurs forment la plus grande partie de la population du Fouta sur le moyen Sénégal, depuis Bakel jusqu'à Dagana; ils occupent les provinces du Damga, du Fouta, du Toro, du Dimar. Tous musulmans, leur nombre dépasse 100.000 .

Mandingues. - Les Mandingues habitent les bassins de la Casamance et de la Gambie ; ils constituent la population dominante du Niani, du Ouli, du Tenda, du Gamon; en Casamance ils occupent le Pakao, le Boudhié, le Jacine, le Brassou, le Balmadou, le Souna; on les trouve aussi dans le Fouladougou et le Firdou mélangés à des Peuhls, dans le Bondou mêlés aux Sarracolès et aux Ouolofs, dans le cercle de Nioro avec des Sérères. Ils sont presque tous musulmans.

Sarracolès. - Les Sarracolès, autrefois nombreux et puissants, sont épars aujourd'hui au milieu des autres races; ils habitent de nombreux villages sur les bords du Sénégal entre Kaédi et Bakel, mais c'est entre Bakel et Bafoulabé qu'ils présentent les populations les plus pures et les plus compactes ; ils occupent les pays de Galam, Guidiaga, Guoye ; on en retrouve également éparpillés dans le Sud au milieu des Mandingues et des Peuhls, depuis les contreforts du Fouta-Djallon jusqu'au Bambouk.

\section{Tous musulmans}

Khassonkès. - Les Khassonkès, métis de Mandés et de Peuhls, vivent dans les environs de Médine, habitent le Khasso, le Guidimaka, le Kamera, le Nadiaga ; sont très mélangés de Sarracolès, Bambaras et Toucouleurs ; tous musulmans.

Le chiffre approximatif des populations de race mandé qui habitent le Sénégal jusqu'à la Falémé est d'environ 70.000 (Mandingues, Sarracolès ou Khassonkès).

Ouolofs. - Le pays occupé par les Ouolofs comprend les provinces du Oualo, du Cayor, du Djolof et une partie du Baol; il est limité au Nord par le Sénégal qui le sépare des Maures, au Sud vers le Cap Vert il touche au pays des Sérères, à l'Ouest il donne sur l'océan Atlantique et à l'Est sur le Fouta des Toucou- 
leurs, couvrant un espace à peu près quadrilatère de 220 kil. Nord-Sud sur 150 Est-Ouest. Dans le Rip, le Ouli, le Bambouk, en Casamance (Carabane et Sedhiou), on trouve en outre de nombreuses agglomérations de la même race, débris du vieil empire Djolof ou colonies de formation récente constituées par des traitants venus pour faire des échanges et installés définitivement dans le pays.

Le nombre des Ouolofs est de $\mathbf{4 4 0 . 0 0 0}$ dont 2 nu 3.000 catholiques, tous les autres sont musulmans.

Sérères. - Les Sérères s'étendent au Sud du Cayor, depuis le Cap Vert jusqu'à la Gambie, embrassant tout le bassin du Saloum et une partie de celui de la Gambie. Leur territoire, qui mesure 12.000 kil. carrés, comprend les régions du Baol, du Sine et du Saloum ; ils se divisent en deux grandes fractions : les Sérères None du Cap Vert à Joal sur la côte et les Sérères Sine dans le bassin du Saloum.

La population sérère est d'environ $\mathbf{1 8 0 . 0 0 0}$ individus, presque tous fétichistes.

Diolas. - Les Diolas occupent la plus grande partie de la basse Casamance entre la Gambie et le Cacheo, jusqu'au Songrougou et à Zighinchor où commencent les Baniounkas; au Nord, ils sont en rapport avec les Mandingues de la Gambie anglaise, au Sud avec les races portugaises des Papels et des Mandiagos, à l'Est avec les Baniounkas.

Les renseignements que l'on possède sur leur nombre sont très incomplets : près de 80.000 , dont quelques chrétiens et tous les autres fétichistes.

Baniounkas. - Les Baniounkas occupent les deux rives de la Casamance, entre les Diolas à l'Ouest, les Mandingues au NordEst, les Balantes au Sud-Est. Ils sont environ 20.000, dont la moitié complètement soumis aux Mandingues du Boudhié et du Yacine et devenus musulmans ; les autres, sauf quelques chrétiens, à Zighinchor, sont restés fétichistes.

Balantes. - Les Balantes occupent la rive gauche de la Casamance entre les Baniounkas à l'Ouest et les Mandingues à l'Est ; ils s'étendent au Sud dans les hauts pays du Geba et dı Cacheo. Chiffre approximatif de leur population: 15.000 , tous fétichistes. 


\section{Les Maures}

Les Maures sont de souche berbère et appartenaient au groupe des Zenagas. Ils sont établis sur la rive droite du Sénégal, auquel ils ont donné leur nom, depuis le vir ${ }^{e}$ siècle ou peut-être seulement depuis le $\mathbf{x I}^{\mathrm{e}}$. Leur peau bronze clair est encore généralement plus claire que celle des nègres et même que celle des Peuhls. Une certaine maigreur relative, leur regard vif et dur, leurs membres nerveux, leur port permettent de les distinguer du premier coup d'œil des vrais noirs, mais eux-mêmes sont aujourd'hui très mêlés. Faisant depuis tant de siècles des esclaves et prenant des femmes parmi leurs voisins noirs, ils se sont condamnés à une nigritisation accélérée. Il n'y a peut-être pas un dixième d'entre eux qui soit de pure souche blanche. Parmi ces blancs, on distingue quelques individus de sang et de type arabes. Pour un tiers, ce sont des nègres purs; le reste, la grande masse, se compose de métis. Ils vivent surtout de l'exploitation des forêts de gommiers. Mais grands éleveurs de chameaux, ce sont aussi des caravaniers. Ils transportent aujourd'hui les barres de sel de Taoudenit jusqu'au haut Niger et l'échangent contre des cotonnades apportées de Saint-Louis et des noix de Kola.

Leur organisation sociale rappelle encore celle des Touareg, mais dans chaque tribu, à cóté de l'aristocratie guerrière des hassanes, s'est formée l'aristocratie religieuse des marabouls, et au-dessous de la classe des tributaires, les esclaves, bien plus nombreux, jouent un rôle beaucoup plus important. Ils ne portent pas le voile sur la figure, comme le font les Touareg et leur vêtement, un peu plus pauvre et plus simple, consiste essentiellement dans le cassouba, chemise ou soutane de coton bleu qui déteint sur la peau, et dans le seronalla, le pantalon turc si répandu.

Ils ont conservé l'amour du cheval, le goût des armes brillantes de leurs ancêtres arabes et berbères. Quoique naimant pas le travail régulier, ils ont parmi eux des artisans qui fabriquent la plupart des objets dont ils ont besoin. Ils habitent la tente en étoffe de poils de chèvre ou de chameau.

Ils ne sont pas rigoureusement monogames comme les Toua- 
reg, et la femme ne jouit pas chez eux de la même considération. Les mœurs sont aussi bien moins sévères puisqu'ils sont pour la plupart de sang mêlé. Le divorce est facile pour les deux conjoints et fréquent. Beaucoup d'usages nègres ont pénétré parmi eux, notamment par les femmes, dans leur façon de se vêtir, de se coiffer, de s'orner, etc., et par la formation d'une classe de griots. Ils méprisent cependant profondément les vrais noirs, à l'égard desquels ils se montrent souvent cruels.

\section{Les Peuhls}

Les Peuhls sont disséminés un peu partout dans les différentes régions du Sénégal et vivent en groupements patriarcaux.

De mœurs douces et paisibles, le Peuhl vit au milieu de ses troupeaux pour lesquels il a un soin méticuleux et une affection profonde. Malgré cela, ses déplacements, à la recherche de pâturages plus riches, sont très fréquents et parfois renouvelés plusieurs fois dans la même année.

Le Peuhl est en général de mœurs pacifiques et de caractère assez doux; les danses et le tam-tam n'exercent aucun attrait sur lui; par contre son intelligence pour les affaires est assez vive et doublée d'une grande méfiance. A l'encontre du Uuolof, il est économe et cache toujours sa richesse de peur d'être volé.

La majorité de ces indigènes est musulmane; toutefois, certaines tribus ont gardé des pratiques fétichistes. Comme tous les musulmans, ils pratiquent avec beaucoup de respect le culte des morts; les funérailles d'un des leurs sont l'occasion d'offrandes en nature et de distributions de moutons aux pauvres. La rencontre d'une tombe sur leur chemin est l'objet de manifestations pieuses et la profanation d'une sépulture est considérée par eux comme un sacrilège.

Les mariages se consacrent en présence d'un marabout; le fiancé est tenu de faire des cadeaux à la famille de la jeune fille et cette dot, représentée généralement en nature, l'honore d'autant plus qu'elle est plus élevée.

La femme peuhle exerce un ascendant considérable sur son mari; son avis est écouté et ses enfants lui manifestent de la 
déférence et de l'obéissance. La polygamie est de règle chez les Peuhls mais l'autorité de la première femme est toujours plus influente que celle des autres.

L’instruction est assez répandue chez ces nomades et presque chaque village compte un marabout chargé de l'éducation des. enfants.

\section{Les Toucouleurs}

Les Toucouleurs, très répandus sur les rives du moyen Sénégal, sont avant tout des musulmans très fanatiques et toujours prêts à troubler le pays sous un prétexte religieux. Très entreprenants et doués d'un certain courage, ils se déplacent facilement pour aller tenter fortune au loin ou pour entreprendre le pillage d'une région.

En général le Toucouleur est de haute stature, les membres sont secs et bien musclés, la coloration est très variable. Les femmes ont moins d'embonpoint que les Ouolofs. Nos régiments de tirailleurs comptent un grand nombre d'indigènes de cette race dans leurs rangs : ce sont en général d'excellents soldats, bien que parfois indisciplinés.

Les écoles musulmanes sont très répandues chez ces tribus qui fournissent un grand nombre de marabouts auxquels est confiée l'instruction des enfants ; l'enseignement consiste dans la connaissance et la lecture du Coran. Les Toucouleurs sont aussi très amateurs de bijoux et de gris-gris qu'ils portent parfois à profusion.

Insolents et orgueilleux, ils ont un profond dédain pour les Bambaras.

\section{Les Mandingues}

Les Mandingues forment le principal élément noir de notre Soudan. Aux xıII et xıve siècles ils étaient les maîtres de l'empire de Tombouctou, fondé par les Souraìs, et depuis ils se sont répandus au loin. Dans tout le Mossi, jusque dans le Mampoursi, ils constituent une couche ethnique ou une classe superposée à un fond indigène plus ancien. Ils sont à l'état de groupes distincts sur le Niger au delà de Say, les Djerma étant des Mandingıes 
venus de la région de Tombouctou, au Nord du bassin de la Volta, dans la montagne de Bandiagara, etc.

Les Dioulas, commerçants en contact avec les Maures comme avec les Ouolofs, sont surtout des Mandingues ou des Mandés.

\section{Les Bambaras}

Les Bambaras sont répandus sur la rive droite du haut Sénégal, dans le Kaarta, jusque sur les deux rives du haut Niger, et sous le Segou. Mêlés assurément à des Toucouleurs, ils sont pris entre les Maures au Nord, les Mandingues au Sud, les Peuhls $\mathrm{au}$ Sud-Ouest et à l'Est. Leurs caractères sont en rapport avec ces diverses contiguités; ils se rattachent cependant surtout au groupe mandingue par leurs traits dominants et par la langue, comme par bien des détails de mœurs. Lorsqu'ils ne vont pas nus ou ne se contentent pas de quelque guenille attachée autour de la taille, leur vêtement consiste en une tunique descendant aux genoux, un pantalon bouffant ou une culotte de coton à deux pointes. Ils sont bons cultivateurs, et ont une organisation et de réelles qualités militaires, qu'ils tiennent sans doute des Mandingues, dans l'histoire desquels ils ont joué un rôle important.

\section{Les Sarakolés et les Kassonkés}

Les Sarakolés ou Poninkés sont un groupe voisin des Bambaras et confinant, d'autre part, aux Kassonkés. Leur origine est à peu près le même. Ils avaient naguère des chefs peubls qui ont fini par se fondre avec eux. Leur langue, comme leur caractère, témoigne de l'influence de ces derniers ; mais leur langage de même que le bambara ne présentent que des différences dialectales avec le mandingue.

A l'Est du Fouta et de la haute Casamance au Sénégal, dans le Bambouk, un rencontre des Mandingues en groupes distincls. Plus loin à l'Est, du haut Sénégal au haut Niger s'étendent les Kassonkés qui sont, comme les Toucouleurs, des noirs en partie d'origine foulane.

Mais ils ne sont formés que de deux éléments principaux, 
Mandingues et Peuhls. On trouve chez eux les mêmes usages d'origine foulane que chez les Toucouleurs, en particulier la coiffure en cimier et celle en échafaudage de tresses et de chiffons, que recouvre le voile de mousseline légère appelé bourtougal.

\section{Les Ouolofs}

L'empire ouolof s'étendait autrefois sur le Djoloff, le Oualo et le Cayor et formait une cohésion puissante : de nombreuses guerres avec les Maures et les Toucouleurs ruinèrent ces régions qui ne connurent la tranquillitẻ que sous notre domination. Toutefois la langue ouolof, si distincte des autres dialectes africains, est demeurée la langue du commerce. et, à ce titre, est parlée par tous les traitants.

Les Ouolofs, depuis longtemps en contact avec les Européens, sont de mœurs assez douces et affables, et ne manifestent pas le fanatisme religieux des Maures et des Toucouleurs. Bien servi par une haute et puissante stature, et possédant des allures qui ne manquent pas de distinction, le Ouolof est d'un naturel très orgueilleux; il place son honneur dans le port ostensible de vêtements de couleurs très voyantes et se pare avec profusion de bijoux en corail, argent, or ou cuivre. Les femmes se couvrent d'une foule d'objets brillants et entretiennent avec soin les trous qui sont destinés à recevoir des boucles d'oreilles; elles se garnissent les bras de lourds bracelets en argent et les enfants eux-mêmes adorent porter quelques bibelots.

Le Ouolof profite de chaque occasion pour se divertir, car il adore le bruit et a une véritable passion pour le tam-tam et les danses dont quelques-unes sont des plus lascives et des plus passionnées.

Les gris-gris sont aussi très en faveur auprès d'eux etils ont une confiance illimitée dans leurs vertus; quelques indigènes en portent de véritables charges, chaque gri-gri doit le protéger contre un danger spécial; les marabouts entretiennent du reste ces croyances avec un soin d'autant plus jaloux qu'ils sont pour la plupart les fournisseurs de ces objets.

La famille est fortement constituée; l'autorité des parents est 
respectée et les vieillards rencontrent beaucoup de déférence. La condition de la femme est du reste assez élevée malgré la polygamie autorisée et réglementée par le Coran.

Les mariages sont l'occasion de fêtes qui durent souvent huit jours et dont les dépenses ruinent parfois les intéressés. Les unions ne se font qu'entre jeunes gens de même caste et un homme libre refusera toujours d'épouser la fille d'un artisan, pas plus qu'un artisan ne consentira à prendre pour femme la fille d'un griot.

Les funérailles d'un personnage important se célèbrent avec un grand cérémonial, et les veuves recouvertes d'un pagne sombre portent le deuil pendant quatre mois. Des distributions de mil et de provisions diverses sont faites le jour de l'ensevelissement aux pauvres et aux enfants en l'honneur du défunt et se continuent encore après pour en perpétuer la mémoire.

La majorité des Ouolofs est musulmane, toutefois l'on compte un certain nombre de catholiques à Saint-Louis, Dakar et Gróe et les scapulaires et autres objets de dévotion remplacent alors les gris-gris.

Les Ouolofs acceptent volontiers notre pouvoir et adoptent même fréquemment nos coutumes avec une préférence marquée pour celles qui leur procurent des distractions ou leur donnent l'occasion de se revêtir de leurs plus beaux boubous.

Ils montrent un vif penchant pour le jeu et se réunissent volontiers autour d'un damier, ou bien encore, ils cultivent les jeux de cartes ; par contre le travail les attire beaucoup moins et s'ils consentent à faire quelques efforts ce n'est pas certes pour se constiturer quelques économies en vue des années de disette ou de vieillesse mais bien pour se procurer plus de luxe. Ce peuple semble d'ailleurs nous être bien acquis et susceptible dans un avenir très rapproché de modifications importantes.

\section{Les Sérères.}

Les Sérères d'origine très ancienne au Sénégal occupent des régions étendues au Sine Saloum et au Baol. Le Sérère est loin d'avoir la finesse du Ouolof, le type est dur et grossier; des 
lèvres grosses, un nez très épaté, des membres inférieurs très grèles, rendent l'ensemble peu harmonieux. Par contre, sa constitution physique vigoureuse lui permet de vaquer aux travaux pénibles de la culture.

Les mœurs rudes et farouches des Sérères s'adoucissent de jour en jour sous l'action bienfaisante de notre influence et au contact des Ouolofs plus civilisés.

Ils sont presque tous fétichistes et croient aux esprits, qu'ils localisent dans les objets les plus divers ; il y a le génie dé la fontaine, du baobab, du village, etc., et pour s'attirer les faveurs de ces esprits, ils leur font des offrandes de lait ou d'animaux.

La mort d'un Sérère est l'occasion de manifestations bruyantes, surtout si elle a lieu dans des conditions favorables, c'est-àdire, si l'on ne soupçonne pas l'intervention du « mangeur d'âme »: Des cris, des coups de fusils accompagnent les funérailles et un repas copieux, où les boissons alcooliques jouent le rôle le plus important, suit la conduite du défunt à sa dernière demeure. Les économies d'un Sérère passent en achat de bétail ou d'alcool ; et il n'est pas rare de voir des villages entiers se réunir pour causer, boire et s'envivrer joyeusement. Cette passion pour l'alcool a du reste fini par atteindre la race et amoindrir sa force.

Les Sérères ne se mélangent pas avec les autres peuplades et les unions ne se font qu'entre les familles d'une même tribu. Comme chez les Ouolofs la polygamie est de règle.

La famille est assez mal organisée et le róle de la femme se résume le plus souvent à celui d'une bête de somme à qui incom: bent les travaux les plus pénibles; les enfants semblent peu compter et sont abandonnés à eux-mêmes.

\section{Les Diolas et les Balantes.}

Ces peuplades constituent des groupes assez importants en Casamance. Pour la plupart fétichistes, malgré des tentatives nombreuses de conversion à l'islamisme de la part des Ouolofs et des Toucouleurs, les Diolas ou Féloups et les Balantes ont gardé des coutumes encore très barbares. Les Balantes se livrent volontiers au pillage et opèrent principalement sur les troupeaux 


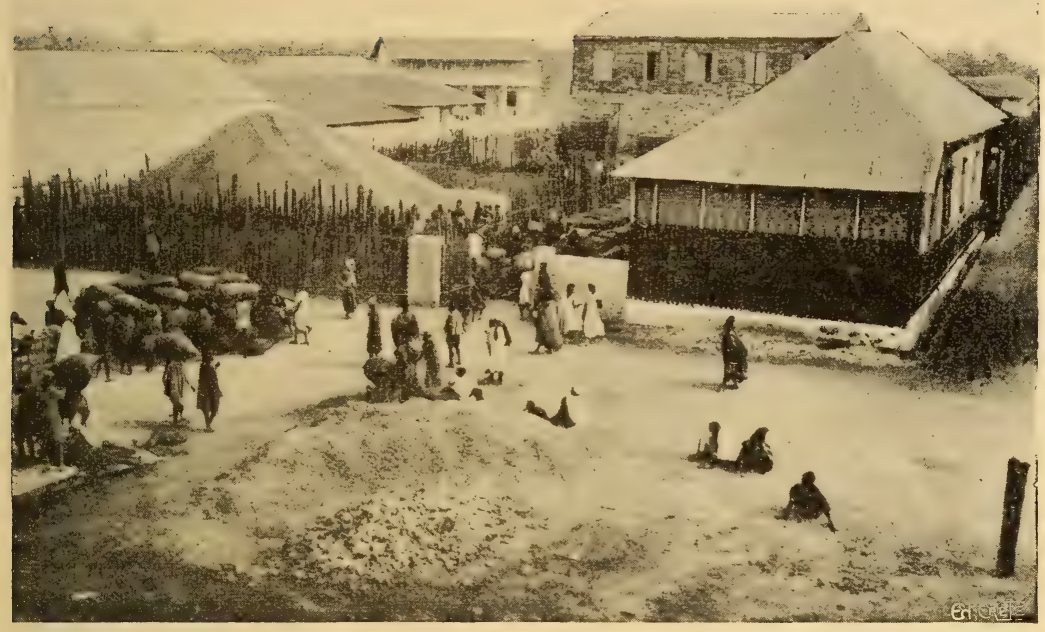

Fig. 11. - Kaolack (Une factorerie).

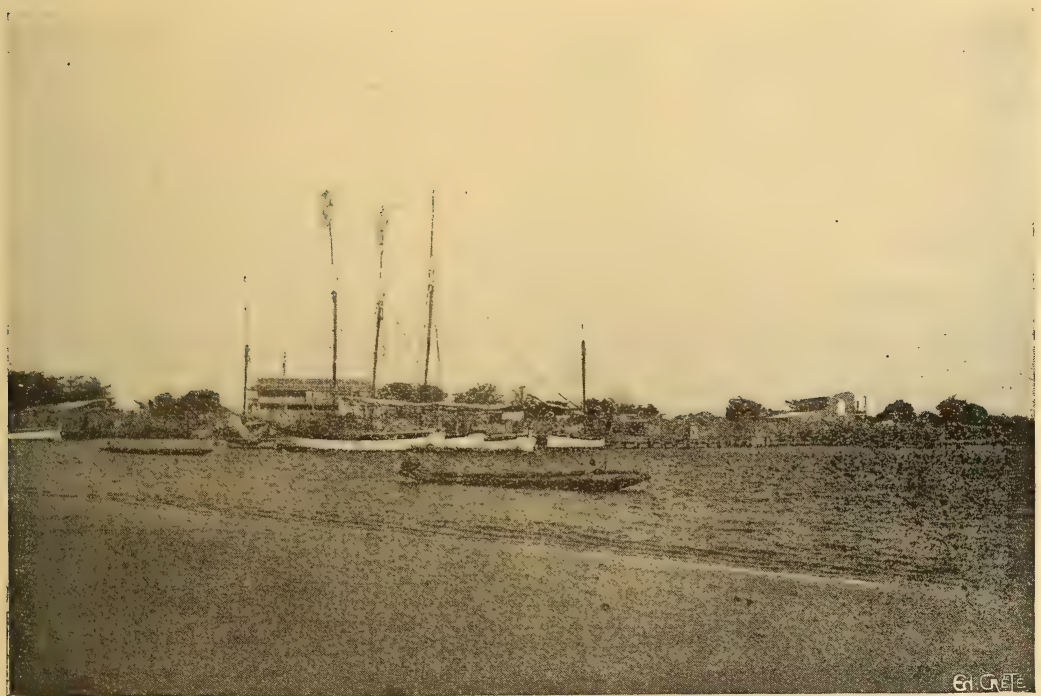

Fig. 12. - Vue de Fatick.

S. 

de leurs voisins; d'un caractère très indépendant, ces indigènes se sont opposés longtemps à notre pénétration, mais l'installation des postes dans les régions qu'ils habitent, les a amené à des sentiments plus doux et l'étranger n'a plus à craindre d'être maltraité et dépouillé. La chasse est une des principales ressources de ces peuplades qui manifestent peu de penchant pour le travail régulier.

Comme les Sérères, les Balantes et Diolas croient aux esprits et n'admettent pas la mort naturelle. Un décès qui ne résulte pas d'un accident est à leurs yeux la preuve de l'intervention du "mangeur d'âme ". Pour le découvrir ils ont recours à l'épreuve du tali. A cet effet ils se réunissent en grand nombre autour d'une fontaine ou dans un endroit déterminé assez loin des villages. Le poison, un composé d'écorce de tali pulvérisée, de chair humaine, et de verre pilé, est apporté dans de grandes calebasses, puis distribué à des indigènes désignés pour représenter chaque village. Dès que l'absorption est faite, les patients doivent prendre une grande quantité d'eau; si les vomissements suivent, c'est une preuve que les patients ne sont pas dangereux et les parents les reconduisent au village au milieu de manifestations bruyantes et joyeuses. Les mangeurs d'àmes au contraire ne vomissent pas le poison et meurent au bout de quelques heures, les cadavres sont abandonnés dans la brousse et les biens des victimes sont partagés entre les habitants de leur village. Personne ne peut se soustraire à l'épreuve du tali, les vieillards, les enfants, les femmes n'en sont pas exempts et celui qui tenterait d'échapper à cette coutume, serait massacré par les siens. Le tali fait ainsi chaque année de nombreuses victimes.

La considération d'un Balante pour son congénère est d'autant plus grande que celui-ci manifeste une habileté supérieure pour l'exécution d'un mauvais coup; du reste les chefs sont en général choisis parmi les indigènes les plus pillards et un mariage avec le jeune homme le plus voleur du pays est très recherché.

L'état social est resté à la famille, les villages n'ont pas de chef réel et chaque chef de famille est le maître chez lui. La 
femme est peu considérée. On lui abandonne l'exécution des travaux pénibles.

Les Baniounkas qui occupent aussi une grande partie de la Basse Casamance, sont de mœurs plus douces : le vol est inconnu chez eux et l'accueil réservé à l'étranger toujours cordial. La famille est mieux organisée que chez les Balantes et les Diolas. Le chef de famille a une certaine influence et la femme est souvent écoutée.

\section{II. - Progrès des indigènes.}

\section{Influence de la colonisation française.}

La tâche d'initiation de l'indigène à nos coutumes et à nos mœurs s'est présentée au Sénégal, avec de nombreuses difficultés provenant de la variété des races sur laquelle notre influence s'exerce. Dans chaque partie de notre colonie, se sont établis des peuples d'origine, de religions et de coutumes différentes; des Maures pour la plupart disciples de Mahomet, dans le sud marocain; des Toucouleurs, musulmans fanatiques plus éclairés, le long du fleuve ; des Ouolofs, musulmans ou catholiques, dans la région côtière; des Sérères en grande partie, fétichistes dans le Saloum ; des Dioulas et Balantes aux coutumes encore barbares, en Casamance ; des Peuhls aux allures nomades, disséminés un peu partout. Si l'on songe qu'il y a quelques années, ces peuplades étaient encore en état d'hostilité permanent, toujours prêtes à lutter entre elles et à se dépouiller mutuellement, on comprendra les efforts que l'Administration a du accomplir pour faire régner la tranquillité chez des éléments aussi étérogènes. Les rapports des Administrateurs de cercles constatent en effet, que la sécurité, sans laquelle tout progrès matériel ou social est impossible, règne à peu près partout au Sénégal, et, les étrangers qui circulent dans le pays, non seulement ne sont plus molestés, mais trouvent un accueil bienveillant sur leur passage. L'indigène peut maintenant se livrer, sans crainte d'être spolié par son voisin des fruits de son labeur, à l'agriculture, à l'élevage ou au commerce, et sa reconnaissance pour la paix que 
nous lui avons donnée, se traduit par une crainte respectueuse de notre puissance et une confiance plus grande dans nos institutions. Sans doute, certaines peuplades peu pénétrées par notre influence, gardent des habitudes de querelle et de vol, et se livrent encore à des pratiques barbares, mais d'une façon générale, le rapprochement de l'indigène vers nous suit une marche normale. Si les progrès accomplis ne sont pas plus rapides, il faudrait se garder d'imputer cette lenteur à un défaut d'organisation de notre part, ou, à un manque d'esprit de suite, mais bien plutôt en chercher la cause dans la nature de l'indigène si différente de la nôtre. L'indigène qui est d'un naturel très simple, ne peut comprendre la complexité de notre existence, et les manifestations si variées de notre activité lui semblent inutiles et au-dessus de ses forces. Notre tâche n'a pas pour objet son assimilation complète, ce qui pourrait bien être chimérique, mais elle comporte une œuvre d'initiation basée sur un ascendant moral soutenu par une force matérielle réservée à la légitime défense de nos droits et à l'exécution des lois humaines de la colonisation.

\section{a) L'enseignement}

Ecoles. - Le concours économique des indigènes nous sera assuré dans des conditions d'autant meilleures que notre enseignement aura amélioré leurs notions et leurs procédés techniques et que nous aurons suscité et développé leurs aptitudes au travail régulier et à la prévoyance, en communiquant aux couches supérieures et moyennes de la population quelque goût pour les sciences et leur application. L'Administration comprenant tout l'intérêt qui s'attachait à cette question, s'est efforcée d'entreprendre une réforme complète de l'enseignement en multipliant et spécialisent les écoles. L'enseignement donné dans les écoles de l'Afrique occidentale comprend un enseignement primaire élémentaire, un enseignement professionnel, un enseignement primaire supérieur et commercial, une école normale commune à toute l'Afrique occidentale française. (Arrêté du 24 novembre 1903). 
Enseignement primaire élémentaire. - Cet enseignement est donné dans les écoles de villages, et les écoles urbaines et régionales. Les écoles de villages ouvertes dans les centres où le nombre d'habitants en justifie la création, sont en général dirigées par un instituteur indigène à moins que le nombre des élèves ne nécessite un instituteur européen. Le programme de l'enseignement comprend essentiellement la langue française parlée et accessoirement l'écriture, le calcul et quelques notions sur l'agriculture. Les écoles régionales sont établies dans les chefslieux de cercle ou dans certains centres importants; l'enseignement est donné de façon plus complète que dans les écoles de village. A chaque école régionale est annexée une section d'agriculture.

Le Directeur d'une école régionale doit être français, il est secondé par des adjoints européens ou indigènes. Les élèves des écoles régionales se recrutent après examen parmi les élèves des écoles de village.

Dans les villes comme Dakar et Saint-Louis où l'élément européen est assez nombreux, les écoles portent la dénomination d'urbaines et comportent exclusivement un personnel européen.

Enseignement professionnel. - Cet enseignement est donné dans les écoles élémentaires professionnelles et dans une école supérieure constituée sous le nom d'école Pinet-Laprade. Le programme suivi comprend des études théoriques et pratiques. Les élèves apprennent suivant la section où ils sont versés, le travail du bois, de la pierre et des métaux.

Enseignement primaire supérieur et commercial. - Une école primaire supérieure commerciale constituée à Saint-Louis sous le nom d'Ecole Faidherbe, comprend une section commerciale, une autre administrative préparant aux emplois coloniaux des travaux publics, douanes et une troisième dont l'objet est de mettre les élèves en mesure de suivre les cours des lycées et collèges de la métropole. Jes bourses peuvent être accordées à des indigènes dignes d'intérêt. L'école est administrée par un Directeur sous le contrôle d'un conseil d'Administration.

Ecole normale. - Cette école a pour but d'assurer le recrute- 
ment des instituteurs indigènes destinés à compléter le recrutement du personnel enseignant et à former le corps des interprètes et des cadis.

Les écoles Pinet-Laprade, Faidherbe reçoivent des élèves de toutes nos colonies de l'Afrique occidentale, mais le Sénégal en fournit le plus fort contingent.

De l'enseignement des filles. - - Des écoles de village et des établissements urbains assurent l'instruction des filles; de plus des écoles spéciales dites ménagères qui seront créées au fur et à mesure du développement social des régions soumises à notre influence, donneront aux jeunes filles indigènes le moyen de s'initier aux choses du ménage.

Situation de l'enseignement au Sénégal. — Le Sénégal compte à l'heure actuelle 37 écoles urbaines, régionales ou rurales fréquentées par près de 5.000 élèves recevant ainsi l'enseignement officiel.

Les écoles de Dakar, Saint-Louis, Rufisque et Gorée donnent l'instruction à environ 3.600 élèves et celles qui sont établies dans les escales du fleuve et de la ligne deviennent de jour en jour plus prospères, à Kaolack, à Bakel, par exemple, l'effectif scolaire a fait plus que doubler en quelques jours. Sans doute quelques peuplades comme les Sérères, Diolas, Balantes manifestent encore une certaine répugnance pour nos écoles et la clientèle publique de nos établissements scolaires ne s'est pas développée rapidement dans certains milieux; mais nous avons rencontré de nombreux et multiples obstacles. A côté de nos écoles primaires, se trouvent une multitude d'écoles musulmanes et si la plupart comptent un nombre restreint d'élèves, quelques-unes d'entre elles atteignent parfois un chiffre important; on peut évaluer à environ 289 le nombre de marabouts dans l'ensemble des territoires d'administration directe et celui des élèves à 4.000. L'enseignement est donné par les marabouts, presque toujours en langue ouolofe; les élèves apprennent à psalmodier les versets du Coran et à reconnaître les caractères arabes. Quelques jeunes indigènes poussent leurs études plus loin et entreprennent l'étude de la gram: maire arabe. 
L'enseignement est donné dans une cour à ciel couvert ou sous un abri formé par une toiture en chaume supportée par des piquets. Le matériel classique est des plus sommaires. Aux heures des cours, geénéralement le matin et l'après-midi, les élèves se réunissent autour du marabout ( Serigne " en langue ouolof) et après s'être accroupis autour du maître, ils répètent tous à la fois les versets du Coran qui sont inscrits sur des planchettes fabriquées d'un bois spécial. La leçon terminée, les enfants lavent les planchettes et regagnent leurs cases. Ciet enseignement se poursuit pendant plusieurs années, jusqu’à la connaissance complète du Coran.Chez les Toucouleurs, linstruction d'un enfant se traite souvent à forfait, et en dehors du paiement du prix convenu, les élèves font la quête pour leurs maitres et lui apportent des provisions et des cadeaux. Les marabouts sont en général très ignorants et ne cherchent pas à donner à leurs élèves des explications sur le texte du Coran, ils se bornent à le faire psalmodier tranche par tranche de la façon la plus machinale ; toutefois, malgré le peu de portée au point de vue instructif de ce genre d'enseignement, il n'en est pas moins vrai que l'influence qu'exerce un marabout sur les autres indigènes et le fanatisme religieux qui l'anime le rendent souvent hostile aux intérêts français, et en particulier à la fréquentation de nos écoles.

De l'enseignement privé. - L'enseignement officiel est concurrencé par l'instruction privée en majorité congréganiste. Le but de ce genre est autant de faire du prosélytisme religieux que de l'instruction. Aussi la clientèle publique de ces établissements ne pouvait se développer, l'indigène éprouvant une répulsion à fréquenter des écoles où sa religion était combattue. Le nombre de ces écoles est aujourd'hui de 14, fréquentées par 300 élèves.

\section{b) Progrès intellectuels}

La nature très rustique de l'indigène, ses mœurs encore rudimentaires, son apathie pour le travail furent autant d'éléments qui s'opposèrent à une réalisation plus rapide, plus accentuée 
des progrès intellectuels accomplis par les jeunes gens fréquentant nos écoles. Néanmoins, on peut constater quelques progrès sensibles, nous avons déjà réussi à former un certain noyau d'hommes intelligents et parlant bien notre langue qui répandent autour d'eux notre civilisation. De nombreux traitants du fleuve savent lire et écrire, et peuvent tenir une petite comptabilité de leur commerce. Quelques jeunes indigènes, instruits dans nos écoles sont employés comme préposés de douanes ou commis des postes; d'autres servent d'interprètes ou d'écrivains dans les bureaux. Les jeunes enfants ne manquent pas d'une certaine vivacité d'esprit et les résultats obtenus aux derniers examens du certificat d'études attestent des progrès réels. L'enseignement, la divulgation de la langue du peuple colonisateur parmi le peuple colonisé sont des facteurs très importantśs de la civilisation, mais exigent une grande lenteur et une infinie persévérance.

\section{c) Progrès matériels}

Habitation. - La plupart des cases indigènes du Sénégal sont construites sur le même modèle et affectent la forme d'une ruche d'abeilles recouverte d'un toit de chaume. On constate dans les environs de Bakel une amélioration des habitations, les cases sont mieux aérées, plus spacieuses, et il n'est pas rare de trouver chez les indigènes, qui les occupent un petit mobilier composé de lits, chaises et tables.

Les Ouolofs en contact plus intime avec les Européens ont déjà réalisé des progrès sensibles; leurs cases autrefois resserrées et étroites, aujourd'hui agrandies, forment contraste avec les huttes basses et inconfortables des Sérères, par contre les villages de ces derniers présentent une symétric et un ordre agréable à la vue. Quelques indigènes, en grande partie des traitants, conmencent à construire des cases carrées en bois ou en argile et se meublent à l'européenne en montrant une préférence marquée pour les objets brillants.

Les Peuhls, dont l'existence est très nomade, habitent des paillotes rondes et parfois de simples gourbis en paille qu'ils 
détruisent quanl ils quittent l'emplacement. Dans les régions riches en pâturages ils établissent un village qu'ils entretiennent avec goût et se construisent des cases élégantes en pisé avec des murs épais et des toits débordant les murailles formant ainsi véranda.

La façon dont est construite une case est chez certaines peuplades un signe de la caste à laquelle appartient l'habitant et de la profession qu'il exerce, les traitants et indigènes aisés habitent en général des baraques en planches assez spacieuses, les nomades n'ont souvent pour abri qu'une légère toiture en paille supportée par quatre piquets, les indigènes de basse classe occupent des cases très étroites. Les cases d'une même famille forment un carré, de telle sorte qu'un village se compose de plusieurs quartiers distincts occupés par des groupes exerçant des métiers différents. Les chefs de villages possèdent plusieurs cases.

On rencontre encore fréquemment des villages protégés par une enceinte puissante en bois ou en terre destinée à former défense en cas d'incursion des populations voisines.

L'administration s'efforce d'améliorer les conditions d'habitat de l'indigène; lors d'un incendie qui détruisit en 1902, un village noir des environs de Saint-Louis, les anciennes cases en chaume furent remplacées aux frais du gouvernement par de petites maisons en briques, beaucoup plus hygiéniques et d'un aspect cxtérieur beaucoup plus propre. Dakar est en voie de transformation complète, et la ville comprendra d'ici peu un quartier réservé à l'élément blanc et un autre occupé par les indigènes. Un règlement prescrira la disposition du village noir.

Vêtement. - Sauf dans quilques régions encore peu pénétrées où les indigènes vont encore nus, dans la plupart des villages le noir commence à se vêtir. Le costume le plus répandu au Sénégal comporte en général pour les hommes, un boubou, sorte de longue chemise sans manches, largement fendue pour donner passage aux bras, et un pantalon (touba), très ample, descendant jusqu'aux genoux.

Les femmes portent autour des reins un pagne, grand carré d'étoffe, ordinairement en cotonnade du pays, le haut du corps 
est également recouvert par un pagne rejeté sur les épaules.

Les Sérères commencent à utiliser le coton produit dans leur pays auquel ils mélangent du coton anglais, ils tissent ainsi des étoffes solides, dont ils se confectionnent des boubous.

Dans le cercle de Bakel, les vêtements portés par les indigènes sont devenus plus luxueux, les commerçants débitent maintenant de fort jolies étoffes dont les noirs se parent avec orgueil. Des teinturiers renommés donnent aux tissus de fort belles couleurs et certains vêtements sont rehaussés de riches broderies dont la confection exige des mois de travail.

Les Ouolofs affectent beaucoup de recherche dans le choix de leurs vêtements; ils aiment à porter avec ostentation des boubous de prix, blancs ou de couleurs voyantes. Au costume ordinaire, ils ajoutent fréquemment d'amples manteaux qui leur sont vendus par les Marocains, et exhibent volontiers des gilets à couleurs chamarrées.

Quelques catholiques ont adopté le costume européen, les hommes portent pantalon et veston et les femmes s'habillent avec des sortes de Inngues robes de chambre. Généralement le costume des enfants est des plus sommaires.

Les indigènes vont le plus souvent les jambes complètement nues, les pieds sont parfois garanties, soit par une simple semelle en cuir retenue par des lanières enroulant la cheville, ou par des sandales de diverses couleurs mais vertes en général.

Dans les centres européens, ils portent des vêtements mieux confectionnés, faits avec de bons tissus tels que le drap, la percale. Le Noir semble toutefois vouloir rester fidèle à son costume national plus en rapport avec son mode de vivre et avec le climat.

Les indigènes ne portent en général aucune coiffure, toutefois les Ouolofs se couvrent volontiers d'un vaste chapeau en paille tressée affectant la forme d'un cône très évasé.

Une coiffure assez répandue est le mbakhané, bonnet cylindrique en calicot ou en velours de couleur.

Les femmes s'entourent la tête d'un mouchoir qui leur couvrc une partie du front et forme une espèce de bonnet noué sur le còté. 
Leurs cheveux sont souvent disposés avec une très grande complexité et il existe de véritables professionnelles chargées d'édifier ces coiffures. L'opération exige beaucoup de temps et se paie très cher. Un morceau de bois ou une arrête de poisson remplacent le peigne; de la graisse et du beurre servent de pommade. La perfection d'une coiffure réside dans la multiplicité des mèches de cheveux tressées. Les enfants ont la tête complètement rasée, et on laisse aux petites filles quelques petites mêches pour y suspendre un gri gri ou une pièce de monnaie. Certaines familles adoptent pour leurs enfants des coiffures de fantaisies consistant en des dessins variés sur le crâne.

Les indigènes sont très amateurs de bijoux et s'en couvrent parfois à profusion, les femmes portent des bracelets à la cheville et des séries de boucles d'oreilles et de perles.

Nourriture. - La base de la nourriture de l'indigène est le couscous préparé avec du mil. A ce mets de chaque jour, il ajoute volontiers du riz, du poisson sec, ou de la viande: La religion musulmane défend à ses adeptes de manger de la viande de porc et de faire usage de boissons alcooliques.

Les Noirs utilisent aussi certains produits naturels tels que le fruit du baobab appelé bouy, les noix de kolas etc. Avec la sève du palmier, ils fabriquent un vin d'apparence laiteuse dont ils font une consommation abondante; ils préparent aussi un hydromel agréable en faisant fermenter le miel du pays. Le dolo est une sorte de bière fabriquée avec du mil germé, des cidres capiteux sont préparés avec les fruits des différents arbres.

Les indigènes aisés améliorent leur couscous en y ajoutant de la viande, des condiments et des volailles et mélangent à leur nourriture des aliments européens. Le sel qui dans certaines régions sert encore de monnaie, est très recherché, et la consommation du sucre croît de jour en jour. Les produits variés de la chasse et de la pêche occupent une place importante dans leur alimentation.

Les aliments sont préparés avec de l'huile d'arachide ou de palme; les mets sont assaisonnés de condiments variés et servis 
avec des légumes ou des fruits de plantes recueillis dans la brousse. Ce n'est qu'exceptionnellement que les indigènes se nourrissent d'arachides ou de plantes à tubercules. Bon nombre d'entre eux cultivent avec soin des petits jardinets ensemensés de tomates, de salades et de choux dont ils sont particulièrement friands.

Hygiène. Santé. - Les indigènes ne semblent pas se soucier beaucoup de l'hygiène et de ses prescriptions multiples. Les villages noirs sont, sauf quelques rares exceptions, dans un état de saleté repoussante et l'intérieur des casesn'engage pas le voyageur à y pénétrer et à y établir son gite; l'abri peu confortable d'une tente dressée à la hâte est préférable à une case indigè̀ne. La même case sert d'ailleurs à la fois de cuisine et de chambre à coucher et l'insuffisance des ouvertures fait de ces habitations de véritables bouges enfumés. Certaines cases sont à moitié enterrées sous le sol, sans air, sans lumière.

L'indigène ne prend du reste aucune précaution pour se préserver des intempéries et se soucie peu de la chaleur qu'il brave continuellement. Il se préoccupe peu de la qualité des aliments qu'il consomme et se désaltère avec la première eau rencontrée dans un marigot.

Les soins sont presque toujours donnés aux malades par les marabouts qui d'une indisposition vulgaire font rapidement une maladie grave et empirent souvent la situation du patient en lui faisant absorber des mixtures de feuilles d'arbre ou d'herbes variées. Certains féticheurs sont très réputés comme médecins et se spécialisent pour les affections de poitrine ou d'yeux, leurs méthodes sont des plus empiriques.

Il existe encore chez certaines peuplades de la Casamance des pratiques fétichistes qui font de nombreuses victimes, la quantité de cadavresabandonnés dans la brousse après l'épreuve du tali est considérable et il faut une forte natalité pour que la race ne soit pas anéantie par ces coutumes barbares.

La mortalité infantile est considérable chez les indigènes, les accouchements se font dans des conditions peu hygiéniques et il en résulte une proportion très grande d'aveugles de naissance. 
L'alcoolisme cause également beaucoup de dégâts, surtout chez les Sérères.

La création d'un service d'assistance médicale indigène dont il sera question plus loin est appelée à donner des résultats satisfaisants; on peut déjà constater une plus grande confiance du Noir dans nos médicaments et le nombre d'indigènes traités dans nos hôpitaux augmente chaque jour.

\section{d) Progrès des exploitations indigènes.}

Les procédés de culture et d'élevage de l'indigène ne se sont pas beaucoup modifiés, ils sont restés ce qu'ils étaient jadis, rudimentaires et primitifs.

La principale culture du Sénégal est, comme nous le verrons de façon plus détaillée en nous occupant de l'agriculture, celle de l'arachide qui a pris dans le pays, une grande extension; à l'époque de la plantation, les Sérères se déplacent en grand nombre, et au moment de la récolte, de longues caravanes de chameaux parcourent la brousse d'un pas lent, lourdement chargés de sacs d'arachides. Rufisque est le mar'ché le plus important de cette denrée.

Des champs de gros et de petit mil couvrent de grandes étendues dans le Cayor. Le maïs est cultivé autour de tous les villages ainsi que le manioc et les niébés, le melon, le riz, les patates douces, etc.

Le coton vient assez bien dans le Sine-Saloum où l'on en rencontre d'assez beaux champs, mais l'indigène ne le cultive que pour ses propres besoins.

Le tabac est produit en petite quantité. L'indigo pousse dans la région du $\mathrm{Baol}$ oriental; le gommier et l'arbre à caoutchouc se rencontrent en petit nombre dans la province de la Haute Gambie. Les essences forestières sont très variées; les régions ombragées et humides de la Casamance renferment des palétuviers, de grands acacias, des bambous et d'immenses lianes; dans les provinces plus sèches du Cayor et du Baol poussent le Baobab, le caïlcedrat, le kevert ou cerisier du Cayor, le rônier; sur les bords des marigots, on trouve le Palmier nain, le tama- 
rin du Sénégal. De nombreux bosquets de palmiers à huile ombragent des frondaisons de fougères.

Elevage. - Les Peulhs et les Sérères entretiennent de nombreux troupeaux de bœufs, de moutons et des porcs, mais l'élevage proprement dit n'existe pas; lindigène ne comprend pas les avantages qu'il pourrait tirer de la sélection et du croisement des belles races, les animaux errent mélangés dans la brousse.

On rencontre sur les rives du fleuve une race chevaline dont le type est de taille assez élevée; le cheval du Cayor est au contraire, de petite taille, $1 \mathrm{~m} .20$ en moyenne mais il est très résistant et d'un entretien bon marché. Le M'Bayar est le cheval de fatigue par excellence. Les indigènes éprouvent beaucoup d'orgueil à posséder une belle monture qu'ils sellent de harnachements très décoratifs. Les hippodromes de Dakar, Rufisque et Saint-Louis présentent aux jours de courses une grande animation et le pari mutuel est encombré de Noirs discutant bruyamment les chances de tel ou tel cheval.

Les indigènes viennent écouler leurs produits sur les marchés des grands centres tels que Dakar et Saint-Louis ; le parcours, à une heure matinale, d'une de ces halles ne manque pas d'intérêt.

Industries indigènes. - L'industrie indigène est très peu développée et limitée aux besoins de la population. Les tisserands assez nombreux chez les Ouolofs, fabriquent des pagnes avec le coton du pays auquel ils ajoutent des fils colorés qui leur sont vendus par les traitants. Les Laobés tressent les fibres de l'écorce des baobabs et en font des cordes très résistantes. Les pièces d'étofte fabriquées par les tisserands sont composées de bandes dites de sor de 20 à 25 centimètres de large sur 4 mètres de long. Pour donner une coloration aux étoffes, les indigènes se servent de l'indigo dont toutes les femmes connaissent l'emploi.

Cordonnerie. - Les cordonniers préparent les peaux au moyen d'un bain composé de chaux de cendres et de fruits. Lorsque le cuir est suffisamment préparé ils confectionnent des sandales, des étuis de sabre et de poignard, des amulettes et des selles. Quelques-uns de ces objets ne manquent pas d'un certain cachet artistique. 
Les Toucouleurs se servent de hauts-fourneaux en terre pour extraire le fer du minerai. Les forgerons forment une caste à part, et sont seuls à s'occuper de la fabrication des couteaux, des haches, des lances ; ils font également les instruments aratoires tels que les dabas, sortes de pioches, l'hilaire, etc.

Les bijoutiers forment une catégorie à part, et malgré un outillage des plus sommaires arrivent à faire des bijoux en filigrane d'un style arabesque qui ne manque pas d'originalité.

Le travail de la poterie est surtout répandu sur les rives du Sénégal; les femmes préparent l'argile, la modèlent et font cuire les ustensiles dans de grands fours chauffés par de la paille ou du bois. Les ustensiles courants sont les marmites, les gargoulettes, les canaris, etc... Les poteries de Dagana et celles de Podor sont particulièrement réputées.

Industrie du bois. - Les Laobés pratiquent l'industrie du bois avec lequel ils font des pilons, des calebasses, des tabourets divers, des massues, etc., ils fabriquent également les caisses des tamtams et des violons. Les griots sont chargés d'achever les instruments. Quelques menuisiers ouolofs travaillent le bois avec goût et utilisent les outils européens pour la fabrication de tables, lits, meubles variés. Les indigènes qui se livrent à la pêche, construisent des pirogues de formes assez élégantes.

D'une manière générale, le travail était considéré autrefois chez beaucoup de castes indigènes, comme une dégradation et un abaissement de la condition sociale; les corporations d'artisans jouissaient de peu d'estime; notre influence et des exemples répétés de la participation du blanc aux divers labeurs, ont en partie fait disparaitre cette répulsion de l'indigène pour le travail. Des travaux importants tels que comblements de marais insalubres, constructions de bâtiments publics, ont pu être accomplis rapidement grâce à une productivité plus grande de la main-d'œuvre noire et une habileté croissante des travailleurs acquise au contact des européens. Les salaires ont augmenté et l'indigène reçoit une rémunération journalière variant entre 2 à 3 francs.

Les moyens de communication s'améliorent de jour en jour ; les Administrateurs des cercles veillent à l'entretien des routes 

et en font établir de nouvelles; de nombreux chemins, débroussaillés trois fois paran, d'une longueur de $\mathbf{7 5 0}$ kilomètres sillonnent le Cayor et rendent les relations plus faciles; des ponts ont été jetés sur les marigots et de nombreux puits creusés ces dernières années fournissent de l'eau en abondance.

Grâce à ces améliorations des moyens de communications, les échanges de produits et le transport des courriers s'effectuent beaucoup plus rapidement et notre action sur le pays devient plus efficace.

Si l'on admet que le développement général d'une nation est marqué par une marche parallèle des progrès sociaux et matériels on constatera que le Sénégal a déjà réalisé des progrès sensibles ; l'indigène produit plus et mieux, sa condition sociale s'améliore et son bien-être a augmenté. Sans doute, notre tâche n'est pas encore terminée, l'œuvre n'est pas au point, mais la colonisation d'un pays ne s'accomplit pas en quelques années, sa marche doit au contraire, être empreinte d'un grand esprit de méthode et de prudence et procéder sans à coup. Pour nous assurer le concours des indigènes il nous a été nécessaire d'adapter nos moyens d'administration à leurs coutumes. La perception des impôts et des taxes n'était pas sans difficulté, nous avons utilisé l'influence des chefs de canton pour la réaliser sans susciter de mécontentement et grâce à ce concours, les recouvrements s'opèrent aujourd'hui de façon régulière. Une réorganisation de la justice musulmane et la création de tribunaux de cercles permettent aux autochtones de régler leurs différends. Le respect des personnes et des biens, l'observation des règlements et le maintien de l'ordre, sont assurés par le fonctionnement d'une police coloniale. La participation de l'indigène à l'administration locale, nous a constitué un cadre de collaborateurs, guides, interprètes, contremaîtres surveillants.

Il était imprudent de livrer sans garantie des populations primitives au régime de la liberté des contrats et une sorte de tutelle était nécessaire pour les garantir contre les procédés des usuriers. Le contrôle de l'Administration empêche déjà les abus 
116 LES CONDITIONS DE LA VIE SOCIALE AU SÉNEGAL

et la création projetée de caisses de prêts deviendra une protection plus efficace et concourra à accroître nolre influence.

Les résultats obtenus sont, on le voit, de bon augure et permettent de concevoir de légitimes espérances pour la réalisation de l'œuvre de pacification et d'humanité que, de tout temps, nous avons poursuivie et dont ces cinq dernières années marquent une étape si décisive. 


\section{TROISIEME PARTIE}

L'ORGANISATION DE LA COLONIE DU SÉNÉGAL 

L'œuvre administrative devait compléter l'action politique. On pourra juger par les pages qui vont suivre que rien n'a été épargné, ni efforts d'aucune sorte, ni crédits, pour doter notre colonie du Sénégal d'institutions dont on a déjà pu apprécier l'heureuse influence sur son développement. 



\section{CHAPITRE VII}

ORganisation politiQue et administrative

\section{I. - Organisation politique.}

Notre colonie du Sénégal, seule parmi nos autres possessions de l'Afrique occidentale française, est représentée au Parlement par un député. Elle possède également, en vertu du décret du 4 février 1879, un Conseil général et a été dotée par les décrets du 10 août 1872 et du 13 décembre 1891 d'institutions municipales.

Avant d'étudier ces diverses institutions dans leurs détails, il est nécessaire de dire quelques mots du régime électoral dans la colonie.

Régime électoral. - Sont seuls électeurs au Sénégal les habitants des communes constituées réunissant les mêmes conditions d'âge, de nationalité et de résidence que celles qui sont exigées pour les élections dans la Métropole. Une liste électorale, unique depuis la loi du ő avril 1884, sert pour les élections à la Chambre des députés, au Conseil général et aux Conseils municipaux et est établie dans les mêmes conditions et dans les mêmes formes qu'en France.

Les règles d'éligibilité sont également les mêmes que dans la Métropole, toutefois les candidats doivent savoir parler, lire et écrire le français : c'est une condition essentielle dans une colonie où des indigènes peu habitués à la vie française, peuvent prendre part aux opérations électorales.

Quant aux élections elles-mêmes, elles sont opérées dans les formes prescrites par les lois des 7 juillet 1874 et 30 novem- 
bre 1875, applicables aux élections législatives, par les décrets spéciaux relatifs aux conseils généraux et enfin par la loi municipale du 5 avril 1884 , rendue applicable, sur ce point, à toutes les communes d'outre-mer.

\section{a) Représentation au Parlement.}

La représentation du Sénégal au Parlement, qui a été, ainsi d'ailleurs que cela s'est passé pour nos autres possessions, tour à tour instituée, supprimée et puis rétablie, date du décret du 5 mars 1848. Cet acte reconnut le droit de représentation aux colonies et accorda en bloc 16 représentants aux établissements d'outre-mer. Une Instruction du 27 avril suivant, réserva un siège de député à notre possession ouest-africaine.

Un décret-loi du 2 avril 1852 supprima la représentation de l'Algérie et des colonies et ce fut seulement le 8 avril 1879 qu'une loi accorda de nouveau et définitivement un député au Sénégal.

\section{b) Le Conseil général.}

L’institution d'un Cionseil général au Sénégal fut prévue par l'ordonnance organique du 7 septembre 1840.

Cette assemblée ne fut toutefois définitivement établie dans la colonie et régulièrement organisée que par un décret en date du 4 février 1879. L'amiral Pothuau, ministre de la Marine et des Colonies, présentant cet acte à la signature du Président de la République exposait ainsi les considérations qui l'avaient amené à prendre cette détermination : "Notre colonie du Sénégal a été dotée d'institutions municipales de plein exercice. La population, initiée aux premiers devoirs de la vie publique, s'est vue, en vertu d'un acte de même date, appelée à participer par des délégués des deux communes de Saint-Louis et de Gorée, à l'établissement, en conseil d'administration, du budget local, et à l'examen des questions intéressant l'assiette de l'impôt et le tarif des contributions publiques de la colonie.

Cette dernière disposition n'était, dans la pensée de mon Département, qu'une sorte de préparation à des institutions plus 
larges et plus conformes aux principes d'autonomiequi tendent à prévaloir dans notre législation coloniale. L'épreuve qui a été faite me porte à croire que si les populations du Sénégal n'ont peut-être pas encore complètement apprécié tous les avantages de la commune, elles ont montré de réelles aptitudes dans le maniement des affaires locales. Le moment me semble donc venu d'instituer, dans cette colonie, un conseil général nommé au suffrage universel et investi de la plupart des attributions que les sénatus-consultes des 3 mai $18 \ddot{4}$ et 4 juillet 1866 ont conférées aux Assemblées locales des Antillles et de la Réunion ".

L'organisation du Conseil général du Sénégal ne comportait, en effet, aucune différence avec celle des assemblées locales de ces autres colonies, seules ses attributions variaient en certains points.

Le décret de 1879 est actuellement encore celui qui régit cette assemblée ef les quelques actes qui sont intervenus à son sujet, dans la suite, à l'exception toutefois de la loi de finances de 1900, n'ont apporté que des modifications insignifiantes dans sá composition ou dans ses attributions.

Composé de 16 membres au début, 10 pour l'arrondissement de Saint-Louis et 6 pour l'arrondissement de Gorée, le Conseil général a vu ce nombre porté à 20 par le décret du 14 avril 1897 : l'arrondissement de Saint-Louis continuant à élire 10 membres, et 4 nouveaux membres soit 10 au total étant affectés à l'arrondissement de Gorée, à répartir par moitié entre la commune de Rufisque et la circonscription de Gorée-Dakar.

Sont éligibles tous les citoyens inscrits sur les listes électorales ou justifiant avant le jour de l'élection qu'ils devraient y être inscrits, âgés de vingt-cinq ans accomplis, sachant parler, lire et écrire le français et domiciliés dans la colonie depuis un an au moins. Toutefois, les fonctionnaires, magistrats, officiers ou agents de tout ordre en activité de service et rétribués sur les budgets de l'Etat ou de la colonie, ainsi que les entrepreneurs de services ou de travaux publics pour le compte de la colonie ne peuvent être nommés conseillers généraux.

Le Conseil dont la réunion habituelle se faisait, sur la convocation du gouverneur, dans le dernier trimestre de l'année, a 
vu sa session annuelle fixée au mois de mai par le décret du 8 avril 1898. Toutefois un arrêté du Lieutenant-gouverneur, peut le convoquer en session extraordinaire, dans des cas urgents.

En matière d'administration, les attributions du Conseil général sont à peu près les mêmes que celles de nos assemblées départementales : il statue sur les acquisitions, aliénations et échanges des propriétés de la colonie, sur leur mode de gestion ainsi que sur les actions à intenter ou à soutenir en son nom et sur les transactions. Il décide de l'acceptation ou du refus des dons et legs ; intervient dans toutes les questions intéressant les routes et chemins, ainsi que sur les concessions à des associations, à des compagnies ou à des particuliers de travaux d'intérêt colonial et sur les projets, plans et devis des travaux exécutés sur les fonds de la colonie.

En ce qui concerne les questions financières, le Conseil général a vu ses attributions singulièrement amoindries par la loi de finances du 13 avril 1900 dont on trouvera, plus loin, l'étude au chapitre : organisation financière.

Commission coloniale. - Le décret du 12 août 1885, dans le but de faciliter et d'accélérer l'étude et la marche des affaires soumises aux délibérations du Conseil général a, conformément d'ailleurs à ce qui avait été fait pour la Martinique, la Guadeloupe et la Réunion, institué une commission coloniale élue par l'assemblée et composée de trois de ses membres au moins et de cinq au plus.

Cette Commission règle les affaires quilui sont renvoyées par le Conseil général, dans la limite de la délégation qui lui est faite. Elle délibère sur toutes les questions qui lui sont déférées par la législation en vigueur et donne son avis au Lieutenant-gouverneur sur toutes les questions qu'il lui soumet ou sur lesquelles elle croit devoir attirer son attention.

A l'ouverture de la session ordinaire, la Commission lui fait un rapport au Conseil général sur l'ensemble de ses travaux et lui soumet toutes les propositions qu'elle juge utile; elle lui expose également ses observations sur le budget proposé par l'Administration et qui lui est communiqué par les soins du Lieutenant-gouverneur. 
Le mode de fonctionnement du Conseil général est déterminé également par le décret de 1879 ; il élit un bureau et un président, conformément aux dispositions de cet acte.

Quant au Lieutenant-gouverneur, il joue vis-à-vis du Conseil général un rôle identique à celui du Préfet dans nos assemblées départementales.

\section{c) Organisation municipale.}

L'organisation municipale au Sénégal comporte des communes de plein exercice et des communes mixtes.

Communes de plein exercice. - La création d'institutions municipales remonte au 10 août 1872. Après le décret du $1^{\text {er février }}$ 1871 qui initiait la population à la vie politique, en la conviant à élire un député à l'Assemblée nationale, le gouvernement métropolitain résolut de compléter cetle mesure libérale, en dotant la colonie d'institutions pouvant lui permettre de prendre une large part dans l'administration de ses propres affaires. Au surplus l'organisation projetée répondait aux besoins des deux villes de Saint-Louis et de Gorée, auxquelles s'appliquait le décret précité de 1872.

En exécution des dispositions contenues dans cet acte, le chef de la colonie, par un arrêté du 20 septembre 1872, a déterminé comme suit les limites des deux communes : la circonscription ayant pour chef-lieu Saint-Louis comprenait la ville de Saint-Louis et les faubourgs de Guet N'Dar, N'Dar Toute et l'ile de Sor ; celle ayant pour chef-lieu Gorée comprenait les villes de Gorée et de Dakar. Afin d'assurer dans cette dernière ville le service de l'état civil, un adjoint spécial fut chargé des fonctions d'officier d'état civil, jusqu'au 17 juin 1887, date à laquelle les deux sections de la commune de Gorée-Dakar ont été, par décret, constituées en communes distinctes.

L'étendue des circonscriptions communales de Saint-Louis et de Gorée-Dakar, fi xée à titre provisoire par l'arrêté local du 20 septembre 1872, a été définitivement maintenue par le décret du 10 mars 1873 qui a englobé dans le territoire de la commune de Gorée-Dakar, la banlieue de cette dernière ville. 
En 1880, un décret portant la date du 10 juin institua au Sénégal une nouvelle commune ayant pour chef-lieu la ville de Rufisque ; ses limites furent déterminées par le décret du 10 septembre 1881 .

En 1884, par décret du 30 décembre, les limites de la commune de Saint-Louis ont été reportées à 2.500 mètres de N'Dar Toute, englobant le village de Gokhoumbaye, situé sur la langue de Barbarie, au Nord-Est de ce iaubourg.

Les divers corps municipaux de la colonie ont été fixés comme suit par les actes organiques qui les concernent :

Un maire, deux adjoints et quinze conseillers municipaux pour Saint-Louis ;

Un maire, un adjoint et douze conseillers municipaux pour Gorée ; ce nombre a été depuis ramené à 10 , dont 8 conseillers ;

Un maire, un adjoint et 8 conseillers municipaux pour Rufisque ;

Un maire, un adjoint et 12 conseillers municipaux pour Dakar.

Les sessions ordinaires des conseils municipaux ont lieu chaque année au commencement de février, mai, août et novembre; leur durée est de dix jours, sous réserve des prorogations accordées par le Gouverneur Général. Toutes les fois que les intérêts de la commune l'exigent, la convocation extraordinaire du conseil municipal est autorisée par le chef de la colonie sur la demande qui lui en est faite. Sous l'empire du décret du 10 août 1872, les séanc es des conseils municipaux n'étaient pas publiques ; cette disposition a été supprimée par le décret du 29 avril 1889 qui a rendu applicables à la colonie les articles 1 à 9 inclus etl'article 54 de la loi du 5̆ avril 1884 sur l'organisation municipale. Déjà diverses modifications avaient été apportées aux prescriptions du décret du 10 aout 1872 ; c’est ainsi que le décret du 26 juin 1884 avait mis en vigueur au Sénégal certaines dispositions de la loi du 5 avril 1884 sur l'élection des conseils municipaux et sur le mode de nomination des maires et des adjoints. C'est à partir de cette époque que ces magistrats municipaux ont cessé d'être nommés par le chef de la colonie.

Les attributions des maires et des conseils municipaux sont réglées par les articles 32 à 45 du décret de 1872 . 
Les dépenses des communes sont obligatoires ou facultatives ; toutes celles qui ne sont pas énumérées à l'article 46 du texte sus visé constituent les dépenses facultatives. Les recettes municipales sont ordinaires ou extraordinaires; les unes et les autres sont déterminées par les articles $\mathbf{4 7}$ et $\mathbf{4 8}$ du décret précité.

Un arrêté en date du 16 juin 1874 règle la comptabilité des communes.

A Saint-Louis, comme à Dakar, les principales ressources communales sont fournies par les droits d'octroi municipal et les droits des marchés. A Gorée, port franc, l'application de modestes taxes permet d'assurer l'équilibre du budget de chaque année. A Rufisque où il n'existe pas d'octroi, la commune a établi une voie ferrée, système Decauville, traversant la ville en tous sens et dont se sert le commerce, moyennant indemnité, pour le transport de ses marchandises et produits; les sommes perçues à ce titre constituent les deux tiers du budget des recettes de cette commune, divers droits et taxes en assurent le complément.

En dehors des emprunts contractés, les dépenses les plus importantes supportées par les communes sont représentées par les contingents qui leur ont été assignés, au titre de l'instruction primaire et de la police. Il n'est fait d'exception à cet égard qu'en faveur de la ville de Gorée qui a été dispensée de ce versement par le Conseil général.

Communes mixtes. - La création des communes mixtes au Sénégal a été prévue par le décret du 13 décembre 1891. Cette institution eut pour but de remédier à la différence qui existait, dans les Territoires d'administration directe entre les circonscriptions de Saint-Louis, Gróe, Dakar et Rufisque, dotées d'institutions municipales et représentées au Conseil général et l'autre partie de ces territoires qui ne possédait aucun de ces avantages.

Le Ministre du Commerce et des Colonies tint à faire disparaitre cette différence si complète de régime et organisa dans les territoires d'administration directe des agglomérations communales analogues à əelles qui existent en Algérie sous le nom de communes mixtes.

Dans le rapport qu'il adressait à ce sujet au Président de la 
République au sujet de cette création, M. Jules Roche s'exprimait en ces termes :

" Ce décret aura pour résultat d'associer les indigènes au maniement des affaires de leur pays, de leur faire comprendre que l'Administration française, en réclamant d'eux le paiement d'impôts, ne cherche pas seulement la consécration tangible de son autorité, mais se préoccupe surtout d'améliorer la situation économique et morale de régions qu'on a dù négliger jusqu'à présent, faute de ressources et de moyens d'action ».

C'est ainsi que fut posé le principe de la création de communes mixtes, mais le principe seulement, car le décret laissait au Gouverneur le soin de décider, par arrêtés pris en conseil privé, la création de ces communes dans les territoires d'administration directe.

L'acte de 1891 prévoyait toutefois l'organisation de ces agglomérations : jusqu'en 1904, ce décret de principe resta sans effet.

Le peu d'importance des escales de la voie ferrée, seuls centres où l'expérience aurait pu être logiquement tentée, le nombre infime des Européens qui y avaient établi leur résidence, l'absence de ressources locales pour asseoir sur des bases rationnelles un budget communal, expliquent suffisamment que les Gouverneurs qui se sont succédé au Sénégal avaient hésité à tenter une expérience qui avait peu de chance de réussir.

"Il n'en est pas de même aujourd'hui, disait en décembre 1904, le Lieutenant-gouverneur Camille Guy dans un rapport au Gouverneur général, le dernier recensement a établi que l'escale de Tivaouane possédait une population totale de 4.252 habitants dont 66 européens, celle de Thiès de 2.707 habitants dont 78 européens, celle de Louga de 1.39 ŏ habitants dont 23 européens. Le commerce a pris dans ces trois centres une importance considérable et qui s'accroît d'année en année. Enfin, les Administrateurs ont été déjà amenés à y créer des taxes locales qui permettront d'alimenter en partie les futurs budgets communaux

Dans ces conditions, le moment parait venu de tenter l'expérience prévue en 1891 et d'ériger les trois escales de Louga, Tivaouane et Thiès en communes mixtes "). 


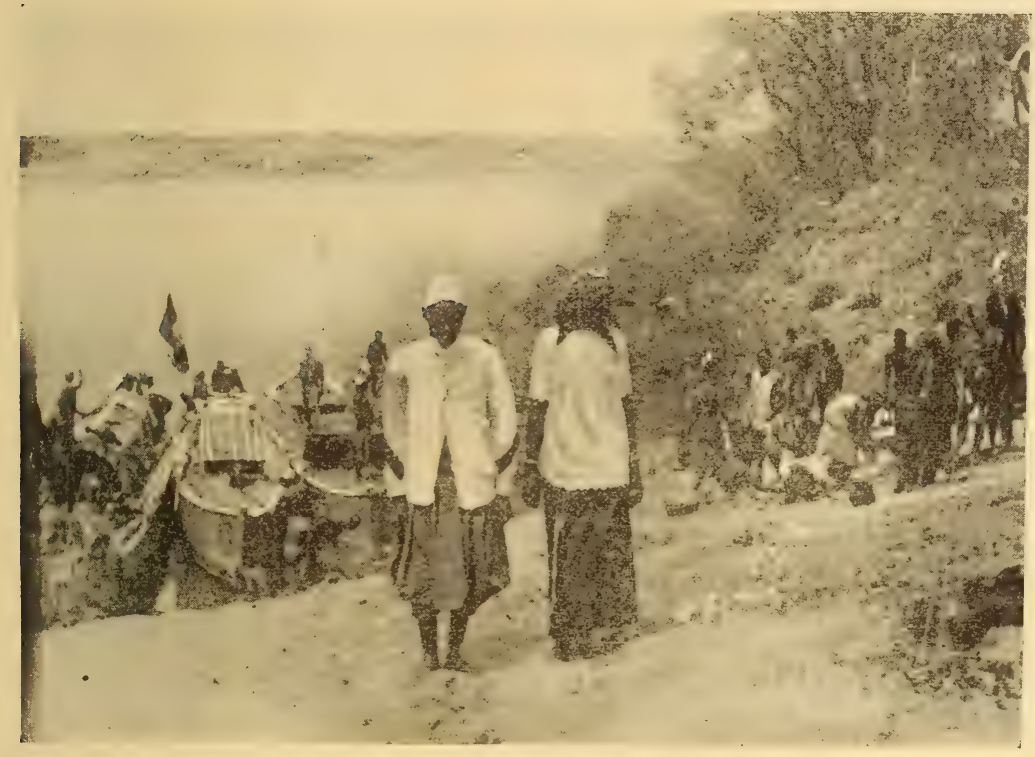

Fig. 19. - Chalands sur le Sinégal.

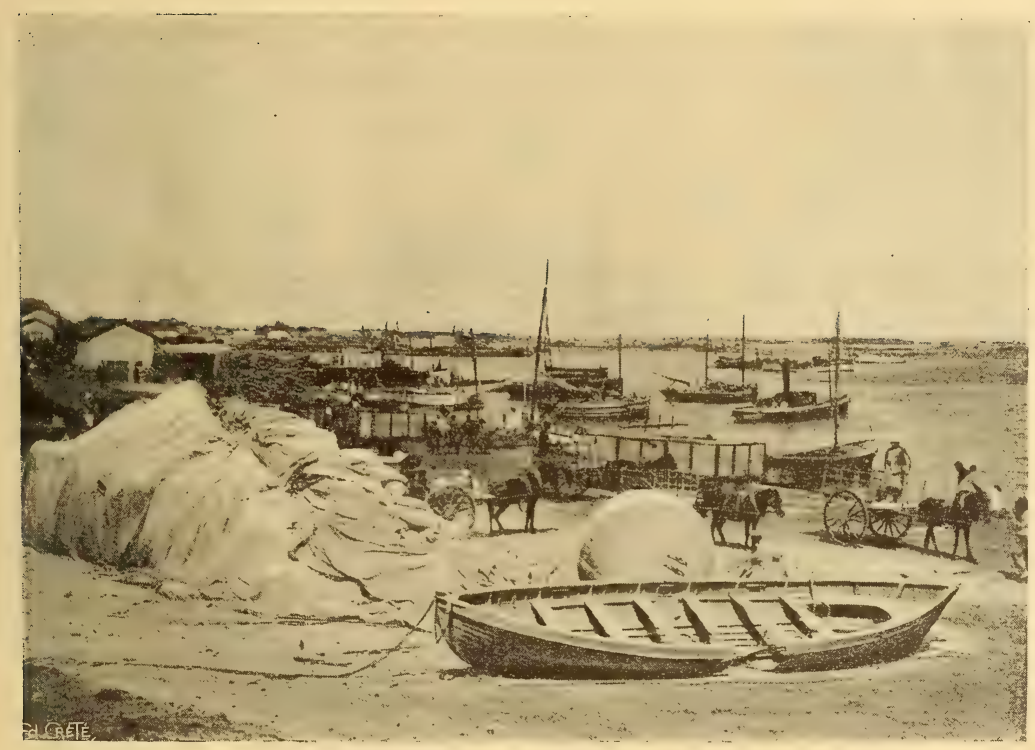

Fig. 20. - Port de Dakar.

S. 

La proposition de M. Guy fut adoptée et un arrêté du Gouverneur général en date du 31 décembre 1904 érigea ces trois escales en communes mixtes.

Les communes mixtes ainsi créées reçoivent la personnalité civile et deviennent aptes à posséder des biens meubles ou immeubles de même que les communes de plein exercice et ses ressources se composent des recettes prévues par le décret du 10 août 1872 concernant ces communes.

Elles sont administrées par une commission municipale composée :

$1^{0}$ De l'administrateur colonial de la circonscription, président;

$2^{0} \mathrm{De}$ cing à neuf habitants notables, ayant voix délibérative, nommés pour trois ans par le Gouverneur et susceptibles d'être renommés.

Cette Commission municipale délibère sur toutes les affaires qui, dans les communes de plein exercice, sont soumises aux Conseils municipaux, et dans la même forme.

\section{II. - Brganisation administrative.}

Notre colonie du Sénégal fait, on le sait, partie du gouvernement général de l'Afrique Occidentale française, qui comprend également le Haut-Sénégal et Niger, la Guinée, la Côte d'Ivoire, le Dahomey, le Territoire Civil de la Mauritanie et le Territoire Militaire du Niger.

Le Sénégal est composé actuellement, avec deux budgets distincts, de pays annexés et de pays protégés

Les pays annexés se subdivisent en territoires de communes constituées, dites communes de plein exercice dont nous nous sommes occupé plus haut, et en territoires dits d'administration directe. Les communes de plein exercice sont celles de SaintLouis, Gorée, Dakar et Rufisque. L'autre fraction des pays annexés, comprend les escales ou stations que nous avons sur le fleuve Sénégal et sur la ligne de chemin de fer de Dakar à Saint-Louis, ainsi que la voie ferrée elle-mème, sur une largeur de 100 mètres et un district de la Casamance.

Les pays de protectorat se répartissent en un certain nombre 
de cercles, auxquels sont rattachés également les pays d'administration directe non constitués en communes : les cercles de Bakel, de Matam, de Podor, de Dagana, de Louga, de Tivaouane, de Thiès, du Sine-Saloum, de Niani-Ouli et de la Casamance.

\section{Administration centrale de la Colonie.}

Le Lieutenant-gouverneur. - L'administration centrale du Sénégal a son siège à Saint-Louis, chef-lieu administratif de la colonie. Elle comprend des services généraux qui relèvent du Lieutenant-gouverneur.

Les pouvoirs de ce haut fonctionnaire sont déterminés par le décret du 18 octobre 1904 qui a réorganiséle Gouvernement général de l'Afrique occidentale française et par la circulaire du Gouverneur général du 24 janvier 1903 relative à l'application de ce décret.

L'Administration générale de la Colonie est, comme elle l'était d'ailleurs avant cet acte, confiée au Lieutenant-gouverneur. Il l'assure sous la haute autorité du Gouverneur général qui peut lui consentir certaines délégations spéciales de ses pouvoirs, en matière de personnel et en matière de finances par exemple.

La correspondance avec le Gouvernement et avec les différents Départements ministériels est en principe réservée au Gouverneur général, toutefois, le Lieutenant-gouverneur est autorisé à transmettre à la Métropole certains documents d'administration courante, limitativement désignés d'ailleurs.

C'est également au Gouverneur général qu'il appartient de promulguer les actes émanant du pouvoir central, mais pour prendre date dans la colonie et y devenir exécutoires, ils doivent être reproduits au Journal Officiel du Sénégal.

L'administration courante de la Colonie est confiée au Lieutenant-gouverneur, cependant, prévoyait le Gouverneur Général dans sa circulaire de 190 , " toute décision ou tout acte de nature à modifier directement ou indirectement l'orientation politique, le régime économique ou administratif, l'organisation des services placés sous vos ordres, doivent, en vertu de l'article 3 du décret du 18 octobre 1904, m’être au préalable soumis et recevoir mon 
approbation. C'est ainsi qu'aucune mesure ne peut être prise par vous, qui affecte la ligne antérieurement suivie, en matière de poli. tique indigène, sans que vous ayez provoqué et reçu de nouvelles instructions de ma part; qu'aucune modification ne peut être apportée à la législation en vigueur sans un arrêté signé par moi ; qu'aucun service ne peut être créé ni voir ses attributions étendues ou réduites sans un acte émanant de mon autorité. Il vous appartient, d'ailleurs, de me faire à ce sujet toutes propositions utiles, de provoquer toutes mesures de nature à assurer le progrès et le développement rapide de votre Colonie et à améliorer le fonctionnement de ses organes administratifs. Il vous appartient, d'autre part, d'arrêter toutes les mesures d'application et de détail que comporte la mise en pratique des actes du Gouvernement général, comme de prendre, à charge de m'en rendre compte immédiatement, toutes les décisions urgentes que pourrait exiger une situation spéciale. Il importe que le départ entre les actes réservés à l'autorité du Gouverneur grénéral et ceux réservés à la vôtre soit très exactement observé, afin d'assurer l'unité de direction que le Gouvernement général a pour mission d'imprimer aux Colonies de l'Afrique occidentale française ".

En ce qui concerne le personnel, le décret de 1904 a maintenu au Gouverneur général le droit de nomination qu'il tenait du décret de 1902, avec faculté de déléguer tout ou partie de ce droit à chaque Lieutenant-gouverneur pour le personnel en service dans sa colonie, et c'est ainsi qu'a été délég'ué à ces hauts fonctionnaires la nomination : $1^{0}$ de tous les agents appartenant à des cadres locaux ou indigènes, chefs, interprètes, instituteurs, gardes de police; $\mathbf{2}^{0}$ de tous les autres agents pour lesquels il n'est pas prévu un mode spécial de nomination, recrutés sur place et dont la solde coloniale annuelle n'excède pas $2.400 \mathrm{fr}$. Le droit de nomination comporte nécessairement le droit de révocation.

De même le Lieutenant-gouverneur a la faculté de répartir selon les besoins du service tout le personnel, sauf celui qui par son brevet est désigné pour un poste spécial, qui est mis à s a disposition et peut arrêter toutes les mutations qui le concernent. 
Au point de vue financier, le Lieutenant-gouverneur du Sénégal établit les deux budgets de sa colonie selon les règlements que nous examinerons plus loin, et en reste l'ordonnateur sous le contròle du Gouverneur général. Il est devenu, en outre, en vertu de l'arrêté du 31 décembre 1901 , sous-ordonnateur du Budget général pour l'exécution, dans toute l’étendue du Sénégal des divers services dépendant du Gouvernement général.

Le conseil privé. - Le Lieutenant-gouverneur est assisté d'un conseil privé qui le seconde dans les actes les plus importants de son administration. Cie conseil doit être consulté dans un certain nombre de cas; mais ses avis ne sont pas obligatoirement suivis.

L'ordonnance organique de 1840 arait prévu au Sénégal la création d'un conseil d'administration dont le décret du 10 août 1872 fixa la composition. Un décret du 24 février $188 \not ̈$ changea la dénomination de conseil dadministration en celle de conseil privé et soumit les membres nolables de ce conseil à la nomination du Président de la République.

La composition du conseil privé du Sénégal qui a varié à diverses reprises se trouve ainsi fixée par le décret du 15 octobre 1902, légèrement modifié par le décret du 6 mai 1904 :

Le Licutenant-gouverneur du Sénégal, président;

Le Secrétaire g'énéral du Sénégal ;

Le Procureur de la République;

L'officier des corps de troupes le plus ancien dans le grade le plus élevé, après le commandant supérieur des troupes, présent dans la colonie ;

Le directeur des travaux publics ;

Deux habitants notables, conseillers privés titulaires;

Deux habitants notables, conseillers privés suppléants.

Les directeurs des services militaires peuvent être entendus à titre consultatif, en séance du conseil privé, pour toutes les questions intéressant leurs services respectifs; pour toutes celles relevant des fonctions civiles dont ils sont investis, ils sont appelés à siéger dans le conseil avec voix délibérative. Dans ce cas, ils prennent rang après le Procureur de la République et avec 
l'officier des corps de troupes, suivant leur grade ou leur ancienneté à grade égal.

Les conseillers privés titulaires ou suppléants sont nommés dans les conditions déterminées par l'article 3 du décret du 24 février 1885 , c'est-à-dire par décret rendu sur la proposition du Ministre des Colonies. Ils ne peuvent être choisis que parmi les citoyens français notables, âgés de trente ans révolus et résidant dans la colonie depuis cinq ans au moins.

La durée de leurs fonctions est de deux années, mais ils peuvent être indéfiniment renommés.

Le conseil privé devient par l'adjonction de deux notables indigènes le conseil d'administration des Pays de Protectorat. Et, selon les prescriptions du décret du 18 octobre 1904, le Lieutenant-gouverneur établit avec cette assemblée le budget de cette partie de la colonie.

Conseil du contentieux administratif. - Le conseil privé du Sénégal se constitue en Conseil du contentieux administratif, par l'adjonction de deux magistrats nommés au commencement de chaque année par arrêté du Lieutenant-gouverneur; le même arrêté pourvoit également à la nomination de deux magistrats suppléants. Ainsi composé, ce tribunal administratif fonctionne selon les prescriptions des décrets des $\breve{~ a ~ a u ̂ t ~ e t ~} 7$ septembre 1881 et du 25 janvier 1890 .

Principaux chefs d'administration et de service. - Le Lieutenant-gouverneur a auprès de lui pour le seconder directement divers chefs d'administration et chefs de service, placés chacun à la tête des diverses branches de l'administration centrale, à qui incombe la direction administrative et financière des deux sections du Sénégal : Territoires d'Administration directe et Pays de Protectorat.

Secrétariat général. - Tonte l'administration intérieure de la Colonie est centralisée par le Secrétariat geénéral. A la tête de se service est placé un Secrétaire Général, fonctionnaire qui a remplacéle directeur de l'intérieur. Il seconde le Lieutenant-gouverneur et celui-ci peut lui déléguer ses attributions administratives ainsi que la signature des affaires financières. C'est d'ailleurs lui qui en cas d'absence ou de congé doit normalement 
remplacer le Jieutenant gouverneur. Il dirige, sous sa responsabilité, les bureaux suivants :

$1^{\text {er }}$ Bureau. $-A$. Administration générale, communes et contentieux.

$B$. Administration générale des Pays de Protectorat.

2. Bureau. - Travaux et Approvisionnements.

$3^{\text {e }}$ Bureau. - Finances; divisé en deux sections : A. Section des territoires d'Administration directe; $B$. Section des Pays de Protectorat.

Le service de ces différents bureaux est assuré par un personnel du cadre général des secrétariats généraux des colonies.

La direction de ce personnel qui comporte :

2 commis principaux ;

10 commis ;

9 écrivains expéditionnaires, est confiée à $\mathbf{2}$ chefs de bureau et à 4 sous-chefs.

Services divers. - Parmi les divers services qui fonctionnent sous l'autorité du Lieutenant-gouverneur, il convient de citer, le service de la própriété foncière, de l'agriculture, des postes, des travaux publics, etc., dont nous nous occuperons plus loin.

Délégation du gouvernement du Sénégal à Dakar. - Devant l'extension prise par Dakar en raison du transfert dans cette ville des services du Gouvernement général et de son mouvement commercial toujours croissant, l'arrêté du $1^{\mathrm{e}}$ janvier 190 y a créé une délégation du Gouvernement du Sénégal. Le délégué du Grouvernement, actuellement Secrétaire général des Colonies, est chargé de la centralisation et de l'instruction des affaires du 2e arrondissement ressortissant aux attributions du Secrétariat général (Police et Prisons, Enregistrement et Contributions, Hospice de Gorée, etc., etc.). Ce fonctionnaire a sous ses ordres un agent spécial, qui est chargé du paiement des salaires d'ouvriers et de la solde des fonctionnaires et employés du Sénégal au moment de leur embarquement en France. Lui-même, signe par autorisation du Lientenant-gouverneur diverses pièces financières. En outre, il a été constitué sous-ordonnateur du Budget général de l'Afrique occidentale française pour la partie des 
dépenses du personnel et du matériel des divers services du Gouvernement général qui sont effectuées à Dakar.

Chefs d'administration et de service. - Parmi les autres chefs d'administration et de service et outre les chefs du service des postes et télégraphes et des travaux publics, il convient de citer :

Le commandant de la défense, le chef du service de santé, et le trésorier-payeur du Sénégal.

Organisation de l'administration régionale. - Les divers services de l'administration régionale du Sénégal reçoivent leur impulsion du Lieutenant-gouverneur qui centralise entre ses mains tous les pouvoirs.

La division administrative des Pays de Protectorat est le cercle, à la tête duquel se trouve un administrateur.

Les diverses circonscriptions administratives sont, aux termes du décret du 18 octobre 1904, déterminées par le Gouverneurgénéral en Conseil de Gouvernement et sur le rapport du Lieutenant-gouverneur.

La colonie est actuellement divisée en dix cercles : ceux de Bakel, de Matam, de Pador, de Dagana, de Louga, de Tivaouane, de Thiès, du Sine-Saloum, de Niani-Ouli et de la Casamance.

Personnel de l'administration régionale. - Le personnel supérieur de l'administration régionale est emprunté au corps des administrateurs coloniaux qui a été organisé pour toutes les colonies, sauf I Indo-Chine par le décret du 6 avril 1900, modifié par les décrets du 19 septembre 1903 et du 27 juin 190弓. Le cadre comprend des administrateurs stagiaires, des administrateurs adjoints, des administrateurs et des administrateurs en chef.

En outre par un récent arrêté, le Gouverneur général a placé dans chacune des colonies de l'Afrique occidentale, un administrateur, chargé d'inspecter les différents cercles de la colonie et dont le titre est "Inspecteur des Affaires indigènes 》.

Les emplois subalternes de l'administration régionale sont occupés par des agents du cadre du personnel des affaires indigènes, nommés par le Gouverneur général et mis par lui à la disposition du Lieutenant-gouverneur. Ce corps comporte quatre classes de commis, deux classes dadjoints et trois classes d'adjoints principaux. 
Le service de l'administration régionale comprend :

2 administrateurs en chef ;

6 administrateurs;

16 administrateurs adjoints ;

15 adjoints des affaires indigènes ;

32 commis.

Il convient également d'ajouter à ce personnel, celui des interprètes.

Attributions des administrateurs. - Le rôle des administrateurs est des plus complexes. Ces fonctionnaires sont, en effet; investis de fonctions politiques, administratives et judiciaires.

En matière politique, ils ont la surveillance et le contrôle des divers chefs que l'on a laissé dans le pays. Les attributions en matière administrative sont multiples, une des plus importantes est l'établissement des rôles d'impôts et souvent sa perception.

Ils sont en outre officiers de police judiciaire et président le tribunal indigène du cercle lorsqu'il en existe un.

Un décret du 30 septembre 1887 a donné un pouvoir de répression considérable à ces fonctionnaires. Aux termes de cet acte, les administrateurs peuvent slatuer au "Sénégal et dépendances " par voie disciplinaire sur les infractions commises par les indigènes non citọ'ens français, contre certains arrêtés du gouvernement, pouvoir qui leur permet d'infliger des pénalités allant jısqu'à quinze jours de prison et cent francs d'amende au maximum.

En outre, l'internement des indigènes non citoyens français et le sequestre de leurs biens pouvaient en vertu de cet acte être ordonnés par le gouverneur en Conseil privé. Ces arrêtés devaient être soumis à l'approbation du Ministre, étaient provisoirement exécutoires. Un décret du 21 novembre 1904 jugeant excessifs les pouvoirs donnés au gouverneur par ce dernier paragraphe a édicté que l'internement des indigènes non justiciables des tribunaux français, dans les colonies dépendant du Gouvernement général de l'Afrique occidentale française, ne pourrait en aucun cas être prononcé pour une durée supérieure à dix ans.

Cet acte énumère ensuite les délits qui pourront provoquer 
ces mesures : insurrection contre l'autorité de la France, troubles politiques graves ou manouvres susceptibles de compromettre la sécurilé publique et ne tombant pas sous l'application des lois pénales ordinaires. En outre dans ces cas déterminés, il peut être imposé aux villages sur les territoires desquels les faits se seront produits et aux collectivités dont les membres y auront participé une contribution spéciale destinée à assurer à l'administration les moyens de r'éprimer les désordres et d'en prévenir le retour.

Mais toutes ces mesures doivent à peine de nullité, faire l'objet d'arrêtés du Gouverneur général pris en Conseil de gouvernement, sur la proposition du Lieutenant gouverneur compétent et l'avis du Procureur g’énéral, chef du service judiciaire Ces arrêtés doivent, en outre, ètre immédiatement portés à la connaissance du Ministre des colonies, accompagnés d'un rapport sur l'aftaire et d'une expédition de la délibération de la commission permanente du Conseil du gouvernement.

Telle est l'organisation actuelle de la colonie. Elle ne saurait être considéréc comme définitive et il n'est pas douteux que le développement même de la colonisation entrainera des modifications. Telle qu'elle se présente néanmoins, elle témoigne des efforts incessants poursuivis par les pouvoirs publics pour mettre en harmonie les nécessités des règlements administratifs avec les constantes transformations de la vie sociale et les variations de la vie économique, dont elle doit toujours être le reflet, et dont elle doit suivre les heureux progrès. 


\section{CHAPITRE VIII}

ORGANISATION FINANCIÈRE

L'organisation financière du Sénégal offre une certaine complication par suite de sa division en deux budgets distincts : celui des Territoires d'Administration directe et celui des Pays de Protectorat. Aussi, avant de passer rapidement en revue les services financiers de la colonie, examinerons nous séparément chacun de ces budgets dans leurs recettes et dans leurs dépenses. Nous allons auparavant dire quelques mots de l'intervention du budget colonial dans les dépenses du Sénégal.

\section{I. - Budgets.}

\section{A. - Le budget colonial.}

Pas plus que nos autres possessions de l'Afrique occidentale française, notre colonie du Sénégal ne reçoit de subvention du budget de la Métropole. L'Etat français supporte seulement la charge des dépenses militaires - dépenses de souveraineté dont une très grande partie est d'ailleurs effectuée " non dans un intérêt purement colonial, mais dans un intérêt national incontestable ». Ces dépenses forment des chapitres spéciaux du budget colonial sous la rubrique : "Groupe de l'Afrique occidentale sauf le Congo.» D’ailleurs le Budget général de l’A frique 
occidentale verse au budget métropolitain une contribution annuelle de $\mathbf{1 0 0 . 0 0 0}$ francs comme "Participation de l'A frique occidentale dans les dépenses militaires de la Métropole ", contribution qui vient en atténuation des sacrifices financiers que s’impose la France pour ses possessions.

\section{B. - Le budget local.}

Le Sénégal est, depuis le décret du 18 octobre 1904, divisé, au point de vue financier, comme au point de vue administratif, en deux personnalités bien distinctes : les Territoires d'Admi. nistration directe et les Pays de Protectorat. Ces Pays des Protectorat englobent, à peu près, ainsi qu'il a été vu, les régions situées en de ça de Kayes, que le décret du $1^{\text {er }}$ octobre 1902 avait groupées avec les Territoires du Haut Sénégal et Moyen Niger pour en faire l'unité administrative et financière qui a porté le ṇom de Sénégambie-Niger.

Cette distinction en deux budgets est la conséquence d'une différence de régime, tant administratif que financier, entre les deux systèmes administratifs qui sont en vigueur. Au point de vue financier, l'Administration directe appliquée aux grands centres du Sénégal et à leur banlieue, laisse un certain pouvoir au Conseil général; le Protectorat au contraire a soumis le reste de la colonie aux mêmes règles administratives et financières que nos autres colonies de la côte Occidentale d'Afrique.

\section{Etablissement des hudgets.}

a) Territoires d'Administration directe. - Le budget des Territoires d'Administration directe est préparé par le Lieutenantgouverneur et soumis cnsuite par ce haut fonctionnaire aux délibérations du Conseil général.

Le cadre de cefte étude est trop étroit pour qu'il nous soit possible de nous étendre longuement sur les attributions de cette assemblée en matière financière. Il est cependant intéressant 
d'indiquer quels sont ses pouvoirs en l'espèce et quelle est son intervention dans l'établissement du budget.

Le budget préparé par le Lieutenant-gouverneur, est avant d'être porté devant le Consęil général communiqué par ses soins à la Commission coloniale, institué ainsi qu'on l'a déjà vu par le décret du 12 août 188\%. La Commission examine ce projet et présente ensuile au Conseil général, dès l'ouverture de la session, et dans un rapport sommaire, ses observations sur le budget proposé par l'Administration.

Après avoir pris connaissance de ce rapport, le Conseil général discute et vote ce projet de budget.

En cette matière, cette assemblée qui tenait ses pouvoirs de l'acte constitutif du 4 février 1879 et qui délibérait sous l'empire du Senatus-Consulte du 4 juillet 1866 a vu ses attributions restreintes par l'article 33 de la loi de finance du 13 avril 1900 qui a apporté de très sérieuses modifications au Senatus-Consulte précité et dont le vote a donné lieu tant à la Chambre des dépu. tés qu'au Sénat à des discussions vives et passionnées.

Cette loi qui laisse à la charge des colonies toutes les dépenses civiles, maintient, pour les colonies à Conseils généraux, la division du budget local des dépenses donnée par le SénatusConsulte de 1866 et conservée au Sénégal par le décret de 1879, en deux sections comprenant: la première les dépenses obligatoires; la seconde les dépenses facultatives.

Les dépenses obligaloires, énumérées limitativement au $\S 2$ de l'article 33 de la loi ne peuvent se rapporter que :

10 Aux dettes exigibles;

$2^{0} \mathrm{Au}$ minimum du traitement du personnel des secrétariats généraux : ce minimum est fixé par décret;

$3^{\circ}$ Aux traitements des fonctionnaires nommés par décret;

$4^{\circ}$ Aux frais de la gendarmerie et de la police et à ceux de la justice ;

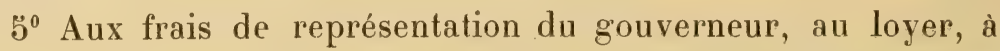
l'ameublement et à l'entretien de son hòtel, aux frais de son secrétariat et aux autres dépenses imposées par des dispositions législatives.

Quant aux dépenses facultatives, il résulte des termes même 
de la loi que " l'initiative des propositions de dépenses est réservée au gouverneur »; elle est donc enlevée au Cionseil général. Cette assemblée n'a pas en effet un rôle d'administration, mais seulement de contrôle ; il lui appartient seulement d'apprécier si les crédits demandés, par l'administration sont justifiés et de les accorder dans la limite du nécessaire.

En ce qui concerne les voies et moyens par lesquels le Cionseil général assurera les dépenses obligatoires d'abord, facultatives ensuite, la loi prévoit qu'il délibérera “ sur le mode d'assiette, les tarifs et les règles de perception des contributions et taxes autres que les droits de douanes qui restent soumis aux dispositions de la loi du 11 janvier 1892 ». Seulement, les tarifs des taxes et contributions qui avant la loi précitée étaient votés définitivement par cette assemblée, prérogative que ne possédaient d'ailleurs pas les conseils généraux de la métropole, ne peuvent être rendus définitifs qu'après avoir été approuvés par un décret en Conseil d'Etat.

Il n’appartient pas, d'ailleurs, à cetle haute assemblée, d'apporter des modifications, de sa propre autorité aux propositions qui lui sont soumises; elle ne peut, si elle ne les juge pas acceptables que les rejeter en bloc. Une nouvelle délibération du Conseil général est donc nécessaire et " jusqu’à l'approbation du Cionseil d'Etat, la perception se fait sur les bases anciennes ».

En résumé, le Conseil général a le devoir d'assurer en principe toutes les dépenses civiles et de gendarmerie et les dépenses obligatoires. Il ne possède pas l'initiative des dépenses facultatives qui appartient au Gouverneur. Il a le choix de sa matière imposable et l'initiative de l'établissement des taxes. Sur les tarifs, le mode d'assiette et les règles de perception ses délibérations doivent recevoir l'approbation du Conseil d'Etat. C'est avec ces moyens et dans ces limites quil vote depuis 1901, le projet de budget local présenté par l'Administration (1).

Ce budget une fois préparé par le Lieutenant-gouverneur, délibéré par le Conseil général, doit être conformément à la législa-

(1) Voir à ce sujet l'ouvrage particulièrement documenté et précis de M. G. Francois : Le budget local des Ciolonies, Larose, éditeur. 
tion en vigueur, arrêté par le Gouverneur général en Conseil de Gouvernement et approuvé par décret rendu sur la proposition du Ministre des Colonies.

b) Pays de Protectorat. - Le budget des Pays de Protectorat est préparé d'une façon beaucoup plus simple et plus rapide.

Il est établi, conformément aux prescriptions du décret du 18 octobre 1904, par le Lieutenant-gouverneur en Conseil privé du Sénégal qui fonctionne alors comme conseil dadministration en ce qui concerne les Pays de Protectorat, après adjonction de deux notables indigènes.

Il est ensuite, de même que les autres budgets de l'Union Ouest Africaine, arrèté par le Gouverneur général en Conscil de Gouvernement et approuvé par décret rendu sur la proposition du Ministre des Colonies.

Examen des budgets. - Les deux budgets du Sénégal, celui des Territoires d'Administration directe de même que celui des Pays de Protectorat, sont divisés en deux grandes sections, les recettes et les dépenses. Chacune de ces divisions comprend des chapitres subdivisés en articles.

Section des dépenses. - Les dépenses sont réparties̊ de la manière suivante :

a) Territoires d'administration directe. - Le budget des dépenses des Territoires d'Administration directe est arrêté pour l'année 1906 à $3.359 .209 \mathrm{fr}$. 75, somme équivalente à celle des recettes prévues et est réparti en $\mathbf{2 4}$ chapitres.

\begin{tabular}{|c|c|c|c|c|}
\hline $\begin{array}{l}\text { Numéros } \\
\text { des } \\
\text { chapitres } \\
\text { - }\end{array}$ & Nature des dépenses & & & $\begin{array}{c}\text { Montant } \\
\text { des } \\
\text { chapitres } \\
-\end{array}$ \\
\hline I. & Contributions et dettes exigibles. & . & . & ) \\
\hline II. & Dépenses d'administration (Personnel) & . & & 231.032 \\
\hline III. & Dépenses d'administration (Matériel) & . & & 28.850 \\
\hline IV. & Conseil général. . & . & . & 34.900 \\
\hline V. & Servicedu Trésor et frais de perception de & limpòt & & 96.500 \\
\hline VI. & Enregistrement, domaine, etc. . : & . & . & 39.810 \\
\hline VII. & Contributions directes. . . . . & . & . & 32.680 \\
\hline VIII. & Instruction Publique et cultes . & . & . & 4.09 .181 \\
\hline & A reporter . . . ... . . & . & . & 872.953 \\
\hline
\end{tabular}




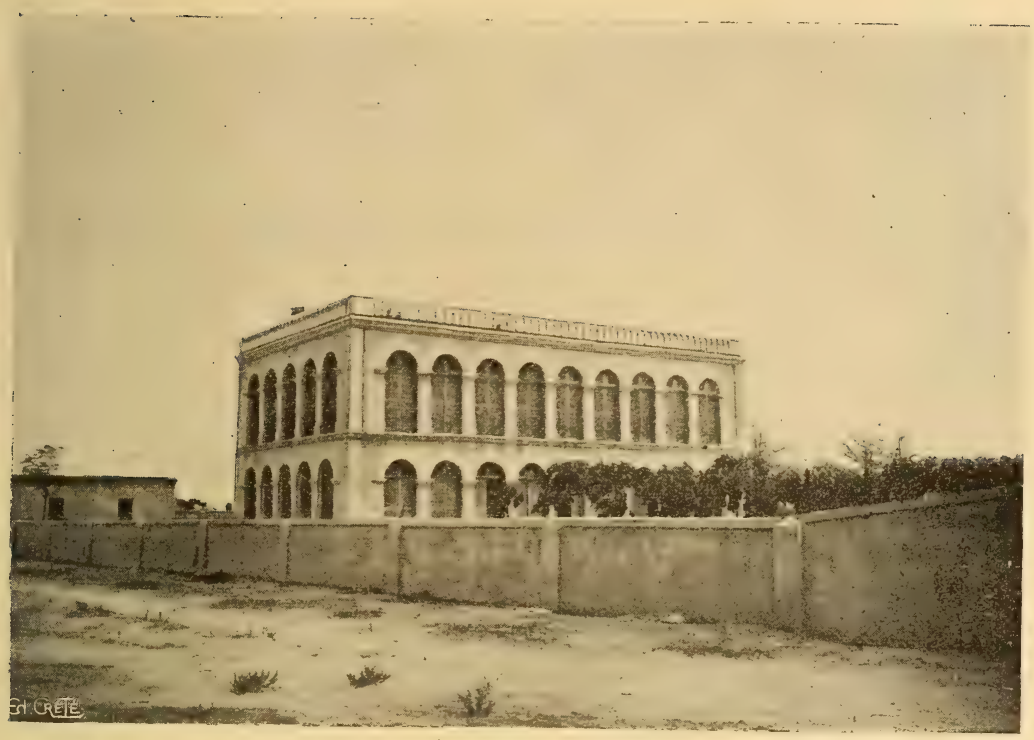

Fig. 21. - Kaolack (La résidence).

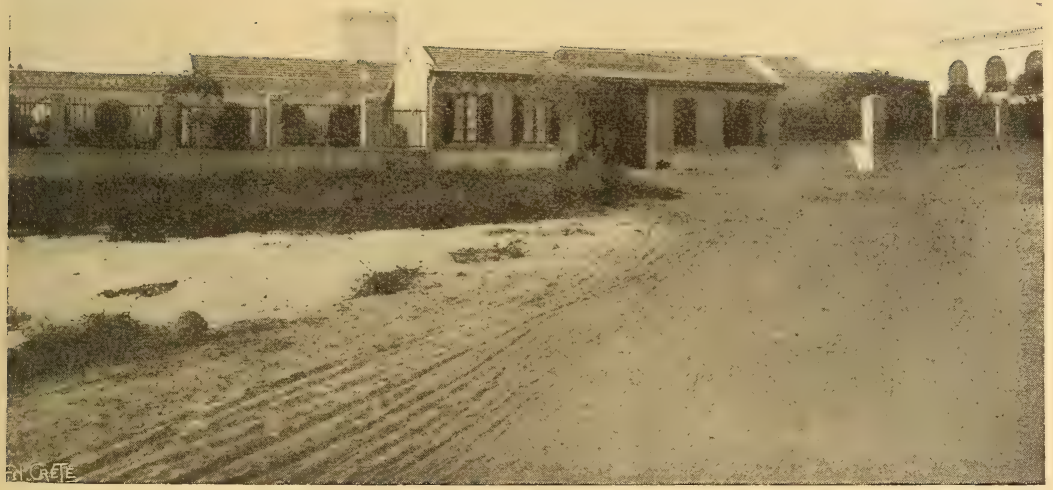

Fig. 22. - L'hòpital de Dakar.

S. 

Numéros

des

chapitres

Nature des depenses

Montant des

chapitres

Report

872.953 ๖0

IX. Matériel de l'Instruction Publique

58.970 )

X. Personnel des Postes, Télégraphes et Téléphones.

$424.930 \quad 35$

XI. Matériel des Postes, Télégraphes et Téléphones.

208.27350

XII. Imprimerie .

$79.410 》$

XIII. Police et prisons

212.10080

XIV. Personnel de l'Assistance Publique et des Services sanitaires.

$154.171 》$

XV. Matériel de l'Assistance Publique et des Services sanitaires .

138.0500

XVI. Personnel des Travaux Publics. . . . . . . 229.992 »
XVII. Travaux neufs et entretien . . . . . . . 687.91250

XVIII. Personnel du Service de la Navigation . . . 82.68310

XIX. Matériel des Ports et Sémaphores . . . . 25.938 )

XX. Transport de matériel et de personnel . . . 7 5.000 "

XXI. Dépenses diverses .

108.825

XXII. Dépenses des exercices antérieurs . . . . . . . . .

XXIII. Dépenses d'ordre

XXIV. Dépenses extraordinaires.

b) Pays de Protectorat. - Le budget des Pays de Protectorat, s'élève en recettes et en dépenses pour 1906 à la somme de 3.557 .000 francs et comporte 15 chapitres :

Numéros
des

Chapitres

I. Contributions et contingents divers

II. Dépenses d'administration (Personnel)

III. Dépenses d'administration (Matériel).

IV. Services financiers.

V. Justice

VI. Instruction Publique.

VII. Pólice et prisons

VIII. Service sanitaire et Assistance Publique.

IX. Travaux Publics

X. Agriculture .
Montant des Chapitres

$1 \quad 160.954$

483.537

อ๊ร. 480

ร54. 580

$60.42 \%$

75.500

321.697

114.900

410.316

92.431

A reporter.

3.329 .820 
Numéros des chapitres

Nature des dépenses

Montant chapitres

Report.

3.329 .820
153.700

36.180

37.300

XIII. Dépenses imprévues

XIV. Dépenses des exercices antérieurs..

$\mathrm{XV}$. Dépenses d'ordre .

$$
\text { Total }
$$

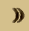

))

3.557 .000

Section des recettes. - Les recettes prévues sont les suivantes :

a) Territoires d'Administration directe:

I. Contributions directes . . . . . . . . . 420.200 »

II. Contributions indirectes et divers produits. . . 623.00020

III. Quote-part des communes dans les dépenses de l'Instruction primaire, de la police, des alié-

IV. Somme excédant le maximum de la caisse de

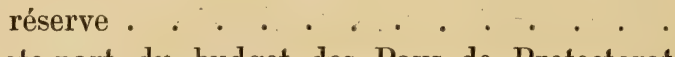

V. Quote-part du budget des Pays de Protectorat

dans les dépenses du Sénégal . . . . . . 421.000 "

VI. Subvention du Budget général de l'Afrique occidentale française . . . . . . . . .

VII. Recettes d'ordre

VIII. Recettes extraordinaires.

$230.250 \quad$

898.49 ร็

766.264

)

) 3.359 .20975

Total.

b) Pays de Protectorat :

I. Contributions directes. . . . . . . 3.507.000 》

II. Produits divers . . . . . . . . . . . . 50.000 »

III. Recettes d'ordre. . . . . . . . . . . . "

IV. Recettes en atténuation de dépenses . . . . . »

Total.

$3.557 .000 》$ 
Les ressources et les impôts.

Nous allons, pour plus de clarté, examiner séparément les diverses ressources qui alimentent chacun des deux budgets de la colonie.

\section{A. - Territoires d'Administration directe.}

Le budget des Territoires d'Administration directe est alimenté :

$1^{0}$ Cote-part des communes de la Colonie et du budget des Pays de Protectorat. - La cote-part des communes s'élève à une somme de $\mathbf{2 3 0 . 2 5 0}$ francs venant en atténuation des dépenses que la Colonie s'impose pour assurer la marche de services (instruction primaire, police, aliénés, cadastre) dont les frais devraient, régulièrement, être supportés par les budgets municipaux.

Pour les dépenses de l'instruction primaire, la ville de Saint Louis verse une somme de $\mathbf{9 0 . 6 0 0 ~ f r a n c s ; ~ c e l l e ~ d e ~ D a k a r ~}$ 44.000 francs et celle de Rufisque $\mathbf{2 2 . 0 0 0 ~ f r a n c s . ~}$

Pour celles de la police, Saint-Louis intervient pour 27.250 francs; Dakar, pour 20.000 francs et Rufisque pour 13.400 franes.

Une somme totale de 3.0110 francs est versée par les municipalités de ces trois villes pour l'entretien des aliénés et Rufisque supporte pour l'année 1906 une dépense de $\mathbf{1 0 . 0 0 0}$ pour frais de cadastre.

La somme de $\mathbf{4 2 1 . 0 0 0 ~ f r a n c s ~ q u i ~ e s t ~ v e r s e ́ e ~ p a r ~ l e ~ b u d g e t ~ d e s ~}$ Pays de Protectorat, représente sa part contributive, dans les dépenses prévues pour le Gouvernement, l'Imprimerie, l'Assistance publique et les Postes et Télégraphes. Cette quote-part est calculée de la manière suivante : la moitié des dépenses du Gouvernement et de l'Imprimerie, le tiers de celles qui sont 
inscrites pour l'Assistance publique et le quart des crédits affectés aux Postes et Télégraphes.

$2^{\circ}$ Subvention du Budget général de l'A frique occidentale francaise. - Le décret du 18 octobre 1904 qui a constitué le Budget général de l'Afrique occidentale française a enlevé à la colonie du Sénégal ses recettes de douane et de navigation pour les affecter au Budget général. Il était naturel et indispensable que cette perte pour le budget local fut compensée et de ce chef le Gouvernement général verse au budget des Territoires d'administration directe une subvention qui, pour 1906, est fixée à $\mathbf{7 6 6 . 2 6 4}$ francs.

$\mathbf{3}^{0}$ Contributions et taxes locales. - Les divers impôts perçus au profit du budget des Territoires d'Administration directe peuvent se grouper en deux catégories :

a) Les contributions directes ou sur rôles;

b) Les contributions indirectes et les divers produits.

a) Contributions directes ou sur róles. - Il convient de citer en première ligne l'impôt personnel, dont il n'est pas sans intérêt de rappeler brièvement l'histoire.

Un décret impérial en date du 4 août 1860 « considérant qu'il importait de mettre les recettes du budget local du Sénégal en rapport avec l'extension donnée aux charges de la colonie et le développement des facultés contributives des habitants " décida qu'un impôt personnel serait établi dans la colonie au profit du budget local et qu'il serait perçu « sur chaque habitant pourvu de ses droits et non réputé indigent " .

Cet acte prévoyait que le mode de pereeption de cette taxe serait déterminé d'après les lois et règlements en vigueur dans la métropole et laissait au Grouverneur le soin d'en fixer le taux. Conformément à ces prescriptions, un arrêtẻ du 9 août 1861 fixa la contribution personnelle à trois journées de travail dont la valeur fut évaluée à 1 franc l'une pour la ville de Saint-Louis, ses faubourgs et pour Gorée et à cinquante centimes pour le restant de la colonie.

Plus tard, une délibération du Conseil général du 8 avril 1881 éleva cette taxe à $1 \mathrm{fr}$. la banlieue de Saint-Louis, dans celle de Dakar et dans les villages sous nos postes militaires "). 
A la suite d'excédents de recettes, le Conseil geénéral jug'ea bon dans sa session de décembre 1898 de supprimer l'impôt personnel en vertu des pouvoirs qu'il tenait du décret du 4 février $\mathbf{1 8 7 9}$, cet acte lui donnant le droit de voter le tarif des taxes et contributions locales nécessaires à l'acquittement des dépenses. Toutefois comme un nouveau décret aurait été nécessaire pour abroger l'acte du 4 août 1860 établissant l'impôt personnel, on jugea préférable de réduire à zéro le produit de la taxe de capitation dans les prévisions budgétaires, plutôt que de supprimer définitivement par un acte du pouvoir exécutif une source de revenus, à laquelle la colonie aurait peut-être besoin de faire appel dans une période moins prospère.

Cette prévision se réalisa, car en 1903, le Conseil général réuni en session ordinaire, vota le rétablissement de l'impot personnel à dater du $1^{\mathrm{e}^{\mathrm{r}}}$ janvier 1904. Cette délibération fut soumise, en conformité de la loi du 13 avril 1900, à l'approbation du Conseil d'Etat, mais la Haute Assemblée jugeant qu'elle ne possédait pas les éléments suffisants pour statuer ne crut pas devoir l'approuver.

Dans sa séance du 6 juin 190马, le Conseil général prit une nouvelle délibération dans le même sens et fixa à 4 francs le taux de l'impot. Le Conseil d'Etat approuva ce vote et le décret du 17 février 1906 le sanctionna.

Il était indispensable pour des raisons diverses de rétablir cette taxe. L'impôt personnel, en effet, institué dans les Territoires de la Sénégambie et du Niger par l'arrêté du 14 novembre 1903, avait été fixé à 4 francs dans les cercles de Louga, Tivaouane, Thiès, Portudal, Dagana et la province du Sine, à 3 francs dans les cercles du Podor, Kaédi, Matam, Bakel et les provinces de Nioro Rip, Niombato, Saloum et à 2 francs dans toute l'étendue de la Casamance. Ces taxes avaient été maintenues malgré le rattachement, par l'acte de 1904, de ces provinces au Sénégal, aussi les indigènes de la même colonie étaient-ils, de ce chef, placés dans des situations différentes, les uns frappés par l'impôt, les autres y échappant. Le résultat immédiat avait été l'émigration des habitants des Pays de Protectorat vers les escales d'Administration. directe où ils étaient 
exonérés de toute taxe de capitation. Il était donc nécessaire et équitable d'établir l'unification de régime à ce point de vue.

De plus, le décret du 18 octobre 1904 ayant enlevé à la colonie du Sénégal pour les affecter au Budget général ses recettes de douanes et de navigation, il était indispensable de donner d'autres ressources à la Colonie.

Le décret du 17 février 1906 a donc rétabli l'impôt personnel dans l'étendue des Territoires d'Administration directe en exceptant toutefois de cette mesure les habitants des quatre communes constituées. Le Gouverneur général, estimant que les habitants de ces villes payaient déjà sous forme de diverses contributions leur part des charges publiques pour une somme de beaucoup supérieure aux 4 francs de la taxe personnelle, jugea qu'il n'était pas utile de leur demander la contribution nouvelle qui était imposée aux habitants de la banlieue et des escales.

Les autres contributions directes et sur rôles, sont :

$1^{\circ} L^{\prime}$ impót locatif qui est une des plus anciennes taxes établies au Sénégal et fut institué par un arrêté local en date du 15 mai 1837. Remanié à diverses reprises, une délibération du Conseil général du 8 juin 1901 approuvée par décret du 19 septembre de la même année en a fixé le taux à :

2 p. 100 de la valeur locative réelle ou estimée, pour les maisons situées à Saint-Louis et dans ses faubourgs, à Gorée, à Dakar et à Rufisque, à l'exception :

Des terrains non bâtis et des cases en paille qui continuent à être exonérés de l'impòt locatif ;

Des maisons, à Gorée, servant d'habitation à leurs propriétaires et dont la valeur locative estimée ne dépasse pas วั00 francs par an.

Les constructions neuves sont exonérées pendant 3 années

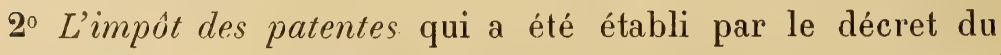
6 aoùt 1881, se compose d'un droit fixe et d'un droit proportionnel. Le droit fixe qui a pour base la nature du commerce exercé est de :

600 francs pour la patente de négociant et de banquier:

400 francs pour la patente de commerçant de $1^{\text {re }}$ classe ; 
200 francs pour la patente de commerçant de $2^{\mathrm{e}}$ classe ;

150 francs pour la patente de commerçant de $3^{\text {e }}$ classe et pour les boulangers;

75 francs pour les baraques du marché et les marchands ayant moins de 1.000 francs de marchandises en magasin.

Le droit proportionnel est basé sur la valeur locative réelle ou estimée des locaux servant exclusivement à l'exercice du commerce et de toutes leurs dépendances; il est de $200 / 0$.

Une patente, dite de colportage, est imposée aux marchands ambulants pour toute la colonie; elle est de 30 francs. par mois.

Le 1/7 des patentes est alloué aux communes de Saint-Louis, Dakar, Rufisque et Gorée.

$3^{\circ}$ Le droit de licence qui fut également établi dans la colonie par le décret du 6 août 1881, comprend trois classes et est ainsi fixé :

$1^{\text {re }}$ classe. - Cafés et cabarets munis de billards, où l'on vend à consommer sur place des boissons alcooliques ou autres, $800 \mathrm{fr}$.

$2^{\circ}$ classe. - Cafés et cabarets non munis de billards, mais ayant chaises et tables ou autres installations analogues où l'on vend à consommer sur place des boissons alcooliques ou autres 600 francs.

$3^{\mathrm{e}}$ classe. - Débits de boissons non installés en cabarets et cafés, n'ayant ni chaises ni tables ou autres installations analogues et où l'on vend sur le comptoir des boissons alcooliques ou autres, à consommer sur place, 300 francs.

Les restaurateurs ne livrant de boissons qu'aux repas servis chez eux sont dispensés du droit de licence.

$4^{\circ}$ Les droits de vérification des poids et mesures fixés par le tarif annexé à l'arrêté local du 20 décembre 1877, qui a institué cette taxe.

b) Contributions indirectes et divers produits. - Les contributions indirectes et les divers produits comprennent :

$1^{0}$ Les droits d'enregistrement, de timbre et d'hypothèques. - Les droits d'enregistrement sont réglés par l'ordonnance du 31 décembre 1828, le décret du 17 juillet 1857, l'article 2 de la loi du 27 ventôse an IX, les articles らૅ et 6 de la loi du 18 mai 1850 .

Les droits de timbre ont été établis par le décret du 4 aoùt 1860, avec application du tarif du 5 juin 1800 , modifié par les 
articles 17 à 28 de la loi du 2 juillet 1862 et par la loi du 25 août 1871 . Le décret du 16 août 1893 a en outre rendu applicables à la colonie certains décrets et certains articles de lois sur les affiches, les effets de commerce et les timbres mobiles, sur les timbres de quittance, acquits, reçus ou décharges de sommes, titres, valeurs ou objets, sur les timbres des connaissements, etc.

Les droits d'hypothèques sont réglés par l'ordonnance du 14 juin 1829, la loi du 5̆ janvier 1875, le décret du 28 août 1875 et l'arrêté du 10 octobre 1877.

Les droits d'hypothèque maritime ont été fixés par le décret du 6 août 1887 et les arrêtés des 26 septembre 1887 et du 21 décembre 1893.

$2^{0}$ Les revenus du domaine. - L'Administration locale afferme les salines de Gandiole et les palmiers de Dakar, Thor Diander et Rufisque ; elle donne à loyer au service de la marine l'immeuble affecté au port militaire à Dakar ő0 francs par an, à la Compagnie du câble Spanish National à raison de 500 francs par an une partie de l'immeuble du Service des Postes et Télégraphes à Saint-Louis et enfin au Service du câble Brest-Dakar, pour la somme de $\mathbf{1 0 . 0 0 0 ~ f r a n c s ~ p a r ~ a n , ~ u n e ~ p a r t i e ~ d e ~ l ' h o ́ t e l ~ d e s ~}$ Postes et Télégraphes à Dakar.

En outre, les terrains vagues dans les territoires annexes sont concédés à des particuliers moyennant une redevance fixée par l'arrêté du らّ janvier 1887 à 0 fr. 50 par hectare et par an. Ces concessions sont aussi accordées à titre gratuit, moyennant certaines conditions à remplir à la charge des bénéficiaires.

$3^{\circ}$ Les droits d'exploration, de recherches et d'exploitation des mines qui ont été établis par les décrets du 6 juillet 1899 et du 19 mars 1903 sont ainsi fixés :

\section{Permis d'exploration :}

5 centimes par hectare.

\section{Permis de recherches:}

10 centimes par hectare jusqu'à 1.000 hectares. 
20 centimes par hectare au-dessus jusqu'à $ّ .000$ hectares.

40 centimes par hectare au-dessus.

La mutation est soumise à un droit proportionnel à la surface du périmètre sans que ce droit, puisse dépasser $0 \mathrm{fr} .50$ par hectare.

\section{Permis d'exploitation :}

2 francs par hectare pour l'or et les gommes.

1 franc par hectare pour toutes autres substances.

La mutation est soumise à un droit proportionnel à la surface du périmètre sans que ce droit puisse dépasser 0 fr. 50 par hectare.

Redevance fixe due à partir de la $3^{\mathrm{e}}$ année de l'institution, payable par année et d'avance :

1 franc par hectare pour l'or et les gommes.

50 centimes par hectare pour toutes autres substances.

Droits d'enregistrement pour cession de permis de recherches ou d'exploitation :

$50 / 0$ du prix de la cession.

Le Conseil général a, en outre, dans une délibération du 15 décembre 1898 , imposé un droit de $20 / 0$ sur la valeur des minerais extraits.

$4^{0}$ Les recettes de l'imprimerie officielle qui exécute pour le compte des particuliers des travaux dont le prix, établi par un tarif officiel, est perçu au profit de la colonie.

$5^{0}$ Les recettes postales et télégraphiques, qui profitent au budget de la colonie dans les conditions déterminées par les règlements spéciaux sur la matière, en particulier par les arrêtés locaux qui ont fixé la taxation des correspondances à l'intérieur, et par les conventions internationales pour les correspondances à l'extérieur.

La taxe des lettres échangées entre la France et le Sénégal et vice versa et entre le Sénégal et les colonies françaises est $0 \mathrm{fr} .10$ par 15 grammes ou fraction de 15 grammes.

Le tarif des correspondances postales circulant dans l'inté- 
rieur de la colonie est également de $0 \mathrm{fr} .10$ par 15 grammes ou fraction de 10 grammes; les cartes de visites et les cartes postales doivent être affranchies à 0 fr. 0 ö. Les papiers d'affaires et les journaux sont assujettis à une taxe de $0 \mathrm{fr}$. 05 par 50 grammes ou fractions de $\breve{0} 0$ grammes; et les échantillons à une taxe de 0 fr. 10 jusqu'à 100 graḿmes; au-delà de ce poids à un supplément de 0 fr. 05 par 50 grammes ou fractions de 50 grammes.

Le tarif des lettres à destination de l'étranger est de 0 fr. 20 pour les pays compris dans l'Union postale. Celui des boites et lettres de valeur déclarées, destiné à l'étranger a également été fixé parla Convention postale internationale signée à Washington le 1 ๖ juin 1897.

L'arrêté du 30 septembre 1884 a fixé à $10 / 0$ le droit à percevoir sur les mandats-postes expédiés dans l'intérieur de la colonie. Quant aux droits sur les mandats d'article d'argent métropolitains ils ont été ainsi établis par le décret du 30 septembre 1899 :

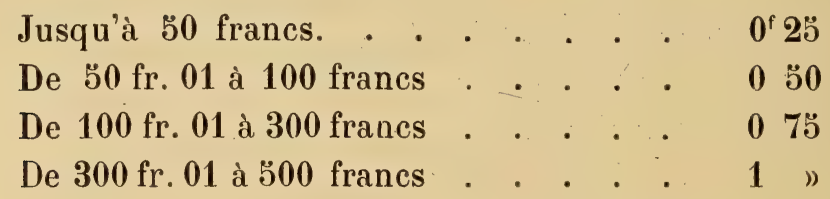

Une taxe additionnelle du change de $1 \mathrm{fr} . \mathbf{2 5}$ c. pour cent est, en outre, perçue au profit de l'Etat (Arrêté local du 31 octobre 1899).

L'arrêté du 2 juillet 1902 a prévu les taxes applicables aux colis postaux :

Dans le service intérieur, tout colis postal à destination des bureaux desservis par la voie ferrée ou par des vapeurs subventionnés est grevé d'un droit de $1 \mathrm{fr}$. 50 pour les colis de 5 kilog. et de 2 fr. 50 pour les colis de $\breve{a ̀ ~} 10$ kilog. ; ce droit est élevé à 3 francs pour les objets de l'espèce (colis de $\breve{b i l o g . ~ s e u l e m e n t) ~}$ dirigés sur tout autre bureau desservi par les courriers piétons.

Les colis postaux de la colonie à destination du Haut-Sénégal et Niger (־ kilog.) acquittent un droit de transport de $1 \mathrm{fr} . \check{00}$. Ces colis sont passibles d'une surtaxe de 6 francs, à leur arrivée à destination, perçue sur le destinataire. 
La taxe pour la France est fixée à 2 francs par colis de 0 à

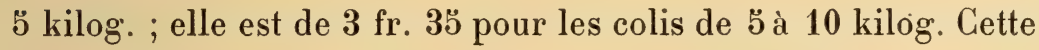
taxe ne comprend pas le droit de timbre de 0 fr. 10 et est augmentée d'autre part de 25 centimes de droit de factage pour la remise à domicile.

Les télégrammes ordinaires, à l'intérieur de la colonie, paient 0 fr. 50 pour une dépêche de 1 à 10 mots et 0 fr. 05 par mot au delà de 10 ; à destination du Haut-Sénégal et Niger, le tarif est le même pour les cercles de Kayes et Médine et doublé pour les autres localités de la colonie. Pour la Guinée française, la Côte d'Ivoire, de Dahomey, par voies terrestres, la taxe est de $0 \mathrm{fr} .20$ par mot avec un minimum de 1 franc par télégramme (arrêté du 12 décembre 1899).

Le tarif de la correspondance télégraphique échangée entre le Sénégal et la France, par la voie du câble Brest-Dakar a été fixé par le décret du 15 mars 1905 à $1 \mathrm{fr}$. 40 par mot. La part qui revient à la colonie sur les télégrammes qui empruntent soit cette ligne soit toute autre voie sous-marine étrangère est fixée :

Pour les correspondances télégraphiques du régime européen :

0 fr. 10 de taxe terminale par mot;

0 fr. 08 de taxe de transit par mot.

Pour celles du régime extra-européen :

0 fr. 20 de taxe terminale par mot;

0 fr. 10 de taxe du transit par mot.

$6^{0}$ Les droits d'emmagasinage des poudres du commerce, taxe unique une fois payée de 0 fr. 20 par kilogramme à chaque entrée dans une des poudrières de la colonie à partir du $1^{\mathrm{er}}$ janvier 1875, quel que soit le temps du séjour des poudres dans la poudrière.

$7^{0}$ Les droits d'emmagasinage de la dynumite, institués par une délibération du Conseil général du 27 janvier 1884. Droit de visite, 50 francs par 100 kilogrammes à percevoir lors des visites trimestrielles faites par les soins de l'artillerie, les frais d'emmagasinage spécial étant en totalité à la charge de l'introducteur.

$8^{0}$ Les produits des Lazarets, fixés par une délibération du Conseil général du 28 juin rendue exécutoire par arrêté du 20 novembre 1885 et approuvée par décret présidentiel du 12 juillet 1886 
et par les délibérations des 9 décembre 1886 et 11 décembre 1890 .

a) Droit de séjour, par jour et par personne :

Officiers ou passagers de chambre considérés comme tels . . . . . . . . . . . . 10 francs.

Sous-officiers ou passagers d'entrepont considérés comme tels . . . . . . . . . . . . 5

Caporaux, soldats ou passagers de pont, ouvriers, domestiques, etc., savoir :

Internés traités à la ration européenne . . . . 3

Internés à la ration indigène . . . . . . . . , 2 -

Ces chiffres sont réduits de moitié pour les enfants au-dessous de 12 ans. Les enfants au-dessous de 3 ans sont admis gratuitement.

b) Droits sur les marchandises désinfectées :

Bagages des passagers, les 100 kilogrammes . .

1 franc.

Cuirs, peaux et autres dépouilles d'animaux, les

100 pièces . . . . . . . . . . .

c) Droits pour l'assainissement des navires sur rade ou des marchandises au lazaret :

Remboursement des dépenses réellement effectuées.

$9^{\circ}$ Les taxes dans les hôpitaux civils de Saint-Louis et de Gorée et qui ont été fixées pour la journée par les délibérations du Conseil général des 28 décembre 1896 et 3 décembre 1904 et le décret du 19 décembre 1901 promulgué par arrêté du 20 janvier 1902.

Ration européenne : $1^{\text {re }}$ classe . . . 8 fr. par jour

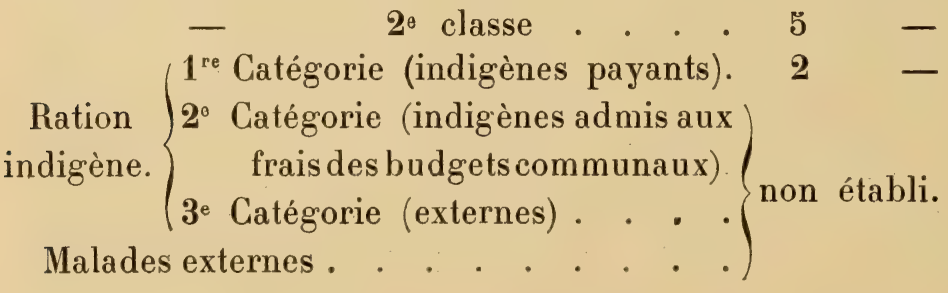


La taxe est due du jour de l'entrée inclusivement au jour de la sortie exclusivement.

$10^{\circ}$ Des taxes diverses et de peu d'importance perçues dans quelques escales.

$11^{\circ}$ On peut ajouter en outre au nombre des ressources de la colonie, le revenu tiré par la colonie, des fonds de la Caisse de réserve placés en rente sur l'Etat, $\mathbf{1 . 5 0 0 . 0 0 0 ~ f r a n c s ~ a ̀ ~} 30 / 0$ soit 45.000 francs.

\section{B. - Pays de Protectorat.}

Les diverses recettes perçues au profit du budget des Pays de Protectorat, peuvent se grouper en deux catégories :

a) Les contributions directes ou sur rôles ;

b) Les divers produits.

\section{a) Contributions directes ou sur rôles.}

Nous signalerons d'abord l'impôt personnel qui fut établi par les arrêtés des 2 juillet et 14 novembre 1903 alors que les régions qui font aujourd'hui partie de la Colonie du Sénégal étaientcomprises dans les territoires de la Sénégambie Niger. Le décret du 18 octobre 1904 qui a soudé cette partie du Sénégal à la première a laissé subsister les obligations financières des indigènes.

Cet impôt est fixé à $\mathbf{4}$ francs dans les cercles de Louga, Tivaouane, Thiès, Dagana et province du Sine (cercle de Kaolack);

3 francs dans les cercles de Podor, Matam, Bakel, les provinces de Nioro-Rip, Niombato, du Saloum oriental et occidental (cercle de Kaolack);

2 francs dans l'étendue de la Casamance et du Niani-Ouli.

Toutefois, les militaires de toutes armes et de tout grade en service en Afrique occidentale française, ainsi que leurs femmes et leurs enfants pendant la durée de leur service; de même que les gens sans ressources et sans famille, atteints d'infirmités qui les mettent dans l'impossibilité de subvenir à leurs besoins sont exempts de cette taxe. 
L’impôt personnel est perçu sur rôles. Les rôles sont collectifs et établis suivant les lieux, par province ou par canton.

Ils sont dressés annuellement et en triple expédition par les soins de l'Administrateur ou du Commandant de cercle et indiquent :

$\mathbf{1}^{0}$ Le nom de chaque - village et celui de son chef avec mention du nombre des contribuables ;

$2^{0}$ Le taux de l'impôt;

$3^{0}$ La somme totale de l'impôt à percevoir ;

$4^{0}$ La part revenant au chef ou à l'agent chargé du recouvrement ;

$5^{0}$ La somme nette qui doit faire retour au Budget.

Il sont soumis à l'approbation du Gouverneur au moment de l'examen du Budget de l'exercice qu'ils concernent.

Les indigènes portés sur les rôles de lïmpôt personnel ne peu. vent quitter la province où ils résident qu'après paiement intégral de leur impôt personnel.

Le recouvrement de l'impôt est effectué sous le contrôle des Administrateurs et Commandants de cercles par les chefs de province, de canton et de village ou par les collecteurs d'impôt désignés à cet effet.

Le montant des sommes perçues est versé dans les caisses des Trésoriers-Payeurs, préposés du Trésor, receveurs régionaux ou agents spéciaux qui en délivrent quittance extraite $d^{3} u n$ registre à souche.

Des remises calculées sur les recettes effectives peuvent être allouées aux chefs ou agents chargés du recouvrement de l'impôt personnel.

En principe, l’impôt est payé en numéraire, toutefois dans les régions qui en sont encore dépourvues, il peut être acquitté en nature, après autorisation spéciale donnée par l'Administration supérieure qui fixe la nature des produits et la limite des quantités à percevoir au cours de l'exercice, dans les magasins du Service local.

Dans tous les cercles où les produits riches (or, ivoire, caoutchouc, etc.,) font déjà l'objet d'un commerce, l'Administration s’interdit de les recevoir au titre de l'impôt. 


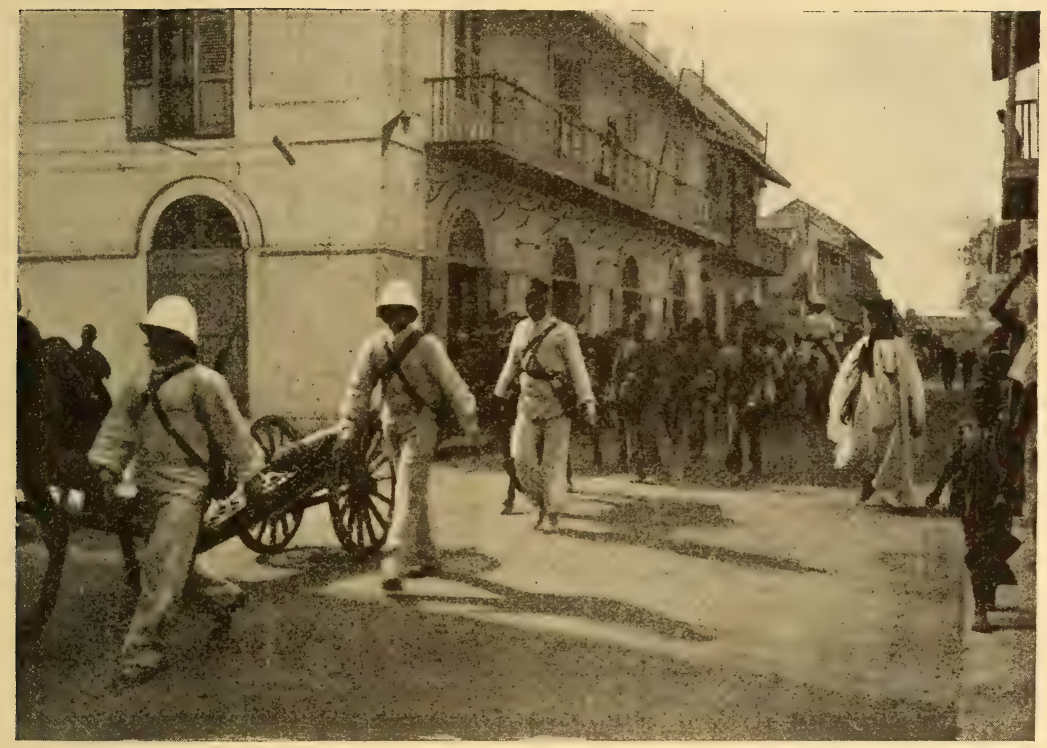

Fig. 23. - L'artillerie a Saint-Louis,

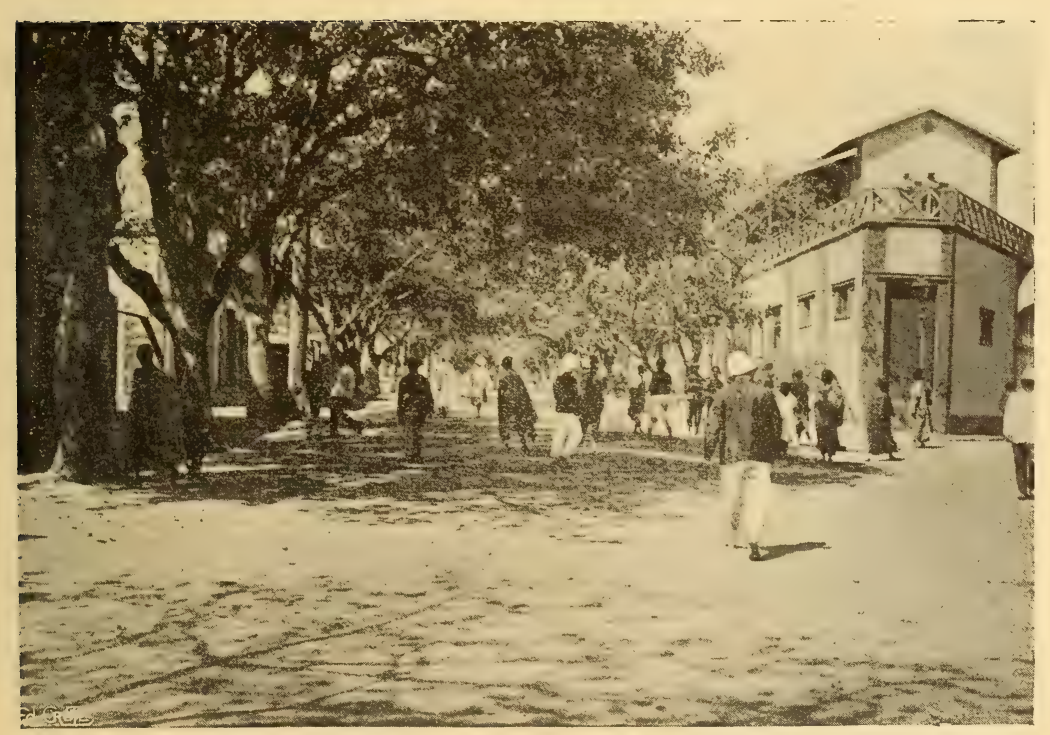

Fig. 24. - Dukar, Boulevard National

S. 

Cette taxe est admise par tous les indigènes qui l'acquittent sans la moindre difficulté, elle est d'ailleurs bien inférieure à leurs facultés contributives. Son revenu présumé pour l'année 1906 figure au budget pour la somme considérable de 3.437.000 francs.

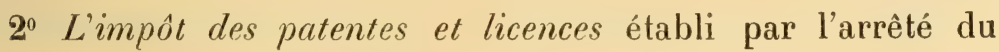
14 novembre 1904.

La contribution des patentes est payée par toute personne exerçant un commerce ou une industrie dans l'étendue des territoires du Sénégal, elle consiste en un droit fixe qui varie avec limportance et la nature du commerce cxercé et comprend quatre catégories :

Patentes de $1^{\text {re }}$ classe : 300 francs. - Commerçants recevant des marchandises de l'extérieur (conserves, liquides, articles de traite) pour les vendre eux-mêmes en gros, ou demi-gros ou pour le faire détailler.

Patentes de classe : 200 francs. - Commercants et traitants vendant en demi-gros ou détaillant les marchandises qui leur sont cédées par les patentables de $1^{\mathrm{r} 0}$ classe.

Patentes de 3 e classe : 190 francs. - Traitants faisant tous leurs achats sur place et tenant des boutiques de détail, bouchers, boulangers, marchands de colas en gros, etc.

Patentes de 4 classe: 60 francs. - Traitants et petits boutiquiers notoirement connus pour ne faire qu'un chiffre d'affaires extrêmement réduit, piroguiers, passeurs, etc.

En outre, toute personne vendant au détail et à consommer sur place des vins, liqueurs et en général des boissons alcooliques ou fermentées, tout aubergiste, traiteur, restaurateur donnant à manger au jour, au mois ou à l'année, sont assujettis à un droit de licence qui est ainsi fixé :

Restaurants, cafés et cabarets ayant des chaises, tables et autres installations analogues

Cabarets où I'on vend sur le comptoir . . 200 -

Fabricants ou marchands de dolo . . . . 60 -

$3^{0}$ Les patentes de colporteurs et dioulas. - Le même arrêté du 14 novembre 1904 a astreint les colporteurs indigènes ou dioulas qui circulent à travers la Colonie avec des caravanes pour 
trafiquer de leurs marchandises, au paiement d'un droit de patente, soit qu'ils agissent pour leur propre compte, soit pour le compte d'un commerçant établi qui, en les envoyant circuler dans les cercles, crée une succursale ambulante de son magasin.

Cette patente, dont le taux varie suivant la classe, est proportionnelle à la valeur des marchandises, y compris celle des animaux porteurs. Elle est délivrée par les administrateurs, commandants de cercles et est valable pour un an dans toute l'étendue des Territoires des Pays de Protectorat, à partir du jour de son établissement.

Le taux des patentes de dioulas est ainsi établi :

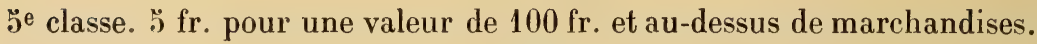

$4^{\mathrm{e}}-10$

$3 \mathrm{e}-20$

- $\quad 200$

$2^{\mathrm{e}}-3 \mathrm{~J}$

500

1 re -50

1.000

1.500

Dans le cas où la valeur dépasse 1.500 francs, une taxe de 2 fr. 00 par 100 francs de marchandises en excédent de la valeur initiale de 1.5000 francs, est imposée au dioula.

$4^{\circ}$ Le permis de circulation, qui est une patente temporaire, accordée aux indigènes qui ne font de commerce que par occasion. Ce permis qui ne sert que pour aller d'un point à un autre doit être renouvelé à chaque voyage. La taxe est fixée à $50 / 0$ de la valeur des marchandises transportées, jusqu’à 100 francs; à $2 \mathrm{fr}$. 50 de surtaxe par 100 francs jusqu'à 1.000 francs et à $10 / 0$ de surtaxe par 100 francs au-dessus de 1.000 francs.

\section{b) Divers produits.}

Au nombre des divers produits, nous citerons :

$1^{\circ}$ Les droits de place sur les marchés établis en vertu de l'arrêté du 2 novembre 1903.

$2^{0}$ Les droits de concessions : Les terrains à bàtir dans les villes sont vendus aux enchères publiques, conformément aux prescriptions de l'arrêté du כ̋ octobre 1898. Les prix de base, variables 
selon l'emplacement sont fixés à 0 fr. 60,0 fr. 2 ə̈ et 0 fr. 05 le mètre carré.

$3^{\circ}$ Les droits sur la recherche et l'exploitation des mines, fixés par le décret du 6 juillet 1899, dont il a déjà été question. Ces droits sont identiques à ceux qui sont perçus dans les Territoires d'Administration directe, sauf toutefois en ce qui concerne le droit d'extraction qui est de $50 / 0$ de la valeur du minerai extrait.

$4^{0}$ Les droits de fourrière (arrêté du 13 octobre 1899) qui sont de 2 francs par jour pour les chameaux, chevaux, mulets et bœufs et de 1 franc pour le premier jour et 0 fr. 50 pour les jours suivants pour les ânes, moutons, chèvres et autres animaux.

$5^{\circ}$ Le produit de la vente des animaux en fourrière et non réclamés.

$6^{0}$ Le droit de port d'arme fixé par l'arrêté du 14 novembre 1903 à 1 franc pour les détenteurs d'armes non perfectionnées ou de

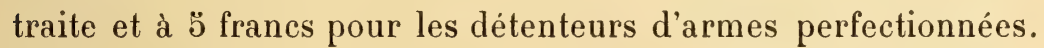

$7^{0}$ Les droits de passage sur les bacs, qui sont établis suivant les règlements et les tarifs spéciaux à chaque cercle dûment approuvés par l'autorité supérieure.

$8^{0}$ Le produit des amendes et des confiscations.

La situation financière et la caisse de réserve.

La situation financière du Sénégal est excellente. La progression constante de son budget pendant ces dix dernières années et que nous exposons dans le tableau ci-après, page 144, en est une preuve irréfutable.

Les constants excédents de recettes que l'on peut constater ont permis à la colonie de se constituer une solide caisse de réserve dans laquelle elle pourrait puiser en cas de besoin et qui a atteint jusqu'à deux millons. Un récent décret en date du 17 novembre 1905 en a toutefois fixé la limite maximum et l'a arrêtée à la somme de $\mathbf{1 . 5 0 0 . 0 0 0 ~ f r a n c s . ~}$

Quant à la section des Pays de Protectorat dont l'organisation financière ne fonctionne que depuis 1905 , sa situation est égale- 
ment bonne puisque la cloture de cet exercice a permis de constater un excédent de recettes de $\mathbf{1 7 4 . 0 0 2} \mathrm{fr} .72$.

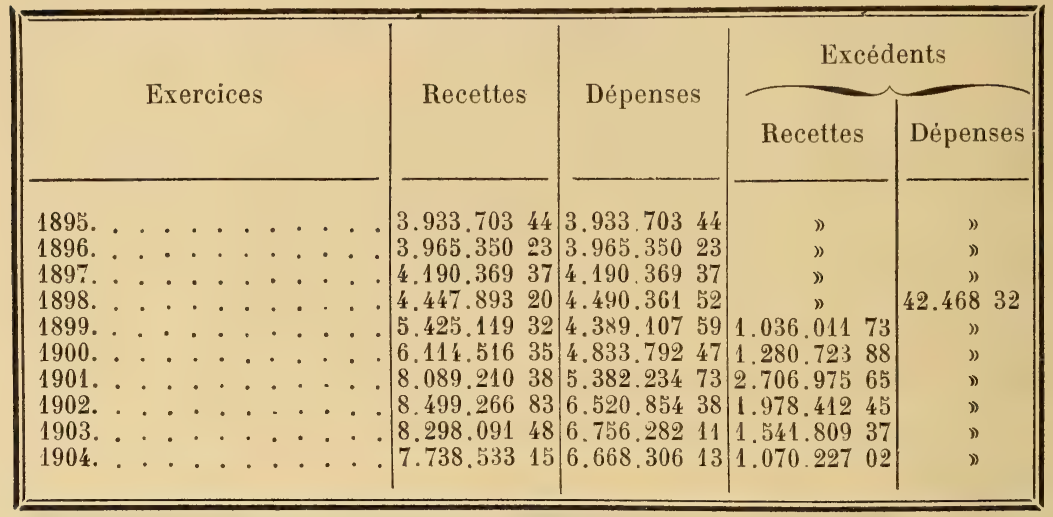

Sa caisse de réserve, également prévue par le décret du 17 novembre 1905 , est constituée par une somme de $300.000 \mathrm{fr}$. prélevée sur la caisse de réserve de l'ancien budget disloqué de la Sénégambie-Niger. Cet avoir ira s'accroissant tous les ans, si les prévisions se réalisent, sans pouvoir toutefois dépasser la somme de 1 million, maximum qui lui a été assigné par le décret de 190ฎ.

\section{II. - Services financiers.}

Les services financiers ont été réglementés, par application des dispositions du décret du 20 novembre 1882, sur le régime financier des colonies, et par divers actes qui ont institué l'organisation actuelle.

Le service de la trésorerie du Sénégal est assuré par un Trésorier-payeur, que le décret du 18 octobre 1904 a en même temps institué Trésorier-payeur de l'Afrique occidentale et qui effectue en outre toutes les opérations concernant les services financiers métropolitains.

Il est assisté d'un Trésorier particulier, percepteur de Dakar, d'un percepteur dans chacune des villes de Saint-Louis et de Rufisque et de divers receveurs régionaux dans l'intérieur de la colonie. 
Ces comptables justiciables de la Cour des comptes, effectuent toutes les opérations en recettes et en dépenses pour le compte du budget de la colonie et de ce chef, bénéficient des remises suivantes :

\section{Au Trésorier-payeur :}

Contributions directes recouvrées par le percepteur de Saint-Louis . . . . . . . . . . $2^{\mathrm{f}} 19$ 0/0

Contributions directes recouvrées par le percepteur de Dakar . . . . . . . . . . . .

Contributions indirectes et divers produits recouvrés par lui ou par les autres comptables du premier arrondissement.

$1750 / 0$

Contributions indirectes et divers produits centralisés par le Trésorier particulier de Dakar . . .

Au Trésorier-particulier, percepteur à Dakar :

Contributions directes recouvrées par lui en sa qualité de percepteur, y compris les 20 centimes par article de rôle recouvré.

$3500 / 0$

Contributions indirectes et divers produits recouvrés par lui en sa qualité de Trésorier-particulier ou par les autres comptables du deuxième arrondissement .

$1500 / 0$

Au Percepteur de Saint-Louis :

Contributions directes, y compris les 25 centimes par article de rôle recouvré

$3500 / 0$

Au Percepteur de Rufisque:

Contributions directes, y compris les 25 centimes par article de rôle recouvré . . . . . . .

Contributions indirectes et divers produits . .

$3 \ddot{20} 0 / 0$

$10 / 0$

Aux Receveurs régionaux :

Contributions indirectes et divers produits recouvrés par eux . . . . . . . . . . . . . . .

Recettes de la Douane ou autres recouvrés par d'alitres comptables et versés à leur caisse. . . 
Aux chefs indigènes, qui dans les Pays de Protectorat sont les premiers collecteurs de l'impôt et les très précieux auxiliaires de l'Administration, des remises sont également allouées.

Contributions directes. - Le contrôle des contributions directes est assuré, sous la direction du Secrétariat Général, par trois fonctionnaires en résidence à Saint-Louis, Dakar et Rufisque. Les contrôleurs des contributions qui sont en même temps vérificateurs des poids et mesures, établissent les róles pour la perception de l'impôt personnel, des droits sur les patentes, les licences, l'impôt locatif et les poids et mesures.

Enregistrement, timbre, domaine, etc. - Deux bureaux d'enregistrement ont été institués dans la colonie, le premier à Saint-Louis et le second à Dakar; ils réunissent dans leurs attributions les différents services de l'enregistrement, du timbre, des domaines, des hypolhèques et de la curatelle aux successions et biens vacants. Ces bureaux sont dirigés par des receveursconservateurs, relevant de l'administration locale; l'arrêté du 3 août 1861 promulguant le décret du 4 août 1860 , fixe le cautionnement et les remises de ces fonctionnaires; ceux en date des 7 et 9 aoùt de la même année réglementent la comptabilité et la manutention du service du timbre. Les receveurs sont chargés de la perception des droits de timbre, d'enregistrement, d'hypothèques, de greffe, de celle des produits domaniaux ainsi que du recouvrement des amendes, des frais de justice et de poursuites.

Le service des douanes était, avant le décret du 18 octobre 1904, assuré par des agents à la solde du budget local du Sénégal. L'acte de 1904 ayant affecté au Budget général les recettes douanières de toutes nos colonies de la Cote occidentale d'Afrique, c'est le Gouvernement général qui pourvoit au service des douanes et c'est à lui également qu'incombe le soin d'en choisir et d'en payer les agents. 


\title{
CHAPITRE IX
}

\author{
ORGANISATION JUDICIAIRE
}

\section{I. - Régime légal. La loi française et la loi indigène.}

Origine de la législation au Sénégal. - En général, "de quelque colonie qu'il s'agisse, il est difficile de définir avec précision comment et dans quelle mesure la législation française est appliquée ; mème lorsque la règle est une assimilation aussi complète que possible, il subsiste toujours quelques différences, car dans aucune de nos possessions les lois de la Métropole ne sont applicables directement et ipso facto ").

Mais la question devient plus complexe, lorsque à côté de la législation française, subsistent les coutumes indigènes (1).

Le Sénégal est dans ce cas ; on y a suivi la règle si heureusement adoptée dans nos colonies de conserver aux peuples conquis leurs "lois et coutumes" en matière civile et surtout en matière de statut personnel, auquel une simple question de loyauté oblige les peuples colonisateurs à ne pas toucher.

Ainsi donc deux législations fonctionnent parallèlement: la législation métropolitaine applicable aux citoyens français et assimilés et la législation indigène, inspirée soit du Coran, soit de la coutume, s'adressant aux autochtones.

La législation française au Sénégal. - Le Sénégal fait partie du groupe des colonies " autres que la Martinique, la Guadeloupe et la Réunion » visées par l'article 18 du sénatus-con-

(1) A. You, Madagascar. Berger-Levrault, éditeurs. 
sulte du 3 mai 18034 et se trouve ainsi soumis au régime dit « des décrets " qui sont la base de sa législation. Toutefois et il en est pour le Sénégal comme pour celles de nos autres possessions qui sont également placées sous le régime des décrets, l'intervention du pouvoir législatif est toujours possible en diverses matières et notamment lorsqu'il s'agit d'une modification territoriale ou lorsque les finances de l'Etat peuvent être engagées même indirectement.

En dehors de ces cas très déterminés les décrets forment donc la règle geénérale. Ils peuvent soit édicter des dispositions spéciales à la colonie, soit prescrire l'application de certaines lois ou règlements en vigueur dans la Métropole. Dans ce cas particulier, le pouvoir exécutif, législateur des colonies ne reprend pas en détail le texte dont il veut faire application à la colonie, il se contente de renvoyer aux dispositions authentiques et connues.

En conséquence, on peut dire qu'aucune loi ne devient applicable au Sénégal si le législateur ne l'a expressément spécifié ou si un décret n'en a décidé l'extension à cette colonie et dans ce cas un nouveau décret peut ultérieurement en modifier la législation.

En outre, le législateur des colonies peut sur certains points et moyennant certaines conditions, déléguer à une autre autorité son pouvoir souverain. C'est ainsi que le Gouverneur général de l'Afrique occidentale française et dans certains cas les Lieutenants-gouverneurs ont qualité pour régler par arrêté les matières d'administration et de police.

En résumé, le législateur ordinaire au Sénégal est le pouvoir exécutif statuant par décret, exceptionnellement le pouvoirlégislatif statuant par une loi et exceptionnellement aussi et par voie de délégation l'administration coloniale statuant par arrêté.

Promulgation et publication des lois, décrets, etc. — Un règlement fait pour la colonie n'y devient applicable et obligatoire qu'à partir du moment où il y a été promulgué et publié.

C'est au Gouverneur général « dépositaire des pouvoirs de la République en Afrique occidentale française » qu'appartient la prérogative de promulguer dans toute l'étendue du territoire les 
actes officiels émanant du pouvoir central. A cet effet, il a été créé un Journal officiel de l'Afrique occidentale française où sont promulgués tous les actes de l'autorité métropolitaine et publiés tous les arrêtés émanant du gouverneur général. Toutefois ces actes doivent être reproduits au Journal officiel de la colonie afin d'y prendre date et de devenir exécutoires.

Loi française et loi indigène. - Le régime légal au Sénégal résulte des ordonnances du 11 février 1838 , du 7 septembre 1840 , du 7 février 1812, du sénatus-consulte du 3 mai 180̈4, des décrets des 9 août 18304, 15 mai 1889, 10 novembre 1903, relatifs à l'organisation de la justice dans ces territoires. Il existe dans la colonie, ainsi que nous l'avons déjà vu, deux ordres de législation : $1^{\circ}$ la loi française applicable d'une manière générale; $2^{\circ}$ la loi indigène ou loi locale.

$1^{\circ}$ Loi française. - La loi française s'applique aux citoyens français et assimilés. Les étrangers relèvent également des tribunaux français, ceux de race européenne restant soumis, de même que s'ils résidaient en France, à leur législation, mais en qui concerne seulement les questions relatives à leur statut personnel (majorité, mariage, tutelle, etc.).

La loi française découle en principe de l'ordonnance du 14 février 18\%8, de l’ordonnance organique du 7 septembre $\mathbf{1 8 4 0 ,}$ du sénatus-consulte du 3 mai $18 \ddot{4} 4$ et du décret du 13 mai 1889 modifié par le décret du 10 novembre 1903.

Les dispositions de nos codes ont été pour la plus grande partie rendues applicables à notre colonie du Sénégal, de telle sorte qu'en matière civile, commerciale et criminelle il existe peu de différence entre la législation appliquée au Sénégal et celle qui est en vigueur dans la métropole.

$2^{0}$ Loi indigène. - Les sources du droit indigène sont, au au Sénégal, de deux sortes : $1^{0}$ pour les musulmans, le Coran; $2^{0}$ pour les autres indigènes, la coutume.

Suivant leur condition, il leur sera donc appliqué par leurs tribunaux spéciaux, soit les prescriptions de la loi coranique, soit les règles de la coutume.

Toutefois le décret du 10 novembre 1903 qui a réglé l’organisation de la justice indigène prévoit que toutes les fois qu'ils le 
désireront, les indigènes pourront réclamer le bénéfice de la juridiction française, et dans ce cas il doit être fait application aux parties des usages et coutumes du lieu, " à moins qu'elles n'aient déclaré dans un acte, qu'elles entendent contracter sous l'empire de la loi française ».

\section{II. - Organisation judiciaire}

Historique. - Comme conséquence naturelle et inévitable de l'installation au Sénégal des compagnies commerciales, d'abord de la Compagnie Normande, puis de la Compagnie des Indes Occidentales qui remplaça la première, des discussions et des conflits d'intérêt ne manquèrent pas de s'élever entre vendeurs et acheteurs, entre traitant et indigènes.

Ces difficultés étaient rapidement tranchées. Le dirccteur de la Compagnie avait pleins pouvoirs pour cela. Il était juge unique et suprême; son bon vouloir était sa seule règle et ses décisions rapides et sans appel.

En 1674 toutefois, un édit royal invita les directeurs des Compagnies à appliquer autant que possible les lois de la métropole et à partir de $\mathbf{1 7 8 2}$ la justice fut rendue par les gouverneurs nommés par le roi.

Mais c'est seulement l'ordonnance du 7 janvier 1822 qui dota la colonie d'un embryon d'organisation judiciaire. Le Sénégal posséda dès lors deux tribunaux : celui de Gorée composé du commandant particulier, du principal employé de la marine et d'un notable, et celui de Saint-Louis composé d'un juge et de quatre notables, dont deux Européens et deux indigènes : c'est là un cas peut-être unique où les Français ont pu être jugés par des indigènes (1). L'appel des jugements rendus par ces tribunaux était porté devant un conseil d'appel siégeant à SaintLouis et composé du commandant, président, de quatre fonctionnaires et de deux habitants ; ce conseil connaissait en outre de toutes les affaires criminelles. 
Cette organisation ne fut modifiée que par l'ordonnance du 19 novembre 1940 qui constitua une cour dappel à Saint-Louis et remplaça le gouverneur et les fonctionnaires par des magistrats de carrière.

Une nouvelle ordonnance rendue peu après, le 27 mars 1844 , remania la composition de la cour d'appel qui comprit un président, un conseiller, l'officier de l'état civil de Saint Louis et deux notables. Une cour d'assises fut également créée et composée du président, du conseiller, de l'officier de l'état civil, du chef du service de santé et de trois assesseurs.

Un décret du 9 août 18034 réorganisa le système judiciaire. La cour d'appel continua à siéger à Saint-Louis et sa juridiction s'étendit sur toutes nos possessions de la côte occidentale d'Afrique, Gabon compris. Un président, chef du service judiciaire, un conseiller auditeur la composèrent. Saint-Louis et Gróe demeurèrent les sièges des tribunaux de première instance dont la composition fut identique : un juge président, un procureur de la République et un greffier qui remplissait en même temps les fonctions de notaire. Le procureur de la République de Saint. Louis était en même temps ministère public près la cour d'appel.

La justice criminelle était administrée par une cour d'assises siégant à Saint-Louis et composée des membres de la cour et de quatre notables désignés par la voie du sort sur une liste dressée tous les ans par le gouverneur.

Le décret du 20 mai 1857 compléta cette organisation en instituant à Saint-Louis un tribunal musulman, composé d'un cadi, d'un assesseur et d'un greffier, et qui connaissait exclusivement des affaires entre indigènes musulmans et relatives aux questions de personnes (état civil, mariage, successions, donations et testaments). Les causes ètaient jugées selon la loi musulmane et l'appel également jugé d'après le Coran était porté devant un conseil composé du gouverneur, président, d'un conseiller à la cour, du directeur des affaires indigènes et du chef de la religion musulmane.

Le décret du 15 mai 1889 dont les dispositions ont régi avec très peu de transformations, jusqu'au décret de 1903 , le service judiciaire dans nos possessions de l'Ouest africain, modifia l'acte 
du 9 août 1854. Cette modification était d'ailleurs devenue indis pensable par suite du développement de la population du Sénégal et de l'importance croissante des transactions commerciales dans nos établissements de la côte.

Le nombre des magistrats des différentes juridictions était augmenté. La cour d'appel qui conservait son siège à Saint-Louis et sa juridiclion sur toutes nos possessions de l'Afrique occidentale comprenait: un président, deux conseillers, un conseiller auditeur, un greffier et-un commis greffier. Les fonctions de ministère public étaient remplies par le procureur de la République près le tribunal de Saint-Louis.

Le tribunal de première instance de Gorée se trouvait transporté à Dakar qui prenait tous les jours plus d'importance ; Saint-Louis conservait le sien qui comportait un juge-président, un procureur de la République, un lieutenant de juge, un substitut et un greffier. La composition du tribunal de Dakar était identique, sauf le substitut dont on n'avait pas jugé la présence indispensable.

Un tribunal spécial composé de l'administrateur du cercle et de deux notables était institué à Bakel et une justice de paix à compétence étendue avec juridiction sur le Soudan était créée à Kayes. Le commandant des cercles de Kayes était investi des fonctions de juge de paix à compétence étendue et un fonctionnaire désigné par le commandant supérieur du Soudan remplissait celles de Ministère Public. Liappel des affaires civiles était porté devant le tribunal de Saint-Louis, quant aux affaires criminelles, elles étaient déférées à la Cour d'assises du Sénégal. Celle-ci était composée : du président de la Cour d'appel, de deux conseillers ou d'un conseiller et du conseiller auditeur, de quatre assesseurs tirés au sort parmi les notables, du Procureur de la République ou de son substitut et du greffier de la Ciour d'appel. Sa compétence s'exerçait sur toutes les affaires criminelles, dont elle était saisie par le Procureur de la République. Le Président de la Cour d'appel était chef du service judiciaire et le demeura jusqu au momentoù le décret du 31 janvier 1891 créa un emploi de Procureur général près la Cour d'appel et confia à ce magistrat les fonctions de chef du service judiciaire. 
A part quelques modifications de détail : création d'un emploi de Procureur général (décret du 31 janvier 1891), augmentation du nombre des conseillers et institution d'une chambre des mises en accusation près la Cour d'appel (décret du 11 aoùt 1899), le service de la justice au Sénégal resta soumis jusqu'au 10 novembre 1903 aux dispositions du décret de 1889 .

Organisation de la justice française et de la justice indigène. - L'organisation actuelle résulte du décret du 10 novembre 1903. Cet acte s'applique à la fois au fonctionnement de la justice française et de la justice indigène : l'ensemble du service de la justice en Afrique occidentale française est placé sous la direction d'un Procureur général, résidant à Dakar, qui est le chef du service judiciaire.

Comme représentant de l'action publique, le Procureur général veille dans l'éiendue du ressort des tribunaux français à l'exécution de lois, ordonnances, arrêtés ou règlements, en signale les infractions a.u Gouverneur général et en dehors de ces ressorts veille à l'application de la justice indigène conformément aux prescriptions dı décret; il fait toutes les réquisitions nécessaires ; poursuit d'office l'exécution des jugements et arrêts dont les dispositions intéressent l'ordre public ; signale à l'autorité administrative les arrêts et jugements en dernier ressort passés en force de chose jugée, qui lui paraissent susceptibles d'être attaquées par voie de cassation dans l'intérêt de la loi; surveille l'administration des successions vacantes, les officiers de police judiciaire et les officiers ministériels ; requiert la force publique dans les cas et selon les formes déterminées par les lois et décrets.

Comme chef du service judiciaire, il veille au maintien de la discipline de la cour et des tribunaux et provoque les décisions du Gouverneur général sur les actes qui lui sont contraires.

Il vérifie les causes de détention dans les prisons, examine les plaintes qui peuvent s'élever de la part des détenus et en rend compte au Gouverneur général. Il veille à l’inspection des registres des greffes et ceux de l'état civil. 
Il examine et transmet avec ses observations, au Gouverneur, qui les envoie au Ministre des Colonies, les états trimestriels et les documents statistiques qui lui sont adressés par les différents procurcurs placés sous ses ordres. Il réunit enfin, pour être envoyés au Département des Colonies, les doubles registres et documents divers destinés à être déposés aux archives coloniales.

\section{A. - La justice française.}

La justice française est rendue :

$1^{0}$ Par une Cour d'Appel qui a son siège à Dakar ;

$2^{\circ}$ Par des tribunaux de première instance établis à SaintLouis et à Dakar ;

$3^{0}$ Par une Cour d'assises qui siège à Dakar mais qui peut, selon les circonstances, être transférée à Saint-Louis.

La Cour d'appel de l'Afrique occidentale française dont la juridiction s'étend sur tous les territoires de nos colonies du Sénégal, du Haut-Sénégal et Niger, de la Guinée et du Dahomey et de la Côte d Ivoire, a son siège à Dakar.

Elle est composée d'un président et de six conseillers et fonctionne dans les limites dévolues aux Cours d'appel de France. Elle comprend en Gutre un greffier et des commis-greffiers dont le nombre est déterminé par arrêté du Gouverneur général.

Un Procureur général, qui est en même temps chef du service judiciaire de l'Afrique occidentale française, assisté d'un avocat général et d'un substitut remplit auprès d'elle les fonctions de Ministère public.

Elle connaît, tant en matière civile et commerciale qu'en matière correctionnelle et de simple police, de l'appel des jugements rendus en premier ressort par les tribunaux de première instance et les justices de paix à compétence étendue. Elle connaît également de l'appel des jugements rendus par les tribunaux musulmans et dans ce cas, statue d'après la loi musulmane en vigueur dans le ressort du tribunal. 


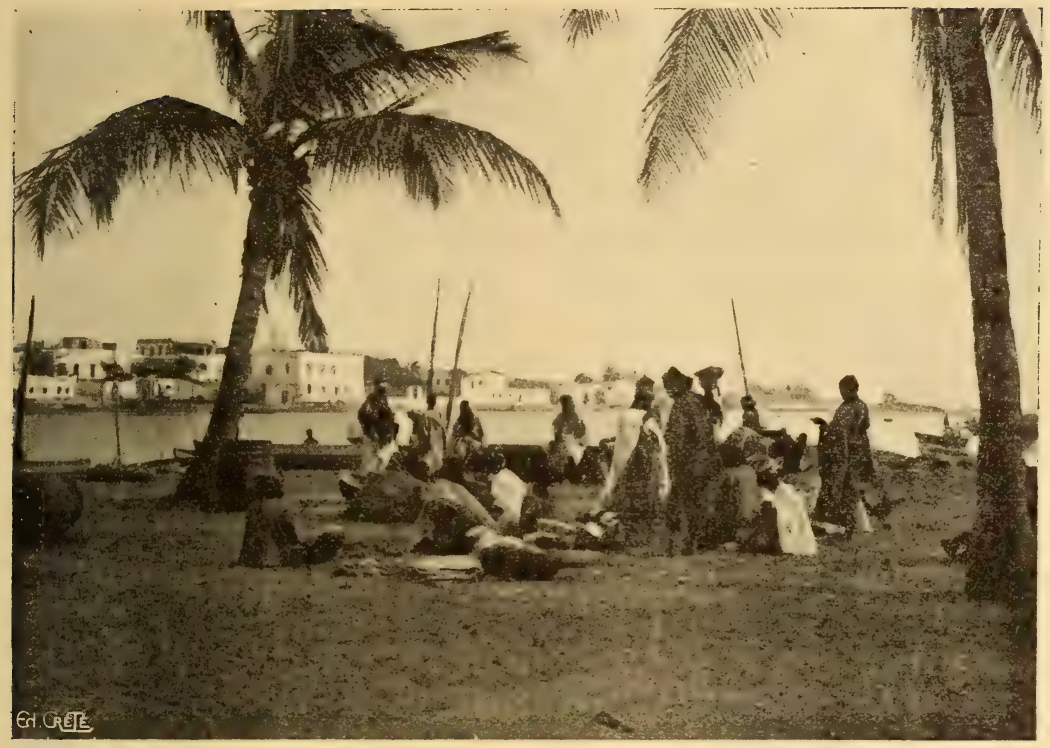

Fig. 2̌̈. - Saint-Louis (Vue du fleuve).

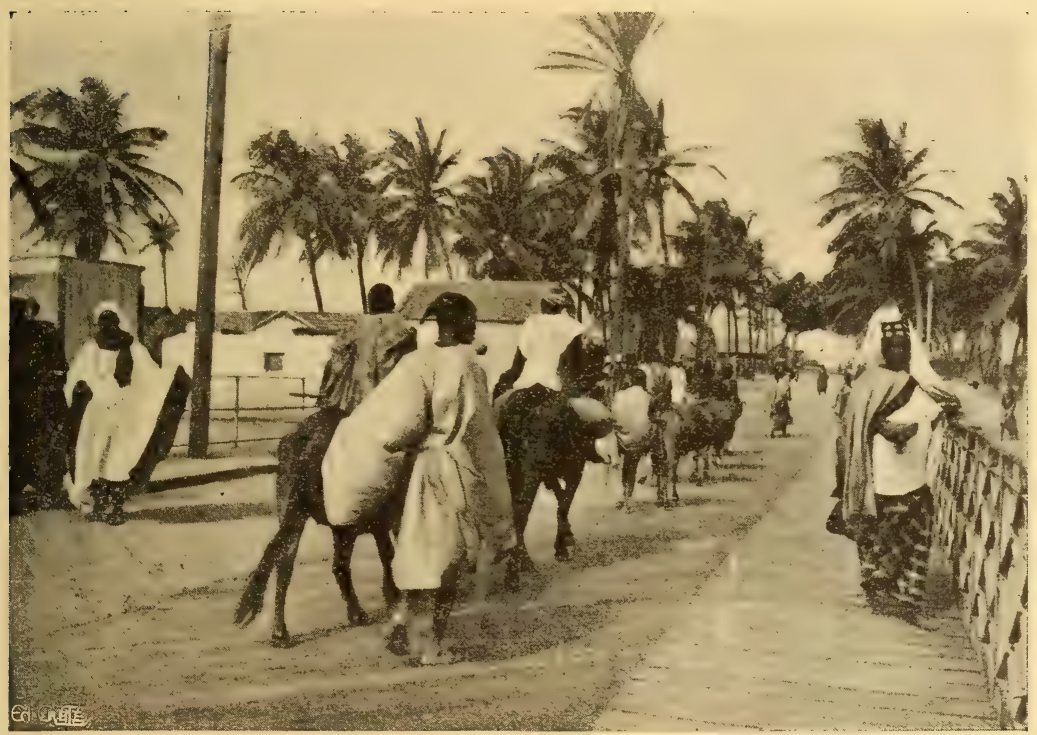

S.

Fig. 26. - Saint Louis (La rue André Lebon). 

Quant aux décisions rendues en premier et en dernier ressort et en toute matière par les tribunaux de première instance et les justices de paix à compétence étendue, elles peuvent être attaquées par la voie de l'annulation devant la Cour d'appel, mais seulement pour excès de pouvoir, incompétence ou violation de la loi. Et dans ce cas, si la Cour prononce l'annulation, elle doit ordonner le renvoi de l'affaire devant le même tribunal qui doit se conformer, pour le point de droit, à la doctrine adoptée par elle.

En toute matière, les arrêts de la Cour d'appel sont rendus, en audience solennelle, par trois conseillers, sauf dans les affaires d'annulation où leur nombre est porté à cinq.

Les tribunaux de première instance siègent à Saint-Louis et à Dakar. Leur ressort respectif a été fixé par l'arrêté du 6 juillet 1904 .

Celui du Tribunal de Saint-Louis comprend les Territoires de la commune de Saint Louis et de sa banlieue el sa juridiction s'étend en outre «sur les territoires et cercles du fleuve Sénégal, jusque et y compris celui de Bakel et les cercles de la ligne du chemin de fer de Dakar à Saint-Louis, jusque et y compris le cercle de Tivaouane $)$.

Celui du Tribunal de Dakar comprend les Territoires des communes de Gorée, Rufisque et Dakar et les banlieues de ces deux dernières communes et sa juridiction s'étend " sur les Territoires des cercles des régions de Thiès, du Sine-Saloum, de la HauteGambie et de la Casamance ».

Ces tribunaux se composent d'un juge président, d'un lieutenant de juge, d'un juge suppléant, d'un procureur de la République, d'un grelfier et de commis-greffiers.

Le juge président rend seul la juslice dans les matières qui sont de la compétence du tribunal de première instance et de la justice de paix. Il possède en outre les attributions diverses accordées aux présidents des tribunaux de première instance et aux juges de paix de France par nos différents Codes.

Le lieutenant de juge remplit les fonctions de juge d'instruction et, le cas échéant, remplace le juge président.

Quant au juge suppléant, il est appelé à remplacer les mem- 
bres du tribunal absents ou empêchés et peut également être chargé des fonctions du ministère public.

Au point de vue de la compétence, les tribunaux de première instance connaissent " de toutes les actions civiles et commerciales en premier et dernier ressort, jusqu'à la valeur de $\mathbf{1 . 5 0 0}$ francs en principal et de $\mathbf{1 0 0}$ francs de revenus et en premier ressort seulement, et, à charge d'appel, devant la Cour, de toutes les actions s'élevant au-dessus de ces sommes ").

Toujours en matière civile et commerciale, ils connaissent de toutes les affaires dans lesquelles sont intéressées des personnes demeurant dans le ressort et appliquent la loi française seule.

Toutefois, dans les affaires concernant les individus non musulmans qui ont conservé le statut indigène, et relatives aux questions qui intéressent l'état civil, les successions, les donations et les testaments, les tribunaux de même que la Cour d'appel s'adjoignent un assesseur avec voix consultative qui est désigné par le Gouverneur général, sur la proposition du Procureur général. 11 est procédé et jugé dans ce cas suivant la coutume locale.

Pour les indigènes musulmans, et ceci est une très heureuse amélioration apportée à l'acte de 1903 par le décret du 22 mai 190 , les causes se rapportant à ces mêmes affaires, sont instruites et jugées par un tribunal spécial suivant la loi musulmane et les formes de procéder en usage chez les musulmans du ressort.

Il a été ainsi créé au Sénégal deux tribunaux musulmans l'un à Saint-Louis, l'autre à Dakar, composés d'un cadi, d'un assesseur qui lc supplée en cas d'empêchement et d'un greffier, tous nommés par arrêté du Gouverneur général.

En toute matière, les indigènes peuvent réclamer le bénéfice de la juridiction francaise. Dans ce cas, il leur est fait application des usages et coutumes du lieu, à moins qu'ils n'aient déclaré dans un acte, qu'ils entendent contracter sous l'empire de la loi française.

En matière correctionnelle et de simple police, les tribunaux de première instance connaissent de tous les délits et contraventions commis dans l'étendue du ressort.

La Cour d'assises du Sénégal, dont ressortissent également 
les territoires du Haut-Sénégal et Niger et de la Mauritanie siège en principe à Dakar; elle peut toutefois, lorsque les circonstances l'exigent, être transportée à Saint-Louis.

Elle se compose de trois membres de la Cour dappel dont l'un remplit les fonctions de président, de quatre assesseurs, désignés par le Procureur général sur une liste de notables dressée par le Lieutenant-gouverneur, du Procureur général ou de l'un des membres de son parquet et du greffier de la Cour d'appel. Dans le cas où la Cour siège à Saint-Louis, le Procureur général et le greffier de la Cour peuvent être remplacés par le Procureur de la République et le greffier du tribunal de première instance, et un ou plusieurs membres de la Cour par des magistrats de ce tribunal.

Les assesseurs sont pris sur une liste de notables dressée par les soins du Lieutenant-gouverneur. Dans la première quinzaine d'octobre, le Gouverneur général, sur la proposition du Procureur g'énéral, désigne sur cette liste les personnes qui doivent composer le collège des assesseurs pour l'année suivante. Ce collège qui comprend $\mathbf{2 1}$ membres doit toujours être tenu au complet. Dix jours avant l'ouverture des assises le président de la Cour d'appel tire au sort, sur la liste des assesseurs les noms des $\mathbf{4}$ assesseurs titulaires et de l'assesseur supplémentaire, nécessaires pour le service de la session. Ainsi que cela se passe en France pour les jurés, les accusés et le ministère public ont concurremment le droit de récusation à l'égard des assesseurs.

L'ouverture des sessions est fixée pour chaque trimestre, suivant les besoins, par ordonnance du Président de la Ciour après avis du Procureur général.

La Cour d'assises connait au Sénégal de tons les crimes et de toutes les autres infractions déférés en France aux Cours d'assises, quels qu'en soient les auteurs.

La procédure devant ces divers tribunaux est à peu près identique à celle qui est en vigueur devant les juridictions métropolitaines de même ordre. Tous les arrêts rendus par la Cour d'appel peuvent être déférés à la Cour de cassation hors les cas 
où elle statue comme Ciour dannulation ou comme Chambre d'homologation.

La Chambre des mises en accusation, qui connait des instructions relatives aux affaires qui sont de la compétence des Cours d'assises et qui lui sont renvoyées par les lieutenants dejuge, ainsi que des oppositions formées contre les ordonnances de ces magistrats, se compose de trois membres de la Cour d'appel, désignés semestriellement par le président de la Cour, après avis du procureur général. Le plus ancien la préside.

\section{B. - La justice indigène.}

Le décret du 10 novembre 1903 a réglé l'importante et difficile question des tribunaux indigènes.

Il a institué, dans les territoires non compris dans le ressort des tribunaux de première instance, des tribunaux de village, des tribunaux de province et des tribunaux de cercle.

Les tribunaux de village, composés du chef de village, font office en matière civile de tribunaux de conciliation et en matière pénale de juges de simple police.

Les tribunaux de province, composés du chef de province et de deux notables, dont fait toujours partie le cadi en matière musulmane sont en matière civile les tribunaux ordinaires, et en matière pénale les tribunaux correctionnels, prononçant des peines ne dépassant pas cinq années d'emprisonnement.

Tous les jugrements des tribunaux de province sont sujets à appel devant les tribunaux de cercle.

L'institution des tribunaux de cercle, innovation du décret de 1903, a pour objet de substituer au contrôle intermittent, irrégulier, et qui pouvait quelquefois être taxé d'arbitraire, exercé par les Administrateurs sur la distribution de la justice indigène, un véritable contrôle judiciaire, régulier et continu.

Le tribunal de cercle est composé de l'administrateur assisté de deux notables, dont fait nécessairement partie le cadi en matière musulmane.

Il est juge d'appel, en matière civile et correctionnelle des jugements des tribunaux de province. 
Il est en outre tribunal criminel.

A ce titre, ses arrêts sont soumis au contrôle d'une chambre spéciale, la Chambre d'homologation placée auprès de la Cour d'appel et composée de trois conseillers, de deux fonctionnaires et de deux assesseurs indigènes, et auprès de laquelle le Procureur général ou l'un des membres de son parquet remplit les fonctions de Ministère public.

En principe, cette Chambre ne peut que donner ou refuser son homologation, et dans ce cas, elle n'èvoque pas l'aftaire, mais la renvoie devant le tribunal de cercle, en indiquant les motifs de son refus. Ce n'est que dans le cas exceptionnel où la Chambre refuserait à nouveau son homologation qu'elle évoquerait l'affaire et statuerait au fond.

Ainsi, le principe posé par le décret de 1902 d'une Chambre d'homologation statuant en matière pénale indigène est maintenu; mais son application est restreinte aux affaires vraiment graves et importantes aux affaires criminelles. Son intervention dans les autres affaires pénales est remplacée par la garantie du double degré de juridiction et de l'examen, en cas d'appel par une autorité européennne, le tribunal de cercle.

\section{C. - La juridiction administrative.}

La juridiction administrative, dont il n'est pas question dans le décret de 1903, appartient au conseil du contentieux administratif, dont l'organisation a déjà été exposée (1). Les Européens ainsi que les indigènes relèvent de ce tribunal.

Les auxiliaires de la justice. - Les auxiliaires de la justice sont :

Les avocats défenseurs, dont l'institution au Sénégal sous le nom de conseils commissionnés avait été autorisée, par l'ordonnance du 4 septembre 18 17̄, réalisée par l’arrêté local du b̆ mars

(1) Voir Chap. VII, Organisation politique et administrative. 
1859 et maintenue par le décret de 1903 . Toutefois un récent arrêté du Gouverneur général ( 2 décembre 1908 ) a réuni en une seule compagnie les conseils commissionnés du Sénégal et les défenseurs de la Guinée et de la Côte d'Ivoire, a réglementé l'exercice de leur profession et donné à ces officiers ministériels la nouvelle et unique dénomination, pour l'étendue de l'Afrique occidentale, d'avocats défenseurs.

Les avocats défenseurs dont le nombre maximum a été fixé à trois au siège de chaque Tribunal de $1^{\text {re }}$ Instance et à cinq au siège de la Cour, doivent avoir 2ò ans, être Français et licenciés en droit. Ils sont nommés par le Gouverneur général sur la proposition du Procurcur général.

Leur ròle est identique à celui de leurs confrères français, ils sont chargés de postuler et de plaider dans l'étendue du ressort pour les parties qui ne le font pas elles-mêmes.

Les notaires. - A la suite du décret du 13 avril 1893 portant organisation du greffe et du notariat, deux études de notaires ont été créées au Sénégal, l'une à Saint-Louis, l'autre à Dakar.

Les huissiers, dont les fonctions ont été prévues, pour le Sénégal, par l'ordonnance du 7 février 1842 sur le service judiciaire de l'Inde, partiellement applicable au Sénégal et qui exercent après les diverses juridictions de leur résidence les mêmes attri butions que ceux de la Métropole.

Les interprètes, institués par l'arrêté du 2 septembre 1889 sont attachés au service de la Cour et des tribunaux. Il convient également de citer les commissaires-priseurs, au nombre de deux, l'un à Saint-Louis, l'autre à Dakar et les experts visiteurs de navires.

Les arrêtés du 15 juin 1855 et du 4 janvier 1886 ont en outre créé au Sénégal un service d'assistance judiciaire qui fonctionne, à peu de différences près, dans les mêmes conditions qu'en France.

On peut juger d'après cet exposé combien l'organisation judiciaire est complète au Sénégal.

Les tribunaux français, assurent aux justiciables les garanties 
essenticlles de la législation française. Quant aux tribunaux indigènes, dans la mesure où cela est compatible avec les principes de notre civilisation, ils garantissent aux populations locales le maintien de leurs coutumes et de leurs traditions. 


\section{CHAPITRE $\mathrm{X}$}

ORGANISATION MILITAIRE

La pacification du Sénégal est depuis bien longtemps un fait accompli. La tranquillité du pays est complète et ses habitants, non seulement ne song'ent pas à s'affranchir de notre administration pacifique et fructueuse, mais ne pensent au contraire qu'à retirer de notre contact le plus de bénéfices possibles.

Il pourrait done paraitre étrange de voir une colonie aussi calme et sûre que celle-là, dotée d'une organisation militaire aussi puissante, si l'on ne songeait à sa situation géographique. Placée sur la route atlantique de l'Europe vers l'Amérique du Sud à l'endroit où l'Afrique se rapproche le plus de ce continent, donnant accès sur le premier pays tropical que l'on rencontre en suivant cette voie, clef du centre africain, et de l'Algérie par le Sud, riche de ses ressources naturelles, peuplée de populations laborieuses et intelligentes, admirablement située pour fournir une base d'opérations offensives, enviée pour tous ces avantages, elle méritait d'être protégée contre toutes les éventualités.

\section{L'organisation militaire.}

Les troupes du Sénégal font partie intégrante de l'armée coloniale, instituée par la loi du 7 juillet 1900. L'organisation des corps d'infanterie et d'artillerie coloniales a été réglée par les décrets généraux sur la matière, en date du 28 décembre 1900 , modifiés par les décrets du 19 septembre 1903. 
Le personnel ressortit d'une manière générale au ministère de la gıerre, mais demeure, pendant son séjour dans notre possession sous l'autorité du Ministre des Colonies.

Recrutement. - Les éléments européens sont tirés des régiments d'infanterie et d'artillerie coloniales stationnés en France. Leur recrutement est, par conséquent, opéré selon les prescriptions des lois du 30 juillet 1893, du 9 juillet 1900 et du 21 mars 1905 , sur le recrutement de l'armée, c'est-à-dire par voie d'engagements et de rengagements successifs, accomplis dans les conditions prévues par le décret du 23 août 1905 modifié par le décret du 21 juin 1906.

Quant au recrutement des troupes indigènes, il a été organisé par le décret du 14 novembre 1904, portant réglementation du recrutement et des réserves indigènes en Afrique occidentale française, il est assuré :

$1^{0}$ Par des engagements volontaires de deux ou quatre ans ;

$2^{0}$ Par des rengagements de un, deux ou trois ans.

Le texte de cet acte vient d'être lég’̀̀rement modifié et seulement d'ailleurs en ce qui concerne la durée du service dans la réserve par le décret du 21 juin 1906.

L'arrêté du 17 juillet 1903, a divisé le Sénégal en deux circonscriptions de recrutement dont une est spécialement affectée aux troupes du point d'appui : celle-ci comprend les cercles de Tivaouane, Dakar, Thiès et de Sine-Saloum; le reste de la colonie forme la seconde circonscription.

La composition des corps européens et indigènes, a été fixée par les décrets du 19 septembre 1903, décrets qui ont eux-mêmes été modifiés par ceux du 29 mai 1906, pris sur la proposition concertée des ministres de la guerre et des Colonies.

Groupement des troupes. - L'organisation militaire actuelle de nos possessions de l'Ouest africain découle du décret du 26 mai 1903, portant organisation du groupement des forces militaires stationnées aux Colonies, qui a créé un groupe de l'Afrique occidentale, placé sous la haute direction d'un général commandant supérieur ef se subdivisant en deux groupes : le groupe de l'Afrique occidentale et celui du Congo.

La répartition des troupes en Afrique occidentale a été fixée 
par le récent décret du 29 mai 1906, de telle façon que chacun des groupes établis dans chacune de nos possessions forme une unité administrative distincte, presque indépendante pour les besoins du service local et régies par les instructions du 23 septembre et du 3 novembre 1903 pour l'application du décret du 26 mai 1903.

Commandement. - Le commandement est exercé dans tout le groupe de l'Afrique occidentale par un officier général qui a le titre de "Commandant supérieur des troupes du groupe". Ses attributions découlent des décrets des 27 janvier 1886 , 3 février 1890, 3 novembre 1901, 26 mai 1903 et 21 juin 1906. Il peut toutefois déléguer une partie de ses pouvoirs de discipline et de commandement aux commandants des détachements stationnés dans les différentes colonies du groupe.

Il a sous sa haute direction le territoire, les forces de l'armée active, de sa réserve, ainsi que tous les services et établissements affectés à ces forces. Il est, sous l'autorité supérieure du Gouverneur général le chef responsable de l'administration militaire dans l'étendue de son commandement.

Les détachements de chacun des groupes ont, nous l'avons vu, une administration séparée d'après les dispositions du décret du 26 mai 1903, de l'instruction du 3 novembre et de la circulaire du 28 novembre 1903. Le commandement est exercé dans les conditions prévues par l'arrêté du 3 juin 190ə̆. Toutefois la place de Dakar, point d'appui de la flotte, et les places annexes de Rufisque et de Thiès constituent un commandement territorial particulier qui est placé sous l'autorité du commandant de la défense de Dakar.

Le Lieutenant-gouverneur, par délégation des pouvoirs militaires du Gouverneur Général et le commandant territorial, par délégation des pouvoirs du Général commandant supérieur, règlent directement toutes les affaires d'ordre administratif et territorial relatives particulièrement à la sécurité intérieure de la Colonie, au recrutement, à l'administration des réserves indigènes, aux appels des réservistes, à l'emplacement et à la répartition des troupes, à l'entretien des camps provisoires, au service général et au personnel militaire exerçant des fonetions politi- 
ques et administratives, en se conformant aux instructions générales qui leur sont données et sous réserve des comptes rendus à faire.

Réserves. - L'organisation régulière des réserves de l'A frique occidentale date de 190\%. Le Gouvernement général avait pensé qu'il pouvait être utile d'une manière générale de profiter des éléments que le pays possède pour contribuer, s'il était nécessaire, à l'augmentation des contingents que la Métropole entre. tient dans nos régions.

L'Afrique occidentale, en effet, constitue en quelque sorte un réservoir précieux de forces de seconde ligne dans lequel, en maintes circonstances et nolamment, lors de l'expédition de Madagascar, on a largement puisé. Les services rendus par ces recrues, comme tirailleurs et conducteurs, leurs qualités naturelles de courage, d'endurance et de discipline ont fait penser qu'elles pouvaient être dressées en vue d'une utilisation sur place.

C'est ainsi qu'on a été amené à la constitution de ces réserves indigènes, composées des anciens tirailleurs, conducteurs et spahis libérés, habitués déjà aux manœuvres et au maniement de nos armes à tir rapide, et des éléments nouveaux qui, répondant volontairement à un premier appel, ont consenti à venir, pendant une période de vingt jours, s'instruire sous la direction de nos officiers et de nos sous-officiers.

Le premier essai a été couronné d'un plein succès. Les rapports fournis par les autorités civiles et militaires ont été unanimes à constater la faveur avec laquelle cette mesure avait été accueillie par les indigènes. Les réservistes se sont présentés en nombre bien supérieur à celui que l'on désirait pour une première expérience; régulièrement payés, traités avec douceur, ils ont fait preuve de la meilleure volonté, d'ardeur même aux exercices militaires et les résultats obtenus dans le laps de temps si court de vingt jours ont été remarquables au point de vue de leur instruction.

Aussi le décret du 14 novembre 1904, suivi par l'arrêté du 20 juillet 1905 , vint-il organiser d'une manière régulière et définitive les réserves indigènes en Afrique occidentale. 
Sont considérés comme réservistes :

Les militaires indigènes retraités pour ancienneté de service;

Les militaires indigènes qui ont terminé le temps de service pour lequel ils sont engagés ou rengagés.

Les indigènes àgés de vingt ans au minimum et de trente ans au maximum, classés par les commissions de recrutement dans la catégorie des réservistes auxiliaires.

La durée du service dans la réserve est de cinq ans pour les militaires indigènes retraités et pour les réservistes auxiliaires ; pour les militaires non retraités, elle est telle que la durée du service à accomplir dans l'armée active et dans la réserve soit de quinze ans.

Pendant la durée de leur service dans la réserve, les militaires indigènes peuvent être appelés sous les drapeaux en cas de mobilisation générale, en cas de mobilisation partielle ou seulement pour des périodes d'exercice ou des revues d'appel.

Les réservistes sont convoqués par arrêté du Gouverneur général qui fixe les conditions de l'appel et les territoires où il doit s'effectuer. La convocation et la réunion des réservistes sont assurées à la diligence des Lieutenants-gouverneurs.

Chacune des Colonies de l'Afrique occidentale constitue une circonscription de réserve. La colonie du Sénégal seule en comprend deux correspondant à ses deux circonscriptions de recrutement.

Chaque circonscription de réserve est destinée en principe, à alimenter en réservistes les corps de troupes de toutes armes, stationnés dans la circonscription. Elle est elle-mème divisée en district de réserve comprenant un ou plusieurs cercles. La circonscription affectée aux troupes de la Place de Dakar est subdivisée en trois districts :

$1^{\mathrm{e}^{\mathrm{r}}}$ District $\left\{\begin{array}{l}\text { Commune de Dakar. } \\ \text { Cercle de Thiès. }\end{array}\right.$

$2^{\mathrm{e}}$ District $\left\{\begin{array}{l}\text { Commune de Rufisque. } \\ \text { Cercle de Tivaouane. }\end{array}\right.$

3e District $\left\{\begin{array}{l}\text { Commune mixte de Thiès. } \\ \text { Cercle de Sine-Saloum. }\end{array}\right.$

En cas d'insuffisance de réservistes d'une colonie, il peut être 
fait appel aux ressources des districts limitrophes de la Colonie voisine : le complément à fournir dans ce cas est déterminé par décision du Gouverneur général, sur la proposition du commandant supérieur des troupes.

L’immatriculation des réservistes indigènes est assurée dans les conditions fixées par l'arrêté du 26 juillet 1904 ; le Lieutenant gouverneur et le commandant territorial exercent chacun en ce qui le concerne une surveillance constante sur la tenue des contrôles.

Cette organisation fonctionne déjà régulièrement et l'on a déjà pu apprécier ses excellents résultats : " mais il importe de préparer les générations futures de réservistes, en apprenant aux indigènes actuellement en activité tous leurs devoirs de réservistes, en faisant entrer définitivement dans leur esprit l'idée encore incomprise, parce qu'clle n’a pas été bien définie, du service dans la réserve, et, c'est aux chefs de corps et aux officiers des corps de troupes qu'il appartient d'entreprendre cette œuvre d'éducation morale et de forger l'outil qui est devenu indispensable en Afrique occidentale " (circulaire du général Perreaux).

Goums. - Un arrêté du 20 septembre 1905, a décidé la création dans les colonies du Sénégal et du Haut Sénégal et Niger de goums réguliers dans les cercles où la population chevaline est suffisante pour permettre de constituer des groupes autonomes de cavaliers indigènes, sous l'autorité de chefs dont la désignation est faite par les Lieutenants-gouverneurs. Ces goums sont exclusivement composés de volontaires choisis par les chefs. Chaque cavalier doit fournir son cheval avec le harnachement; quant à l'armement et à l'équipement ils lui sont délivrés par l'autorité militaire chaque fois qu'il y a lieu.

Les goums peuvent être convoqués soit pour une mobilisation partielle ou totale, soit pour une opération à l'intérieur, pour des appels ou exercices de mobilisation ordonnés par le Gouverneur général et pendant la durée de leur convocation, ils ont droit aux allocations de solde et de vivres attribuées aux autres indigènes.

Ces troupes en raison de leur facilité de déplacement et de la 
rapidité de leur rassemblement peuvent rendre les services les plus signalés soit dans des opérations de police soit comme escorte, et c'est surtout cet espoir qui a motivé leur création. Les troupes régulières ne sont, en effet, pas toujours disponibles et la convocation des réservistes, demande toujours un certain délai.

Composition des troupes au Sénégal. - La répartition des troupes de l'Afrique occidentale, telle qu'elle était établie par les décrets du 19 septembre 1903 ne répondait plus à l'organisation politique donnée à nos possessions de l'Ouest Africain par le décret du 18 octobre 1904 .

Les décrels du 29 mai 1906 qui réglèrent celte question ont procédé non pas à une réorganisation générale du corps d'occupation, mais plutôt à un remaniement de ses unités, en vue d'un groupement nouveau, mieux adapté aux besoins de la défense extérieure, aux nécessités du recrutement des corps indigènes et de leurs réserves et à l'organisation territoriale des colonies composant le Gouvernement général.

La garnison affectée à la défense de la place de Dakar. point d'appui de la flotte, est placée sous le commandement d'un colonel "Commandant de la défense de Dakar " et comprend :

Infanterie. -1 bataillon d'infanterie coloniale, le $\mathbf{4}^{\mathrm{e}}$ régiment de tirailleurs sénégalais à 9 compagnies;

Artillerie. - Le $6^{\text {e }}$ régiment d'artillerie coloniale, qui comprend 1 groupe de 3 batteries à pied et 1 groupe de 3 batteries montées, 1 compagnie indigène d'ouvriers d'artillerie coloniale.

Génie. - 1 section indigène du génie.

En raison du rôle spécial de cette garnison, tous ses éléments, sans exception, doiṿcnt rester en tout temps, à la disposition de l'autorilé chargée de la préparation de la défense de la place et aucun d'eux ne doit en être distrait, à moins de nécessité impérieuse et urgente. La préparation de la défense ne peut, en effet, être bien assurée que si tout le personnel de la garnison possède une parfaite connaissance des fronts d'attaque et des secteurs sur lesquels il peut être appelé à combattre.

En outre, l'ensemble des colonies du Sénégal et du Haut-Sénégal et Niger comprend les forces suivantes : 
Le $1^{\mathrm{er}}$ régiment de tirailleurs sénégalais ;

Le $2^{\mathrm{e}}$ régiment de tirailleurs sénégalais ;

1 groupe de 3 batteries de montagnes du $6^{\text {e }}$ d'artillerie coloniale ;

1 détachement d'ouvriers d'artillerie coloniale ;

1 escadron de spahis.

Les dépenses militaires.

Les crédits qui sont nécessaires pour l'acquittement des dépenses militaires au Sénégal sont inscrits ainsi d’ailleurs que pour toutes nos colonies, au budget colonial. Toutefois le Gourernement général de l'Afrique occidentale française verse au budget de la Métropole une contribution annuelle de 100.000 francs qui est prévue au Budget général sous la rubrique "Participation de l'Afrique occidentale dans les dépenses militaires de la Métropole ".

Administration des crédits militaires. - Au point de vue de l'emploi des crédits, la réglementation générale, déterminée par le décret du 20 novembre 1882 et les actes subséquents, en particulier par le décret du 21 juin 1906 est encore en vigueur, de même que sont également appliqués, les principes posés par le décret du 31 mai 1862 sur la comptabilité publique et par le règlement du 14 janvier 1869 .

Le directeur de l'intendance qui, depuis le décret du 21 juin 1906 a remplacé le directeur du commissariat est chargé de l'ordonnancement des dépenses de tous les services. Il reçoit du Ministre des Colonies la délégation des crédits par l'intermédiaire du Gouverneur général et du Commandant supérieur des troupes : il sous-délègue tout ou partie de ces crédits aux fonctionnaires de l'intendance placés sous ses ordres. Lorsque dans une localité où la présence d'un sous-ordonnateur est reconnue nécessaire, il n'existe pas de fonctionnaire de l'intendance, les fonctions de sous-ordonnateur sont confiées à un chef de corps ou de service militaire ayant rang d'officier et, à défaut, 
à un fonctionnaire civil en service à cet endroit et désigné par le Ministre des Colonies.

L'ordonnateur s'assure de la régularité des dépenses qu'il est chargé d'ordonnancer il procède ou fait procéder, à cet effet, aux revues d'effectif, recensements de matériel, inventaires et autres moyens de vérification prévus par les règlements ou prescrits soit par le Gouverneur général soit par le Commandant supérieur des troupes. Ce role de surveillance administrative s'étend aussi bien sur les corps des troupes, que sur les directions d'artillerie ou sur le service des hópitaux.

L'exercice une fois clos, les comptes financiers de la colonie sont rendus dans la forme d'un état de développement des dépenses militaires qui vient se fondre dans le compte général du Département et sur lequel s'exercent le contrôle du Parlement et de la Cour des comptes.

Affectation des crédits militaires. - Les crédits prévus au budget colonial pour l'acquittement des dépenses militaires peuvent se répartir sous trois rubriques: $1^{\circ}$ solde etaccessoires; $2^{\circ}$ vivres, casernement, habillement et campement; $3^{\circ}$ transports.

Solde et accessoires. - Les tarifs de solde ont été déterminés pour les troupes aux colonies par le décret du 29 décembre 1903 qui prévoit que la solde coloniale est le double de la solde d'Europe.

Quant au transport des personnes et des hagages, aux indemnités de route etc., le personnel militaire est régi par les décrets du 3 juillet 1897 et du 6 juillet 1904 .

Vivres, habillement, équipement, campement et couchage. - Le système de la masse de racitaillement a été étendu dans nos colonies par le décret du 28 octobre 1904. Les corps doivent assurer eux-mêmes leur alimentation, et reçoivent pour cela des allocations en argent calculées de façon à laisser un léger excédent. C'est cet excédent qui constitue le boni qui supporte les pertes de toute nature ainsi que certaines dépenses mises autrefois à la charge de l'Etat.

Les tarifs de la masse sont fixés par homme et par jour ; les crédits alloués sont perçus par chaque conseil d'administration qui les répartit entre les compagnies, batteries ou détachements. 
La gestion en est confiée au capitaine et les comptes en sont rendus conformément à des dispositions spéciales.

L'habillement, le grand équipement, le campement et le couchage sont également acquis sur les fonds du budget colonial et délivrés en nature aux troupes européennes par les soins de l'intendance.

\section{Dakar point d'appui de la flotte.}

L'importance stratégique du port de Dakar est telle que le décret du 3 juin 1902 l'a classé, avec ceux de Bizerte, DiegoSuarez, Saïgon, Port-Courbet (baie d'Along), Nouméa et Fort de France, au nombre des points d'appui de la flotte.

On sait le rôle considérable que sont appelés à jouer en temps de guerre les points d'appui : prótégés par une défense terrestre et maritime importante, disposant de bassins et d'ateliers, possédant d'énormes stocks de charbon et de matières grasses et fortement pourvus de matériel de rechange et de personnel disponible, ils doivent être à même d'offrir aux navires de guerre en même temps qu'un abri, toutes les facilités de radoub et de ravitaillement. Il est done indispensable de munir ces places d'une puissante défense terrestre ainsi que d'une forte défense maritime, assurée par des torpilleurs et des sous-marins.

La situation géographique de Dakar désignait particulièrement celle ville pour remplir ce rôle : facilement défendable au point de vue terrestre, son port peut offrir un abri large, sûr et profond, tandis que son arrière pays offre des ressources presque inépuisables en hommes et en ravitaillement.

En outre, Dakar constitue l'un des sommets du vaste triangle statégique de l'Océan, dont les deux autres sommets aboutissent l'un à Brest, l'autre à Fort de France. Son rôle en temps de guerre doit être de servir de base d'opérations aux croiseurs à grande vitesse opérant contre le commerce ennemi, dans la 
guerre " industrielle " ou " guerre de course ". En outre son port doit servir de lieu de relàche pour les forces navales à destination de l'Orient (Madagascar ou l'Indo-Chine) et qui suivraient forcément la voie de l'Atlantique, le canal de Suez devant être inaccessible soit, parce qu'en raison de l'état de guerre il serait fermé, soit encore parce qu'il ne pourrait se prêter au passage des grosses unités de combat dont le tirant d'eau serait trop considérable pour sa profondeur relativement faible.

Au point de vue offensif, Dakar menace de flanc la grande roule commerciale dite "route des détroits" qui ceinture le globe par Gibraltar, Suez, le détroit de Malacca et Panama; cette route, traverse l'Océan à peu près à égale distance entre Brest et Dakar ce qui à ce point de vue-là, met la ville sénégalaise sur un pied d'égalité avec notre grand port militaire de l'Océan.

Son intérêt au point de vue stratégique apparait donc nette. ment: d'abord lieu de relâche et de ravitaillement pour nos divisions navales à destination de l'Orient, ensuite base d'opérations de premier ordre contre les flottes ennemies dans l'Océan.

Situation matérielle actuelle. - Une grande jetée déjà construite, abrite un vaste mouillage qui doit ètre approfondi à 9 mètres; les travaux qui sont actuellement en cours ont dû être interrompus en 1904. La Compagnie Hersent qui en avait l'entreprise ayant rencontré dans ses dragages un fond de roches alors que ses sondages lui avaient fait espérer n'avoir à faire qu'à de la vase.

Un bassin de 200 mètres de long est également en voie d'achèvement en même temps qu'un arsenal situé à l'Est de la ville.

Les défenses terrestres comportent de nombreuses batteries récemment construites.

La station locale ne comprend aujourd'hui qu'un aviso de $2^{\mathrm{e}}$ classe, le Goëland. Toutefois depuis deux ans, le budget de la Marine prévoit l'envoi à Dakar de trois torpilleurs de $1^{\text {re }}$ classe dont les numéros sont déjà désignés.

Il ne reste plus à orginiser que la défense maritime : lignes 


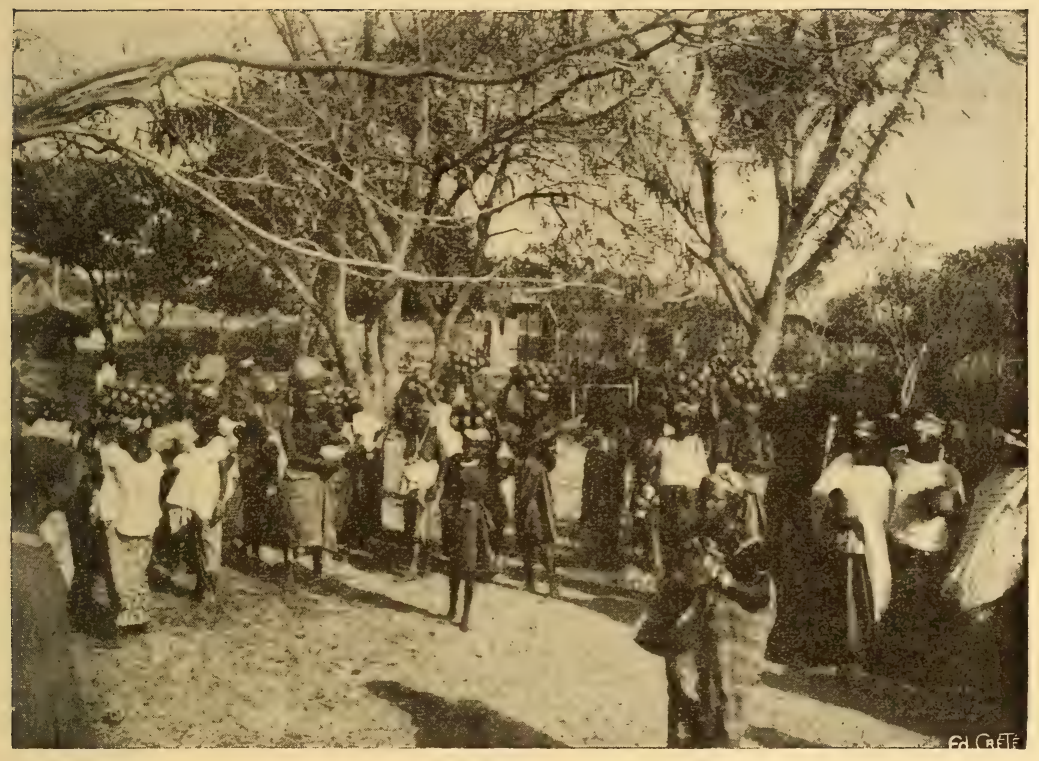

Fig. 27. - Tiranuane (Le marché).

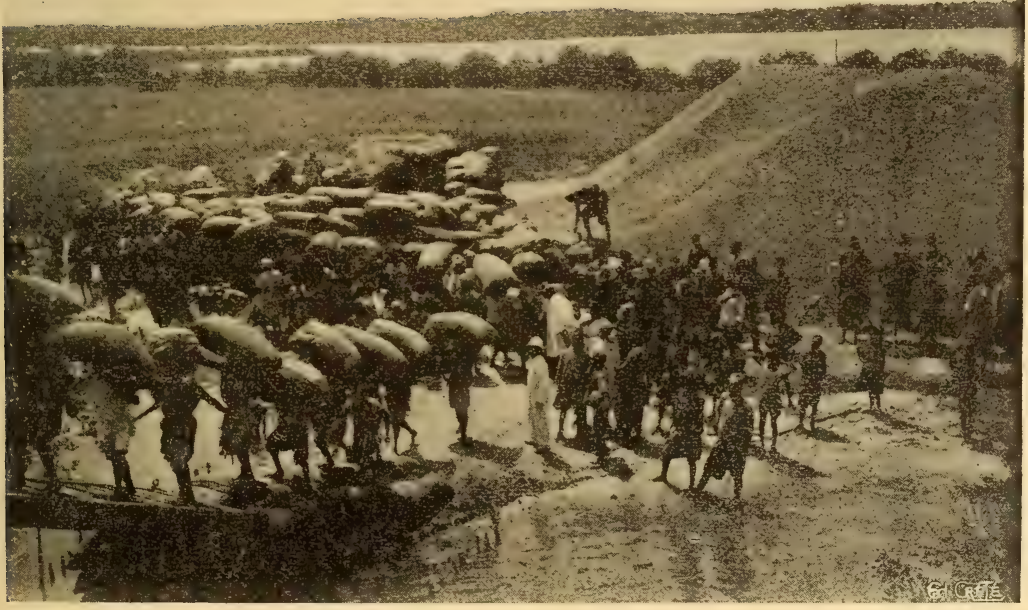

Fig. 28. - Chargement d'arachides dans te Sine saloum. 

de torpilles, projecteurs, torpilleurs, sous-marins avec leurs services accessoires (usine électrique et appareils de compression) pour que Dakar soit à même de rendre, le cas échéant, tous les services que l'on est en droit d'en attendre. 


\section{CHAPITRE XI}

ORGANISATION DES DIVERS SERVICES

Il est nécessaire, afin de donner une idée aussi complète que possible de l'organisation de notre colonie du Sénégal de dire quelques mots des divers services dont il n'a pas été question dans les pages qui précèdent.

Nous allons examiner successivement :

A) Le service de la santé;

B) Le service des travaux publics;

C) Le service des postes et télégraphes;

D) Le service de l'imprimerie officielle;

E) Le service de la police et des prisons;

F) Les divers services (enregistrement, domaines, contributions directes, service de l'agriculture);

G) L'instruction publique;

H) Les cultes.

\section{A. - Service de la santé}

S'il est, dans l'œuvre accomplie au Sénégal, un résultat qui doive nous causer un légitime orgueil, c'est assurément celui qui a été obtenu dans l'amélioration de la santé publique. On ne saurait trop louer notre administration d'avoir apporté un zèle persévérant et une ténacité inlassable à poursuivre ce but, ni trop se féliciter que ses efforts aient été couronnés de succès.

Les hauts fonctionnaires à qui incombe la redoutable respon- 
sabilité de la direction de nos possessions de l'Ouest africain ont pensé qu'ils avaient plus et mieux à faire qu'à se montrer habiles administrateurs, politiques avisés ou financiers avertis. Ils ont compris que leur mission ne consistait pas seulement à assurer le développement économique de ces colonies, à initier leurs habitants aux bienfaits de la civilisation, mais encore et surtout à les défendre, tant Européens qưindigènes, contre les nombreux fléaux qui les décimaient.

"Nous n’aurions pas rempli, disait le Gouverneur général (1), tout notre devoir envers la population si nous avions négligé d'étudicr les mesures d'assistance et d'hygiène publiques qui sont de toute nécessité dans un pays exposé à la malaria, à la fièvre jaune, à la filariose, à la variole et à la peste. Ces questions vitales sont au premier rang de nos préoccupations ".

OEuvre sanitaire. - De bonne heure, l'administration du Sénégal s'est préoccupée de prendre des mesures d’hygiène dans les centres dont l'importance devenait tous les jours plus considérable et où les Européens commençaient à s'installer. En 1867, un arrêté du gouverneur organise deux conseils d'hygiène publique et de salubrité à Saint-Louis et à Gorée, en 1881 la même création est faite à Rufisque et en 1883 la ville de Dakar est dotée d'un conseil du même genre. Un décret du 29 août 1884 organise le service sanitaire du Sénégal et des hospices civils sont ouverts à Saint-Louis et à Gorée.

Mais c'est seulement un peu plus tard que la lutte pour l'hygiène est entreprise avec vigueur et succès. Les causes du mal sont connues : elles sont imputables aux méfaits des différents moustiques transmetteurs des germes du paludisme, du terrible stegamya, porteur du typhus amaryl ou fièvre jaune dont l'épidémie de 1900 avait eu des conséquences si désastreuses et un retentissement si considérable. Il importait done de supprimer, dans la mesure du possible, les germes des fléaux, germes qui résidaient surtout dans les marais, aux eaux croupissantes, qui environnaient les principales villes du Sénégal. Il était également

(1) Discours prononcé à la séance d’ouverture du Conseil de gouvernement le 14 novembre 1903. 
indispensable, étant donné l'importance toujours croissante de ces centres de les doter d'une canalisation complète d'égouts.

Une somme considérable ( 5.450 .000 francs), prélevée sur les fonds de l'emprunt de 63 millions, émis en 1903 par le Gouvernement général de l'Afrique occidentale française, devait être consacrée à cette œuvre d'assainissement. En voici l'affectation :

Egouts de Saint-Louis $350.000 \mathrm{fr}$.

Desséchements des marais de Saint-Louis. 1.650 .000

Egouts de Dakar y compris le comblement des ravins.

Desséchement des marais de Dakar . . .

Egouts de Rufisque .. . . . . . . .

Desséchement des marais de Rufisque

1.000 .000

La variole exerçait également des ravages considérables. Elle avait à peu près disparu des centres urbains, Saint-Louis, Dakar, Gorée, Thiés, Rufisque, où les vaccinations et les revaccinations étaient faciles. Mais elle avait, en revanche, conservé toute sa forme épidémique chez les populations rurales du Cayor, du N'Diambour, du Oualo, du Baol, du Sine-Saloum, dans le pays Ouolof en Casamance et même dans les escales du fleuve. Elle pouvait et peut malheureusement encore, être considérée comme un des principaux facteurs de la dépopulation dans ces régions.

Il était nécessaire d'agir vigoureusement. Un centre vaccinogène qui fut installé à Saint-Louis, permit d'avoir sous la main de la vaccine possédant toutes les qualités désirables de frâlcheur et d'activité, qualités qui, atténuées lorsque les tubes vaccinaux arrivaient de France à Saint-Louis ou à Dakar, disparaissaient complètement lorsqu'ils étaient transportés dans l'intérieur. D'autre part le Conseil de gouvernement de l'Afrique occidentale française décida dans sa session de 1903 que quatre médecins se consacreraient uniquement à la vulgarisation de la vaccine et parcourraient le pays en tous sens pour inoculer les indigènes. 
Très récemment encore, le Gouverneur g'énéral obéissant à la même préoccupation de permettre à chacune de nos colonies de posséder de la lymphe vaccinale active, a décidé par un arrêté en date du f janvier 1906, l'installation dans l'intérieur de chacune de nos possessions, d'un centre vaccinogène qui produirait luimême la lymphe nécessaire et d'où rayonneraient les médecins qui seraient chargés de l'innoculer aux indigènes.

Il convenait également de donner à l'administration des pouvoirs assez étendus pour qu'elle puisse, le cas échéant, prendre les mesures qui lui sembleraient opportunes soit pour enrayer une épidémie, soit pour en supprimer les causes. Le décret du 14 avril 1904, relatif à la protection de la santé publique en Afrique occidentale française a atteint ce but. Il rend en premier lieu la vaccination antivariolique obligatoire au cours de la première année de la vie, ainsi que la revaccination au cours de la onzième et de la vingt et unième année. L'autorité administrative est autorisée, moyennant certaines conditions : avis du comité supérieur, approbation du Gouverneur général, à prendre toutes mesures de désinfection ou même de destruction des maisons dont la conservation constituerait un danger pour la salubrité publique qui lui paraîtraient nécessaires. De même le Gouverneur général peut en cas d'épidémie prendre par arrêté toutes les dispositions propres à enrayer le mal.

Cie même acte institue en outre au siège du Gouvernement général un comité supérieur d'hygiène et de salubrité publiques qui est appelé à donner son avis sur toutes les questions d'hygiène publique et de police sanitaire qui lui sont soumises par le Gouverneur général.

Il est présidé par le Gouverneur général ou, à son défaut, par le Secrétaire général du Gouvernement geénéral et se réunit sur sa convocation et est ainsi composé :

Le ('iénéral commandant supérieur des troupes;

Le Secrétaire général du gouvernement général;

Les Lieutenants gouverneurs, et les habitants notables ayant siégé à la dernière session du Conseil du gouvernement quand ils sont présents au siège du Gouvernement général ; 
Le Procureur général, chef du service judiciaire de l'Afrique occidentale française ;

Le directeur du service de santé de l'Afrique occidentale française, inspecteur des services sanitaires civils ;

L'inspecteur des travaux publics de l'Afrique occidentale française ;

Le commandant de la marine ;

Le pharmacien des troupes coloniales le plus élevé en grade ;

Cinq membres désignés pour deux ans par le Gouverneur général parmi les médecins, ingénieurs, légistes, commercants, etc.;

Le médecin adjoint à l'inspecteur des services sanitaires, secrétaire.

Comme suite à ce décret un arrêté du Gouverneur général, en date du 5ّjanvier 190ฎ, institua un service municipal d'hygiène dans les quatre communes de plein exercice du Sénégal et " éventuellement dans les centres ou agglomérations érigées en communes ». Le service municipal d'hygiène comprenant un certain nombre d'agents assermentés placés sous les ordres directs du commissaire de police, est chargé, sous l'autorité du maire et la surveillance technique de l'autorité sanitaire, de l'exécution des dispositions qui résultent du décret précité et des règlements sanitaires édictés par le Lientenant gouverneur. Un médecin nommé par arrêté de ce haut fonctionnaire et placé sous les ordres du chef du service de santé est chargé de la surveillance technique du service. Il a sous son contrôle, non seulement les immeubles privés, mais encore le service de la voirie, des eaux, des vidanges, de l'enlèvement des ordures, des égouts, etc.

" Désormais, pouvait alors dire le Gouverneur Général dans le discours qu'il prononça en décembre 1905 à la séance d'ouverture du Conseil du gouvernement, désormais toutes les colonies de l'Afrique occidentale française ont à leur disposition les armes légales nécessaires pour combattre le paludisme, pour prévenir et faire cesser les maladies épidémiques, pour imposer la pratique de la vaccine. En même 
temps les organes chargés spécialement de l'application de ces règlements, c'est-à-dire les services municipaux d'hygiène et les brigades sanitaires, ont été constitués. Ils fonctionnent au Sénégal depuis le $1{ }^{\text {er }}$ janvier de cette année, et ont été créés successivement dans les autres colonies. Il est donc difficile de se rendre, dès à présent, un compte exact des résultats obtenus; cependant, je puis vous faire connaître à titre d'indication, dont vous apprécierez certainement l'intérêt, quelques chiffres qui se rapportent à la ville de Dakar et qui me paraissent singulièrement significatifs. Les nombreux travaux qui s'exécutent dans cette ville y ont amené un afflux notable de population tant européenne qu'indigène, et ces travaux, qui bouleversent le sol de la ville et de ses abords, n'ont pas été interrompus même pendant la saison des pluies. Malgré ces circonstances défavorables, et quoique l'hivernage ait été au moins aussi accentué que l'année dernière, le nombre brut des malades entrant à l'hópital a diminué de $\mathbf{2 1 0}$, dans la période du $1^{\text {er }}$ janvier au 31 octobre. Les entrées pour paludisme offrent une différence plus grande encore ; elles ont diminué de plus de moitié ; elles passent en effet de 407, en 1904, à 242 en 1905, et les médecins qui pratiquent en ville accusent, eux aussi, une diminution de moitié de cas de paludisme ; enfin la mortalité générale a diminué sensiblement, elle est passée de 12,5 0/0 à $10,10 / 0$ ).

C'étaient là, en effet, des résultats bien remarquables et vraiment encourageants mais l'avenir permet d'en espérer de plus satisfaisants encore.Comme complément de ces diverses mesures, un service d'assistance médicale d'indigène a été créé par un arrêté du 8 février 190 s.

Il était reconnu,en effet,que les médecins urbains, les médecins des troupes coloniales, dont le dévouement a d'ailleurs toujours été au-dessus de tout éloge, étaient en nombre insuffisant et que leurs occupations ne leur permettaient pas de se déplacer comme il aurait été nécessaire. Aussi bien, lorsqu'ils faisaient une tournée dans une région, leur était-il difficile sinon impossible de transporter avec eux les médicaments indispensables. C'est à ces divers inconvénients que l'arrêté dont il est question a porté remède. 
Un certain nombre de docteurs en médecine recrutés parmi les médecins civils de France ou parmi les médecins des troupes coloniales hors cadres sont déjà installés dans nos diverses colonies de la côte occidentale d'Afrique et donnent leurs soins gratuits aux indigènes. Il y en a malheureusement peu encore, " mais, disail M. le médecin principal Gallay, dans son rapport, au fur et à mesure que les ressources budgétaires permettront de développer le nouveau service, c'est une centaine de postes médicaux civils que nous espérons voir se créer et compléter avec les postes militaires existant déjà, un réseau médical couvrant notre Afrique occidental française de mailles suffisamment serrées pour qu'en chacune d'clles le médecin qui y résidera puisse arriver à connaître complètement la parcelle du pays qu'elle enserre, et à être en contact intime avec toute la population qu'elle abrite.

Mais, même quand ils seront au complet, la tàche des médecins de l'assistance indigène sera lourde, et vaste encore sera le domaine que chacun d'eux aura à parcourir s'il veut porter partout le secours de son art, et attirer à lui, de tous les points du territoire qui lui sera réservé, la sympathie et la confiance des populations.

Aussi l'idée se répand-elle parmi les Chefs du Service de santé qui sont le plus désireux de voir se multiplier les contacts entre le médecin et les indigènes, de la nécessité d'un nouvel agent, en même temps interprète-délégué, ou aide à l'occasion, agent qui puisse, lui, plus facilement pénétrer partout dans l'intimité noire, qui soit plus aisément mobile que le médecin blanc, et qui, tout en restant sous sa dépendance, puisse le renseigner rapidement sur la nécessité de sa présence, et, en l'attendant, porter, où la chose serait nécessaire, quelques premiers secours rudimentaires.

Un agent qui puisse même, à l'occasion être installé à poste fixe dans certains centres trop éloignés du médecin, et avec un bagage scientifique modeste, y rendre des services aux populations, lutter contre l'influence maraboutique et jouer le rôle précieux d’informateur, pour le médecin sous la dépendance duquel il se trouverait placé. 
Il s'agit là, vous le voyez, de la création de véritables médecins indigènes 1$)$.

Et c'est ainsi que l'on fut amené à organiser un corps d'aidesmédecins indigènes qui doivent être les plus utiles collaborateurs des médecins de l'Assistance médicale.

"C'est localement, disait encore le médecin principal Gallay en soumettant au Gouverneur général un projet d'arrêté portant création de ces aides-médecins, qu'il faudrait recruter, soit des infirmiers intelligents, ayant déjà été dans les hôpitaux en contact avec les malades; soit à la sortie de l'école, des jeunes gens comprenant bien le français, et le lisant et l'écrivant, si possible, et en faire des aides ou des élèves des médecins de l'Assistance médicale indigène.

Leur faire une situation modeste d'abord, avec la perspective d'une carrière assurce au bout de deux années, par exemple, s'ils sont à même de passer un examen sommaire sur les éléments de la médecine pratique.

Chaque médecin dressera ses aides aux pratiques de l'antisepsie, pour les pansements, et lui enseignera, avec les soins essentiels à donner dans les maladies les plus fréquentes dans le pays. la réduction des fractures, la pratique de la vaccine.

Un examen passé au chef-lieu, devant un jury présidé par le Chef du Service de santé, suffirait pour leur donner la licence nécessaire pour être définitivement employés comme aidesmédecins indigènes dans leur colonie d'origine.

Bien entendu il serait désirable de créer à ces auxiliaires une situation qui leur assure une vie honorable dans leur milieu indigène, de même qu'il serait indispensable de les laisser toujours dans le rayonnement du médecin résidant au centre du cercle dans lequel ils seraient employés.

La présence de semblables auxiliaires aiderait singulièrement à la diffusion de nos idées médicales parmi la population noire. Elle serait un premier pas de fait dans la lutte indispensable à engager contre les pratiques maraboutiques ou fétichistes. Elle multiplierait les moyens d'action du médecin de l'Assistance médicale indigène, en mettant à son service, dans sa province, 
toute une série d'informateurs, et toute une série de stations préparées à l'avance pour ses propres tournées ".

Par l'arrêté du 7 janvier 1906 le Gouverneur général donna sa complète approbation à cette idée et ce corps spécial fut ainsi officiellement organisé à dater de ce moment.

Des médecins d'assistance médicale indigène sont ainsi installés un peu partout, des collaborateurs, les aides-médecins indigènes, leur sont donnés " ce n’est pas assez (1), il faut leur donner l'outillage nécessaire, il faut organiser dans les campagnes des centres, si modestes qu'ils soient, d'assistance médicale. Nos médecins doivent pouvoir disposer d'abris dans lesquels seront hospitalisés au moins les malades les plus graves; nous ne devons plus revoir ce pénible spectacle d'indigènes accourus de tous les points du cercle à la consultation du médecin et qui, après avoir reçu les soins indispensables sont réduits, même les plus malades d'entre eux, à coucher à la belle étoile, et que, par pitié, le médecin recueille sous sa vérandah. Nous devons prendre pleine conscience de nos devoirs envers ces populations dont nous avons assumé la direction et qui, en retour de l'impôt qu'elles nous paient, en doivent recevoir la contre partie non seulement en sécurité, en travaux d'utilité publique, mais aussi sous forme d'assistance médicale que toute nation civilisée doit à ses ressortissants et qui est le bienfait le plus immédiatement tangible qu'elles puissent recevoir ").

C'est en vue de pourvoir à ces besoins élémentaires que des recherches ont été faites dans le but de trouver un type de ces dispensaires qui seraient installés dans les postes pourvus de médecins de l'assistance médicale indigène. Le projet présenté par M. Gallay Inspecteur des services sanitaires civils, a éié adopté. Chaque ambulance doit comprendre $\mathbf{2 4}$ lits, placés dans deux pavillons, 12 lits du côté des hommes, 12 lits du côté des femmes ; un dispensaire qui abritera une salle de pansement, une salle d'opération, une pharmacie et une tisanerie et des annexes où logeront les médecins, les infirmiers, etc. Une somme de 1 mil-

(1) Discours prononcé par Mí. Roume à la séance d'ouverture de la session extrajordinaire du Conseil du Gouvernement en mai 1906. 


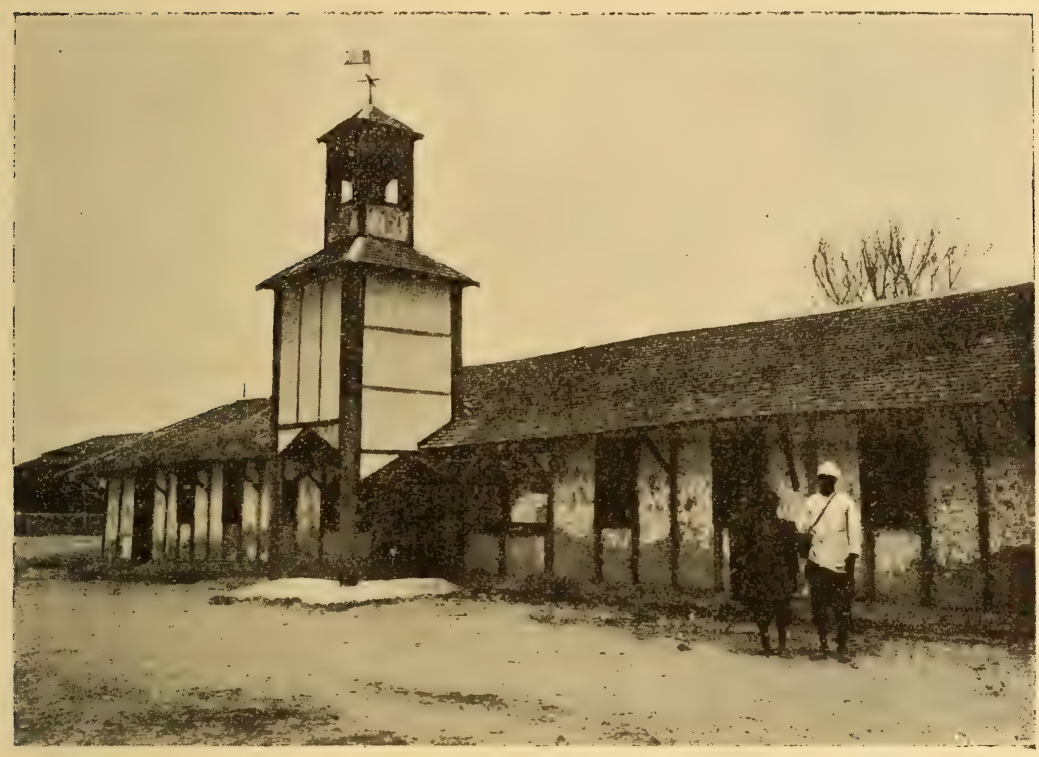

Fin. 29. - Kaolack (l'Écolc).

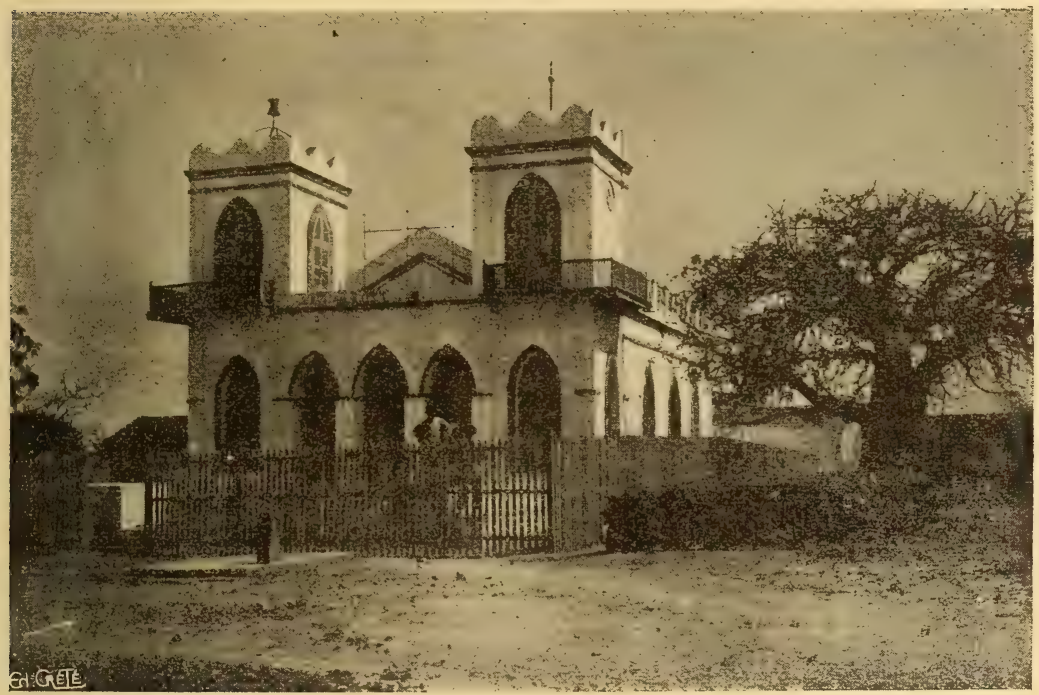

Fig. 30. - Dakar (la Mosiquéo).

s. 

lion doit être affectée, sur les fonds de l'emprunt projeté, à la construction et à l'installation de plusieurs ambulances.

Le prix de revient de chacune de ces formations sanitaires étant évalué à 50,000 francs environ, il sera possible dinstaller dans un bref délai un nombre considérable de ces groupes dans chacune des colonies de l'Afrique occidentale française.

Etablissements hospitaliers. - De très bonne heure, la colonie du Sénégal a été doté d'hôpitaux : le mouvement commercial qui de tout temps a été considérable, l’affluence de troupes, le nombre important de fonctionnaires qui depuis longtemps déjà habitent les villes principales avaient rendu indispensable l'installation d'établissements hospitaliers.

Des hòpitaux sont installés à Saint-Louis, à Dakar et à Gorée.

L'hôpital civil de Saint-Louis est placé sous la haute direction du chef du service de santé du Sénégal, son personnel comprend 1 pharmacien, 1 économe, 1 surveillant chef, 1 sage-femme, 3 dames infirmières, 10 infirmiers et divers gens de service.

L'hôpital de Gorée qui est l'un des plus anciens de la colonie, est placé sous la direction d'un médecin qui est assisté de $\mathbf{2}$ dames infirmières et de 1 infirmier.

La ville de Dakar possède un hôpital colonial qui a suivi la fortune de la ville. D'abord destiné à n'être qu'une simple ambulance, annexe de l'hôpital de Gorée, il s'est peu à peu développé pour faire face aux besoins que créaient chaque année l'importance croissante de la ville. Le transfert des services du Gouvernement geénéral à Dakar ainsi que celui de la Cour d'appel de l'Afrique occidentale française, l'augmentation de la garnison, la création du port militaire, l'afflux de la population, rendent indispensable son agrandissement. La somme de 50.000 francs qui est nécessaire pour cela sera prélevée sur l'emprunt de 100 millions dont le projet est actuellement soumis à l'approbation du Parlement.

Une somme de 300.000 francs qui sera également prélevée sur les fonds de cet emprunt doit ètre consacrée à la construction d'un hôpital indigène à Dakar où il n'en existe pas. Cet établissement d'après les intentions du Gouverneur général doit comprendre : 
“ $1^{\circ}$ Un service de femmes et une maternité ;

$2^{\circ}$ Un service où puissent être hospitalisés les chroniques indigènes qu'il peut être indispensable d'abriter temporairement;

$3^{\circ}$ Des salles pour les indigènes susceptibles de rembourser le prix de leur journée ;

$4^{\circ}$ Des salles pour le personnel indigènc des Services : gardes des cercles, agents des ports, de la police, des douanes, etc.;

$\check{\partial}^{\circ}$ Des salles spéciales dans lesquelles les militaires indigènes, sous-officiers et soldats, puissent être traités par les médecins militaires, suivant le mode des hôpitaux mixtes;

$6^{0}$ A la distance nécessaire, un pavillon de contagieux.

Pour rendre le prix de la journée remboursable, accessible au plus grand nombre, il est bien entendu que l'organisation intérieure de cet établissement devra être combinée de façon à satisfaire aux habitudes et aux besoins spéciaux des indigènes.

Il sera important de prévoir, dans les annexes de cet établissement, les locaux nécessaires pour le fonctionnement d'un dispensaire largement ouvert où puisse se donner commodément de nombreuses consultations : se faire convenablement des pansements et se pratiquer de larges distributions de médicaments.

Toute idée monumentale et coûteuse doit être écartée pour arriver à la réalisation de l'hôpital indigène que nous désirons voir s'élever à Dakar.

Mais rien ne doit être négligé, en revanche, pour assurer à cet établissement la bonne aération, les facilités de propreté et d'approvisionnement en eau. En un mot, toutes les commodités pour le service des malades et les meilleures conditions de confort indigène.

Procédant à une création de toutes pièces, il est désirable d'organiser au seuil de notre Afrique occidentale française, un hôpital indigène qui puisse avoir l'ambition de servir de modèle aussi bien aux étrangers, qu'aux Français, négociants, officiers et fonctionnaires, qui passent à Dakar avant d'aller dépenser leur activité dans les Colonies du Sud »).

Un lazaret est également installé dans chacun des ports de Dakar et de Saint-Louis sous la surveillance permanente d'un gardien chef qui veille à l'observation des prescriptions du 
décret du 31 mai 1897, sur le service sanitaire aux colonies. La police intérieure est exercée par un médecin qui ne doit y résider que lorsque les circonstances l'exigent et sur un ordre du directeur du Service de santé. Ce médecin est chargé de soigner et de visiter gratuitement les quarantenaires, de constater leur état de santé à l'expiration de la quarantaine et de veiller à l'exécution de toutes les mesures prescrites.

Chacune des quatre villes du Sénégal possède, en outre, ainsi qu'il a été dit plus haut un Service municipal d'hygiène qui fonctionne selon les prescriptions du Lieutenant-gouverneur sous la direction de médecins urbains.

Le service de santé estégalement bien organisé dans l'intérieur de la Colonie : $\mathbf{4}$ médecins de l'assistance médicale indigène sont établis dans différents postes, en outre Louga Tivaouane, Ziguincher et Kaolack possèdent chacune un docteur.

A titre documentaire il nous parait intéressant de citer les sommes qui depuis 1898 ont été consacrées chaque année au Sénégal au service sanitaire et à l'assistance. On pourra constater par leur constante progression limportance croissante que l'on a donné au développement de cette œuvre.

fr. c.

$\begin{array}{rrrrrrrrrr}1898 . & . & . & . & . & . & . & . & 40.655 & 90 \\ 1899 . & . & . & . & . & . & . & . & 165.617 & 80 \\ 1900 . & . & . & . & . & . & . & . & 165.489 & 80 \\ 1901 . & . & . & . & . & . & . & . & 168.889 & 80 \\ 1902 . & . & . & . & . & . & . & . & 162.850 & 90 \\ 1903 . & . & . & . & . & . & . & . & 178.791 & 80 \\ 1904 . & . & . & . & . & . & . & . & 246.177 & 80 \\ 1905 . & . & . & . & . & . & . & . & 332.870 & 40 \\ 1906 . & . & . & . & . & . & . & . & 407.121 & \end{array}$

B. - Service des Travaux publics.

Le service des Travaux publics est chargé pour le compte de la Colonie de la préparation des projets, plans, devis et cahiers des charges des Travaux publics, autres que ceux qui rentrent 
dans les attributions des services militaires, ainsi que de la conduite et de la surveillance de ces ouvrages. Il est préposé à l'entretien et à la conservation des routes, des chemins, des rives, des ouvrages d'art, des quais, des jetées, des bâtiments civils, etc. Il prépare les arrêtés d'alignement le long des routes et chemins. Il est également chargé de la conservation des terrains, faisant partie du domaine de la Colonie; du contrôle des travaux exécutés par les concessionnaires pour le compte de la Colonie, ainsi que de celui des travaux exécutés par les municipalités avec le concours des fonds du budget local.

Le Service des travaux publics est dirigé par un ingénieur en chef, placé sous l'autorité du Lientenant-gouverneur et qui a sous ses ordres tout le personnel du service.

Ce personnel, régi par le décret du 18 janvier 1905 , comprend :

\section{a) Territoires d'Administration directe.}

1 ingénieur en chef, chef du service;

1 ingénieur de $2^{\mathrm{e}}$ classe;

1 sous-ingénieur;

2 conducteurs principaux;

2 conducteurs;

2 commis principaux;

6 commis;

2 comptables;

4 dessinateurs;

6 surveillants;

3 magasiniers;

1 officier d'administration du génie est chef du service topographique et assisté de :

4 géomètres;

1 dessinateur;

1 écrivain;

Il faut ajouter, en outre, le personnel chargé d'assurer le service de l'alimentation en eau des villes de la Colonie et qui se répartit ainsi : 


\section{Ville de Saint-Louis :}

1 chef mécanicien;

1 mécanicien;

2 fontainiers;

1 chef plombier.

\section{Ville de Dakar:}

1 mécanicien breveté de $\mathbf{1}^{\text {ro }}$ classe ;

2 chauffeurs;

1 chauffeur stagiaire ;

1 fontainier;

2 fontainiers stagiaires;

1 ajusteur-mécanicien.

\section{Ville de Rufisque :}

1 mécanicien ;

1 chauffeur mécanicien;

1 fontainier auxiliaire;

2 chauffeurs stagiaires.

Il convient également de citer dans cette énumération le personnel du service de la navigation employé dans les rades de Saint-Louis, Gorée, Rufisque et dans le port de Dakar. Ce service est placé sous la direction de capitaines et lieutenants de port dont les altributions sont déterminées par des règlements spéciaux et qui ont sous leurs ordres tout un personnel indigène comprenant des maîtres, quartiers-maitres et laptots.

\section{Port de Saint-Louis :}

1 lieutenant de port;

2 quartiers-maîtres;

12 laptots.

\section{Port de Dakar:}

1 capitaine de port;

1 second maître;

1 quartier-maitre;

12 laptots. 


\section{Port de Gorée :}

1 second maître ;

6 laptots.

Port de Rufisque:

1 capitaine de port ;

1 quartier-maitre;

亏 laptots.

Le service de la barre du fleuve Sénégal est confié à :

1 capitaine de port;

1 lieutenant de port.

L'entretien des différents feux, phares et sémaphores de la côte est ainsi assuré :

\section{Ville de Saint-Louis:}

1 guetteur-allumeur au sémaphore.

Villes de Dakar et de Rufisque:

1 gardien-chef;

8 gardiens;

1 allumeur du feu à Rufisque.

\section{b) Pays de Protectorat.}

Le personnel employé au service des travaux publics des Pays de Protectorat est, on le conçoit, infiniment plus restreint et comporte :

1 capitaine, chef d'arrondissement;

1 conducteur;

1 conducteur auxiliaire ;

1 surveillant;

Des équipes de travaux;

2 pilotes à carabane. 


\section{C. - Service des Postes et des Télégraphes.}

Personnel du service des Postes et Télégraphes.

Ce service, dont la charge financière est supportée uniquement par le budget des Territoires d'administration directe, est assuré par des fonctionnaires et agents empruntés à l'Administration métropolitaine des Postes et Télégraphes et soumis au point de vue de leur solde et de leur situation administrative au décret du 4 mars 1905, et par des agents du cadre local. Un arrêté du Gouverneur général en date du 10 janvier 1906 a réglé d'une façon uniforme le recrutement et l'organisation du personnel des Postes et Télégraphes dans l'étendue de nos possessions de l'Ouest africain.

Le service des Postes et Télégraphes est dirigé par un chef de service qui relève de l'autorité immédiate du Lieutenantgouverneur. Il correspond avec les diverses autorités de la Colonie et prend toutes les mesures d'exécution nécessaires. Il a sous ses ordres directs tout le personnel de la Colonie et le répartit suivant les besoins dans les divers bureaux sous l'approbation du Lieutenant-gouverneur.

Le personnel prévu pour 1906 se décompose ainsi :

\section{Cadre métropolitain :}

1 inspecteur chef de service;

2 commis principaux ;

5 commis ;

2 surveillants.

Cadre local :

3 receveurs locaux;

13 dames employées;

3 commis principaux;

11 commis ;

14 surnuméraires ;

7 commis auxiliaires ; 
1 mécanicien ;

4 chefs surveillants ;

30 surveillants;

1 brigadier facteur;

1 facteur chef ;

14 facteurs;

4 convoyeurs ;

2 convoyeurs auxiliaires;

33 surveillants auxiliaires;

23 facteurs auxiliaires ; soit au total 220 unités (1).

\section{D. - Imprimerie officielle.}

La Colonie du Sénégal (Territoires d'Administration directe et Pays du Protectorat), possède une imprimerie officielle installée à Saint-Louis. Elle est chargée des tra vaux d'impression, de reliure et de brochage des divers services publics de la Colonie ; et effectue l'impression des différentes publications officielles. Elle exécute en outre pour le compte des particuliers des commandes qui sont une source de recettes appréciables au profit du budget local.

Personnel de l'imprimerie. - Le personnel de l'imprimerie de Saint-Louis comprend :

1 chef de $1^{\text {re }}$ classe, chef comptable;

1 chef de $2^{\mathrm{e}}$ classe;

7 compositeurs;

4 imprimeurs ;

3 relieurs;

5 apprentis ;

3 manœuvres tourneurs;

Publications. - Les principales publications sortant des presses de l'imprimerie officielle sont:

(1) Voir au paragraphe : Contributions indirectes et divers produits, les diffèrentes taxes postales et télégraphiques et au chapitre: Outillage économıque de la Colonie, l'organisation des communications postales et télégraphiques. 
Le Journal officiel du Sénégal paraissant le jeudi de chaque semaine à Saint-Louis ;

Le Bulletin officiel du Sénégal paraissant tous les mois et qui est le recueil des actes administratifs intéressant la Colonie ;

Les Délibérations du Conseil général;

L'annuaire du Sénégal;

Le calendrier des marées;

Les budgets du Sénégal : celui des territoires d'Administration directe et celui des Pays de Protectorat;

Les comptes définitifs ;

Les rapports et procès-verhaux des Commissions administratives, etc.

Cette imprimerie, qui assurait auparavant le service des publications du Gouvernement général de l'Afrique occidentale française, a perdu un peu de son importance depuis l'installation à Dakar d'une imprimerie qui est chargée de ce soin.

\section{E. - Police et prisons}

Police. - Le service de la Police dans la Colonie a été organisé par les arrêtés locaux du 15 mai 1878 et du $20 ̈$ mai 1897. Ce texte a déterminé les attributions de la Police au point de vue administratif, municipal et judiciaire. Il a également organisé le personnel (qui comprend des commissaires, des commissaires adjoints, des sergents de ville, des brigadiers et des agents) au point de vue du recrutement, de l'avancement et de la discipline, fixé le traitement et enfin indiqué l'uniforme et l'armement des agents.

Le maintien de l'ordre est en outre assuré à Saint-Louis et à Dakar par des forces de gendarmerie.

Le personnel de la police des Territoires d'Administration directe comprend :

\section{Ville de Saint-Louis.}

1 commissaire de police ;

1 commissaire de police-adjoint; 
1 sergént de ville;

1 secrétaire;

3 brigadiers ;

20 agents ;

1 interprète ;

1 maréchal des logis de gendarmerie;

1 brigadier ;

6 gendarmes.

Ville de Dakar:

1 commissaire de police ;

2 sergents de ville;

1 secrétaire;

8 agents;

9 agents stagiaires;

1 interprète;

1 maréchal des logis de gendarmerie;

6 gendarmes.

Ville de Gorée:

1 commissaire de police;

6 agents.

\section{Ville de Rufisque:}

1 commissaire de police ;

1 sergent de ville;

1 brigadier;

7 agents.

En outre 30 agents sont répartis dans les diverses localités et escales des Pays de Protectorat.

De plus dans cette partie du Sénégal la sécurité publique est assurée par une garde régionale qui comprend :

2 gardes principaux ;

6 brigadiers chefs;

15 brigadiers;

150 gardes.

Prisons. - Il existe dans chacune des villes de Saint-Louis 
et de Dakar, une prison civile dont l'Administration intérieure est confiée à un Régisseur ayant sous ses ordres un personnel composé d'un gardien chef européen et de surveillants indigènes.

Un arrêté local en date du 21 juillet 1888, a institué des Comités de surveillance des prisons de la Colonie. Ces Comités inspectent les prisons et surveillent tout ce qui concerne la salubrité, l'alimentation, la discipline, la tenue des registres réglementaires, la conduite des agents de la prison et s'occupent de la réforme morale des détenus en application des prescriptions de la loi du 14 août 1885 .

La ration journalière des détenus a été améliorée sur un vœu émis par la Commission de surveillance. Outre une légère augmentation dans la quotité des rations délivrées, il a été compris dans l'ordinaire des prisonniers, divers condiments destinés à préserver ces derniers de certaines maladies qui ont sévi pendant de longues années dans ces établissements pénitentiaires et qui tendent à disparaître aujourd'hui grâce aux mesures préventives prise par l'Administration locale.

Dans le même ordre d'idées l'Administration désireuse de combattre l'épidémie de béri-béri, périodiquement constatée dans les prisons de la Colonie par suite de l'inaction des détenus a décidé de leur confier certains travaux à l'extérieur. C'est ainsi que les prisonniers dont la conduite est satisfaisante sont mis chaque jour sur leur demande à la disposition du Commissaire de police pour la propreté de la ville moyennant une indemnité journalière de 0 fr. $2 \ddot{2}$, conformément à l'arrêté du 15 a vril 1864 .

Une partie de cette somme sert au paicment des frais de justice dus par les intéressés et le reste, leur revenant, est mis en réserve, jusqu'à leur libération.

Le travail des prisonniers à l'extérieur est réglementé par l'arrêté du 14 mars 1892.

\section{F. - Services divers.}

Parmi les autres services de la Colonie, il convient de citer : a) Le service de l'enregistrement, des domaines, etc., qui est 
réparti en deux bureaux l'un à Saint-Louis, l'autre à Dakar, dirigés par des receveurs, assistés de commis et relevant de l'administration locale. Ces fonctionnaires réunissent dans leurs attributions les différents services de l'enregistrement, du timbre, des domaines, des hypothèques et de la curatelle aux successions et bien vacants (1).

b) Le service des contributions directes, qui est assuré par trois contrôleurs résidant respectivement à Saint-Louis, Dakar et Rufisque (2).

c) Le service de l'agriculture, dont les dépenses sont uniquement supportées par le budget des Pays de Protectorat est placé sous la direction d'un chef du Service de l'agriculture. Il comprend en personnel un vétérinaire militaire hors-cadres chargé du service de zootechnie et d'épizootie, un inspecteur des plantations et divers agents de culture.

Le service de l'agriculture recoit d'utiles indications du Comité agricole du Sénégal dont la constitution remonte au mois de janvier 187 .

Ce Comité, dont il est intéressant de rappeler brièvement l'histoire, reçut à sa création le nom de Société d'agriculture du Sénégal.

Il était dû a l'initiative des habitants et des commerçants de Saint-Louis, et le nombre de ses membres était illimité. Il avait pour but de faire naitre, de propager et d'encourager le goût de l'agriculture au Sénégal ; à cet effet les statuts de la société instituaient des concours agricoles annuels ou bi annuels à la suite desquels des récompenses devaient être distribuées.

Cette société, après avoir fonctionné quelque temps, fut réduite à l'inaction, faute de ressources et par suite du départ de la Colonie et du décès d'un grand nombre de sociétaires, chargés de l'administration.

En 1896, l'initiative en fut reprise par l'administration locale. Un arrêté en date du 15 octobre institua à Saint-Louis un Comité agricole dont la présidence appartenait au directeur de l'inté-

(1) Voir au paragraphe: Services financiers.

(2) $I d$. 
rieur aujourd'hui secrétaire général. La composition de ce Comité a été remaniée par un arrêté du 14 septembre 1899, par suite de la création au Sénégal, par l'arrêté du 21 juin 1898, d'une inspection d'agriculture chargée de centraliser tous les renseignements agricoles utiles et d'imprimer à l'agriculture une impulsion nouvelle par la vulgarisation des ressources qu'offre le pays.

Les attributions du Comité agricole consistent dans l'étude de tous les moyens propres à développer les cultures déjà existantes et à en implanter de nouvelles dans la Colonie.

Depuis la reconstitution de cette chambre d'agriculture et la création d'un service agricole, des progrès nombreux ont été réalisés dans la Colonie où de plus en plus s'implante les systèmes de culture perfectionnés.

Une station agricole fonctionne régulièrement à Sor, des fermes d'expériences sont établies en divers points du territoire, et une somme relativement importante est prévue au budget de 1906 pour encourager les essais de cotonniers entrepris dans la Colonie et permettre l'installation de cocoteries (1).

En vue de l'amélioration de la race chevaline, il a été créé en 1898 un haras à N'Diourbel dans le Baol (cercle de Thiès).

\section{G. - Instruction publique.}

Le service de l'Instruction publique a été réorganisé au Sénégal, comme dans les autres Colonies de l'Afrique occidentale française par l'arrêté du 24 novembre 1903. On trouvera au paragraphe : Progrès des indigènes, les détails de son fonctionnement. Nous nous bornons à indiquer ici qu'il fonctionne dans la Colonie sous la direction d'un Inspecteur primaire chef du service de l'enseignement et qu'il est assuré par 8 professeurs, 54 instituteurs et 20 institutrices répartis dans le Territoire selon les besoins du service. Ce personnel est recruté soit parmi les instituteurs de la Métropole, soit parmi les indigènes sortant de l'Ecole Normale de Saint-Louis.

(1) Voir le chapitre spécial à l'agriculture. 
Il parait intéressant d'exposer la progression des dépenses qui depuis 1899 ont été consacrées à l'enseignement dans notre Colonie du Sénégal.

\begin{tabular}{|c|c|c|c|c|c|c|c|c|c|c|}
\hline 1899 & & & . & & & & & . & . & 344.057 \\
\hline 1900 & . & • & . & & & . & 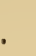 & . & • & 355.976 \\
\hline 1901 & . & • & . & & & . & 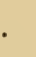 & . & . & 361.288 \\
\hline 1902 & . & . & . & & & . & • & . & - & 368.ก้11 \\
\hline 1903 & . & . & 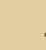 & & & . & 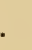 & . & 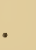 & 378.942 \\
\hline 1904 & . & . & 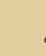 & & & . & 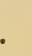 & : & . & 414.415 \\
\hline $190 \ddot{2}$ & . & . & . & & & . & - & • & . & 540.608 \\
\hline 1906 & . & • & & & & . & . & . & . & 5ั43.6.ّ1 \\
\hline
\end{tabular}

H. Cultes.

Le Concordat n'ayant jamais été promulgué au Sénégal, c'est en vertu de dispositions spéciales qu'ont été réglés dans la Colonie les rapports du Clergé et des pouvoirs publics.

Culte catholique. - L'organisation du culte catholique du Sénégal est soumise à la loi du $\mathbf{1 8}$ germinal an 10 et aux arrêtés du 13 messidor an 10 et du 12 frimaire an 11. Un décret du 13 germinal an 12 a confié le recrutement du clergé et le monopole du service religieux dans toutes nos possessions à la Congrégation des Pères du Saint-Esprit; des ordonnances du 3 février et du $5 ٌ$ avril 1816, du 23 juillet et du 3 septembre 1817 ont confirmé ce privilège et accordé une subvention aux prêtres, sous la réserve qu'ils seraient nommés par le Ministre.

La direction du culte dans la Colonie et ses dépendances est exercée par un Préfet apostolique qui réunit, sous son autorité, les deux juridictions de la Préfecture apostolique du Sénégal et du Vicariat a postolique de la Sénégambie. D'abord simple prê. tre, il a été autorisé par décret du 29 juillet 1876 à accepter un titre d'évêque in partibus in fidelium.

Il existe au Sénégal quatre paroisses : Saint-Louis, Dakar, Gorée et Rufisque. Le service religieux y est assuré par onze desservants.

En dehors de l'organisation officielle, la mission catholique de 


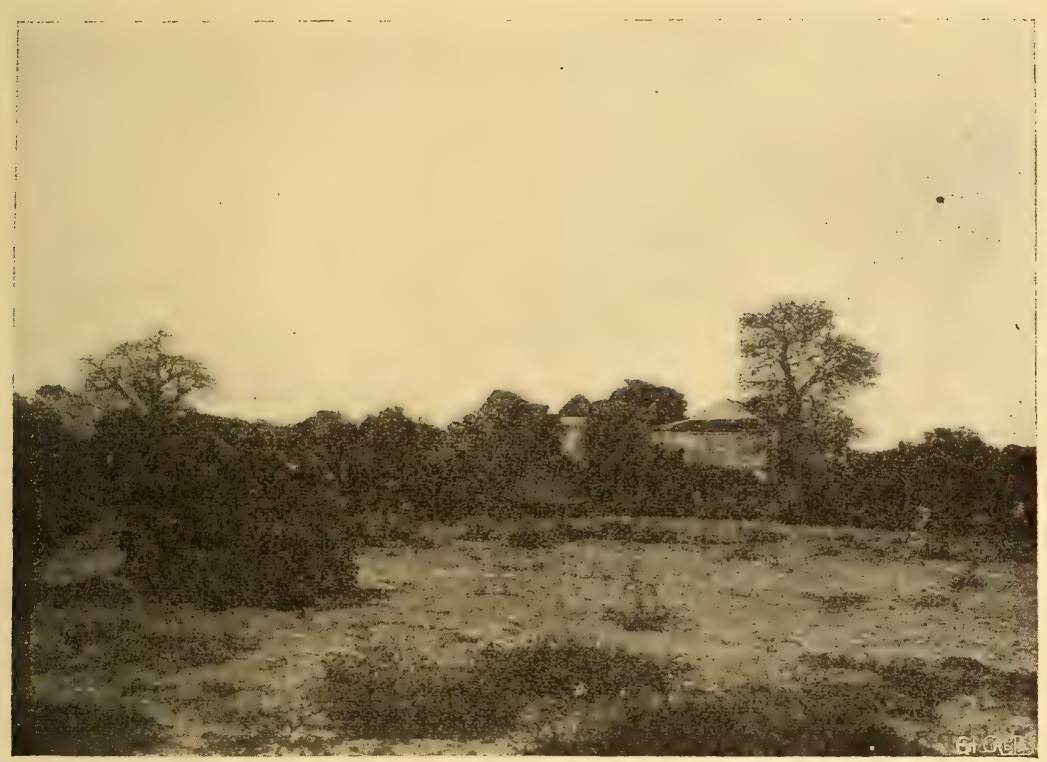

Fig. 31. - Paysage du sénegal.

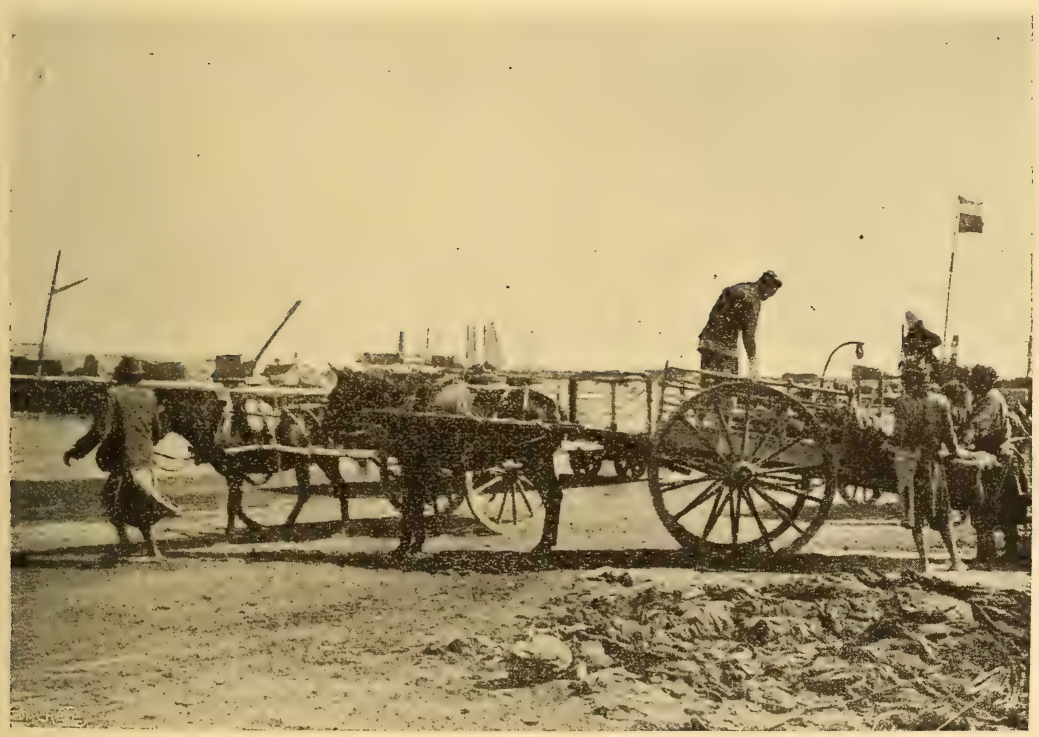

Fig. 32. - Dakar (les quais).

S. 

la Sénégambie qui est une filiale de la Congrégation du SaintEsprit, mais dont les ressources sont absolument distinctes et proviennent de la "propagation de la Foi " entretient un certain nombre de missionnaires à la tête d'Etablissements professionnels et agricoles tels que ceux de Thiès, N'Gazobil et Sedhiou, d'établissements charitables comme l'orphelinat de N'Gazobil, le dispensaire de Joal, et assure le fonctionnement de chapelles et d'écoles créées par ses propres ressources à Fadhiout, Ziguinchor et Carabane.

Culte protestant. - C'est en 1863 que le culte protestant a été établi au Sénégal, et depuis cette époque, des missionnaires y ont toujours représenté " la Société des Missions Evangéliques chez les peuples non chrétiens ») dont le sièg'e est à Paris. Cette mission a entretenu d'abord des Pasteurs à Sedhiou, Gorée et Herlalla, près Dagana ; mais depuis 1890, elle n'a plus d'organisation réelle qu'à Saint-Louis où elle entretient un pasteur missionnaire, un instituteur, un évangéliste indigène, un interprète remplissant les fonctions d'instituteur-adjoint. Elle a, en outre, fondé une école française à Saint-Louis dans le faubourg de Sor; l'enseignement du français et un peu d'instruction religieuse en constituent le programme.

Culte musulman. - La presque totalité de la population indigène pratique avec ferveur la religion musulmane.

Il existe une mosquée à Saint-Louis et à Dakar. A Rufisque, à Gorée et dans quelques escales du fleuve ou de la voie ferrée, c'est dans des oratoires (Diakka en ouoloff et Mossalla en arabe) que se fait la prière; les faubourgs de Saint-Louis et de Dakar, possèdent également des mossalla.

Le culte musulman ne comporte pas de clergé. Un officiant (iman en arabe et élimane en ouoloff) choisi parmi les marabouts les plus réputés pour leur science et leur zèle religieux, est placé à la tête de chaque mosquée ou oratoire et dirige la prière; lorsque l'heure approche, le fidèle de bonne volonté se place à la porte de la mosquée ou de l'oratoire, et proclame l'Ezzan (appel à la prière) à haute voix, pour inviter ses frères au Salam. 



\section{QUATRIÈME PARTIE}

LA MISE EN VALEUR DU SÉNÉGAL 
Par les rapides indications que nous avons données, sur la flore, la faune et les produits minéraux du Sénégal, on a pu juger des richesses variées de notre colonie. Certaines d'entre elles, ainsi qu'on a pu le voir, sont connues et exploitées depuis des siècles, d'autres au contraire nous sont à peine révélées.

Le rôle de l'Etat, est de fixer les rapports qui doivent exister entre la source de ces richesses et ses conditions d'exploitation. A lui appartient la haute direction par vues d'ensemble et la confection des règlements en ce qui concerne notamment le régime des terres et de la main-d'œuvre. La responsabilité de la mise en train que lui seul peut effectuer vite et bien, lui incombe également.

Nous nous proposons, au cours de cette quatrième partie, d'examiner ce qui a été fait au Sénégal dans ce sens, en y étudiant tour à tour les conditions de la production et du commerce, l'outillage de la vie économique, et les résultats atteints au triple point de vue agricole, industriel et commercial. 


\section{CHAPITRE XII}

CONDITIONS DE LA PRODUCTION ET DU COMMERCE

L'économie politique nous apprend que toute production de richesses comporte trois facteurs essentiels : la nature, le travail et le capital. Si nous appliquons à notre cas particulier cette vérité d'ordre général, nous trouverons qu'il faut au colon trois éléments essentiels : de la terre, de la main-d'œuvre et du crédit.

Afin de nous rendre compte des conditions de la production et du commerce au Sénégal, il sera nécessaire de considérer successivement :
A. - Le régime des terres;
B. - La population et la main-d'œuvre;
C. - Le crédit.

\section{A. - Le régime des terres}

Il nous faut envisager le régime des terres au Sénégal au triple point de vue :

a) Du domaine (public ou privé) ;

b) Du régime des biens fonds ;

c) Du régime forestier.

a) Du domaine (décret du 23 octobre 1904). Domaine public. - Font partie du domaine public dans les colonies et territoires de l'Afrique occidentale française :

a. Le rivage de la mer jusqu'à la limite des plus hautes 
marées, ainsi qu'une zone de 200 mètres, mesurée à partir de cette limite ;

$b$ Les cours d'eau navigables ou flottables dans les limites déterminées par la hauteur des eaux coulant à pleins bords avant de déborder, ainsi qu'une zone de passage de $20 ̈$ mètres de large à partir de ces limites sur chaque rive et sur chacun des bords des îles;

$c$. Les sources et les cours d'eau non navigables ni flottables dans les limites déterminées par la hauteur des eaux coulant à pleins bords avant de déborder ;

$d$. Les lacs, étangs et lagunes dans les limites déterminées par le niveau des plus hautes eaux avant débordement, avec une zone de passage de 25 mètres de large à partir de ces limites sur chaque rive extérieure et sur chacun des bords des îles;

$e$. Les canaux de navigation et leurs chemins de halage, les canaux d'irrigation et de desséchement et les aqueducs exécutés dans un but d'utilité publique, ainsi que les dépendances de ces ouvrages;

$f$. Les chemins de fer, les routes, les voies de communication de toute nature, les ports et rades, les digues maritimes et fluviales, les sémaphores, les ouvrages d'éclairag'e et de balisage, ainsi que leurs dépendances;

g. Les lignes télégraphiques et téléphoniques, ainsi que leurs dépendances ;

$h$. Les ouvrages déclarés d'utilité publique en vue de l'uti. lisation des forces hydrauliques et du transport de l'énergie électrique ;

$i$. Les ouvrages de fortification des places de guerre ou des postes militaires, ainsi qu'une zone large de 200 mètres autour de ces ouvrages ;

$k$. Et généralement les biens de toute nature que le Code civil et les lois françaises déclarent non susceptibles de propriété privée.

Le domaine public frappe de certaines servitudes les propriétés privées : ainsi les riverains des cours d'eau non navigables ni flottables sont soumis à une servitude de passage sur une zone large de 10 mètres sur chaque rive. 
En outre, les terrains et bâtiments des propriétés privées sont soumis à toutes les servitudes de passage, d'implantation, d'appui et de circulation nécessaires pour l'établissement, l'entretien, l'exploitation des lignes télégraphiques et téléphoniques et des conducteurs d'énergie électrique, classés dans le domaine public, et aucune indemnité n'est due de ce chef aux propriétaires.

Le Lieutenant gouverneur accorde les autorisations d'occuper le domaine public et d'y édifier des établissements quelconques suivant les conditions déterminées par les règlements généraux.

Il peut de même autoriser des dérogations à la servitude de passage appliquée aux riverains des cours d'eau non navigables.

Toutefois, toutes ces autorisations peurent être révoquées à toute époque, sans indemnité, pour un motif d'intérêt public, par un arrêté rendu en Conseil d'administration.

Les portions du domaine public qui sont reconnues sans utilité pour les services publics peuvent être déclassées par un arrêté du Gouverneur Général et rentrent dans le domaine de l'Etat après approbation de cet arrêté par le Ministre des Colonies.

Des règlements généraux arrêtés par le Gouverneur Général en Conseil de gouvernement édictent les règles relatives à la police, à la conservation et à l'utilisation du domaine public, ainsi qu'à l'exercice des servitudes d'utilité publique et des servitudes militaires.

Les contraventions à ces règlements sont punies d'une amende de 1 franc à 300 francs, sans préjudice de la réparation du dommage causé et de la démolition d'office des ouvrages indùment établis sur le domaine public et dans les zones de servitude. Elles sont constatées par des procès-verbaux dressés par des agents commissionnés par les lieutenants gouverneurs.

Les détenteurs de terrains compris dans le domaine public, qui possèdent ces terrains en vertu de titres réguliers et définitifs antérieurs à la promulgation des décrets du 20 juillet 1900 pour le Sénégal et dépendances, ne pourraient être dépossédés, 
si l'intérêt public venait à l'exiger, que moyennant le payement ou la consignation d'une indemnité.

Il en serait de même dans le cas où l'intérêt public exigerait la démolition des constructions ou l'enlèvement de clótures ou plantations établies par ces mêmes détenteurs antérieurement à la promulgation de ce décret.

L'indemnité doit être fixée, sauf recours au Conseil du contentieux administratif, par une commission arbitrale de trois membres, dont un est désigné par le Lieutenant Gouverneur, un autre par le propriétaire, et le troisième par les deux premiers, d'un commun accord.

Domaine privé. - Les terres vacantes et sans maître appartiennent à l'Etat. Celles qui forment la propriété collective des indigènes ou que les chefs indigènes détiennent comme représentants de collectivités indigènes, ne peuvent être cédées à des particuliers par voie de vente ou de location qu'après approbation par arrêté du Lieutenant Gouverneur, en Conseil d'administration.

L'occupation de la partie de ces terres, nécessaire pour la création de centres urbains, pour des constructions ou travaux d'utilité publique, est prononcée par le Lieutenant Gouverneur, en Conseil d'administration, qui statue sur les compensations que peut comporter cette occupation.

Le régime des concessions de terres. - Comme on n'a pas voulu, au contraire de ce qui a été fait par certains pays, d'une exploitation directe par l'Etat et ses agents des richesses de la colonie, l'aliénation des terres domaniales a été prévue et soumise aux règles suivantes:

$1^{0}$ Les lots de terrain urbains compris dans un plan de lotissement arrêté par le Lieutenant Gouverneur en conseil d'administration, et les concessions de moins de $\mathbf{2 0 0}$ hectares, sont accordés par le Lieutenant Gouverneur en Conseil d'administration, aux conditions déterminées dans chaque cas par l'acte de concession lui-même, suivant le lieu, la nature du sol et de l'exploitation à entreprendre;

$2^{0}$ Les concessions portant sur une étendue comprise entre 
200 et 2.000 hectares sont accordées par le Gouverneur Général, sur la proposition du Lieutenant Gouverneur, après avis du conseil d'administration ;

$3^{0}$ Les concessions portant sur une étendue supérieure à 2.000 hectares sont accordées par décret rendu sur le rapport du Ministre des Colonies, sur la proposition du Gouverneur Général, et après avis de la commission des concessions coloniales.

Dans ces deux derniers cas, les conditions de la concession sont stipulées dans un cahier des charges annexé à l'acte de concession, qui fixe également le taux des redevances.

L'octroi de toute concession doit être précédé d'une publicité suffisante pour que tous les intérêts en cause puissent se produire et être examinés utilement avant l'établissement de l'acte de concession.

L'acte de concession doit faire mention des conditions de cette publicité et être inséré au Journal officiel de la colonie.

Représentation en justice. - Ces dispositions ont été complétées par un décret du $1^{\text {er }}$ avril 1906 qui détermine les pouvoirs des autorités chargées de la représentation en justice des domaines de l'Etat et des colonies en Afrique occidentale fran. çaise.

Dans toutes les procédures et instances suivies devant les juridictions coloniales ou métropolitaines, pour la défense des droits de leur domaine en Afrique occidentale française, l'Etat et le Gouvernement Général sont valablement représentés par le Gouverneur Général et les colonies relevant du Gouvernement Général par les Lieutenants Gouverneurs.

Toutefois, dans le cas où les intérêts de l'Etat et ceux du Gouvernement Général se trouveraient en opposition, l'Etat doit être représenté par le Gouverneur Général et le Gouvernement Général de l'Afrique occidentale française par le Secrétaire Général du Gouvernement Général.

La même capacité est confirmée spécialement et respectivement au Gouverneur Général et aux Lieutenants Gouverneurs pour toutes les procédures et instances commencées en matière domaniale avant la promulgation de ce décret. 
Les procédures et instances qui sont engageées à la requête $\mathrm{du}$ Gouverneur Général et des Lieutenants Gouverneurs sont poursuivies à la diligence des fonctionnaires du service des domaines.

Dans le cas où les intérêts de l'Etat, d'une part, du Gouvernement Général ou des colonies, d'autre part, se trouveraient en opposition, les procédures des actions ou défenses intéressant l'Etat seraient poursuivies à la diligence des agents du domaine, celles intéressant le Gouvernement Général et les colonies par des fonctionnaires désignés ad hoc par le Gouverneur Général.

Cet acte présente pour le Sénégal en particulier, par suite notamment de l'extension prise par Dakar, une réelle importance, aucune disposition précise n'ayant antérieurement déterminé les pouvoirs respectifs du Gouverneur Général et du Lieutenant Gouverneur, et la jurisprudence ayant varié à plusieurs reprises.

b) Régime des biens-fonds (Décret du 24 juillet 1906). Jusqu'au décret du 24 juillet 1906, le régime foncier en vigueur au Sénégal, résultait du décret du 20 juillet 1900 qu'avait inspiré le décret de 1899 instituant au Congo l'immatriculation des immeubles. La nouvelle réglementation - il sera facile de s'en convaincre par l'exposé qui va suivre - est allée beaucoup plus loin que l'acte de 1900 dans la voie des réformes. Ses dispositions sont groupées sous les quatre grandes divisions ci-après :

Titre $I^{\text {er. }}$ - Etablissement du régime foncier.

Chapitre I ${ }^{e r}$. - Organisation (Articles 1 à 18 inclus).

Сhapttre II. - Législation.

$\S 1 \mathrm{er}$. - Législation française (Articles 19 à 57 inclus).

§ 2. - Droit coutumier indigène (Article 58).

Titre II. - Fonctionnement du régime foncier.

Chapitre I ${ }^{\mathrm{er}}$. - Immatriculation des immeubles.

$\S 1 \mathrm{er}$. - De la procédure d'immatriculation (Articles 59 à 93 inclus).

§ 2. - De la formalité de l'imrnatriculation (Articles 94 à 99 inclus).

§3. - Du changement de régime (Articles 100 à $10{ }^{\prime}$ inclus).

Chapitre II. - Publication des droits réels.

$\S 1$ er. - De la formalité de l'inscription (Articles 105 à 133 inclus).

§ 2. - De la réunion et de la division des titres fonciers (Articles $\mathbf{1 3 6}$ à 138 inclus). 
Chapttre III. - Consultation des livres fonciers.

$\S$ unique. - De la communication des renseignements (Articles 139 à 141 inclus).

\section{Titre III. - Sanctions.}

Сhapitre Ier. - Responsabilité du conservateur (Articles 142 à 151 inclus).

Chapitae II. - Pénalités diverses (Articles 1522 à 130 inclus). Titre IV. - Dispositions gẻnẻrales (Articles 157 à 160 inclus).

Le texte de ce décret - reproduit dans la notice consacrée au Gouvernement général - a été inséré dans le numéro du Journal officiel de la République française du 4 aoùt 1906.

Exposer une à une les dispositions de cet acte important par lui-même et par les réformes qu'il consacre sortirait du cadre de cette étude. Nous nous contenterons d'indiquer ici comment est établi le nouveau régime foncier que ce décret institue et d'attirer l'attention sur celles de ses dispositions qui nous paraissent le plus intéressantes.

Le but de l'institution de la "Conservation de la propriété foncière et des droits fonciers " est d'assurer aux titulaires la garantie des droits réels qu'ils possèdent sur les immeubles (art. 1 ${ }^{\text {cr }}$ ).

Cette garantie est obtenue (art. 2) au moyen de la publication sur des livres fonciers à un compte particulier ouvert pour chaque immeuble de tous les droits réels qui s'y rapportent ainsi que des modifications de ces mêmes droits. Cette publication est précédée de la vérification des justifications produites et fait foi à l'égard des tiers.

Pour permettre cette formalité, les immeubles doivent être au préalable immatriculés sur les livres fonciers (art. 3), et cette immatriculation est autorisée quel que soit l'état ou le statut des propriétaires (art. 1).En d'autrestermes, les indigènes tiennent de cet article le droit qu'ils ne possédaient pas antérieurcment de faire immatriculer leurs immeubles. C'est là une des principales et des plus intéressantes innovations du décret du 24 juillet 1906 et qui ne peut avoir au point de vue économique que d'heureux résultats. En effet, aux yeux des européens, des com- 
merçants surtout, il est bon que les immeubles des indigènes puissent être susceptibles de constituer à un moment donné le gage des avances demandées. Le crédit est ainsi accordé aux autochtones et les affaires offrant une sécurité plus grande ne peuvent manquer de prendre plus de souplesse et plus d'ampleur.

Sauf dans deux cas où elle est obligatoire : aliénation ou concession de terre domaniale, immeuble faisant pour la première fois l'objet d'un contrat écrit et suivant la loi française, l'immatriculation est facultative (art. 5); mais elle est alors définitive (art. 6), en ce sens qu'un immeuble une fois immatriculé ne peut être soustrait au régime ainsi adopté pour être placé à nouveau sous l'empire de celui auquel il était soumis antérieurement.

Pour assurer le fonctionnement de l'immatriculation des immeubles et la publication des droits réels (immeubles par l'objet auquel ils s'appliquent) un "bureau de la conservation de la propriété et des droits fonciers " est créé au siège de chacun des tribunaux de première instance de la colonie (art. 7), par conséquent au Sénégal dans les villes de Saint-Louis et de Dakar. Ces bureaux sont gérés (art. 9) par des préposés qui portent le titre de conservateurs de la propriété foncière. Ces fonctionnaires sont chargés (art. 10): $1^{0}$ de la suite à donner aux demandes d'immatriculation ; $2^{0}$ de la formalité de l'immatriculation comportant l'établissement du titre foncier de chaque immeuble soumis à ce régime $; 3^{\circ}$ de l'inscription, à la suite des titres fonciers et de leurs copies, des droits réels constitués sur les immeubles immatriculés et devant, par suite, être publiés ; $4^{\circ}$ enfin, de la communication au public des renseignements contenus dans leurs archives et relatifs aux propriétés et propriétaires fonciers.

Les livres fonciers sont affectés, à raison d'une feuille ouverte par immeuble, à l'enregistrement et à l'inscription ultérieure en vue de leur conservation, des droits réels soumis à la publicité (art. 11). L'ensemble des mentions consignées sur une feuille ouverte des livres fonciers constitue le titre foncier. Ces mentions sont appuyées et complétées (art. 12) par l'adjonction de bordereaux analytiques établis par le conservateur, des actes et 
pièces produits comme justification des droits réels publiés. A chaque titre foncier correspond un dossier comprenant : $\mathbf{1}^{0}$ les pièces de la procédure d'immatriculation ; $2^{\circ}$ le plan définitif de l’immeuble ; $3^{\circ}$ la série des bordereaux analytiques successivement établis $; 4^{\circ}$ les pièces et actes analysés (art. 13) Outre les livres fonciers et les dossiers correspondants dont nous venons d'indiquer la composition, les conservateurs ont encore à tenir, aux termes de l'article 10 , les registres suivants : $a$ ) pour la suite de la procédure d'immatriculation : $1^{0}$ le registre d'ordre des formalités préalables à l'immatriculation; $2^{\circ}$ le registre des oppositions; b) pour la constatation des demandes d'inscription sur les livres fonciers: le registre des dépôts des actes à inscrire; c) pour la communication des renseignements au public: le répertoire des titulaires de droits réels et la table, par bulletins mobiles, dudit répertoire.

Les immeubles par nature ou par l'objet auquel ils s'appliquent sont soumis à la loi française, c'est-à-dire au Code civil, sauf les dérogations apportées par les articles 20 à 58 inclus du décret du 24 juillet 1906. C'est ce qui explique le désordre apparent de cette partie de la nouvelle réglementation; les lacunes rencontrées dans le texte du décret se trouvent comblées en rétablissant les dispositions du Code maintenues dans leur intégrité : nous ne signalerons que les principales de ces dérogations ou celles qui présentent un intérêt primordial.

L'article 20 donne la nomenclature des immeubles par l'objet auquel ils s'appliquent, nomenclature plus étendue que celle de l'article כ226 du Code civil. Ce sont :

a) Les droits réels immobiliers, savoir :

$1^{\circ}$ La propriété des biens immobiliers ;

$2^{\circ}$ L'usufruit de ces mêmes biens ;

$3^{\circ}$ Les droits d'usage et d'habitation;

$4^{0}$ L'emphythéose ;

$5^{0}$ Le droit de superficie ;

$6^{\circ}$ Les servitudes et services fonciers ;

$7^{0}$ L'antichrèse ;

80 Les privilèges et hypothèques.

b) Les actions qui tendent à revendiquer un immeuble. 
Indiquons en passant que, d'après le nouveau régime, l'hypothèque est (art. 30) forcée ou conventionnelle; donc, plus d'hypothèque judiciaire. L'hypothèque forcée résulte d'une décision de justice sans le consentement du débiteur et dans les cas limitativement déterminés par le décret. L'hypothèque conventionnelle est celle qui résulte des conventions et qui peut être consentie au gré des parties (art. 40) soit par acte authentique, soit par acte sous signatures privées.

Notons également, toujours au sujet des hypothèques, l'article 43 ainsi conçu : "La publication de l'hypothèque conventionnelle peut, dans les cas de prêts à court terme, être différée pendant un délai maximum de 90 jours, sans que le créancier soit exposé à perdre le rang qu'il occupe et qui lui est et demeure acquis à condition par lui de se conformer aux dispositions de l'article 32 du présent décret ". Cet article 32 dispose que a si l'inscription d'une hypothèque garantissant un prêt à court terme est différée, par application de l'article $\mathbf{4 3}$, l'acte constitutif de cette hypothèque n'en doit pas moins être rédigé dans les formes ordinaires et un original ou une expédition, suivant le cas, en est remis, avec la copie du titre foncier, au créancier hypothécaire; celui-ci effectue le dépôt à la conservation, en faisant défense par écrit au conservateur de déférer à aucune réquisition d'inscription au préjudice de son droit dans un délai qui ne peut être supérieur à 90 jours. Ce dépôt, valable pour ledit délai comme opposition, est inscrit à sa date au registre des dépòts et mention provisoire en est faite sur le titre foncier, dans le cadre réservé à cet effet. Exceptionnellement cette mention n'est pas reproduite sur la copie du titre foncier. Si, dans le cours du délai de validité de l'opposition, une nouvelle inscription vient à être requise, le conservateur procède préalablement à l'inscription de l'hypothèque différée, qui prend rang du jour du dépôt pour opposition. Dans le cas contraire à l'expiration du délai de 90 jours, le créancier est invité à retirer ses pièces ou à requérir l'inscription régulière de son droit, qui a cessé d'être garanti par le dépôt pour opposition.

La combinaison de ces deux articles crée une nouvelle sorte d'hypothèque, l'hypothèque différée, très en usage en Austra- 


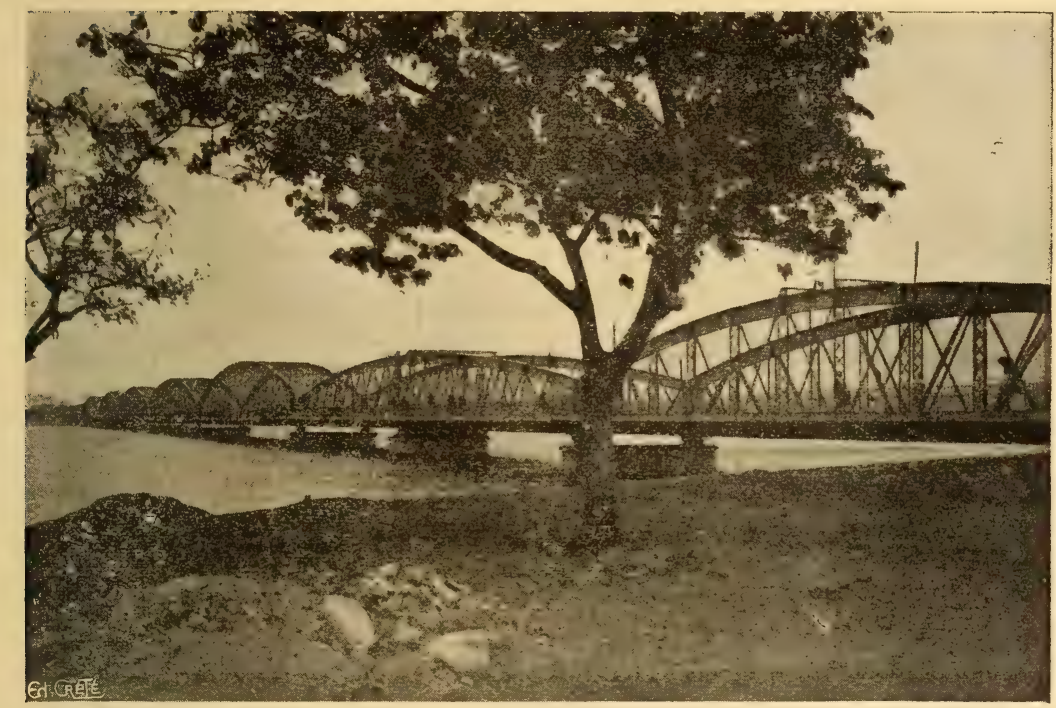

Fig. 33̈. - Le pont Faidherbe à Saint-Louis.

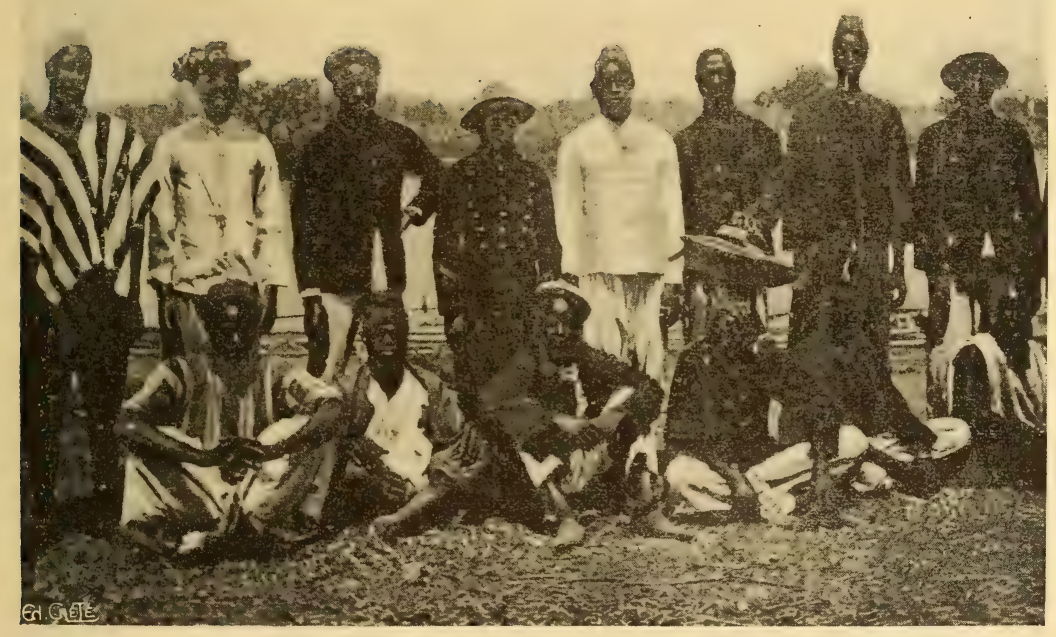

Fig. 36. - Laptots sénégalais.

s. 

lie (1). C'est là une innovation très heureuse qui facilite les prêts à court terme, si utiles dans des pays agricoles comme nos colonies africaines. Cette disposition est dautant plus utile que le nouveau régime est applicable aux immeubles possédés par les indigènes. Commerçants et traitants noirs trouveront les uns et les autres des avantages à user de cette faculté d'hypothèque différée : ceux-ci pour se faire consentir des avances en donnant des sûretés réclles, ceux-là en étant entị̂rement garantis par les termes de l'article 32. Les intérêts opposés du créancier et du débiteur sont de la sorte l'un et l'autre sauvegardés, puisqu'il ne doit pas rester trace sur le titre constitutif des droits de l'emprunteur de sa gêne momentanée, que le créancier est, de toutes façons, garanti, et que, le cas échéant, son hypothèque prend rang du jour du dépôt de l'opposition.

Dans un ordre d'idées analogues, il est intéressant de signaler les articles 22 et suivants qui facilitent la réalisation du gage et aideront ainsi puissamment, il faut l'espérer, à l'élévation d'abord, à l'extension ensuite du crédit hypothécaire. L'article 55 notamment, permet d'inscrire dans les contrats de prêts la " clause de voie parée » 2); en d'autres termes la disposition qui nous occupe, donne au créancier et au débiteur la possibilité de convenir d'un mode d'expropriation plus simple et plus économique que celui qui est réglé par le décret.

Enfin, comme conséquence des principes sur lesquels repose le nouveau système, la prescription disparait (art. 57). En effet, les livres fonciers font foi de leur contenu et aucun droit ne peut s'acquérir ni s'éteindre en dehors d'une inscription régulière. D'autre part, on ne saurait admettre la bonne foi de possesseurs dont les droits ne figureraient pas sur des registres réputés publics : leur usurpation de fait ne peut détruire les droits des propriétaires inscrits, en admettant même qu'il soit possible qu'elle se produise.

(1) V. Avant-projet d'un décret établissant le régime de la propriètè foncière dans les colonies et territoires de l'Afrique occidentale française par A. Boudillon, sousinspecteur de l'Enregistrement et des Douanes. Gorée. Imprimerie du gouvernement genéral, 1905, p. 85 et 144 .

(2) V. Boudillon, op. cit., p. 89. 
Nous arrivons à l'une des réformes les plus considérables réalisées par le décret du 24 juillet 1906 dans son article 58 . " Dans les parties de l'Afrique occidentale française où la tenure du sol par les habitants ne présente pas tous les caractères de la propriété privée telle qu'elle existe en France, le fait, par un ou plusieurs détenteurs de terres d'avoir éiabli, par la procédure de l'immatriculation, l'absence de droits opposables à ceux qu'ils invoquent a pour effet, quels que soient les incidents de la dite procédure, de consolider leurs droits d'usage et de leur conférer les droits de disposition reconnus aux propriétaires par la loi française $)$. Cette disposition, conséquence du principe posé dans l'article 4, a pour but d'aider à la transformation de la propriété foncière indigène en Afrique occidentale; elle permet dès maintenant, elle permettra surtout dans l'avenir, au fur et à mesure de l'évolution qui ne manquera pas de se produire, la constatation du droit des indigènes, soit isolés, soit à l'état collectif, sur le sol qu'ils cultivent ou qu'ils exploitent d'une façon quelconque; elle assure également dans les limites de la nouvelle réglementation la consolidation de ces droits. Il n'est pas besoin d'insister pour montrer que ce texte est éminemment favorable à la population indigène, et qu'il peut produire, au point de vue économique et social, les résultats les plus heureux.

Telles sont les dispositions fondamentales du nouveau régime foncier instauré en Afrique occidentale par le décret du $\mathbf{2 4}$ juillet 1906. Ainsi que nous l'avons indiqué plus haut, nous ren. voyons au texte du décret lui-même pour tout ce qui concerne le fonctionnement de l'immatriculation et la publication des droits réels.

c) Régime forestier (Décret du 20 juillet 1900). - Le décret du 23 octobre 1904 est resté muet en ce qui concerne le régime forestier. Il laisse donc subsister les dispositions du décret du 20 juillet 1900, relatif à l'exploitation des bois domaniaux et des bois appartenant à des particuliers.

a) Bois domaniaux. - L'exploitation des forêts domaniales 
est soumise à des règles assez strictes, d'ailleurs parfaitement - justifiées et qu'il paraît intéressant d’exposer. Leur sévérité n'a malheureusement pas produit tous les résultats attendus.

Aux termes des dispositions en vigueur, aucune exploitation forestière dans les bois du domaine ne peut être entreprise sans une autorisation du Gouverneur général ou de son délégué. Ce permis, strictement personnel, n'est délivré qu'à titre temporaire et fixe en même temps la redevance imposéc à l'exploitant.

Les exploitations doivent se faire de proche en proche par voie de jardinage, en allant toujours dans le même sens, sans aucune solution de continuité.

Les parties de forêts exploitées doivent être mises en réserve et ne peuvent être exploitées à nouveau que sur l'autorisation du Gouverneur général ou de son délégué.

Tous les arbres qui, n'ayant pas atteint leur complet développement, n'ont que 1 mètre de tour et au-dessous, mesure prise à 1 mètre du sol ainsi que les arbres à latex, doivent être respectés.

Les arbres doivent être abattus rez de terre afin de faciliter la régénération par les rejets de souche et les arbres de grandes dimensions qui, dans leur chute, pourraient endommager le sous-bois, doivent autant que possible être ébranchés avant l'abatage.

La récolte des écorces tannifères ou tinctoriales, des gommes, résines, caoutchouc et gutta-percha doit être faite de manière à ne pas détruire les végétaux producteurs.

Il est, en outre, interdit de déboiser ou de défricher les ver. sants des montagnes et coteaux offrant un angle de 30 degrés et au-dessus, ainsi que les terrains désignés par arrêté motivé du Gouverneur général.

En dehors de ces exceptions, aucune étendue supérieure à 200 hectares ne pourra être déboisée sans autorisation del'Administrateur, chef de région.

Dans les forêts où il existe des essences de grande valeur, l'exploitant est tenu de faire planter chaque année, à ses frais, un nombre de plants de même essence, ou d'une essence aussi riche, au moins double de celui des arbres abattus dans le cours 
de l'année. Les essences précieuses, soumises à cette obligation sont spécifiées par arrêté du Gouverneur général. L'exploitant est tenu également de planter annuellement un nombre d'arbres ou de lianes à latex qui ne doit pas être inférieur à 150 pieds d'arbres ou 200 pieds de lianes par tonne de caoutchouc ou de gutta-percha récoltée dans l'année.

L'exploitant, doit en outre, faire tenir par ses chefs de chantier un carnet d'attachement sur lequel doivent être consignés chaque jour : le nombre d'arbres abattus, leur essence avec la désignation de leur nom indigène, leur circonférenee à 1 mètre du sol, leur longueur. De plus, dans chaque factorerie, il doit être tenu pour les résines, gommes, caoutchouc et autres produits, un registre constatant les opérations faites chaque jour et indiquant les régions de provenance ainsi que le poids et le volume de chacun de ces produits, registre qui doit être communiqué à toute réquisition des représentants de l'Administration, et visé par eux.

Les produits forestiers ne peuvent circuler au Sénégal que si les bois sont revêtus de l'empreinte d'un marteau de forme triangulaire portant la marque de l'exploitant, marque qui doit être déposée par l'exploitant au greffe du tribunal de première instance.

Les infractions à ces prescriptions et aux arrêtés pris par le Gouverneur général pour son exécution sont punies d'amende considérable et pouvant aller jusqu'à 1.000 francs.

Des agents du Service forestier, ou à leur défaut, d'autres agents de l'administration, désignés à cet effet et assermentés sont chargés de faire respecter les règlements et de poursuivre les délinquants. Ils dressent des procès-verbaux et les poursuites sont portées devant le tribunal de première instance de la région jugeant correctionnellement.

b) Bois particuliers. - Les particuliers exercent sur les bois qui leur appartiennent tous les droits résultant de la propriété. Cependant les dispositions des articles du décret du 20 juillet 1900 , relatives au déboisement et aux marques leur sont applicables, ainsi que les pénalités qu'il établit.

En outre, le Gouverneur général peut, par des arrêtés pris en 
Conseil d'administration, mettre en demeure les particuliers de reboiser les terrains leur appartenant. Toutefois, ils ne peuvent être tenus de reboiser chaque année qu'un cinquième de la superficie à reboiser leur appartenant, sans qu'on puisse exiger un repeuplement de plus de cinq hectares paran.

Dans le cas où les particuliers consentent à effectuer euxmêmes les travaux de reboisement, les graines et les plants nécessaires peuvent leur être fournis gratuitement. S'ils se refusent à pratiquer cette opération, l'administration se charge du reboisement et poursuit par voie de contraintes le remboursement de ses dépenses à cet effet.

c) Réserve des droits des indigènes. - Les indigènes continuent à exercer dans les bois et forêts dépendant du domaine et non concédés à des particuliers les droits d'usage (marronage, affouage, pâturage, chasse, etc.) dont ils jouissent actuellement. Toutefois si leurs procédés ou l'abus de ces droits compromettent les richesses forestières du domaine, le Gouverneur général peut prendre par arrêté toutes mesures protectrices el prohibitives nécessaires.

\section{B. - Le régime de la main-d'ouvre et la population.}

Le problème de la main-d'œuvre ne se pose pas au Sénégal avec une gravité aussi absolue que dans certaines de nos autres possessions. Ainsi qu'on va en juger, le pays est assez peuplé et les populations qui l'habitent suffisamment intelligentes pour pouvoir être employées aux travaux de toute nature que nécessite la vie et le développement économique d’un pays.

Nous allons examiner les ressources qu'est susceptible de fournir la main-d'œuvre locale en indiquant les mesures qui ont été prises pour la protéger et la réglementer. Nous exposerons ensuite les résultats du recensement de la population, qui fut opéré d'une façon très précise en 1904. 
La main-d'œuvre locale.

La question de savoir si le Sénégal est capable de fournir de la main-d'œuvre, est depuis longtemps résolue. Les ouvriers sénégalais, que l'on trouve en abondance, jouissent en effet d'une réputation méritée d'habileté, sur toute la côte occidentale d'Afrique, et pendant longtemps même, ils furent les seuls que l'on ait pu trouver et employer dans les chantiers des travaux publics.

Les menuisiers et les charpentiers que l'on rencontre en abondance, travaillent presque aussi bien que les Européens, ils appartiennent d'ailleurs aux corporations les plus avancées; on trouve même parmi eux des ouvriers d'une habileté remarquable.

Les forgerons et serruriers sont fort nombreux, et bien dirigés, peuvent donner un bon travail.

Par contre, les maçons sont rares et surtout peu adroits et une surveillance active est nécessaire pour arriver à de bons résultats. Ils travaillent indistinctement avec de la brique ou de la pierre, matériaux qui sont en usage dans la Colonie.

Les manœuvres abondent et se recrutent principalement parmi les Toucouleurs et les Bambaras.

D’une manière générale, la main-d'œuvre au Sénégal est suffisante et l'on peut utiliser très avantageusement les éléments que l'on trouve dans la Colonie à la condition d'exercer une surveillance constante sur les indigènes qui sont par nature un peu indolents et inattentifs. Nous donnons dans le tableau ci-contre, une indication des prix payés habituellement à Dakar et à Saint-Louis pour une journée de dix heures de travail, ainsi que l'abondance de la main d'œuvre et sa qualité.

Emigration. - Les indigènes des autres régions ouest-africaines n'étant en mesure que de fournir des terrassiers, ou ne pouvant être employés qu'à des travaux très grossiers, il en est résulté des recrutements si importants de Sénégalais pour l'étranger que l'émigration a dû être surveillée et réglementée. 
CONDITIONS DE LA PRODUCTION ET DU COMMERCE 249

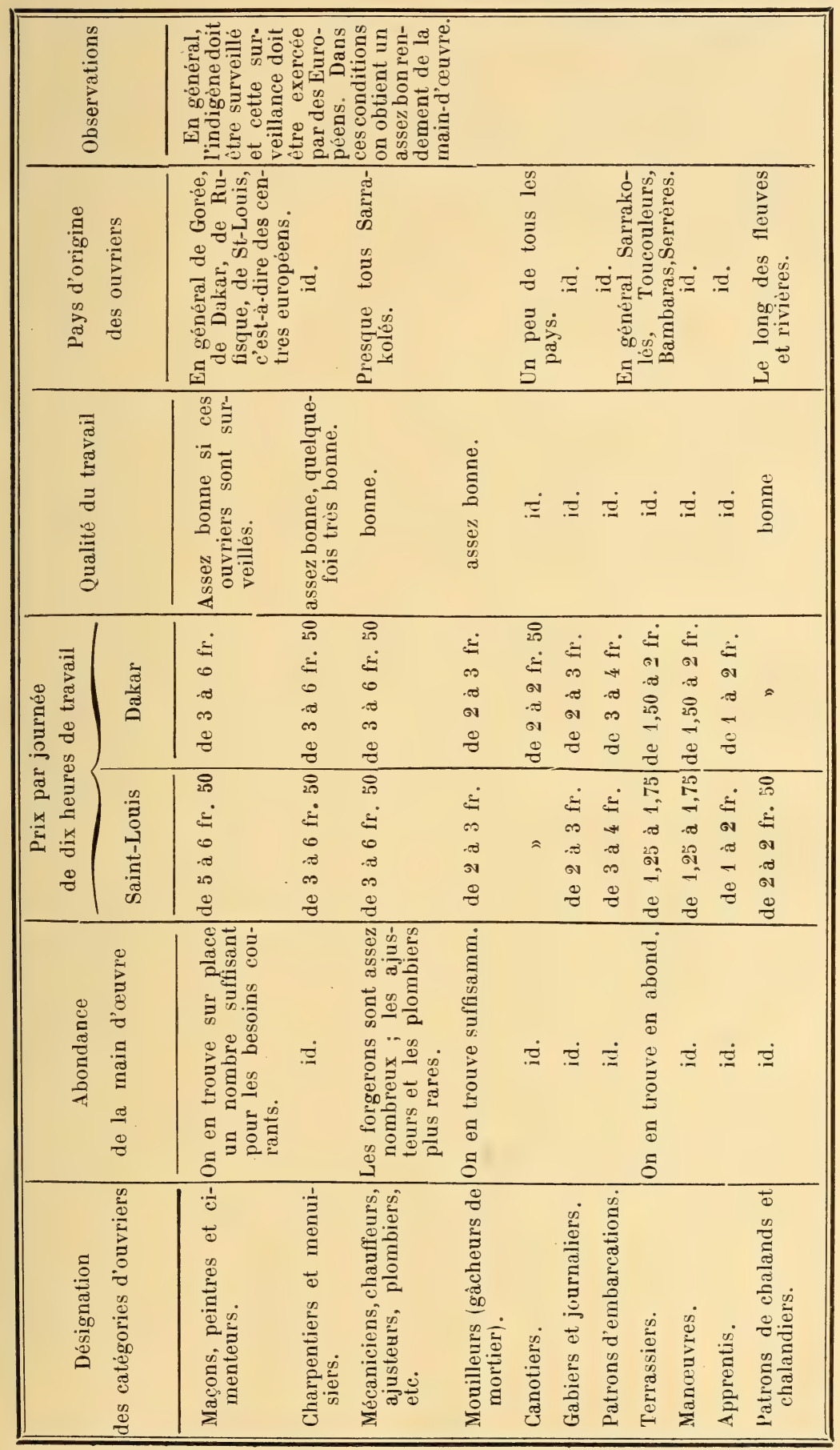


Les bases de cetteréglementation furent posées par le décretdu 17 juin $189 \%$. Les pénalités prévues par cet acte ont en outre été aggravées par un décret du 12 janvier 1897 qui a remplacé les articles 7, 8, 9 et 10 du décret de 189 ə. En raison de l'importance de cette question, il nous a paru nécessaire de donner ciaprès le texte des deux décrets combinés.

Décrets des 17 juin 1895 et 12 janvier 1897 :

Article prenier. - - Nul ne peut entreprendre au Sénégal et dans les pays protégés relevant de cette Colonie les opérations d'engagement et de transport des émigrants ou de recrutement des travailleurs engagés à temps, sans l'autorisation du Gouverneur, en Conseil privé.

Авт. 2. - Les compagnies ou agences d'émigration ou de recrutement de travailleurs, pour des Colonies ou pays n'appartenant pas à la France, ne pourront être autorisées à entreprendre les opérations d'engagement et de transport des émigrants qu'à titre essentiellement temporaire et exceptionnel et à la condition de fournir un cautionnement dont le minimum est fixé à la somme de $\mathbf{4 0 . 0 0 0}$ francs.

Art. 3. - Les compagnies ou agences agissant pour le compte et sous la garantie de l'administration d'une Colonie française pourront être dispensées de la formalité du cautionnement par le Gouverneur, en Conseil.

Art. 4. - Le cautionnementsera versé en numéraire et portera intérêt à raison de $30 / 0$ par an.

Il ne pourra être restitué que six mois après la déclaration faite par les compagnies ou agences qu'elles renoncent à l'exercice de leur industrie, ou après le retrait de l'autorisation, ou le décès des personnes autorisées.

Art. כ. - L'autorisation sera toujours révocable par le Gouverneur, soit d'une façon générale, soit pour un pays déterminé :

$1^{0}$ En cas d'abus grave ;

$2^{0}$ Toutes les fois que la situation économique ou politique de 
la Colonie sera jugée de nature à nécessiter la suppression des opérations pour lesquelles aura été délivrée l'autorisation.

Art. 6. - Les compagnies sont responsables de leurs agents, qui doivent être munis d'une procuration authentique.

ArT. 7. - Aucun capitaine ou amateur pouvant recevoir des passagers ne devra, sans autorisation de l'administration, recevoir à son bord un ou plusieurs indigènes à destination de pays étranger.

Cette autorisation sera constatée au moyen d'un bulletin délivré par le Directeur de l'intérieur ou son délégué mentionnant le nom et le pays d'origine du passager, la date d'embarquement et le lieu de destination.

Авт. 8. - Le Gouverneur peut, en conseil, prendre tous les arrêtés d'exécution qu'il jugera utiles pour assurer l'exécution du service de l'émigration.

Art. 9. - Toute infraction aux dispositions des articles 1, 2, $3,4, \ddot{5}, 6,7,8$, sera poursuivie devant les tribunaux de police correctionnelle et punie, soit d'une amende de 50 à 5.000 francs, soit d'un emprisonnement de 6 mois à 1 an, snit des deux peines cumulées.

Arт. 10. - En cas de récidive dans l'année, l'amende sera portée au double et obligatoirement cumulée avec le maximum de la peine d'emprisonnement. L'article 463 du Code pénal ne sera pas applicable.

Art. 11. - Les délits et contraventions pourront être constatés, savoir :

$1^{0} \mathrm{Au}$ Sénégal, par les commissaires de l'émigration, en qualité d'officiers de police du Procureur de la République, par tous les officiers de police judiciaire et par les fonctionnaires et agents qu'un arrêté du Gouverneur aura investis, soit définitivement, soit temporairement, des attributions de commissaire de l'émigration ;

$2^{0} \mathrm{~A}$ bord des navires français, dans les ports étrangers, par les consuls.

Les procès-verbaux font foi jusqu'à preuve du contraire; ils seront visés pour timbre et enregistrés en débet. 


\section{La population.}

De toutes les colonies de l'Afrique occidentale française, le Sénégal est la seule où un recensement méthodique ait été opéré (1).

Il eut été intéressant de comparer les résultats du recensement de 1904, le dernier qui ait été effectué, avec ceux qui avaient été obtenus lors de celui de 1891, mais, d'une part, le territoire du Sénégal comprenait à cette époque une superficie d'environ dix fois supérieure, et, d'autre part, le recensement n'avait été opéré d'une façon assez précise que pour les quatre communes constituées. Il ne faut pas oublier également que le Sénégal ne comprenait en 1904 que le périmètre communal et la banlieue de ses quatre communes, les escales de la ligne, du Fleuve, du Saloum et de la Casamance, à raison de deux kilomètres carrés pour chacune et une bande d'un kilomètre de chaque côté de la voie ferrée depuis Saint-Louis jusqu'à Dakar, soit au total 1.13 kilomètres carrés, ce qui donne une population approximative de $\mathbf{9 5}$ habitants par kilomètre carré $(\mathbf{2})$.

Cette population du Sénégal ainsi constitué était, au $1^{\text {er }}$ mai 1904, de 107.026 habitants dont 105.113 pour la population civile et $\mathbf{2 . 7 1 3}$ pour l'élément militaire. Sur ce chiffre, il faut distinguer 4.479 européens ou assimilés dont $3.25 \% 1$ pour la population civile et 1.228 pour les troupes (10̈7 officiers, 1.071 sous-officiers et soldats). Cette population se répartirait à peu près en $\mathbf{2 . 8 0 4}$ (troupes comprises) européens et 1.670 assimilés ou créoles.

Les étrang'ers, qu'il s'agisse des indigènes, nés en dehors des villes et des escales, ou des européens qui se sont installés dans la Colonie, représentent un chiffre de 3.878, dont 38 habitants originaires d'Europe ou d'Amérique.

Il reste donc, pour les indigènes nés au Sénégal et jouissant de leur qualité de français, un chiffre de 99.469 habitants.

Il convient de remarquer que le nombre des femmes (

(1) Voir le très intéressant rapport de M. Camille Guy, Lieutenant Gourerneur du Sénégal.

(2) La population de la France est évaluée à 72 habitants par kilomètre carré. 
est sensiblement égal à celui des hommes (̋3.508). D'autre part, au point de vue de làge, le recensement donne comme résultat : 62.388 majeurs et $\mathbf{4 0 . 4 3 8}$ mineurs.

Si l'on envisage la répartition des habitants au point de vue des métiers et des professions, on trouve : 16 armateur's, 713 commerçants, $\mathbf{1 . 0 2 3}$ employés de commerce, 99 employés de chemin de fer ou agents de transports, 570 traitants, 644 boutiquiers et 359 bijoutiers, $\check{3}$ entrepreneurs, 27 habitants consacrés aux professions libérales (médecins, sage-femme, pharmaciens, avocats, officiers ministériels) et 1.778 marchands en boutique ou ambulants, bien que le recensement donne, en plus, un chiffre de $\mathbf{4 7}$ indigènes et de 26 dioulas qui ont déclaré exercer la profession de colporteurs. Si à cette nomenclature on ajoute $\mathbf{4 3 . 1 2 1}$ habitants qui ont déclaré être sans profession et 327 qui se sont inscrits comme propriétaires, nous aurons une idée à peu près exacte de la répartition de la population sénégalaise. Ceux qui n’ont pas été mentionnés exercent le méticr de bouchers (148), de boulangers (130), de cafetiers (39), de charpentiers (252), de coiffeurs (14), de cordonniers (259), de couturières (164), de maçons (773), de ferblantiers (17) et de tisserands (363).

Le chiffre de 912 fonctionnaires et agents de tout ordre surprendra peut-être ceux qui, adoptant la manière ordinaire de raisonner en cette matière, comparent toujours et sans qu'on puisse savoir pourquoi, le nombre des fonctionnaires non à celui de la population totale mais à celui des colons européens ou ceux qui ne remarqueront pas que sur ces 900 agents plus de 300 sont occupés aux Travaux publics, aux Postes, à l'Imprimerie et à la Police, c'est-à-dire à des Services de première nécessité. En réalité, à juger sainement de la proportion entre les fonctionnaires ou agents et la population totale, on obtient un fonctionnaire par 120 habitants, ce qui est sensiblement égal aux chiffres de la Métropole, sensiblement inférieur, toutes proportions gardées, à la proportion constatée dans les Colonies anglaises de la Côte d'Or et de Sierra-Leone. Encore ce chiffre, pour être absolument exact, devrait-il être dirninué des fonctionnaires du Gouvernement général, des officiers de l'état-major et 
des magistrats de la Cour d'appel, qui résident au Sénégal, mais dont l'autorité s'étend à toute l'Afrique occidentale et aussi des fonctionnaires communs à la Colonie et à la Sénéga mbie (administrateurs, adjoints des Aftaires indigènes, commis, gardes régionaux, agents des Postes dans les escales, etc.)

La population tout entière du faubourg de Guet-N'Dar, ainsi qu'une partie des indigènes de Rufisque et de Dakar, se livre à l'industrie de la pêche ou aux professions maritimes, ce qui explique le nombre considérable de pêcheurs révélés par le recensement $(2.250)$ et celui des marins ou laptots (2.682). Enfin, il ne faut pas oublier que la principale, et pour ainsi dire, l'unique occupation des femmes est au Sénégal, de piler le mil destiné à la nourriture de la famille et de laver, en même temps que leur linge, celui de quelques clients, d'où le chiffre de $\mathbf{9 . 8 0 2}$ pileuses de mil et de 289 blanchisseuses.

La ville de Saint Louis qui était de $\mathbf{1 3 . 9 8 0 ~ h a b i t a n t s ~ e n ~} \mathbf{1 8 7 8 ,}$ atteignait 20.173 au recensement de 1891 et s'élevait en 1904 à 24.070 habitants pour le territoire communal. Si à ce chiffre on ajoute celui de la banlieue (4.399) on obtient un total de 28.469 habitants. Saint-Louis (ville) possède 10.209 hommes

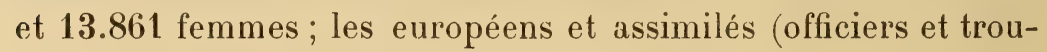
pes non compris) atteignent le chiffre de 1.077 .

L'accroissement le plus rapide et d'ailleurs le plus facile à prévoir a été celui de la ville de Dakar. De $1.50 \% 6$ àmes en 1878, le nombre des habitant atteignait 8.737 en 1891 et arrivait à $\mathbf{1 8 . 4 4 7}$ en 1904 soit, en treize ans, une augmentation de plus de 100 pour 100. Le développement du grand port de l'Afrique occidentale s'est encore considérablement accentué depuis, grâce aux travaux immenses entrepris dans la rade, tant par la Marine que par la Colonie et par le transport dans cette ville du siège du Gouvernement geénéral.

En tenant compte de la banlieue, on obtiendrait une population globale de $\mathbf{2 3 . 4 3 2}$ habitants sur laquelle il faut signaler 1.268 européens ou assimilés.

Quand Rufisque fut érigée en commune en 1881, elle n'avait encore que 1.500 habitants, en 1891 elle était sensiblement égale à Dakar ; aujourd'hui elle atteint 12.446 habitants. 
Avec la banlieue, cette population s'élèverait à 19.177 sur lesquels il n'existe que 317 européens ou assimilés.

Gorée, l'ancien entrepôt général des marchandises du Sénégal, n'est plus aujourd'hui que l'ombre d'elle-même. Sa population descendue, dès 1878, à 3.243 habitants, n'était plus en 1891 que de 2.068 ; le recensement de 1904 ne lui en donne plus que $\mathbf{1 . 5 6 0 .}$ Encore ce chiffre n'est-il qu'apparent, car, un grand nombre des électeurs inscrits sur les listes électorales ont dù, pour gagner leur vie, s'installer à Dakar ou sur la Petite Côte et n'habitent jamais à Gorée.

Les tableaux, ci-après, donnent le chiffre de la population agglomérée dans chaque escale et distinguée avec soin entre indi. gènes d'une part, européens et assimilés d'autre part. On remarquera que certaines d'entre elles ont pris en peu d'années un développement considérable comme par exemple : Louga, Tivaouane, Thiès, Ziguinchor et Fatick. Les trois premières été d'ailleurs dotées, ainsi qu'on l'a vu plus haut (1), d'une organisation municipale analogue à celle des communes mixtes de l'Algérie.

Progrès du peuplement françis et européen au Sénégal. - Le Sénégal ne pouvait prétendre devenir une colonie de peuplement, aussi le nombre des colons est-il très restreint et la majeure partie des européens qui l'habitent s'adonne au commerce.

Cayor. - Le nombre de blancs vivant dans cette région augmente de jour en jour, et de nombreux comptoirs se fondent dans l'inlérieur du pays. La culture des arachides provoque une activité commerciale considérable; les européens font d'importants achats de ce produit aux indigènes et leur vendent des articles manufacturés.

Provinces Sérères. - Une vingtaine de commerçants se sont établis à Nianning, Joal et plusieurs y vivent avec leur famille. Le commerce consiste, comme dans le Cayor, dans l'achat d'arachides et la vente à l'indigène de tout ce dont il peut avoir besoin.

Quelques Pères se sont adonnés à la culture et possèdent à

(1) Voir Chap. VII. Organisation administrative. 
N'('razobil une vaste concession. Leurs essais de coton ont échoué, mais l'exploitation d'une forêt de rôniers a été rémunératrice. Ils ont également construit un atelier d'imprimerie, une forge très bien outillée, une huilerie d'arachides et une scierie mécanique. Autour de ce bâtiment, poussent quelques plantations de cocotiers, papayers et des rizières.

Thiès compte 31 commerçants, à peu près autant d'employés de commerce et $\mathbf{2} \mathbf{4}$ dames, si l'on ajoute à ce nombre celui des fonctionnaires civils et militaires on arrive à une centaine d'enropéens vivant dans cette localité.

Sine-Saloum. - Le développement que prend le cercle du Sine-Saloum grâce au commerce qui y devient de jour en jour plus important, a eu pour conséquence un accroissement considérable du nombre des européens qui l'habitent et, principalement dans l'escale de Fatick, dont l'étendue mesure près de trois kilomètres en bordure du Sine. Au $1^{\text {er }}$ avril 1906, Fatick comptait 47 européens, 6 assimilés, 3 dames européennes et 2 assimilées ; Kaolack, 19 européens, 7 assimilés et, Foundiougne, 12 européens soit un total de 97 européens presque tous français.

Casamance. - Les européens sont en Casamance, déduction faite des agents de l'administration, au nombre de 70, pour la plupart employés de commerce. En 1900 le nombre des européens du cercle n'excédait pas 20 . Il y a donc une augmentation considérable qui ira en s'accentuant à mesure que la soumission des indigènes se fera plus complète et que l'établissement des voies de communications aura rendu plus faciles, les opérations commerciales.

Rives du fleuve (Dagana, Matam, Podor, Bakel). - Le peuplement européen n'a pas suivi une marche aussi favorable, sur les rives du Sénégal que dans les autres parties de la Colonie et peu de blancs sont venus s'installer dans ces régions où le commerce est encore peu développé. Toutefois Podor compte 17 français et 3 européens non français.

La culture du coton semble possible dans les environs de Bakel, les indigènes récoltent ce produit en abondance et une direction européenne saurait tirer plus de profit d'un sol fort 


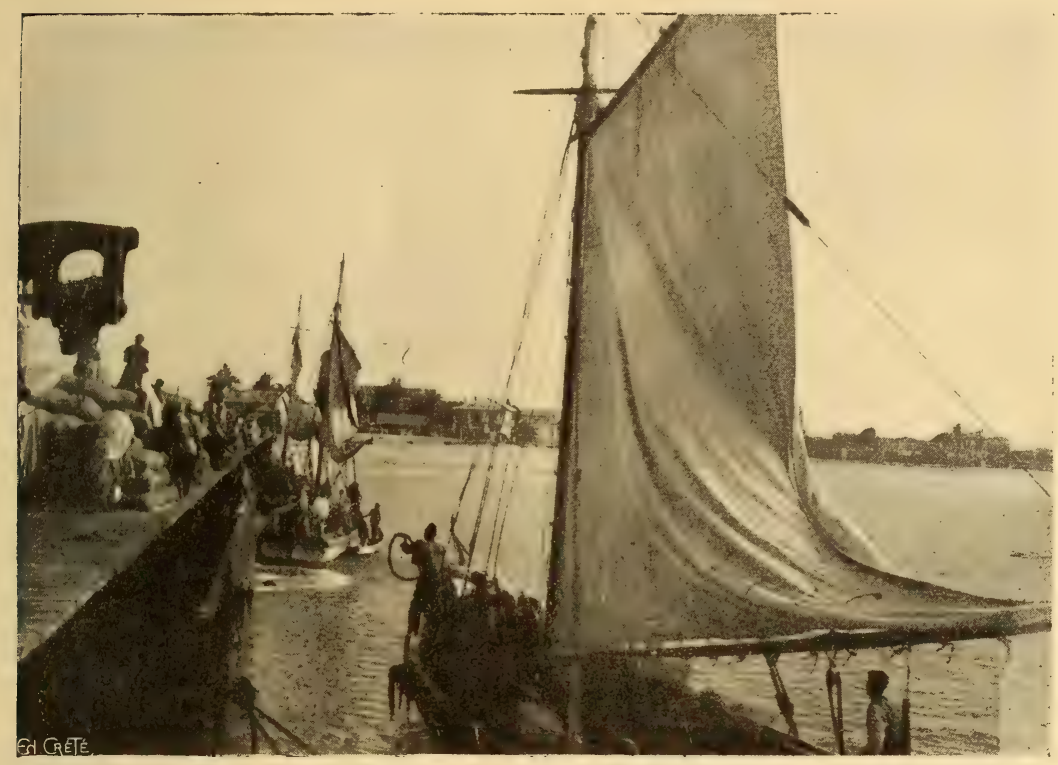

Fig. 35. - Le Warf de Rufisque.

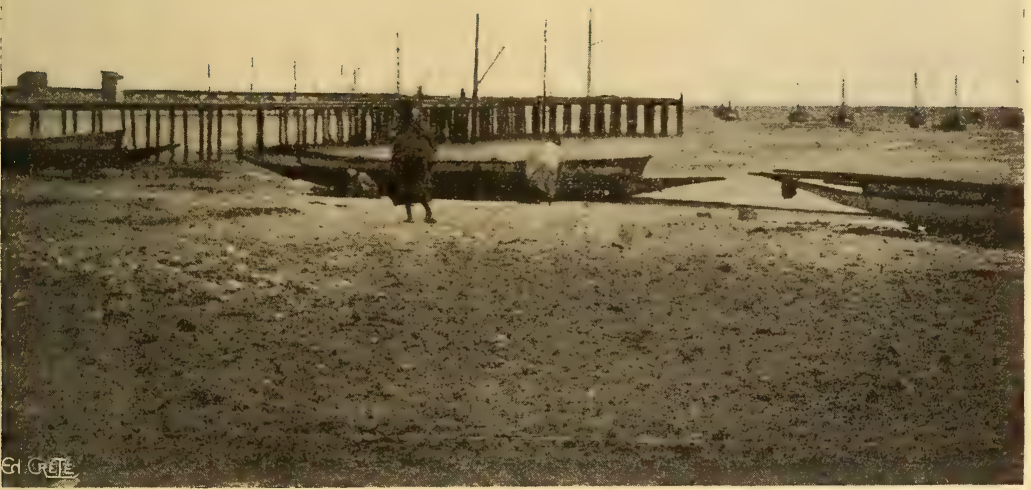

Fig. 36. - Le Warf de Rufisque. 

propice à cette culture. Des essais de culture ont été faits par les administrateurs de Bakel, les bananiers, papayiers, orangers, viennent admirablement et ce succès pourra décider l'installation de colons. Les provinces de la Haute-Gambie renferment du caoutchouc et il serait nécessaire que les indigènes ne soient pas abandonnés à eux.mêmes.

La population européenne a-t-elle en général augmenté au Sénégal depuis 1891 ? A s'en tenir aux chiffres approximatifs fournis par le recensement de 1891, le nombre des Européens ou assimilés serait aujourd hui à peu près identique, peut-être même un peu inférieur à celui qui fut constaté à cette époque. Notre opinion est que le chiffre n'a, pour ainsi dire, pas varié, et cela seul suffit pour attester que le Sénégal n'a rien perdu de son importance. Car si on veut bien se souvenir qu'il y a treize ans, les colonies du Sud n'existaient, pour ainsi dire, pas et que les Européens n'y étaient qu'en nombre infime, que le Soudan était une marche militaire où le commerce tentait timidement ses premiers essais, on se rendra compte que le Sénégal était le seul point de l'Afrique occidentale que connaissaient et fréquentaient les Européens Aujourd'hui, il n'est pas de maison de commerce sénégalaise qui n'entretienne au Soudan un ou plusieurs agents ; Conakry compte un grand nombre d'Européens ; le Dahomey et la Côte-d'Ivoire ont une population non négligeable d'habitants français et c'est donc pour le Sénégal un résultat heureux et presque inattendu que d'avoir conservé, malgré ces conditions avantageuses pour la France, mais défavorables pour lui, le même nombre d'habitants européens. 


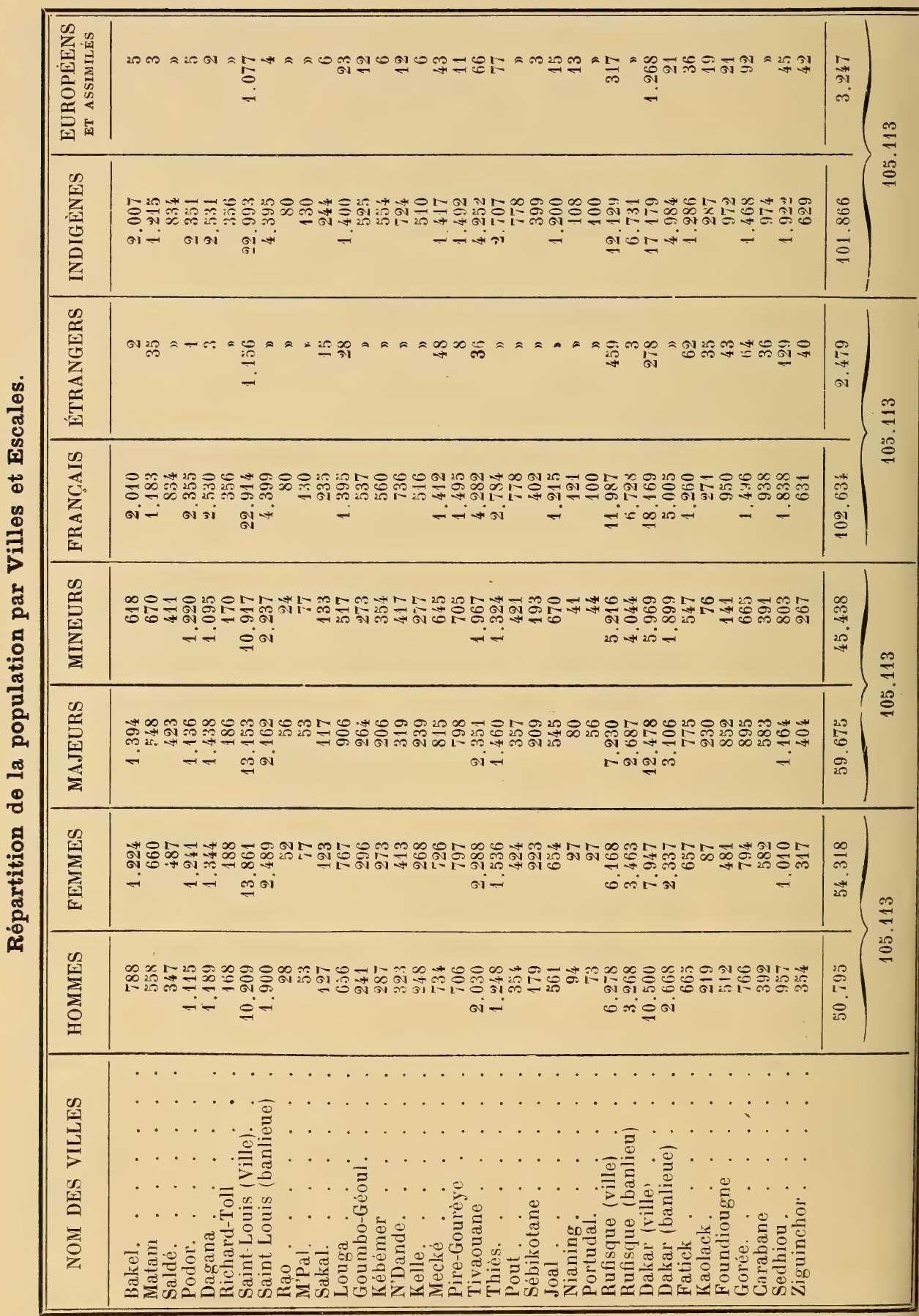




\section{Répartition par professions}

\begin{tabular}{|c|c|c|c|c|c|c|c|c|c|}
\hline tis. . & & & & & & & & & \\
\hline Armateurs . & . & & . & 6 & ardiniers . & . & . & & 47 \\
\hline Ajusteurs. & & . & . & 10 & Laitiers & . & . & & \\
\hline Boutiquiers & & . & . & 4 & atelassiers . & . & . & & \\
\hline ergers & & . & . & 8 & . & . & & & \\
\hline Bijoutiers. & & . & . & 9 & anœuvres . & . & & & \\
\hline seuse & & . & . & 289 & bouts & & & & \\
\hline rs. . & . & . & . & 148 & Marins . . & & & & \\
\hline ers . & • & . & . & 130 & iciens . & . & & & \\
\hline $\mathrm{ns}$. & & . & . & 2 & s . & . & & & \\
\hline Irs & & . & . & 47 & & & & & \\
\hline ari & & & . & 449 & & & & & \\
\hline , Rest & & rants. & & 39 & le lan & ngues & & & \\
\hline adi & & . & . & $\breve{~}$ & se & e colas & & & \\
\hline ts. & & . & . & 27 & res & & & & \\
\hline villag & & . & . & 13 & ninis & istériel & & & \\
\hline & & . & . & 29 & & & & & \\
\hline irs. & & . & . & 252 & & . & & & 80 \\
\hline & & . & . & 70 & & . & & & \\
\hline & & . & . & 21 & & . & & & 25 \\
\hline & & . & . & 14 & rs. & . & . & & \\
\hline ints & $\mathrm{s}$ & . & 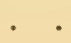 & & & . & & & \\
\hline & 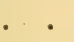 & . & . & & ns. & . & . & & \\
\hline & & . & . & & & u . & & & \\
\hline & & . & . & 534 & & . & & & 32 \\
\hline Irs . & & $\cdot$ & . & 22.493 & & . & & & \\
\hline & & $\cdot$ & . & 26 & & 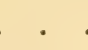 & & & \\
\hline des. & & . & . & 820 & & . & & & \\
\hline & & . & & 27 & & . & & & \\
\hline & & . & & 3.014 & & . & & & \\
\hline eurs & & 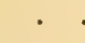 & - & כ" & fessio & on . & & & 43.12 \\
\hline & & 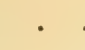 & & 66 & 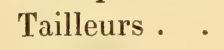 & 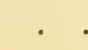 & & & 3 \\
\hline & co & & & 1.023 & es & . & & & $\delta$ \\
\hline aire & & & & 912 & & . & & & \\
\hline & & . & & 209 & iers & & & & \\
\hline & & . & & 8 & nts. & 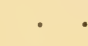 & & & 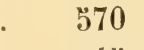 \\
\hline & chem & nin de & efer. & 91 & ses & & & & \\
\hline & anspo & ort & 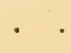 & & mme. & . & & - & \\
\hline & 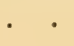 & 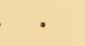 & & 204 & as . . & . & & & \\
\hline & - & . & & & Avocats & & & & \\
\hline aptots & & & & & & & & & \\
\hline
\end{tabular}


Tableau de la population répartie par nationalités.

Français nés en Europe . . . . . . . . . . . 2.804

Français nés dans les Colonies françaises . . . . . . . .

Noirs indigènes nés au Sénégal et jouissant de la qualité de français. .................

Noirs originaires des pays francais de l'Afrique occidentale autres que le Sénégal, . . . . . . . . . . . . . . .

\begin{tabular}{|c|c|}
\hline Allemands . . . . . . & 5 \\
\hline Américains . . . . . . & 7 \\
\hline Anglais. . . . . . . & 4 \\
\hline Belges .......... & 2 \\
\hline Espagnols . . . . . . & 3 \\
\hline Italiens. . . . . . . & 8 \\
\hline Portugais. . . . . . . & 8 \\
\hline Suisse ........... & 1 \\
\hline Colonies anglaises. . . . . . & 562 \\
\hline Golonies portugaises. . . . & 225 \\
\hline Colonies espagnoles. . . . & 5 \\
\hline$\ldots \ldots \ldots$ & 101 \\
\hline$d$ (marocains). . . . . & 112 \\
\hline & \\
\hline
\end{tabular}

Etrangers nés en Europe ou en Amérique ........

Noirs ètrangers nés dans les colonies européennes....

Etrangers nés en Asie (Syriens).

Total

Recensement à la date du $1^{\text {er }}$ juin 1904 des militaires résidant dans les territoires de la colonie du Sénégal.

\begin{tabular}{|c|c|c|c|c|}
\hline \multirow{2}{*}{ Lieux de résidence } & \multicolumn{3}{|c|}{ Militaires européens } & \multirow{2}{*}{$\begin{array}{l}\text { Militaires } \\
\text { indigènes }\end{array}$} \\
\hline & officiers & $\begin{array}{c}\text { hommes } \\
\text { de troupe }\end{array}$ & total & \\
\hline $\begin{array}{l}\text { Saint-Louis. } \\
\text { Dakar } \\
\text { Gorée } \\
\text { Rufisque } \\
\text { Thies. } \\
\text { M'Pal. } \\
\text { Louga } \\
\text { Dagana. } \\
\text { Podor } \\
\text { Bakel. } \\
\text { Kaolack } \\
\text { Sedhiou } \\
\text { Ziguinchor }: \cdots\end{array}$ & $\begin{array}{r}56 \\
87 \\
2 \\
3 \\
2 \\
1 \\
1 \\
2 \\
1 \\
》 \\
D \\
1 \\
1\end{array}$ & $\begin{array}{r}398 \\
503 \\
74 \\
14 \\
56 \\
7 \\
4 \\
4 \\
3 \\
2 \\
1 \\
4 \\
1\end{array}$ & $\begin{array}{r}454 \\
590 \\
76 \\
17 \\
58 \\
8 \\
5 \\
6 \\
4 \\
2 \\
1 \\
5 \\
2\end{array}$ & $\begin{array}{r}622 \\
277 \\
59 \\
173 \\
17 \\
98 \\
39 \\
40 \\
22 \\
32 \\
50 \\
34 \\
22\end{array}$ \\
\hline & 157 & 1.071 & 1.228 & 1.485 \\
\hline
\end{tabular}




\section{C. - Le crédit.}

L'organisation du crédit dans une colonie, doit occuper une place aussi importante dans les préoccupations de l'Etat colonisateur que la question foncière ou celle de la main-d'œuvre. Et on a pu dire très justement, à ce propos, que le crédit " est l'ensemble des divers moyens par lesquels le capital est mis à la disposition du travail pour l'exploitation agricole, industrielle et commerciale des colonies ».

La question du crédit a été posée de bonne heure au Sénégal où les activités se sont depuis longtemps manifestées. Elle a été heureusement résolue par l'établissement dans la colonie, de la Banque du Sénégal, transformée en 1901 en Banque de l'Afrique occidentale, qui a permis aux opérations de commerce et de banque de se développer avec toute la souplesse et l'ampleur nécessaires. Nous allons, après avoir dit quelques mots de la monnaie au Sénégal, étudier le fonctionnement de cet établissement de crédit et indiquer les opérations auxquelles il se livre.

La monnaie. - La monnaie circulant au Sénégal est la monnaie française ; elle est la seule ayant cours légal. Partout les transactions se font en argent, sauf toutefois avec les Maures, dans certaines escales du fleuve, où la valeur d'échange est constituée par les " guinées ». Encore l'usage des guinées va-t-il en diminuant au fur et à mesure de l'organisation de la Mauritanie.

Banque de l'A frique occidentale. - La circulation fiduciaire est assurée par les billets de la banque de France et par ceux de la banque de l'Afrique occidentale (art 10 du décret du 29 juin 1901) qui a une succursale à Saint-Louis et deux agences à Dakar et Rufisque.

Il est donc indispensable de dire quelques mots de cet établissement de crédit qui a succédé à la banque du Sénégal.

Institution. - Décret du 29 juin 1901. - La Banque de l'Afrique Occidentale, banque d'émission: de prêt et d'escompte a été 
instituée par décret du 29 juin 1901, avec privilège de 20 ans à partir du jour de sa constitution définitive (1).

Dans les colonies ou pays de protectorat où elle a des succursales ou des agences, la banque de l'Afrique occidentale est investie des droits et privilèges édictés par la loi au profit des banques coloniales ainsi que du droit d'émettre à l'exclusion de tous autres établissements, des billets remboursables au porteur et à vue. Ces billets sont des coupures de 1.000, 500, 100,

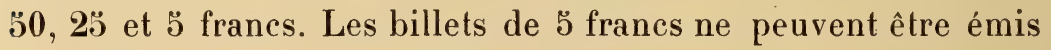
qu'avec autorisation du Ministre des Colonies, après avis conforme du Ministre des Finances. Il ne peut être émis de billets que par les succursales. Ces billets sont remboursables à vue, comme nous l'avons déjà indiqué, par la succursale ou agence qui les a émis et, en outre, par toutes succursales ou agences qui seraient désignées d'un commun accord par le Ministre des Colonies et la Banque. Le montant des billets en circulation de chaque succursale ne peut, en aucun cas, excéder le triple de son encaisse métallique dans laquelle est comprise celle des agences rattachées. De plus, le montant cumulé des billets en circulation, des comptes courants et des autres dettes de la banque ne peut excéder le triple du capital social et des réserves. Dans les colonies et protectorats français où la banque possède des établissements, les billets sont reçus comme monnaie légale dans la circonscription des succursales où ils sont payables.

Telles sont les principales dispositions du décret de création de 1901 qui approuve les statuts de la banque. Cet acte a été complété et modifié par un décret du 21 décembre 1901 donnant au Conseil d'administration la possibilité de déléguer tout ou partie de ses pouvoirs, et par deux autres décrets des 4 juin 1904 et 28 janvier 1906 portant modification aux statuts.

Statuts de la Banque. - Aux termes des statuts, le capital social primitivement fixé à $\mathbf{1 . 5 0 0 . 0 0 0 ~ f r a n c s , ~ p u i s ~ a ̀ ~} 5.895 .000 \mathrm{fr}$., a été porté (Décret du 28 janvier 1906) à 5986.000 francs et divisé en 11.973 actions de 500 francs chacune dont 9 entièrement

(1) Néanmoins, dans le cours de l'année 1911, un décret pris sur la proposition des ministres des Colonies, des Finances et des Affaires étrangères, pourra faire cesser le privilège à la date du 31 décembre 1912. 
libérées et $\mathbf{1 1 . 9 6 4}$ libérées seulement de $12 \%$ francs. Ces dernières sont jusqu'à leur entière libération, nominatives. Après leur libération elles sont, au choix des actionnaires, nominatives ou au porteur. Elles sont indivisibles, la société ne connaissant qu'un propriétaire par action.

La Banque ne peut en aucun cas et sous aucun prétexte faire d'autres opérations que celles qui lui sont permises par ses statuts.

Ses opérations. - Ces opérations consistent (Décret du 4 juin 1904):

$1^{\circ}$ A émettre des billets à vue et au porteur dans les conditions déterminées par le décret constitutif de la Banque ;

$2^{0}$ A escompter les billets à ordre ou effets de place, à deux ou plusieurs signatures, notoirement solvables, et dont l'échéance ne doit pas dépasser cent quatre-vingts jours; à consentir, dans les mêmes conditions, des avances en compte courant, sans que la durée de ces prêts puisse excéder six mois ;

$3^{\circ} \mathrm{A}$ créer, à négocier, à escompter ou acheter des traites, mandats ou chèques directs et à ordre sur la colonie, la métropole ou l'étranger.

L'échéance de ces traites ou mandats ne doit pas dépasser cent quatre-vingts jours.

$4^{\circ} \mathrm{A}$ escompter des obligations négociables ou non négociables garanties :

a) Par des warrants ou des récépissés de márchandises déposées soit dans les magasins publics, soit dans les magasins particuliers dont les clés auront été régulièrement remises à la Banque, soit dans les magasins appartenant à la Banque ou loués par elle;

b) Par des cessions de récoltes pendantes;

c) Par des connaissements à ordre et régulièrement endossés et accompagnés des documents d'assurance d'usage ; ‘̀ l'arrivée du navire, les connaissements peuvent être convertis en warrants ou récépissés de tout ou partie des cargaisons sous les conditions de dépôt ci-dessus stipulées ;

d) Par des nantissements réguliers consistant en valeurs françaises sur lesquelles la Banque de France fait des avances ou en valeurs créées ou garanties par les gouvernements ou les 
municipalités des pays dans lesquels les succursales ou les agences sont établies, ou en actions de la Banque ;

e) Par des dépôts de lingots, de monnaies ou de matières d'or, d'argent, de cuivre ou de pierres précieuses ;

f) Par des hypothèques maritimes constituées sur des navires français ou francisés dans les pays où sera mise en vigueur la législation française sur l'hypothèque maritime ;

$\breve{\partial}^{\circ} \mathrm{A}$ acheter et à vendre des matières d'or, d'argent ou de cuivre ;

$6^{\circ}$ A consentir des avances sur lingots, monnaies, matières d'or, d'argent ou de cuivre ;

$7^{\circ} \Lambda$ recevoir le dépôt volontaire de toutes sommes en comptes courants avec ou sans intérêts, de tous titres, monnaies et matières d'or, d'argent ou de cuivre.

Les opérations consistent aussi, à Paris et dans les succursales et agences :

$8^{\circ}$ A se charger, pour le compte des particuliers ou pour celui des établissements publics, de l'encaissement et du recouvrement des effets qui lui sont remis et à payer tous mandats et assignations ;

$9^{\circ}$ A recevoir, avec l'autorisation du ministre ou des gouverneurs de colonies, les produits des émissions et des souscriptions publiques ouvertes soitdans les colonies, soit dans la métropole;

$10^{\circ}$ A émettre des billets à ordre, traites ou mandats ;

$11^{\circ}$ A délivrer contre garanties des lettres de crédit;

$12^{\circ}$ A faire escompter en France ou à l'étranger, pour son compte, des traites ou mandats à deux signatures commerciales, ou garantis par des connaissements à ordre dûment endossés et accompagnés des documents d'assurance d'usage ;

$13^{\circ} \mathrm{A}$ faire acheter des matières d'or, d'argent ou de cuivre.

En outre, la Banque peut participeraux emprunts d Etatémis dans tous les pays où elle possède des établissements, sans toutefois que le montant total de ces participations puisse, sauf autorisation spéciale du Ministre des Colonies et après avis conforme du Ministre des Affaires étrangères lorsqu'il s'agit d'emprunts émis par un gouvernement étranger, dépasser la moitié des réserves. 
Elle peut également, dans les mêmes conditions et dans les mêmes limites, participer à la création ou à la constitution d'entreprises financières, industrielles ou commerciales ayant leur objet dans les pays où elle possède des établissements.

La Banque peut également traiter pour le compte de tiers et les représenter.

L'une des signatures exigées aux termes des statuts (art. 16) peut être suppléée, s'il s'agit d'effets de place ou d'obligations non négociables, soit par un dépôt de titres mobiliers, soit par la remise d'un warrant, récépissé ou acte de dépôt de marchandises, soit par la cession d'une récolte pendante aux conditions qui sont ci-après déterminées, soit par un dépôt de lingots, monnaies, matières d'or, d'argent ou de cuivre, soit par un transfert réguilier des créances dues par les municipalités légalement autorisées par le gouvernement colonial ou l'administration des protectorats; s'il s'agit de traites ou de mandats, par un connaissement avec affectation spéciale de la marchandise, accompagné de documents d'assurance.

La deuxième signature de la traite peut être également supplée par une déclaration d'acceptation anticipée envoyée par le tiré à la Banque ou par la notification à la Banque d'un crédit ouvert par le tiré au tireur.

Des règlements intérieurs arrêtés par le conseil d'administration déterminent dans quelle quotité et pour quelle valeur, les objets ou titres destinés à suppléer l'une des signatures statutaires prescrites pour les billets, traites ou obligations escomptés par la Banque, ou sur lesquels peuvent être consenties des avances, peuvent être acceptés par elle.

La proportion ne peut excéder les prix courants dressés par les courtiers ou par les Chambres de commerce, sil s'agit de marchandises déposées ou chargées ;

la valeur intégrale, s'il s'ágit de monnaies d'or et d'argent et de lingots ;

la valeur d'après le poids et le titre, s'il s'agit de matières d'or et d'argent;

le tiers de la valeur de la récolte ;

les 80 p. 100 de la valeur des titres indiquée par la dernière 
cote officielle connue dans la colonie, s'il s'agit de rentes sur l'Etat ou de valeurs garanties par les gouvernements ou les municipalités des pays où la Banque a des succursales ou des agences, et les 75 p. 100 s il s'agit de valeurs françaises sur lesquelles la Banque de France fait des avances ;

les 60 p. 100 de la valeur moyenne des actions cotées pendant les six derniers mois ;

les marchandises déposées ou chargées doivent être assurées par les soins des propriélaires et par une compagnie d'assurance agréée par la Banque.

Les divers effets escomptés par cet établissement doivent être timbrés, si la législation du timbre est appliquée dans les pays où elle possède des établissements.

La Banque refuse d'escompter les effets dits de circulation créés entre les signataires, sans cause ni valeur réelles. Aucun effet ou engagement revêtu de la signature d'un des agients de l'établissement ne peut être admis à l'escompte. Ces employés ne peuvent d'ailleurs faire aucun commerce, ni s'intéresser dans aucune entreprise commerciale.

Là Banque ne peut fournir des traites ou mandats que lorsque la provision a été préalablement faite.

Les titres représentant en totalité ou en partie le capital social et les réserves pourront être déposés en nantissement dans une banque de la métropole désignée par le ministre des Colonies, la Commission de surveillance entendue. Est considérée comme provision, l'existence totale ou partielle du capital social et de la réserve en France, ou le crédit otvert par un établissement de crédit de la métropole désigné par le ministre des Colonies, la Commission de surveillance entendue.

La Banque peut consentir des prêts sur récolte soit aux individus, soit aux collectivités agricoles ayant qualité de personne civile, dans les conditions de la loi organique des banques coloniales.

Lorsque ces prêts ont lieu avec le concours ou la garantie de l'administration locale, ils sont effectués dans les formes et conditions établies d'un commun accord par ladite administration et la Banque. 
Les obligations non négociables appuyées d'une cession de récoltes et donnant lieu à l'ouverture d'un compte courant, peuvent être à l'échéance prorogées jusqu'à l'achèvement de la récolte cédée.

La Banque peut stipuler que les denrées provenant de la récolte sont, au fur et à mesure de la réalisation, versées dansles magasins de dépôts désignés à cet effet, conformément aux prescriptions de la loi, et cela, de manière à convertir le prêt sur cessions de récoltes en prêt sur nantissement.

Les entrepôts de douane, les magasins appartenant à la Banque et tous autres magasins désignés, à cet effet, par le Gouverneur en Conseil privé sont considérés comme magasins publics, où peuvent être déposées les marchandises affectées à des nantissements couvrant complémentairement des eflets du portefeuille de la Banque. La marchandise est représentée par un récépissé ou warrant, qui peut être transporté par voie d’endossement.

En outre, la remise à la Banque des clés d'un magasin particulier est suffisante pour effectuer la tradition légale du gage déposé lorsque cette remise est régulièrement constatée, au moment de la négociation, par un récépissé du directeur de la succursale ou de l'agence, visé, s'il y a lieu, par le censeur administratif.

A défaut de remboursement à l'échéance des sommes prêtées, la Banque est autorisée, huitaine après une simple mise en demeure, à faire vendre aux enchères partous officiers publics, nonobstant toute opposition, soit les marchandises, soit les matières d'or, d'argent et de cuivre, soit les pierres précieuses données en nantissement, soit les récoltes cédées, soit leur produit, soit les titres mobilicrs donnés en garantie, sans préjudice des autres poursuites qui peuvent être exercées contre les débiteurs jusqu'à entier remboursement des sommes prêtées, en capital, intérêts et frais.

Lorsque le payement d'un effet a été garanti par l'une des valeurs énoncées aux articles 16 et 17 du décret du 4 juin 1904, la Banque pent, huit jours après le protêt, ou après une simple mise en demeure, faire vendre les marchandises ou les valeurs 
pour se couvrir jusqu'à concurrence due ; s'il s'agit de récoltes pendantes, la Banque a le choix de procéder à la vente sur pied ou de se faire envoyer en possession pour la fabrication.

Si les obligations ou effets garantis par l'une des valeurs désignées sous le numéro 4 de l'article 16 du décret précité, ne sont pas à ordre, le débiteur a le droit d’anticiper sa libération, et il lui est fait remise des intérêts à raison du temps à courir jusqu'à l'échéance.

Les garanties additionnelles données à la Banque ne font pas obstacle aux poursuites contre les signataires des effets; ces poursuites peuvent être continuées concurremment avec celles qui ont pour objet la réalisation des garanties spéciales constituées au profit de la Banque jusqu'à l'entier remboursement des sommes avancées en capital, intérêts et frais.

L'escompte est perçu ì raison du nombre de jours à courir et même d'un seul jour. Pour les effets payables à plusieurs jours de vue, l'escompte est calculé sur le nombre des jours de vue, et si ces effets sont payables soit hors du lieu où ils sont présentés à l'escompte, soit même hors de la colonie, le nombre des jours de vue est augmenté d'un délai calculé d'après les distances.

La Banque détermine par un règlement intérieur les conditions à remplir pour l'ouverture de comptes d'escomptes et de comptes courants. Elle fournit des récépissés des dépôts volontaires qui lui sont faits; le récépissé exprime la nature et la valeur des objets déposés, le nom et la demeure du déposant, la date du jour où le dépôt a été fait, et celui où il peut être retiré, enfin le numéro du registre d’inscription. Le récépissé n'est pas à ordre et ne peut être transmis par voie d'endossement.

La Banque perçoit immédiatement sur la valeur des dépôts sur lesquels il n'a pas été fait d'avances un droit de garde dont la quotité est fixée par les règlements intérieurs. Lorsque, sur la demande du déposant, des avances lui sont faites avant l'époque fixée pour le retrait du dépôt, le droit de garde perçu reste acquis à la Banque. Sa situation est publiée tous les mois au Journal officiel, à Paris.

Chaque succursale ou agence publie également sa situation 
mensuelle dans le journal de la colonie désigné à cet effet par le Gouverneur.

Fonds de réserve et dividende. - Les livres et les comptes sont balancés et arrêtés tous les 6 mois à l'époque du 30 juin et du 31 décembre. Le résultat des opérations de la banque est établi, sans que les créances en souffrance puissent être comprises dans le compte de l'actif pour un chiffre excédent le $1 / 5$ de leur valeur nominale.

Sur les bénéfices nets et réalisés pendant le semestre, il est fait un prélèvement de $1 / 20 / 0$ du capital versé destiné à former un fonds de réserve. Un premier dividende équivalent à $500 / 0$ par an du capital versé est ensuite distribué aux actions.

Ces prélèvements faits, lè surplus des bénéfices se partage de la manière suivante :

$100 / 0$ à un fonds de prévoyance; $100 / 0$ au Conseil d'administration; et les $800 / 0$ de surplus sont répartis entre toutes les actions proportionnellement à la somme dont elles sont libérées, comme second dividende.

Sur cette dernière attribution de $800 / 0$, faite aux actionnaires, l'assemblée générale pourra, sur la proposition du Conseil d'administration, décider la création de réserves spéciales ou temporaires.

Dans le cas où l'insuffisance des bénéfices ne permettrait pas de distribuer aux actionnaires un dividende de $ّ 0 / 0$ par an sur le capital versé, la somme nécessaire pour atteindre cette proportion de כٌ $0 / 0$ peut être prélevée sur le fonds de prévoyance et les réserves spéciales et temporaires.

Aucune de ces répartitions ne pourra être faite sans l'approbation du Ministre des Colonies.

Tous les dividendes qui ne sont pas réclamés dans les כ̋ années de l'exigibilité sont prescrits au profit de la société. Ces dividendes sont payés, après approbation du Ministre des Colonies, aux caisses de la banque à $\mathrm{P}$ aris et dans les succursales.

\section{Administration de la Banque.}

a) Assemblée générale. - Luniversalité des actionnaires est représentée par l'assemblée générale. L'assemblée générale se 
compose de tous les actionnaires possédant au moins dix actions.

Tous propriétaires de moins de dix actions peuvent se réunir pour former le nombre de dix et se faire représenter par l'un d'eux. Toutefois, nul actionnaire non français ne peut faire partie de l'assemblée générale, s'il n'a son domicile depuis cinq ans au moins dans une colonie française ou en France.

Les propriétaires d'actions au porteur doivent en faire le dépôt cinq jours a vant la date de l'assemblée générale et en échange, il leur est délivré un récépissé nominatif qui sert de carte d'entrée.

On dresse ensuite une liste des actionnaires ayant déposé leurs actions; cette liste contient les noms et domiciles des actionnaires, ainsi que le nombre d'actions dont chacun d'eux est porteur, et le jour de l'assemblée elle est placé sur le bureau.

Nul ne peut se faire représenter à l'assemblée que par un mandataire membre de l'assemblée. Par exception, le délégué d'une société actionnaire représentera valablement cette société sans être lui-même personnellement actionnaire.

Les délibérations sont prises à la majorité des voix des membres présents. Dix actions donnent droit à une voix, sans que la même personne puisse réunir plus de dix voix, tant en son nom que comme mandataire.

L'assemblée générale se réunit de droit chaque année, dans le courant du second semestre, au siège de la société ou au lieu indiqué par les avis de convocation. Elle est convoquée par le conseil d'administration et présidée par le président du conseil, à son défaut par le vice-président ou un administrateur désigné par ses collègues.

Les fonctions de scrutateur sont remplies par les deux plus forts actionnaires présents, et, à leur refus, par ceux qui les suivent, par ordre d'inscription, jusqu'à l'acceptation. Le bureau désigne le secrétaire.

L’assemblée générale entend le rapport du Conseil d'administration sur la situation des affaires sociales et sur les questions à l'ordre du jour. Elle discute, approuve ou rejette les comptes, fixe les dividendes à répartir conformément aux articles 32 et 33 des statuts et nomme les administrateurs.

Les nominations ont lieu par bulletin secret si la demande en 


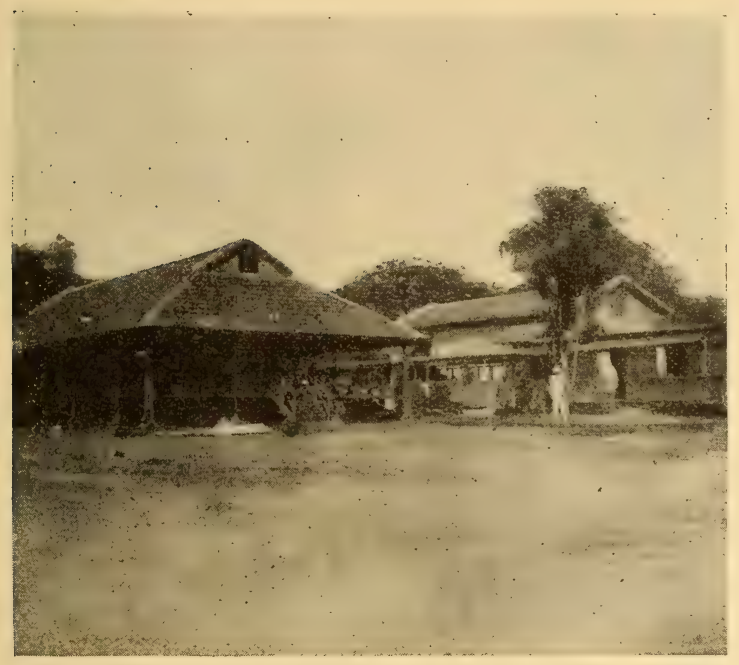

Fig. 37. - Gare de chomin de fer.

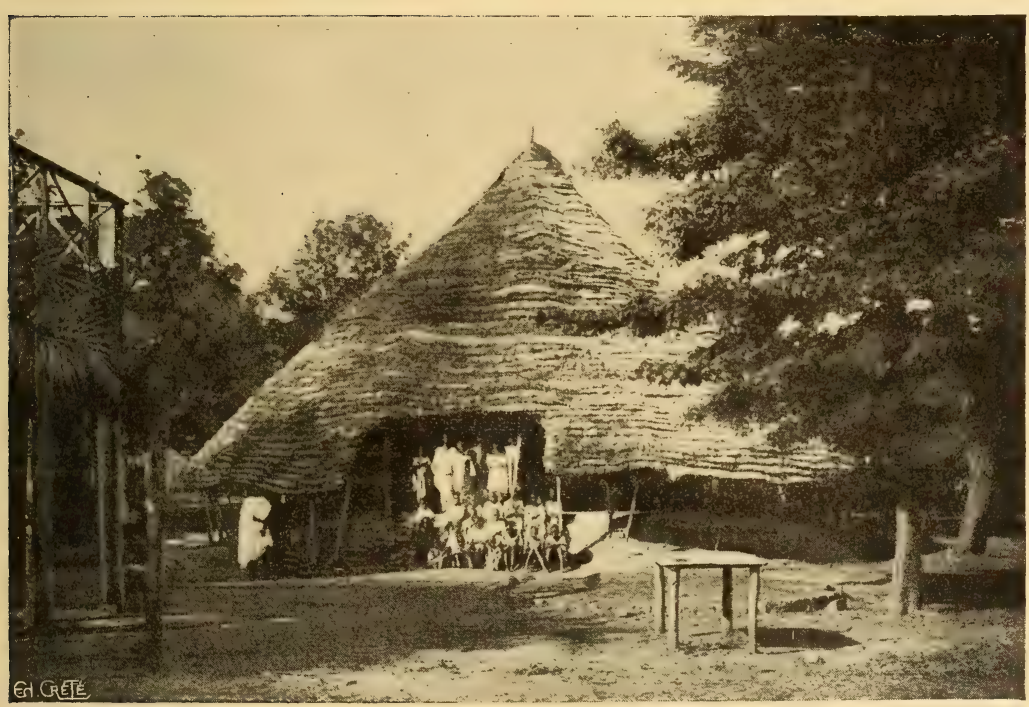

Fig. 38. - Une école indigine. 

est faite, et à la majorité absolue des suffrages des membres présents. Après deux tours de scrutin, s'il ne s'est pas forméde majorité absolue, l'assemblée procède au scrutin de ballottage entre les deux candidats qui ont réuni le plus de voix au second tour. Lorsqu'il y a égalité de voix au scrutin de ballottage, le plus agé est élu.

Elle délibère sur toutes les questions qui lui sont soumises par le conseil et, notamment, sur l'augmentation ou sur la réduction $\mathrm{du}$ fonds social, sur l'extension à donner aux affiaires de la société, sous réserve des stipulations de l'article 5, sur la création de nouvelles succursales, sur les modifications à apporter aux statuts, sur la prolongation ou la dissolution anticipée de la société, sur sa transformation en société de toute autre forme, notamment en cas de cessation des privilèges qui lui sont accordés par le décret de constitution, et généralement sur toutes les propositions prévues et non prévues par les statuts.

L'assemblée générale doit être composée d'un nombre d'actionnaires représentant le quart au moins du capital social.

Si elle ne réunit pas ce nombre, une nouvelle assemblée est convoquée dans le délai d'un mois, el elle délibère valablement, quelle que soit la proportion du capital représenté par les actionnaires présents, mais seulement sur les objets qui ont été mis à l'ordre du jour de la première réunion.

L’assemblée générale peut être convoquée extraordinairement toutes les fois que le conseil d'administration en reconnaîtra la nécessité.

Elle doit être convoquée extraordinairement:

$1^{0}$ Lorsque des actionnaires, réunissant ensemble le tiers au moins des actions, en ont adressé par écrit, au conseil d'administration, la demande motivée, auquel cas la convocation de l'assemblée générale doit avoir lieu dans un délai de deux mois ;

$2^{0}$ Dans le cas où les pertes résultant des opérations de la Banque réduiraient le capital de moitié.

Les ass emblées générales appelées à délibérer sur les modifications aux statuts, sur des propositions de continuation de la société au delà du terme fixé pour sa durée ou de dissolution 
avant ce terme, ne sont règulièrement constituées et ne délibèrent valablement qu'autant qu'elles sont composées d'un nombre d'actionnaires représentant au moins la moitié du capital social. Les avis de convocation indiquent sommairement l'objet de la réunion.

Si les assemblées générales appelées à délibérer sur les modifications aux statuts, sur des propositions de continuation de la société au delà du terme fixé pour sa durée, ou de dissolution avant ce terme, ne réunissent pas un nombre d'actionnaires représentant la moitié au moins du capital social, une seconde assemblée cst convoquée dans le délai d'un mois et elle délibère valablement, quel que soit le nombre des actionnaires présents ou représentés.

Les convocations ordinaires et extraordinaires sont faites pour les actions nominatives par lettres individuelles adressées aux actionnaires membres de l'assemblée générale, au domicile par eux indiqué sur les registres de la Banque, et, pour toutes les actions sans distinction, par un avis inséré quinze jours au moins avant la réunion, dans les deux journaux de Paris désignés pour la publication des actes de société, et un mois au moins dans le Journal officiel de l'Afrique occidentale.

Les lettres et l'avis doivent contenir l'indication sommaire de l'objet de la convocation. Tout actionnaire qui veut soumettre une proposition à l'assemblée générale doit l'adresser cinq jours à l'avance au conseil d'administration, qui décide s'il y a lieu de la porter à l'ordre du jour. Aucune autre question que celles inscrites à l'ordre du jour arrêté par le conseil d'administration et consignées dans le registre des délibérations, ne peut être mise èn délibération. Huit jours avant la réunion, un résumé de la situation de la Banque sera tenu à la disposition des actionnaires, au siège de la société.

Les délibérations des assemblées prises conformément aux statuts obligent tous les actionnaires, même ceux qui sont absents ou dissidents. Elles sont constatées par des procès-verbaux insčrits sur un registre spécial et signés par le président, les scrutateurs et le secrétaire. Ce registre reste au siège de la société. Une feuille de présence, destinée à constater le nombres des 
membres assistant à l'assemblée et celui de leurs actions, demeure annexée à la minute du procès-verbal; elle est revêtue des mêmes signatures.

Les justifications à faire, vis-à-vis des tiers, des délibérations de l'assemblée générale résultent des copies ou extraits certifiés par le président du conseil d'administration ou par deux administrateurs.

Le Conseil d'administration : sa composition. - La Banque est administrée par un conseil d'administration composé de

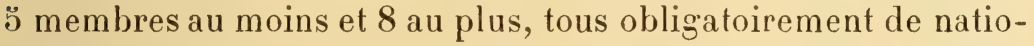
nalité française.

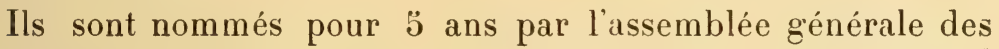
actionnaires et leur renouvellement a lieu par cinquième chaque année; ils sont rééligibles. En entrant en fonctions, chacun des administrateurs est tenu de justifier qu'il est propriétaire de 20 actions. Ces actions doivent être libres et demeurer inaliénables pendant toute la durée de ses fonctions. Les administrateurs recoivent des jetons de présence dont le montant est déterminé par l'assemblée générale.

Ses pouvoirs. - Le conseil est investi des pouvoirs les plus étendus pour l'administration des affaires de la Banque. Il délibère notamment sur toutes les affaires, il fait tous les règlements du service intérieur de la Banque, fixe le taux de l'escompte et de l'intérêt, les changes, commissions et droits de garde, le mode à suivre pour l'estimation des lingots, monnaies ou matières d'or et d'agent, des marchandises ou récoltes.

Il autorise dans la limite des statuts toutes les opérations de la Banque et en détermine les conditions et fixe l'emploi de la réserve et $d u$ fonds de prévoyance ; il fait choix des effets ou engagements qui peuvent être admis à l'escompte, sans avoir besoin de motiver le refus, autorise l'emploi des disponibilités en achat de papier sur la France et l'étranger.

Il statue sur la signature dont les billets de la Banque doivent être revêtus, sur les retraits et l'anuulation de ces billets; autorise tous les traités, transactions, emplois de fonds, transferts de rentes sur l'Etat et autres valeurs, achats de créances et autres droits incorporels, cessions des mêmes droits avec ou sans 
garanties, désistements d'hypothèques ou privilèges, abandons de droits personnels ou réels, mainlevées d'inscription ou d'oppositions, le tout avec ou sans payement; exerce toutes les actions judiciaires, tant en demandant qu'en défendant, participations à des concordats amiables ou judiciaires, acquisitions ou aliénations d'immeubles, emprunts et constitutions d'hypothèques.

Il autorise la demande de toutes concessions d'immeubles et autres, aux conditions qui seront imposées par actes et décrets de concession, toutes les opérations et tous les travaux faisant l'objet de la société, le renouvellement et l'encaissement de toutes créances, effets de commerce et valeurs de toute nature appartenant à la société, il veille à ce que la Banque ne fasse d'autres opérations que celles déterminées par ses statuts et dans les formes prescrites par les règlements intérieurs de la Banque ; il convoque les assemblées générales, arrête leur ordre du jour et détermine les questions qui y seront mises en délibération. Il fixe en outre l'organisation de bureaux, les appointements, salaires, rémunérations et gratifications des agents ou employés, et les dépenses générales de l'administration.

Il est expressément convenu que les pouvoirs qui viennent d'être indiqués sont purement énonciatifs et non limitatifs, et n'apportent aucune restriction au principe qui confère tous pouvoirs au conseil d'administration.

Le conseil peut déléguer tout ou partie des pouvoirs qui précèdent (D. 29 décembre 1901), et il nomme un président, un vice-président pris dans son sein et un secrétaire.

Il est tenu un registre de ses délibérations et le procès-verbal, est signé par le président et par le secrétaire. 11 se réunit au siège social au moins une fois par mois, mais il peut se réunir extraordinairement toutes les fois que les intérêts de la société l'exigent ou que la demande en est adressée au président, par le commissaire du Gouvernement.

Les délibérations sont prises à la majorité des voix des membres présents; en cas de partage, la voix du président est prépondérante. 
Les administrateurs absents peuvent se faire représenter aux délibérations du conseil, pour un objet spécial et déterminé, par un de leurs collègues. En aucun cas, cette taculté ne peut donner au même administrateur plus d'une voix en sus de la sienne. Aucune délibération n'est valable si trois administrateurs au moins n'ont pris part à la discussion.

Le compte des opérations de la Banque, qui doit être présenté à l'assemblée générale, est arrêté par le conseil d'administration ; ce compte est imprimé et adressé au Ministre des Colonies ; il est remis à chacun des membres de l'assemblée générale.

Le conseil d'administration nomme, avec l'agrément du Ministre des Colonies, les directeurs chargés, sous son autorité, de la gestion des affaires sociales et fixe leur traitement. Ces directeurs représentent la société à l'égard des tiers pour l'exécution des décisions du conseil.

Il est établi auprès de chaque succursale un conseil d'escompte dont la composition, les attributions et les émoluments ont été déterminés par un règlement du conseil d'administration.

Les actions judiciaires sont exercées au nom du conseil d'administration, poursuites et diligences du directeur. La Banque peut être assignée, au choix du demandeur, soit devant la juridiction du siège social, soit devant la juridiction du siège de la succursale intéressée, sauf les cas prévus expressément (article 69 du Décret du 29 juin 1901).

En entrant en fonctions, le directeur doit justifier de la propriété de quarante actions qui demeureront inaliénables pendant la durée de ses fonctions et restent déposées dans les caisses de la Banque.

Commissaire du Gouvernement et censeurs administratifs. Un commissaire du Gouvernement nommé par le Ministre des Colonies est établi auprès de la Banque de l'Afrique occidentale.

Le commissaire du Gouvernement est convoqué à chaque séance du conseil d'administration et de l'assemblée générale des actionnaires. Il veille à l'exécution des statuts et des règlements de la banque; il excerce sa surveillance sur toutes les parties de l'établissement, il se fait représenter l'état de caisse, 
les registres et les portefeuilles, il requiert tous les extraits et copies des livres de la Banque. 11 propose toutes les mesures qu'il croit utiles, et peut faire inscrire de droit ses propositions et observations sur le registre des délibérations du conseil d'administration. Il adresse chaque mois, au Ministre, un rapport sur la marche de la Banque, appuyé de la copie certifiée des procès-verbaux du conseil d'administration et des situations mensuelles de la Banque et de chacune des succursales.

En cas d'absence ou d'empêchement du commissaire du Grouvernement, le Ministre des Colonies lui nomme un suppléant.

Un censeur administratif peut être nommé par le Ministre des Colonies, près de chaque succursale de la Banque; pour les succursales sises en dehors du territoire de la République, cette désignation est faite après avis du Ministre des Affaires étrangères.

Les censeurs administratifs remplissent dans les succursales les fonctions attribuées au commissaire du Gouvernement au siège social. Ils requièrent inscription de leurs observations sur un registre destiné à cet effet, ils correspondent avec le Gouverneur et le Ministre, et rendent compte chaque mois, et plus souvent s'il y a lieu, de la surveillance qu'ils excercent.

En cas de décès, de démission ou d'empêchement d'un censeur administratif, le Gouverneur de la colonie désigne un intérimaire.

Le traitement du commissaire du Gouvernement et des censeurs administratifs, est fixé par arrêté du Ministre des Colonies, et payé par la Banque.

Le Ministre et les Gouverneurs, soit d'office, soit sur la demande de la commission de surveillance des banques coloniales, peuvent, lorsqu'ils le jugent convenable, faire procéder par les agents qu'ils désignent, à toute vérification des registres, des caisses et des jopérations de la Banque.

Pour donner une idée des opérations des succursales et agences au Sénégal de la banque de l'Afrique occidentale nous donnons ci-après le bilan au 10 juin, le dernier publié. 

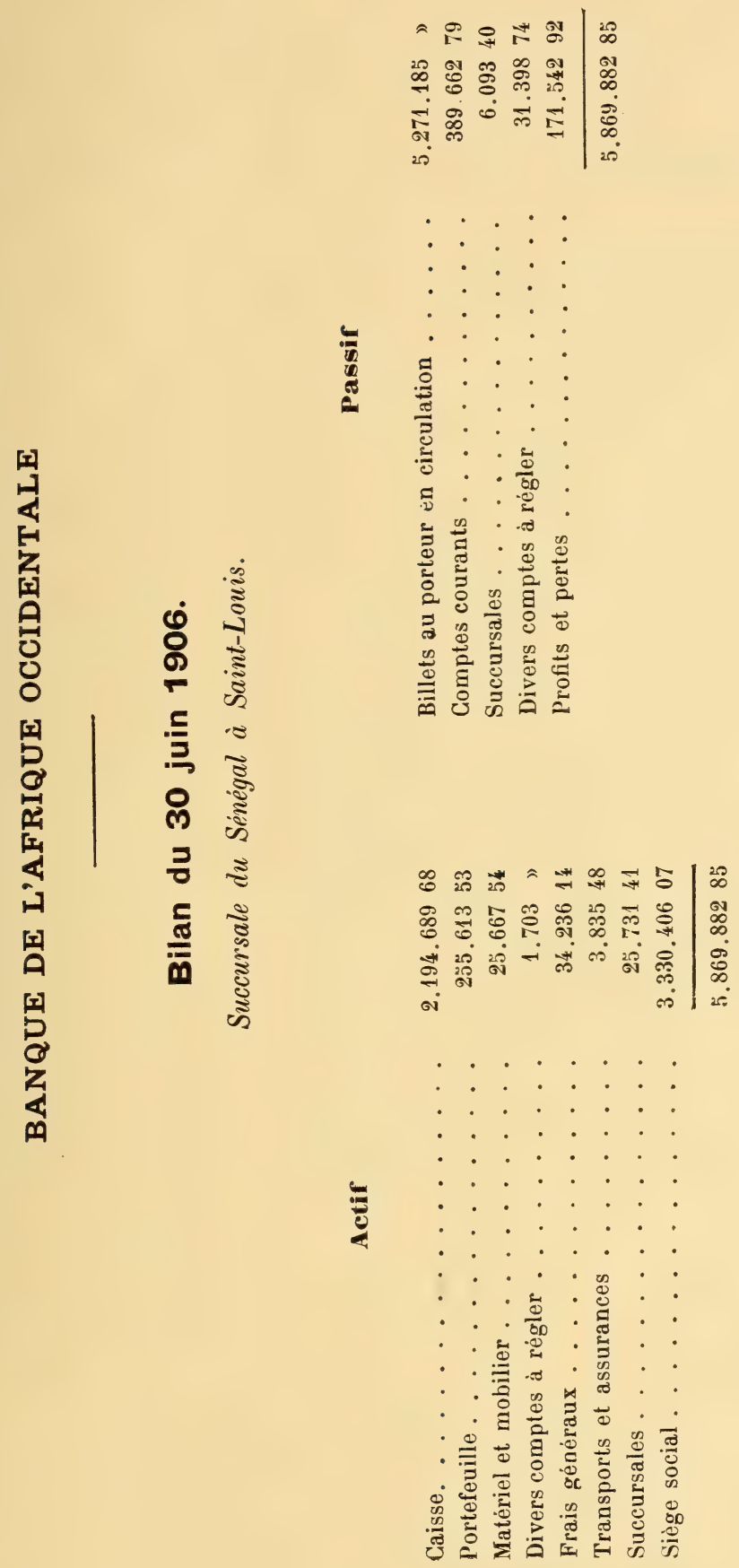


\section{CHAPITRE XIII}

OUTILLAGE ÉCONOMIQUE

La colonisation n'est possible qu'avec des moyens de communication, et cette vérité apparait au Sénégal peut-être plus clairement que partout ailleurs. Colonie essentiellement commerciale et agricole, on peut juger de quelle utilité lui est le fleuve Sénégral, cette large voie navigable, qui draine tout le trafic de l'arrière pays et du Soudan et combien il est nécessaire d'en améliorer le cours encore difficile. On verra le mouvement énorme de voyageurs et de marchandises qui s'effectue sur le chemin de fer de Dakar à Saint-Louis et on pourra apprécier la nécessité et l'urgence des travaux d'agrandissement et d'aménagement que l'on effectue actuellement dans les grands ports de la colonie. On devinera enfin l'essor considérable que ne pourra manquer de donner au commerce, non seulement du Sénégal mais encore de tout le Soudan, la construction de la ligne projetée entre Thiès et Kayes.

Nous allons donc examiner au cours de ce chapitre les divers travaux qui ont été exécutés et indiquer ceux qui sont projetés, pour donner à la colonie un outillage économique conforme à son développement.

Nous étudierons successivement :

A. Les voies fluviales et l'aménagement des ports ;

B. Les chemins de fer ;

C. Les travaux divers et les ouvrages projetés;

D. Les communications postales et télégraphiques. 


\section{A. - Voies fuviales et aménagement des ports.}

Ainsi que nous l'avons dit, le fleuve Sénégal est un merveilleux instrument de communication entre l'Océan et l'arrière pays. Tous les produits des fertiles régions qui sont traversées, peuvent trouver gràce à cette voie un débouché facile et peu coûteux. Malheureusement, ce large fleuve, ainsi d'ailleurs que la plupart des autres cours d'eau africains, a un cours fort difficile par moment et un lit souvent encombré d'écueils. Aussi a-t-il été nécessaire, dans le but de remédier à ces inconvénients, de procéder à une étude complète et approfondie du fleuve.

En 1903 furent constituées à cet effet deux missions d'études l'une dite "Mission hydrographique " chargée plus spécialement de l'établissement d'une carte de la navigation sur le fleuve, l'autre dénommée "Mission topographique " et qui devait procéder au nivellement général de la région.

Mission hydrographique du Sénégal. - La mission hydrographique dont le chef était le Lieutenant de vaisseau Mazeran, connu déjà par une remarquable mission de même ordre sur le Mékong, commença par recueillir pendant plus d'une année tous les renseignements nécessaires à l'établissement d'une carte détaillée du lit du fleuve. En même temps qu'un levé était fait au théodolite, des sondages nombreux étaient exécutés suivant des lignes transversales, espacées de 50 mètres au plus, donnant ainsi en tout point la profondeur et la nature du fond. Ces sondages étaient rapportés à des repères provisoires et ramenés ensuite au niveau des plus basses eaux, au moment de l'étiage.

Ce travail fut exécuté en plusieurs campagnes. Les officiers de la Mission s'occupent actuellement de coordonner leurs diverses observations pour établir une carte. Celle-ci doit comprendre environ $2 \ddot{b}$ feuillets au $1 / 3000$ et formera un atlas donnant les renseignements les plus complets.

Les cotes de différents points portés sur les cartes et repérés 
par rapport aux basses eaux ont été comprises dans le nivellement général. Il sera donc possible d'avoir, avant peu, la cote d'un point quelconque du lit par rapport au niveau de la mer.

Dès que le lieutenant de vaisseau Mazeran eût achevé l'hydrographie de la partie amont du fleuve, le balisage fut entrepris.

Le lit du Sénégal est généralement constitué par des banes de sable placés au pied de deux berges argileuses. En certains points cependant des éperons rocheux, parfois très élevés au-dessus du fond, font saillie dans ces terrains, et constituent de véritables éceuils. Sur chacun de ces rochers a été placé une tour en maçonnerie éclairée pendant la nuit.

En d'autres points, particulièrement dans la région voisine de Kayes, le sable est reinplacé par un vaste banc rocheux, à peu près plat, formé par d'énormes dalles dont le courant a usé successivement toutes les saillies, si bien qu'il n'en reste guère qui dépassent 50 centimètres. Ces seuils ne peuvent être à proprement parler considérés comme des dangers et leur fâcheuse renommée tient surtout à la faible durée de la période de la crue pendant laquelle ils sont surmontés d'une hauteur d'eau suffisante, de sorte que pendant le reste de l'année, les chalands s'y échouent et s'y disjoignent. Dès que la hauteur d'eau existe il n'y a qu'un faible avantage à y adapter une route particulière, qui ne peut faire gagner que quelques décimètres. Le balisage de ses seuils a donc été prévu dans les mêmes conditions que celui du reste du fleuve, une échelle de crue devant toutefois être placée dans la région pour indiquer aussi exactement que possible aux navigateurs la profondeur qu'ils sont assurés de trouver.

Jans le balisage général du fleuve, les alignements n'ont généralement, pas été employés, les connaissances des pilotes indigènes ne permettent pas actuellement d'espérer qu'ils en comprendraient les indications. Il est établi sur les rives un certain nombre de signaux faisant connaitre en chaque point à quelle distance approximative il faut passer de la rive. Ce système très complet et très simple de balisage permet, mème à 
un capitaine qui remonte pour la première fois, de contrôler continuellement les indications du pilote.

Aussi depuis l'exécution de leurs balises en 1904, n'a-t-on signalé aucun échouage dans les parties balisées du fleuve Sénégal, autrefois si redouté des capitaines et inconnu même des pilotes. En outre, la sécurité plus grande permet de mieux profiter de la crue et de tenter plus tôt et plus longtemps le passage de certains seuils, sur lesquels une route plus favorable est aujourd'hui repérée.

Mission topographique. - En même temps que la Mission hydrographique opérait dans le lit du fleuve, lạ Mission topographique sous les ordres du capitaine du Génie Mathy procédait sur les berges au nivellement général de Kayes à Saint-Louis. Les opérations furent faites au moyen de niveaux Goulier à lunette. En même temps était levée à la planchette une carte générale des berges.

Des repères ont été placés en différents points intermédiaires.

Le résultat des opérations a causé un étonnement geénéral. D'après les idées reçues on estimait que Kayes se trouvait à près de 100 mètres au-dessus du niveau de la mer. Or, c'est une différence de $\mathbf{2} \mathbf{4}$ mètres seulement qui a été constatée entre Kayes et le zéro de Saint-Louis. Cette pente particulièrement faible peut faciliter considérablement la canalisation ou l'amélioration de la navigabilité du Sénégal.

La surface supérieure du fleuve a été rapportée également au nivellement général.

Port de Saint-Louis. - L'arrivée à Bamako, puis à Koulikoro, du chemin de fer de Kayes au Niger, les améliorations apportées par le balisage à la navigabilité du Sénégal, qui auront dès maintenant pour résultat de diminuer le prix dı fret, en attendant que des travaux d'aménagement soient entrepris sur cette voie de pénétration, permettent d'espérer pour les années prochaines un développement rapide du commerce du Soudan. On n'ignore pas que dans les conditions actuelles, ce commerce se fait par la voie fluviale entre Saint-Louis et Kayes, principalement pendant la période des crues. Les navires de mer qui peuvent à cette époque faire plusieurs voyages jusqu'à 
Kayes, déposent à Dakar une partie de leur chargement pour arriver à franchir avec un faible tirant d'eau la barre du Sénégal. Cies marchandises sont pendant ce temps envoyées à SaintLouis et reprises en ce dernier point par ces mêmes bâtiments. Si onéreuses que soient ces opérations, elles sont les seules qui permettent d'effectuer le commerce avec le Soudan et l'on voit quelle importance en résulte pour le port de Saint-Louis.

Pendant la saison d'étiage le ròle de cette place reste également prépondérant. C'est là que sont transbordées dans les chalands ou bàtiments fluviaux qui peuvent remonter le Sénégal, toutes les marchandises amenées par les bateaux de mer ou par le chemin de fer de Dakar à Saint-Louis.

A l'exportation, c'est à Saint-Louis que s'effectue l'opération inverse.

Or, en aucun point, les quais actuels n'offrent plus d'un mètre cinquante de tirant d'eau, cette hauteur descend parfois au dessous de $0 \mathrm{~m}$. 50 obligeant ainsi les navires à se tenir éloignés des quais et à opérer leur chargement ou leur déchargement par l'intermédiaire de passerelles volantes. En outre, l'espace compris entre les quais et l'alignement des constructions reste partout insuffisant, variant de 6 mètres seulement à l'extrémité Sud.

Les quais actuels, séparés en deux tronçons par le Pont Faidherbe, comprennent seulement :

Dans la partie Nord, une longueur de 360 mètres au bout de laquelle la largeur moyenne disponible pour les opérations commerciales atteint à peine 10 mètres, offrant ainsi au commerce une superficie de $\mathbf{3 . 6 0 0}$ mètres carrés environ.

Dans la partie Sud, une longueur de $\mathbf{4 0 0}$ mètres, réservant pour les opérations commerciales sur les quais une surface de 6.000 mètres carrés environ.

La surface totale sur laquelle actuellement s'effectuent les opérations commerciales est donc inféricure à 10.000 mètres carrés pour une longueur de quais inférieure à 800 mètrcs.

Ces chiffres indiquent nettement combien ces ouvrages sont insuffisants et l'on conçoit de quelle utilité seraient de nouveaux quais présentant à leur pied une hauteur d'eau beaucoup plus 
considérable et offrant une superficie telle que les navires puissent, en toutesaison, se livrer à leurs diverses manutentions avec la facilité désirable.

Le 22 juillet 1904, un arrêté du Gouverneur général de l'Afrique Occidentale française, promulguant le décret du 3 juillet précédent, autorisait l'ouverture des travaux de construction de quais à Saint-Louis.

Les difficultés spéciales causées par le fond vaseux du lit du fleuve sous lequel il faut fonder les ouvrages à une profondeur de 8 mètres, les précautions que nécessitera l'exécution de ces travaux dans des terrains malsains, le peu d'importance des crédits prévus qui ne permettent pas de dépenser plus de $1.300 \mathrm{fr}$. environ par mètre courant d'ouvrage, ont exigé des études et des essais d'une longue durée.

A la suite de ceux-ci, il a été soumis à l'approbation ministérielle un programme de concours, laissant toute latitude aux entrepreneurs dans le choix du système de construction.

Les grandes lignes de ce programme peuvent être résumées comme suit :

Les nouveaux quais seront établis sur le grand bras du fleuve en avant des quais actuels.

$\mathrm{Au}$ nord du pont Faidherbe ils s'étendront sur 625 mètres de longueur, avec des hauteurs d'eau à leur pied de $3 \mathrm{~m} .50$ à 4 mètres et réserveront aux opérations commerciales une superficie de 13.350 mètres carrés.

$\mathrm{Au}$ sud de ce pont ils auront 520 mètres de longueur avec des hauteurs d'eau à leur pied de $3 \mathrm{~m}$. 50 à 4 mètres et pourront offrir au commerce jusqu à $\mathbf{1 4 . 8 5 0}$ mètres carrés de surface de quais.

Au total la longueur des quais sera portée de 760 mètres à 1.150 mètres, la surface affectée aux opérations commerciales passant ainsi de 9.700 à 28.200 mètres carrés et le tirant d'eau moyen atteignant 4 mètres au lieu de 1 mètre.

Il est en outre prévu qu'une cale de halage destinée aux chalands sera notablement améliorée et pourvue d'un berceau posé sur galets de roulement et de treuils de puissance suffisante. Enfin dernièrement, les quais existant à l'extrémité Nord de l'île 
ont été remis en état et sont accessibles sur 510 mètres de longueur aux batiments de 1 mètre de tirant d'eau.

Port de Dakar. - L'anse de Dakar est le seul point du littoral occidental de l'Afrique qui soit naturellement protégé des grosses mers : la rade sùre, spacieuse et profonde qu'elle offre aux bateaux devait faire de cette ville un grand port maritime.

Placée à l'extrémité de la presqu'île la plus avancée dans l'Océan Atlantique, sa situation géographique la désigne comme escale rationnelle des grandes lignes de navigation de l'Amérique du sud et de l'Afrique méridionale.

Longtemps, le commerce du Sénégal fut concentré à Gorée, où étaient établis les grands entrepôts des maisons de commerce et à Saint-Louis qui, situé près de l'embouchure du Sénégal, commande la navigation fluviale et sert de point de passage obligé à toutes les marchandises en provenance ou à destination du Soudan ou du Niger.

Si l'accès de ce fleuve n'était pas gêné par la barre mouvante et capricieuse qui oblige les bateaux à attendre quelquefois de longues heures et rend toujours la manœuvre dangereuse et pénible, il n'est pas douteux qu'on eût fait de Saint-Louis à la fois le port maritime et fluvial du Sénégal.

Mais Dakar possédait sur Saint-Louis des avantages nombreux, notamment une position unique, et ce qui est mieux encore une rade merveilleuse.

Il devait fatalement ramener à lui la plus grande partie du commerce du Sénégal; le développement aussi brillant que rapide qu'il acquit dès qu'on songea à le doter des premiers ouvrages constitutifs d'un port, le montre clairement.

Les aménagements successifs qui ne datent pas de longtemps, et bien qu'insuffisants, apportèrent déjà une grande amélioration et rendirent d'immenses services au commerce.

Ce fut d'abord la grande jetée Nord de $\mathbf{4 0 0}$ mètres de longueur, qui ferme la rade et abrite 250 mètres de quais près desquels sont établis les pares à charbon de l'Etat et ceux des Messageries maritimes ; puis la petite jetée dont le quai Ouest seul praticable fournit 280 mètres de quais accostable aux vapeurs d'un tirant d'eau allant jusqu'à $ّ$ m. $ّ 0$. 


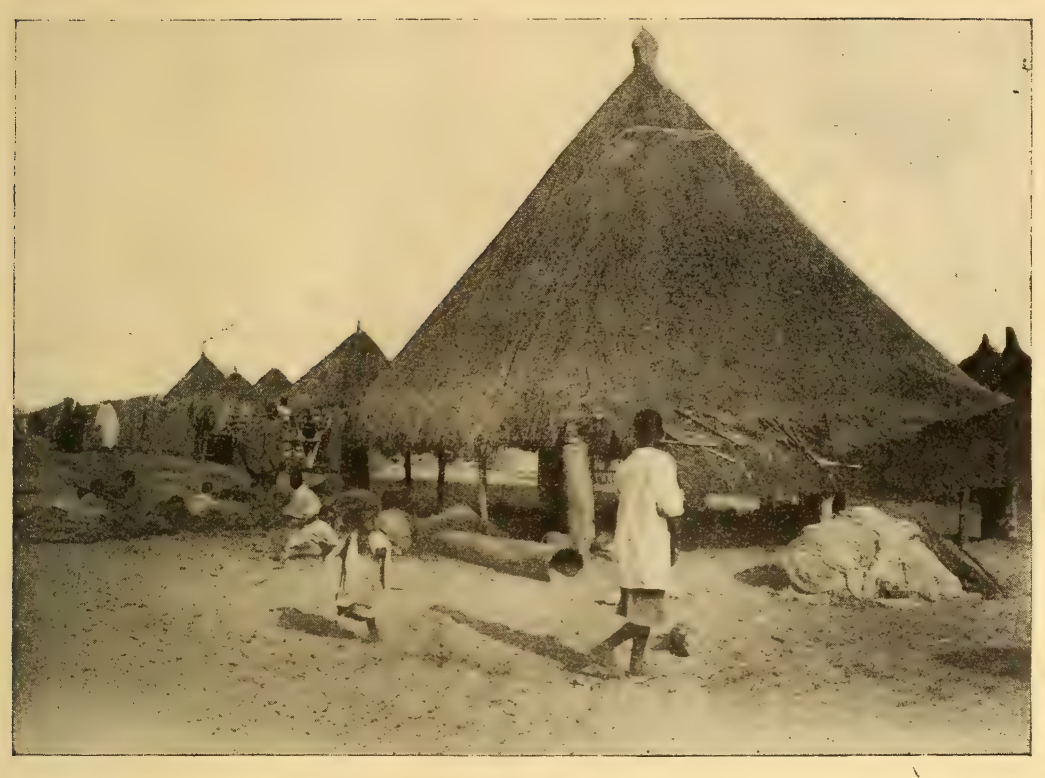

Fig. 39. - Rufisque (village noir).

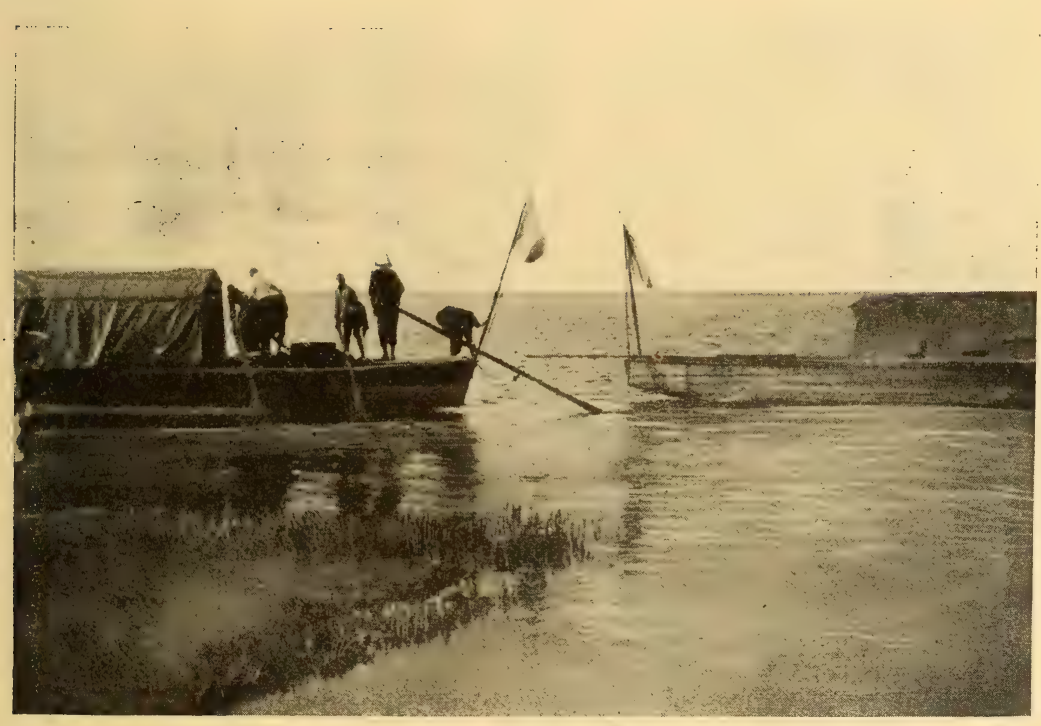

Fig. 40. - Chaland sur le Sénégal.

S. 

Enfin 270 mètres de quais abrités par la petite jetée dont il vient d'être question, les appontements dits de Gorée, des Messageries, des Travaux publics et de la rue Dagorne, et la digue de l'Aiguade, complétèrent heureusement ces travaux, et en servant à la petite batellerie donnèrent en même temps toutes les facilités désirables aux opérations maritimes. Des galeries filtrantes conduisant les eaux des dunes dans des reservoirs permettant de distribuer à quai l'eau douce dontles bateaux ont tant besoin. Mais ces travaux ne purent longtemps satisfaire le connmerce qui se développait de plus en plus; on dut envisager la création d'un port commercial vraiment digne de ce nom.

En 1899 le Conseil général du Sénégal ayant voté un emprunt 14 millions, décida de consacrer $\mathbf{1 . 2 0 0 . 0 0 0}$ francs à l'amélioration du port de Dakar.

La première étude d'ensemble qui ait été entreprise date de cette époque. Les fonds dont on disposait étaient notoirement insuffisants mais un programme rationnel devait être suivi, et les ouvrages exécutés au fur et à mesure des besoins et des disponibilités budgétaires devaient former un tout complet très satisfaisant.

Cet emprunt ne fut jamais réalisé et les choses en restèrent là jusqu'au jour où la constitution du budget général de l'Afrique occidentale française permit d'émettre un emprunt de 63 millions sur lesquels 10 millions étaient affectés à la transformation et à l'aménagement immédiats du port de commerce de Dakar.

On décida de créer un port comprenant les installations les plus perfectionnées, l'outillage le plus récent, en un mot de ne rien négliger pour donner à Dakar le rang quilui est dévolu par ses avantages naturels et pour en faire un port colonial pouvant rivaliser avec les ports européens.

La direction des études et des travaux fut confiée à M. Ficatier, ingénieur en chef des Ponts et Chaussées, directeur des Travaux de l'arsenal de Dakar, et le projet définitif fut approuvé par le ministre des Colonies le 7 juillet 1904.

Il prévoyait primitivement:

$1^{0}$ Le dragage de deux bassins distincts approfondis l'un à la cote $6,50 \mathrm{au}$-dessous des plus basses mers l'autre à la cote 8,00 . 
$2^{0}$ Le remblaiement d'une partie du rivage actuel de façon à gagner sur la mer de vastes terre-pleins et deux móles de 300 mètres de longueur, s'avançant vers le large.

Les produits de dragages et le dérasement des dunes existant près de bakar devaient fournir le remblai nécessaire à la constitution des terre-pleins et des môles de 80 et 100 mètres de largeur qui délimitent les deux darses.

$3^{0}$ Des murs de quai bordant les terre-pleins et entourant les môles assuraient l'accostage des plus grands bateaux fréquentant le port.

Ces ouvrages assis sur une fondation d'enrochements immergés dans une souille profonde de 1,50 et bien régularisée au scaphandrier comprenaient, suivant le bassin dans lequel ils sont établis, trois ou quatre rangées de blocs en maçonnerie surmontés d'une murette en maçonnerie et d'un couronnement en pierre de taille. Un fort massif d'enrochements du côté des terres les renforce et augmente leur stabilité.

$4^{\circ}$ La construction d'une digue entre le port militaire et le môle projeté $\mathrm{n}^{0} 1$ sur 528 mètres devait servir aux opérations de la petite batellerie et permettre l'aménagement des cales de hâlage et d'ateliers de réparations des côtres et chalands.

Une seule rangée de blocs reposant sur un remblai d'enrochements bien réglés et rangés à la main à la cote $\mathbf{0 , 0 0}$ constituait cette digue qu'une murette en maçonnerie et un couronnement complétaient.

$5^{0}$ Enfin la construction des ouvrages accessoires comprenant le renforcement et l'élargissement de la grande jetée, la construction d'appontements, l'étude des aqueducs et caniveaux pour l'écoulement des eaux, les hangars, magasins, installations de grues, les voies ferrées, canons d'amarres, bollards et organeaux, escaliers etc., qui sont le complément indispensable d'un port et rendent les manœuvres faciles et rapides.

Depuis l'approbation, quelques légères modifications ont été apportées à ce projet.

La digue a été modifiée sur une partie de sa longueur et doit être établie à la cote 0,00 sur les 200 premiers mètres seulement le reste étant formé de 2 files de blocs dont l'un posé à la cote 
1,80 permettra l'accostage des côtres même aux heures des plus basses mers.

La direction des môles a été changée ; ces môles qui devaient être parallèles à la grande jetée ont été déviés vers l'Est de $12^{\circ}$ afin de les rendre plus facilement accostables et de leur donner une position mettant les bateaux plus à l'abri des grosses mers.

La ligne délimitant les terre-pleins a également été déviée.

Le dragage à $-6,50$ d'une zòne située à l'Ouest du môle $\mathrm{n}^{0} 1$ a été décidé et on a substitué un mur de quai de 122 mètres de long à la partie de digue primitivement prévue. Cette dernière modification a eu pour heureux résultat d’augmenter de 425 mètres la longueur des quais, de 6,50 de profondeur.

Enfin on a substitué le béton à la maçonnerie ordinaire pour la confection de tous les blocs se trouvant au-dessous des plus basses mers.

A la suite d'un marché passé le 28 juin 1904 et approuvé par le Ministre des Colonies le 7 juillet suivant, MM. Jammy et Galtier ont été déclarés adjudicataires des travaux dont le montant s'élève à 8.3500 .000 franes.

Immédiatement les entrepreneurs ont commandé le matériel nécessaire et ont désigné MM. Renoux et Brizard, ingénieurs, pour les représenter à Dakar et diriger les travaux.

A peine arrivés dans la colonie, MM. Renoux et Brizard ont immédiatement organisé leurs chantiers. Ils ont tout d'abord fait construire des bureaux et des logements pour leur personnel européen pendant qu'ils s'occupaient du tracé et de la construction des voies de chemin de fer devant servir à apporter à pied d'œuvre les pierres et le sable des maçonneries et les remblais de terre-pleins.

Le débarquement du matériel, le montage et la mise en marche de l'excavateur et des voies y aboutissant, menés très rapidement a permis de commencer les terrassements fin novembre ; le 31 décembre les entrepreneurs avaient déjà une situation de travaux de $\mathbf{2 9 . 0 0 0}$ francs environ.

Depuis c'est avec une activité continue, sans relâche et sans perte de temps, qu'ils ont continué l'installation de leurs vastes chantiers, par le montage et la mise en marche de dragues, 
remorqueurs, chalands, grues, voies de chemin de fer allant aux carrières, concasseur, malaxeur, bétonnière, ponton-mâture, ateliers à bois et mécaniques, etc., de telle manière aujourd'hui, qu'après 16 mois de travaux, compris presque entièrement dans la période d'organisation, les dépenses atteignent plus de 2.650.000 francs se répartissant ainsi :

Terrassements Francs

Maçonnerie de blocs 659.750

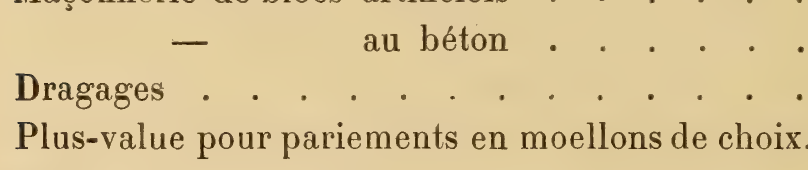
292.380 492.690

Mise en place des blocs. 884.000

Enrochements pour fondations de quai ou massifs. 8.125

Règlement des enrochements. . . . . . 65.200 96.430 Approvisionnements divers de matériaux à pied d'œuvre .

$$
\text { Total . . . . . . }
$$

Malgré les quelques additions dont nous avons parlé plus haut, faites au marché, les adjudicataires espèrent terminer avant le délai de 3 ans $1 / 2$ fixé pour la durée d'achèvement de l'ensemble des travaux.

Cette période comptant à dater de la notification de l'approbation du marché, le 7 juillet 1904, c'est donc avant janvier 1908 que le port de commerce de Dakar pourrait être mis en exploitation; les différentes parties seront d'ailleurs livrées au fur et à mesure de leur achèvement.

Nouvelles questions à l'étude et outillages. - En dehors des travaux à l'entreprise, diverses installations complémentaires ont été mises à l'étude. C'est d'abord : l'outillage du futur port dont on a examiné tous les détails.

Un port est d'autant plus fréquenté, son essor d'autant plus certain, plus rapide, et plus considérable, que les navigateurs y trouvent toutes les commodités désirables.

A ce point de vue Dakar n'aura rien à envier aux grands ports européens; on profitera de l'expérience acquise, pour le 
doter immédiatement du matériel qui lui permettra de satisfaire à toutes les exigences.

Deux files de hangars discontinus seront établis sur chacun des môles, d'autres seront également établis au bord des quais de rive; ils suffiront pour la manutention et le dépôt des marchandises. Leur surface totale atteindra $6.700 \mathrm{mq}$. et leur largeur variera entre 20 et 2 ö mètres; quatre voies les desserviront et permettront le chargement en wagon de chaque côté ou le chargement direct du bateau en wagon, lorsque les marchandises seront immédiatement expédiées.

Enfin une voie centrale de manœuvre et des aiguillages, plaques tournantes, etc., permettront à toutes les manœuvres de s'effectuer avec commodité.

Des entrepôts seront aménagés et dégageront les hangars des marchandises qui devraient rester trop longtemps en dépôt, en même temps qu'elles donneront aux commerçants la facilité d'avoir des approvisionnements plus considérables à un moment donné, sans être tenu à construire des magasins supplémentaires.

Des grues électriques au nombre de :

10 de 1.500 kilos de force

\section{4 de 3.000}

1 de $\mathbf{1 0 . 0 0 0}$

assureront les opérations rapides de chargement et de déchargement.

Des canalisations avec prise à quai et compteurs, permettront de distribuer à bord l'eau douce.

Un système double d'éclairage : le premier pour l'éclairage normal des colis pendant la nuit, le deuxième pour l'éclairage intensif pour la manutention de nuit, compléteront ces installations.

Mouvement du port de Dakar de 1900 à 1905. - Le tableau comparatif suivant donne le tonnage des marchandises embarquées et débarquées à Dakar de 1900 à 1903 et montre la progression rapide de ce tonnage. Il est à prévoir que ces chiffres s'augmenteront sensiblement quand le nouveau port sera construit et outillé. 
Tonnage des marchandises importées et exportées par le port de Dakar pendant les années 1900 à 1905

$$
\text { (Le charhon n'est pas compris). }
$$

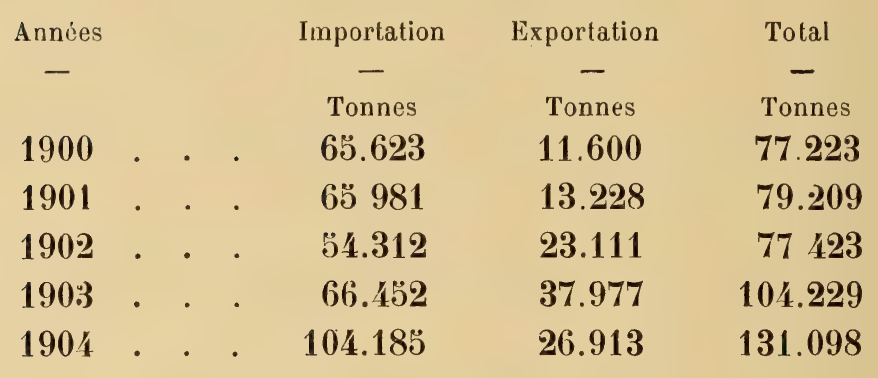

Relevé du charbon importé et exporté pendant les années 1900 à 1905.

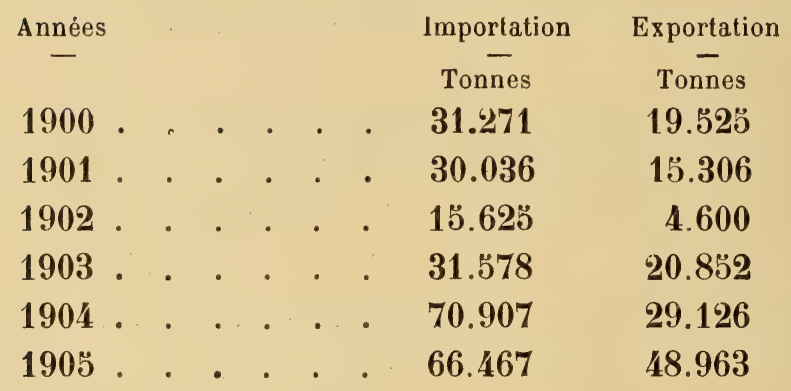

Le charbon reçu par la Compagnie des Charbonnages n'a été relevé que depuis l'année 1904.

Autant pour éviter de désagrément du charbonnage près des quais que pour dégager le port, un bassin spécial permettant d'avoir sur rade au moins 6 bateaux, fait l'objet d'un projet en préparation.

Enfin la question d'élargissement de la grande jetée et de l'aménagement de la jetée du port de guerre au point de vue commercial, a fait l'objet de rapports très documentés, desquels on peut conclure que la rade de Dakar par sa situation naturelle se prête à un développement presque illimité des ins- 
tallations du port de commerce quelque brillant qu'on puisse envisager l'avenir.

Port de Rufisque. - Une somme de 500.000 francs a été affectée sur les fonds de l'emprunt de 63 millions à la construction d'un nouveau wharf et à la remise en état des wharfs existants du port de Rufisque.

Utilisalion du Sénégal. - La navigation commerciale entre Saint-Louis et Kayes est assurée par une entreprise subventionnée de transports fluviaux.

La durée normale des voyages postaux sans remorque, entre Saint-Louis et Kayes, est, pour chaque parcours d'aller, de cinq jours et pour chaque parcours de retour, de quatre jours, sauf le cas de force majeure.

$1^{0}$ MM. Devès et Chaumet effectuent, pendant toute l'année, un service postal fluvial sans remorque partant de Saint-Louis des Messageries Maritimes faisant escale à Dakar. Ils exécutent de ce chef vingt-six voyages doubles (aller et retour) par an entre Saint-Louis et Kayes, pendant la période des hautes eaux, ou l'escale qu'ils peuvent atteindre pendant l'étiage. Le départ de Saint-Louis a lieu le mardi à quatre heures du soir.

$2^{\circ}$ Outre les parcours ainsi prévus, les entrepreneurs exécutent le nombre de voyages nécessaires pour leur permettre de parfaire l'exécution des engagements qu'ils ont assumés à l'égard de l'Etat et assurer les besoins du commerce.

Tarifs commerciaux entre Saint-Louis et Kayes

Passagers.

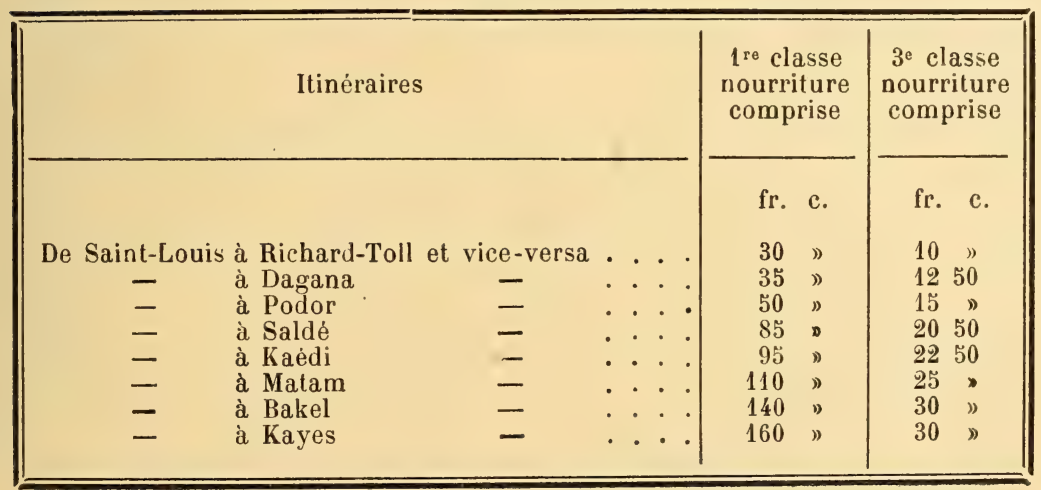


Prix du passage et du frêt entre deux escales intermédiaires : à débattre.

Goureaux dits "Kolas » pour Bakel et Kayes : 10 francs le panier; pour les escales inférieures : ら francs le panier.

Petits colis : minimum : 5 francs par colis au-dessus de Podor : 2 francs par colis jusqu'à Podor.

Espèces, or, argent et valeurs : 1/2 0/0 de la valeur. Matières enflammables et explosifs : double frêt.

\section{Marchandises et produits.}

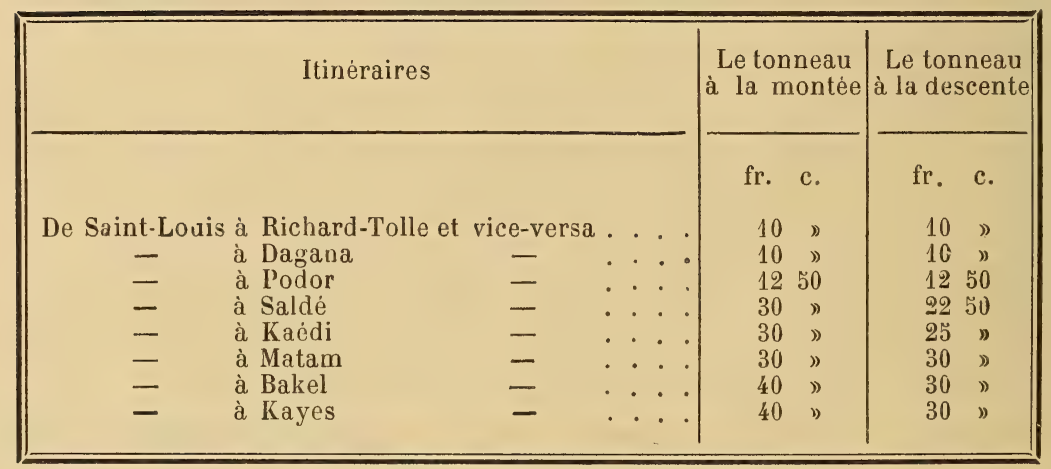

Réduction de : 10 0/0 par expédition de 50 tonnes ; $150 / 0$ par expédition de 100 tonnes; $200 / 0$ par expédition de 200 tonnes; $250 / 0$ par expédition de 500 tonnes et au-dessus.

Tarif réduit à $12 \mathrm{fr} .50$ la tonne de 1.000 kilos pour : $1^{0}$ coton indigène, quelque soit la quantité; $2^{\circ}$ tous autres produits ou marchandises (à l'exception du caoutchouc) quand la quantité chargée dépasse 20 tonnes.

\section{B. - Chemins de fer.}

a) Chemin de fer de Dakar à Saint Louis.

Historique de la construction. - La question de la construction d'une voie ferrée reliant Saint-Louis au port de Dakar, remé- 
diant aux inconvénients graves de la barre du Sénégal, assurant la possession du Cayor, et contribuant ainsi puissamment au développement matériel et commercial de la colonie, remonte à l'année 18ə̋6. L'idée en avait été émise par le gouverneur PinetLaprade, et reprise en 1863, par le gouverneur Faidherbe. Elle fut l'objet, en 1878 et 1879, d'une étude détaillée et d'un projet dressé par le Directeur des Travaux publics de la colonie.

Au mois de février 1880, le Ministre de la Marine et des Colonies déposait, sur le bureau de la Chambre, un projet de loi comprenant :

$1^{0}$ Une ligne de Dakar à Saint-Louis ;

$2^{0}$ Une ligne de Médine au Niger ;

$3^{0}$ Une ligne reliant les deux précédentes.

L'Etat se réservait la construction de la seconde ligne, les deux autres devant faire l'objet d'une concession avec garantie d'intérêt.

A la suite de diverses discussions, la ligne de Dakar à Saint-Louis fut détachée de l'ensemble du projet, et mise en adjudication. Trois concurrents se présentèrent : MM. Cavalley, Joret et $\mathrm{C}^{\mathrm{ie}}$ et la Société de construction des Batignolles; les offres étaient les suivantes :

Prix kilométrique

79.600

Garantie.

3.980

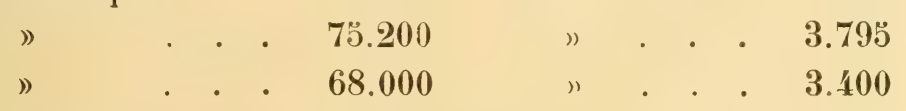

La Société de construction des Batignolles, qui avait fait les conditions les plus avantageuses, fut déclarée adjudicataire, le 30 octobre 1880.

Toutefois, à la suite de divers amendements proposés par les Commissions de finances, et après avis du Conseil général des Ponts et Chaussées, les conditions essentielles de la Convention du 30 octobre 1880, approuvée par la loi du 29 juin 1882, furent les suivantes :

L'Etat fournirait les $3 / 4$ du capital, et la Compagnie, qui devait se substituer au premier concessionnaire, se constituerait un capital-actions d'au moins cinq millions, garanti par 
un revenu net annuel de $\mathbf{1 . 1 5 4}$ francs par kilomètre exploité.

Les reconnaissances et études préliminaires ont été faites en 1881 et 1882 , et les installations nécessaires commencées à la fin de cette dernière année, malgré la terrible épidémie de fièvre jaune qui sévissait à ce moment. Les travaux furent entrepris à la fois du côté Dakar et du côté Saint-Louis ; les sections furent ouvertes successivement à l'exploitation, et l'inauguration de la ligne totale eut lieu le 6 juillet 188 .

La réception définitive fut prononcée le 18 janvier 1886.

Quant à la Compagnie elle avait été constituée le 4 juin $\mathbf{1 8 8 3}$, au capital de $\breve{b}$ millions de francs.

Le prix de l'adjudication avait été de $\mathbf{6 8 . 0 0 0}$ francs par kilomètre, prix peu élevé, si l'on considère les difficultés que présentait l'exécution d'un chemin de fer dans un pays malsain, dépourvu de toutes ressources, et incomplètement soumis. Les auteurs du projet, ne prévoyant pour cette ligne qu'un trafic insignifiant, avaient avant tout cherché à en rendre l'exécution économique, estimant que, si les résultats étaient supérieurs aux prévisions, il serait temps de compléter les installations insuffisantes. Ces prévisions ayant été dépassées d'une façon aussi rapide qu'inattendue, la Compagnie a dû entreprendre des travaux complémentaires de premier établissement qui ont porté le prix de revient de la ligne à $\mathbf{2 3 . 2 0 0 . 4 7 8 ~ f r . ~} 98$.

Cies travaux sont:

La reconstruction de stations, le ballastage de la ligne, le remplacement des traverses, prévues en pin par le cahier des charges, par des traverses en hêtre, puis par des traverses métalliques, l'augmentation du matériel roulant, etc..

Etat actuel de la ligne. - La ligne est actuellement ballastée sur toute sa longueur : les ouvrages d'art sont nombreux, mais relativement peu importants, sauf un pont de 120 mètres d'ouverture sur le marigot de Leybar au km. 2ə̋8.500.

Les rampes maxima sont de $13 \mathrm{~m} / \mathrm{m}$ pour mètre; les rayons minima de 300 mètres. Le rail est en acier à patin de $20 \mathrm{~kg}$. par mètre courant, de $7 \mathrm{~m} .80$ de longueur, reposant sur 10 traverses espacée de 0,80 d'axe en axe. Les traverses sont au nombre de 360.886 , dont 232.377 en acier de $32 \mathrm{~kg}$. La substitution 
des traverses métalliques aux traverses en bois n'est donc pas encore terminée, mais elle se poursuit régulièrement.

Sauf les gares de Dakar et de Saint-Louis, qui n'ont pu encore être reconstruites, par suite de l'exécution des travaux du port de Dakar et de l'assainissement de Saint-Louis, les gares ont été reconstruites sur un type, variant de dimensions suivant l'importance, mais présentant un caractère identique ; il est constitué par un bâtiment entouré d'une vaste véranda, protégé, à l'étage des logements, contre les moustiques, à l'aide de toile métallique. Les gares ordinaires comprennent des voies supplémentaires, des quais de chargement, et des plaques tournantes; des ponts tournants sont installés dans six gares, et des ponts à bascule dans huit, y compris les gares terminus.

Il y a quatre dépôts sur la ligne.

Les alimentations sont assez nombreuses, et ont donné lieu à de grandes difficultés en raison de la rareté de l'eau ct de sa mauvaise qualité. On a dû forer des puits profonds ; l'eau est élevée dans des réservoirs à l'aide de pulsomètres à vapeur.

Exploitation technique et commerciale. - Le matériel roulant actuel se compose de :

27 locomotives (dont 11 avec tenders séparés);

58 voitures à voyageurs ;

10 fourgons ;

302 wagons à marchandises;

3 wagons de secours ;

2 wagons-grues.

Deux trains sont mis en circulation régulièrement chaque jour, partant respectivement de Dakar et de Saint-Louis, à 6 h. 40 et

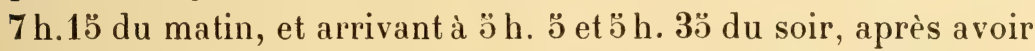
subi en route 110 minutes d'arrêt dans les gares, dont $40^{\prime}$ au buffet de Kelle. La durée du trajet est donc de 10 h. 20 , soit une vitesse commerciale de 2 ö kilomètres.

Des trains dits de section, circulent entre Dakar et Tivaouane, du 15 novembre au 15 mai.

De plus, à chaque arrivée ou départ de courrier, il est mis en marche un train, dit express, faisant le trajet total en 8 heures. Outre ces trains, il est prévu dans chaque sens, 14 trains facul- 
tatifs, qui sont mis en marche suivant les besoins du service : pendant la traite, la moyenne journalière de ces trains est de 10 environ.

Les prix des tarifs généraux sont les suivants:

Voyageurs : $1^{\text {re }}$ classe, 0 fr. $120 ; 2^{\text {e }}$ classe, 0 fr. $08 ; 3$ e classe, $0 \mathrm{fr} .0$ อ̋ par voyageur et parkilomètre.

Marchandises : 0 fr. 24, 0 fr. 20 et 0 fr. 13 par tonne et par kilomètre, suivant la classe.

Toutefois, la Compagnie a créé un certain nombre de tarifs spéciaux qui réduisent sensiblement les prix ci-dessus et ont fortement contribué au développement du trafic.

La Compagnie exploite suivant une convention aux termes de laquelle les dépenses rapportées au kilomètre, sont évaluées à forfait d'après la formule :

$$
\mathrm{F}=3.2 \check{0}+\frac{\mathrm{R}}{3}+0.05 \mathrm{~T}+0.01 \check{\mathrm{V}} \text { dans laquelle : }
$$

$\mathbf{R}$ représente la recette kilométrique totale;

$\mathrm{T}$ et $\mathrm{V}$ le nombre de tonnes de marchandises et de voyageurs transportés à distance entière.

Les économies réalisés sur cette formule, déduction faite de 20 0/0 attribués à la Compagnie à titre de prime, servent lorsqu'il y a lieu, à compléter un fonds de réserve destiné à l'exécution de travaux complémentaires de Premier établissement, ou sont reversées à l'Etat.

La formule d'exploitation qui est indiquée ci-dessus à été établie en 1900, depuis cette époque, les sommes revenant à l'Etat sont les suivantes :

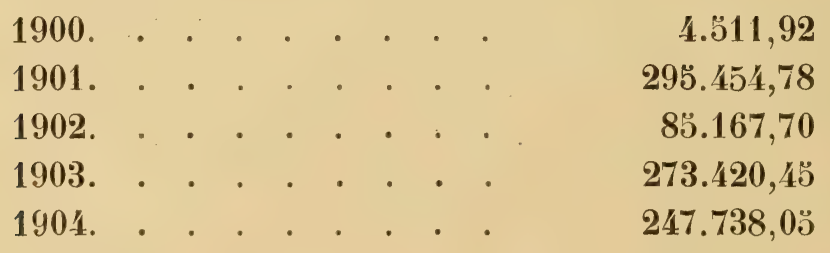

En d'autres termes la Compagnic fait actuellement depuis 1900, des affaires suffisamment bonnes pour, au bout de vingt années. d'exploitation, pouvoir commencer a rembourser à l'Etat les 
garanties d'intérêt versées au titre des exercices antérieurs. C'est là une situation merveilleuse sur laquelle il convient d'attirer l'attention. Elle a fortement frappé d'ailleurs l'administration et les autorités locales. C'est un exemple sur lequel on a pu a juste titre s'appuyer pour hâter la construction des chemins de fer de l'Afrique Occidentale Française.

La Compagnie étudie actuellement, d'accord avec l'administration, une nouvelle formule se rapprochant d'avantage des conditions actuclles de l'exploitation.

Il est intéressant de signaler ici les importantes et intelligentes mesures d'hygiène prises par la Compagnie pour ses employés. Elle a principalement à lutter, au point de vue sanitaire, contre les effets du paludisme, et, éventuellement, de la fièvre jaune. Ces maladies étant transmises par les moustiques, c'est contre eux qu'elle doit se défendre, et pour cela, elle a employé divers moyens.

En premier lieu, elle a mis les logements à l'abri de ces insectes en garnissant de toiles métalliques les portes, les fenêtres et les vérandas des habitations du personnel, ainsi que tous les orifices pouvant permettre l'accès des moustiques : elle a de plus recommandé aux agents, appelés par leur service à sortir après le coucher du soleil, de se couvrir la figure d'un masque en tulle et les mains de gants, afin d'éviter d'être piqués.

En second lieu elle a cherché à empêcher, au moins dans ses emprises, la reproduction de l'animal en supprimant toute collection d'eau, qui est absolument nécessaire à son développement, ou en le mettant dans l'impossibilité de se servir de l'eau qui ne peut être supprimée, soit en recouvrant de toile métallique tout récipient contenant de l'eau destinée à la consommation, soit en versant du pétrole ou du goudron dans les bassins ou réservoirs. Elle veille, en outre, à ce que la plus grande propreté règne dans ses locaux, et qu'il ne subsiste aucun endroit pouvant servir de refuge ou de lieu de reproduction aux moustiques.

En dehors de ces mesures préventives, la Compagnie a organisé un service sanitaire qui fonctionne d'une façon très sérieuse, et dont la haute direction est confiéc au médecin en chef des 
colonies, directeur du Service de santé de l'Afrique occidentale française. A Dakar, à Saint-Louis, et dans plusieurs escales de la ligne, des médecins sont chargés de visiter et de soigner les employés et leurs familles : les malades sont envoyés à Dakar, dans l'hópital de la Compagnie où sont également reçues les familles des agents hospitalisés qui sont en résidence normale sur la ligne.

Enfin, afin, d'assurer autant que possible le bien-être de son personnel, la Compagnie s'est attachée à construire, suivant les principes d'hygiène les meilleurs, les bâtiments destinés à servir de logements, c'est-à-dire que les pièces y sont élevées et bien aérées, qu'elles peuvent facilement être lavées, et qu'elles sont protégées des rayons du soleil par de larges vérandas régnant sur les quatre côtés du bàtiment.

Nous donnons ci-après le graphique indiquant les recettes kilométriques annuelles $\mathrm{G}$. V. et $\mathrm{P} . \mathrm{V}$ et totales depuis 188 ä ainsi que divers tableaux indiquant le détail des recettes, le mouvement des voyageurs, leur nombre moyen par trains, le mouvement des marchandises, et les transports effectués pour les trois principaux produits alimentant le trafic, les arachides, le mil et les animaux vivants. 


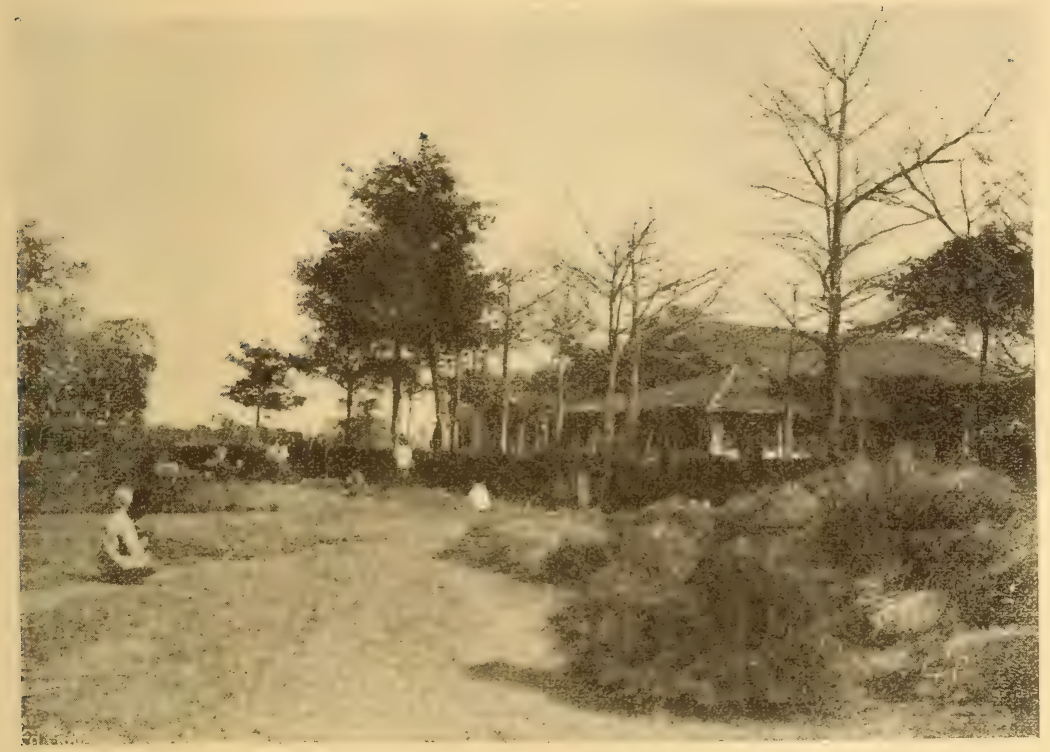

Fig. 41. - Environs de-Thies.

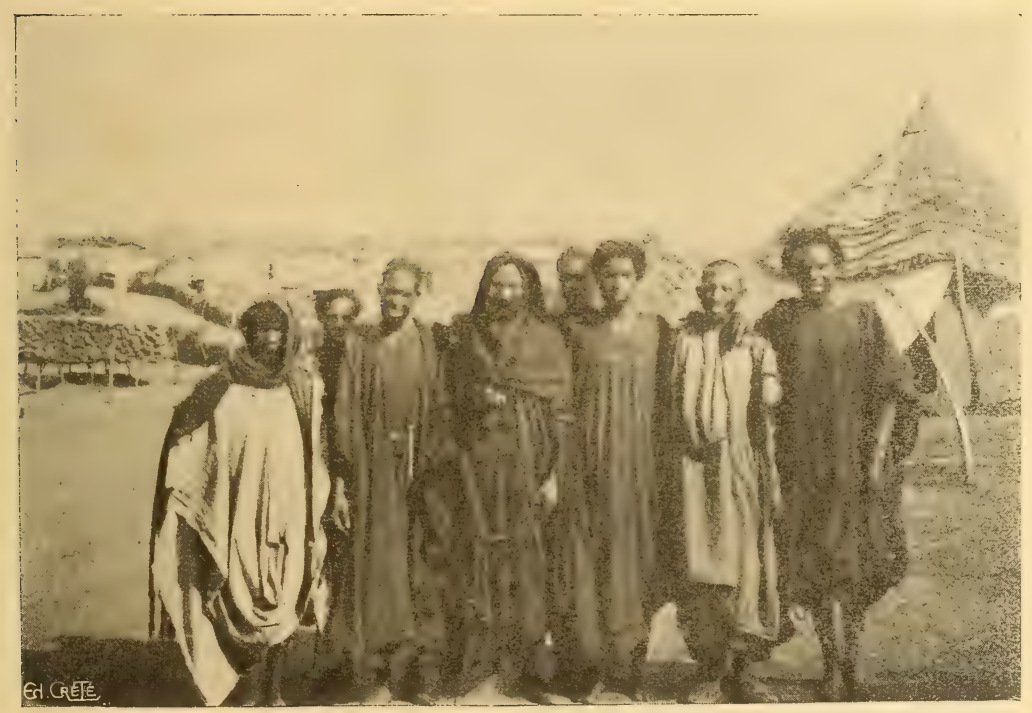

Fig. 40. - Groupe de Manres.

s. 



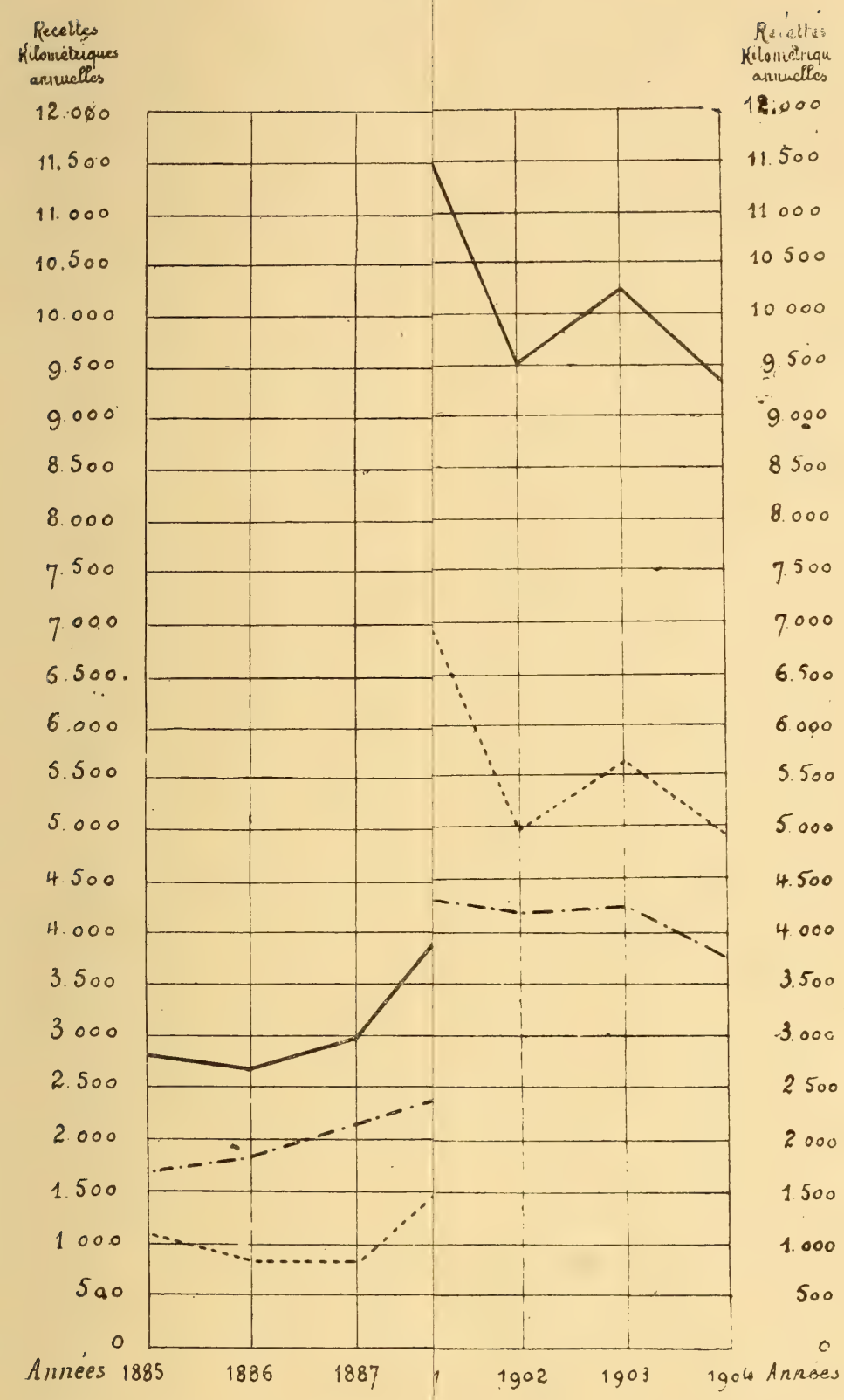



<smiles>C#CCCCCCCCCCCCCCCCCC</smiles> 



\begin{tabular}{|c|c|c|}
\hline & $\frac{0}{\stackrel{0}{0}}$ & 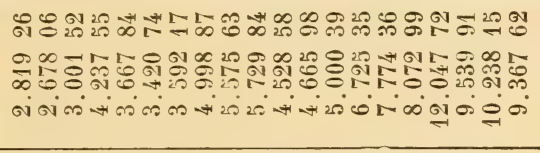 \\
\hline & 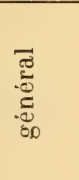 & 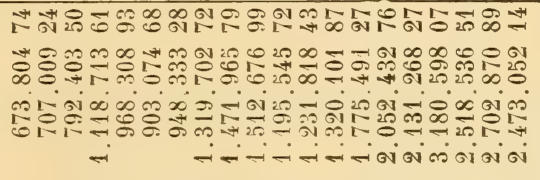 \\
\hline & 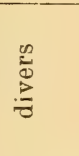 & 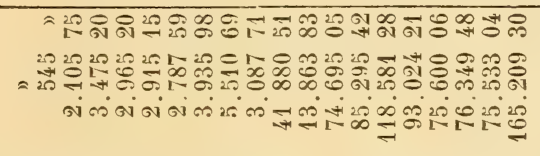 \\
\hline & 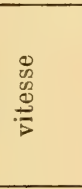 & 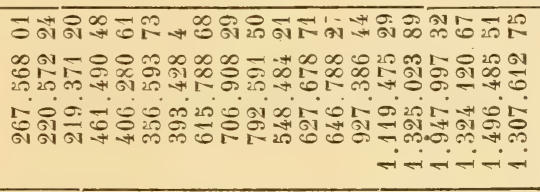 \\
\hline & & 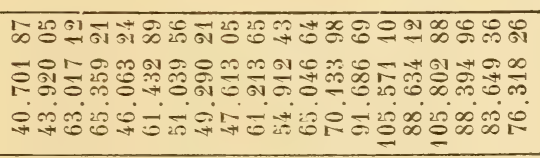 \\
\hline & & 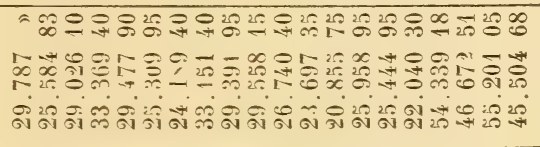 \\
\hline \multirow{4}{*}{ 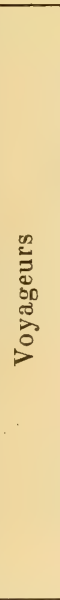 } & 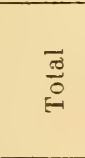 & 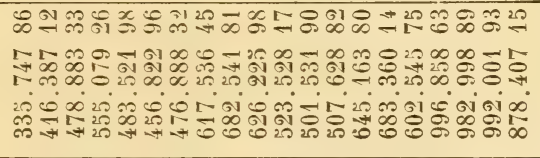 \\
\hline & 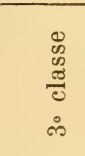 & 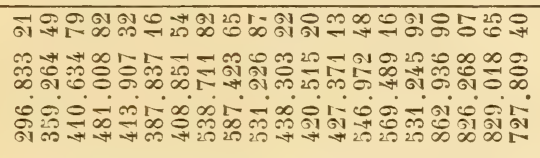 \\
\hline & 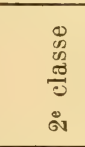 & 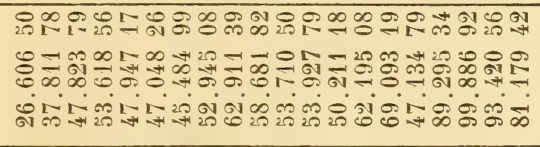 \\
\hline & 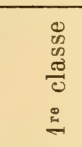 & 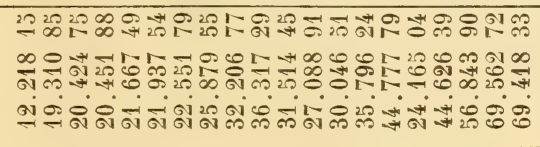 \\
\hline \multicolumn{2}{|c|}{ 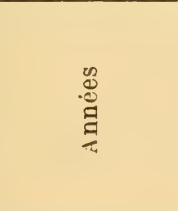 } & 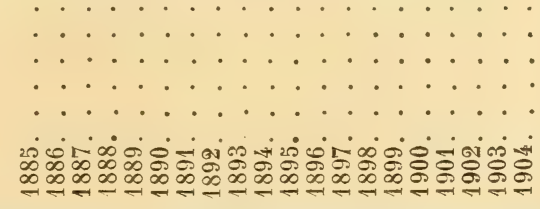 \\
\hline
\end{tabular}


30 Mouvement des voyageurs.

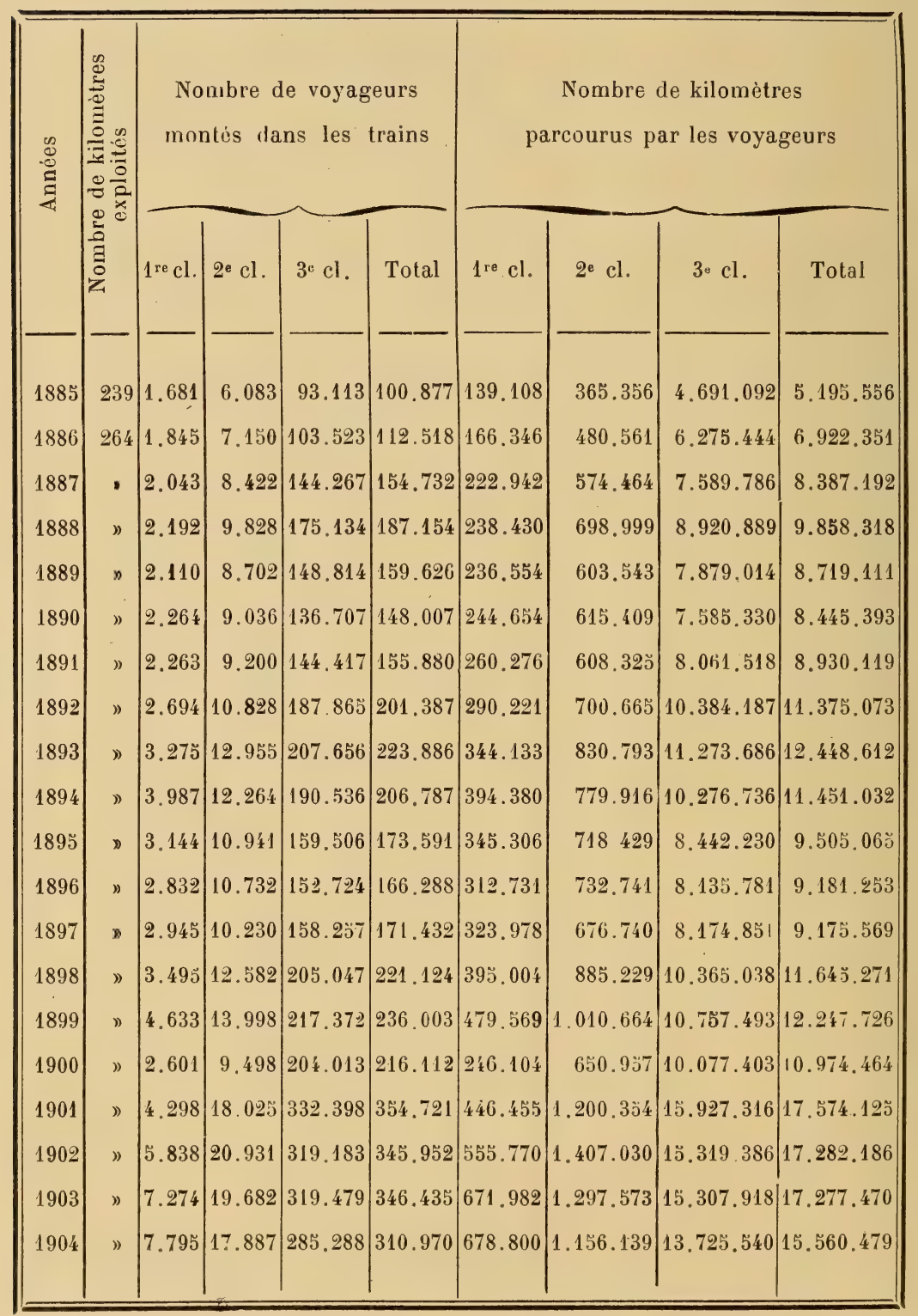


$4^{0}$ Nombre moyen des voyageurs par train.

\begin{tabular}{|c|c|c|c|c|c|}
\hline & Années & $1^{\mathrm{re}}$ classe & $2^{\mathrm{e}}$ classe & 3e classe & Total \\
\hline 1885 & $\ldots \ldots$ & 2 & 6 & 92 & 100 \\
\hline 1886 . & $\ldots \ldots$ & 2 & 9 & 126 & 137 \\
\hline 1887. & $\ldots \ldots \ldots$ & 3 & 11 & 193 & 207 \\
\hline 1888 . & $\ldots \ldots$ & 3 & 13 & 234 & 250 \\
\hline 1889. & $\ldots \ldots \ldots$ & 3 & 11 & 193 & 207 \\
\hline 1890 . & $\ldots \ldots$ & 2 & 10 & 143 & 157 \\
\hline 1891. & $\ldots \cdot \ldots$ & 2 & 10 & $15 \tilde{~}$ & 167 \\
\hline 1892 . & 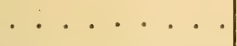 & 2 & 8 & 137 & 147 \\
\hline 1893. & $\ldots \ldots \ldots$ & 3 & 11 & 173 & 187 \\
\hline 1894 & $\ldots \ldots$ & 3 & 8 & 130 & 141 \\
\hline 18930 & $\cdots \cdot \cdots \cdot$ & 2 & 7 & 109 & 118 \\
\hline 1896 . & $\ldots \ldots$ & 2 & 7 & 104 & 113 \\
\hline 1897 . & $\cdots \cdot \cdot \cdot \cdot$ & 2 & 7 & 108 & 117 \\
\hline 1898 . & $\ldots \cdot \ldots$ & 2 & 9 & 140 & 151 \\
\hline 1899 . & $\ldots \ldots$ & 3 & 9 & 146 & 158 \\
\hline 1900 . & $\cdots \cdot \cdot \cdot \cdot$ & 2 & 8 & 176 & 186 \\
\hline 1901 . & $\cdots \cdots \cdot$ & 3 & 12 & 220 & 235 \\
\hline 1902 & 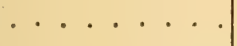 & 4 & 14 & 213 & 231 \\
\hline 1903 & $\cdots \cdot \cdot \cdot \cdot$ & 5 & 13 & 210 & 228 \\
\hline 1904 & $\ldots \ldots$ & 5 & 11 & 181 & 197 \\
\hline
\end{tabular}


$5^{\circ}$ Marchandises P. V.

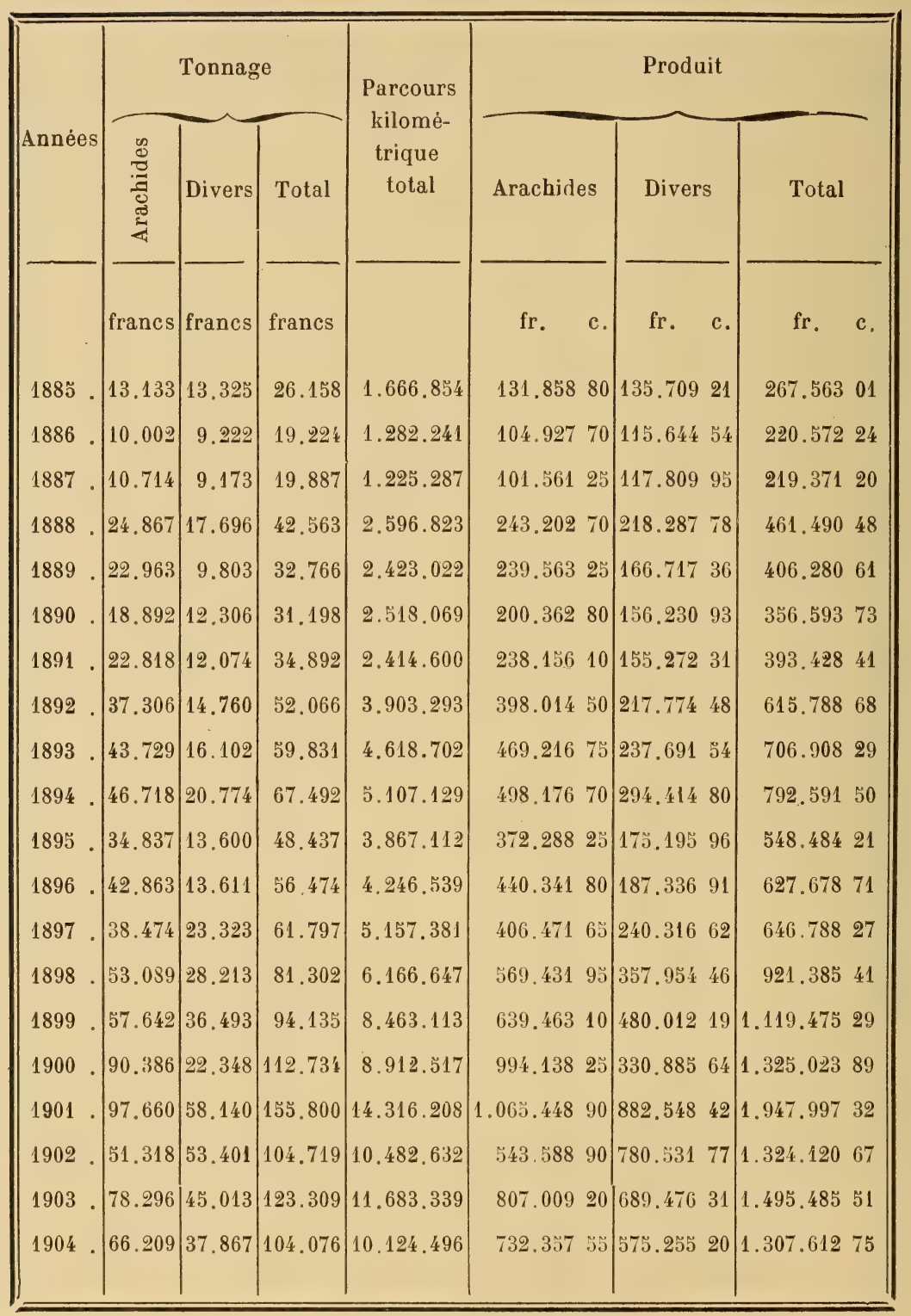




\begin{tabular}{|c|c|c|c|c|c|c|c|c|c|c|c|c|c|c|c|}
\hline 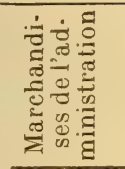 & & $\begin{array}{l}\stackrel{\infty}{\Xi} \\
\Xi \\
\Xi\end{array}$ & & $=$ & $\hat{=}$ & & 2 & $\begin{array}{l}0 \\
0 \\
\infty \\
\infty\end{array}$ & & $\dot{\dot{s}}=$ & $=$ & $\approx$ & $\approx$ & $=$ & 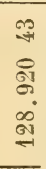 \\
\hline 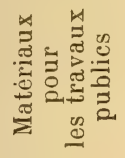 & & $\begin{array}{l}\text { D } \\
\stackrel{2}{\Xi} \\
\stackrel{0}{0}\end{array}$ & $\approx$ & 덩 & $\stackrel{\mathscr{D}}{\circ}$ & $\stackrel{20}{\stackrel{20}{\bullet}}$ & $\begin{array}{l}\overrightarrow{0} \\
20\end{array}$ & $\begin{array}{c}8 \\
\text { if } \\
\stackrel{2}{-1}\end{array}$ & & $\begin{array}{l}\dot{0} \\
\dot{\sharp}\end{array}$ & $\stackrel{\hat{\sigma}}{\text { जे }}$ & $\begin{array}{l}\infty \\
0 \\
8 \\
\vdots \\
- \\
=\end{array}$ & 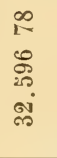 & $\begin{array}{l}0 \\
\text { ज十 } \\
0 \\
\text { it } \\
\infty \\
0\end{array}$ & $\begin{array}{l}\infty \\
\infty \\
\text { ণे } \\
\text { ஸे }\end{array}$ \\
\hline 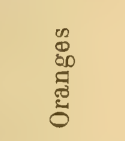 & & $\begin{array}{l}\text { D } \\
\stackrel{\Xi}{\Xi} \\
\stackrel{\Xi}{0}\end{array}$ & & $=$ & $\approx$ & $\stackrel{\infty}{\rightarrow}$ & $\beth$ & $\stackrel{ }{=}$ & & $\dot{\dot{m}}=$ & $=$ & $=$ & $\begin{array}{l}80 \\
80 \\
8\end{array}$ & $\begin{array}{l}20 \\
8 \\
8\end{array}$ & $\begin{array}{l}\text { 우 } \\
\infty \\
\infty \\
+1\end{array}$ \\
\hline 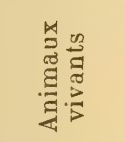 & & & $\therefore$ & & 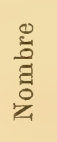 & ஜூ & $\stackrel{\infty}{\infty}_{0}^{\infty}$ & $\stackrel{N}{\infty}$ & & $\begin{array}{l}\dot{0} \\
\dot{m}\end{array}$ & $\approx$ & $\approx$ & $\begin{array}{l}\infty \\
\stackrel{20}{-1}\end{array}$ & $\begin{array}{l}\text { के } \\
\text { on } \\
\text { जैं } \\
\text { - }\end{array}$ & $\begin{array}{l}\text { ธิ } \\
\infty \\
\infty \\
\text { ơ } \\
\text { - }\end{array}$ \\
\hline 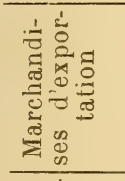 & & 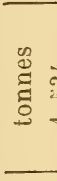 & & $\underset{20}{\mathscr{0}}$ & $\frac{\sigma}{\sigma}$ & ஜ̊ & 웅 & $\underset{\infty}{\infty}$ & & 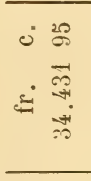 & $\begin{array}{l}20 \\
200 \\
\text { al } \\
\text { r. } \\
\text { के }\end{array}$ & $\begin{array}{l}\text { जू } \\
\text { जू } \\
\infty \\
\text { के }\end{array}$ & 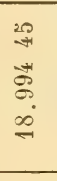 & $\begin{array}{l}\text { के } \\
\text { की } \\
\infty \\
\text { जे }\end{array}$ & $\begin{array}{l}20 \\
20 \\
0 \\
0 \\
0 \\
0 \\
01\end{array}$ \\
\hline 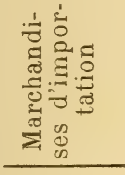 & 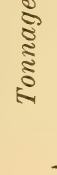 & 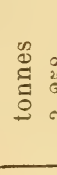 & & $\begin{array}{l}\mathscr{\infty} \\
\infty \\
\infty \\
-i\end{array}$ & $\begin{array}{l}5 \\
\stackrel{5}{0} \\
\stackrel{-}{-}\end{array}$ & $\stackrel{\stackrel{\text { g }}{\sigma}}{\stackrel{-}{r}}$ & $\begin{array}{l}\text { 이 } \\
20 \\
\infty \\
\stackrel{0}{2}\end{array}$ & $\begin{array}{l}\text { :ै } \\
: \\
\text { is }\end{array}$ & $\begin{array}{l}\overrightarrow{\tilde{\Xi}} \\
\tilde{\Xi} \\
0 \\
2\end{array}$ & 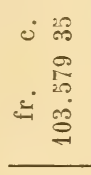 & 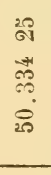 & 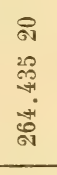 & 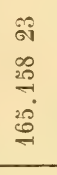 & 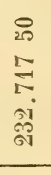 & 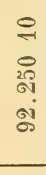 \\
\hline 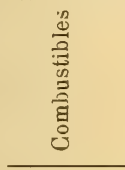 & & 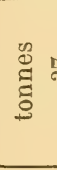 & & $\approx$ & $\stackrel{20}{\stackrel{20}{6}}$ & $\begin{array}{l}\text { 엄 } \\
-i\end{array}$ & $\begin{array}{l}\text { ज्ञ } \\
\text { - }\end{array}$ & $\stackrel{\Im}{=}$ & & 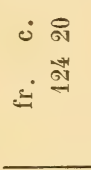 & $=$ & 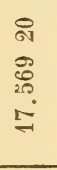 & 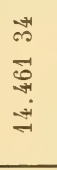 & $\begin{array}{l}\infty \\
\infty \\
\infty \\
\infty \\
\ddot{\infty}\end{array}$ & $\begin{array}{l}2 \\
2 \\
\infty \\
\infty \\
-i\end{array}$ \\
\hline 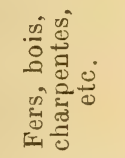 & & 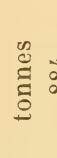 & & $\underset{\text { }}{\infty}$ & 落 & $\begin{array}{l}\infty \\
20 \\
20 . \\
20 \\
-i\end{array}$ & $\stackrel{2}{\tilde{1}}$ & $\vec{\square}$ & & 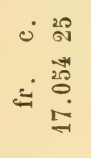 & $\begin{array}{l}\stackrel{2}{2} \\
\& \\
0 \\
\dot{r}\end{array}$ & $\begin{array}{l}\prod_{1}^{\infty} \\
\stackrel{\infty}{\infty} \\
\dot{0}\end{array}$ & $\begin{array}{l}\infty \\
\infty \\
\infty \\
\text { जै } \\
\stackrel{m}{m}\end{array}$ & \begin{tabular}{l}
20 \\
0 \\
\multirow{0}{0}{} \\
20
\end{tabular} & $\begin{array}{l}20 \\
0 \\
\text { "ै } \\
\infty \\
-1\end{array}$ \\
\hline 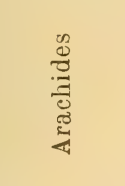 & & 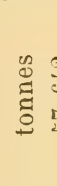 & & $\begin{array}{l}\infty \\
\infty \\
\infty \\
\ddot{8} \\
\dot{8}\end{array}$ & $\begin{array}{l}8 \\
8 \\
0 \\
\dot{5}\end{array}$ & $\underset{20}{\stackrel{\infty}{m}}$ & $\begin{array}{l}\mathscr{D} \\
\text { ज! } \\
\infty \\
\infty\end{array}$ & $\begin{array}{l}\text { ஓे } \\
\text { जे. } \\
\dot{8}\end{array}$ & & 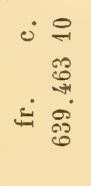 & 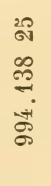 & \begin{tabular}{l}
8 \\
$\infty$ \\
$\infty$ \\
\multirow{2}{*}{.} \\
20 \\
8 \\
0 \\
$-i$
\end{tabular} & 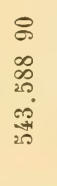 & 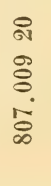 & 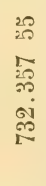 \\
\hline 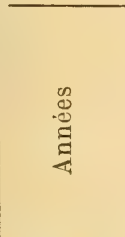 & & & $\underset{\infty}{\infty}$ & : & $\begin{array}{c}\dot{ } \\
: \\
\dot{8} \\
\dot{8}\end{array}$ & $\begin{array}{l}\dot{ } \\
\dot{ } \\
\dot{ } \\
\dot{0} \\
\dot{8} \\
\dot{8}\end{array}$ & 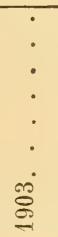 & 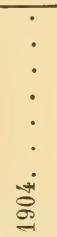 & & $\begin{array}{l}\dot{ } \\
\dot{ } \\
\dot{0}\end{array}$ & $\begin{array}{l}: \\
: \\
\dot{8}\end{array}$ & $\begin{array}{l}\dot{ } \\
: \\
\dot{ } \\
\dot{5} \\
\dot{5}\end{array}$ & 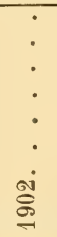 & $\begin{array}{l}: \\
\vdots \\
\vdots \\
:\end{array}$ & $\begin{array}{l}\dot{ } \\
: \\
\dot{8} \\
\dot{\Xi}\end{array}$ \\
\hline
\end{tabular}


70 Tran

\begin{tabular}{|c|c|c|c|c|c|c|c|c|}
\hline Années & Dakar & Tiaroye & $\begin{array}{l}\text { Rufis- } \\
\text { que }\end{array}$ & $\begin{array}{l}\text { Sébiko- } \\
\text { tane }\end{array}$ & Pout & Thiès & Tivaouane & Pire \\
\hline & Tonnes & Tonnes & Tonnes & Tonnes & Tonnes & Tonnes & Tonnes & Tonnes \\
\hline 1892 & 2 & ) & 29 & 150 & 727 & 6.393 & 13.437 & 2.919 \\
\hline 1893 & ” & 3 & 278 & 130 & 640 & 7926 & 16.075 & 3.660 \\
\hline 1894 & 51 & 2 & 209 & 155 & 920 & 9534 & 13.189 & 2.703 \\
\hline $1895 \ldots$ & 22 & 1 & 6 & 111 & 466 & 8.111 & 10.084 & 2.962 \\
\hline 1896 & 13 & 2 & 45 & 163 & 628 & 11.675 & 13.420 & 3.101 \\
\hline 1897 & 1 & " & 51 & 144 & 485 & 10.019 & 10.311 & 2.254 \\
\hline $1898 \ldots$ & 1 & 3 & 25 & 229 & 649 & 13,273 & 13.943 & 3.046 \\
\hline 1899. & 59 & 19 & 20 & 209 & 1.201 & 11.360 & 16.054 & 3.199 \\
\hline 1900. & 57 & 1 & 17 & 511 & 865 & 20.238 & 21.429 & 6.009 \\
\hline $1901 .$. & 35 & 66 & 449 & 993 & 1.498 & 21.496 & 24.371 & 8.556 \\
\hline 1902 . . & 37 & 55 & 53 & 836 & 1.071 & 12.459 & 12.462 & 4.084 \\
\hline 1903. & 43 & 118 & 101 & 1.214 & 1.604 & 23.119 & 18.439 & 6.373 \\
\hline $1904 \ldots$ & ) & 4 & 37 & 440 & 6003 & 15.030 & 17.278 & 5.159 \\
\hline $1892 \ldots$ & 578 & ” & 32.163 & 6 & 6 & 4 & 26 & 1 \\
\hline 1893 & 566 & 》 & 38.748 & 2 & 7 & 2 & 6 & 1 \\
\hline $1894 \ldots$ & 185 & 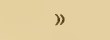 & 40.051 & 2 & 11 & 21 & 21 & 7 \\
\hline $1895 \ldots$ & 30 & 1 & 32.047 & 1 & 2 & 2 & 4 & ” \\
\hline 1896 & 58 & 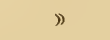 & 39.618 & 3 & 1 & 7 & 23 & 1 \\
\hline 1897 . & 48 & 1 & 34.555 & 3 & 4 & 14 & 7 & 7 \\
\hline 1898 & 476 & 2 & 45.556 & 7 & 8 & 11 & 4 & 3 \\
\hline 1899 & 68 & 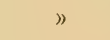 & 49.004 & 15 & 6 & 1 & 9 & 6 \\
\hline 1900 & 245 & D & 77.823 & 25 & 4 & 2 & 1 & 3 \\
\hline 1901 & 294 & 4 & 85.968 & 7 & 3 & 53 & 183 & 32 \\
\hline 1902 & 70 & 1 & 45.313 & 7 & 7 & 32 & 29 & 6 \\
\hline 1903 & 205 & 9 & 72.037 & 1 & 2 & 9 & 8 & 2 \\
\hline 1904 & 201 & 7 & 58.995 & 1 & 1 & 13 & 5 & 2 \\
\hline
\end{tabular}


aides.

\begin{tabular}{|c|c|c|c|c|c|c|c|c|}
\hline N'Dande & $\begin{array}{c}\text { Kébé. } \\
\text { mer }\end{array}$ & Guéoul & Louga & Sakal & M'Pal & Rao & St-Louis & Total \\
\hline Tonnes & Tonnes & Tonnes & Tonnes & Tonnes & Tonnes & Tonnes & Tonnes & Tonnes \\
\hline 1.209 & $72 \pi$ & 872 & 1.376 & 148 & 573 & 62 & 72 & 37.306 \\
\hline 1.683 & 980 & 1.332 & 1.536 & 31 & 101 & 29 & 40 & 43.729 \\
\hline 1.967 & 1.075 & 1. 426 & 3.669 & 311 & 354 & 212 & $3 \dot{4}$ & 46.718 \\
\hline 1.666 & 324 & $75 \pi$ & 1.774 & $14 i$ & 204 & 62 & 2 & 34.837 \\
\hline 2.009 & 608 & 753 & 1.673 & 239 & 267 & 141 & 4 & 42.863 \\
\hline 2.513 & 828 & 943 & 1.771 & $2 \% 8$ & วั0วั & 427 & 3 & 38.474 \\
\hline 2.605 & 1.723 & 2.130 & $4.24 !$ & 364 & $71 \ddot{3}$ & 361 & 2 & ว̈3.089 \\
\hline 3.294 & 1.928 & 2.710 & 6.946 & 913 & 840 & 232 & 7 & $5 \pi .642$ \\
\hline 3.082 & 3.507 & 5.082 & 7.303 & 1.733 & 1.449 & 683 & 4 & 90.386 \\
\hline 3.905 & 3.608 & 4.824 & 7.003 & 1.662 & 941 & 809 & 3 & 97.660 \\
\hline 1.500 & 2.262 & 1.874 & 3.300 & 1.020 & 370 & $89 x$ & 13 & 51.318 \\
\hline 2.393 & 2.716 & 2.006 & 2.800 & 829 & 264 & 671 & 1 & 78.296 \\
\hline 3.211 & 3.412 & 3.330 & 2.757 & 902 & 323 & 530 & 16 & 66.209 \\
\hline$》$ & 8 & 3 & 6 & 1 & 9 & 7 & 4.484 & 37.306 \\
\hline 1 & $"$ & 3 & 10 & 2 & 7 & $\ddot{3}$ & 4.369 & 43.729 \\
\hline 1 & " & $"$ & 17 & 》 & 1 & 1 & 6.393 & 46.718 \\
\hline 11 & $"$ & 1 & 32 & 1 & 4 & $"$ & 2.691 & 34.837 \\
\hline " & " & 1 & 13 & 》 & 》 & 2 & 3.133 & 42.863 \\
\hline 2 & ” & 2 & 1 & D & 1 & " & 3.820 & 38.474 \\
\hline " & .3 & ” & 1 & $"$ & 1 & 1 & 7.007 & 53.089 \\
\hline 3 & 3 & 2 & 2 & 4 & 1 & 3 & 8.504 & 57.642 \\
\hline$"$ & 8 & 》 & 1 & $"$ & 2 & 4 & 12.261 & 90.386 \\
\hline 11 & 42 & 3 & 2 & $"$ & $"$ & " & 10.987 & $9 \pi .660$ \\
\hline 》 & $i$ & $\cong$ & 9 & 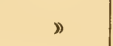 & " & 13 & 3.763 & 31.318 \\
\hline 2 & 1 & 4 & 11 & 7 & 20 & 28 & $5.9^{\prime} 8$ & 78.296 \\
\hline 1 & 1 & 2 & 29 & 4 & 4 & 8 & 6.999 & 66.209 \\
\hline
\end{tabular}


$8^{0}$ Trans

\begin{tabular}{|c|c|c|c|c|c|c|c|c|c|c|c|}
\hline \multicolumn{4}{|c|}{ Années } & \multirow{2}{*}{$\begin{array}{l}\text { Dakar } \\
\text { Tonnes }\end{array}$} & \multirow{2}{*}{ Tiaroye } & \multirow{2}{*}{$\begin{array}{c}\begin{array}{c}\text { Rufis- } \\
\text { que }\end{array} \\
\text { Tonnes }\end{array}$} & \multirow{2}{*}{$\begin{array}{c}\begin{array}{c}\text { Sébiko- } \\
\text { tane }\end{array} \\
\text { Tonnes }\end{array}$} & \multirow{2}{*}{$\begin{array}{c}\text { Pout } \\
\text { Tonnes }\end{array}$} & \multirow{2}{*}{$\begin{array}{l}\text { Thiès } \\
\text { Tonnes }\end{array}$} & \multirow{2}{*}{$\begin{array}{l}\text { Tivaotiane } \\
\text { Tonnes }\end{array}$} & \multirow{2}{*}{$\begin{array}{c}\text { Pire } \\
\text { Tonnes }\end{array}$} \\
\hline & & & & & & & & & & & \\
\hline 1892. & . & . & & 2 & ) & 53 & 2 & 9 & 198 & 405 & 69 \\
\hline 1893. & . & . & . & 7 & $》$ & 62 & 4 & 9 & 249 & 349 & 78 \\
\hline 1894 . & • & . & . & 4 & $》$ & 130 & 1 & 3 & 58 & 52 & 17 \\
\hline 1895. & . & • & . & 1 & ) & 19 & 3 & 11 & 153 & 213 & 34 \\
\hline 1896. & • & . & . & 3 & 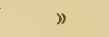 & 61 & 3 & 8 & 216 & 108 & 19 \\
\hline 1897. & · & . & . & 14 & $》$ & 37 & 6 & 39 & 112 & 65 & 16 \\
\hline 1898 . & . & . & . & 1 & $》$ & 51 & 60 & 81 & 73 & 64 & 6 \\
\hline 1899. & . & . & . & 4 & ” & 38 & 9 & 89 & 225 & 84 & 13 \\
\hline 1900 . & • & . & . & 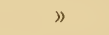 & $》$ & 67 & 18 & 50 & 39 & 30 & 3 \\
\hline 1901. & · & . & . & 1 & 》 & 7 & 2 & 11 & 211 & 79 & 24 \\
\hline 1902. & . & . & . & 2 & ) & 41 & 10 & 35 & 440 & 194 & 40 \\
\hline 1903. & . & . & . & 154 & 1 & 75 & 23 & 56 & 574 & 294 & 83 \\
\hline 1904. & . & . & . & 3 & 1 & 141 & 10 & 16 & 493 & 263 & 105 \\
\hline 1892. & . & . & . & 291 & 21 & 419 & 6 & 14 & 7 & 9 & 1 \\
\hline 1893. & · & . & . & 153 & 23 & 169 & 2 & 16 & 7 & 28 & 10 \\
\hline 189k. & . & • & . & 69 & 8 & 50 & 4 & 15 & 6 & 35 & 14 \\
\hline 1895. & . & . & . & 282 & 29 & 126 & 8 & 16 & 12 & 6 & $\eta$ \\
\hline $1896^{\circ}$. & . & . & . & 218 & 17 & 127 & 7 & 8 & 4 & 49 & 26 \\
\hline 1897. & . & . & . & 199 & 20 & 82 & 3 & 3 & 34 & 73 & 9 \\
\hline 1898. & • & . & . & 123 & 12 & 64 & 3 & 3 & 50 & 143 & 48 \\
\hline 1899 . & . & . & . & 256 & 31 & 141 & 2 & 6 & 9 & 29 & 15 \\
\hline 1900 . & • & . & . & 73 & 23 & 12 & 1 & 1 & 19 & 66 & 22 \\
\hline 1901. & · & • & . & 138 & 25 & 65 & 6 & 17 & 2 & 15 & 3 \\
\hline 1902 . & • & • & . & 318 & 63 & 155 & 9 & 13 & 10 & 31 & 12 \\
\hline 1903. & · & . & . & 444 & 265 & 108 & 3 & 6 & 6 & 42 & 6 \\
\hline 1904. & · & . & . & 686 & $9 \check{~}$ & 277 & 20 & 87 & 33 & 67 & 24 \\
\hline
\end{tabular}




\begin{tabular}{|c|c|c|c|c|c|c|c|c|c|c|c|c|}
\hline \multicolumn{3}{|c|}{ Années } & \multirow{2}{*}{\multicolumn{2}{|c|}{ 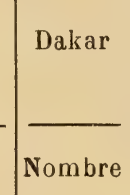 }} & \multirow{2}{*}{ Tiaroye } & \multirow{2}{*}{$\begin{array}{c}\begin{array}{c}\text { Rufis- } \\
\text { que }\end{array} \\
\text { Nombre }\end{array}$} & \multirow{2}{*}{$\begin{array}{c}\begin{array}{c}\text { Séviko- } \\
\text { tane }\end{array} \\
\text { Nombre }\end{array}$} & \multirow{2}{*}{ Pout } & \multirow{2}{*}{ Thiès } & \multirow{2}{*}{ Tivaouane } & \multirow{2}{*}{$\begin{array}{c}\text { Pire } \\
\text { Nombre }\end{array}$} & $\mathrm{Mol}$ \\
\hline & & & & & & & & & & & & Nom \\
\hline 1894 . & . & . &. & 16 & 1 & 27 & 1 & 4 & 17 & 119 & 6 & \\
\hline 1895. & . & . &. & 31 & 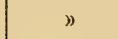 & 81 & 2 & 5 & 39 & 108 & 15 & 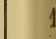 \\
\hline 1896 . & • & . &. & 22 & 2 & 78 & 2 & 3 & 31 & 132 & 20 & 4 \\
\hline 1897. & . & . & & 19 & 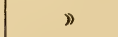 & 56 & $"$ & , & 29 & 115 & 7 & : \\
\hline 1898 & . & . & $\cdot$ & 34 & 1 & 43 & ) & 7 & 36 & 102 & 10 & $\vdots$ \\
\hline 1899 & . & . & . & 12 & $\gg$ & 52 & $"$ & 3 & 28 & 86 & 14 & ? \\
\hline 1900 & . & . & . & 32 & $"$ & 28 & 2 & 3 & 41 & 67 & 11 & ? \\
\hline 1901 & . & . & . & 31 & 》 & 42 & 》 & 6 & 41 & 72 & 6 & \\
\hline 1902 & . & . & . & 28 & 》 & 52 & 》 & 2 & 44 & 166 & 9 & \\
\hline 1903 & . & • & . & 37 & 》 & 112 & $"$ & 1 & 101 & 150 & 31 & \\
\hline 1904 & . & . & . & 91 & 3 & 98 & 3 & 17 & 140 & 167 & 31 & \\
\hline 1894 & . & . & . & 101 & 6 & 103 & 1 & 7 & 20 & 74 & 8 & \\
\hline 1895 & . & . & $\cdot$ & 94 & 4 & 124 & 1 & 7 & 39 & 57 & 10 & \\
\hline 1896 & . & . & . & 98 & 3 & 154 & 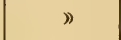 & ) & 43 & 81 & 8 & \\
\hline 1897 & . & . & . & 102 & 1 & 107 & ) & 2 & 45 & 55 & 7 & \\
\hline 1898 & . & . & . & 112 & 2 & 97 & 3 & 16 & $5 \%$ & 43 & 2 & \\
\hline 1899 & • & . & . & 142 & 4 & 102 & $"$ & 2 & 32 & 60 & 1 & \\
\hline 1900 & . & . & $\cdot 1$ & 137 & 2 & 91 & 2 & 1 & 42 & 69 & 4 & \\
\hline 1901 & . & . & $\cdot$ & 126 & 3 & 69 & 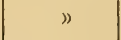 & 6 & 68 & 73 & 4 & \\
\hline 1902 & . & . . & . & 261 & 1 & 107 & ” & 6 & 57 & 58 & 5 & \\
\hline 1903 & . & . . & . & 934 & 6 & 173 & 2 & 5 & 82 & 62 & 6 & \\
\hline 1904 & . & . & & $6 i 85$ & 8 & 223 & 2 & 5 & 79 & 68 & 1 & \\
\hline
\end{tabular}


naux vivants.

\begin{tabular}{|c|c|c|c|c|c|c|c|c|}
\hline N'Dande & $\begin{array}{l}\text { Kèbé- } \\
\text { mer }\end{array}$ & Guéoul & Louga & Salal & N'Pal & Rao & St-Louis & Total \\
\hline Nombre & Nombre & Nombre & Nombre & Nombre & Nombre & Nombre & Nombre & Nombre \\
\hline 5 & 4 & $\triangleright$ & 24 & $"$ & 1 & $\ddot{\partial}$ & 146 & 418 \\
\hline 12 & 2 & 1 & 21 & 1 & 1 & 1 & 88 & $4 \div 3$ \\
\hline 45 & 4 & 2 & 19 & 1 & 13 & " & 98 & 523 \\
\hline 20 & 6 & 2 & 18 & 4 & 7 & 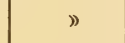 & 84 & 410 \\
\hline 28 & 7 & 》 & 22 & $"$ & 6 & 1 & 98 & 439 \\
\hline 36 & 6 & " & 12 & 3 & 7 & 2 & 151 & 442 \\
\hline 15 & 4 & ๖ & 8 & $"$ & 2 & 4 & 128 & 419 \\
\hline 18 & 9 & 2 & 22 & 2 & 3 & 2 & 180 & 489 \\
\hline 9 & 14 & 7 & 66 & 1 & 1 & 4 & 155 & 602 \\
\hline 37 & 13 & 87 & 699 & 8 & 3 & 2 & 137 & 1.489 \\
\hline 15 & 9 & 23 & 261 & 15 & 3 & 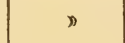 & 330 & 1.260 \\
\hline 3 & 2 & tit & 17 & 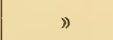 & 3 & 2 & 32 & 418 \\
\hline 11 & 5 & 4 & 10 & 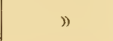 & $\stackrel{2}{2}$ & $"$ & $4 i$ & 143 \\
\hline 4 & 5 & 2 & 13 & $"$ & 3 & 2 & 6.3 & 323 \\
\hline 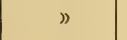 & 3 & 7 & 16 & 1 & 7 & 1 & $3 \dot{x}$ & 410 \\
\hline 8 & $\ddot{0}$ & $"$ & 17 & 2 & 3 & ") & 48 & 439 \\
\hline 1 & 3 & 1 & 34 & $n$ & 6 & $"$ & $3 \check{5}$ & 40 \\
\hline 4 & 1 & 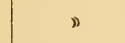 & 17 & $"$ & 3 & $"$ & $\simeq 6$ & 419 \\
\hline 4 & 3 & $"$ & 53 & 3 & 2 & 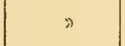 & $4 \bar{T}$ & 49 \\
\hline$"$ & 2 & วั & 23 & 1 & $\cong$ & $"$ & 50 & 602 \\
\hline 5 & 2 & 5 & 32 & " & 1 & 1 & 151 & 1. 89 \\
\hline 7 & 6 & 16 & 44 & 1 & 1 & 1 & 90 & 1.260 \\
\hline
\end{tabular}




\section{b) Chemin de fer de Thiès à Kayes}

Suivant la proposition de M. le Gouverneur général Roume qui, dès son entrée en fonctions, s'était préoccupé de cette question vitale pour l'avenir de nos territoires de SénégambieNiger, une dépêche du Ministre des Colonies en date du 9 décembre 1902 avait décidé l'organisation d'une mission d'études du chemin de fer Sénégal-Soudan.

Cette mission, placée sous la direction du colonel Rougier, déjà directeur du chemin de fer de Kayes au Niger, comprenait le chef de bataillon du génie Belle, qui devait ultérieurement prendre le commandement effectif de la mission, les capitaines du génie Friry et Gérard et le docteur Conan, médecin de $\mathbf{2}^{\circ}$ classe des troupes coloniales.

Conformément à la lettre du 9 janvier 1903, contenant les instructions du Gouverneur général, le but de la mission était l'étude d'un tracé destiné à relier à la ligne de Dakar à SaintLouis le chemin de fer de Kayes au Niger, en desservant sur son parcours les régions déjà cultivées ou susceptibles d'être mises en valeur et dont elle assurerait ainsi le développement graduel.

Le point de départ étant fixé à Thiès, le tracé devait être tenu dans la direction de Diourbel, en vue de pouvoir desservir la région habitée et cultivée du Baol, mais en restant en dehors de la zone d'action de la rivière Saloum. Ensuite il convenait de s'infléchir vers le Sud, de manière à se rapprocher de la rivière Gambie jusqu'à la distance à maintenir pour que le rendement économique de la ligne ne fut pas influencé par le voisinage de cette voie navigable.

La mission fut divisée en deux groupes :

Le premier, sous les ordres du colonel Rougier, auquel était adjoint le capitaine Friry, opérait des reconnaissances de l'itinéraire dont les résultats étaient successivement transmis au deuxième groupe, opérant snus les ordres du commandant Belle, avec le capitaine Gérard comme adjoint, et qui effectuait le relevé du tracé.

Parti de Thiès le 19 janvier 1903, le premier groupe arriva à Kayes le 20 mars suivant et, le colonel Rougier reprenant ses 
fonctions de Directeur du chemin de fer de Kayes au Niger, le capitaine Friry prit le commandement du premier groupe qui revint sur son itinéraire, pour en relever le tracé, à la rencontre du deuxième groupe.

Cette rencontre se produisait le 9 juin 1903, en un point situé entre les villages de Onoro-Daouda et Ouméré; le premier groupe venait ainsi d'exécuter, en moins de trois mois, le lever à la planchette et au $1 / 10,000^{\mathrm{e}}$ d'un véritable canevas dont le développement atteignait 250 kilomètres.

De son côté, le deuxième groupe, parti de Thiès le 21 janvier 1903, n'avait pas mis cinq mois pour faire le même travail sur une longueur de $\mathbf{4 3 2}$ kilomètres.

La mission rentra ensuite en France pour effectuer la mise au net des résultats de ses opérations et l'avant-projet qu'elle produisit fut adopté, avec éloges, par le Comité des Travaux publics des Colonies, dans sa séance du 11 juillet 1904. Le tracé ainsi admis, répondait aux instructions données par le Gouverneur général de l'Afrique occidentale française. Partant de Thiès, il se dirige d'abord vers l'Est à traver's les terres fertiles du Baol, puis s'infléchit vers le S.-E. pour contourner le Ferlo. Il coupe la vallée du Saloum et rejoint le bassin de la Gambie dont il suit ou traver'se plusieurs affluents. Remontant alors vers le N. E., la ligne atteint le faite de partage des eaux et entre dans le bassin du Sénégal : elle franchit la Falémé, rejoint le fleuve à Ambidedi et le remonte jusqu'à Kayes.

Le parcours total ainsi défini est de 682 kilomètres, mais la mission, dans ses rapports, indique qu'elle a reconnu la possibilité de supprimer les brisures du tracé entre N'Gahaye et Ouarnéo et entre Ouarnéo et Guériméo, ce qui conduirait à une réduction de parcours de 10 à 12 kilomètres.

En raison des faibles variations dans le relief des terrainś traversés, les pentes et rampes ont pu être maintenues à une limite de $0 \mathrm{~m} .01$ par mètre,

La ligne sort de Thic̀s à la cote $(64,50)$, descend plusieurs fois au-dessous de la cote $(10,00)$ à la traversée des vallées, atteint son altitude maxima à la cote (111), au kilomètre 331 , point de 
partage des eaux des bassins de la Gambie et du Sénégal, et rejoint le fleuve à Ambidedi à la cote (28).

La plupart des courbes ont 1,000 mètres de rayon et il n'existe sur tout le parcours que deux courbes de 300 mètres, de faible longueur, et une de כ̋00 mètres.

L'ensemble des parties en courbe ne représente que un dixième du développement total.

Les terrassements sont en général de peu d'importance et seule la traversée du seuil de partage des eaux entraine une tranchée de 22,000 mètres cubes dont 18,000 dans le grès fissuré.

Les ouvrages d'art sont peu nombreux et ne comportent guère que le pont sur la Falémé de $220 ̈$ mètres, deux ponts de 50 mètres, quatre de 25 mètres, deux de 20 mètres, trois de 15 mètres et dix de 10 mètres.

Le ballast se trouve en général sur place, sauf sur une partie où il exigera un transport de 50 kilomètres.

Le rails seraient de $\mathbf{2 5}$ kilos au mètre courant et les traverses en acier doux du type «Soudan 》.

Il est prévu cinquante-deux stations ou haltes dont six grandes stations, vingt moyennes, quatorze petites et douze haltes.

En admettant des prix unitaires assez largement calculés, l'ensemble des dépenses s'élèverait à 45 millions, y compris l'alimentation d'eau à raison de 1.000 francs par kilomètre, le matériel roulant à raison de 7.500 francs par kilomètre et une somme de 500.000 francs pour installation d'ateliers; ce qui mettrait à 66.000 francs environ le prix de revient du kilomètre. La commission du comité des Travaux publics avait demandé d'augmenter les prévisions de un dixième pour tenir compte des aléas, ce qui porterait la dépense totale à 50 millions.

En raison de l'intérêt considérable que présente cette ligne, non seulement au point de vue des communications avec le Soudan, mais aussi à celui de l'exploitation des régions productives d'arachides du Baol et du Saloum, des pourpalers ont été engagés avec la Compagnie du chemin de fer de Dakar à SaintLouis pour la construction d'une longueur de $\mathbf{1 4 0}$ kilomètres de cette ligne, depuis Thiès jusqu'à N'Gahaye. Il y aurait lieu de 


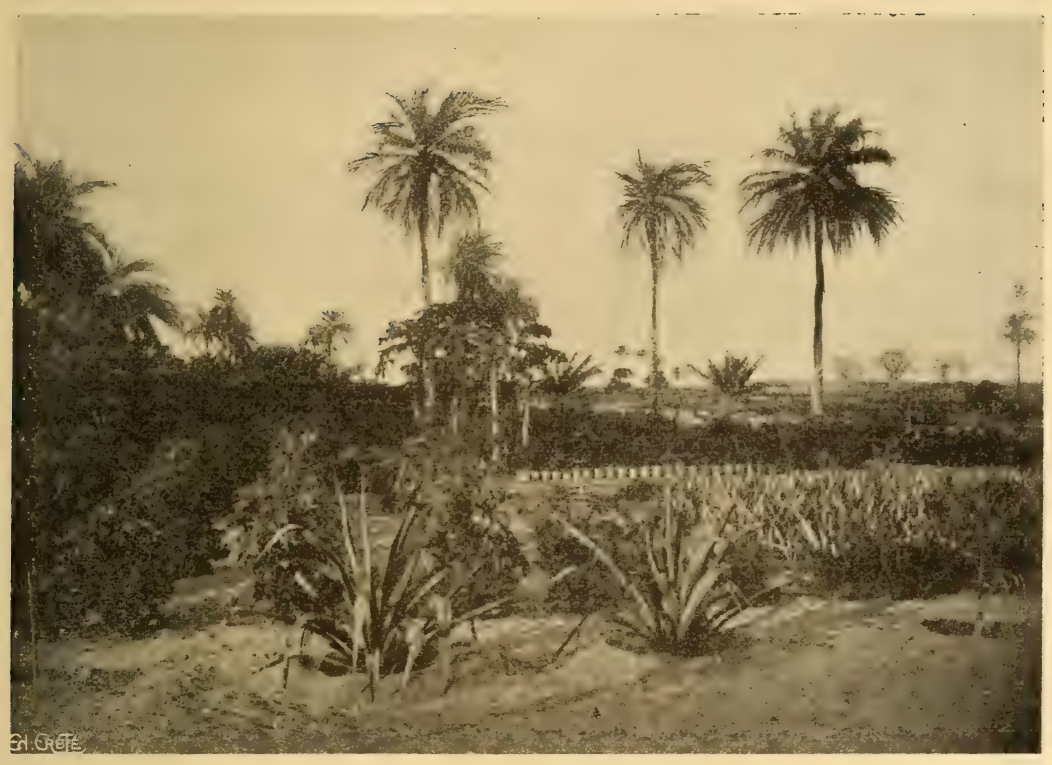

Fig. 33. - Dakar (Le jardin d'essai).

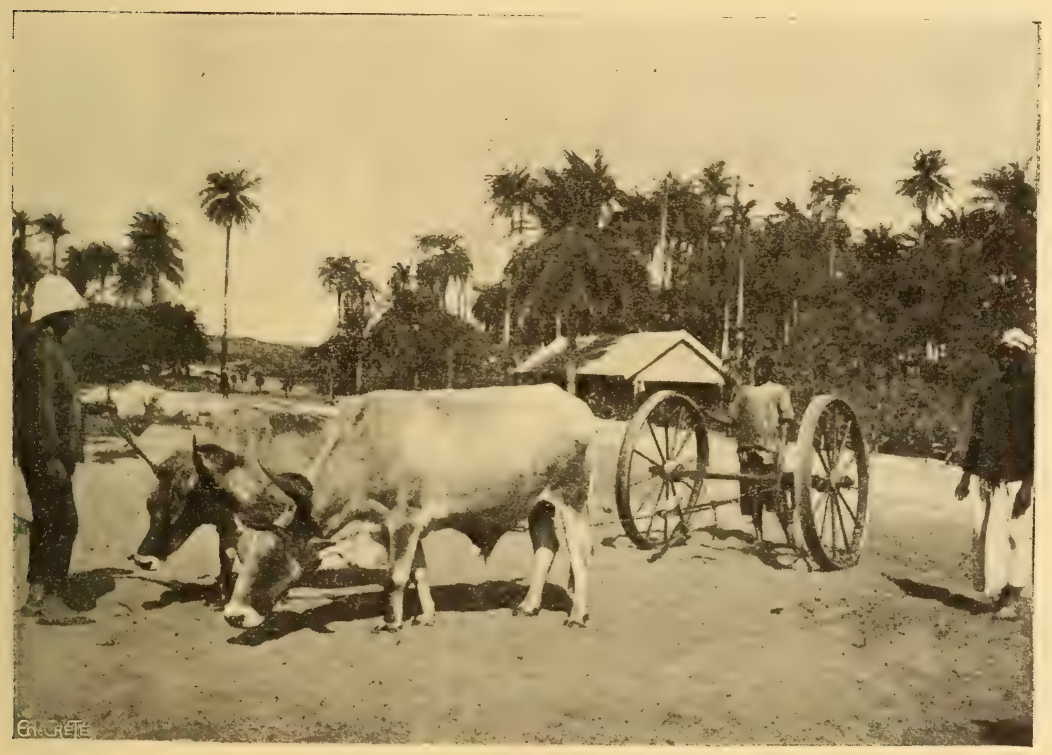

Fig. 34. - Attelage de bœufs.

s. 

construire également au plus tôt la section de 42 kilomètres environ de longueur de Kayes à Ambidedi.

Ajoutons qu'une somme de 10 millions qui sera prélevée sur l'emprunt de 100 millions soumis actuellement à l'approbation du Parlement doit être affectée à la construction de la ligne entre Thiès et N'Gahaye.

\section{** \\ C. - Travaux divers}

\section{a) Eclairage des côtes et des rades}

Les principaux feux et phares du Sénégal sont :

$A$ Saint-Louis, sur le gouvernement, un leu de port fixe blanc, qu'on peut apercevoir du large de 4 ou 5 milles.

Au cap Vert, sur la mamelle la plus ouest, un phare à feu tournant blanc, montrant son éclat le plus brillant de 30 secondes en 30 secondes. Il est élevé de 113 mètres au-dessus du niveau de la haute mer, et, avec une atmosphère claire, on peut le voir d'une distance de 27 milles. L'appareil d'éclairage est dioptrique ou à lentilles de premier ordre. La tour a 20 mètres d'élévation, elle est ronde, blanche avec des corniches noires, et la lanterne est en bronze. Le feu éclaire tout l'horizon en mer et l'on peut toujours le voir de Dakar, qui est à 9.760 mètres de distance; mais on voit rarement la lumière fixe de Gorée.

Position : $14^{\circ} 43^{\prime} 30^{\prime \prime}$ nord, $19^{\circ}$ 5้1'8" ouest.

Pointe des Almadies. Phare. - Feu fixe, variant par des éclats alternativement blancs et rouges de 30 en 30 secondes.

Cap Manuel. Phare. - Le $1^{\text {er }}$ décembre 1866, on a allumé un feu fixe rouge sur la falaise du cap Manuel; il est élevé de 52 mètres au-dessus de la haute mer, et, avec un atmosphère claire, on peut le voir d'une distance de 8 milles sur tout l'horizon. L'appareil d'éclairag’e est dioptrique et de quatrième ordre. La tour est carrée, élevée de 12 mètres au-dessus du sol. Elle est située à 5 milles $9 / 10$ au sud $42^{\circ}$ est du phare du cap Vert.

Feu de la jetée Est de Dakar. - Le feu vert de la jetée Est de 
Dakar, $n^{\circ}$ 39, Série $E$, du livret des pharcs, a été remplacé en 1904 par un feu rouge de port, avec cabane en tôle, à optique de $0 \mathrm{~m} .30$ de diamètre à sept éléments verre poli.

Ce feu est élevé de 6 mètres au-dessus du seuil du cabanon, lequel repose sur un socle en maçonnerie, dont la partie supérieure est à $3 \mathrm{~m} .10$ au-dessus du niveau de la haute mer.

Il est pratiquement visible à 5 ou 6 milles.

L'entrée de la passe est indiquée par deux feux (rouge à babord, vert à tribord), placés sur des chevalets à environ 4 mètres au-dessus des basses mers. Ces feux sont visibles à une distance de deux milles environ.

Position : $14^{\circ} 40^{\prime} 30^{\prime \prime}$ nord, $19^{\circ} 45^{\prime} 45^{\prime \prime}$ ouest.

Feu de Rufisque. - Le feu fixe rouge de Rufisque, dont l'avis $\mathrm{n}^{0} \mathbf{2 0} / 99,1879$, a annoncé l'allumage, est placé dans la tour située de l'Ouest q. Sud-Ouest de la ville ; il est élevé de 16 mètres au-dessus des hautes mers moyennes et sa portée lumineuse est de 3 milles.

Position : $14^{\circ} 42$ ' 39" nord. $-19^{\circ} 38^{\prime} 6^{\prime \prime}$ ouest.

Feude Carabane. - On allume chaque nuit, depuis le coucher du soleil jusqu'à cinq heures du matin, au-dessus du poste de Carabane, un feu rouge, élevé de 16 mètres et visible d'une distance de 6 milles.

\section{b) Travaux d'assainissement.}

Dans la répartition des crédits provenant de l'emprunt de 63 millions une somme de $\mathbf{5 . 4 5 0 . 0 0 0 ~ f r a n c s ~ e ́ t a i t ~ a f f e c t e ́ e ~ a ̀ ~ d e s ~}$ travaux dassainissement à effectuer au Sénégal, colonie si souvent ravagée jusqu'ici par le terrible fléau qu'est Ia fièvre jaune.

Assainissement de Saint-Louis - Ainsi que cela était projeté, les travaux d'assainissement ont porté à Saint-Louis sur les marais de la pointe Nord de l'île, qui vont être entièrement comblés, et sur les marais de Sor, que l'on a remblayés dans un rayon de $10 \ddot{0} 0$ à 200 mètres autour de tous les points habités.

Des caniveaux et des égouts ont été établis pour assurer l'écoulement des eaux, des plantations ont été faites pour absorber l'humidité du sous-sol et ces quartiers, qui étaient à l'état de 
marais croupissants, prendront l'aspect des belles promenades publiques. On étudie en même temps l'amélioration des moyens d'évacuation des vidanges pour lequel un crédit de 330.000 francs est inscrit dans le programme des travaux.

Assainissement de Dakar. - Suivant les prévisions, le grand effort pour l'assainissement de Dakar a porté sur l'établissement d'un système d'égouts destiné à évacuer les vidanges et les eaux ménagères, sur le comblement des ravins situés à l'intérieur de la ville et qui depuis longtemps constituaient les dépotoirs du pays.

Actuellement la portion principale des égouts comprenant de grands collecteurs aboutissant à la mer est terminée, les branchements secondaires sont entrepris et poursuivis avec activité et, sous peu, toutes les habitations de Dakar pourront user du " tout à l'égout".

Toutes les dépressions, dont certaines étaient considérables et qui se trouvaient, soit à l'intérieur, soit aux abords de la ville, telle qu'elle était en 1902, ont été comblées et régularisées par un système de chaussées qui constitueront, d'après un plan d'alignement, les grandes artères de la ville, au fur et à mesure que les constructions se développeront. Tout un réseau de caniveaux et d'égouts pour eaux pluviales a été installé pour assurer l'écoulement des eaux dans des conditions satisfaisantes, de sorte que la ville de Dakar qui, tout récemment encore, n'était qu'un ensemble de masures informes, irrégulièrement groupées dans des terrains vagues et malsains, prend l'aspect d'une grande ville aux larges avenues, suffisamment pourvue d'égouts pour les besoins actuels et offrant toutes les garanties de salubrité nécessaires dans ces climats. Néanmoins, ainsi que l'indiquait le rapport dressé le 21 novembre 1902 par le Directeur des 'Travaux publics du Sénégal pour l'établissement du programme des premiers travaux, il est indispensable que ces travaux d'assainissement soient encore étendus pour correspondre au développement progressif de Dakar et faciliter les cultures nécessaires à l'alimentation d'une ville qui doit posséder tontes les ressources d'un grand port de ravitaillement.

Assainissement de Rufisque. - La ville de Rufisque était 
entourée par trois marigots importants, un premier au Nord qui séparait la ville du quartier de la gare, un autre à l'Est où se concentraient les eaux se déversant d'un plateau voisin et un troisième à l'Ouest qui formait l'émissaire principal à la mer des eaux de la région.

Le marigot Nord qui, en tout temps, formait des mares croupissantes au milieu des parties fréquentées et même habitées, a été comblé et un système d'égouts a été établi pour assurer l'écoulement des eaux pluviales dans ces parties de la ville et les quartiers voisins.

Le marigot Est a été séparé de la ville par une chaussée et l'écoulement direct de ses eaux à la mer a été assuré par un canal et un ouvrage spécial pour le débouché sur le rivage.

Enfin on procède à la régularisation du cours du marigot Ouest et de ses abords, de manière à y éviter toute stagnation d'eau.

On étudie en même temps l'amélioration des moyens d'évacuation des eaux de vidanges qui, suivant les prévisions, doit compléter l'assainissement de Rufisque, mais qui, de même qu'à Saint-Louis, présente, par suite des conditions locales, certaines difficultés de réalisation.

\section{c) Travaux divers}

Parmi les travaux divers, exécutés au Sénégal, il convient de signaler :

$\mathbf{1}^{\circ}$ Le pont Faidherbe qui relie l'île Saint-Louis à Bouët-Ville (faubourg de Sor) en traversant le grand bras du fleuve Sénégal.

Le pont qu'il remplaça datait de 1860. Il se composait d'un pont fixe en charpente et d'un pont de bateaux offrant une partie mobile de 20 mètres pour le passage des navires. Son état était très défectueux et les réparations annuelles qu'il exigeait ne s'élevaient pas à moins de $\mathbf{4 0 . 0 0 0}$ francs. Il était urgent, en raison de la circulation active qui s'y produisait, de le remplacer par un pont fixe métallique avec travée tournante.

La construction en fut décidée et le 9 octobre 1894, après appel à la concurrence, un marché de gré à gré fut passé entre 1e Ministre des Colonies et la maison Nouguier, Kessler et Cie 
qui s'engageait à reconstruire le pont dans un délai de trois années.

Inauguré officiellement le 15 octobre 1897 par M. André Lebon, Ministre des Colonies, cet ouvrage présente les caractéristiques suivantes :

Sa longueur est de 506 mètres et sa largeur de $10 \mathrm{~m} .20 \mathrm{com}$ prenant une chaussée de 7 mètres et deux trottoirs de $1 \mathrm{~m} .60$ chacun. Ce pont se compose de sept tabliers métalliques reposant sur deux culées et sept piles.

La culée de rive droite et les sept piles ont été fondées à l'air comprimé au moyen de caissons métalliques; la culée de rive gauche a été fondée sur pilotis noyés à leur tête dans un massif de béton.

Les sept travées métalliques indépendantes se composent de deux poutres principales dont les membrures inférieures sont horizontales et les membrures supérieures paraboliques.

Ces poutres sont réunies, à leur partie inférieure par des entretoises porteuses; à leur partie supérieure, mais dans la région centrale seulement, par des entretoises et des contreventements en croix de Saint-André.

La chaussée est faite en béton hydraulique reposant sur des tôles cintrées en acier de 0 m. 008 d'épaisseur s'appuyant sur cinq cours de longerons et deux poutrelles de rive.

Les trottoirs constitués par des madriers, sont supportés par des consoles placées en encorbellement au droit de chaque pièce de pont et reliées par des poutrelles de rive surmontées d'un garde-corps métallique de $\mathbf{1}$ mètre de hauteur.

La deuxième travée, à partir de la rive droite, d'une longueur de 70 mètres, est mobile autour d'un pivot fixé au centre d'une pile. Elle repose sur un cercle de galets coniques de $7 \mathrm{~m}$. 50 de diamètre. La manœuvre se fait à bras. Pour alléger cette travée tournante, on a remplacé en 1889, la chaussée en béton par un pavage en bois.

Le nouveau pont Faidherbe ainsi établi a coûté 1.990 .000 francs. Cette dépense de premier établissement est considérable eu égard aux ressources du service local; elle est compensée dans une certaine mesure par les économies que l'on peut réaliser sur les 
frais d'entretien que nécessitait l'ancien pont de bateaux ; elle est justifiée en tous cas par les services que rend le nouvel ouvrage, snumis à une circulation des plus intenses.

$2^{0}$ Le pont de Guet $N^{\prime} D a r$ qui fait communiquer l'ile SaintLouis aux faubourgs de Guet N'Dar et N'Dar Toute (langue de Barbarie) en traversant le petit bras du fleuve.

Il a remplacé un pont de bois, bâti sur rôniers, très vieux et en fort mauvais état.

Une adjudication sur concours eût lieu en avril 1897 et M. le Roy dont le projet fut adopté s'engagea à reconstruire le pont suivant les prescriptions du cahier des charges, pour la somme de 172.530 francs.

Nous donnons ci-après les caractéristiques de l'ouvrage :

Sa longueur est de 135 mètres se dé oomposant comme suit: $1^{\circ} 6$ travées de 8 mètres de chaque côté du fleuve; $2^{\circ}$ deux palées doubles de $2 \mathrm{~m} .70$ à proximité de la travée tournante; $3^{\circ}$ une travée tournante d'une longueur de $\mathbf{3 4}$ mètres $\mathbf{4 0}$.

La largeur est de 9 mètres comprenant 6 mètres de chaussée et deux trottoirs de $1 \mathrm{~m} .50$ de largeur chacun.

Les travées fixes se composent detrois files de poutres reposant sur des palées à 3 pieux. Les trottoirs sont supportés par des consoles rivées aux poutres de rives.

La travée tournante se compose de deux poutres de $1 \mathrm{~m} . \breve{0}$ de hauteur au milieu et $0 \mathrm{~m} .50$ aux extrémités, réunies par des entretoises porteuses espacées de $2 \mathrm{~m}$. 50. L’entretoise placée dans l'axe transversal est supportée elle-même par un pivot.

Des galets au nombre de six se déplacent sur un cercle de roulement de $5 \mathrm{~m} .50$ de diamètre et conservent l'équilibre du tablier pendant la rotation. Extérieurement à ce cercle est rivée une cornière supportant une chaîne Galle engrenant avec le pignon moteur de la travée.

La palée métallique supportant cette travée se compose de huit pieux au pourtour et d'un pieu central. Ils sont contreventés à deux hauteurs.

Les deux palées voisines de la travée tournante sont à six pieux placés sur deux rangs et les palées courantes sont à trois pieux entretoisés à deux hauteurs dans le sens transversal. 
Le platelage de la chaussée et des trottoirs est constitué en madriers de pitchpin.

\section{d) Travaux projetés}

Dans le projet de loi déposé sur le bureau de la Chambre et tendant à autoriser le gouvernement général à réaliser un nouvel emprunt de 100 millions, les travaux suivants sont prévus par le Sénégal :

Titre $I^{\mathrm{er}}$. - Chemins de fer de pénétration.

d) Ligne Thiès-N'Gahaye . . . . . . 10.000.000

Titre II. -- Aménagement des ports et des voies navigables.

a) Port de Dakar :

1) Adduction d'eau . . . . . . . . . . $\quad \mathbf{2 . 0 0 0 . 0 0 0}$

2) Assainissement. . . . . . . . . 1.500 .000

3) Mouillage pour les opérations du charbonnage des navires. . . . . . . 1.000 .000

4) Eclairage des abords . . . . . . 250.000

d) Outillage de dragage et balisage (Saloum et Casamance) . . . . . . . . . 800.000

e) Installation de la baie du Levirier. . . $\$ 500.000$

Titre III. - Assistance médicale indigène.

Construction d'un hôpital indigène à Dakar, agrandissement de l'hôpital colonial, à valoir sur le crédit de 3 millions.

Titre IV. - Constructions militaires.

Une partie du crédit de 5 millions sera affectée à la réfection des casernements au Sénégal.

\section{Les communications postales et télégraphiques}

Le développement des voies postales et télégraphiques joue un rôle capital dans la vie économique d'un pays. Nous allons 
rapidement examiner comment le Sénégal est doté à ce point de vue.

Service postal maritime. - Le service maritime postal est assuré par trois Compagnies:

$1^{\circ} \mathrm{La}$ Compagnie des Messageries maritimes, dont les lignes du Brésil et de la Plata, partant de Bordeaux tous les quatorze jours touchent Dakar. Les prix des passages de Bordeaux à Dakar sont les suivants :

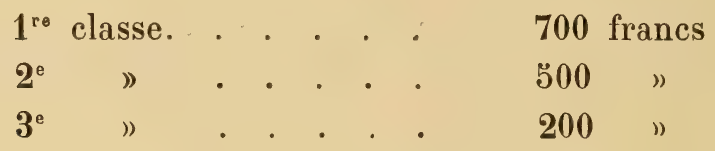

$2^{\circ}$ La Compagnie des Chargeurs Réunis qui effectue tous les mois un voyage commercial, c'est-à-dire, avec escales nombreuses dont le départ a lieu du Havre le 11 de chaque mois et de Bordeaux le 15; tous les mois également elle fait partir un paquebot rapide quittant Bordeaux le 2ə. C'est cette ligne qui constitue le service postal subventionné tous les deux mois. Les prix de Bordeaux à Dakar sont :

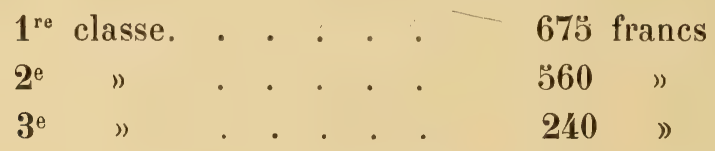

La Compagnie Fraissinet avec une ligne libre allant tous les deux mois de Marseille à Cotonou et une ligne subventionnée allant tous les deux mois également de Marseille à Loango. Les départs ont lieu tous les 5 du mois et les prix de passage entre Marseille et Dakar sont :

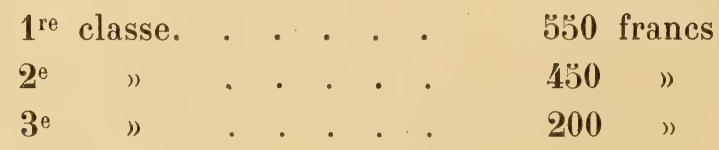

Service postal intérieur. - Entre Dakar et Saint-Louis, les correspondances sont échangées par des trains circulant journellement; en outre, un train supplémentaire, de novembre à mai, dessert les stations comprises entre Saint-Louis et Louga, 
d'une part; et Dakar et Tivaouane de l'autre. Tous les bureaux situés sur leur parcours bénéficient d'un deuxième service postal.

Le service postal entre Dakar et Grorée est obligatoire aux heures de départ suivantes :

De Dakar

6 heures 30 du matin;

11 heures du matin;

$\zeta$ heures du soir;

6 heures $40 \ddot{~ d u ~ s o i r . ~}$
De Gorée

5 heures $4 \ddot{\jmath}$ du matin;

10 heures 15 du matin;

1 heure $\mathbf{4 0}$ du soir;

6 heures du soir.

La Casamance est desservie deux fois par mois par un service à vapeur subventionné. Le port d'attache du vapeur chargé de ce service est Saint-Louis d'où les départs doivent avoir lieu de façon à permettre au navire de quitter Dakar $\mathbf{2 4}$ heures après l'arrivée du paquebot des Messageries Maritimes.

Le service entre Dakar, Gorée et Saint-Louis-Ziguinchor est effectué moyennant une subvention annuelle de $\mathbf{7 0 . 0 0 0}$ francs. Sédhiou, chef-lieu de la Casamance, est également desservi par un vapeur de la Compagnie commerciale dont les départs et les arrivées à Ziguinchor coïncident a vec les mouvements du Roitele t de la Compagnie de Cabotage à vapeur. Pour assurer ce service, la Colonie accorde une subvention de 3.500 francs par an, payée sur le Budget des Pays de Protectorat.

MM. Devès et Chaumet sont chargés du transport des dépêches postales entre Saint-Louis et Podor pendant la saison des bases eaux, moyennant une indemnité de 100 francs par voyage.

Les vapeurs de commerce concourent également a u transport des correspondances postales; ce service est effectué gratuitemen $t$ par les navires français recevant la prime de navigation.

Courriers piétons. - Un service de courriers piétons, organisé depuis que fonctionne la ligne télégraphique du Sine-Saloum (1893) dessert les bureaux de Toul, Fissel, Fatick, Foundiougne, Kaolack et Niorn. Les correspondances, peu nombreuses d'ailleurs, à destination de Malem, Diambour, Sine et Bangol sont envoyées par l'intermédiaire des surveillants chargés de la visite des lignes.

La marche des courriers piétons est indiquée ci-après : départ 
des points extrêmes (Tivaouane et Foundiougne) tous les trois jours : les $1^{\text {er }}, \mathbf{4}, \mathbf{7}, \mathbf{1 0}, \mathbf{1 3}$, etc...

Les courriers piétons de Tivaouane à Fatick franchissent une distance de 100 kilomètres en $\mathbf{2 6}$ heures au moyen de $\mathbf{4}$ relais.

Lorsque l'importance des courriers l'exige, les bureaux intermédiaires, prévenus par Tivaouane, engagent des piétons supplémentaires.

Le départ du courrier piéton de Fatick à Kaolack a lieu les 2, $5,8,11$, etc.., tous les trois jours, à 4 heures $30 \mathrm{du}$ soir.

Le départ du piéton de Kaolack à Fatik a eu lieu également tous les trois jours : les $3,6,9, \mathbf{1 2}$, etc., ̀̀ 4 heures 30 du soir.

Le courrier de Kaolack à Nioro à lieu tous les 6 jours : les $1^{\text {er }}$, 6, 12, 18 et 24 , à ò heures du soir ;

Celui de Nioro à Kaolack effectue un voyage tous les 6 jours : les $3,8,14,20$ et 26 , ̀̀ 3 heures du soir.

Les courriers piétons de Rufisque et de Joal partent les dimanche et les jeudi, à 8 heures du matin, pour se rencontrer à Portudal où ils échangent les dépêches ;

Le départ du courrier piéton de Saldé à Cascas à lieu les $1^{\mathrm{er}}, \breve{5}$, $10,15,20$ et 25 de chaque mois; départ de Saldé à 6 heures du matin ;

Le piéton de Cascas à Saldé effectue son voyage les $\mathbf{2}, \mathbf{6}, \mathbf{1 1}$, 16, 21 et 26 de chaque mois, à 6 heures du matin;

Le courrier piéton d'Aéré à Demette a lieu tous les trois jours: les 1 er $, 4,7,10$, etc., à 6 heures du matin, départ de Demette à Aéré les mêmes jours, à midi;

Le transport des correspondances pour les postes du Sénégal situés sur le fleuve et pour le Haut-Sénégal est assuré par le service de cette Colonie, à partir de Podor, pendant la saison des basses eaux. Les porteurs sont recrutés par l'intermédiaire des bureaux de Podor, Saldé, Matam et Bakel toutes les fois que les canots à vapeur du système "Voruz " ou les pirogues postales en acier ne sont pas employées et sont payés par les soins des receveurs régionaux et des agents spéciaux du Sénégal pour le compte de la Colonie voisine.

Les courriers dı Bas et du Haut-Fleuve, sont expédiés tous les 


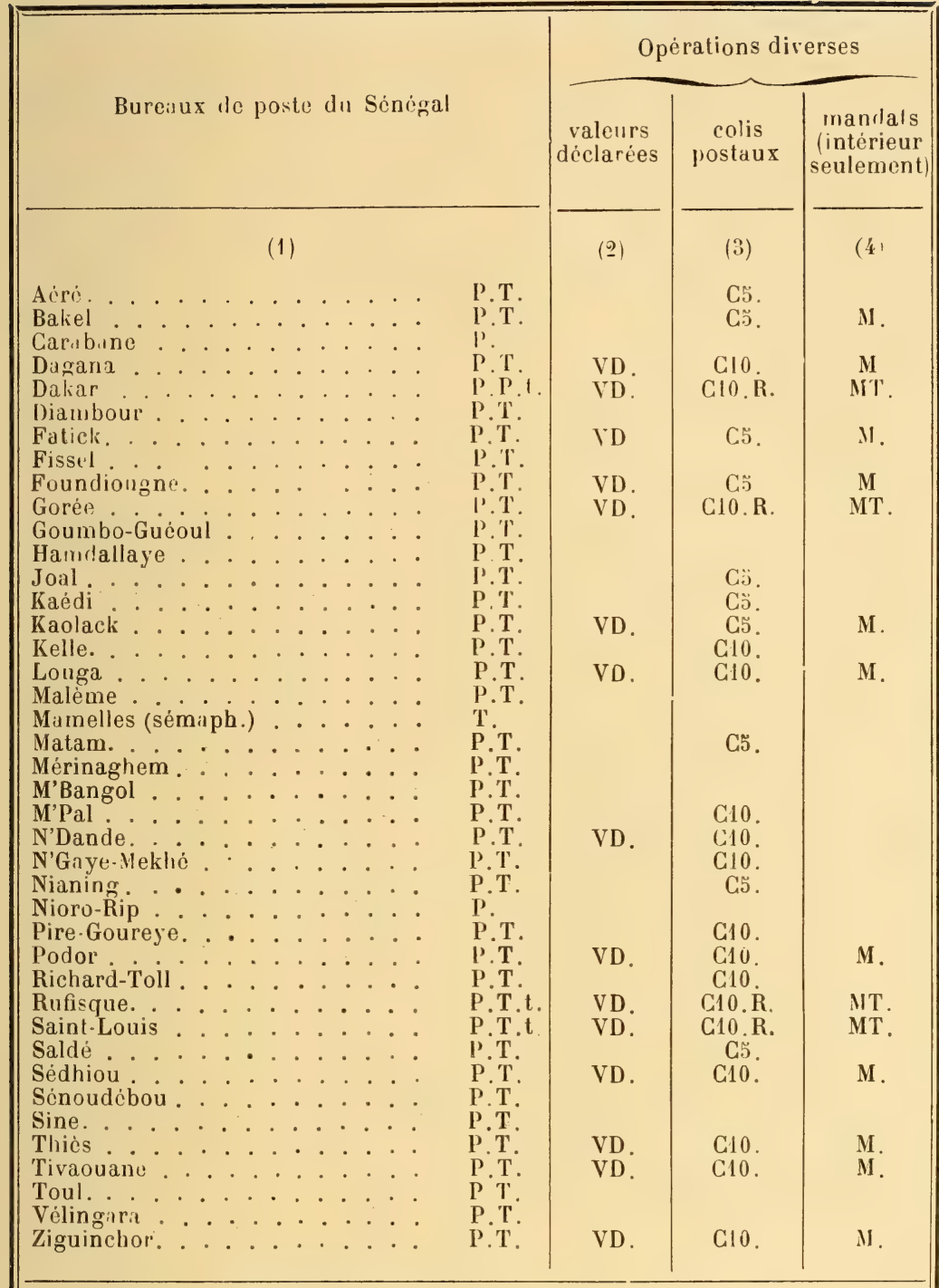

(1) P. : Service postal. - T . : Service tóligraphique. - t. : Service tieléphonique privé urbain.

(2) Les bureaux marqués de l'in lice VD. effectuent le Servi'c des rale:ırs déclarées.

NOTA. - Ln moximum de li déclaration de valeur est de 10.000 franes pour les lettres et boîtes, et de 500 francs pour les colis postaux.

(3) C5. : Bureaux acceptant les colis postaux jusqu'à 5 kilos seulement. - C10. : Burcaux acceptant les colis postaux jusqu'à 10 kilos. - R. : Bureaux admettant les colis grevés de remboursement jusqu'a 5000 francs.

(4) M. : Bureaux effectuant l'emission et le paiement des manlats postaux intérieurs. - MT. : Bureaux effectuant l'émission et le paiement des mandats postaux et télégraphiques intérieurs. 
quinze jours, le mardi suivant l'arrivée à Saint-Louis du courrier apporté par les paquebots des Messageries Maritimes.

Nous croyons utile de donner la liste des bureaux de poste de la colonie et d'indiquer les opérations qu'ils effectuent.

Services électriques. - Les relations télégraphiques ont la plus grande importance dans un pays, non seulement au point de vue commercial, mais encore au point de vue administratif. Par le tableau ci-contre on peut voir que tous les bureaux de poste sont pourvus du télégraphe. Tous les centres administratifs ou commerciaux de la colonie sont en effet reliés par des lignes télégraphiques, qu'on a même dủ doubler en certains endroits, en raison de l'importance du trafic.

L'installation du téléphone a également fait l'objet des préoccupations de l'administration locale et tous les centres un peu importants sont pourvus d'un réseau téléphonique.

Cábles sous-marins. - Les communications internationales de la colonie sont assurées par quatre câbles sous-marins :

$1^{0}$ Le câble Brest-Dakar ligne exclusivement française reliant directement le Sénégal à la métropole;

$2^{0}$ Le câble Spanish national assurant la communication entre notre colonie et l'Europe, par Ténériffe et Cadix ;

$3^{0}$ Le câble Ouest africain, appartenant à la France et mettant le Sénégal en communication avec la Côte Occidentale d'Afrique, et, par Saint-Vincent du Cap-Vert-Madère, avec l'Europe, ainsi que par la colonie du Cap avec Zanzibar et Aden ;

$4^{0}$ Le câble de la Compagnie South American partant de SaintLouis pour aboutir à Pernambuco.

De ce rapide exposé, il résulte que l'outillage économique du Sénégal sans être complet est déjà très important. ỉl devient d'ailleurs, ainsi qu'on a pu en juger, chaque jour plus considérable et se développe au fur et à mesure des besoins de la colonie. 


\section{CHAPITRE XIV}

LES RÉSULTATS ÉCONOMIQUES

\section{A. - Agriculture (1).}

Au Sénégal les cultures sont presque exclusivement pratiquées par les indigènes et pendant la saison des pluies, sauf sur les terres soumises à l'inondation du fleuve. Dans ces dernières, les semis se font après le retrait des eaux; la plante parcourt les phases de sa végétation en saison sèche gràce à l'eau dont le sol est profondément imbibé et qu'il abandonne peu à peu ; certaines variétés de gros mil, le maïs, la patate, le melon indigène sont cultivés ainsi. L'abondance des récoltes varie avec celle des crues, c'est-à-dire est en raison directe de l'étendue de terrain couverte par l'inondation.

La réussite des cultures d'hivernage dans les autres terres, dépend de son côté de l'abondance des pluies annuelles. Les petits mils, quelques gros mils et l'arachide sont les principales cultures de cette saison.

Toutes les façons culturales, depuis la préparation du sol jusqu'à la récolte, se donnent au moyen d'un seul instrument dont la forme varie selon les peuplades. L'hilaire sorte de ratissoire à pousser et le dalia, houe à manche court, sont les instruments les plus répandus.

Vers la fin de la saison sèche, avant la saison des pluies ou

(1) Nous renvoyons pour plus amples renseignements aux ouvrages spéciaux publiés à l'occasion de l'Exposition coloniale de Marseille. 
avant l'inondation selon les terres mises en culture, le noir et sa famille débroussent le sol, coupent au ras de terre les arbres et les arbustes dont les souches émettent annuellement des rejets. Ces branches et ces herbes, une fois desséchées sont brûlées et les cendres, répandues, constituent en général le seul engrais que reçoit le champ. Toutefois dans quelques régions, en HauteGambie notamment, on pratique sans beaucoup de précautions d'ailleurs le parcage des animaux sur les terrains de culture.

Les principales productions agricoles du Sénégal sont :

Le mil. - Les semis se font, dans les terres inondées, au fur et à mesure du retrait des eaux. A l'aide d'un morceau de bois terminé en pointe les indigènes pratiquent des trous profonds de 10 cent. environ et distants de $1 \mathrm{~m}$. en moyenne. Ils déposent dans chacun d'eux 4 ou כّ graines de gros mil qu'ils recouvrent d'un peu de sable.

Les plantes adventices sont enlevées à l'aide de binage qui, fréquemment renouvelés, diminuent l'évaporation du sol. Dès que les tiges de mil commencent à monter pour former l'inflörescence, elles sont butées. Cette opération provoque le développement des racines adventives sur la partie inférieure de la tige assurant ainsi à la plante une alimentation abondante et une plus grande stabilité.

Les cultures de mil d'hivernage se font suivant des procédés analogues à des dates un peu différentes et dans des terres plus ou moins sableuses selon les variétés. Les trous sont pratiqués au moyen de l'hilaire; la quantité de semence nécessaire est supérieure à celle employée dans les terres inondées. Quelque temps après la levée les touffes trop épaisses sont éclaircies et réduites à 4 ou ö tiges; le sol est fréquemment biné pendant toute la durée de la végétation.

Les diverses variétés de gros mil sont cultivées en particulier dans la vallée du Sénégal, le Sine-Saloum, le Rip, la HauteGambie et la Haute-Casamance ; les petits mils surtout dans le Cayer, le Baol, le M’Badane et le cours supérieur du Sénégal.

L'arachıde. - L'arachide est semée lorsque l'hivernage est bien établi c'est-à-dire à la première forte pluie. On met une 


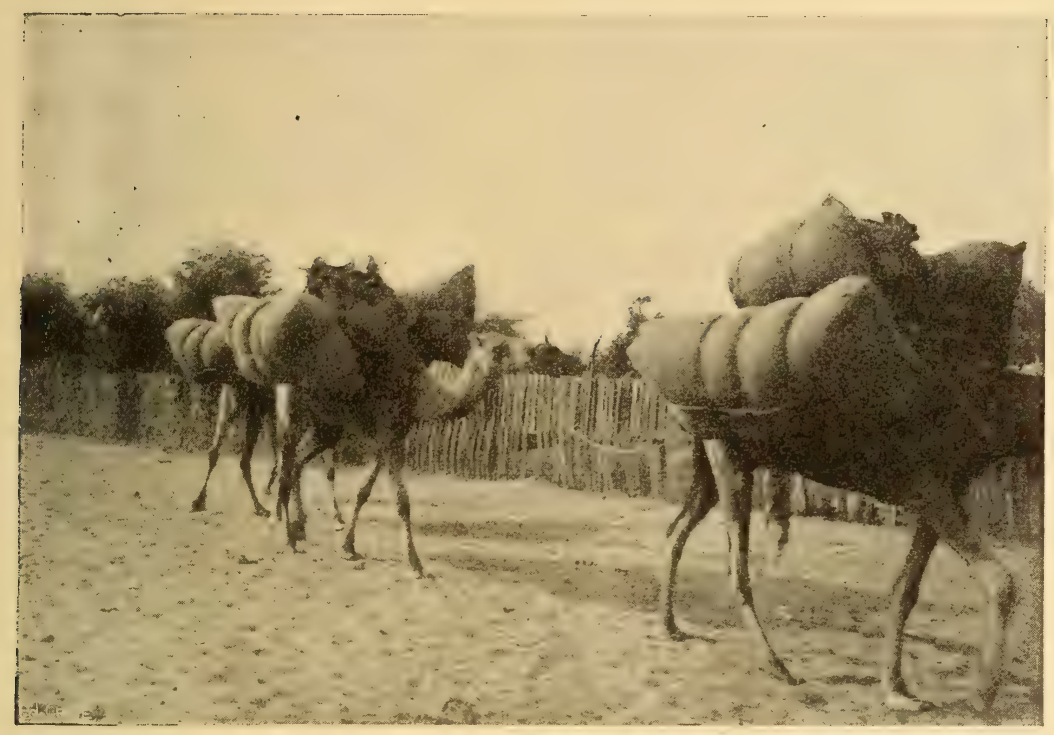

Fig. 35. - Convoi de chameaux.

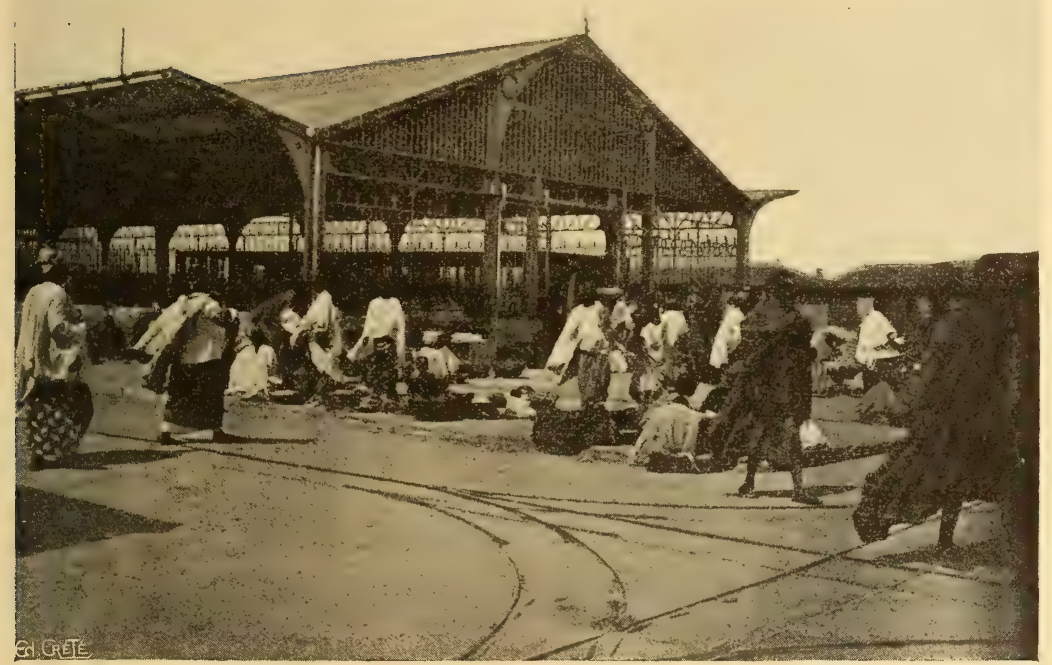

Fig. 36. - Rufisque (le marché).

s. 

ou deux graines dans chaque trou profond de 3 à 5 centimètres et l'espacement varie de $\mathbf{4 0}$ à $\mathbf{7 0}$ centimètres.

La végétation de l'arachide dure environ quatre mois; un premier sarclage est donné lorsque ses pousses ont 5 à 6 centimètres de longueur; sans ce limage hátif, la plante, très délicate à son premier âge, serait vite étouffée par les mauvaises herbes plus vigoureuse qu'elle; les limages ultérieurs sont en nombre variable selon l'abondance de la végétation adventice. Il importe que le sol soit rendu meuble afin que l'ovaire fécondé puisse pénétrer dans le sol où il doit s'enfoncer pour mûrir à une profondeur de 4 à 6 centimètres. C'est en partie pour cette raison que l'arachide réclame un sol léger; une terre forte opposerait un grand obstacle à la pénétration du fruit, la récolte serait difficile et une partie des graines resterait dans le sol En fait, les terres du Cayor les plus légères de tout le Sénégal sont aussi celles qui produisent les arachides les plus estimées. Les arachides cultivées dans des terres plus ou moins argileuses provenant de la région du fleuve et de la Casamance sont inférieures en qualité.

Le Riz. - La culture du riz, qui peut encore figurer au rang des principales, se pratique surtout en Casamance un peu dans le Sine-Saloum et en Haute-Gambie. Elle pourrait l'être en d'autres points. En Casamance les rizières sont installées sur les terrains bas, imperméables, où l'eau des pluies d'hivernage se rassemble; l'idigène l'y retient par des levées de terres.

Le repiquage se fait au milieu de l'hivernage, la récolte en décembre ou janvier.

En somme ces cultures, quelle que soit l'imperfection des procédés en usage, suffisent presque complétement à l'alimentation de la population noire, et en même temps, gràce à l'arachide, fournissent près des deux tiers de la valeur des produits du crû exportés.

L’agriculture forme donc la base de la prospérité de la Colonie. A ce titre elle doit être l'objet des études et des efforts les plus persévérants en vue de toutes les améliorations possibles.

L'état de chose actuel résultant d'une suite de progrès insensi- 
bles est prospère mais de nombreux problèmes sont encore à résoudre.

Depuis que le Sénégal a été considéré comme une colonie de culture, et la date en est ancienne, des efforts constants ont été faits pour y développer la production agricole. Les tentatives des promoteurs de cette œuvre vouées, par les conditions défavorables dans lesquelles elles furent faites, à un échec inévitable sont particulièrement intéressantes.

Elles ne portèrent pas en effet exclusivement sur les cultures riches, café, cacao, canne à sucre, etc..., qui faisaient alors la prospérité des colonies, mais aussi sur les plantes qui prospéraient naturellement sur le sol du Sénégal.

Dès 1818 on remarqua parmi elles le cotonnier et l'indigo et des essais de plantation en furent sérieusement encouragés.

On institua d'abord des primes élevées à la culture. Ce système donna lieu à des abus et les primes à la culture furent pour cette cause remplacées par des primes à l'exportation qui furent maintenues pendant quelques années. Elles ne donnèrent pas de résultats, mais la cause de l'insuccès ne résidait pas foncièrement dans les vices de la méthode. En réalité toute tentative de ce genre était à cette époque prématurée ; la Colonie était réduite à une ville : Saint-Louis ; la traite des noirs s'exerçait sourdement et nous ne possédions à l'intérieur que de rares installations parmi des peuplades non soumises à notre influence et souvent en guerre entre elles.

La conquête et la pacification du pays étaient les conditions nécessaires du développement de l'agriculture.

L'arachide, cultivée de toute ancienneté par les noirs et qui servait d'appoint dans l'alimentation indigène aux autres produits vivriers, fut l'objet de ce développement.

En 1840 pour la première fois on importa en France de la graine d'arachide; le rendement en huile fut trouvé favorable et dès lors le produit demandé.

Le commerce des négriers aboli, la pacification progressant, le commerce rendu libre dans toute l'étendue du Sénégal et les produits d'importation pénétrant peu à peu partout, dès que l'attention du noir fut éveillée par des achats de ce produit, et la 
culture alla se développant par l'effet des demandes croissantes.

Les indigènes s'habituèrent rapidement à fournir chaque année un effort de plus en plus grand.

L'exportation qui n'était en 1846 que de 173 tonnes s'éleva dans la période 1867-1880 à une moyenne annuelle de 20.000 tonnes; elle est aujourd'hui de $137.773 .000 \mathrm{kgr}$. (statistique de 1904) ce qui correspond à plus de 150.000 hectares mis en culture par la primitive hilaire.

La pacification est pour beaucoup dans ce résultat ainsi que l'ouverture de voies de communication. La construction du chemin de fer de Dakar à Saint-Louis notamment a eu un grand effet sur le développement agricole des régions traversées.

Ce résultat prouve également que le noir est capable d'une certaine initiative dans l'effort.

Ce développement agricole unilatérale si satisfaisant soit-il a fait naitre des craintes fondées à quelques égards. L'arachide a eu a subir des crises dont la principale a été amenée par la concurrence des huiles de coton épurées de provenance américaine. L'huile d'arachide cependant a conservé sa place sur le marché. La situation actuelle, établie après plusieurs oscillations, a acquis une stabilité qui parait durable. Le cours de 15 francs les 100 kilos est rénumérateur pour l’indigène; il pourrait s'abaisser encore sans donner d'inquiétude et en fait, dans l'intérieur, l’indigène vend fréquemment à un prix bien inférieur.

Cependant, bien qu'il soit peu probable qu'un avilissement des prix se produise, on ne peut affirmer d'une façon absolue que ce soit chose impossible. Il faut envisager cette éventualité et essayer de contrebalancer cette tendance fàcheuse en relevant la quantité du produit.

Cette année le service de l'agriculture réorganisé au Sénégal, s'est occupé de cette question. Toutefois l'amélioration de la culture par l'introduction de nos méthodes européennes, l'emploi de la charrue par exemple n'est pas à recommander.

Ainsi que le dit un maître en la matière, M. Dybowski, l'agriculture constitue un ensemble dont on peut difficilement modi- 
fier l'un des facteurs sans toucher à ceux qui lui sont liés ou qui en dérivent.

L'emploi des instruments primitifs dont se servent les indigènes a chez eux une raison d'être : il correspond à l'ensemble des méthodes qui sont mises en usage et ce n'est qu'en usant de transitions ménagées qu'on arrivera à introduire des modifications profitables.

La méthode de sélection en grand, consistant à faire distribuer dans un rayon déterminé une certaine quantité d'arachi. des provenant d'une région productrice de graines de bonne qualité est une de celles qui doivent donner de bons résultats.

On a tenté aussi cette année quelques essais avec les variétés d'Egypte, de Java et du Mozambique.

Ces variétés présentent des caractères un peu différents à ceux de l'arachide sénégalaise ; elles sont en particulier d'une plus grande productivité. Il sortira peut-être de ces essais un enseignement intéressant à l'égard des améliorations à apporter à cette culture qui, sans modifier des procès primitifs a fait à elle seule la richesse de la Colonie.

L'agriculture se développant sera dans la nécessité d'user de méthodes qui jusqu'à présent n'avaient pas eu leur raison d'ètre afin de tirer tout le parti possible du capital inutilisé en partie que constitue le Sénégal.

Parmi les plantes anciennement cultivées on n'en voit point maintenant qui pourraient être l'objet d'une évolution spontanée semblable à celle de l'arachide.

Le cotonnier. - Le cotonnier est un des produits qui semble avoir le plus d'avenir. Très anciennement cultivé en Afrique occidentale, il fut remarqué dès 1818 et sa plantation fut encouragée. Les efforts faits dans ce sens furent nombreux sans doute et souvent méritoires, mais isolés et dirigés sans entente véritable de la question, ils ne parvinrent point à développer la production cotonnière. La culture de l'arachide, facile et productive, était aussi un obstacle à l'extension de celle du coton qui, pour un moindre produit net exige plus de travail et de soins.

Les essais entrepris à Richard Toll la première station culturale du Sénégal, en 1864 et 186ə̈, montrèrent du moins nette- 
ment que la seule culture possible en ce pays où la hauteur des pluies annuelles est souvent inférieure à 50 et même à 40 centimètres, était la culture irriguée.

La crise subie depuis quelques années par l'industrie cotonnière française a remis la question cotonnière de nouveau et plus sérieusement à l'ordre du jour,

En Afrique occidentale française, M. le Gouverneur général Roume a créé en 1902, une inspection d'agriculture chargée d'étudier toutes les questions agricoles intéressant cette vaste partie de notre domaine africain. Le problème cotonnier est l'un des principaux.

A Richard-Toll il a été entrepris en 1904 des essais de culture irriguée sur les variétés égyptiennes à longues soies si appréciées et des rendements comparables à ceux que l'on obtient en Egypte ont été observés, la fibre a conservé ses qualités.

Le service d'agriculture du Sénégal poursuit maintenant ces essais en vue de préciser les résultats déjà acquis. Il y a dans la vallée du Sénégal de grandes surfaces où la culture cotonnière pourra être pratiquée le jour où l'irrigation sera possible, d'autre part, l'utilisation du Sénégal comme fleuve d'irrigation fait l'objet d'études qui ont déjà montré la possibilité de solutions partielles. L'avenir reste ouvert de ce côté aux améliorations les plus profitables.

Une station agronomique vient d'être créée en Casamance sur le domaine de Mangacounda, ancienne concession de la compagnie des caoutchoucs. Cette station dont la création à Mangacounda se justifie par le milieu particulièrement proprice qu'est la Casamance s'occupera d'une façon spéciale d'essais cotonniers.

La quantité d'eau qui tombe annuellement dans cette région donne lieu de penser que les variétés moyennes américaines y végèteront normalement et donneront des produits d’aussi grande valeur que dans leur pays d'origine, la vallée humide de Mississipi.

Enfin pour achever le tableau des richesses agricoles de la Colonie, il est nécessaire de dire quelques mots de ses ressources proprement naturelles. 
Les forêts du Sénégal bien moins denses que celles de la zône équatoriale n’ont pas été aussi ménagées qu'il aurait été nécessaire. L'imprévoyance naturelle de l'indigène, la nécessité de pourvoir de bois et de charbon des villes de la Colonie, enfin le défrichement qui s'est exercé d'une façon inévitable dans les régions où la culture de l'arachide a pris de l'extension sont les causes qui ont contribué au déboisement relatif au Sénégal. Il est essentiel, ici plus encore qu'ailleurs, d'empêcher le recul de la forêt dont le rôle est complexe et si important, et c'est un difficile problème.

Indépendamment de leur utilité générale, ces forêts renferment de nombreuses espèces végétales qui fournissent ou pourraient fournir des produits utilisables. Parmi les arbres à bois d'ébénisterie et à bois dur, les plantes gommifères, oléagineuses, alimentaires, fourragères, textiles, tinctoriales, tannantes, médicinales, nous citerons quelques-uns des principaux.

Gomme. - La gomme au Sénégal, presqu'aussi estimée que la gomme arabique est fournie par l'accacia Vereck. Elle a fait longtemps l'objet presque unique du commerce sénégalais ; l'exportation tend à diminuer depuis 1902 à cause de l'abondance des gommes d'Egypte sur le marché.

Caoutchouc. - Le caoutchouc au Sénégal s'exporte seulement de la Casamance; la production s'accroît d'année en année et les territoires de la Haute-Casamance sont encore en partie inexploités.

Il y a là des réserves de lianes qui fourniront longtemps du caoutchouc, à condition que l'on prenne les précautions nécessaires pour la reconstitution des peuplements épuisés.

Huile de palme et palmiste. - L'amande du fruit du palmier à huile qui croit aussi en Casamance s'exporte sous le nom de palmiste; on tire de cette amande une huile utilisée pour la savonnerie fine.

Cocos-coprah. - Le cocotier végète très bien dans la zône maritime ; il pourrait être planté sur d'immenses terrains inutilisés et fournir un produit rénumérateur.

Huile. - Le somp (ouolof) ou Balanites Egyptiaca, arbre 
commun au Sénégal, donne un fruit ressemblant à une datte, à noyau dur et dont l'amande fournit de l'huile.

Les graines du Ben ailé (maringa Pterygos perma) très répandu également au Sénégal donnent une huile douce, fluide, employée en parfumerie et en horlogerie.

Le carafia Touloucouna, très répandu en Casamance donne des noix fournissant $350 / 0$ d'une huile méridionale utilisable aussi dans l'industrie.

Tannin. - Comme plantes tannifères il faut citer le palétuvier dont l'écorce renferme une forte proportion de tannins et les diverses acacias (gousses sèches). Ces produits pourraient être exportés en grandes quantités.

Teintures. - Le combretum glutinosom (Ratt), le cochlos formum tinctarium (Fayard), sont des plantes tinctoriales utilisées par les indigènes. Le principe tinctorial jaune est fourni par l'écorce de la tige et de la racine. L'indigo vient en très grande abondance et on en rencontre de véritables champs près du fleuve Sénégal vers Kaëdi et Bakel.

Textiles. - Parmi les plantes nombreuses donnant des fibres textiles on peut citer les divers palmiers (rôniers, phienix senegalensis, etc...), les agaves, les sanseviera, le calotropis le fromager, et les arbres à Kapok, le Baobab.

Animaux domestiques. - Aux progrès de l'agriculture sont étroitement unis le développement et l'amélioration de la population animale domestique.

De vastes régions au Sénégal nourrissent de nombreux troupeaux qui appartiennent principalement à une race nomade de pasteurs (Peulh) et aussi aux Toucouleurs et aux Sérères.

Les chevaux sont communs partout au Sénégal sauf en Casamance dont le climat humide leur est défavorable. On les rapporte à deux races, la race dite du fleuve Narou Gror d'assez grande taille et qui présente parfois des types remarquables, et la race M'Bayar plus petite dont le centre de production est le Baol ; tous ces chevaux ont de précieuses qualités d'endurance et de sobriété. Les ânes sont fort nombreux, rustiques et solides, ils sont très employés pour les transports ainsi que les chameaux amenés par les Maures du Nord du fleuve. 
On distingue aussi deux races dans la population bovine du pays, la race Gobra (bœufs à bosse) et la race N'Dama (bœufs sans bosse). Les bœufs à bosse souvent de très grande taille et qui peuvent atteindre un poids de $700 \mathrm{kgr}$. sont utilisés comme bêtes de somme, les bœufs sans bosse sont de petite taille généralement bien conformés ; l'aptitude laitière est peu développée chez les femelles. Les moutons et les chèvres sont très répandus. Aucune de ces races d'animaux n'a été soumise à une amélioration méthodique et des épizooties les ont décimées maintes fois.

Par leurnombre et leurs qualités naturelles ils constituent une fraction importante de la richesse du pays, richesse latente qu fait l'objet d'un commerce bien peu important par rapport à celui qu'elle pourrait alimenter.

Le service zoatechnique et des epizooties rattaché au service de l'agriculture qui vient d'être constitué, est chargé à présent de la police sanitaire des animaux, de l'étude des races et des procédés d'amélioration qu'il conviendra de leur appliquer.

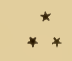

Quelque incomplet que soit cet exposé succinct, on peut par lui se rendre compte de la variété des ressources de la colonie du Sénégal.

Les efforts qui ont été faits pour les mettre en valeur rendent témoignage de la foi que l'on a eue à toutes les époques en l'avenir agricole du pays. Les expériences tentées plus ou moins heureusement n'auront pas été sans fruit pour ceux qui reprennent l'œuvre aujourd'hui.

La colonie du Sénégal a un passé plus qu'honorable et un présent qui est un gage sérieux de ce que peut être son avenir.

\section{B. - L'industrie}

L'industrie au Sénégal, comme dans tous les pays neufs, est encore assez peu développée. Elle ne pourra prendre définitivement son essor que lorsque l'agriculture aura fécondé la plus 
grande partie du sol, aidé au développement de la population, augmenté sa capacité de travail, ses besoins et ses facultés d'achat.

Il existe dans la colonie une fabrique d'huile d'arachides et une briqueterie européenne pourvue d'un matériel assez perfec. tionné.

D'autre part les indigènes fabriquent également des briques. L'huilerie d'arachides installèe à Saint-Louis appartient à la maison $\mathrm{Ch}$. Peyrissac et $\mathrm{C}^{\mathrm{ie}}$ et sa création remonte à 1890. Cette fabrique bien outillée qui possède 9 presses hydrauliques et un moteur de 70 chevaux, fonctionna avec succès pendant quelques années. On obtenait un rendement de $23 \mathrm{kgr}$. d'huile pour 100 kilogr. de graines traitées et le litre d'huile pouvait se vendre 1 franc.

Mais depuis cette époque les usines françaises ont pris l'habitude d'introduire dans leurs produits une certaine quantité d'huile de coton à bon marché et elles ont pu s'assurer des débouchés importants par les sous-produits. Elles ont pu ainsi arriver à fournir l'huile aux commerçants du Sénégal dans des conditions plus avantageuses que l'usine de Saint-Louis et la fabrication a du être suspendue dans celle-ci.

Elle vient cependant d'être remise en état et des essais satisfaisants ont élé faits er vue d'une reprise prochaine dans des conditions d'organisation meilleures.

La briqueterie européenne est celle de Bop N'kior. Elle fut fondée en 1898 par la maison Mange Frères qui constitua une société filiale sous la raison sociale Bruzeaux, Poyard et $C^{\text {ie }}$.

L'emplacement fut choisi au Nord de l'île de Saint-Louis, en un point voisin de marigots d'où l'on pouvait extraire une argile d'assez bonne qualité, mais renfermant malheureusement quantité de racines la rendant impropre à l'étirage des produits creux.

L'outillage du début, plutôt rudimentaire, consistait en un malaxeur à manège, une machine à étirer à bras et plusieurs calibreuses. La cuisson était faite par un four intermittent chauffé au bois ct après un triage laborieux, on obtenait une certaine quantité de produits d'une qualité assez satisfaisante. Ceux-ci vendus 60 francs le mille furent accueillis sur la place 
avec une réelle faveur. La production atteignait 3 à 4.000 briques par jour.

L'entreprise réussissait donc et, dès l'année suivante, une transformation de l'usine fut décidée. Le matériel s'augmenta d'un malaxeur, d'un broyeur etc., un moteur fut installé ainsi qu'un four système Hoffmann à feu continu permettant d'obtenir une cuisson plus régulière.

Ces produits continuèrent à se vendre aussi bien qu'au début, mais, dans la fabrication des produits creux et tuiles, l'échec fut complet. Cet échec provenait, soit de l'insuffisance de préparation de la matière première, soit du défaut de moulage, soit peut-être encore de l'inhabileté de la main-d'œuvre.

On se confina donc dans la fabrication des produits pleins et jusqu'en 1900 la situation resta stationnaire. A cette époque la fièvre jaune, jetant la perturbation dans la colonie, occasionna la fermeture de l'usine jusqu'en 1901. Deux années après la société fut dissoute et l'usine abandonnée jusqu'en 1905.

Dans le cours de l'année $190 \leftrightarrows$, une nouvelle société se constitua, toujours sous les auspices des anciens commanditaires, et racheta à l'ancienne Société Bruzeaux, Poyard et C Cie, l'usine et ses dépendances.

Après diverses modifications, l'ancien matériel fut remis en état, augmenté d'un malaxeur à grand débit, de presses à tuiles et à carreaux et le travail reprit activement.

Les produits obtenus, supérieurs à ceux de jadis, couramment employés dans les travaux de l'Administration, peuvent soutenir la comparaison avec les produits similaires de France.

La terre est aujourd'hui prise à 1 kilomètre de l'usine dans un marigot un peu plus éloigné que le point d'extraction primitif ; c'est une argile grasse, plastique, renfermant une assez forte proportion d'oxydes de fer et qui demande pour se mouler convenablement une forte trituration et l'adjonction de matières dégraissantes.

La fabrication atteint quotidiennement $\mathbf{4 . 0 0 0}$ briques et les prix sont fort inférieurs à ceux des produits similaires de la métropole, ainsi que l'indique le tableau ci-contre. 


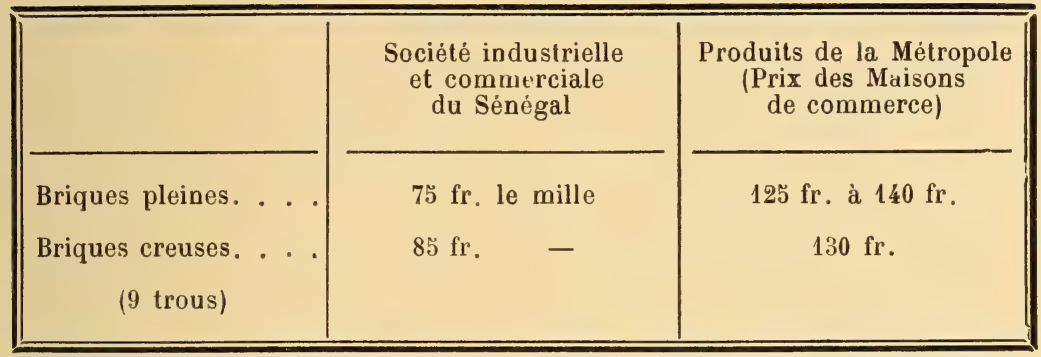

Briques indigènes. - On donne ce nom dans le pays, aux produits fabriqués par quelques indigènes de la région de SaintLouis aux époques de la baisse des eaux.

Ils établissent des chantiers rudimentaires au bord des marigots, de préférence entre Khor et Bop N'Kior, où l'argile leur paraît utilisable.

Ils faconnent grossièrement les briques, les cuisent de même et obtiennent d'ailleurs un résultat assez médiocre. Leurs briques sont vendues 20 francs le mille à Saint-Louis et sont surtout utilisées par les indigènes pour leurs constructions ou encore employées dans les constructions européennes à bon marché, pour la constitution de murs que l'on crépit ensuite.

Il existe à Saint-Louis 4 briquetiers qui, dans les bonnes années, arrivent à produire 800.000 briques. Cette production tend à diminuer peu à peu en raison de la défectuosité des produits et de la concurrence de la briqueterie de Bop N'Kior.

A ce genre d'industrie, s'il est possible de donner ce nom aux établissements qui viennent d'être sommairement décrits, il faut ajouter l'industrie de la pêche assez développée au Sénégal et l'industrie minière encore naissante.

Pêcheries. - La pêche se pratique soit en mer le long de la côte depuis la baie du Lévrier jusqu'à Dakar, soit dans le fleuve Sénégal.

a) Pêche maritime. - A la pêche maritime est étroitement rattachée la question des pêcheries du banc d'Arguin. Avant la dernière réorganisation du Gouvernement général de l'Afrique occidentale française le banc d'Arguin sur la côte mauritanienne dépendait du Sénégal, il est aujourd'hui compris dans la colonie de la Mauritanie. 
Toutes les tentatives faites jusqu’à ce jour pour l'exploitation des pêcheries du banc d'Arguin n'ont pas été couronnées de succès. La Compagnie concessionnaire de l'île d'Arguin - laquelle appartient en toute propriété et souveraineté à la France - a été déchue de ses droits en 1902.

Mais la question du banc d'Arguin vient d'entrer dans une phase nouvelle à la suite des résultats obtenus par les missions exécutées en 190马-1906 par M. Gruvel, maitre de conférences à la Faculté des Sciences de l'Université de Bordeaux. Cet éminent spécialiste s'est livré, à la baie du Levrier et sur la côte mauritanienne à des expériences de capture, de séchage, de salaison et de conservation du poisson. Toutes ces opérations ont été étudiées au double point de vue scientifique et pratique. Au point de vue de l'utilisation industrielle des pêcheries, les conclusions de M. Gruvel sont éminemment satisfaisante, tant en ce qui concerne la quantité que la qualité des poissons pêchés, séchés, salés ou conservés en vert.

Saisi de ces indications, M. le Gouverneur général Roume a demandé que des encouragements et des facilités soient accordées aux pêcheurs, aux armateurs qui se livreraient à l'industrie de la pêche dans les eaux territoriales mauritaniennes. Il est vraisemblable qu'une prime à l'armement - anılogue à celle allouée pour la pêche dans les mers d'Islande - ne tardera pas à être prévue pour la pêche à la baie du Levrier et sur la côte de Mauritanie. De plus, le département des Colonies s'est mis d'accord avec le Ministère des Finances sur les formalités à remplir pour l'admission de franchise dans la métropole du poisson capturé dans ces parages par des équipages et des bateaux français (1).

En outre, dans le projet de loi autorisant le Gouvernement général de l'Afrique occidentale française à emprunter une nouvelle somme de 100 millions, un crédit de 500.000 francs a été prévu pour les installations de la baie du Levrier. Elles consistent en construction de plusieurs phares de portées diverses,

(1) Voir pour plus de détails : Le Gouvernement général de l'Afrique occidentale française. Notice de l'Exposition Coloniale de Marseille, par M. G. François. 
d'un appontement, d'un poste militaire, d'un poste de douane en l'établissement d'un dépôt de charbon et de citernes.

Ces installations provisoires sont commencées et un ancien bateau de la station locale cédé par la marine sert actuellement de ponton-citerne.

Enfin, un marin pêcheur breton vient d'être envoyé au Sénégal pour la création d'une école de pêcherie et de préparation du poisson.

Pêehe fluviale. - La pêche dans le fleuve Sénégal a été réglementée par les décrets des 27 février et 4 décembre 1904 pris par le pouvoir central pour sanctionner d'une manière suffisante les pénalités édictées par les arrêtés locaux du Lieutenant gouverneur (arrêté du 5̆ décembre 1903 notamment). Aux termes de ces actes, il est interdit de se servir, pour la pêche dans le fleuve Sénégal, de filets à mailles de moins de 6 centimètres ou de filets de plus de 50 mètres de longueur, quelle que soit la dimension de leurs mailles. Tout délinquant peut être condamné à une peine de trois à quinze jours d'emprisonnement et de 50 à 100 franes d'amende.

"Si les filets forment barrage du fleuve, la peine sera de cinq à quinze jours d'emprisonnement, et l'amende de 50 à 100 francs.

"Ces dispositions ne s'appliquent pas, sur les berges du fleuve et dans les marigots, à l'usage des engins à mailles de 6 centimètres et au-dessous, pourvu que leur longueur ne dépasse pas 50 mètres " (Décret 4 décembre 1904).

"Quiconque aura jeté dans les eaux de la dynamite, du poison ou autre drogue de nature à enivrer le poisson ou à le détruire sera condamné dans le premier cas à un emprisonnement de trois à quinze jours et à une amende de $2 \breve{a ̀ ~} 100$ francs, et dans le second à une peine de cinq à quinze jours d'emprisonnement et de 50 à 100 francs d'amende.

Au moment de la constatation du délit, les filets et engins de pêche prohibés seront saisis par l'agent verbalisateur.

Le jugement en ordonnera la destruction par les soins du commissaire de police.

La vérification de la dimension des mailles des filets s'effec- 
tuera au moyen d'un instrument en forme de pyramide quadrangulaire portant à sa surface les traits accompagnés de chiffres indiquant les longueurs des côtes des mailles. Cet instrument sera fourni par l'Administration et poinçonné par elle. Un exemplaire en sera déposé au greffe du tribunal de Saint-Louis.

En cas de refus de la part des délinquants de remettre immédiatement le filet déclaré prohibé après la sommation de l'agent verbalisateur, ils seront condamnés pour ce seul fait à une amende de 10 francs, qui ne se confondra pas avec celle qu'ils pourraient encourir pour délit de pêche.

Les présentes dispositions sont applicables à la zone ci-après déterminée :

"Fleuve Sénégal, depuis son embouchure, en remontant son cours, petit bras du fleuve, marigot de N'Diago, marigot de Botebki, marigot de Mambatio, marigot de Khassack, marigot de Kantey, marigot de Khor, fleuve Sénégal jusqu'à son embouchure " (Décret du 4 décembre 1904).

Mines. - L'industrie minière, encore naissante en Afrique occidentale, a été réglementée par deux décrets principaux : décret du 6 juillet 1899 (modifié pour des questions de détail par celui du 19 mars 190อ̈) et décret du 4 août 1901 qui apporte certaines dérogations au décret de 1899 en ce qui concerne la recherche et l'exploitation de l'or et des métaux précieux dans le lit des fleuves, rivières et cours d'eau.

Les décrets de 1899 et 1901 ont été sur certains points interprétés par une circulaire qui porte la date du $1^{\text {er }}$ avril 1902.

Le décret de 1899 (1), dans ses dispositions générales, spécifie (art. 5) que : " on peut acquérir, dans un périmètre déterminé et sous les conditions stipulées par le décret un droit exclusif d'explorer, de rechercher ou d'exploiter ».

Le décret distingue donc trois espèces de permis :

Le permis d'exploration (art. 13 à 17) le permis de recherches (art. 18 à 27), le permis d'exploitation (art. 28 à 41), les pénalités sont prévue au titre $\mathrm{V}$ (art. 42 à 49).

(1) Les dispositions intégrales de cet acte important sont insérées avec ses modifications dans la notice consacrée au gouvernement général de l'Afrique occidentale française. 


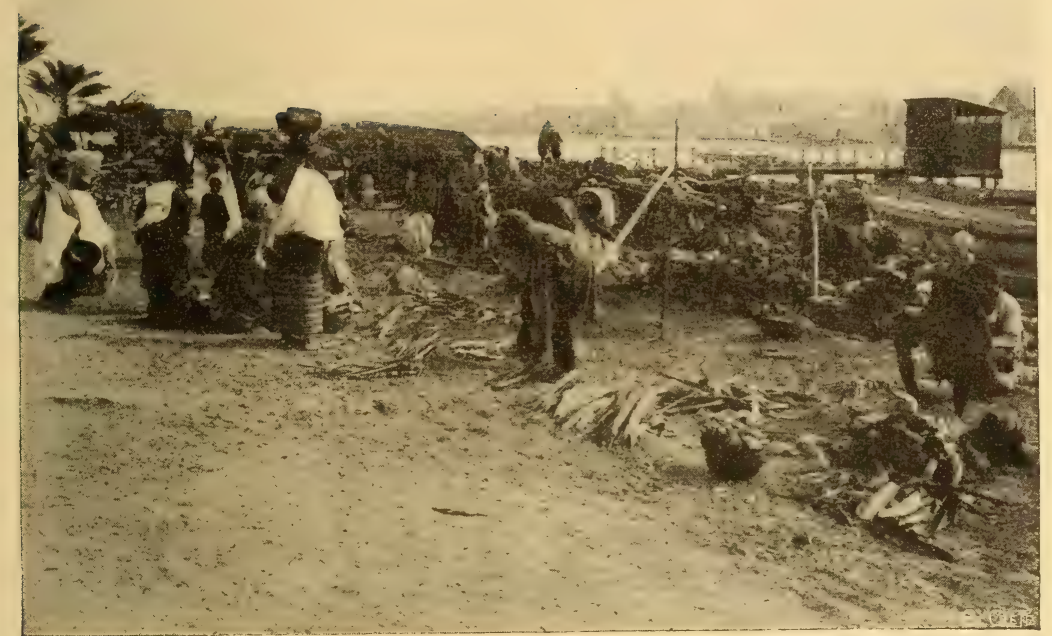

Fig. 37. - Marché sur les berges d'une riviere.

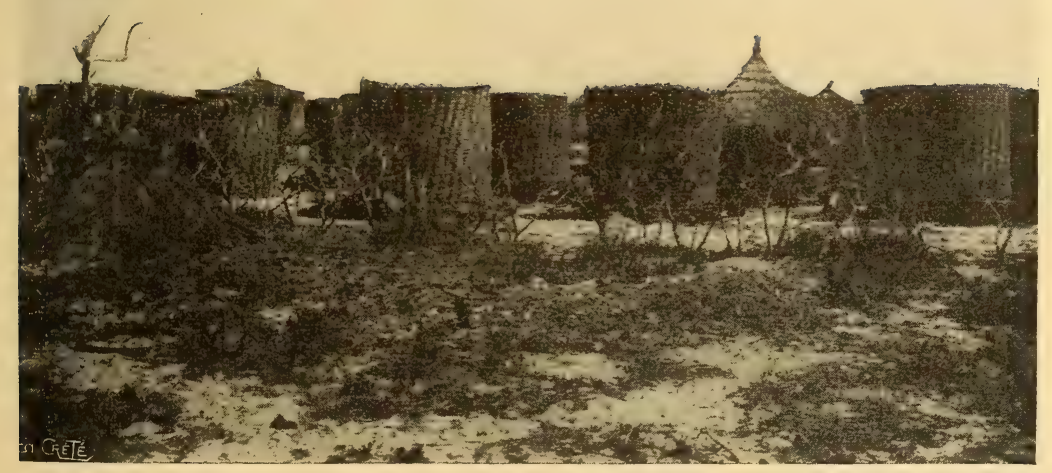

Fig. 38. - Greniers à mil.

s. 

Ces dispositions s'appliquent également aux permis de recherches par dragages en ce qu'elles ne sont pas contraires aux termes de décret du 4 août 1901 .

Mais par dérogation à l'article 19 du décret du 6 juillet 1899 , le périmètre de recherche, d'une étendue de 8.000 hectares au plus, est constitué, non par un cercle, mais par deux lignes, droites ou polygonales, parallèles à l'axe moyen du cours d'eau, distantes de cet axe de $\mathbf{1 0 0}$ mètres au moins de chaque côté, et par deux normales à l'axe du cours d'eau.

Il doit être annexé à la demande de permis de recherche un croquis indiquant la situation et les limites de ce périmètre, avec rattachement des quatre sommets extrêmes à des points géographiques définis d'une façon précise. Ces sommets devront être et rester signalés matériellement à la surface, dès que la demande aura été présentée et après que le permis aura été accordé.

L'intéressé doit indiquer avec détail, dans sa demande, la méthode de recherche qu'il se propose de faire suivre.

Le permis porte mention des conditions imposées par le Gouverneur, et auxquelles le permissionnaire sera tenu de se soumettre en ce qui concerne tant la méthode de recherche autorisée que les obligations jugées nécessaires pour assurer la libre navigation et la conservation du chenal.

Par dérogation à l'article 27 du décret du 6 juillet 1899, une même personne ou une même société peut détenir simultanément des périmètres de recherches contigus.

Par dérogation à l'article 29 du décret du 6 juillet 1899 , le périmètre d'exploitation, d'une étendue de 24 hectares au moins et de 800 hectares au plus, est constitué par deux lignes, droites ou polygonales, parallèles à l'axe moyen du cours d'eau, distantes de cet axe de 100 mètres au moins de chaque cóté, et par deux normales à cet axe, sans obligation d'un rapport minimum entre la largeur et la longueur du périmètre.

Il doit être annexé à la demande en permis d'exploitation un croquis indiquant la situation et les limites de ce périmètre, avec rattachement des quatre sommets extrêmes à des points géographiques définis d'une façon précise. 
L’intéressé doit en outre faire connaitre avec détail, dans sa demande, la méthode d'exploitation qu'il se propose de suivre et le projet des travaux quil se propose d'exécuter.

Le permis porte également mention des conditions imposées par le Gouverneur, et auxquelles le permissionnaire sera tenu dese soumettre, en ce qui concerne tant la méthode d'exploitation à suivre et les travaux à exécuter, que les obligations jugées nécessaires pour assurer la libre navigation et la conservation du chenal.

Les dispositions de l'article 32 du décret du 6 juillet 1899 ne s'appliquent pas aux exploitations par dragage.

Circulaire du 1er avril 1902. - L'application des articles 14, 19 et 30 du décret du 6 juillet 1899, relatifs au mode d'établissement des demandes de permis d'exploration, de recherches et d'exploitation, a donné lieu à des interprétations différentes suivant les Colonies, interprétations qui peuvent amener, dans l'avenir, des contestations, soit entre les concessionnaires, soit entre ces derniers et l'Administration.

Il a donc paru nécessaire de préciser et de réglementer l'application des articles susvisés.

Considérations générales. - Les documents exigés des concessionnaires à l'appui de leurs demandes par les articles 14, 19 et 30 doivent satisfaire à quatre conditions principales :

$1^{\circ}$ Surface du périmètre. - Fournir des éléments indiscutables pour la détermination de la surface du périmètre en vue du calcul de la redevance à payer par hectare.

$2^{\circ}$ Report sur le terrain. - Permettre le report sur le terrain des limites du périmètre par des opérations topographiques aussi simples que possible.

$3^{0}$ Report sur la carte. - Faciliter à l'Administration le report sur les cartes ou plans des différentes demandes de permis en vue de vérificr les droits d'antériorité des demandeurs.

$4^{\circ}$ Contestation au sujet de la position de deux périmètres voisins. - En cas de contestation entre deux concessionnaires voisins, permettre à l'Administration de trancher le litige au moyen d'opérations topographiques aussi simples que possible. 
Il y a lieu d'examiner successivement à ces différents points de vue la rédaction des articles 14,19 et 30 du décret du 6 juillet 1899, en indiquant de quelle façon ils doivent être áppliqués et interprétés.

$1^{0}$ Permis d'exploration. - L'article 14 est ainsi libellé :

“ La demande doit faire connaitre avec croquis ou cartes à l'appui les limites et l'étendue de la région sollicitée. "

Il importe que le croquis contienne tous les éléments nécessaires pour que la surface du périmètre puisse se déduire des dimensions inscrites sur le croquis lui-même.

Il y aurait donc lieu de recominander, de préférence, l'emploi de surfaces géométriquement définies, telles que cercle, carré, rectangle, trapèze, triangle ou polygone décomposé en éléments triangulaires.

Les limites naturelles, cours d'eau, lignes de partage des eaux, crêtes de montagnes, bassins hydrographiques sont, en général, beaucoup trop mal connues dans les pays ouverts seulement à l'exploration pour pouvoir être acceptées, sauf dans des circonstances exceptionnelles, pour définir les limites d'un périmètre.

En vue de faciliter le report par l'Administration sur une carte d'ensemble, il parait utile, sinon indispensable, d'adopter officiellement une édition d'une carte de la colonie, de préférence à l'échelle du 1/500,000 et d'imposer aux demandeurs l'obligation d'employer pour la rédaction du croquis, soit cette carte, soit un agrandissement de cette carte. Sans cette précaution, il sera impossible, en raison de la divergence considérable qui existe entre les diverses cartes de la côte occidentale d'Afrique, d'effectuer correctement le report et de vérifier les droits d'antériorité des demandeurs de deux périmètres voisins.

$\mathrm{Si}$, au cours de la durée du permis d'exploration, il s'élève une contestation entre deux détenteurs de périmètres voisins, le seul procédé consiste à effectuer le report sur le terrain, des limites, des périmètres, et dans ce but, il convient de repérer exactement par rapport à des points connus un des côtés du périmètre.

Le moyen le plus sûr et le plus simple d'effectuer le repérage consiste à indiquer la distance du point à repérer au point connu, 
ainsi que l'orientation par rapport au Nord vrai de la ligne qui joint les deux points.

Les prospecteurs font souvent emploi de la boussole et peuvent ainsi être amenés à employer le Nord magnétique au lieu du Nord vrai.

Si cette éventualité se produit, le Service des Mines devra faire compléter la demande de permis par la mention suivante :

"La déclinaison magnétique en l'année est de degrés Est ou Ouest.

Comme points connus, on choisira, bien entendu, des points dont la position ne peut donner lieu à aucune contestation tels que villages, confluents de deux cours d'eau, etc. En aucun cas on ne devra admettre la définition par les coordonnées géographiques, longitude et latitude, dontla détermination à l'intérieur des terres peut entraîner des erreurs de $\mathbf{1 0}$ à 20 minutes représentant 18 à 36 kilomètres, écart souvent supérieur à la dimension du périmètre à définir.

Si le report des limites sur le terrain permet de constater que deux périmètres empiètent l'un sur l'autre, il convient de faire porter la réduction sur celui dont la demande a été faite à une date postérieure.

Dans ce cas, l'Administration devra, soit rembourser au demandeur qui a supporté la réduction le montant des droits perçus en trop ou bien lui accorder sur sa demande un nouveau périmètre dont la surface correspond à la réduction opérée.

Aux termes de l'article $\mathbf{1 5}$ du décret, l'approbation aux demandes de permis d'exploration dont la surface est supérieure à ̋0.000 hectares est réservée au Ministre, mais le titre II relatif à la délivrance de permis ne contient aucune restriction en ce qui concerne le nombre de permis à délivrer au même titulaire, ainsi que la distance minima qui doit séparer deux périmètres voisins.

Fn s'en tenant aux termes stricts du décret, il semblerait donc permis de délivrer au même titulaire une série de permis d'exploration contigus, ce qui rendrait illusoire la réserve de l'approbation ministérielle prévue pour les périmètres supérieurs à 50.000 hectares. En conséquence, il convient qu’il ne soit déli- 
vré plusieurs permis d'exploration au même titulaire, qu'à la condition expresse que la surface totale ne dépasse pas 50.000 hectares, mais dans certains cas spéciaux, des propositions du Gouveruement, tendant à accorder à un demandeur des périmètres dépassant 50.000 hectares pouvant être examinées favorablement.

Droit de priorité. Cas d'envoi par la poste. - Des contestations se sont produites au sujet des droits de priorité des demandes adressées par la poste ou de demandes incomplètes qui ont dû être renvoyées à leurs auteurs. Il y a lieu à ce sujet de distinguer entre les différentes sortes de permis, et les articles 13, 15,21 et 28 du décret doivent recevoir l'interprétation donnée ci-après.

Permis d'exploration. - Art. 13 et 15 . En vertu des articles 13 et 15 du décret, le Gouverneur est seul juge des considérations et motifs qui le conduisent à accorder, ajourner ou refuser un permis d'exploration.

Le droit conféré par la priorité de la demande n'existe donc pas et l'antériorité compte seulement de la date de délivrance du permis et non de l'inscription de la demande.

Dans ces conditions, il ne parait pas possible d'exiger du demandeur de sa présence effective sur le terrain, comme l'a prévu le décret pour le permis de recherches.

Les demandes de permis d'exploration peuvent donc être adressées par la poste par des personnes habitant la métropole, mais sans que la date d'arrivée dans la colonie puisse être invoquée par le demandeur comme lui conférant un droit de priorité. 


\section{Modèle de demande de permis d'exploration.}

Je soussigné , demeurant à faisant élection de domicile à , muni de l'autorisation $\mathrm{n}^{\circ} \quad$, prévue par l'article 8 du décret du 6 juillet 1899 , ai l'honneur de demander au Gouverneur de la colonie de

, un permis d'exploration dont le périmètre est défini ci-après, conformément au croquis ci-annexé.

A partir du [centre du village de Lessené], situé [sur la rivière Irima], je détermine le sommet $\mathbf{A}$ du périmètre en portant une longueur de [8 kilomètres] dans la direction [N. 65०0.] (1).

$\mathrm{Du}$ point $\mathrm{A}$ je trace la base du trapèze rectangle en portant une longueur de $\mathbf{7 0}$ kilomètres dans la direction $\mathrm{AB}$, faisant avec le Nord vrai au point $\mathrm{A}$ un angle de [N. 22 0 . $]$.

$A$ u point A, j’élève dans la direction $\left[S .112^{\circ} 0.\right]$ une perpendiculaire $\mathrm{AD}$, d'une longueur de [30 kilomètres].

Au point $\mathrm{B}$, j'élève dans la direction $\left[\mathrm{S} .112^{\circ} 0.\right]$ une perpendiculaire $\mathrm{BC}$ d'une longueur de [20 kilomètres].

La surface du périmètre $A B C D$ ainsi défini est de

$$
\left[\frac{70.000 \times \frac{20.000+30.000}{2}}{10.000}\right]
$$

soit [175.000 hectares].

Ci-joint un récépissé de versement d'une somme de [8.750 fr.], montant de la redevance calculée à raison de $0 \mathrm{fr}$. 0 Ð par hectare.

Jes limites du périmètre sont d'autre part définies par le croquis ci-annexé établi d'après la carte , mais il est entendu qu'en cas de contestation, il pourra être procédé à la vérification de la position des points en litige en partant de la position [du village de Lessené] qui a servi de point de départ au repérag'e du périmètre.

(1) Les orientations indiquées ci-dessus sont rapportées au Nord vrai [ou sont rapportẻes au Nord magnétique faisant en 1902 un angle de avec le Nord vrai]. 
2。 Permis de recherches. - L'article 19 est ainsi libellé :

( Le permis donne le droit exclusif de faire

dans l'étendue d'un cercle de 5 kilomètres de rayon au plus, tracé d'un centre qui doit être rattaché à un point géographique défini d'une façon précise, tant dans la demande que dans le croquis qui doit lui être joint. Ce centre devra être et rester signalé matériellement à la surface dès que la demande aura été présentée et après que le permis aura été accordé ").

Il parait utile de tenir la main à l'exécution de cette dernière prescription, qui a pour effet de limiter l'octroi de permis de recherches aux seuls demandeurs ayant par eux-mêmes ou par mandataires fait acte de présence non seulement dans la colonie, mais encore sur le terrain du périmètre de recherches.

Il y a également à examiner s'il ne convient pas de préciser, suivant les localités, la forme et les dimensions du signal, qui pourrait être constitué soit par un poteau en bois, soit par une pyramide de pierre avec inscription.

Comme le signal peut être détruit ou enlevé, il est nécessaire de le rattacher d'une façon aussi précise que possible à un point connu, une case d'un villag'e, un confluent de cours d'eau, etc...

Comme pour les permis d'exploration, le repérage doit être effectué par l'inscription de la distance des deux points et l'indication de l'orientation par rapport au Nord vrai de la ligne qui joint les deux points.

Les dimensions des permis de recherches pouvant être, dans certains cas, très restreintes, il importe de signaler aux demandeurs l'importance d'un repérage précis.

Bien entendu, pour les motifs indiqués ci-dessus, au sujet des permis d'exploration, il ne peut être question de déterminer le point de repère par ses coordonnées géographiques.

Pour la facilité dı report des demandes, il y a intérêt à adopter une carte à une échelle suffisante pour que l'on puisse y inscrire ultérieurement les périmètres des permis d'exploitation, périmètres dont une des dimensions peut s'abaisser à 250 mètres. L'échelle du 1/50.000 permettrait de représenter un côté de 
250 mètres par une longueur de 5̆ millimètres, dimension suffisante pour être facilement lisible.

Il parait indiqué, à défaut de l'existence d'une édition de carte au 1/50.000 d'utiliser une amplification de la carte au 1/500.000 qui a servi à reporter les périmètres d'exploration.

En cas de contestation entre deux concessionnaires de périmètres voisins, il convient de vérifier la distance du point en litige aux deux centres des périmètres de recherches, et, à ce sujet, il est inconcient de signaler aux demandeurs que le seul moyen pour eux de maintenir l'intégrité de leurs droits consiste à placer et à entretenir le poteau-signal marquant le centre du périmètre.

Si la vérification des distances faisait ressortir que le point en litige se trouve compris à la fois dans les limites des deux périmètres voisins, il serait tenu compte de l'antériorité de la demande, et l'Administration devra rembourser au concessionnaire évincé le montant des droits perçus en trop.

\section{Modèle de demande de permis de recherches.}

Je soussigné,

faisant élection de domicile à demeurant à:

, muni de l'auto risation $\mathrm{n}^{0} \quad$, prévue par l'article 8 du décret du 6 juillet 1899 , ai l'honneur de demander à Monsieur le Gouverneur de la colonie de , de vouloir bien me délivrer un permis de recherches d'un rayon de [2 kilom. 500] compté à partir d'un signal placé sur le terrain et consistant en [un poteau en bois], de [diamètre], et de

[hauteur] au-dessus du sol, muni [d'une planchette indicatrice] portant les inscriptions ci-après :

Ce signal se trouve [à 1.150 mètres] du [puits situé à proximité du poste de Touba] dans une direction faisant [à partir du puits] un angle de [N. (Nord vrai) $\mathbf{4 2}^{\circ} \mathrm{E}$. $]$ (1), suivant croquis ci-annexé.

(1) Les orientations indiquées ci-dessus sont rapportées au Nord vrai, ou [sont rapportées au Nord magnétique faisant en [1902 un angle de avec le Nord vrai]. 
La surface de ce périmètre est de [1.963] hectares.

Ci-joint un récépissé constatant le versement d'une somme de [292 fr. 60] calculée à raison de :

0 fr. 10 pour les $\mathbf{1 . 0 0 0}$ premiers hectares;

0 fr. 20 pour les [963] hectares en supplément.

$3^{\circ}$ Permis d'exploitation. - Art. 30. Le périmètre d'exploitation est obligatoirement constitué par un rectangle dont un côté doit être repéré par rapport à un point connu.

Si le permis d'exploitation est demandé à la suite d'un permis de recherches, il y a lieu de recommander aux demandeurs de choisir comme point connu le centre du permis de recherches.

En opérant de cette façon on évitera toute contestation ultérieure, soit au sujet de l'inscription du périmètre d'exploitation dans le périmètre de recherches, soit au sujet de la distance minima qui doit séparer deux périmètres d'exploitation par application de l'article 32.

Les règles indiquées ci-dessus pour le repérage du centre du permis de recherches par rapport à un point connu sont applicables au repérage d'un des sommets du rectangle.

La position des quatre sommets sera ensuite déterminée par les déux dimensions du rectangle et l'orientation d'un des côtés.

Enfin, il y a lieu de rappeler aux demandeurs que s'ils ne se conforment pas à l'article 34 prescrivant l'abornage dans le délai de six mois, ils s'exposent à voir leurs droits contestés par les détenteurs de périmètres voisins.

Droit de priorité au sujet des permis de recherches et d'exploitation - Art. 21 et 28. Les permis de recherches et d'exploitation, sauf opposition de tiers, doivent être accordés à la priorité de la demande, d'après la date et l'heure du dépôt.

Le demandeur a done tout intérêt à effectuer, soit par luimême, soit par mandataire, le dépôt de la demande dont il lui est délivré récépissé séance tenante.

Toutefois, l'Administration ne peut pas refuser une demande régulière et complète qui lui parviendrait par la poste.

Mais, dans ce cas, s'il parvient à l'Administration plusieurs demandes par le même courrier, les demandeurs ne peuvent élever aucune réclamation au sujet de l'ordre d'inscription. 
Si une demande est reconnue incomplète et irrecevable, il ne sera pas procédé à l'affichage. Elle sera retournée au demandeur pour être modifiée et complétée. Ce dernier sera prévenu que la première inscription est considérée comme nulle et non avenue et que son droit de priorité ne comptera que du dépôt de la nouvelle demande.

Pour éviter toute contestation, il parait utile de procéder au renvoi par lettre recommandée avec accusé de réception.

Cet accusé de réception servirait de pièce à l'appui de l'annulation de la première inscription.

\section{Modèle de demande de permis d'exploitation.}

Je soussigné, faisant élection de domicile à , demeurant à

, muni de l'autorisation $\mathrm{n}^{0} \quad$, ou [titulaire du permis de recherches $\mathrm{n}^{0} \quad$ ], ai l'honneur de demander à Monsieur le Gouverneur de

, de vouloir bien me délivrer un permis d'exploitation dont le périmètre est figuré dans le croquis ci-annexé.

Le périmètre de ce permis d'exploitation est ainsi défini par rapport au signal du permis de recherches $n^{0} \quad$ [ou par rapport à un point connu].

A [1.600 mètres du signal], dans la direction [S. 1550 E. $]$ (1), se trouve le point $A$, sommet du rectangle.

Le point $B$ se trouve à 1.500 mètres du point $A$, dans une direction faisant avec le Nord vrai un angle de (N. $32^{\circ}$ E.].

Aux points $\mathbf{A}$ et $\mathbf{B}$, s'élèvent deux perpendiculaires $\mathrm{BC}$ et $\mathrm{CD}$ dans une direction faisant avec le Nord vrai un angle de $\left[\mathrm{S} \cdot \mathbf{1 2 2}^{\circ}\right.$ E.), et je porte dans cette direction $[\mathrm{AD}=\mathrm{BC}=\mathbf{1 . 0 0 0}$ mètres $]$.

Le surface du périmètre ainsi défini est [de

$$
\left.\frac{1.500 \times 1.000}{10.000}=150 \text { hectares }\right]
$$

(1) Les orientations indiquées ci-dessus sont rapportėes au Nord vrai [ou sont rapportées au Nord magnétique faisant en 1902 un angle de avec le Nord vrai]. 
Ci-joint un récépissé de versement de [300 francs], calculé à raison de 2 francs par hectare.

$4^{0}$ Permis de dragages. - Aux termes de l'article 2 du décret du 4 août 1901, les quatre sommets du périmètre doivent être rattachés à des points géographiques définis d'une façon précise.

D'autre part, en vue de déterminer la surface du périmètre, le demandeur doit indiquer la largeur de la bande mesurée à compter de l'axe du cours d'eau, ainsi que la longueur totale de cette bande.

Il peut arriver qu'il n'y ait pas concordance entre la position des extrémilés du périmètre et la longueur portée sur la demande ponr servir de base au calcul de la redevance

Comme il ne peut y avoir aucune contestation entre les détenteurs de périmètres contigus si la détermination des extrémités est faite par rapport à des points connus, il convient de ne considérer la longueur portée sur la demande que comme une base provisoire d'évaluation de la redevance. Si on reconnait ultérieurement que la longueur effective est plus grande ou plus petite que la longueur inscrite, il sera tenu compte du tropperçu ou du moins-perçu sur la redevance.

Enfin, il convient de rappeler aux demandeurs qu'aux termes du décret, ils doivent faire connaitre à l'Administration les procédés de dragages qu'ils comptent employer.

Pour faciliter la rédaction des demandes de permis, quatre modèles ont été annexés à la présente circulaire.

Ces modèles devront être mis à la disposition des demandeurs de concession pour faciliter l'établissement de leurs demandes.

\section{Modèle de demande de permis de dragages.}

Je soussigné, , demeurant à faisant élection de domicile à , muni de l'autorisation $\mathrm{n}^{\circ} \quad$, exigée par l'article 8 du décret du 26 juillet 1899, ai l'honneur de demander à Monsieur le Gouverneur de la colonie de , de vouloir bien me délivrer un permis de recherches [ou d'exploitation] par dragages sur [la rivière Fere dougouba]. 
Le périmètre de recherche par dragage est délimité ainsi qu'il suit :

A [1.000 mètres en amont du village de Faraminaka], je trace la normale $\mathrm{AB}$ au cours de la rivière et pour déterminer les points $\mathrm{A}$ et $\mathrm{B}$, je porte [ $\mathbf{4 0 0}$ mètres] à droite et [ $\mathbf{4 0 0}$ mètres] à gauche de l'axe de la rivière.

Les points $\mathrm{C}$ et $\mathrm{D}$ qui limitent d'autre part le périmètre sont situés à [ 2 kilomètres en aval de Gouandougou et $\mathbf{4 0 0}$ mètres à droite et à gauche de l'axe de la rivière].

La distance mesurée en suivant les sinuosités de la rivière est d'environ [60 kilomètres], mais il est entendu que cette distance ne doit servir qu'à l'évaluation provisoire du montant de la redevance.

Si la distance effective était supérieure à la distance de $[60$ kilomètres], je m'engage à verser à l'Administration le montant du moins-perçu, de même que si cette distance est inférieure, je devrai être remboursé de la somme versée en trop.

Ci-joint un récépissé constatant le versement d'une somme de [640 francs] à titre de redevance calculée à raison de 0 fr. 10 par hectare.

Je compte procéder aux recherches par dragages de la façon suivante et au moyen du matériel désigné ci-après : 


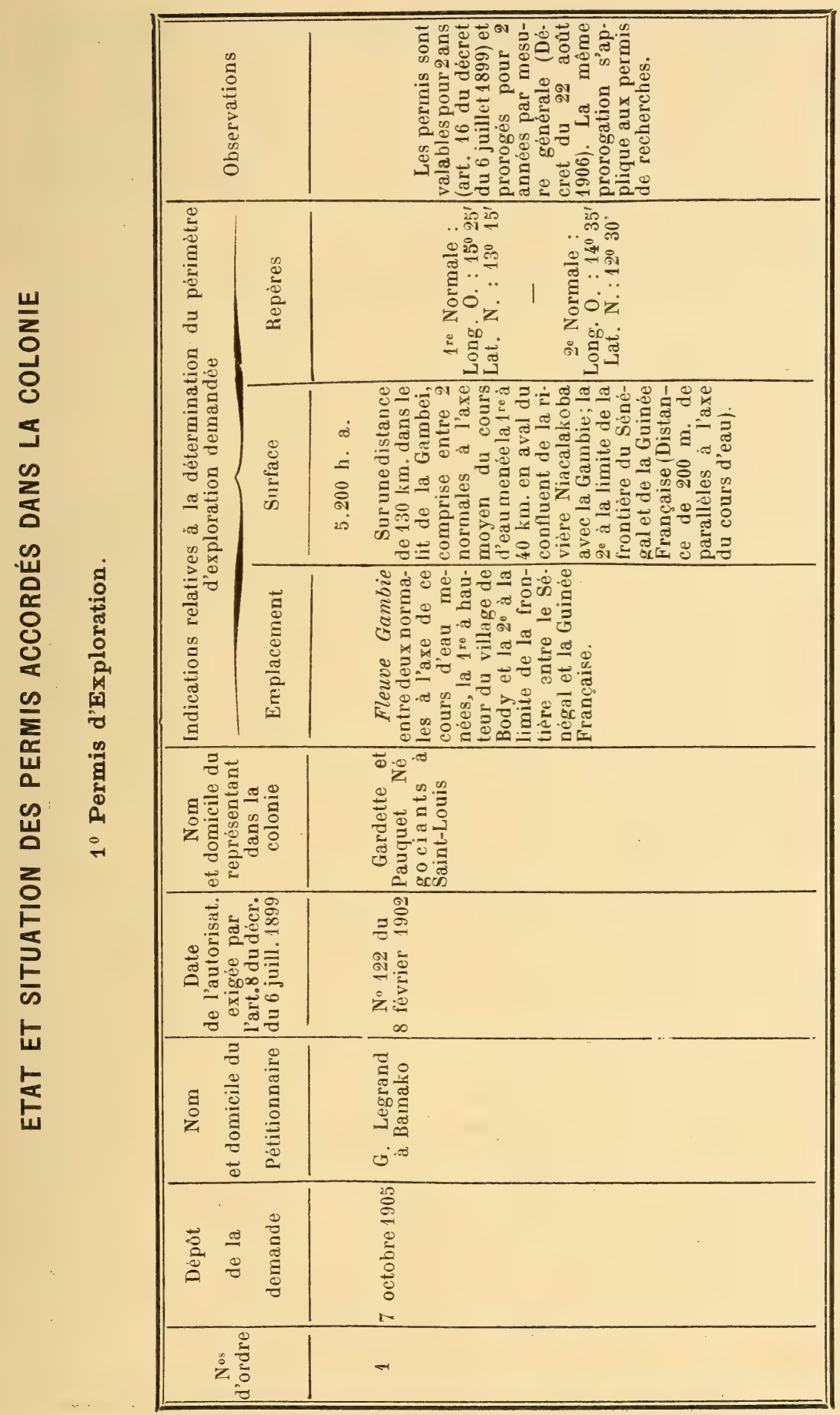




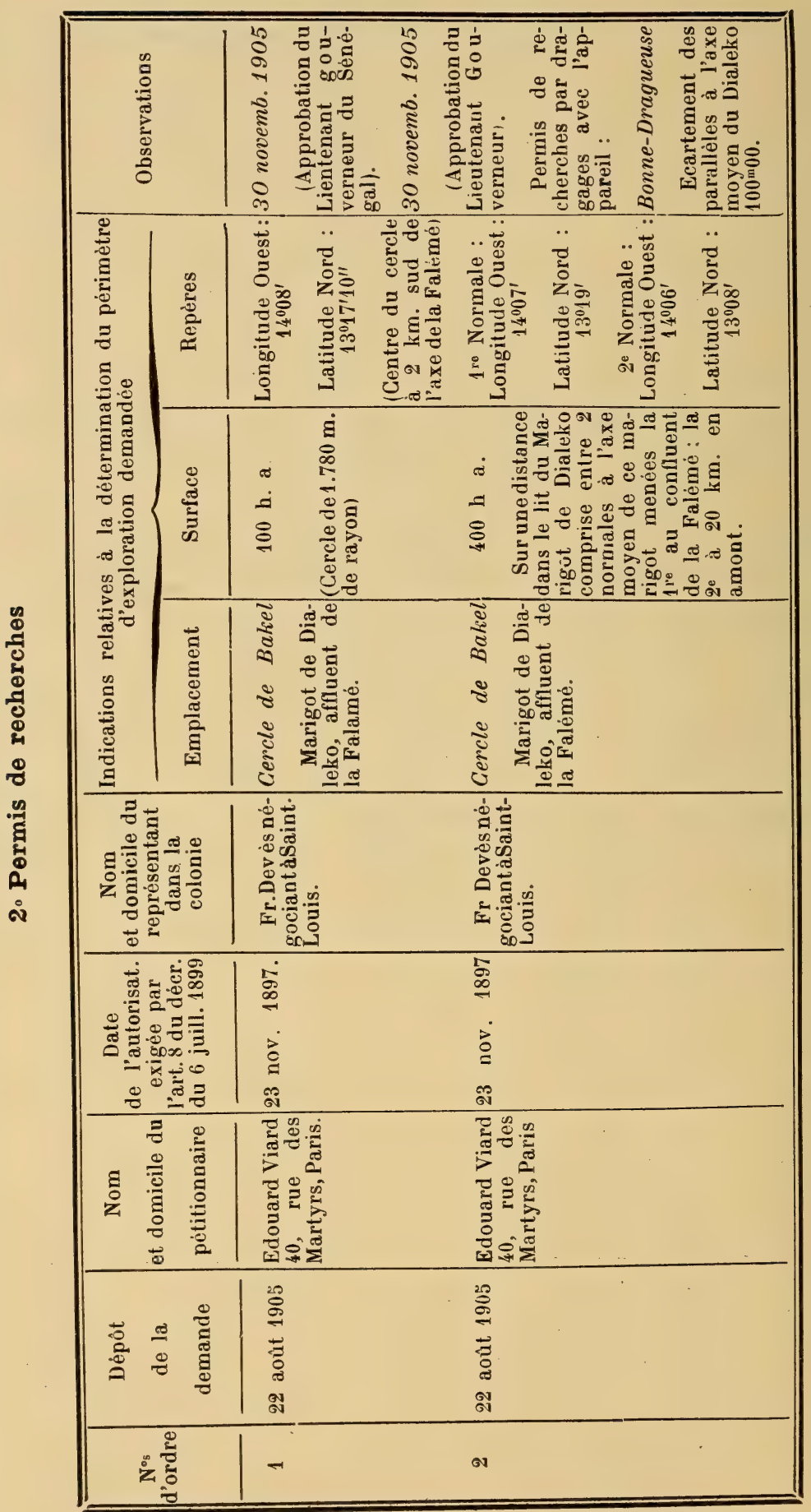




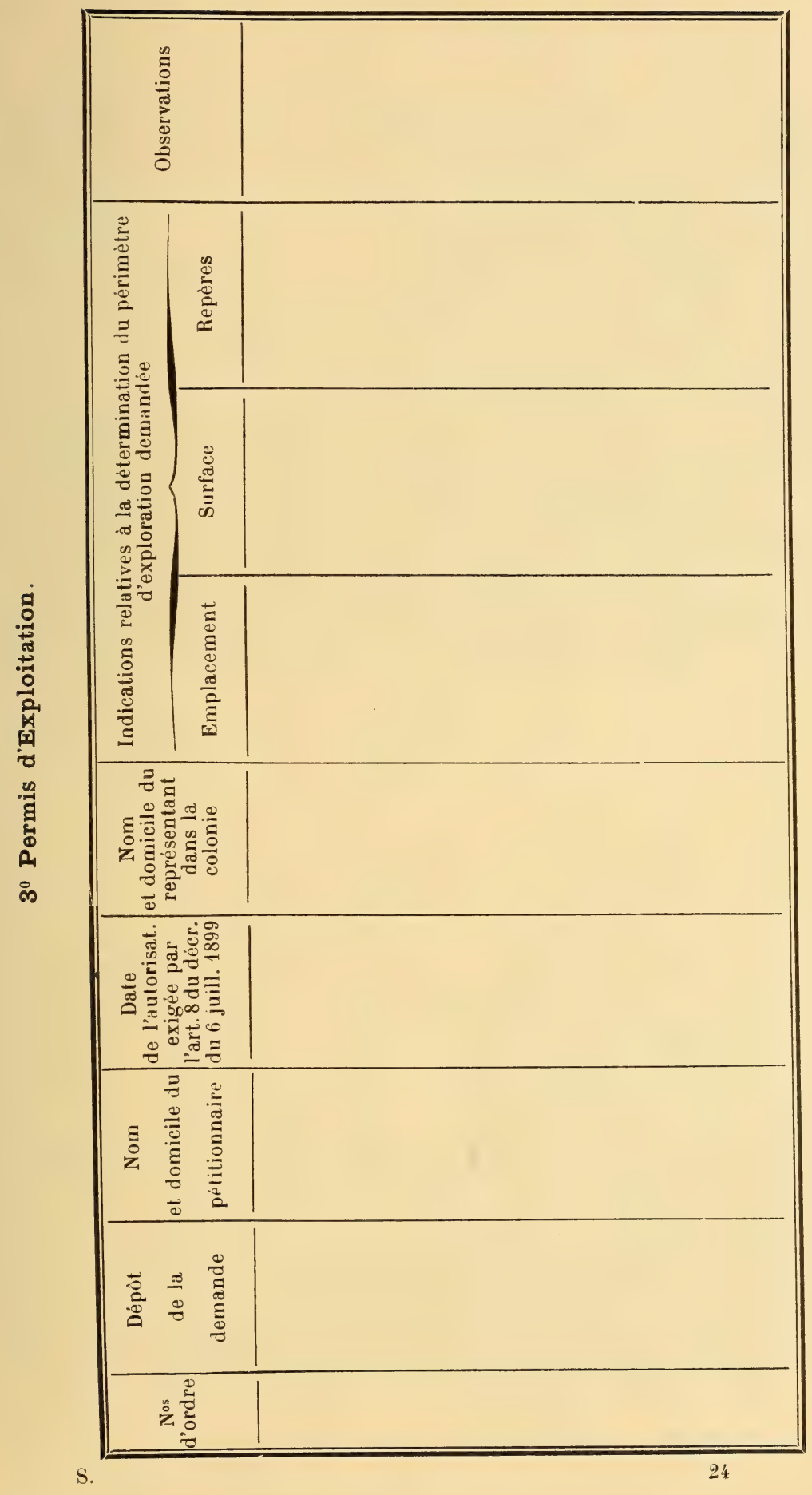




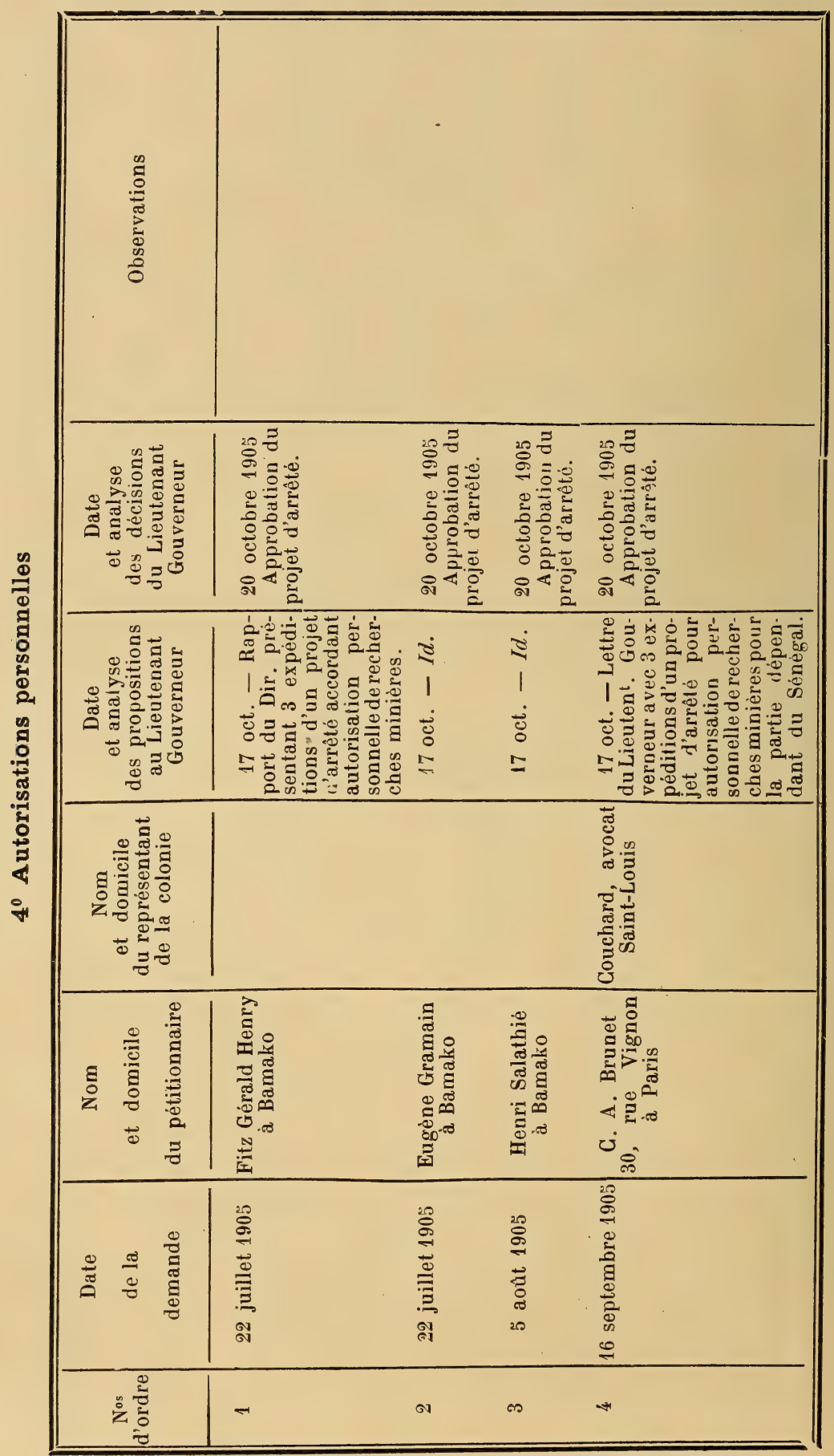




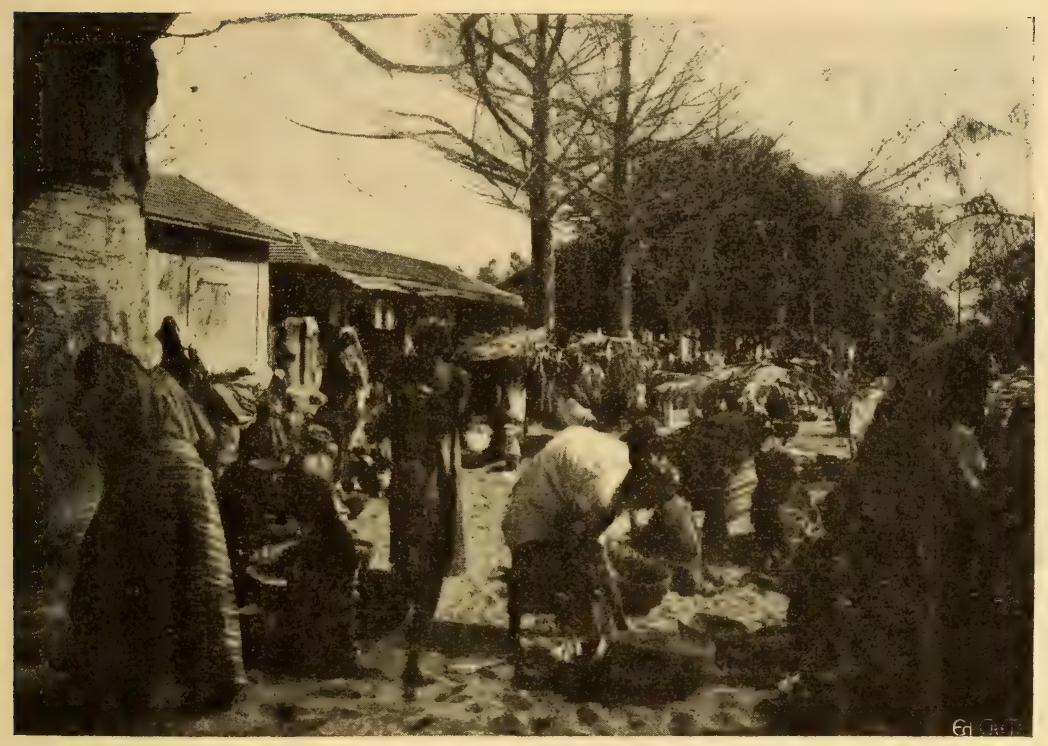

Fig. 39. - Marché de Tivaouane

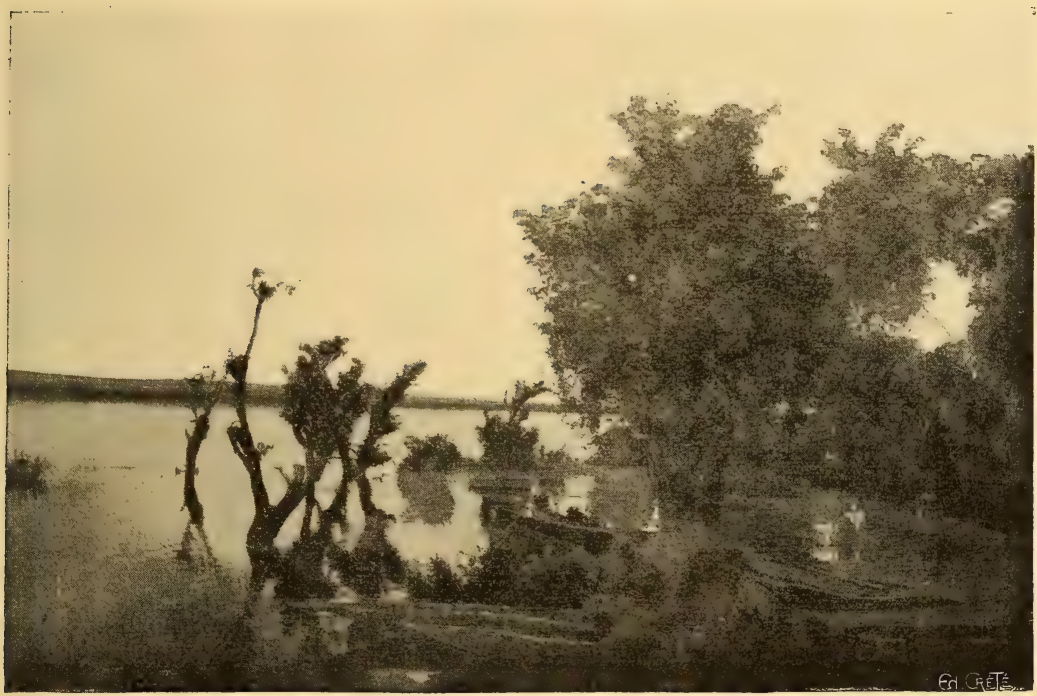

Fig. 40. - Inondation du fleuve 



\section{Le commerce.}

Après avoir donné un aperçu geénéral de la situation du Sénégal, nous examinerons le mouvement commercial qui a augmenté d'une façon si encourageante; nous indiquerons ensuite les produits naturels d'exportation et les principaux articles d'importation; nous donnerons enfin quelques indications sur le régime douanier de la colonie.

\section{Le mouvement commercial}

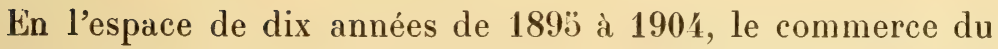
Sénégal-Soudan a doublé passant de $\mathbf{4 0 . 7 0 3 . 9 4 2}$ francs à 79.797.632. Il avait atteint l'année précédente le chiffre énorme de 92 millions; mais cet accroissement ne saurait être considéré comme normal et tenait à des causes accidentelles (grands travaux publics, matéricl d'approvisionnements de l'administration) (1).

Le tableau ci-contre et les diagrammes qui l'accompagnent montreront, mieux que de longs développements, la marche du mouvement commercial de la colonie, l'importance des importations et des exportations, la part qui revient à la France et à l'étranger dans les transactions.

Les statistiques de 1905 accusent une diminution de 1.880.499 par rapport aux chiffres de 1904. La diminution a porté entièrement sur l'exportation qui se trouve être de $\mathbf{2 4 . 5 6 4 . 3 5 5 ~ c o n t r e ~}$ 29.290.893 en 1904. A l'importation au contraire nous trouvons un excédent de 3.468 .039 soit 5̋3.314.778 contre 49.846 .739 en 1904. Diverses causes, les unes passagères comme les circonstances climatériques, la mise à exécution de certains travaux ou

(1) Voir plus loin les développements consacrés au commerce en 1905. 


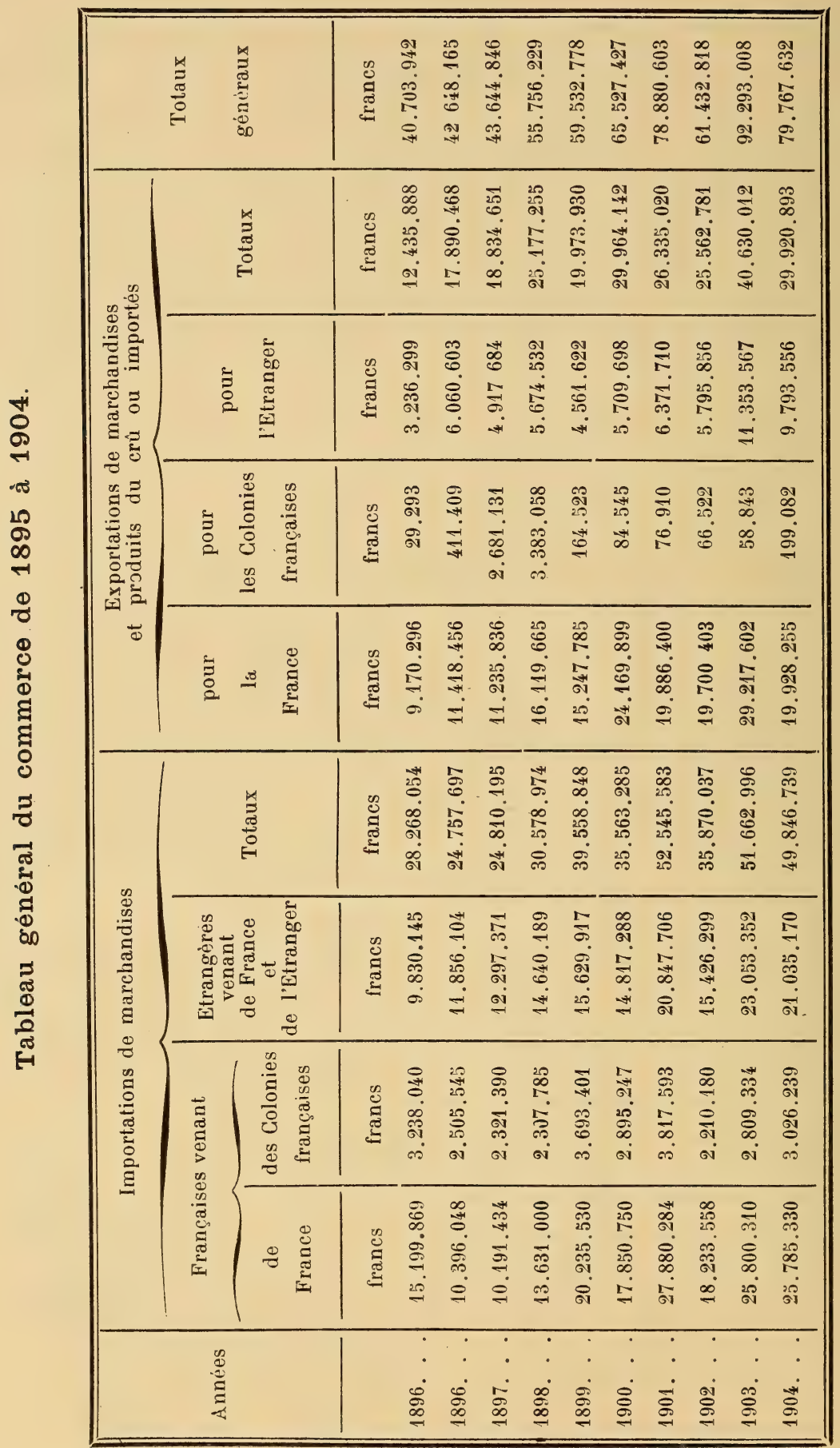


l'achèvement de certains autres, d'autres durables comme le développement économique de la Colonie ont exercé leur influence sur le mouvement commercial.

Importations. - A l'importation les diminutions constatées en 1905 portent principalement sur les Kolas, les spiritueux, le charbon, les métaux et ouvrages en métaux.

A l'égard des Kolas, la baisse n'est qu'apparente. Dans les statistiques précédentes, cet article était évalué à 8 francs le kilo. Cette valeur a pu être exacte dans le passé, elle ne correspond plus aujourd'hui à la réalité. Aussi, dans la mercuriale officielle, le prix des kolas a-t-il été sensiblement réduit. Il a été mis à 6 francs puis à 4 francs le kilo. Et c'est pourquoi la diminution des importations de kolas se trouve être de 1.500.000 francs en valeur, alors que la quantité introduite a été seulement inférieure de 31.495 kilogs à 1904 .

En ce qui concerne les spiritueux la moins-value constatée est certainement due à l'application du nouveau tarif douanier. " C'est là, a dit le gouverneur général de l'Afrique occidentale française, un heureux résultat que nous n'avons cessé de poursuivre. C'est en effet pour enrayer la consommation de l'alcool, et non pour obtenir une majoration de recettes, laquelle au delà d'un certain taux ne prut plus se produire, que le tarif sur l'alcool a été revisé et sensiblement élevé ").

Si nous constatons en 1905 une diminution importante des importations de charbon, le fait n'est pas dû à un ralentissement de la navigation, mais à ce que la Compagnie des Charbonnages ayant en 1904 fait construire de vastes hangars et les ayant entièrement garnis n'a eu en 1905 qu'à répondre aux besoins de la consommation courante.

De même, c'est à l'achèvement du chemin de fer de Kayes au Niger qu'il faut attribuer la diminution sur les métaux et les ouvrages en métaux, d'autant plus qu'en 1903 et 1904 des apports exceptionnels avaient été faits pour la construction du marché de Saint-Louis et pour l'installation du gros matériel nécessaire aux travaux du port de commerce de Dakar.

Ainsi donc, et sauf en ce qui concerne les spiritueux pour lesquels la baisse était désirée, on peut dire que les fléchisse- 
ments qui se sont produits à l'importation, ou bien ne sont qu'apparents comme pour les kolas, ou bien sont dûs à des causes particulières et n'affectent en aucune facon la situation économique de la colonie.

Par contre, on peut considérer comme d'heureux symptômes pour l'avenir les augmentations réalisées à l'importation, lesquelles visent surtout les vins, la bière, le pétrole, les livres, l'outillage économique et surtout les tissus.

En ce qui concerne les vins et la bière, l'augmentation est d'autant plus heureuse, qu'elle se produit en même temps qu'une diminution sur les alcools. Elle s'explique en partie par l'accroissement de la population européenne, mais l'usage du vin commence aussi à se répandre parmi les indigènes et beaucoup de noirs qui faisaient usage d'alcool, préfèrent aujourd hui cette boisson tonique. A l'égard des vins, le développement de la consommation au Sénégal aura cet avantage que les importations sont entièrement fournies par la métropole: 1369.000 francs sur 1.471.000 francs soit $930 / 0$ et que, parses relations directes avec Bordeaux, le Sénégal sera toujours tributaire de cette place pour la fourniture de l'article qui nous occupe.

L'augmentation sur les huiles de pétrole est de 100 0/0. Ces articles ont passé de $\mathbf{4 1 3 . 0 0 0}$ à 816.000 francs. Il faut surtout attribuer cette augmentation à ce fait que les huiles de pétrole sont de plus en plus utilisées comme combustible par les nombreuses embarcations de rade ou de rivières.

Nos efforts pour la diffusion de l'instruction par l'ouverture de nombreuses écoles et l'organisation d'un plan général d'enseignement primaire ont eu leur répercussion immédiate sur les importations de papiers et de livres qui ont presque doublé en 1905.

- Nous trouvons une augmentation de 925.000 francs pour l'outillage économique et le matériel fluvial maritime. Lẹs travaux d'intérêt public, le développement de la navigation sénégalaise, l'établissement de services sur le Niger expliquent ces accroissements.

Mais c'est principalement en ce qui concerne les tissus que l'augmentation mérite d'être signalée. "C'est en effet le meil- 
leur critérium de la prospérité économique d'un pays. C'est la preuve que les ressources de l'indigène se sont accrues et c'est aussi le signe qu'il échappe à sa vie misérable pour venir peu à peu à la civilisation ". L'augmentation est de près de 4 millions, soit 30 0/0 sur celle de l'année dernière. Dans ce chiffre les guinées figurent pour 1.4033.423 francs. La part de la France dans ces importations a été beaucoup plus considérable que les années précédentes. Elle s'élève à 8.662 .000 francs, soit près de 200.000 de plus qu'en 1904. L'augmentation profite done pour $500 / 0$ à notre commerce national. Et cette augmentation n'est pas accidentelle. Ciest la progression saisissante que n'ont cessé de suivre les importations de tissus français :

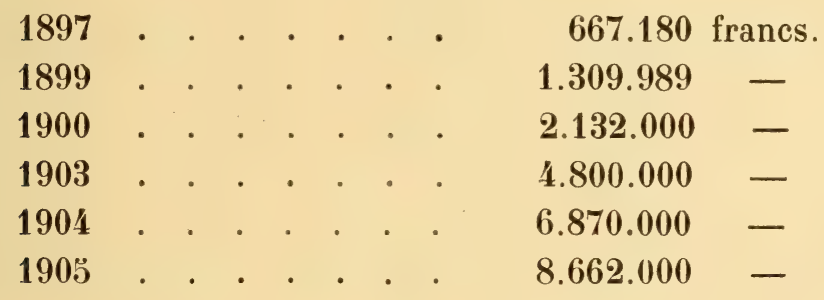

Exportations. - La diminution considérable à l'exportation des chiffres de 190 sur ceux de 1904 porte sur un seul produit: l'arachide. La recrudescence des pluies à la fin de 1904, alors que l'hivernage paraissait terminé et que les arachides venaient d'être récoltées, a occasionné la perte d'une très grande partie de ces graines. Cette circonstance est d'autant plus regrettable que la récolte avait été très abondante; elle aurait même pu avoir les conséquences les plus fâcheuses pour les années suivantes, si l'administration n'avait pris soin de fournir aux indigènes qui se sont trouvés manquer d'arachides, les semences dont ils avaient besoin. L'exportation totale n'en a pas moins été très importante puisqu'elle s'élève encore à 20 millions de francs. Les produits d'exportation autres que l'arachide et notamment les caoutchoucs, les animaux vivants, les dépouilles d'animaux accusent des augrmentations sérieuses; et c'est là un point qu'il importe surtout de noter. La situation économique 
du Sénégal-Soudan n'est plus à la merci d'une mauvaise récolte du principal produit d'exportation. Une diminution aussi considérable que celle sur les arachides n'a pas très sensiblement affecté le résultat global du commerce, comme le montre d'ailleurs le produit des recettes de douane qui a été en augmentation de $\mathbf{6 1 9 . 0 0 0}$ francs.

Au surplus, le chiffre des exportations est bien inférieur à la réalité. Le caoutchouc forme avec l'arachide le principal élément de nos exportations. Les sorties de caoutchouc ont atteint en 1905, 4.698000 francs, mais ce chiffre eut été beaucoup plus élevé si, pour son établissement, il avait été tenu compte de la valeur réelle des caoutchoucs.

La valeur de ce produit a été portée aux mercuriales suivant les sortes pour 1 franc, 4 francs et 5 franes le kilo alors que les caoutchoucs du Soudan atteignent couramment 9 francs, 10 francs, 11 francs et même plus, le kilo, sur les marchés d'Europe. On peut donc sans exagération évaluer au double la valeur exacte des caoutchoucs exportés $(1)$. Elle serait alors de 9.400.000 francs et l'exportation totale du Sénégal en 1905 se trouverait de la sorte remonter à 29.200 .000 francs et nos échanges totaux à 82.514.000 francs.

En résumé et malgré des circonstances climatériques défavorables comme il ne s'en était pas produit depuis longtemps au Sénégal, le commerce de cette colonie n'en a pas moins été dans son ensemble réellement prospère.

Commerce avec la France. - Les échanges a vec la métropole ont été particulièrement actifs tant à l'importation qu'à l'exportation.

A l'importation, la part des produits français s'élève à 35.500 .000 francs, ce qui sur une importation totale de 53.300.000 francs, donne une proportion de $670 / 0$. Et il faut tenir compte de ce fait que, dans les $330 / 0$ représentant la part des produits étrangers, figurent des articles tels que les kolas

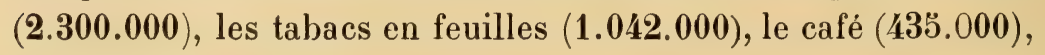

(1) La question de la fixation de la valeur officielle du caoutchouc est actuellement à l'étude. 
et quelques autres denrées coloniales que la métropole ne produit pas, ou bien encore d'autres produits : les huiles de coton $(\mathbf{1 . 0 1 5 . 0 0 0 )}$ la houille $(\mathbf{2 . 1 0 0 . 0 0 0 )}$ pour lesquels elle ne peut song'er à lutter avec l'étranger. Si l'on déduit ces divers articles, la part de la France dans les importations n'est pas moins de 80 0/0.

A l'exportation, même prépondérance du commerce français : 17.280.000 francs sur 24.560.000 francs, soit environ 70 0/0. Cette part est appelée à grandir encore avec la création d'un marché français de caoutchouc. De plus, cette situation brillante du commerce français pourra encore être facilement et rapidement améliorée. Sur quelques articles nos négociants pourraient obtenir des avantages plus décisifs que ceux qu'ils ont acquis jusqu'à ce jour. Notamment pour les tissus, il leur sera possible d'accroître la superbe progression signalée plus haut en s'efforçant d'approprier leur fabrication au goût des indigènes.

Nous allons passer en revue maintenant, d'une façon plus détaillée, les principaux articles d'importation et d'exportation.

\section{a) Principaux articles d'importation.}

Conserves de viandes de toutes sortes. - Les conserves de viandes de toutes sortes comprennent les conserves de viandes et de gibier en boites et en terrines préparés par tous procédés.

L'importation des conserves de viandes a suivi le mouvement que lui ont imprimé les besoins de la population européenne ou assimilée qui, seule en fait une grande consommation surtout en cours de voyage et dans les centres dépourvus de boucherie.

L'Etranger fournit certaines qualités telles que : les Ham, Corned beef, Linchtong, etc. qui représente environ le 1/20 de l'importation totale. La France produit le reste.

Farines. - Les farines de froment sont de bonne qualité et proviennent des minoteries françaises pour la presque totalité.

La plupart des farines s'importaient autrefois dans des barils de 90 ou 100 kilogs. De nos jours, on a substitué en grande 
partie à ces barils un emballage moins coûteux qui consiste en sacs ou balles dont la contenance est de 50 ou 100 kilos.

Les farines destinées au Soudan ou aux approvisionnements militaires sont généralement renfermées dans des caisses de fer blanc de 25 et 50 kilos.

L’indigène à cause de la modicité de ses ressources, n'en fait qu'un usage restreint bien qu'il soit très friand de pain. Cet aliment lui est plus familier depuis quelques années; ainsi il n'est pas maintenant de festins organisés par les noirs de nos villes, dans lesquels le pain n'ait sa place à côté des victuailles de toutes sortes préparées à la mode indigène.

Biscuits. - Les biscuits de mer sucrés ou non sucrés s'importent en caisses de 25,30 ou 50 kilos. Il y a quelque temps, ces biscuits étaient ronds ou carrés suivant qu'ils étaient sucrés ou non sucrés. Cette dernière forme ne répond plus au goùt de l'acheteur; aussi la plupart des biscuits de mer de toutes sortes sont-ils ronds et pèsent environ 25 grammes. Cet aliment est très gộté de l'indigène qui le détrempe dans de l'eau sucrée. Les Maures, les Toucouleurs et les Noirs du Cayor en font une grande consommation.

De même que les farines, les biscuits sont des articles de préparation française.

$R i z$. - Les riz qui ont pris une part progressive dans l'alimentation locale s'importent en quantités considérables pendant les époques de disette, c'est-à dire lorsque le rendement des cultures vivrières locales ne sulfit pas aux besoins de la popula. tion. Ils arrivent en sacs de 100 et 50 kilos, voire même de 30 , $25,20,18$ et 16 kilos, ces dernières quantités étant plus facilement transportables et plus en rapport avec la faculté d'achat des indigènes. Les riz destinés aux subsistances militaires sont emballés dans des caisses garnies de fer blanc, d'un poids moyen de 25 kilos. Les riz importés contiennent en assez grande pro portion des brisures de riz. Ils sont en grande partie originaires des colonies françaises et transitent par la France. Les riz d'importation et le mil du pays sont les deux principaux éléments de la nourriture du noir qui dans les villes fait usage de l'un et de l'autre dans des proportions à peu près égales; celui de la brousse 
a naturellement une préférence marquée pour le mil qu'il récolte et qu'il n'a pas à acheter. Le riz possède l'avantage d'être rapidement préparé; le mil doit au contraire être réduit en farine par le pilon des ménagères, avant cuisson.

Noix de kola. - La noix de kola constitue un article de luxe très goûlé des noirs, mais qui a peu de succès en pays maure et diola.

Ses propriétés régénératrices étant utilisées dans la préparation de certains toniques, la fabrication de ces derniers a été pendant une certaine époque l'objet d'une industrie qui a presque complètement disparu de la Colonie. Ce fruit est principalement originaire des colonies anglaises de la Côte, bien que le tarif des droils en vigueur soit sensiblement favorable aux provenances des colonies françaises. L'indigène préfère le colas de SierraLéone, qui serait plus amer, moins aqueux et de conservation plus facile.

Sucres de toutes sortes. - Les sucres se répartissent en sucres bruts et surtout vergeoises, en sucres raffinés pilés, en morceaux irréguliers, en pains et sciés. L'emballage des sucres bruts et des vergeoises est le baril qui contient de 200 kilos à 100 kilos. Cet article se consomme un peu partout, dans les villes comme dans les escales, en raison de la modicité de son prix d'achat. Les sucres pilés s'importent également en fùts de 90 kilos et quelquefois en sacs de $\mathbf{4 0}$ à $\mathbf{1 0 0}$ kilos. Les chiffres de leur importation sont peu élevés. L'emballage est encore le même pour les sucres en morceaux irréguliers qui ne sont autre chose que les déchets du cassage ou du sciage en morceaux réguliers. Quant aux sucres sciés, ils se composent de morceaux réguliers réunis

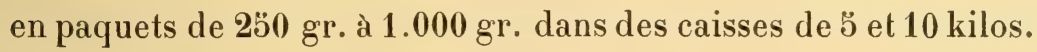
Ils sont aussi rangés dans les caisses sans être empaquetés. Leur consommation s'accroît de plus en plus au détriment de celle des sucres pilés. Les sucres en pains sont en caisses de 40 à 75 kilos ou en barils de 80 kilos environ. Les pains sont plutôt petits; on en vend qui ne pèsent pas plus de $0 \mathrm{k}$. $200 \mathrm{gr}$. Ils constituent la qualité préférée des Maures.

Les sucres viennent presque entièrement de France.

Tabacs en feuilles. - Les tabacs en feuilles qui ont joui d'une 
valeur monétaire à l'époque où le commerce du troc se pratiquait, sont encore considérés comme article d'échange dans les pays éloignés de la Côte. Leur commęrce est prospère dans le fleuve, le Cayor, le Sine-Saloum et en Casamance mais presque nul au Soudan. Des champs de tabac cultivés dans les vallées du Niger et du Bani suffisent aux besoins des populations qui les entretiennent. Les tabacs en feuilles arrivent en $1 / 2$ boucauts de 350 kilos environ et en quarts de boucauts. Les indigènes fument non seulement les tabacs en feuilles, mais ils le transforment en tabac à priser lequel n'est pas un article d'importation. Cette petite industrie est réservée aux personnes à qui l'àge ne permet plus la pratique d'un travail pénible.

Les principaux fournisseurs directs sont : les Etats-Unis et l'Angleterre. Ce produit transite également par la France et l'Allemagne.

Huiles comestibles de toutes sortes. - Les huiles comestibles de toutes sortes se divisent en huiles d'olive, de palme, de coton et d'arachides. Les huiles d'olive sont d'origine française. Elles sont importées en estagnons ou bidons et plus souvent en caisses de 12 litres et sont consommées par la population européenne ou assimilée. Les huiles de palme sont fournies par les colonies françaises et anglaises de la côte et arrivent en fûts de 110 à 200 litres. Quant aux huiles de coton, elles ont conquis une large place sur le marché sénégalais au détriment des huiles d'arachides qui ne s'achètent que fort peu. Elles sont reçues en fûts de 165 kilos environ. Leur origine est étrangère bien qu'elles proviennent parfois du transit de la Métropole.

Bois de construction. - Les bois de construction pin, sapin et pitchpin viennent en majeure partie de la Suède, de la Norvège et de l'Amérique du Nord. lls sont généralement importés par des voiliers et rarement par des vapeurs.

Les bois de chêne et de frêne en plateaux de 5 à 6 mètres de longueur proviennent surtout de France.

Les bois de sapin sont employés dans les charpentes de toutes sortes, dans les planchers et parquets et dans la construction des embarcations. Le pitchpin reçoit les mêmes destinations, à l'exception des charpentes, et sert à la confection des meubles. 
Vins de toutes sortes. - Dans cette classe sont compris les vins ordinaires et supérieurs en futailles, les vins en bouteilles et les vins de liqueurs.

Ils proviennent intégralement de France, sauf quelques hectolitres fournis par l'Espagne et ses colonies.

La contenance des futailles est d'environ 225 litres et celle des demi-fùts de 110 litres.

Le vin ordinaire destiné au Soudan est quelquefois importé en bonbonnes de 20 à 28 litres.

Les vins fins ainsi que les vins de liqueurs arrivent en caisses de 12 bouteilles ou de 21 demi-boutei!les s'il s'agit de champagne.

Les vins de qualité inféricure, dits de traite, ne sont qu'un article de peu d'importance; les essais tentés en vue de le substituer à l'alcool dans les provinces sérères et diolas n’ont abouti, en effet, à aucun résultat sérieux.

Boissons distillées. - Les boissons distillées importées sont : les alcools, les absinthes, cognacs, rhum et similaires, le genièvre, les eaux-de-vie autres et les liqueurs.

L'alcool à dédoubler connu dans le pays sous le nom de sangara est de toutes ces boissons celle dont le commerce est le plus considérable. Il est expédié dans la colonie en fûts de ö0 à 250 litres, le plus souvent de 90 à 110 litres, en dames jeannes de 5 à 25 litres. Sa richesse alcoolique varie généralement de 75 à $90^{\circ}$.

L'alcool est consommé en grandes quantités par les indigènes du Sine-Saloum et de la Casamance où il joue un rôle très actif dans le commerce des arachides. Les importations de France n'ont pas représenté jusqu'ici la part qui doit revenir à notre industrie pour la production de cet article, mais un droit protecteur de 30 francs par hectolitre d'alcool pur qui vient d'être institué réserve une plus large part à nos producteurs s'ils veulent tenter un léger effort.

Jusqu'à présent la préférence n'a pas été donné à l'Etranger en raison seulement de la différence du prix, mais encore à cause de la mauvaise qualité des récipients français.

La futaille défectueuse occasionne en effet pendant la traversée 
d'abord, et le séjour en magasin sous le climat tropical ensuite, un fort coulage qui grève considérablement le prix de revient déjà plus élevé du produit français.

D'après une communication de la Chambre de commerce de Bordeaux qui remonte à $\mathbf{1 8 9 8}$, les distillateurs allemands n'emploieraient pas des futts en bois neuf, mais des futts refaits avec les douelles des fûts d'importation américaine ayant contenu du saindoux.

L’islamisme qui accuse des progrès manifestes dans le pays, notamment dans la région du Niger et en Casamance, réduira sans doute dans un avenir qui ne peut être déterminé les chiffres de l'importation des alcools de traite.

Les absinthes, cognacs, rhums et similaires s'importent en caisses de $\mathbf{1 2}$ bouteilles ou de $\mathbf{2 4}$ demi-bouteilles et quelque peu en barils de 30, 65 et 110 litres.

Leur richesse alcoolique est en moyenne de $72^{\circ}$ pour les absinthes de marques, $40^{\circ}$ pour les absinthes de traite, $50^{\circ}$ pour les rhums et similaires.

Les genièvres sont reçus en dames jeannes qui ne contiennent pas plus de 25 litres et en caisses de 12 bouteilles, 24 demibouteilles et $\mathbf{4 8}$ quarts de bouteilles. Ces bouteilles ont toujours la forme carrée des bouteilles de genièvre hollandaises. Leur degré alcoolique est de 25 à $35^{\circ}$.

Parmi les eaux-de-vie sont classés les alcools de menthe. Leur importation s'accroit daus de notables proportions. Ils titrent $86^{\circ}$ lorsqu'ils sont de bonne qualité ; mais ceux de traite n'ont qu'un degré bien inférieur.

Les alcools de menthe s'expédient en flacons de petites dimensions de $5,10,15$ et 20 centilitres.

Quant aux liqueurs, elles ne s’importent qu'en caisses de 12 litres ou bouteilles. Leur degré d'alcool dépend de la marque et de la qualité. Celles de traite ne sont qu'en très petite quantité. Sauf les alcools et les genièvres la majorité des spiritueux provient de France.

Matériaux de construction. - Les matériaux de construction: briques, tuiles, chaux, ciment etc., ont pris une plus grande place dans le commerce local. 

Les briques et tuiles arrivent naturellement en vrac. Les briques sont pleines ou tubulaires à $4,6,9$ et 12 trous.

Il n'entre que très peu de chaux grasse.

La chaux éteinte est importée comme partout en sacs de 50 kilos.

Les ciments sont en barils de 100 et 200 kilos,

Les carreaux rouges ou la qualité commune sont reçus en vrac. Il n'en est pas de même des carreaux blancs et noirs ou de qualité supérieure mesurant $0,20 \mathrm{~cm}$. qui sont emballés en caisses.

Les matériaux de construction proviennent de Marseille.

Houille. - La houille est destinée principalement à faire face aux besoins de la navigation; Dakar en est le principal port d'importation. Par suite de l'extension de ce port et de l'augmentation du nombre des navires qui s'y approvisionnent, les arrivages de charbon ont pris une importance croissante pendant ces deux dernières années.

Les briquettes de charbon supportent facilement les manipulations des transbordements et embarquements sans s'effriter.

Le transport des charbons qui se faisait il y a quelques années par voiliers est effectué maintenant par de grands vapeurs jaugeant de 1.200 à 2.000 tonnes. Les charbons venant de France sont chargés sur les bateaux des maisons de commerce de la Colonie.

L'Angleterre tient naturellement le premier rang dans l'importation de cet article. Les provenances de la Métropole ne représentent que le $1 / 20$ environ de la totalité.

Fers de toutes sortes. - Cet article comprend les fers en barres, les tôles laminées de fer ou d'acier, les fers d'angles et à $T$, les fils de fer et d'acier.

La barre de fer plat mérite une mention spéciale ne serait-ce que pour rappeler qu'elle servait d'unité de mesure dans l'ancienne traite. De nos jours elle est surtout employée par les indigènes à la confection d'instruments tranchants et de l'outil aratoire appelé hilaire. Les grosses barres sont importées en vrac, celles de petites dimensions sont liées en paquets.

Les fers en barres, destinés à la traite, sont originaires de 
Suède pour la plus grande partie. Les fers sous d'autres formes sont surtout expédiés par la France.

Sels marins. - Les sels marins de toutes sortes sont en partie importés de la France et de la colonie portugaise du Cap Vert.

Les sels bruts sont généralement en sacs de $\mathbf{2 b}$ à $\mathbf{3 0}$ kilos.

Les sels en barres ou en plaques sont mis en caisses de 25 à 30 kilos environ.

Ce produit fait l'objet d'un important trafic dans toutes les régions de l'intérieur.

Parfumeries. - Les 9/10 des parfumeries importées constituent les articles de traite, c'est-à-dire de qualité inférieure et sont préparés avec les essences fortes, telles que musc, patchouly, girofle et lavande. Les indigènes ne consomment pas ou très peu de savons parfumés.

Toutes les races du Sénégal : Ouolof, Maures, Bambaras, Sérères, Diolas etc., recherchent les parfums européens et en font une consommation exagérée, lorsque leurs ressources le leur permettent.

La France fournit les 8/10 de cet article ; le reste se répartit entre l'Angleterre et l'Allemagne qui n'importent que des qualités inférieures.

Savons. - Les savons importés sont en caisses de 40 à 50 kilogs. Le poids de chaque barre est généralement de 2 kilogs.

On vend les savons blancs, jaunes et bleus ou marbrés au talc. Cette dernière sorte est bon marché, mais les deux premières sont préférées en raison de leur qualité.

Les savons se vendent partout, ils constituent un article de traite courant. A défaut du savon importé, les indigènes se servent d'un produit composé par eux en faisant bouillir de la cendre avec un corps gras.

La presque totalité des savons vient de Marseille.

Verroterie (grains). - Les verroteries ou vitrifications arrivent fréquemment en colis postaux, surtout depuis l'admission des colis de 10 kilogs.

Elle comprend de nombreuses espèces : rassade, charlottes, rocailles, sokmates, perles dorées, imitation d'ambre, de cornaline, de corail, etc. 
La forme varie : ronde, oblongue, aplatie, griffe de lion, etc. La même diversité existe dans les dimensions des perles.

Le fournisseur expédie à cet égard ce que lui commande le commerçant qui s'inspire lui-même des goûts de sa clientèle.

Les indigènes font usage des perles comme articles de parures. Les femmes en ornent leur coiffure et en font des bracelets, des colliers et des ceintures.

La Métropole en fournit environ les $3 / \check{3}$.

Fils de coton. - Les fils de coton arrivent le plus souvent en balles de 100 kilos comprenant plusieurs paquets de 0 k. 500 à 5 kilogs. Les paquets se composent d'échevaux de poids variables. On en reçoit de $80,50,40$ et même 15 et 12 grammes.

La presque totalité des importations est employée à la fabrication des pagnes du pays.

Les fils de coton préférés des indigènes sont les écrus, simples ou retors et teints en bleu simple ou retors.

La France tient le premier rang dans l'importation des fils de toutes sortes.

Guinées. - Les guinées sont originaires de l'Inde Française (guinée filature), de la France et de l'Etranger, principalement de Hollande (Guinée Shandora).

Elles sont encore de nos jours l'article d'échange dans le commerce de la gomme en Mauritanie. Certaines races du Sénégal, autres que les Maures, en font également tous les frais de leurs costumes.

Les guinées s'importent en balles contenant généralement 100 ou 25 pièces. La pièce est de 15 ou de 60 mètres; celle de 15 mètres a une valeur monétaire; quant à celle de 60 elle sert à la vente du détail. Pour cette dernière destination, on importe aussi des pièces de longueurs variables. Les guinées destinées au Soudan sont en ballots et représentent un poids moyen de 30 kilogs constituant la charge d'un porteur.

Autres tissus de coton. - Les tissus de coton autres s'importent presque toujours en balles ou ballots et rarement en caisses. Le poids des balles et ballots de même que le nombre des pièces et leur métrage n'a naturellement rien d'uniforme. Tontefois les expéditions au Soudan sont souvent en ballotins de 25 à $30 \mathrm{kgs}$. 
Les tissus écrus sont presque entièrement représentés par l'escamite dont la largeur et le poids varient suivant l'usage que doit en faire l'acheteur indigène. Les voiles de pirogues sont faites en escamite.

Les tissus blanchis comprennent les calicots, les bazins, les percales et shirting.

Les prix de facture des calicots dont la consommation est assez considérable varient entre $0 \mathrm{fr} .15$ et $0 \mathrm{fr}$. 25 le mètre ; ils atteignent toutefois celui de 0 fr. 30 qu'ils excèdent rarement. Ils proviennent en grande partie d'Angleterre.

Les percales sont surtout consommées dans les villes. Leur prix, au lieu de production, commence ou celui du calicot finit, soit à partir de $0 \mathrm{fr}$. 32 jusqu'à $0 \mathrm{fr}$. 00 . 0 n ne vend que très peu de shirting.

L'écoulement des bazins est important; leurs prix naturellement très variables s'étendent de 0 fr. 30 à 1 fr. 70 le mètre. Ils sont tirés d'Angleterre, de France et d'Alsace.

Les tissus imprimés consistent en liménéas et en indiennes. Les premiers ne comportent que deux teintes : bleu et blanc, le bleu dominant; ils sont le plus souvent à rayures. Les prix de facture sont de $0 \mathrm{fr}$. 29, $0 \mathrm{fr} .30$ à $0 \mathrm{fr}$. 70. L'industrie française réussit bien cet article pour les qualités d'une valeur minimum de $0 \mathrm{fr} .40$ le mètre.

Les indiennes viennent en grande partie d'Angleterre. Le prix de facture lo plus bas est de $0 \mathrm{fr}$. 18 le mètre. Lorsqu'il s'agit de qualités d'une valeur de $0 \mathrm{fr}$. 35 le mètre et au-dessus les tissages de la Métropole peuvent consentir des conditions à peu près égales à celles de l'Etranger tout en fournissant d'excellentes étoffes.

Dans les tissus teints en pièces rentrent principalement les roums, les sucretons, les guinées déjà citées et les Tiewaly. Tous ces tissus sont bleus et tous sont unis à l'exception du Tiewaly qui est parfois croisé. La teinte bleue varie avec l'espèce: les roums sont assez clairs, les sucretons sont plus foncés et glacés ; enfin les Tiewaly reçoivent généralement la teinte indigo des guinées.

Les roums s'achètent en Europe de 0 fr. 18, 0 fr. 19 à 0 fr. 38 ; 
les sucretons de 0 fr. 22 à 0 fr. 60 et les Tiewaly de 0 fr. 30 à 0 fr. 60.

On désigne au Sénégal par l'expression "Tissus ménage ", tous les tissus fabriqués avec des fils teints, lesquels sont le plus souvent à rayures ou à carreaux. Leur prix d'achat varie de $0 \mathrm{fr} .33$ à 1 fr. le mètre. La Métropole peut fournir les articles de ce genre surtout lorsque leur valeur atteint $0 \mathrm{fr}$. 50 le mètre. Ils bénéficient à la sortie du remboursement à forfait institué par l'article 10 de la loi du 11 janvier 1892.

L'industrie française ne peut encore produire les tissus de qualités inférieures à des prix aussi bas que les industriels étrangers, mais dès que le prix du mètre atteint $0 \mathrm{fr}$. 40 ou 0 fr. 50 et même 30 et $\mathbf{4 0}$ pour certaines espèces, elle n'a pas de sérieuse concurrence à redouter et peut concourir avec quelques efforts des manufactures et la bonne volonté du commerce local à l'approvisionnement du marché sénégalais dans une proportion beaucoup plus élevée que celle qu'elle a obtenu jusqu'ici.

Il est indispensable que les fournisseurs s'inspirent du goût des indigènes. Un échantillonnage ne peut donner que des indications incomplètes sur les besoins de la population, mais le Sénégal n'est qu'à sept jours de Bordeaux et il est facile à ceux qui s'intéressent à son commerce d'aller le visiter. Ils emporteront après un court séjour tous les renseignements utiles.

Vêtements et confections. - Les vêtements et confections consistent principalement en vêtements et confections de coton et de drap.

L'élévation de la température exige pendant la moitié de l'année l'usage des vêtements légers ; aussi la plupart des confections importées sont-elles de coton et quelque peu seulement de drap. Le prix des vêtements de coton est de $\mathbf{1 6}$ à $\mathbf{2 5}$ francs l'un. Ils comprennent un pantalon et un veston forme coloniale et sont blancs ou de teinte cachou.

La presque totalité de cette marchandise est expédiée par la France.

Machines de toutes sortes. - Les machines de toutes sortes à vapeur et autres qu'à vapeur sont des articles français en grande partie. 
Ils comprennent d'une part les machines motrices de navigation et autres, les chaudières, les locomotives, les locomobiles, les machines hydrauliques, les machines à coudre, les machines pour l'agriculture, les machines-outils, etc.

Ouvrages en fonte et fer. - Les ouvrages en fonte ainsi que les ouvrages en fer sont également fournis en majeure partie par la Métropole. Dans cette catégorie sont classés la ferronnerie grosse et petite, la serrurerie, les chaînes, ancres et grappins, les clouteries et visseries, les ouvrages en tôle ou en fer blanc et articles de ménage, les pots et marmites en fonte.

Armes de toutes sortes. - Les armes de toutes sortes se divisent en armes blanches et en armes à feu.

Les armes blanches consistent en lames de sabre expédiées sans la poignée que les artisans indigènes ajoutent au goût du propriétaire. Elles arrivent par caisses de 50 ou 100 et proviennent en majeure partie de l'Etranger.

Les armes à feuimportées sont les fusils à silex; le port des fusils de chasse perfectionnés, des carabines et revolvers ne sont permis qu’à la population européenne ou assimilée et leur introduction dans la Colonie est soumise à un contrôle sévère.

Les fusils à silex s'importent le plus souvent en caisses de 20 fusils. Ils sont fabriqués en Angleterre, en Belgique et en Allemagne.

Poudres à tirer. - Les poudres à tirer comprennentla poudre de chasse et la poudre de traite.

La poudre de chasse est exclusivement utilisée par la population européenne. Elle est importée en boîtes de 100 grammes et par caisses de 10 à 25 kilos.

La poudre de traite expédiée en barils de 600 à 800 grammes jusqu'à ő et même 10 kilos est utilisée par les indigènes non seulement pour la chasse mais dans certaines cérémonies telles que mariages, enterrements, etc.

La poudre de chasse est fournie presque exclusivement par la France. La poudre de traite provient en majeure partie de la Métropole et de l'Allemagne.

Ouvrages en bois et Bimbeloterie. - Parmi les principaux 
articles d'importation doivent encore figurer les ouvrages en bois et la bimbeloterie.

Les ouvrages en bois comprennent les futailles vides, montées ou démontées, les balais, les pièces de charpente, lames et frises de parquet, la boissellerie, les rames et avirons, etc.

Les 2/3 en sont fournis par la France. Ils sont importés en vrac, en paquets ou en caisses suivant leur nature.

La dénomination de Bimbeloterie s'applique aux jouets et à une foule d'objets désignés communément sous le nom d'articles de Paris.

La France en est le principal fournisseur.

A l'exception des alcools et des tissus, la Métropole approvisionne le Sénégal de toutes les marchandises qu'elle produit en quantité suffisante pour faire l'objet d'un commerce d'exportation et qui ont cours dans les transactions de la Colonie. Les produits similaires des autres pays n'occupent qu'un rang secondaire et souvent effacé et les articles étrangers qui y prévalent sont ceux que l'industrie française ne saurait procurer à notre commerce colonial tels que les tabacs en feuilles, les bois de sapin et de pitchpin.

L'examen des tableaux comparatifs par pays de destination des principaux produits exportés, indique dans quelle proportion la Métropole et les autres puissances achètent les produits d'exportation de la Colonie.

b) Principaux produits d'exportation.

Les principaux produits exportés sont: les peaux brutes de bœufs, les peaux d'oiseaux et les plumes de parures, les dents d'éléphants, les arachides, les amandes de palme, les gommes, le caoutchouc et l'or de Galam.

Peaux brutes de boufs. - Les peaux brutes de bœufs s'exportent en vrac et sont fournies par les boucheries. L'indigène 
n'en fait pas, en effet, un objet de commeree et les peaux des bœufs tués dans l'intérieur du pays sont utilisées par les cordonniers indigènes.

La valeur des peaux de bœufs s'établit d'après leur poids, à raison de $\mathbf{0} \mathrm{fr}$. 40 environ le kilogramme.

La France achète la presque totalité de ce produit.

Peaux d'oiseaux et plumes de parures. - Parmi les peaux d'oiseaux sont classées celles des foliotocoles, oiseaux de riche plumage dont le prix d'achat sur place est de 10 ou 20 francs l'unité, des merles métalliques, évêque, veuves, colibris, geais, etc. Elles sont surtout exportées de la Casamance.

Les plumes de parures comprennent principalement les plumes d'aigrette qui s'achètent sur place à raison de $0 \mathrm{fr}$. 70 et 0 fr. 80 le gramme. On expédie également des plumes d'autruche et d'autres plumes de moindre valeur, telles que celles de marabout, de pélican, etc. Toutefois depuis deux ou trois ans l'exportation des plumes d'autruche a presque complètement cessé par le Sénégal.

Arachides. - Les arachides constituent le principal article d'exportation. On distingue les arachides de Rufisque et du Cayor qui sont traitées à Rufisque et dans les escales de la voie ferrée ; les arachides de Galam qui proviennent du haut fleuve ; les arachides de la Petite-Côte récoltées dans le Sine-Saloum et celles de la Casamance qui comme l'indique leur nom, sont fournies par cette dernière province. Les qualités les plus estimées sont celles de Rufisque et du Cayor et celles de la Petite-Côte. Les arachides se sèment dès les premières pluies qui tombent au début de l'hivernage, c'est-à-dire à partir du 15 juin et se récoltent ordinairement du 15 octobre au $1^{\text {er }}$ décembre. La récolte est à peine terminée que la traite commence pour se terminer vers fin avril. Les principaux centres d'achat sont d'abord les escales de la voie ferrée, de Rufisque à Saint-Louis dont les plus importantes sont: Thiès, Tivaouane et Louga ; puis Foundiougne, Fatick et Kaolack dans les provinces du Sine-Saloum et enfin Carabane ou Ziguinchor et Sedhiou, sur la rivière Casamance. Les arachides de Galam se traitent surtout à Kayes, Bakel et Médine. Le fleuve Sénégal n'étant plus navigable à l'époque de la récolte, 
elles ne sont transportées à Saint-Louis que pendant l'année qui suit la traite. Les principaux ports d'exportation sont par ordre d'importance : Rufisque, Foundiougne, Saint-Louis et Carabane. Les prix d'achat des graines sur place sont naturellement déterminés par les cours d'Europe, lesquels varient suivant la quantité des sésames disponibles sur les marchés. Les stocks considérables de ces graines ont provoqué une dépréciation sensible des arachides pendant ces deux dernières années. Cotées sur place à 18 et 25 francs en 1900 et 1902 ; elles sont tombées à 16 et 15 francs en 1903 et 1904 . Les $2 / 3$ de ce produit sont exportés en France. Le reste se répartit entre la Hollande, l'Allemagne, l'Angleterre et les autres pays.

Amandes de palme. - Les amandes de palme sont tirées exclusivement de la Casamance et utilisées dans les savonneries en Europe.

Elles s'expédient décortiquées et en vrac à destination de : l'Allemagne et de l'Angleterre. L'exportation pour la France est presque nulle.

Gommes. - Les gommes comprennent celles du bas du fleuve, de Galam et du Cayor et sont toutes de bonne qualité.

La gomme se récolte en deux fois. Une première fois en novembre et la seconde de mars à mai durant la saison des vents d'Est dont la sécheresse et le degré de chaleur gercent l'écorce des acacias et provoquent l'écoulement de la gomme.

Le marché des gommes de Galam est Médine. C'est de cette localité desservie par le fleuve Sénégal et le chemin de fer du Soudan que descendent sur Saint Louis et Dakar, principaux ports d'exportation, les produits récoltés dans le Soudan.

Les gommes du fleuve se traitent ordinairement à Podor et Dagana. Quant à celles du Cayor, leur commerce a lieu à Louga.

Le prix sur place des gommes a flèchi considérablement depuis 1901. Il est actuellement pour la meilleure qualité de 0 fr. 50 le kilo ; alors qu'en 1900 il atteignait 1 franc. La caúse de cette dépréciation est due, comme pour les arachides, à la concurrence sur les marchés d'Europe des similaires d'Egypte.

La totalité des gommes est expédiée sur la France sauf quelques tonnes exportées en Angleterre et en Allemagne. 
Caoutchoucs. - Les caoutchoucs exportés du Sénégal sont originaires du Soudan et de la Casamance.

Ceux du Soudan sont de première qualité et bénéficient sur les marchés européen de cours élevés. Le prix du caoutchouc de Casamance dont la préparation laissait à désirer il y a quelques années, va sans cesse en augmentant. Cette hausse est causée par l'application de procédés plus perfectionnés à la coagulation du latex et par les soins apportés en général à la formation des boules.

L'Administration a pris récemment des mesures en vue d'assurer l'exploitation régulière des lianes et l'amélioration des caoutchoucs de l'Afrique occidentale.

La prospérité du commerce de ce produit en a encouragé l'exploitation, et son exportation a suivi une marche progressive pendant ces dernières années. Les envois sur la Métropole ont particulièrement profité de cette extension, laquelle à contribué malgré la concurrence des marchés d'Anvers, de Liverpool et de Hambourg, au développement du marché de caoutchouc. créé à Bordeaux il y a peu de temps. Les caoutchoucs s'expédient en sacs de 30 à 50 kilos ou en ponchons dont le poids peut dépasser 150 kilos

Les $9 / 10$ e des caoutchoucs exportés sont destinés à la France. Les autres pays, l'Angleterre et l'Allemagne, notamment, se partagent la différence.

Or de Galam. - L'or de Galam est tiré des provinces aurifères que possèdent certaines régions du Soudan dont la concession et l'exploitation sont régies par une réglementation spéciale

Une fraction importante de l'or recueilli reste dans le pays où il est employé à la préparation des bijoux indigènes. 


\section{DIAGRAMME}

du mouvement des provenances de France et de l'Etranger et des exportations à destination de France et de l'Etranger de $\mathbf{1 8 9 5}$ à 1904 .

\section{Légende :}

Provenances françaises

Provenances étrangères

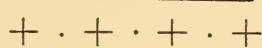

Exportations à destination de l'Etranger - - - . - . -

Exportations à destination de la France -............

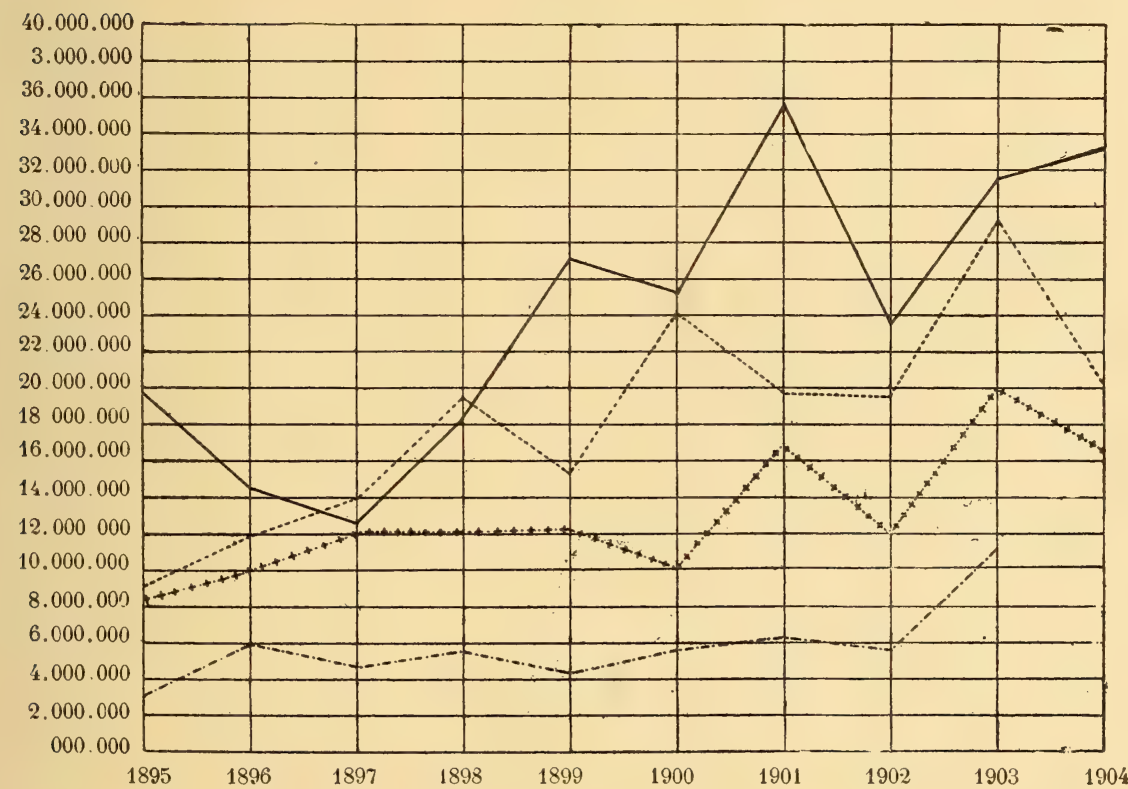





\section{DIAGRAMME}

du mouvement des exportations par pays de destination de 1895 à 1904

\section{Légende :}

France el Colonies

Angleterre et Colonies' $+\cdot+\cdot+\cdot+$

Allemagne
Belgique $\quad-\cdot-\cdots$

Hollande

Autres pays

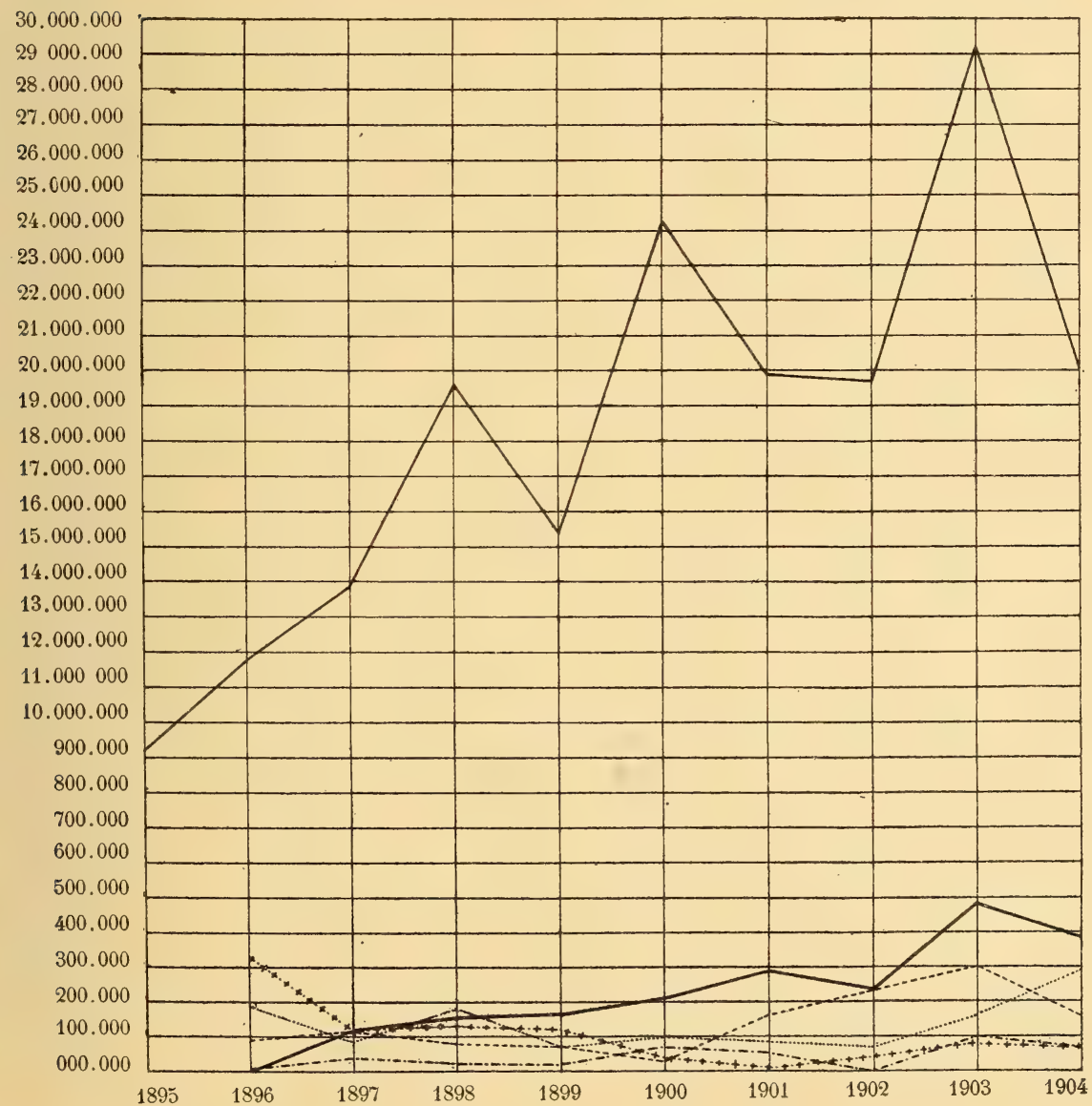





\section{DIAGRAMME}

du mouvement des importations par pays d'origine de 1895 à 1904

\section{Légende :}

\section{France}

Colonies françaises

Angleterre et colonies

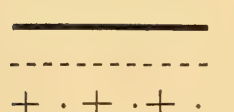

Allemagne

Suède et Norvège

Autres pays

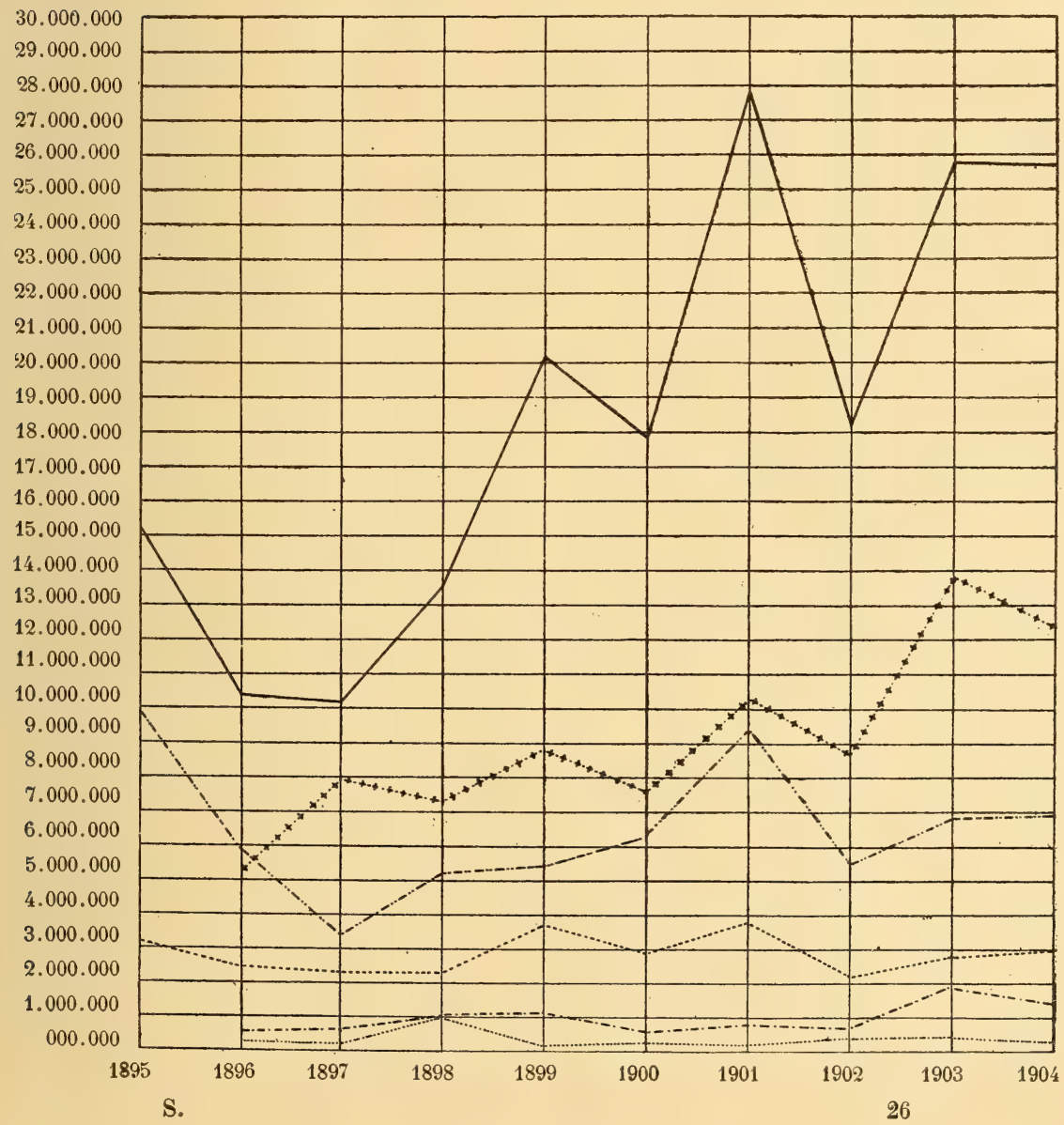





\section{DIAGRAMME}

du mouvement général des importations et des exportations et du mouvement commercial total de 1895 à 1904

\section{Légende :}

\section{Importations}

Exportations

Mouvement commercial total $+\cdot+\cdot++$.

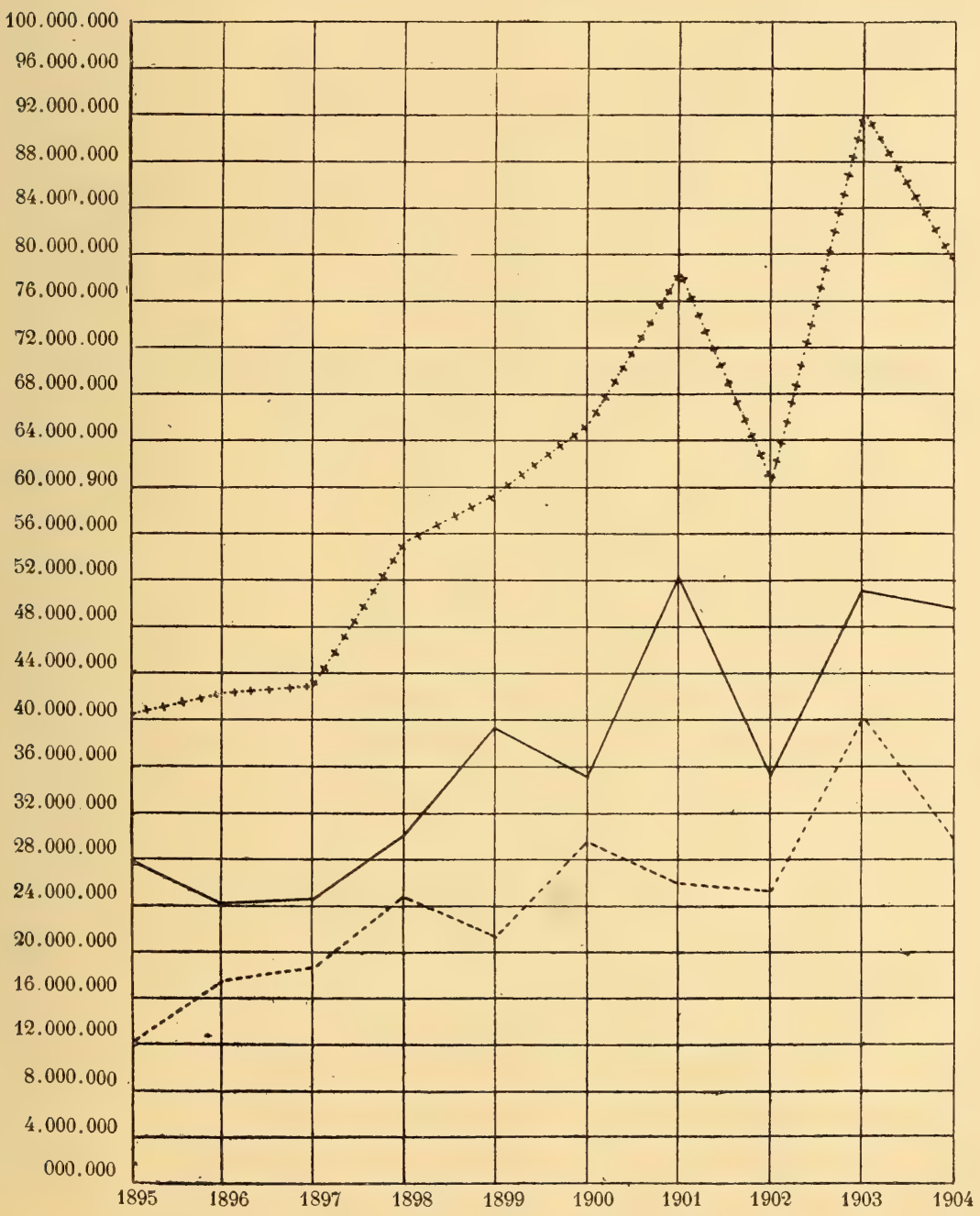





\section{TABLEAU}

des principales marchandises importées au Sénégal de 1895 à 1904. 
Tableau des principales marchandis

\begin{tabular}{|c|c|c|c|c|c|c|c|c|c|}
\hline \multirow{2}{*}{ 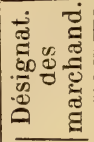 } & \multirow{2}{*}{ 邑 } & \multicolumn{2}{|c|}{ France et colonies } & \multicolumn{2}{|c|}{ Anglet. et colonies } & \multicolumn{2}{|c|}{ Allemagne } & \multicolumn{2}{|c|}{ Etats-Unis } \\
\hline & & Poids & Valeurs & Poids & Valeurs & Poids & Valeurs & Poids & Valeu \\
\hline & 1895 & $\begin{array}{c}\text { kilogr. } \\
95.319\end{array}$ & $\begin{array}{c}\text { francs } \\
187.402\end{array}$ & $\begin{array}{c}\text { kilogr. } \\
1.845\end{array}$ & $\begin{array}{c}\text { francs } \\
3.209\end{array}$ & $\begin{array}{r}\text { kilogr. } \\
293\end{array}$ & $\begin{array}{r}\text { francs } \\
952\end{array}$ & $\begin{array}{l}\text { kilogr. } \\
14.590\end{array}$ & franc \\
\hline 范 & 1896 & 122.234 & 233.755 & 2.094 & 4.149 & 602 & 1.166 & 15.484 & 23.77 \\
\hline 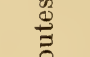 & 1897 & $81.5 \div 1$ & 157.598 & 1.462 & 3.381 & 73 & 202 & 6.007 & 9.19 \\
\hline & 1898 & 107.083 & 226.395 & 1.977 & 3.654 & 629 & 858 & 8.260 & 12.51 \\
\hline تृ & 1899 & 264.653 & 463.960 & 1.285 & 3.200 & 827 & 692 & 9.840 & $15.46:$ \\
\hline$\frac{\pi}{7}$ & 1900 & 104.123 & 173.490 & 1.738 & 3.952 & 38 & 79 & 1.050 & 1.60 \\
\hline 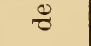 & 1901 & 151.379 & 303.623 & 416 & 693 & 270 & 723 & כั.438 & 8.38 \\
\hline 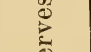 & $19: 2$ & 220.143 & 297.405 & 933 & 2.519 & 870 & 2.374 & 2.876 & 4.66 \\
\hline है & 1903 & 218.058 & 406.754 & 5.069 & 9.416 & 1.200 & 3.438 & 2.119 & 3.33 \\
\hline & 1904 & 140.707 & 321.867 & 2.678 & 5. 849 & 386 & 872 & 2.374 & 3.72 \\
\hline & 1895 & 755.409 & 278.3400 & $"$ & 》) & $"$ & $n$ & 15.000 & 6.10 \\
\hline & 1896 & 840.983 & 285.574 & 72 & 25 & 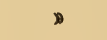 & ” & $"$ & ” \\
\hline & 18.97 & 912.274 & 290.927 & ) & ) & $\eta$ & 》 & 95.408 & 30.53 \\
\hline & 1898 & 1.038 .632 & 363.521 & 1.357 & 475 & ” & $》$ & 17.257 & 6.04 \\
\hline 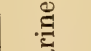 & 1899 & 1.579 .636 & 552.873 & " & ») & $"$ & D & 17.549 & 6.14 \\
\hline 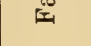 & 1900 & 978.206 & 293.462 & $"$ & 》 & $》$ & ” & 13.340 & 4.00 \\
\hline & 1901 & 1.424 .860 & 427.458 & 1.027 & 308 & $n$ & $"$ & 65.003 & 19.50 \\
\hline & 1902 & 1.642 .834 & 410.708 & " & 》 & 》 & ") & 11.556 & 2.88 \\
\hline & 1903 & 2.664 .573 & 666.142 & $1.06 \dot{z}$ & 266 & 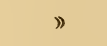 & 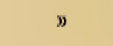 & 17.353 & 4.38 \\
\hline & 1904 & 2.463 .851 & 615.961 & 2.500 & 625 & 》 & $"$ & $n$ & , \\
\hline & 1895 & 435.545 & 231.392 & 150 & 90 & $"$ & $n$ & 1.545 & 59 \\
\hline & 1896 & 717.974 & 359.308 & 719 & 359 & ” & ” & $»$ & ” \\
\hline & 1897 & 346.811 & 173.402 & 1.277 & 638 & $"$ & $"$ & 3.550 & 1.77 \\
\hline & 1898 & 426.034 & 213.017 & 1.620 & 810 & D & ” & 8.422 & 4.21 \\
\hline$\stackrel{\infty}{=}$ & 1899 & 434.579 & 191.161 & 426 & 213 & 3.250 & 1.625 & 4.590 & 2.29 \\
\hline .0 & 1900 & 625.977 & 308.681 & 120 & 131 & " & $》$ & $"$ & $"$ \\
\hline & 1901 & 1.287 .833 & $568.51 \simeq$ & 1.602 & 749 & 1.000 & 862 & 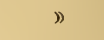 & v \\
\hline & 1902 & 894.179 & 430.799 & 990 & 484 & $n$ & $n$ & 》 & D. \\
\hline & 1903 & 1.495 .463 & 563.256 & 54 & 19 & 》 & ” & s & " \\
\hline & 1904 & 879.440 & 335.548 & 2.383 & 892 & ) & $"$ & 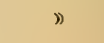 & $n$ \\
\hline
\end{tabular}


ortées au Sénégal de 1895 à 1904.

\begin{tabular}{|c|c|c|c|c|c|c|c|}
\hline \multicolumn{2}{|c|}{ Espagne } & \multicolumn{2}{|c|}{ Autres pays } & \multicolumn{2}{|c|}{ Tolal de l'étranger } & \multicolumn{2}{|c|}{ Total général } \\
\hline jids & Valeurs & Poids & Valeurs & Poids & Valeurs & Poids & Valeurs \\
\hline ogr. & francs & kilogr. & francs & kilogr. & francs & kilogr. & francs \\
\hline$》$ & 》 & 3.542 & 7.492 & 20.270 & 33.168 & 115.589 & 220.570 \\
\hline D & > & 2.732 & 6.114 & 20.912 & 35.203 & 143.146 & 268.958 \\
\hline$»$ & 》 & 3.558 & 5.526 & 11.100 & 18.307 & 92.641 & 175.905 \\
\hline ) & D & 1.607 & 3.528 & 12.473 & 20.559 & 119.556 & 246.954 \\
\hline " & $n$ & $3 . \$ 97$ & 6.348 & 15.449 & 25.702 & 280.102 & 489.662 \\
\hline$n$ & » & 2.281 & 4.966 & 5.107 & 10.597 & 109.230 & 184.037 \\
\hline D & 》 & 1.857 & 3.390 & 7.981 & 13.188 & 159.360 & 316.811 \\
\hline D & D & 3.241 & 8.247 & 8.020 & 17.807 & 228.163 & 315.212 \\
\hline ” & $”$ & 2.826 & 4.767 & 11.214 & 20.958 & 229.272 & 427.712 \\
\hline " & " & 4.175 & 6.210 & 9.613 & 16.656 & 150.320 & 348.523 \\
\hline 力 & 》 & 25.405 & 10.549 & 40.405 & 16.652 & 795.814 & 294.997 \\
\hline 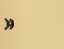 & D & 44.746 & 16.957 & 44.818 & 16.982 & 885.801 & 302.506 \\
\hline 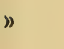 & ” & 8.053 & 2.577 & 103.461 & 33.108 & 1.015 .735 & 324.035 \\
\hline 》 & ” & 21.618 & 7.566 & 40.232 & 14.081 & 1.078 .864 & 377.602 \\
\hline & D & 2.760 & 966 & 20,309 & 7.108 & 1.599 .945 & 559.981 \\
\hline ) & D & 22.170 & 6.651 & 35.510 & 10.653 & 1.013 .716 & 304.115 \\
\hline 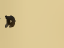 & 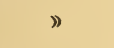 & 5.750 & 1.725 & 71.780 & 21.534 & 1.496 .640 & 448.992 \\
\hline$»$ & ○ & 7.768 & 1.942 & 10.324 & 4.831 & 1.662 .158 & 415.539 \\
\hline$)$ & $》$ & 2.200 & 6.550 & 20.617 & 5.154 & 2.685 .190 & 671.296 \\
\hline 300 & 2.575 & 1.480 & 369 & 14.280 & 3.569 & 2.478 .131 & 619.530 \\
\hline 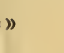 & $"$ & 2.551 & 1.582 & 4.246 & 2.264 & 438.791 & 253.656 \\
\hline 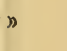 & $》$ & 4.680 & 2.279 & 5.399 & 2.638 & 723.373 & 361.946 \\
\hline ) & ” & 175 & 87 & 5.002 & 2.560 & 351.813 & 175.902 \\
\hline 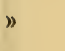 & ) & 5.322 & 2.666 & 15.374 & 7.687 & 441.408 & 220.704 \\
\hline 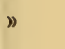 & " & 1.000 & 500 & 9.266 & 4.633 & 443.845 & 195.794 \\
\hline ) & 》 & 10.585 & 8.689 & 10.705 & 8.820 & 636.682 & 317.501 \\
\hline D & ” & 3.199 & 1.458 & 5.801 & 3.069 & 1.293 .634 & 571.581 \\
\hline 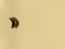 & ” & 5.040 & 3.329 & 6.030 & 3.813 & $90 C .209$ & 434.612 \\
\hline ) & 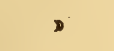 & 108 & 38 & 162 & 57 & 1.495 .625 & 563.313 \\
\hline 》 & , & 39 & 14 & 2.422 & 906 & 881.862 & 336.454 \\
\hline
\end{tabular}


Tableau des principales marchandis

\begin{tabular}{|c|c|c|c|c|c|c|c|c|c|}
\hline \multirow{2}{*}{ 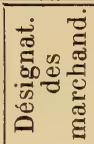 } & \multirow{2}{*}{ 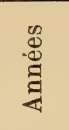 } & \multicolumn{2}{|c|}{ France et colonies } & \multicolumn{2}{|c|}{ Anglet. et colonies } & \multicolumn{2}{|c|}{ Allemagne } & \multicolumn{2}{|c|}{ Etats-Unis } \\
\hline & & Poids & Valeurs & Poids & Valeurs & Poids & Valeurs & Poids & Vale \\
\hline \multirow{11}{*}{$\stackrel{N}{*}$} & & kilogr. & francs & kilogr. & francs & kilogr. & francs & kilogr. & fran \\
\hline & 1895 & 6.452 .125 & $|1.459 .502|$ & 120.250 & 25.628 & 90.245 & & & $x$ \\
\hline & 1896 & 7.197 .676 & 1.510 .492 & 131.103 & 27.545 & 104.025 & 21.740 & $》$ & \\
\hline & 1897 & 7.172 .517 & 1.411 .705 & 52.965 & 11.123 & 15.284 & 3.208 & " & \\
\hline & 1898 & 12.668 .092 & 2.661 .157 & 263.975 & 55.424 & 2.921 .981 & 613.912 & $»$ & \\
\hline & 1899 & 7.662 .882 & 1.610 .207 & 22.477 & 4.716 & 59.443 & 12.483 & $»$ & \\
\hline & 1900 & 8.660 .628 & 1.821 .018 & 135.718 & 28.537 & 432.125 & 90.746 & $»$ & \\
\hline & 1901 & 29.077 .806 & 6.144 .248 & 6.881 & 1.439 & 162 & 34 & ๑ & \\
\hline & 1902 & 7.861 .196 & 1.650 .851 & 1.776 & 373 & 68.000 & 14.280 & ” & \\
\hline & 1903 & 12.269059 & 2.658 .524 & 85.688 & $18.8 \dot{4} 1$ & 1.220 .131 & 273.825 & D & \\
\hline & 1904 & 10.634 .948 & 2.236 .586 & 13.058 & 2.742 & 313.856 & 65.910 & 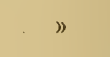 & \\
\hline \multirow{10}{*}{$\begin{array}{l}\frac{\pi}{0} \\
\vdots 1 \\
0 \\
0 \\
\frac{\pi}{0} \\
z\end{array}$} & 1895 & 6.827 & 19.549 & 224.582 & 886.910 & 》 & ” & " & \\
\hline & 1896 & 2.732 & 13.65 & 281.569 & 1.574 .349 & $»$ & 》 & 》 & \\
\hline & 1897 & 13.358 & 66.791 & 290732 & 1.513 .666 & 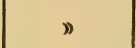 & 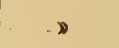 & 》 & \\
\hline & 1898 & 1.236 & 6.180 & 231.489 & 1.517 .445 & , & 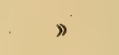 & " & \\
\hline & 1899 & $8.53 t$ & 68.273 & 168.488 & 1.347 .904 & $»$ & $n$ & , & \\
\hline & 1900 & 4.295 & 17.180 & 190.342 & 1.522 .736 & $"$ & D & 》 & \\
\hline & 1901 & 5.348 & 21.392 & 437.363 & 3.498 .902 & $》$ & ” & 》 & \\
\hline & 1902 & 4.534 & 18.136 & 422.163 & 3.377 .304 & " & " & 》 & \\
\hline & 1903 & 6.830 & 27.320 & 304.802 & $\$ .038 .416$ & $n$ & $n$ & $n$ & \\
\hline & 1904 & 8.536 & 31.144 & 481.361 & 3.850 .891 & $》$ & , & , & » \\
\hline \multirow{10}{*}{ 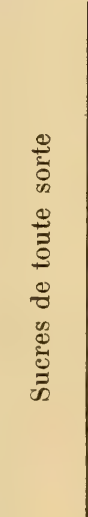 } & 1895 & 1.676 .575 & 845.445 & 》 & " & ” & 》 & , & \\
\hline & 1896 & 879.389 & 778.376 & $"$ & $"$ & $"$ & $"$ & , & \\
\hline & 1897 & 2.091 .330 & 911.080 & $n$ & " & $"$ & ” & ถ & , \\
\hline & 1898 & 1.840 .858 & 807.444 & $n$ & $n$ & 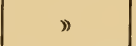 & " & " & \\
\hline & 1899 & 2.664 .315 & 1.172405 & 2.251 & 1.238 & 1.091 & 600 & $”$ & " \\
\hline & 1900 & 2.661 .348 & 1.124 .250 & 10 & 4 & , & $"$ & $"$ & ” \\
\hline & 1901 & 4.326 .560 & 1.847 .471 & 40 & 20 & 500 & 250 & 1.000 & 35 \\
\hline & 1902 & 2.740 .610 & 1.155 .186 & 150 & 75 & $"$ & " & $"$ & $n$ \\
\hline & 1903 & 4.991 .83 t & 1.879 .246 & 86 & 122 & 1.500 & 450 & " & 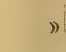 \\
\hline & 1904 & 3.852 .410 & 1.545 .921 & 14 & 6 & $"$ & $"$ & $»$ & $"$ \\
\hline
\end{tabular}


portées au Sénégal de 1895 à 1904 (Suite).

\begin{tabular}{|c|c|c|c|c|c|c|c|}
\hline \multicolumn{2}{|c|}{ uède et Norvège } & \multicolumn{2}{|c|}{ Autres pays } & \multicolumn{2}{|c|}{ Total de l'étranger } & \multicolumn{2}{|c|}{ Total général } \\
\hline oids & Valeurs & Poids & Valeurs & Poids & Valeurs & Poids & Valeurs \\
\hline D & - & $\begin{array}{l}\text { kilogr. } \\
392.899\end{array}$ & $\begin{array}{l}\text { franes } \\
71.242\end{array}$ & $\begin{array}{l}\text { kilogr. } \\
513.394\end{array}$ & $\begin{array}{l}\text { francs } \\
116.327\end{array}$ & $\begin{array}{c}\text { kilogr. } \\
6.965 .519\end{array}$ & $\begin{array}{c}\text { francs } \\
1.575 .829\end{array}$ \\
\hline 》 & ” & 402.984 & 80.948 & 638.112 & 130.233 & 7.835 .788 & 1.640 .725 \\
\hline 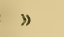 & $》$ & 11.758 & 3.368 & 80.007 & 17.699 & 7.252 .524 & 1.429 .404 \\
\hline » & $”$ & 627.203 & 131.719 & 3.813 .159 & 801.055 & 16.481.20ั1 & 3.462 .212 \\
\hline 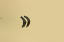 & 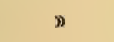 & 1.077 & 226 & 82.997 & 17.425 & 7.745 .879 & 1.627 .632 \\
\hline$»$ & $》$ & 197.732 & 41.766 & 765.575 & 161.049 & 9.426 .203 & 1.982 .067 \\
\hline ) & $》$ & 119.754 & 25.148 & 126.797 & 26.621 & 29.204 .603 & 6.170 .869 \\
\hline ) & 》 & 12.562 & 5.227 & 82.338 & 19.880 & 7.943 .534 & 1.670 .731 \\
\hline 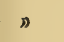 & 》 & 353.841 & 81.407 & 1.659 .660 & 374.073 & 13.928 .719 & 3.032 .597 \\
\hline$》$ & D & 39.537 & 8.303 & 366.451 & 76.955 & 11.001 .399 & 2.413 .541 \\
\hline$\eta$ & 》 & ) & $"$ & 224.582 & 886.910 & 231.469 & 906.459 \\
\hline$\pi$ & $》$ & ) & ” & 281569 & 1.374 .349 & 284.301 & 1.388 .004 \\
\hline 》 & 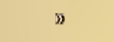 & $n$ & ) & 290.732 & 1.513 .666 & 304.090 & 1.580 .457 \\
\hline ) & ” & ) & ) & 231.489 & 1.517 .445 & 232.775 & 1.163 .625 \\
\hline , & ) & ) & ” & 168488 & 1.347 .904 & 177.022 & 1.416 .177 \\
\hline ” & ” & 550 & 4.440 & 190.892 & 1.527 .136 & 195.187 & 1.544 .316 \\
\hline ” & ) & 200 & 1.600 & 437.563 & 3.5200 .502 & 442.911 & 3.521 .894 \\
\hline ” & ) & 182 & 1.456 & 422.345 & 3.378 .760 & 426.879 & 3.396.896 \\
\hline ) & $》$ & $》$ & 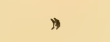 & 504.802 & 4.038 .416 & 511.632 & 4.065 .736 \\
\hline D & $》$ & 8 & 64 & 481.369 & 3850.955 & 489.905 & 3.885 .099 \\
\hline 》 & $》$ & 24.304 & 14.387 & 24.304 & 14.387 & 1.700 .879 & 859.332 \\
\hline D & $n$ & 13.487 & 6.067 & 13.487 & 6.037 & 892.876 & 784.443 \\
\hline ) & . & 23.672 & 9.773 & 23.672 & 9.773 & 2.115 .002 & 920.853 \\
\hline$》$ & $》$ & 7.945 & 3.420 & 7.945 & 3.420 & 1.848 .803 & 810.864 \\
\hline$》$ & 刃 & n & 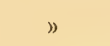 & 3.342 & 1.838 & 2.667 .657 & 1.174 .243 \\
\hline 》 & $》$ & 8.715 & 3.065 & 8.725 & 3.069 & 2.670 .073 & 1.127 .319 \\
\hline i) & ) & 10.190 & 3.693 & 11.730 & 4.313 & 4.338 .290 & 1.851 .784 \\
\hline 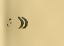 & ” & 1.086 & 543 & 1.236 & 618 & 2.741846 & 1.155 .804 \\
\hline$\bowtie$ & $》$ & 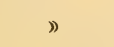 & 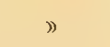 & 1.586 & 572 & 4.993 .420 & 1.879 .818 \\
\hline ) & 》 & 33 & 15 & 47 & 21 & 3.852 .457 & 1.545 .942 \\
\hline
\end{tabular}


Tableau des principales marchandis

\begin{tabular}{|c|c|c|c|c|c|c|c|c|c|}
\hline \multirow{2}{*}{ 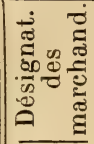 } & \multirow{2}{*}{ 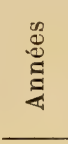 } & \multicolumn{2}{|c|}{ France et colonies } & \multicolumn{2}{|c|}{ Angl-t. et colonies } & \multicolumn{2}{|c|}{ Allemagne } & \multicolumn{2}{|c|}{ Etats-Unis } \\
\hline & & $\begin{array}{l}\text { Poids } \\
\text { et autres } \\
\text { quantités }\end{array}$ & Valeurs & \begin{tabular}{|l|} 
Poids \\
et autres \\
quantités
\end{tabular} & Valeurs & $\begin{array}{l}\text { Poids } \\
\text { et autres } \\
\text { quantités }\end{array}$ & Valeurs & $\begin{array}{l}\text { Poids } \\
\text { et autres } \\
\text { quantités }\end{array}$ & Vale \\
\hline & & kilogr. & francs & kilogr. & francs & kilogr. & franes & kilogr. & fran \\
\hline & 1895 & " & " & 38.150 & 64.805 & D & 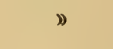 & 906.127 & 1.540 \\
\hline क & 1896 & 》 & ) & 3.395 & 6.281 & 》 & 》 & 678.098 & 1.194 \\
\hline$\overline{8}$ & 1897 & $n$ & D & » & 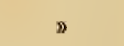 & » & $D$ & 703.915 & 1.229 \\
\hline ฮี & 1898 & 4 & 7 & 237.166 & 438.757 & $"$ & ” & 669.851 & 1.239 \\
\hline \& & 1899 & ) & ” & 128.212 & 237.192 & 145.458 & 269.097 & 659.622 & 1.230 \\
\hline $\bar{\Xi}$ & 1900 & ) & v & 11.330 & 20.394 & 19.983 & 35.969 & 401.115 & 722 \\
\hline वี & 1901 & ” & & 7.891 & 14.204 & 1.161 & 2.090 & 1.201 .117 & 2.216 \\
\hline : & 1902 & 13 & 22 & 8.066 & 13.712 & 5.788 & 9.840 & 763.257 & 1.297 \\
\hline$E$ & 1903 & ” & 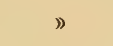 & 327.828 & 557.308 & 79.553 & 135.239 & 998.347 & 1.697 \\
\hline & $190 t$ & 682 & 1.159 & 104.867 & 178.273 & $"$ & " & 297.278 & 505 \\
\hline & 1895 & 542.045 & 459.002 & 78.206 & 51.935 & 25.952 & 25.785 & 18.545 & 15 \\
\hline : & 1896 & 728.282 & 684.693 & 84.415 & 57.840 & 25.634 & 25.634 & 20.025 & 18 \\
\hline a & 1897 & 289.693 & 224.509 & 183.032 & 109.559 & 14.791 & 14.791 & 229.607 & 155 \\
\hline อ & 1898 & 143.692 & 135.723 & 841.904 & 477.269 & 14.934 & 7.467 & 510.321 & 171. \\
\hline ت & 1899 & 124.177 & 146.075 & 349.454 & 218.580 & , & , & 52.673 & 31 \\
\hline$\frac{0}{0}$ & 1900 & 65.600 & 107.965 & 149.080 & 99.750 & 350 & 280 & 481.619 & 313 \\
\hline$\stackrel{8}{8}$ & 1901 & 212.437 & 202.653 & 325.143 & 231.537 & 22.216 & 15.551 & 1.257 .413 & 880 \\
\hline 0 & 1902 & 132.443 & 217.411 & 1.006 .013 & 714.426 & 285 & 228 & 120.509 & 84 \\
\hline$\stackrel{0}{\Xi}$ & 1903 & 331.084 & 409.938 & 984.190 & 707.801 & 64.681 & 48.302 & 44.930 & 32 \\
\hline$I$ & 1904 & 497.879 & 451.938 & 716.022 & 506.579 & 82.729 & 57.980 & 890 & \\
\hline & 1895 & $\begin{array}{l}\text { stères } \\
1.093\end{array}$ & 126.420 & $\begin{array}{c}\text { stères } \\
7\end{array}$ & 1.210 & $\begin{array}{c}\text { stères } \\
\Downarrow\end{array}$ & D & $\begin{array}{r}\text { stères } \\
383\end{array}$ & 46 \\
\hline & 1896 & 1. & 11 & 2 & วั & $n$ & ” & 603 & 55 \\
\hline & 1897 & 1.481 & 121.435 & 19 & 1.484 & 5 & 425 & 725 & 56 \\
\hline تٍِّ & 1898 & 1.524 & 137.497 & 14 & 1.210 & $"$ & D & 323 & 26 \\
\hline हैं & 1899 & 2.260 & 181.602 & $"$ & ") & " & $"$ & 98 & 8 \\
\hline 0 & 1900 & 2.360 & 218.132 & $"$ & " & " & , & 490 & 48 \\
\hline$=$ & 1901 & 3.118 & 226.476 & 2 & 172 & 2 & 198 & 72 & 6 \\
\hline$\approx$ & 1902 & 1.383 & 104.117 & 42 & 2.620 & 28 & 2.639 & 1.134 & 64 \\
\hline & 1903 & 2.424 & 281.150 & " & 》 & 69 & 4.290 & 2.016 & 133 \\
\hline & $190 k$ & 1.603 & 101.047 & 69 & 4.855 & 568 & 35.853 & 2.792 & 196 \\
\hline
\end{tabular}


jortées au Sénégal de 1895 à 1904 (Suite).

\begin{tabular}{|c|c|c|c|c|c|c|c|}
\hline \multicolumn{2}{|c|}{ onies portugaises } & \multicolumn{2}{|c|}{ Autres pays } & \multicolumn{2}{|c|}{ Total de l'étranger } & \multicolumn{2}{|c|}{ Total gènéral } \\
\hline $\begin{array}{l}\text { oids } \\
\text { autres } \\
\text { untités }\end{array}$ & Valeurs & $\begin{array}{l}\text { Poids } \\
\text { et autres } \\
\text { quantités }\end{array}$ & Valeurs & $\begin{array}{l}\text { Poids } \\
\text { et autres } \\
\text { quantités }\end{array}$ & Valeurs & $\begin{array}{c}\text { Poids } \\
\text { et autres } \\
\text { quantitès }\end{array}$ & Valeurs \\
\hline $\log r$. & francs & kilogr. & franes & kilogr. & franes & kilogr. & francs \\
\hline ” & ) & 1.783 & 3.031 & 946.060 & 1.608 .261 & 946.060 & 1.608 .261 \\
\hline x & $"$ & 》 & 》 & 681.493 & 1. 200.659 & 681.493 & 1.200 .659 \\
\hline$n$ & 》 & $”$ & ） & 703.915 & 1.299 .869 & 703.91 วั & 1.299 .669 \\
\hline " & 》 & $\eta$ & 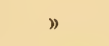 & 1.104 .937 & 2.044 .215 & 1.104 .941 & 2.044 .222 \\
\hline 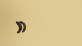 & ) & 98.153 & 181.584 & 1.031 .445 & 1.908 .174 & 1.031 .445 & 1.908 .174 \\
\hline ” & ” & 120.756 & 217.360 & 533.184 & 995.730 & 553.184 & 995.730 \\
\hline " & ) & 160.869 & 276.965 & 1.394 .038 & 2.509 .270 & 1.394 .038 & 2.509 .270 \\
\hline ” & ${ }^{\prime}$ & 30.329 & 51.560 & 807.440 & 1.372 .648 & 807.453 & 1.372 .670 \\
\hline$n$ & ” & 251.896 & 428.223 & 1.657 .624 & 2.817 .958 & 1.657 .624 & 2.817 .958 \\
\hline$)$ & 》 & 66.143 & 112.443 & 468.288 & 796.087 & 468.970 & 797.246 \\
\hline .095 & 5.062 & 41.05 วั & 26.008 & 170.853 & 124.762 & 712.898 & 583.764 \\
\hline .101 & 6.101 & 40.180 & 25.659 & 176.285 & 131.071 & 904.567 & 815.764 \\
\hline .283 & 4.395 & 42.044 & 42.046 & 478.757 & 326.777 & 768.450 & 551.286 \\
\hline .514 & 36.514 & 119.518 & 71.620 & 1.353 .191 & 764.566 & 1.666 .883 & 900.289 \\
\hline .560 & 9.560 & 20.931 & 123.300 & 610.618 & 383.044 & 740.795 & 529.119 \\
\hline .330 & 4.330 & 244.810 & 162.336 & 880.189 & 579.749 & 945.789 & 687.714 \\
\hline 493 & 345 & 380.776 & 267.567 & 1.986 .041 & 1.395 .189 & 2.198 .478 & 1.597 .842 \\
\hline .356 & 2.356 & 343.555 & 244.237 & 1.472 .718 & 1.045 .604 & 1.605 .161 & 1.263 .015 \\
\hline .893 & 17.949 & 160.928 & 117.459 & 1.278 .682 & 924.371 & 1.609 .706 & 1.334.309 \\
\hline .518 & 2.148 & 221.145 & 155.538 & 1.022 .304 & 922868 & 1.520 .183 & 1.174 .806 \\
\hline$\overline{\text { iède et }}$ & Norvège & stères & & stères & & stères & \\
\hline " & 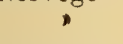 & 2.432 & 237.268 & 2.822 & 284.983 & 3.914 & 411.403 \\
\hline 371 & 288.160 & ” & ” & 4.001 & 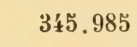 & 5. 344 & 464.824 \\
\hline .994 & 175.490 & 30 & 2.970 & 2.773 & 236.753 & 4.254 & 358.188 \\
\hline .829 & 316.104 & 19 & 3.140 & 4.185 & 347.320 & 5.709 & 474.817 \\
\hline .313 & 190.827 & 91 & 7.312 & 2.502 & 206.842 & 4.762 & 388.444 \\
\hline .512 & உ26.102 & 364 & 34.006 & 3.666 & 308.997 & 5.726 & 527.109 \\
\hline .371 & 191.877 & 1.459 & 126.263 & 3.906 & 32 อั. 964 & 7.024 & 551.740 \\
\hline .545 & 362.957 & 994 & 54.733 & 7.703 & 485.177 & 9.086 & 589.294 \\
\hline .368 & 390.826 & 1.783 & 117.931 & 10.278 & 648.905 & 12.702 & 930.055 \\
\hline .297 & 259.198 & 3.106 & 195.193 & 10.832 & 691.971 & 12.435 & 793.018 \\
\hline
\end{tabular}


Tableau des principales marchandi

\begin{tabular}{|c|c|c|c|c|c|c|c|c|c|}
\hline \multirow{2}{*}{ 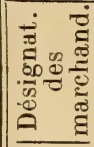 } & \multirow{2}{*}{. } & \multicolumn{2}{|c|}{ France et colonies } & \multicolumn{2}{|c|}{ Anglet, et colonies } & \multicolumn{2}{|c|}{ Allemagne } & \multicolumn{2}{|c|}{ Etats-Unis } \\
\hline & & $\begin{array}{l}\text { Poids } \\
\text { et autres } \\
\text { quantités } \\
\end{array}$ & Valeurs & $\begin{array}{l}\text { Poids } \\
\text { et autres } \\
\text { quantités }\end{array}$ & Valeurs & $\begin{array}{l}\text { Poids } \\
\text { et autres } \\
\text { quantités }\end{array}$ & Valeurs & $\begin{array}{l}\text { Poids } \\
\text { et autres } \\
\text { quantités }\end{array}$ & Vale \\
\hline \multirow{11}{*}{ 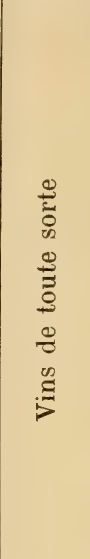 } & & litres & francs & litres & francs & litres & francs & litres & fra \\
\hline & 1895 & 1.266 .385 & 801.117 & $》$ & 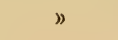 & ) & 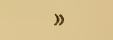 & 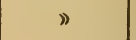 & \\
\hline & 1896 & 1.594 .326 & 839.272 & ” & 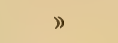 & ) & 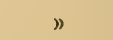 & 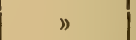 & \\
\hline & 1897 & 1.223 .927 & 748.599 & 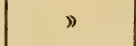 & ఐ & 》 & $n$ & D & \\
\hline & 1898 & 1.403 .060 & 133.903 & $»$ & 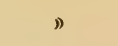 & 》 & D & ) & \\
\hline & 1899 & 2.329 .736 & 1.486 .616 & $"$ & $》$ & $"$ & $"$ & " & \\
\hline & 1900 & 1.414 .319 & 973.183 & ” & " & 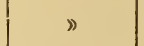 & n & $"$ & \\
\hline & 1901 & 1.224 .960 & 915.711 & $”$ & $”$ & ” & $"$ & ) & \\
\hline & 1902 & 1.812 .305 & 1.059 .160 & ” & 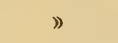 & ” & 》 & $n$ & \\
\hline & 1903 & 2.419 .880 & 1.551 .415 & $》$ & $\eta$ & $"$ & 》 & 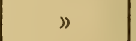 & \\
\hline & 1904 & 1.675 .150 & 1.082 .998 & 124 & 472 & 25 & 88 & $"$ & \\
\hline \multirow{10}{*}{ 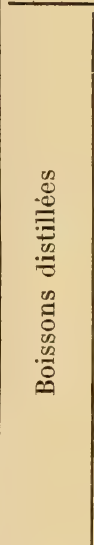 } & 1895 & 52496 & 66.379 & 5.201 & 3.113 & 15,919 & 8.515 & \multicolumn{2}{|c|}{ Hollande } \\
\hline & 1896 & 231.207 & 159.900 & 10.669 & 1.878 & 607.667 & 284.791 & " & \\
\hline & 1897 & 222.558 & 240.075 & 4.825 & 3.255 & 811.622 & 291.454 & 22.277 & 11.1 \\
\hline & 1898 & 526.921 & 340.080 & 2.953 & 1.505 & 246.243 & 118.866 & $n$ & \\
\hline & 1899 & 448.082 & 531.868 & 2.178 & 1.105 & $1.224 .026 \mid$ & 560.047 & $n$ & \\
\hline & 1900 & 202.705 & 376.922 & 118.214 & 59.107 & 385.247 & 193.370 & ” & \\
\hline & 1901 & 337.012 & 505.597 & 3.492 & 2.338 & 729.663 & 369.775 & v & \\
\hline & 1902 & 171.011 & 353.407 & 191 & 392 & 726.822 & 372.803 & $"$ & \\
\hline & 1903 & 237.561 & 498.638 & $D$ & $»$ & 1.115 .436 & 544.393 & D & \\
\hline & 1904 & 271.118 & 625.289 & 1.306 & 1.638 & 888.147 & 431.427 & $"$ & \\
\hline \multirow{10}{*}{ 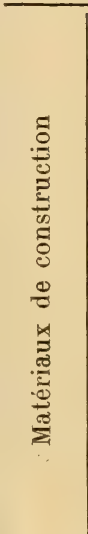 } & 1895 & $\begin{array}{l}\text { kilogr. } \\
6.897 .791\end{array}$ & 484.262 & $\underset{\#}{\text { kilogr. }}$ & - & $\underset{\text { kilogr. }}{\text { k }}$ & 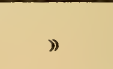 & $\underset{\text { kilogr }}{\text { kilo }}$ & \\
\hline & 1896 & 4.589 .128 & 261.522 & $"$ & ఎ & 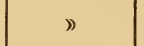 & $n$ & $"$ & \\
\hline & 1897 & 3.436 .156 & 283.587 & § & $"$ & $》$ & $》$ & $n$ & \\
\hline & 1898 & 6.776 .909 & 280.935 & $》$ & $》$ & $»$ & $》$ & $"$ & \\
\hline & 1899 & 5.950 .500 & 471.576 & 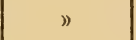 & 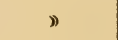 & $》$ & $"$ & $"$ & \\
\hline & 1900 & 4.650 .302 & 228.170 & ” & ø & $》$ & $"$ & 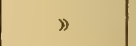 & \\
\hline & 1901 & 7.354 .000 & 615.487 & $n$ & $》$ & $\triangleright$ & $n$ & 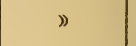 & \\
\hline & 1902 & 4.595 .551 & 722.247 & $"$ & D & $»$ & * & 》 & \\
\hline & 1903 & 15.395 .549 & 2.250 .412 & $"$ & ه & $》$ & $》$ & $"$ & \\
\hline & 1904 & 44.481 .851 & 2.383 .510 & 10.000 & 800 & 5.630 & 436 & D & \\
\hline
\end{tabular}


ortées au Sénégal de 1895 à 1904 (Suite).

\begin{tabular}{|c|c|c|c|c|c|c|c|}
\hline \multicolumn{2}{|c|}{ Espagne } & \multicolumn{2}{|c|}{ Autres pays } & \multicolumn{2}{|c|}{ Total de l'étranger } & \multicolumn{2}{|c|}{ Total général } \\
\hline $\begin{array}{l}\text { ids } \\
\text { utres } \\
\text { atités }\end{array}$ & Valeurs & $\begin{array}{l}\text { Poids } \\
\text { et autres } \\
\text { quantités }\end{array}$ & Valeurs & $\begin{array}{l}\text { Poids } \\
\text { et autres } \\
\text { quantités }\end{array}$ & Valeurs & $\begin{array}{l}\text { Poids } \\
\text { et autres } \\
\text { quantités }\end{array}$ & Valeurs \\
\hline res & franes & litres & franes & litres & francs & litres & francs \\
\hline ) & 》) & 6.683 & 7.700 & 6.683 & 7.700 & 1.273 .068 & 808.817 \\
\hline ) & 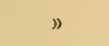 & 33.468 & 32.572 & 53.468 & 32.572 & 1.647 .794 & 871.844 \\
\hline$)$ & $》$ & 4.836 & 5.491 & 4.836 & 5.491 & 1.228 .763 & 754.090 \\
\hline$D$ & 》 & 76.779 & 48.008 & 76.779 & 48.008 & 1.479 .839 & 981.911 \\
\hline 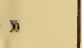 & $»$ & $9 \dot{4} .143$ & 53.274 & 94.143 & 53.274 & 2.423 .879 & 1.539 .890 \\
\hline 》 & 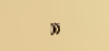 & 59.693 & 35.158 & 59.693 & 35.158 & 1.474 .012 & 1.008 .341 \\
\hline 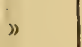 & $》$ & 225.300 & 129.252 & 225.300 & 129.252 & 1.450 .260 & 1.044 .963 \\
\hline 638 & 29.672 & 237.807 & 108.260 & 302.445 & 137.952 & 2.114 .750 & 1.197 .112 \\
\hline 213 & 59.813 & 41.150 & 21.817 & 167.363 & 81.630 & 2.587 .243 & 1.633 .045 \\
\hline 519 & 46.750 & 195.848 & 92.366 & 291.516 & 139.676 & 1.966 .666 & 1.222 .674 \\
\hline Ita & & & & & & & \\
\hline ) & * & 128 & 102 & 21.120 & 11.628 & $73.616^{\circ}$ & 78.007 \\
\hline 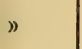 & 》 & 26.776 & 26.889 & 645.712 & 312.958 & 876.919 & 472.858 \\
\hline 184 & 8.200 & 393 & 778 & 862.896 & 319.372 & 1.085 .454 & 529.447 \\
\hline ) & " & 42.539 & 21.948 & 292.128 & 142.513 & 819.049 & 482.993 \\
\hline 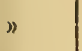 & 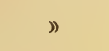 & 87.915 & 43.995 & 1.314 .119 & 605.147 & 1.762 .201 & 1.137 .015 \\
\hline$"$ & $n$ & 8.991 & 4.837 & 512.452 & 257.314 & 715.157 & 634.236 \\
\hline$\gg$ & $\triangleright$ & 145.691 & 75.082 & 878.846 & 447.195 & 1.215 .858 & 952.792 \\
\hline ) & D & 26.016 & 13.926 & 753.029 & 387.121 & 924.040 & 740.528 \\
\hline 》 & 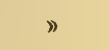 & 55.815 & 29.829 & 1.171 .251 & 574.222 & 1.408 .812 & 1.072 .860 \\
\hline 》 & 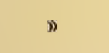 & 105.366 & 55.696 & 994.819 & 488.761 & 1.265 .937 & 1.040 .050 \\
\hline gr. & D & $\begin{array}{l}\text { kilogr. } \\
7.060\end{array}$ & 815 & kilogr. & 815 & $\begin{array}{c}\text { kilogr. } \\
6.904 .851\end{array}$ & 485.077 \\
\hline 》 & 》 & 1.889 .595 & 65.131 & 1.889 .595 & 6ว. 131 & 6.478 .723 & 326.653 \\
\hline$》$ & D & 24.275 & 1.216 & 24.275 & 1.216 & 3.460 .431 & 286.803 \\
\hline » & 》 & 5.220 & 448 & 5.220 & 448 & 6.782 .129 & 281.383 \\
\hline$》$ & 》) & * & ) & 》 & 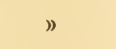 & 5.950 .500 & 471.576 \\
\hline n & D & 40.000 & 2.165 & 40.000 & 2.165 & 4.690 .302 & 330.335 \\
\hline$»$ & ” & ” & ” & 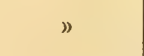 & ) & $7.35 \% \div .000$ & 615.487 \\
\hline » & 》 & 5.050 & 491 & 5.050 & 491 & 4.600 .501 & 722.738 \\
\hline 》) & $》$ & 24.550 & 1.267 & 24.550 & 1.267 & 15.420 .098 & 2.251 .679 \\
\hline 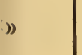 & " & 18.530 & 1.100 & 34.160 & 1.100 & 44.516 .011 & $2,385.846$ \\
\hline
\end{tabular}


Tableau des principales marchandi

\begin{tabular}{|c|c|c|c|c|c|c|c|c|c|}
\hline \multirow{2}{*}{ 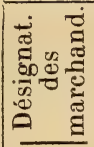 } & \multirow{2}{*}{ 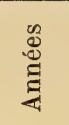 } & \multicolumn{2}{|c|}{ France et colonies } & \multicolumn{2}{|c|}{ Anglet. et colonius } & \multicolumn{2}{|c|}{ Allemagne } & \multicolumn{2}{|c|}{ Hollande } \\
\hline & & Poids & Valeurs & Poids & Valeurs & Poids & Valeurs & Poids & Vale \\
\hline \multirow{11}{*}{ 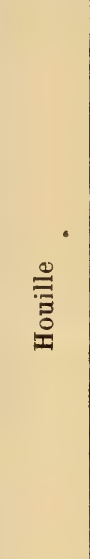 } & & kilogr. & francs & kilogr. & francs & kilogr. & francs & kilogr. & Tlat \\
\hline & 1895 & 195.452 & 7.684 & 11.451 .405 & 536.111 & 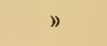 & $”$ & $》$ & \\
\hline & 1896 & 201.765 & 8.868 & 13.060 .842 & 536.016 & 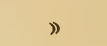 & $»$ & $»$ & \\
\hline & 1897 & 158.324 & 7.416 & 15.613 .900 & 625.371 & ” & 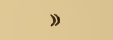 & D & \\
\hline & 1898 & 5.214 .324 & 234.434 & 36.427 .405 & 1.460 .430 & " & 》 & $"$ & \\
\hline & 1899 & 2.931 .813 & 115.880 & 38.052 .461 & 1.199 .497 & 》 & ) & 》 & \\
\hline & 1900 & 2.788 .509 & 69.466 & 31.460 .260 & 692.131 & ” & 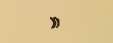 & ” & \\
\hline & 1901 & 4.254 .114 & 148.879 & 30.929 .523 & 942.951 & $n$ & 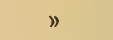 & 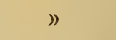 & \\
\hline & 1902 & 2.578 .171 & 86.584 & 16.531 .143 & 500.744 & 40.000 & 1.200 & 》 & \\
\hline & 1903 & 4.447 .495 & 155.252 & 33.183 .324 & 1.006 .650 & ” & $"$ & $"$ & \\
\hline & 1904 & 3.992 .310 & 138.631 & 72.356 .014 & 2.203 .824 & 50.000 & 1.750 & 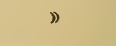 & \\
\hline \multirow{10}{*}{ 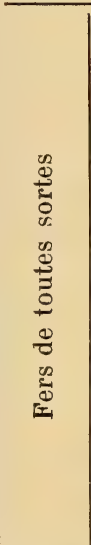 } & 1895 & $\begin{array}{l}\text { kilogr } \\
114.047\end{array}$ & 36.619 & $\begin{array}{l}\text { kilogr. } \\
9.484\end{array}$ & 2.371 & $\underset{\text { kilogr. }}{\text { y }}$ & 》 & kilogr. & \\
\hline & 1896 & 113.916 & 35.723 & 45.324 & 11.338 & » & . & 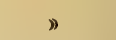 & \\
\hline & 1897 & 117.212 & 18.384 & 54.598 & 13.649 & $n$ & D & $"$ & \\
\hline & 1898 & 115.643 & 37.321 & 39.039 & 15.830 & 25.480 & 6.370 & D & \\
\hline & 1899 & 210.557 & 82.812 & 28.102 & 8.567 & 28.480 & 7.120 & $n$ & \\
\hline & 1900 & 335.870 & 160.277 & 56.090 & 19.089 & 11.000 & 3.430 & ” & \\
\hline & 1901 & 309.413 & 97.465 & 3.760 & 1.415 & 28.279 & 7.237 & 31.103 & 10 \\
\hline & 1902 & 51.414 & 18.714 & 120.513 & 33.795 & 20.801 & 5.435 & 232.460 & 5 \\
\hline & 1903 & 649.828 & 217.928 & 92.352 & 30.905 & 7. 397 & 1.849 & 3.780 & 1. \\
\hline & 1904 & 988.711 & 300.383 & 156.308 & 63.747 & 86.612 & 20.054 & $"$ & \\
\hline \multirow{10}{*}{ 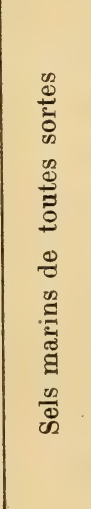 } & 1895 & 290.535 & 8.371 & 53.051 & 2.681 & 2.880 & 948 & " & \\
\hline & 1896 & 1.378 .660 & 34.793 & 32.564 & 2.087 & 9.075 & 273 & $"$ & \\
\hline & 1897 & 602.727 & 17.887 & 255.223 & 12.652 & " & $"$ & $"$ & \\
\hline & 1898 & 493.892 & 20.938 & 49.165 & 1.997 & 27.500 & 1.238 & $n$ & \\
\hline & 1899 & 1.209 .149 & 47.206 & 3.380 & 208 & 24.370 & 625 & $"$ & \\
\hline & 1900 & 1.195 .484 & 44.887 & 133.700 & 4.045 & 》 & $"$ & $"$ & \\
\hline & 1901 & 2.290 .506 & 79.262 & 36.910 & 2.824 & 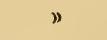 & 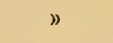 & $"$ & \\
\hline & 1902 & 1.159 .576 & 43.414 & 13.726 & 888 & 310.200 & 9.306 & " & \\
\hline & 1903 & 2.127 .115 & 65.771 & 103.394 & 4.167 & 141.130 & 4.234 & $"$ & \\
\hline & 1904 & 3.358 .226 & 102.005 & 3.763 & 775 & 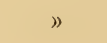 & D & $》$ & \\
\hline
\end{tabular}


rtées au Sénégal de 1895 à 1904 (Suite).

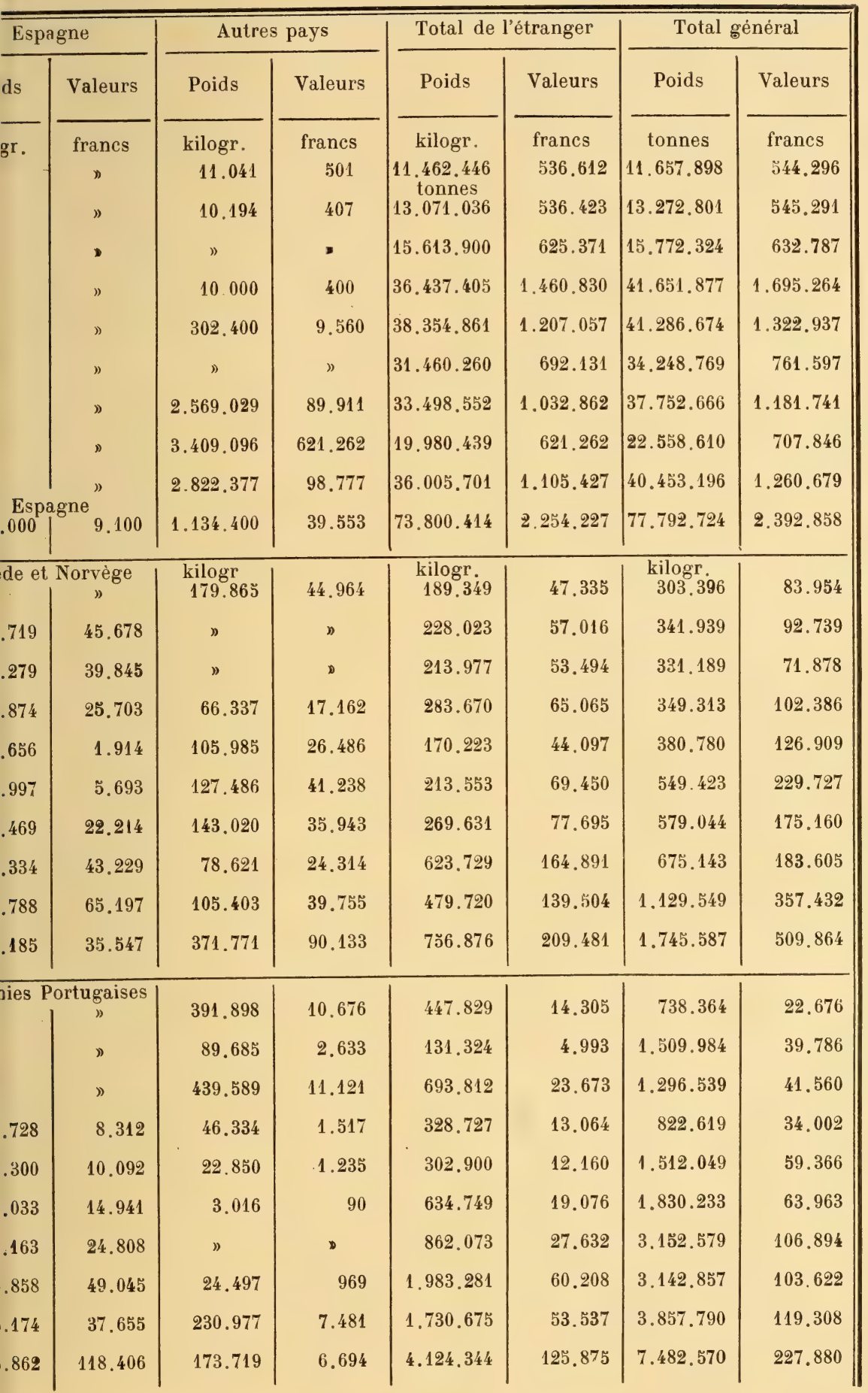


Tableau des principales marchand

\begin{tabular}{|c|c|c|c|c|c|c|c|c|c|}
\hline \multirow{2}{*}{ 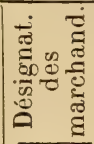 } & \multirow{2}{*}{ 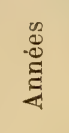 } & \multicolumn{2}{|c|}{ France et colonies } & \multicolumn{2}{|c|}{ Anglet. et colonies } & \multicolumn{2}{|c|}{ Allemagne } & \multicolumn{2}{|c|}{ Etats-Uni: } \\
\hline & & Poids & Valeurs & Poids & Valeurs & Poids & Valeurs & Poids & $\mathrm{V}$ \\
\hline & 4895 & kilogr. & franes & kilogr. & francs & kilogr. & francs & kilogr. & \\
\hline & 1896 & 33.385 & 105.054 & 1.989 & 7.914 & 100 & 269 & 609 & \\
\hline 范 & 1897 & 70.045 & 82.635 & 673 & 4.562 & 787 & 1.937 & $n$ & \\
\hline$\stackrel{\infty}{=}$ & 1898 & 20.871 & 86.389 & 1.325 & 2.314 & 8.494 & 12.830 & $»$ & \\
\hline 9 & 1899 & 43.646 & 134.968 & 684 & 1.196 & 459 & 747 & $»$ & \\
\hline in & 1900 & 67.139 & 150.172 & 1.737 & 6.916 & ” & 》 & 刃 & \\
\hline 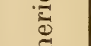 & 1901 & 45.774 & 213.103 & 367 & 994 & 708 & 1.678 & $»$ & \\
\hline 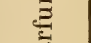 & 1902 & 65.757 & 168.481 & 788 & 1.094 & 1.062 & 1.480 & $»$ & \\
\hline$\approx$ & 1903 & 88.487 & 239.113 & 932 & 3.012 & 2.930 & 4.931 & $»$ & \\
\hline & 1904 & 57.785 & 215.633 & 709 & 1.552 & 927 & 1.741 & , & \\
\hline & 1895 & 541.985 & 213.702 & $》$ & ” & 2.123 & 899 & $»$ & \\
\hline & 1896 & 649.779 & 259.996 & $»$ & 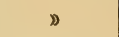 & 4.705 & 1.882 & $n$ & \\
\hline & 1897 & 509.464 & 203.644 & 8.322 & 3.329 & $n$ & $"$ & $"$ & \\
\hline & 1898 & 603.013 & 241.205 & 2.688 & 1.075 & 1.985 & 794 & D & \\
\hline$\stackrel{\text { s }}{0}$ & 1899 & 653.180 & 261.272 & 2.780 & 1.112 & ” & $"$ & $》$ & \\
\hline 离 & 1900 & ô28.581 & 251.432 & 199 & 80 & $n$ & $"$ & N & \\
\hline & 1901 & 995.183 & 398.073 & 350 & 140 & $"$ & ” & $"$ & \\
\hline & 1902 & 725.985 & 317.544 & 90 & 36 & 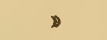 & 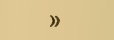 & $D$ & \\
\hline & 1903 & 1.256 .574 & 565.457 & 4.099 & 1.845 & 》 & " & 》 & \\
\hline & $190 \dot{x}$ & 831.839 & 374.327 & 5. 964 & 2.684 & 90 & 40 & 》 & \\
\hline & 1895 & 26.154 & 38.722 & 11.604 & 17.035 & 14.786 & 20.072 & " & \\
\hline & 1896 & 47.275 & 60.537 & 1.542 & 2.198 & 50.207 & 75.487 & $n$ & \\
\hline & 1897 & 18.096 & 40.418 & 670 & 1.885 & 12.315 & 18.579 & $»$ & \\
\hline శ్ & 1898 & 25.676 & 55.126 & 566 & 5.875 & 23.127 & 69.400 & D & \\
\hline & 1899 & 76.309 & 107.924 & 4.219 & 9.309 & 42.082 & 62.269 & 》 & \\
\hline 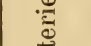 & 1900 & 21.314 & 85.429 & 6.147 & 16.852 & $20.49 i$ & 54.890 & $n$ & \\
\hline$\approx$ & 1901 & 70.544 & 233.921 & 1.156 & 1.963 & 84.454 & 180.935 & $n$ & \\
\hline & 1902 & 26.282 & 45.956 & 2.848 & 4.022 & 61.929 & 92.514 & 》 & \\
\hline & 1903 & 46.523 & 187.130 & 4.699 & 11.601 & 25.999 & 56.416 & » & \\
\hline & 1904 & 27.457 & 150.148 & 1.993 & 7.869 & 13.741 & 58.374 & ” & \\
\hline
\end{tabular}


rtées au Sénégal de 1895 à 1904 (Suite).

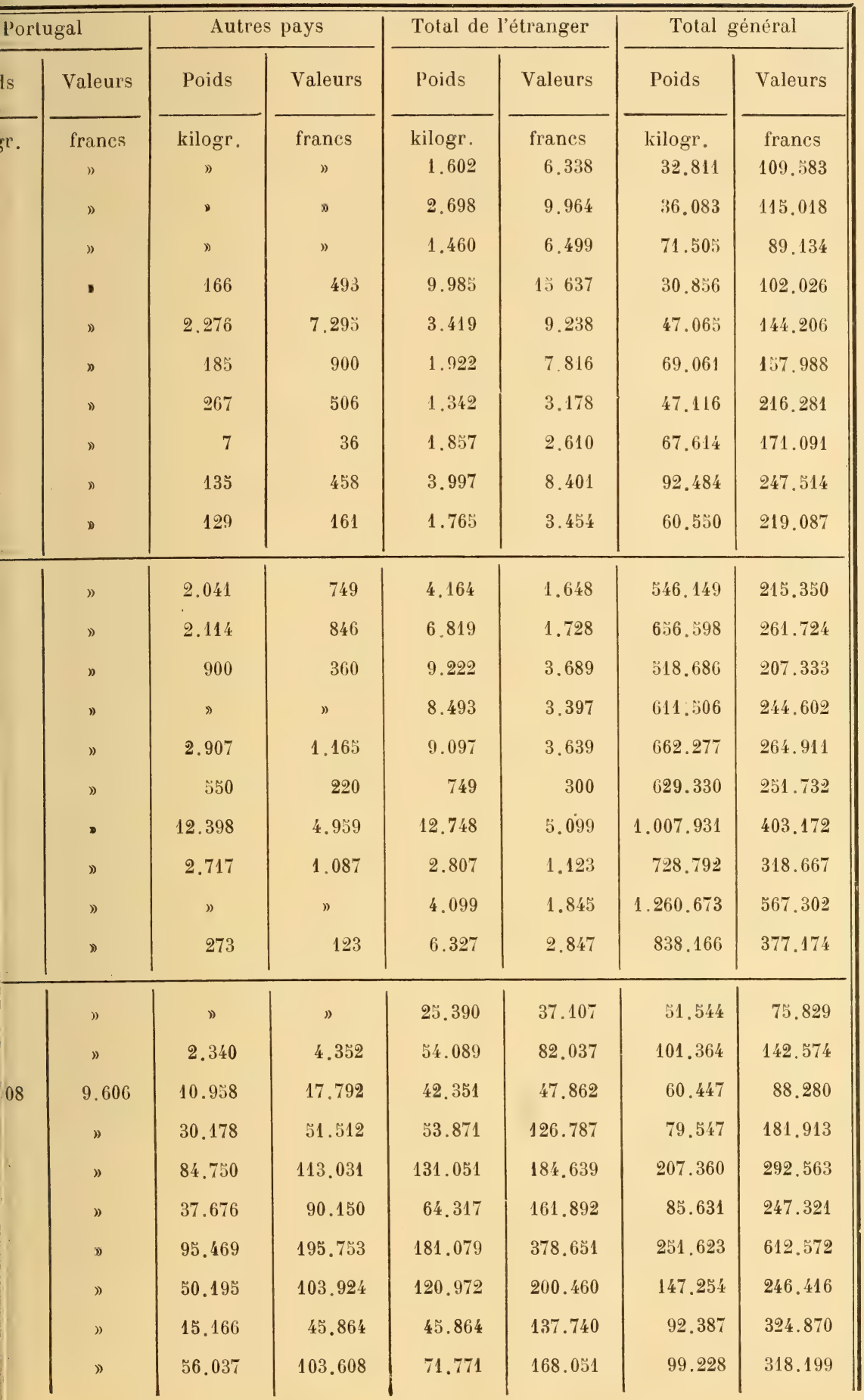

$\mathrm{S}$, 
Tableau des principales marchanc

\begin{tabular}{|c|c|c|c|c|c|c|c|c|c|}
\hline \multirow{2}{*}{ 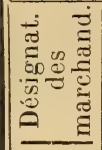 } & \multirow[b]{2}{*}{ 导 } & \multicolumn{2}{|c|}{ France et colonies } & \multicolumn{2}{|c|}{ Anglet et colonies } & \multicolumn{2}{|c|}{ Allemagne } & \multicolumn{2}{|c|}{ Belgiqu } \\
\hline & & $\begin{array}{l}\text { Poids } \\
\text { et autres } \\
\text { quantités }\end{array}$ & Valeurs & $\begin{array}{l}\text { Poids } \\
\text { et autres } \\
\text { quantités }\end{array}$ & Valeurs & $\begin{array}{l}\text { Poids } \\
\text { et autres } \\
\text { quantités }\end{array}$ & Valeurs & $\begin{array}{l}\text { Poids } \\
\text { et autres } \\
\text { quantités }\end{array}$ & Va \\
\hline \multirow{10}{*}{ 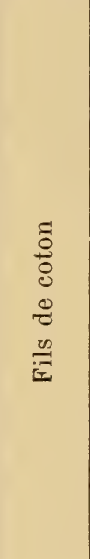 } & $180 \%$ & kilogr. & francs & kilogr. & francs & francs & franes & kilogr. & f \\
\hline & 1896 & 3 & 3 & 22.628 & 883 & ) & $\eta$ & 31.726 & \\
\hline & 18 & 34.270 & 190.895 & 3.649 & 14.047 & 1.050 & 5.000 & 28.202 & \\
\hline & 1998 & 48.524 & 147.706 & 34.010 & 86.935 & 1.208 & 5.990 & ” & \\
\hline & 1899 & 66.798 & 192.328 & 40.342 & 110.999 & 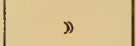 & " & n & \\
\hline & 1900 & 76.885 & 193.302 & 24.456 & $64.64 \dot{4}$ & 21 & 105 & $"$ & \\
\hline & 1901 & 145.417 & 450.822 & 35.514 & 100.636 & s & 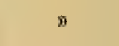 & ) & \\
\hline & 1902 & 72.188 & 242.793 & 58.421 & 170.621 & 250 & 563 & D & \\
\hline & 1903 & 64.173 & 208.268 & 59.311 & 186.972 & 967 & 4.725 & " & \\
\hline & 1904 & 95.066 & 311.504 & 39.223 & 142.675 & 1.963 & 8.717 & $"$ & \\
\hline \multirow{10}{*}{ 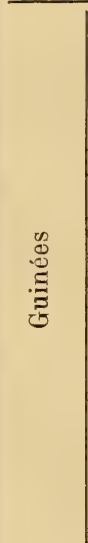 } & 1895 & $\begin{array}{l}\text { pièces } \\
472.060\end{array}$ & 3.304 .381 & $\begin{array}{c}\text { pièces } \\
10.769\end{array}$ & 66.187 & $\begin{array}{c}\text { pièces } \\
\text { " }\end{array}$ & " & $\begin{array}{c}\text { pièces } \\
190.023\end{array}$ & \\
\hline & 1896 & 711.307 & 3.238 .185 & 45.290 & 195.063 & ) & $"$ & 305.327 & 1.5 \\
\hline & 1897 & 510.914 & 3.210 .552 & 33.592 & 210.409 & 2.860 & 20.860 & 86.002 & 5 \\
\hline & 1898 & 489.602 & 2.996 .573 & 7.443 & 55.822 & , & 》 & 84.789 & 6 \\
\hline & 1899 & 814.715 & 4.562 .125 & 11.664 & 87.483 & ” & $n$ & 44.140 & 3 \\
\hline & 1900 & 697.797 & 3.932 .413 & 16.853 & 45.398 & 12.750 & 95.625 & 15.799 & 1 \\
\hline & 1901 & 1.206 .591 & 6.924 .766 & 13.388 & 100.409 & " & D & 9.357 & \\
\hline & 1902 & 436.858 & 2.427 .599 & 7.777 & 58.328 & 》) & ” & 5.769 & \\
\hline & 1903 & 566.044 & 3.340 .684 & 22.139 & 159.997 & " & " & 23.845 & 1 \\
\hline & 1904 & 494.024 & 3.092 .090 & 9.616 & 67.312 & 3.801 & 26.607 & ” & \\
\hline \multirow{10}{*}{ 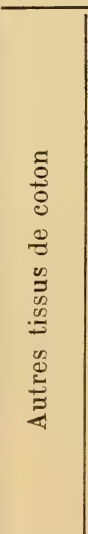 } & 1895 & $\begin{array}{l}\text { kilogr. } \\
131.003\end{array}$ & 503.569 & $\begin{array}{l}\text { kilogr. } \\
\text { ऽ45.107 }\end{array}$ & 2.919 .945 & $\begin{array}{c}\text { kilogr. } \\
6.087\end{array}$ & 8.597 & \multicolumn{2}{|c|}{ Etats-Uni } \\
\hline & 1896 & 128.670 & 640.072 & 643.969 & 2 & 2.108 & 65 & 刃 & \\
\hline & 1897 & 617.640 & 1.133 .091 & 1.679 .709 & 5.951 .668 & 9.524 & 42.549 & 600 & \\
\hline & 1898 & 460ั.527 & 504.009 & 2.886 .484 & 3.022 .225 & 16.184 & 33.766 & 43.933 & \\
\hline & 1899 & 251.533 & 790.654 & 1.762 .115 & 5.145 .091 & 13. 541 & 56.187 & 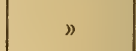 & \\
\hline & 1900 & 229.695 & 617.879 & 2.099 .600 & 4.649 .576 & 2.793 & 13.010 & $n$ & \\
\hline & 1901 & 242.447 & 1.049 .133 & 1.495 .521 & 4.912 .641 & 30.727 & 115.337 & D & \\
\hline & 1902 & 370.322 & 1.028 .231 & 948.584 & 3.241 .658 & 19.149 & 81.517 & $"$ & \\
\hline & 1903 & 383.172 & 1.527 .755 & 1.975 .461 & 5.941 .245 & 72.330 & 273.623 & $"$ & \\
\hline & 1904 & 448.597 & 2.042 .083 & $2.846 .01 \%$ & 4.743 .654 & 35.090 & 172.735 & 290 & \\
\hline
\end{tabular}


ortées au Sénégal de 1895 à 1904 (Suite).

\begin{tabular}{|c|c|c|c|c|c|c|c|}
\hline \multicolumn{2}{|c|}{ Portugal } & \multicolumn{2}{|c|}{ Autres pays } & \multicolumn{2}{|c|}{ Total de l'étranger } & \multicolumn{2}{|c|}{ Total général } \\
\hline $\begin{array}{l}\text { ids } \\
\text { utres } \\
\text { ntités }\end{array}$ & Valeurs & $\begin{array}{c}\text { Poids } \\
\text { et autres } \\
\text { quantités }\end{array}$ & Valeurs & $\begin{array}{l}\text { Poids } \\
\text { et autres } \\
\text { quantités }\end{array}$ & Valeurs & $\begin{array}{c}\text { Poids } \\
\text { et autres } \\
\text { quantités }\end{array}$ & Valeurs \\
\hline & $"$ & $\begin{array}{l}\text { kilogr. } \\
\text { 5. } 059\end{array}$ & $\begin{array}{l}\text { francs } \\
13.504\end{array}$ & $\begin{array}{l}\text { kilogr. } \\
29.738\end{array}$ & $\begin{array}{l}\text { francs } \\
\quad 82.878\end{array}$ & $\begin{array}{l}\text { francs } \\
59.083\end{array}$ & $\begin{array}{l}\text { francs } \\
178.387\end{array}$ \\
\hline & $n$ & 5.042 & 13.324 & 59.396 & 147.035 & 89.522 & $24 \dot{4} .008$ \\
\hline & " & 4.435 & 18110 & 37.536 & 113.077 & 71.806 & 213.972 \\
\hline & v & 67.018 & 211.722 & 102.236 & 304.647 & 150.760 & $4 ว 2.353$ \\
\hline & $n$ & 49.351 & 135.633 & 89.693 & 246.632 & 156.491 & 438.960 \\
\hline & $"$ & 209.271 & 500.344 & 233.748 & 565.029 & 310.633 & 758.331 \\
\hline & 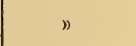 & 56.801 & 153.029 & 92.315 & 253.665 & 237.732 & 704.487 \\
\hline & ) & 13.180 & 26.505 & 71.851 & 197.689 & 144.039 & 440.482 \\
\hline & $»$ & 24.454 & 84.255 & 84.730 & 275.952 & 148.903 & 484.440 \\
\hline & ) & 31.233 & 90.590 & 72.419 & 241.982 & 167.485 & 553.486 \\
\hline ces & 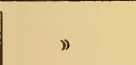 & $\begin{array}{l}\text { pièces } \\
21.500\end{array}$ & 164.000 & $\begin{array}{l}\text { pièces } \\
221.292\end{array}$ & 1.750 .371 & $\begin{array}{l}\text { pièces } \\
693.352\end{array}$ & 5.054 .752 \\
\hline 325 & 1.450 & 28.798 & 136.427 & 379.750 & 1.885 .240 & 1.091 .057 & 5.123 .425 \\
\hline 431 & 744.839 & 1.765 & 10.214 & 221.650 & 1.562 .255 & 732.664 & 4.772 .807 \\
\hline 528 & 738.960 & 61.080 & $4: 8.100$ & 251.840 & 1.888 .799 & 741.742 & 4.885 .372 \\
\hline 393 & 1.318 .751 & 11.437 & 83.527 & 25 รั. 334 & 1.798 .741 & 1.070 .049 & 6.360 .866 \\
\hline 342 & 1.157.394 & 2.600 & 19.500 & 202.535 & 1.428 .747 & 900.332 & 6.360 .860 \\
\hline 629 & 669.403 & 20.861 & 156.459 & 139.235 & 992.771 & 1.345 .826 & 7.917 .537 \\
\hline 366 & 716.562 & 4.355 & 32.662 & 120.267 & 847.935 & 557.12. & 3.275 .531 \\
\hline 514 & 1.067 .598 & 8.239 & 57.673 & 206.737 & 1.452 .183 & 772.781 & 4.792 .867 \\
\hline & $》$ & $\begin{array}{c}189.599 \\
\text { y compris }\end{array}$ & $\begin{array}{l}\text { 1.327.194 } \\
\text { Belgique }\end{array}$ & 203.016 & 1.421 .113 & 697.040 & 4.513 .203 \\
\hline 400 & 777 & kilogr & 1.350 & $\begin{array}{l}\text { kilogr } \\
552.624\end{array}$ & ๘.930.669 & $\begin{array}{l}\text { kilogr } \\
683.627\end{array}$ & 3.439 .538 \\
\hline & $"$ & 113.128 & 1.202 .988 & 759.205 & 3.804 .921 & 887.875 & 4.444 .993 \\
\hline & $》$ & 1.109 & 3.544 & 1.690 .942 & 6.000 .657 & 4.308 .582 & 7.133 .748 \\
\hline 320 & 1.606 & 1.037 .919 & 841.400 & 3.984 .840 & 3.909 .794 & 4.450 .367 & 4.413 .803 \\
\hline & ) & 198.233 & 612.577 & 1.973 .889 & 5.813 .855 & 2.225 .422 & 6. 604509 \\
\hline & ” & 765.536 & 1.540 .596 & 2.867 .931 & 6.202 .682 & 3.097 .626 & 6.820 .561 \\
\hline & ” & 998.348 & 2.811 .676 & 2.524 .596 & 7.838 .654 & 2.967 .043 & 8.887 .987 \\
\hline & ” & 342.178 & 824.433 & 1.309 .911 & 4.147 .608 & 1.683 .293 & 5. 175.839 \\
\hline & ) & 257.188 & 1.008 .676 & 2.304 .879 & 7.223 .544 & 2.688 .051 & 8.751 .299 \\
\hline & 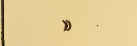 & 488.892 & 1.923 .836 & 3.370 .284 & 6.841 .836 & 3.818 .881 & 8.884 .719 \\
\hline
\end{tabular}


Tableau des principales marchandi

\begin{tabular}{|c|c|c|c|c|c|c|c|c|c|}
\hline \multirow{2}{*}{ 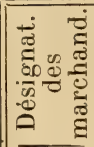 } & \multirow{2}{*}{ 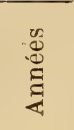 } & \multicolumn{2}{|c|}{ France et colonies } & \multicolumn{2}{|c|}{ Anglet. et colonies } & \multicolumn{2}{|c|}{ Allemagne } & \multicolumn{2}{|c|}{ Etats-Unis } \\
\hline & & Poids & Valeurs & Poids & Valeurs & Poids & Valeurs & Poids & Vale \\
\hline \multirow{11}{*}{ 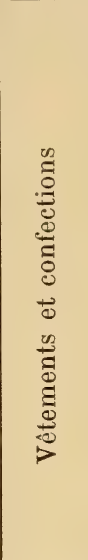 } & & kilogr. & francs & kilogr. & francs & kilogr. & francs & kilogi & fran \\
\hline & 1895 & 49.152 & 571.489 & 1.259 & 15.548 & 545 & 2.985 & ) & ” \\
\hline & 1896 & 59.819 & 584.490 & 2.859 & 21.387 & 446 & 2.148 & ” & 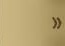 \\
\hline & 1897 & 69.652 & 398.436 & 4.298 & 22.191 & 3.247 & 19.068 & 200 & \\
\hline & 1898 & 103.192 & 444.404 & ร. 634 & 28.500 & 3.698 & 12.520 & 》 & " \\
\hline & 1899 & 269.384 & 1.658 .504 & 6.662 & 27.219 & 1.301 & 6.554 & 25 & \\
\hline & 1900 & 126.097 & 597.178 & 6.782 & 25.504 & 24 & 177 & 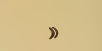 & ") \\
\hline & 1901 & 131.524 & 644.926 & 8.851 & 50.097 & 266 & 11.886 & $》$ & ” \\
\hline & 1902 & 188.412 & 599.618 & 37.253 & 35.507 & 1.253 & 7.711 & " & " \\
\hline & 1903 & 100.884 & 613.168 & 20.277 & 52.241 & 75.226 & 23.897 & 44 & \\
\hline & 1904 & 193.132 & 1.024 .623 & 6.840 & 30.935 & 6.417 & 29.971 & 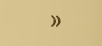 & $x$ \\
\hline \multirow{10}{*}{ 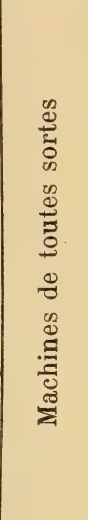 } & 1895 & 761.661 & 741.183 & 13.383 & 6.709 & 18 & 155 & ) & \\
\hline & 1896 & 37.403 & 37.917 & 6.450 & 5.711 & 54 & 120 & ” & \\
\hline & 1897 & 49.120 & 51.968 & 1.167 & 1.092 & 45 & 131 & ) & \\
\hline & 1898 & 51.195 & 116.531 & 44.738 & 56.826 & 273 & 1.208 & ” & \\
\hline & 1899 & 891.337 & 521.081 & 565 & 1.143 & 》 & $"$ & $"$ & \\
\hline & 1900 & 128.409 & 162.042 & 492 & 883 & $"$ & $"$ & D & \\
\hline & 1901 & 626.546 & 986.109 & 514 & 2.054 & 230 & 374 & 5 & \\
\hline & 1902 & 1.171 .225 & 1.081 .530 & 1.986 & 3.839 & 417 & 1.221 & , & \\
\hline & 1903 & 868.274 & 1.270 .439 & 339.805 & 195.608 & 2.229 & 7.033 & 67 & 7 \\
\hline & 1904 & 386.497 & 629.989 & 45.477 & 45.094 & 135.263 & 131.760 & 12 & 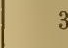 \\
\hline \multirow{10}{*}{ 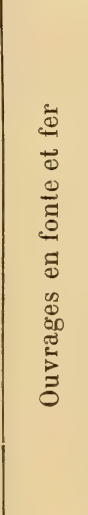 } & 1895 & 1.250 .949 & 1.014 .952 & 21.601 & 17.489 & 31.487 & 11.105 & 300 & \\
\hline & 1896 & 286.435 & 550.949 & 37.264 & 51.550 & 1.331 & 2.603 & 》 & \\
\hline & 1897 & 605.846 & 391.653 & 50.173 & 32.925 & 4.450 & 4.980 & 325 & \\
\hline & 1898 & 925.896 & 739.419 & 39.50 วั & 33.715 & 20.804 & 18.418 & 100 & \\
\hline & 1899 & 4.657 .691 & 2.867 .739 & 171.122 & 84.450 & 26.669 & 34.511 & $"$ & \\
\hline & 1900 & 4.768 .875 & 3.512 .336 & 48.211 & 31.197 & 20.310 & 16.756 & 》 & \\
\hline & 1901 & 3.684 .268 & 3.065 .835 & 51.092 & 48.403 & 23.387 & 18.303 & 4.101 & 2.1 \\
\hline & 1902 & 4.482836 & 3.830 .931 & 59.381 & 53.205 & 34.965 & 38.834 & 918 & 6 \\
\hline & 1903 & 2.549 .903 & 1.303 .993 & 45.803 & 40.036 & 106.157 & 125.707 & 268 & 7 \\
\hline & 1904 & 7.388 .894 & 3.091 .356 & 121.140 & 52.999 & 63.782 & 53.970 & 5 & \\
\hline
\end{tabular}


Tableau des marchandises impor

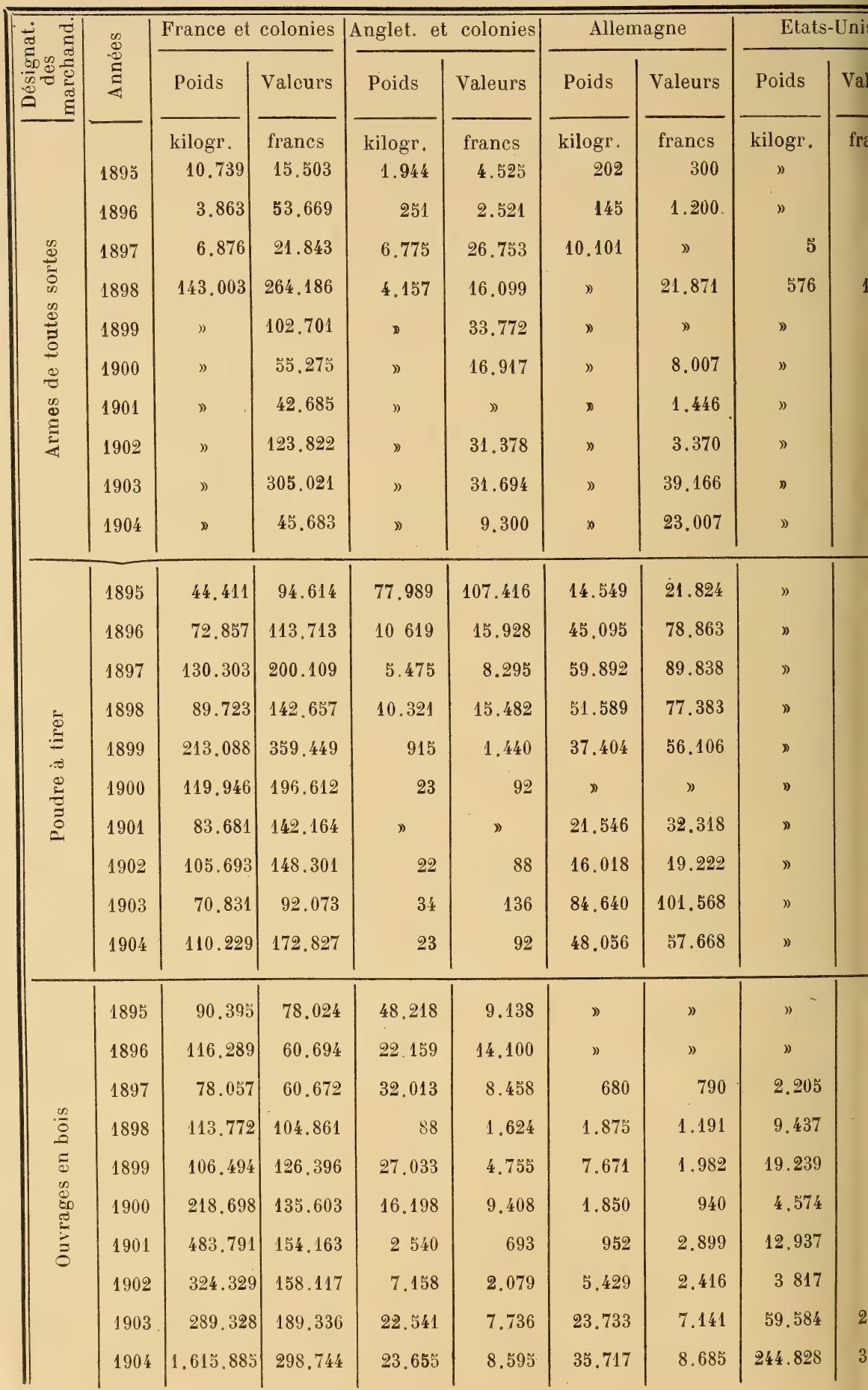


Tableau des principales marchandi

\begin{tabular}{|c|c|c|c|c|c|c|c|c|c|}
\hline \multirow{2}{*}{ 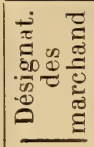 } & \multirow{2}{*}{ 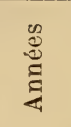 } & \multicolumn{2}{|c|}{ France et colonies } & \multicolumn{2}{|c|}{ Anglut. et colonies } & \multicolumn{2}{|c|}{ Allemagne } & \multicolumn{2}{|c|}{ Etats-Unis } \\
\hline & & Poids & Valeurs & Poids & Valeurs & Poids & Valeurs & Poids & Vale \\
\hline \multirow{10}{*}{$\begin{array}{l}\stackrel{0}{0} \\
\frac{0}{0} \\
\frac{0}{0} \\
\frac{0}{0} \\
\frac{0}{0}\end{array}$} & $189 \check{~}$ & $\begin{array}{r}\text { kilogr. } \\
7.309\end{array}$ & $\begin{array}{l}\text { francs } \\
21.504\end{array}$ & $\begin{array}{l}\text { kilogr. } \\
19.985\end{array}$ & $\begin{array}{c}\text { francs } \\
97.452\end{array}$ & $\begin{array}{c}\text { kilogr. } \\
4.209\end{array}$ & $\begin{array}{c}\text { francs } \\
8.753\end{array}$ & $"$ & 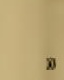 \\
\hline & 1896 & 8.775 & 22.431 & 20.036 & 98.064 & 6.192 & 11.634 & ” & $n$ \\
\hline & 1897 & 36.510 & 122.831 & 1.708 & 3.463 & 694 & 1.453 & » & 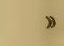 \\
\hline & 1898 & 19.793 & 64.944 & 90 & 262 & 177 & 230 & " & ") \\
\hline & 1899 & 72.171 & 131.188 & 1.920 & 3.558 & $"$ & 》 & 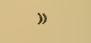 & 5 \\
\hline & 1900 & 32.149 & 93.395 & 273 & 368 & 3 & 12 & 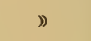 & 》 \\
\hline & 1901 & 29.096 & 143.777 & 1.071 & 2.537 & 479 & 2.100 & $"$ & $»$ \\
\hline & 1902 & 62.476 & 111.003 & 1.512 & 8.791 & 1.735 & 6.593 & $"$ & 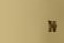 \\
\hline & 1903 & 109.699 & 247.963 & 1.988 & 5.070 & 2.090 & 6.378 & $»$ & w \\
\hline & 1904 & 122.175 & 353.591 & 4.256 & 9.729 & 2.603 & 9.133 & ” & n \\
\hline
\end{tabular}


ortées au Sénégal de 1895 à 1904 (Suite).

\begin{tabular}{|c|c|c|c|c|c|c|c|}
\hline \multicolumn{2}{|c|}{ Hollande } & \multicolumn{2}{|c|}{ Autres pays } & \multicolumn{2}{|c|}{ Total de l'étranger } & \multicolumn{2}{|c|}{ Total général } \\
\hline jids & Valeurs & Poids & Valeurs & Poids & Valeurs & Poids & Valeurs \\
\hline 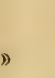 & D & $\underset{\Downarrow}{\text { kilogr }}$ & $\begin{array}{c}\text { francs } \\
»\end{array}$ & $\begin{array}{l}\text { kilogr. } \\
24.194\end{array}$ & $\begin{array}{c}\text { franes } \\
106.205\end{array}$ & $\begin{array}{r}\text { kilogr. } \\
31.503\end{array}$ & $\begin{array}{c}\text { francs } \\
127.709\end{array}$ \\
\hline ) & $》$ & ) & D & 26.228 & 109.698 & 3 วั.003 & 132.129 \\
\hline ) & ” & 》 & ) & 2.402 & 4.916 & 38.912 & 127.747 \\
\hline & ” & 799 & 2.056 & 1.066 & 2.548 & 20.859 & 67.492 \\
\hline D & 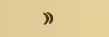 & 1.635 & 5.480 & 3.555 & 9.038 & 75.726 & 140.226 \\
\hline D & 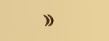 & 10 & 12 & 286 & 392 & 32.435 & 93.747 \\
\hline 》 & D & 1.564 & 4.993 & 3.114 & 10.690 & 32.210 & 154.467 \\
\hline$\infty$ & 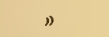 & 1.323 & 2.845 & 4.670 & 18.229 & 67.046 & 129.262 \\
\hline ) & ” & 3.490 & 6.691 & 7.568 & 18.139 & 117.267 & 266.102 \\
\hline 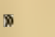 & D & 3.252 & 10.138 & 10.111 & 29.000 & 132.286 & $382.5 ั 91$ \\
\hline
\end{tabular}



TABLEAU

des principaux produits du crû exportés du Sénégal de 1895 à 1904. 
Tableau des principaux produits du

\begin{tabular}{|c|c|c|c|c|c|c|c|c|c|}
\hline \multirow{2}{*}{ 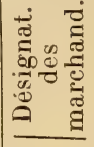 } & \multirow{2}{*}{ 怘 } & \multicolumn{2}{|c|}{ France } & \multicolumn{2}{|c|}{ Angleterre } & \multicolumn{2}{|c|}{ Allemagne } & \multicolumn{2}{|c|}{ Belgique } \\
\hline & & Poids & Yaleurs & Poids & Valeurs & Poids & Valeurs & Poids & Vale \\
\hline \multirow{11}{*}{ 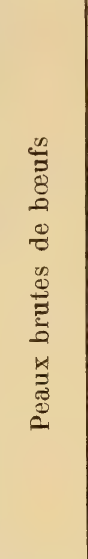 } & & kilogr. & franes & kilogr. & franes & kilogr. & francs & & \\
\hline & 1895 & 22.103 & 8.841 & 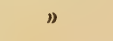 & 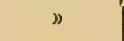 & $»$ & $»$ & v & 》) \\
\hline & 1896 & 14.452 & 6.155 & 389 & 194 & $》$ & ” & $n$ & " \\
\hline & 1897 & 21.836 & 10.510 & $》$ & 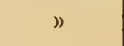 & $"$ & 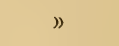 & $"$ & ” \\
\hline & 1898 & 22.215 & 8.890 & $》$ & $»$ & $》$ & 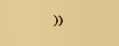 & $"$ & $n$ \\
\hline & 1899 & 29.095 & 12.088 & $»$ & 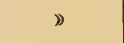 & $"$ & $"$ & $»$ & " \\
\hline & 1900 & 16.583 & 6.633 & ") & 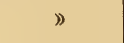 & $n$ & 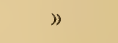 & 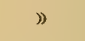 & $n$ \\
\hline & 1901 & 17.510 & 7.004 & $"$ & ” & " & 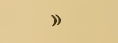 & 》 & ) \\
\hline & 1902 & 38.453 & 15.382 & $”$ & $"$ & 75 & 30 & $"$ & $"$ \\
\hline & 1903 & 41.664 & 16.666 & 946 & 378 & 3.723 & 1.489 & 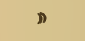 & ” \\
\hline & 1904 & 80.153 & 32.062 & 2.505 & 1.002 & 6.403 & 2.561 & " & 》 \\
\hline \multirow{10}{*}{ 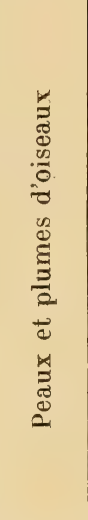 } & 1895 & $"$ & 47.350 & 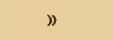 & 563 & 》 & $"$ & 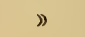 & » \\
\hline & 1896 & - & 63.153 & 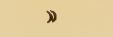 & 116.449 & $"$ & 500 & $"$ & » \\
\hline & 1897 & $"$ & 202.611 & 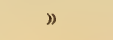 & 2.333 & $n$ & $"$ & $"$ & " \\
\hline & 1898 & $”$ & 206.472 & 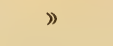 & 971 & $》$ & 16.400 & 》 & " \\
\hline & 1899 & $”$ & 122.643 & 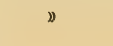 & 4.970 & " & 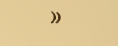 & 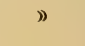 & $\pi$ \\
\hline & 1900 & 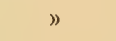 & 69.458 & 》 & 9.150 & $"$ & " & $"$ & " \\
\hline & 1901 & 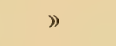 & 28.995 & $»$ & $n$ & $"$ & 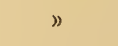 & $"$ & $"$ \\
\hline & 1902 & ) & 30.405 & 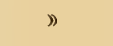 & 37 & $"$ & 》 & 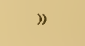 & $"$ \\
\hline & 1903 & $》$ & 51.498 & 》 & $》$ & 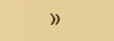 & $》$ & ” & " \\
\hline & 1904 & $"$ & 1.016 & $»$ & 4 & $"$ & 》 & ; & ” \\
\hline \multirow{10}{*}{ 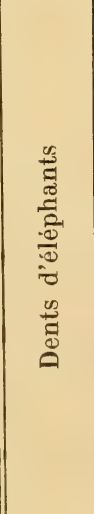 } & 1895 & 1.605 & 13.347 & $"$ & $"$ & 》 & $»$ & 》 & » \\
\hline & 1896 & 1.251 & 9.990 & $》$ & ) & " - & $》$ & $》$ & " \\
\hline & 1897 & 1.003 & 8.021 & 292 & 2. 336 & 115 & 920 & $"$ & " \\
\hline & 1898 & 5.363 & 42.907 & 1.115 & 8.916 & 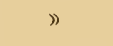 & $"$ & $\pi$ & " \\
\hline & 1899 & 4.031 & 32.248 & 703 & 5.624 & " & $"$ & 》 & " \\
\hline & 1900 & 5.450 & 27.848 & $\tilde{5} 4$ & 216 & ” & ") & $n$ & $\bar{y}$ \\
\hline & 1901 & 4.331 & 17.448 & $"$ & $n$ & 23 & 184 & $"$ & II \\
\hline & 1902 & 7.479 & 30.147 & $"$ & 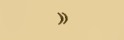 & 23 & 184 & $》$ & $»$ \\
\hline & 1903 & 8.522 & 37.684 & 314 & 1.592 & 54 & 356 & $"$ & ") \\
\hline & 1904 & 10.943 & 92.067 & $»$ & $"$ & 39 & 234 & $"$ & » \\
\hline
\end{tabular}


ortés du Sénégal de 1895 à 1904.

\begin{tabular}{|c|c|c|c|c|c|c|c|}
\hline \multicolumn{2}{|c|}{ Hollande } & \multicolumn{2}{|c|}{ Autres pays } & \multicolumn{2}{|c|}{ Total de l'étranger } & \multicolumn{2}{|c|}{ Total général } \\
\hline ids & Valeurs & Poids & Valeurs & Poids & Valeurs & Poids & Valeurs \\
\hline$g \mathrm{~g}^{\mathrm{r}}$ & francs & kilogr. & francs & kilogr. & franes & kilogr. & francs \\
\hline 年 & ) & 3.940 & 1.577 & 3.940 & 1.577 & 26.043 & 10.418 \\
\hline 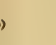 & ) & 389 & 194 & 389 & 194 & 14.841 & 6.349 \\
\hline 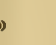 & "; & ) & ) & ) & ) & 21.886 & 10.510 \\
\hline 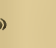 & ) & ) & ) & ) & ) & 22.215 & 1.890 \\
\hline 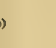 & $\eta$ & ) & 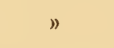 & ) & $\eta$ & 29.095 & 12.088 \\
\hline 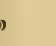 & ) & 372 & 149 & 372 & 149 & 16.955 & 6.782 \\
\hline ) & ) & 50 & 20 & 50 & 20 & 17.560 & 7.024 \\
\hline ) & ) & 2.220 & 888 & 2.295 & 918 & 40.748 & 16.300 \\
\hline ) & ) & 1.412 & 565 & 6.081 & 2.432 & 47.745 & 19.098 \\
\hline b) &.$\quad$ & 200 & 80 & 9.108 & 3.643 & 89.261 & 35.705 \\
\hline )) & ) & ) & ) & ) & 563 & ) & 47.913 \\
\hline )) & $D$ & ) & n & ) & 116.949 & ) & 180.102 \\
\hline D) & $D$ & ) & ) & ) & 2.333 & ) & 204.944 \\
\hline D) & ) & ) & D & D & 17.371 & ) & 223.843 \\
\hline ) & ) & ) & ) & , & 4.940 & n & 127.583 \\
\hline ) & ) & ) & $n$ & $D$ & 9.150 & ) & 78.568 \\
\hline ) & ) & ) & ) & ” & ) & ) & 28.995 \\
\hline ) & ) & 》 & ) & 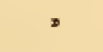 & 37 & ) & 30.442 \\
\hline D & ) & ) & 》 & ) & D & 》 & 61.498 \\
\hline ) & 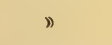 & ) & ) & ) & 4 & ) & 35.331 \\
\hline )) & ” & 58 & 468 & 58 & 468 & 1.663 & 13.815 \\
\hline n & D & ) & n & $\eta$ & ) & 1.251 & 9.990 \\
\hline 》) & ) & ) & 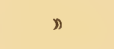 & 407 & 3.256 & 1.410 & 11.277 \\
\hline D) & $n$ & ) & ) & 1.115 & 8.916 & 6.478 & 51.823 \\
\hline 31 & 3.448 & ) & ) & 1.134 & 9.072 & 5.165 & 41.320 \\
\hline ) & ) & ) & ) & 54 & 216 & 5. ว04 & 28.064 \\
\hline ) & 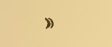 & ) & ) & 23 & 184 & 4.354 & 17.632 \\
\hline 》) & ) & $》$ & ) & 23 & 184 & 7.502 & 30.331 \\
\hline 60 & 1.040 & ) & ) & 628 & 2.988 & 9.150 & 40.672 \\
\hline$D$ & 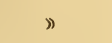 & ) & ) & 39 & 234 & 10.982 & 92.301 \\
\hline
\end{tabular}


Tableau des principaux produits du

\begin{tabular}{|c|c|c|c|c|c|c|c|c|c|}
\hline \multirow{2}{*}{ 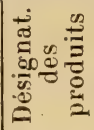 } & \multirow{2}{*}{ 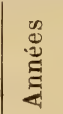 } & \multicolumn{2}{|c|}{ France } & \multicolumn{2}{|c|}{ Angleterre } & \multicolumn{2}{|c|}{ Allemagne } & \multicolumn{2}{|c|}{ Belgique } \\
\hline & & Poids & Valeurs & Poids & Valeurs & Poids & Valeurs & Poids & Vale \\
\hline \multirow{10}{*}{ 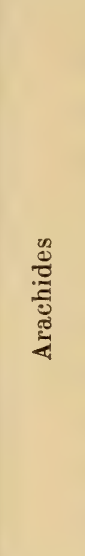 } & 1895 & $\begin{array}{c}\text { kilogr. } \\
34.366 .747\end{array}$ & $\begin{array}{c}\text { francs } \\
4990.007\end{array}$ & $\begin{array}{c}\text { kilogr. } \\
143.323\end{array}$ & $\begin{array}{c}\text { francs } \\
20.178\end{array}$ & $\begin{array}{l}\text { kilogr. } \\
3.579 .574\end{array}$ & $\begin{array}{l}\text { francs } \\
547.132\end{array}$ & kilogr. & fran \\
\hline & 1896 & 45.304 .358 & 6.429 .691 & 244.865 & $\begin{array}{l}52.569 \\
\end{array}$ & 6.021 .527 & 903.229 & n & * \\
\hline & 1897 & 41.329 .498 & 5.817 .670 & " & $n$ & 6.137 .044 & 920.562 & 2.804 .000 & 420 \\
\hline & 1898 & 73.348 .163 & 10.326 .005 & 930.881 & $\begin{array}{l}139.632\end{array}$ & 4.966 .952 & 745.073 & 1.831 .000 & 274 \\
\hline & 1899 & 66.175 .969 & 9.227 .917 & 150.689 & 15.069 & 4.973 .710 & 746.056 & 740.000 & 111 \\
\hline & 1900 & 113.324 .042 & 19.371 .701 & 303.060 & 30.306 & 7.669 .163 & 1.380 .449 & 3.482 .780 & 603 \\
\hline & 1901 & 90.601 .386 & 15.353 .296 & 135.455 & 13.545 & 8.364 .033 & 1.505 .526 & 3.385 .601 & 609 \\
\hline & 1902 & 83.649 .332 & 15.651 .771 & 77.687 & 13.981 & 10.873 .503 & 2.121074 & $"$ & " \\
\hline & 1903 & 108.190 .428 & 25.062 .702 & $1.736 \quad 021$ & 2 2วั. 394 & 10.730 .900 & 2.453 .360 & 4.147 .000 & 1.036 \\
\hline & 1904 & 93.337 .607 & 14.356 .339 & 1.052 .284 & 160.070 & 8.161 .143 & 1.289 .188 & $4.516: 620$ & 722 \\
\hline \multirow{10}{*}{ 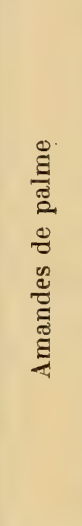 } & 1895 & 438.939 & 74.619 & 49.377 & 8.394 & $n$ & " & " & " \\
\hline & 1896 & 344.258 & 58.524 & 28.836 & 4.052 & " & $"$ & , & " \\
\hline & 1897 & 332.496 & 56.534 & 45.381 & 7.715 & , & 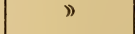 & $"$ & ' \\
\hline & 1898 & 230.232 & 34.535 & 22.500 & 3.375 & 》 & ” & ") & 。 \\
\hline & 1899 & 411.827 & 61.774 & " & $"$ & D & " & ") & ” \\
\hline & 1900 & 250.559 & 37.584 & $n$ & , & $n$ & ) & 18.000 & 27. \\
\hline & 1901 & 731.002 & 109.650 & 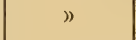 & 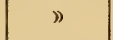 & 1.926 & 289 & 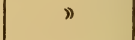 & " \\
\hline & 1902 & 38.513 & 5.777 & 52.500 & 7.875 & 400.567 & 60.085 & ${ }^{\circ}$ & " \\
\hline & 1903 & 23.482 & 3.522 & D & ' & 748.927 & 112.340 & 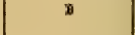 & $\pi$ \\
\hline & 1904 & 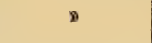 & ' & 103.213 & 16.514 & 799.438 & 127.910 & $x$ & n \\
\hline \multirow{10}{*}{ 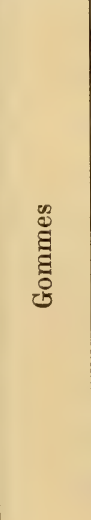 } & 1895 & 3.979 .292 & 2.328 .816 & D & D & " & D & $"$ & 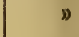 \\
\hline & 1896 & 3.639 .918 & 2.977 .981 & 》 & » & 》 & 》 & s & " \\
\hline & 1897 & 4.928 .403 & 4.721 .495 & $"$ & x & " & $"$ & $"$ & " \\
\hline & 1898 & 5.144 .150 & 4.228 .506 & 161.267 & 145.140 & ") & $"$ & $"$ & " \\
\hline & 1899 & 4.216 .314 & 3.521 .875 & 》 & 》 & ) & $n$ & ” & " \\
\hline & 1900 & 2.509 .128 & 2.317 .052 & 9.710 & 9.616 & $"$ & 》 & 9.427 & 9 \\
\hline & 1901 & 3.196 .008 & 2.910 .948 & " & $"$ & $"$ & 》 & ") & " \\
\hline & 1902 & 3.083 .371 & 1.647 .018 & $"$ & " & 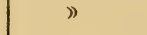 & " & $"$ & " \\
\hline & 1903 & 2.160 .417 & 979.319 & 12.300 & 4.920 & 25.068 & 12.534 & $n$ & 》 \\
\hline & 1904 & 2.301 .681 & 1.087 .388 & 66.727 & 32.844 & $n$ & $D$ & $"$ & D \\
\hline
\end{tabular}


rtés du Sỏnégal de 1895 à 1904 (Suite).

\begin{tabular}{|c|c|c|c|c|c|c|c|}
\hline \multicolumn{2}{|c|}{ Hollande } & \multicolumn{2}{|c|}{ Autres pays } & \multicolumn{2}{|c|}{ Total de l'étranger } & \multicolumn{2}{|c|}{ Total général } \\
\hline is & Valeurs & Poids & Valeurs & Poids & Valeurs & Poids & Valeurs \\
\hline & francs & $\begin{array}{c}\text { kilogr. } \\
13.510 .702\end{array}$ & $\begin{array}{c}\text { franes } \\
2.118 .201\end{array}$ & $\begin{array}{c}\text { kilogr. } \\
17.233 .599\end{array}$ & $\begin{array}{c}\text { francs } \\
2.685 .511\end{array}$ & $\begin{array}{c}\text { kilogr. } \\
\text { 51 } 600.346\end{array}$ & $\begin{array}{c}\text { francs } \\
7.675 .518\end{array}$ \\
\hline .500 & 170.040 & 10.803 .350 & 1.620 .483 & 18.251 .242 & 2.716 .321 & 63.355 .600 & 9.146 .012 \\
\hline .957 & 1.117 .644 & 401.205 & 60.180 & 16.793 .206 & 2.518 .986 & 58.122 .704 & 8.336 .656 \\
\hline .191 & 1.377 .628 & 5.013 .811 & 752.071 & 22.206 .935 & 3.289 .054 & 95.955 .098 & 13.615 .056 \\
\hline .626 & 1.579 .894 & 2.977 .573 & 439.136 & 19.374 .598 & 2.891 .1555 & $85.5 ั 500.567$ & 12.119 .072 \\
\hline '.555 & 2.132 .949 & 4.1450 .320 & 721.548 & 27.597 .878 & 4.868 .604 & 140.921 .920 & 24.240 .305 \\
\hline .691 & 2.989 .962 & 4.034 .516 & 645.482 & 32.881 .246 & ร. 763.923 & 123.462 .632 & 21.117 .219 \\
\hline .213 & 2.343 .430 & 2.243 .000 & 394.300 & 26.575 .403 & 4.872 .785 & 110.224 .735 & 20.524 .756 \\
\hline .537 & 4.867 .674 & 3.595 .610 & 898.902 & 40.652 .068 & 9.512 .080 & 148.842 .536 & 34.574 .782 \\
\hline .247 & 3.814 .707 & 6.388 .608 & 977.226 & 44.445 .902 & 6.963 .850 & 137.783 .509 & 21.320 .189 \\
\hline & ) & ) & 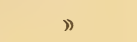 & 49.377 & 8.394 & $\mathbf{4 8 8 . 3 1 6}$ & 83.013 \\
\hline & ” & ” & " & 28.836 & 4.052 & 373.094 & 62576 \\
\hline & > & ) & D & 45.381 & 7.515 & 377.877 & 64.249 \\
\hline 300 & 55.245 & 3.700 & 555 & 394.500 & 59.175 & 624.732 & 93.710 \\
\hline & ) & ” & ” & $n$ & $n$ & 411.827 & 61.774 \\
\hline & ) & D & ” & 180.000 & 27.000 & 430.559 & 64.584 \\
\hline & ) & ) & ) & 1.926 & 289 & 732.928 & 109.939 \\
\hline & ” & ” & ) & 453.067 & 67.960 & 491.580 & 73.737 \\
\hline & $》$ & 》 & $\eta$ & 748.927 & 112.340 & 772.409 & 115.862 \\
\hline & ) & ” & 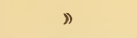 & 902.651 & 144.424 & 902.651 & 144.424 \\
\hline & ) & ) & ) & ) & 》 & 3.979 .292 & 2.328 .816 \\
\hline & ) & - & ) & ) & ) & 3.641 .679 & 2.979 .742 \\
\hline & " & 》 & ) & » & D & 4.928 .403 & 4.721 .495 \\
\hline .664 & 92.381 & 586 & 218 & 216.517 & 237.739 & 5.420 .667 & 4.466 .245 \\
\hline & ” & 4.131 & 3.718 & 4.131 & 3.718 & 4.220 .445 & 3.525 .593 \\
\hline & ) & 》 & ) & 19.137 & 18.950 & 2.528 .265 & 2.336 .002 \\
\hline & 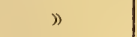 & ” & 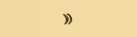 & D & ” & 3.196 .008 & 2.910 .948 \\
\hline & n & , & " & ) & " & 3.083 .371 & 1.647 .018 \\
\hline & 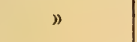 & 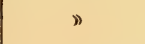 & ) & 37.368 & 17.454 & 2.197 .785 & 996.773 \\
\hline & ” & 1.623 & 649 & 68.350 & 33.493 & 2.370 .031 & 1.120 .881 \\
\hline
\end{tabular}


Tableau des principaux produits du

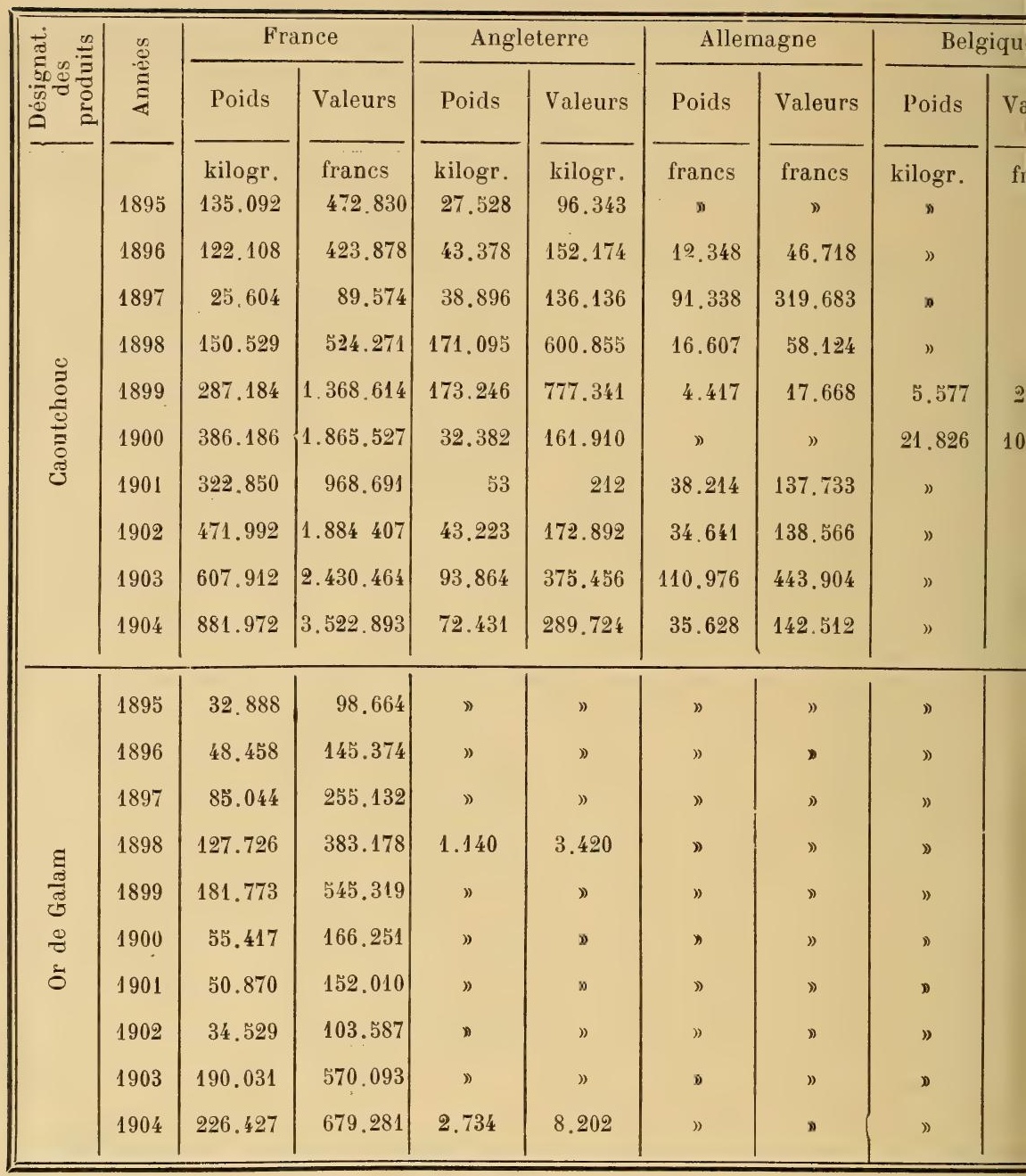


rtés du Sénégal de 1895 à 1904 (Suite).

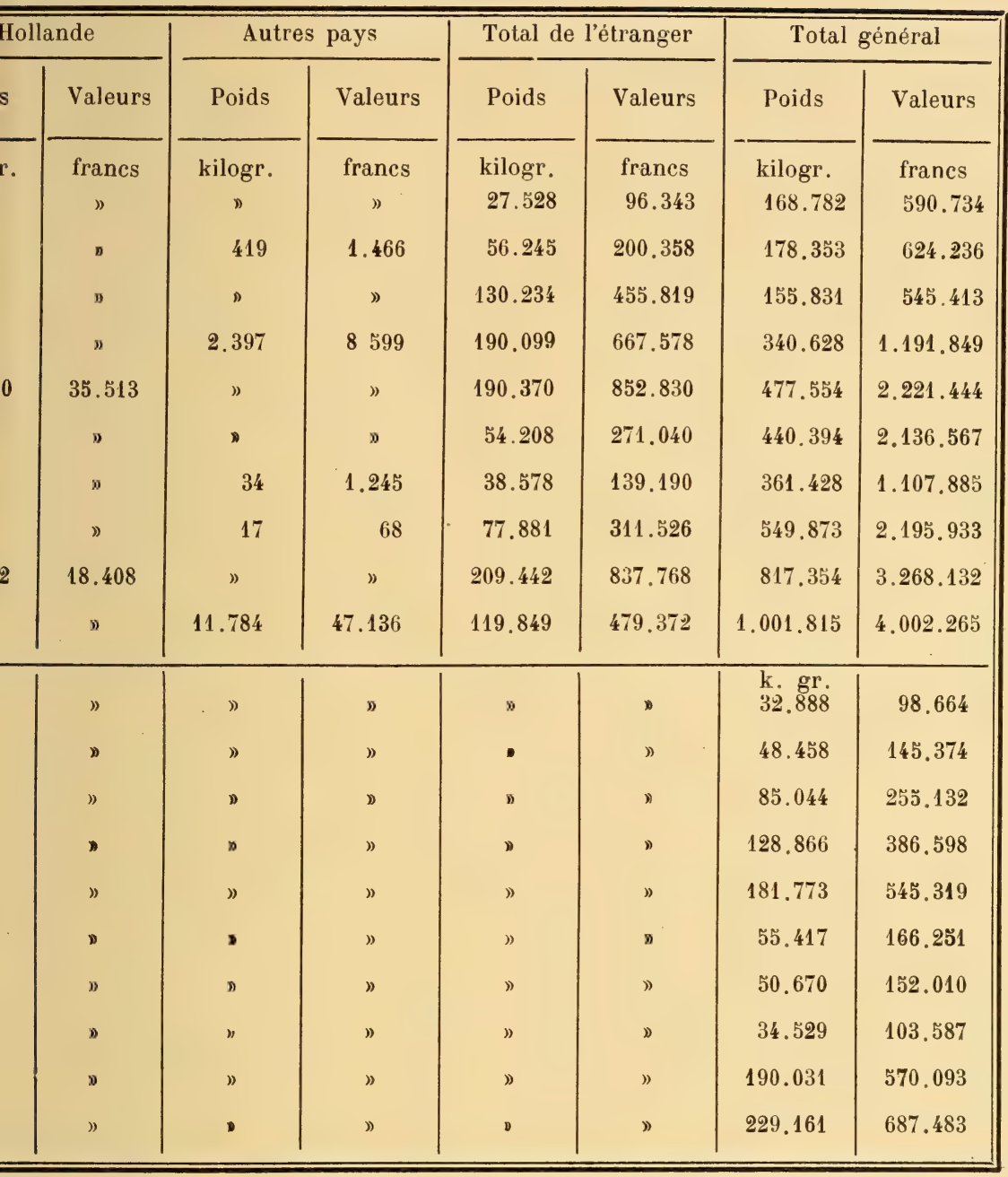

S. 


\section{Les centres commerciaux du Sénégal.}

Comment, sur le territoire de la Colonie, est réparti le commerce d'importation ou d'exportation : en d'autres termes quels sontles différents centres commerciaux du Sénégal, quelle est leur importance respective, quel genre de trafic y fait-on, quelles régions déservent-ils. Telles sont les questions auxquelles répondent les développements qui vont suivre.

Antérieurement à 1890 (1) les comptoirs commerciaux n'existaient guère qu'à Saint-Louis et à Gorée. Ceux de Saint-Louis avaient installé de nombreux traitants sur le fleuve et trafiquaient par leur intermédiaire ou directement avec les Maures vendeurs de gommes et acheteurs de " guinée ", ainsi qu'avec les noirs de la rive droite et d'une partie du Soudan Des agences de Gorée relevaient les factoreries de Rufisque, de la Petite-Cote, de Foundiougne, de Casamance et des rivières du Sud.

Gorée. - Gorée avait acquis jadis une prospérité assez considérable en raison de sa position géographique qui permettait au commerce de demeurer à l'écart des hostilités des tribus de l'intérieur, et à la faveur des privilèges de l'ordonnance royale du 7 janvier 1822 qui en fit l'unique entrepôt non seulement de la Colonie mais encore de toute une partie de la Côte occidentale, ainsi que du décret du 24 décembre 1864 qui a créé sa franchise et lui a réservé en même temps qu'à Saint-Louis l'importation des marchandises de toute nature, de toute provenance et par tout pavillon, de même que l'exportation des produits du crû pour toute destination et par tout pavillon.

Mais Gorée, port sans abri où les navires ne pouvaient trouver ds bons mouillages, ne répondit plus aux besoins du trafic dès que la mise en valeur des territoires soumis à notre influence prit son essor.

Il devint dès lors indispensable, de favoriser le développement des postes secondaires de la Cote qui se prêtaient facilement aux opérations de débarquement et d'embarquement et permet-

(1) Voir notice de l'exposition de 1900 où se trouve un historique complet de la question depuis 1626. 
taient d'entretenir des relations directes avec les populations aborigènes Deux de ces points, l'un possédant une rade sûre et bien abritée, l'autre en relations déjà avec de vastes provinces qu'il était appelé à desservir réalisaient ces conditions. C'étaient Dakar et Rufisque où le commerce bénéticie dès 1880 de l'entrepôt fictif.

L'ancienne capitale de nos possessions de la Côte demeurait néanmoins le lieu de transit des marchandises destinées à la Petite-Côte, au Saloum, à la Casamance et aux rivières du Sud, quand le décret du $1^{\mathrm{er}}$ août 1889 en accordant une autonomie administrative aux rivières du Sud et en transportant à Konakry la résidence du Lieutenant-gouverneur précédemment fixé à Gorée, vint lui porter un coup fatal.

L'administration, avec le concours du commerce, se préoccupa de doter la nouvelle colonie d'un port de façon à assurer l'importation directe des marchandises et l'exportation des produits à destination de la France et de l'étranger, Konakry, la capitale, fut le lieu choisi et les navires au long cours ne tardèrent pas à le fréquenter.

D'un autre côté, le chemin de fer de Dakar-St-Louis inauguré dès 1885 mit davantage en rclief le port de Rufisque où le trafic des arachides était déjà centralisé et vers lequel ont émigré en 1889-1890 les ay'ences des grandes maisons de commerce du $2^{e}$ arrondissement installées à Gorée. Une des conséquences de ce transfert a été le rattachement des opérations de la Petite Côte et du Saloum à celles de Rufisque.

Enfin, vers la même époque, les négociants de la Casamance à qui la petite île servait d'entrepôt, cédèrent leurs comptoirs à la Société commerciale et agricole de la Casamance laquelle choisit naturellement Dakar comme port de transit.

Ainsi s'éteignit après des siècles de prospérité la vitalité de Gorée dont les eaux ne sont aujourd'hui que rarement troublées par les grands navires, malgré la franchise du port et de l'île.

Rufisque et voie ferrée. - A cette époque, l'affermissement de notre autorité en différents points du territoire sénégalais et notamment dans les provinces du Cayor et du Baol avait donné au commerce une nouvelle impulsion. Une législation libérale 
tout en garantissant la protection dûe à l'industrie nationale avait ordonné par le décret du 2 décembre 1890 les tarifs précédemment en vigueur et chacun des ports de Dakar et Rufisque, délivré des entraves qui en faisaient une dépendance de Gorée, subissait une transformation individuelle et vivait de son existence propre.

Le chemin de fer a joué un rôle très important dans l'évolution commerciale qui se produisit. Ce puissant agent de prospérité accrut non seulement les relations de l'extérieur avec l'intérieur mais il augmenta rapidement la production de l'arachide dont la culture n'attendait que des facilités de transfert pour se développer. Dès le début de l'exploitation quelques boutiques se groupèrent près des gares et un important courant commercial pris bientôt naissance.

Il fut aussi un élément de pacification. Avant 1890 la soumission du pays qu'il traversait n'était pas complète et le désarmement des Tiédos mécontents du Baol n’a eu lieu qu'en 1891.

Les populations des provinces du Cayor et du Baol plus heureuses sous notre protectorat que sous la domination arbitraire et brutale des Damels et des Teignes se sont livrées paisiblement à la culture de leurs champs. Elles se transportèrent par les routes et les chemins créés et entretenus par notre administration vers les stations de la voie ferrée pour y vendre leurs graines et se procurer en retour les marchandises d'importation.

Le commerce fut amené à augmenter le nombre de ses succursales. Des constructions de briques ou de pierres furent substituées aux baraques de la première heure. Les arachides affluèrent et les escales formèrent des agglomérations si importantes que trois d'entre elles: Louga, Thiès et Tivaouane, en raison de l'accroissement de leur population et du mouvement commercial, furent constituées en communes mixtes par arrêté du 31 décembre 1904.

Rufisque devint le port et l'entrepôt des escales de la voie ferrée, de la Petite-Cote, du Sine-Saloum et plus tard d'une partie de la Casamance. Là furent centralisées les affaires du Cayor, du Baol et du Diender.

L'initiative adininistrative et celle du commerce unirent leurs 
efforts pour doter le port et la ville des aménag'ements réclamés par les besoins du trafic. Les négociants s'installèrent confortablement. De vastes magasins en pierres avec charpente métallique ont été construits pour abriter les graines contre les intempéries. La manutention des marchandises et des arachides fut accélérée par l'établissement dans toutes les rues de voies Decauville qui relicnt les maisons de commerce à la gare et aux appontements.

Un premier warhf public construit en 1888 devint bientôt insuffisant et il fallut établir en 1899-1900 un nouvel appontement métallique qui comme le premier s'avance à près de 200 mètres dans la mer.

Le port ainsi outillé fut fréquenté par la plupart des navires qui faisaient autrefois escale à Gorée.

Le chiffre de la population augmenta considérablement; de 8.091 habitants en 1891, il s'est élevé en 1904 à 12.446 habitants, soit avec la banlieue $\mathbf{1 9 . 1 7 7}$ habitants.

Les chiffres de ses affaires ont doublé pendant ces dix dernières années. Ainsi le mouvement commercial a atteint en 1904 : 27.567.080 francs contre 10.640 .198 francs en 1895 , valeurs qui se répartissent ainsi :

\begin{tabular}{|c|c|c|c|c|}
\hline Années & & Importation & Exportation & $\begin{array}{l}\text { Mouvement } \\
\text { commercial }\end{array}$ \\
\hline - & & - & - & - \\
\hline 1895 & • & 4.441 .091 & 5.704 .011 & 10.145 .102 \\
\hline 1904 & • & 10.392 .757 & 10.8950 .329 & 21.258.086 \\
\hline En plus & . & 5.951 .666 & ๖.191.318 & $\overline{11.142 .984}$ \\
\hline
\end{tabular}

Le tonnage des arachides exportées accuse la même augmentation :

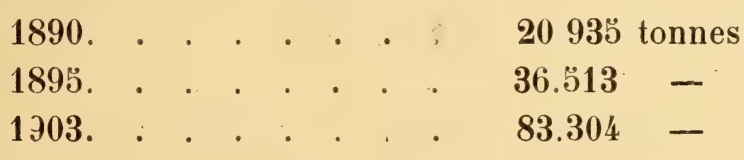

Cette progression est rassurante pour l'avenir car les différentes provinces qu'alimente le port de Rufisque nont pas encore atteint au point de vue économique toute leur maturité. La concurrence faite en Europe aux arachides par les sésames de l'Asie 
peut constituer toutefois un danger pour l'avenir. Le prix moyen d'achat des graines dans la Colonie qui était de 22 francs en 1890 est aujourd hui descendu à 15 francs les 100 kilogs. Ce taux est encore suffisamment rémunérateur mais il ne faudrait pas qu'il baissât.

Sine-Saloum. - Dans le Sine-Saloum, les transactions ne sont pas moins prospères. La sécurité du pays a contribué à l'extension des cultures et de nombreuses routes convergeant vers les escales rendent les comptoirs plus accessibles à l'indigène en même temps qu'elles favorisent le transport des graines.

Foundiougne, Kaolack et Fatick sont les principaux centres d'achat des arachides.

Les longs courriers qui autrefois s'arrêtaient à Foundiougne remontent de nos jours le Saloum jusqu'à Kaolack, poste qui a acquis beaucoup d'importance bien que le commerce n'y ait placé ses factoreries qu'à partir de 1889. Leur chargement est généralement allégé à l'entrée et complété à la sortie au port de Foundiougne, bureau des douanes et entrepôt de toutes les arachides traitées à Fatick et dans le Niamboto, l'estuaire du Saloum n'étant pas praticable jusqu'à Kaolack pour les navires d'un tirant d'eau élevé qui ne sauraient franchir le passage de Koudame.

La création d'un poste de douane à Djinnack sur les frontières de la Gambie, en prévenant l'infiltration illicite de quelques marchandises a permis d'ouvrir à Messira des comptoirs qui dispensent les indigènes d'aller vendre ailleurs leurs graines ou y chercher les marchandises dont ils ont besoin.

Quelques chiffres feront ressortir la marche ascendante des affaires dans les provinces en question.

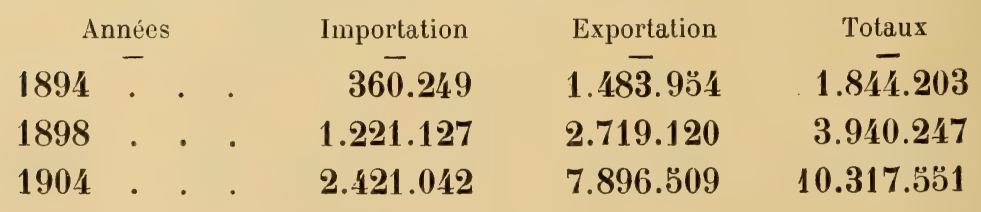

La même progression existe dans l'exportation des arachides qui sont le principal, sinon l'unique produit du Sine-Saloum. 


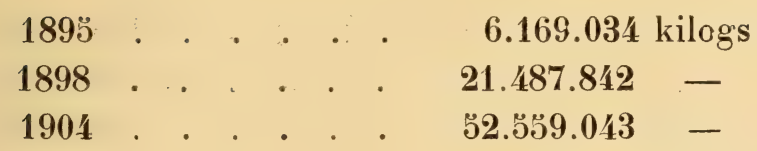

Il ne faudrait pas toutefois se laisser séduire par l'éloquence de ces chiffres qui méritent d'être interprétés.

L'écart si considérable accusé à l'importation provient de ce qu'autrefois le Sine-Saloum tributaire de Rufisque s'approvisionnait surtout en marchandises dans les entrepôts de ce dernier port et quelquefois dans ceux de Dakar.

Dans la suite, de nombreux commerçants profitant de la fréquentation des navires au long cours et des avantages que présente le dédouanement au port même de destination ont reçu directement leurs commandes de l'extérieur et ont rempli les formolités douanières à Foundiougne. De sorte que les chiffres des cinq dernières années représentent la plus grande partie du mouvement commercial tandis que ceux des années antérieures étaient rattachés dans une proportion assez considérable aux ports de Rufisque et de Dakar.

En ce qui concerne l'exportation, les différences signalées en faveur de 1904 sont l'expression presque sincère des progrès accomplis.

Quelles qu'aient été d'ailleurs la fréquence pendant ces dernières années, des navires importateurs à Foundiougne, l'excédent constaté est suffisamment élevé pour établir une supériorité incontestable à la période en cours.

Le commerce du Sine-Saloum s'accroît done d'année en année. Son avenir est intimement lié à celui de l'arachide. Aussi l'Administration s'est-elle préoccupée d'en améliorer la culture afin d'obtenir un rendement plus élevé. Il est rassurant de constater que malgré la baisse des cours l'exportation des graines n'a guère cessé d'augmenter.

Casamance. - Un mouvement ascensionnel du commerce de la Casamance est également à signaler. Il est dù à la création de nouveaux magasins ou opérations et au développement de l'exploitation des produits par les indigènes.

En dehors de la colonne dirigée en 1901 contre Fodé Daba 
chef du Fogni et la répression des Floups en 1903 aucune expédition militaire n'a été entreprise pendant ces dix dernières années dans cette province. L'œuvre de la colonisation s'est poursuivie pacifiquement de 1895 à nos jours. Pendant cette période l'indigène a vu s'installer en des points éloignés des principales escales des traitants européens ou indigènes qui lui procurent des marchandises et lui achètent ses produits, amandes de palme, caoutchouc, cire brute, etc.

Les premiers commerçants établis obtinrent à vil prix ces articles, notamment le caoutchouc qui jouissait cependant sur les marchés d'Europe des cours relativement élevés. Mais la concurrence ne tarda pas à rehausser la valeur d'achat sur place et l'indigène en présence de l'élévation des prix s'adonna davantage à la préparation ou à la récolte des produits des forêts.

L'administration l'incita en outre à étendre la culture de l'arachide dans les terrains découverts.

Le caoutchouc, produit riche dont la vente procurait de gros bénéfices fut en particulier l'objet d'une exploitation très active. Son commerce qui n'a été introduit qu'en 1883 donna les résultats suivants à l'exportation :

1883. 59.623 kilos exportés.

1884. 103.347

1885. les résultats manquent. 1886.

")

))

1887. 150.000 kilos.

1888. 128.807 »

1889. 96.863 »

1890. les résultats manquent.

1891. 139.169 kilos.

1892. 193.13วّ ”

1893. 238.471 »
1894. les résultats manquent. 1895. 144.592 kilos.

1896. 126.878 》

1897. 200.353 »

1898. 297.349 ”

1899. 387.167 ,

1900. 302.517 》

1901. 210.029 "

1902. 224.927 »

1903. 379.912 》

1904. 382.204 »

La réduction des chiffres de l'exportation constatée en 189ð̈ et 1896 par rapport à ceux des précédentes années a eu deux causes : la mauvaise qualité du caoutchouc acheté pendant les années 1894 et 1893 et le courant commercial qui s'était créé par terre vers la Gambie. 
Une amélioration se produisit bientôt et les affaires ne tardèrent pas à reprendre leur marche normale.

Avant 1890, les entreprises commerciales avaient apporté une grande prudence dans leur trafic. Elles trouvèrent profit à céder vers cette époque leurs installations à une société dont le programme était comme l'indiquait sa raison sociale, d'entreprendre des affaires commerciales et agricoles. Bien que disposant de vastes concessions la nouvelle Compagnie éprouva des revers et n'eut qu'une existence fort limitée. Elle vendit elle-même ses immeubles et son matériel à d'autres négociants qui lui succédèrent et réussirent sous une direction habile et accoutumée par une longue expérience aux affaires coloniales à accroître le nombre de leurs comptoirs et à prospérer.

Ziguinchor devint le siège de la plupart des maisons. Son rapprochement des principaux centres de production et la navigabilité de la rivière Casamance qui permet aux navires d'y entrer en tout temps le désignèrent comme entrepôt de la Casamance au détriment de Carabane.

Ziguinchor qui n'était qu'un modeste village changea rapidement d'aspect. De belles habitations furent élevées et des rues tracées et bétonnées. On y construisit des écoles et tout récem. ment un marché. Un administrateur y réside et un bureau de douane vient d'y être créé. Son développement atteste l'aisance commerciale de la région.

Le commerce avec l'extérieur augmenta en effet dans des proportions considérables en l'espace de dix ans. Il ne pouvait en être autrememt, la production des amandes de palme, des arachides et du caoutchouc qui sont les principaux articles d'exportation ayant été de plus en plus abondante.

Années

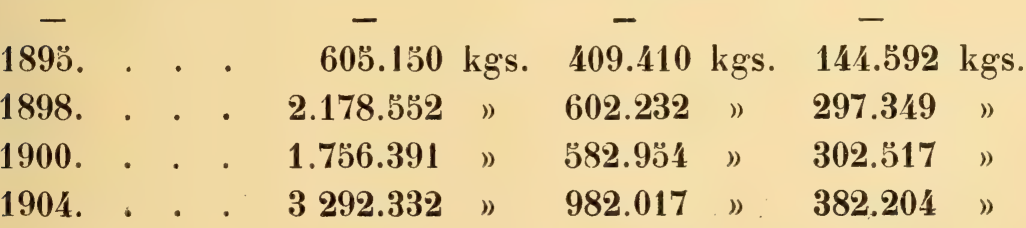

Le commerce de la Casamance s'est développé d'une façon 
satisfaisante, il est loin cependant d'atteindre son maximum de prospérité car cette belle province possède de grandes richesses ; une partie seulement de ses forêts est exploitée et la fertilité de terrains étendus n'a pas encore été sollicitée. La soumission complète des villages à nos institutions va offrir de nouveaux débouchés et permettre d'intéresser au travail de la terre, des indigènes que les libéralités de la nature prédisposent à l'inactivité.

Dakar. - Tandis que Rufisque, la région traversée par la voie ferrée, les escales du Saloum et de la Casamance se développaient et manifestaient ın progrès économique réel, Dakar dont la rade sûre avait attiré tous les navires qui autrefois faisaient escale à Gorée, se transformait chaque jour et devenait le port principal de la Colonie.

Sa situation géographique, sa position stratégique et l'étendue d'une rade abritée le désignaient comme un port de relàche et un port commercial et militaire à la fois. De grands travaux furent entrepris pour utiliser tous les avantages offerts par la nature.

Dakar étant choisi comme point d'appui de la flotte militaire on s'est préoccupé de l'établissement d'un arsenal. Les travaux ouverts en 1899 ont été adjugés à MM. Hersent qui disposent d'un matériel puissant et complet permettant de mener activement à bien la tâche commencée.

L'entreprise Jammy et Galtier a obtenu l'aménagement du port de commerce. Il s'agit de la construction de moles et terrepleins limités par des quais en eau profonde pour faciliter les opérations des plus grands navires.

Le projet comprend l'exécution de remblais assez étendus pour permettre l'installation ultérieure d'une gare maritime et de docks importants ainsi que de tout le matériel mécanique dont l'industrie moderne a fait bénéficier l'exploitation des ports.

Enfin, une usine électrique suffisamment puissante pour éclairer la ville et le port et fournir en sus la force motrice à un service de tramways au travers des voies principales de la commune sera bientôt construite.

Dakar s'est développé non seulement comme port mais aussi 
comme ville. Le chiffre de sa population s'est sensiblement accru. Celle-ci, comptait en 18781 อ̆อ̆6 âmes, en 1891 8.737; il est de 18.447 d'après le recensement de 1904, soit avec la banlieue 23.452 habitants.

Les constructions se sont élevées de toutes parts. L'administration elle-même a dù procéder à l'édification de nombreux bâtiments destinés aux services publics. La ville présente à l'heure actuelle l'aspect d'un vaste chantier. D'importants travaux d'assainissement sont entrepris, tels que la construction d'un réseau d'égoûts, le nivellement du sol, l'exécution des trottoirs et des chaussées ou leur réfrection.

Le nombre des vapeurs touchant à Dakar pour s'y ravitailler en charbon s'est multiplié pendant ces dernières années et le stock d'approvisionnement de combustible a dù augmenter pour faire face aux besoins de la navigation. La Compagnie descharbonnages possède un matériel considérable qui lui permet de remplir en peu de temps les soutes d'un navire.

Il est à prévoir quavec le développement du port au double point de vue militaire et commercial les installations deviendront elles mêrnes insuffisantes et qu'elles devront être étendues.

L'importation des charbons au port de Dakar a augmenté sensiblement ainsi que le prouvent les chiffres ci-après.

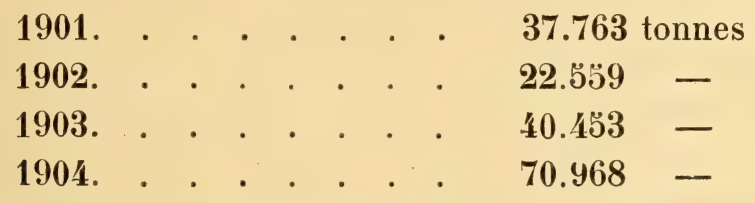

L'augmentation de sa population et l'amélioration de son port furent naturellement favorables au mouvement du commerce et de la navigation. Les importations et exportations se sont accrues dans des proportions peu ordinaires.

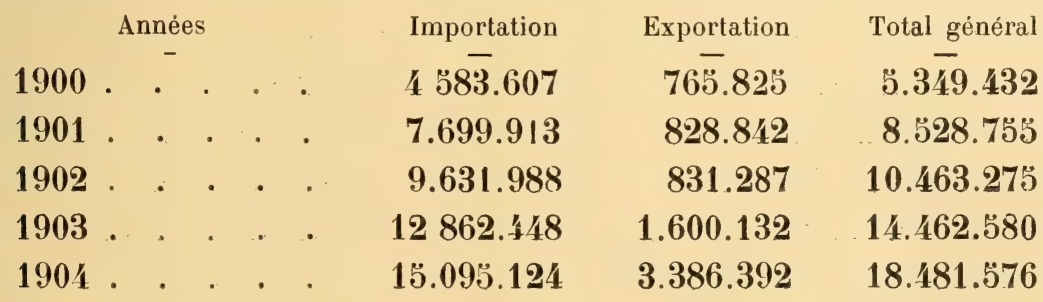


On trouvera plus loin au chapitre de la navigation des indications sur le nombre de navires qui fréquentent la rade.

Nul doute que cet accroissement ira en s'augmentant et que Dakar convenablement outillé sera la relàche forcée des navires de toutes nationalités qui sillonnent les routes conduisant de l'Europe dans l'Afrique et l'Amérique Australes.

Saint-Louis-le-Soudan. - L'ère des progrès réalisés dans cette partie du Sénégal où s'étaient élevées au détriment de Gorée des villes aussi importantes que Dakar et Rufisque fut aussi celle de l'expansion d'une activité qui, confinée à l'origine dans l'île de Saint-Louis et le long du fleuve Sénégal, se déploya peu à peu à travers les riches territoires qu'en pays soudanais la vaillance de nos troupes avait gagnés à la domination française.

Là aussi, la marche ascendante du commerce fut subordonnée à celle de la pacification. Il fallut au Soudan notamment briser les résistances de certains chefs indigènes puissamment armés.

Dès lors, le commerce prit son élan, les factoreries se multiplièrent et l'exploitation d'un produit riche et abondant, le caoutchouc, fit la prospérité de certains articles tels que ceux de Bougouni, Sikasso, Bobo-Dioulasso et Koutiala.

Le port de Saint-Louis situé à l'extrémité du parcours du fleuve Sénégal qui constitue la principale voie de communication des territoires intérieurs surtout depuis qu'une voie ferrée le relie au Niger, est le lieu de transil de la plupart des marchandises destinées à la colonie du Haut-Sénégal et Niger et du Soudan en général, ainsi que des produits qui en proviennent.

Ses entrepôts alimentent pendant une grande partie de l'année au moyen de vapeurs fluviaux et de chalands d'un faible tonnage naviguant avec leurs propres moyens où à la remorque des premiers, les escales du fleuve et les différents comptoirs du Haut-Sénégal et du Niger. Les vapeurs du service fluvial partent de Saint-Louis le surlendemain de l'arrivée des paquebots des Messageries Maritimes à Dakar, emportant le courrier et les passagers et remorquant des chalands chargés de marchandises. 
La période intensive des expéditions des marchandises s'étend du 15 juillet au $1^{\mathrm{er}}$ octobre. C'est la saison des hautes eaux pendant laquelle Kayes est accessible aux longs courriers. A cette époque un certain nombre de vapeurs y débarquent directement les marchandises de l'extérieur et en exportent des chargements de caoutchouc, de gommes et d'arachides à destination de l'Europe.

Malgré la crise qui a atteint le commerce des gommes, le mouvement commercial de ce port, bénéficiant du progrès des transactions dans le Soudan, s'est accentué d'année en année.

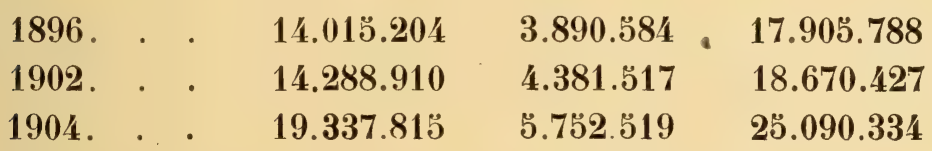

Saint-Louis est loin de présenter aujourd'hui la même physionomie qu'à l'époque où le commerce du troc se pratiquait non seulement dans les postes éloignés mais aussi dans les villes.

La création de factoreries dans les différentes parties du pays, un peu partout, dans le haut fleuve surtout, a écarté les caravanes du chef-lieu. Ses maisons de commerce font beaucoup moins d'opérations de détails sur place et s'occupent plus spécialement de la direction des succursales de l'intérieur et de la centralisation de leurs affaires.

Le trafic du caoutchouc du Soudan est heureusement venu s'ajouter à celui des gommes dont les cours avilis ne laissent qu'un léger bénéfice aux exportateurs.

L'accès du port n'est malheureusement pas toujours facile à cause des bancs de sable qui obstruent par intervalles l'entrée du fleuve et ne peuvent être franchis que par les navires d'un faible tirant d'eau. Avant de se présenter devant la barre du Sénégal les bateaux se délestent habituellement à Dakar ou à Rufisque.

Saint-Louis, créée depuis longtemps, n'a pas eu à se développer comme Dakar ou Rufisque depuis une dizaine d'années, elle n'en est pas moins l'une des plus jolies villes de la Cote occidentale d'Afrique.

Les ouvrages de création récente intéressant le commerce 
sont: le grand pont métallique reliant le faubourg de Sor et la gare à la ville, celui de Guet-N'Dar et le marché couvert de N'Dar-Toute remarquable par son animation permanente. La population qui n'était que de $\mathbf{1 5 . 9 8 0}$ habitants en 1878 s'est élevée à 20.1'73 en 1891. Elle est d'après le dernier recensement de $\mathbf{2 4 . 0 7 0}$ habitants soit avea la banlieue 28.469 habitants.

\section{Trafic avec la F'rance et l'Etranger.}

En résumé, l'évolution économique du Sénégal a été considérable durant ces dix dernières années ainsi que l'attestent les chiffres des importations et des exportations (Voir ci-dessus les tableaux du commerce de 1895 à 1904).

Comparativement à 1895 , le mouvement commercial a atteint des valeurs deux fois supérieures pendant la période décennale visée. Les échanges avec la Métropole ont suivi une progression sensiblement égale à celle des chiffres généraux malgré quelques alternatives de recrudescence et de diminution.

La France fournit principalement à la Colonie, les viandes salées, les conserves de viandes de toutes sortes, les produits et dépouilles d'animaux tels que saindoux, fromages, lait conservé, beurre; les farineux alimentaires, les denrées coloniales de consommation dans lesquels rentrent les sucres; les vins, les savons, certains matériaux de construction briques, tuiles, chaux et ciment; des vêtements confectionnés et une grande quantité de métaux et d'ouvrages en métaux.

L'étranger a acquis une place prépondérante dans l’impor. tation de certains articles, soit que ceux-ci comme les tabacs en feuilles, les huiles de coton, la houille, les bois de construction, pin et pitchpin constituent une production spéciale à quelques pays, soit que d'autres, tels que les tissus, défient la concurrence française par la réduction de leur prix de vente.

La France n'occupe pas la place qui lui revient sur le marché du Sénégal. Elle pourrait avec quelques efforts augmenter la valeur de ses importations, notamment de celles des tissus de coton.

Le commerce d'exportation avec la Métropole a naturelle- 
ment suivi le mouvement du commerce d'importation. Il accuse une augmentation qui aurait été plus sensible si les gommes et les arachides n'avaient subi dans ces derniers temps une baisse de prix par suite de la concurrence pour les premières des produits d'Egypte et pour les secondes des sésames de l'Inde dont les huileries font un important usage.

Les échanges de la Colonie avec l'Etranger se sont accrues parallèlement à son commerce avec la Métropole. Elles ont augmenté à l'importation dans les mêmes proportions que pour la France. A l'exportation elles marquent une progression plus rapide car les expéditions pour l'étranger ont à peu près triplé leurs chiffres de 189 cependant que celles destinées à la France passaient de $\mathbf{9}$ à 20 millions.

Navigation. - Si nous avons pu constater que dans le mouvement des affaires, la métropole tenait une part importante, prépondérante même, l'examen des statistiques de la navigation nous conduira à une remarque aussi satisfaisante.

Nous donnons ci-après :

$1^{0}$ Un tableau du mouvement de la navigation (A. Entrées. B. Sorties) pendant les dix dernières années. A noter que le tonnage nominal ou débarqué est en augmentation croissante.

Pour rendre plus saisissant le mouvement de la navigation, nous avons également fait reproduire huit diagrammes présentant de 1895 à 1904 :

$1^{\circ}$ Le nombre des bateaux entrés ;

$2^{\circ}$. Le nombre des bateaux sortis ;

$3^{\circ}$ Les tonnages nominaux des bateaux entrés;

$4^{0}$ Les tonnages nominaux des bateaux sortis;

$5^{0}$ Les tonnages embarqués;

$6^{0}$ Les tonnages débarqués ;

$7^{\circ}$ La valeur des chargements embarqués;

$8^{\circ}$. La valeur des chargements débarqués.

Chacun de ces diagrammes montre le mouvement total d'une part, et distingue entre les bateaux étrangers et les bateaux français.

La simple inspection de ces différents tableaux fait ressortir que le pavillon national tient la première place. 


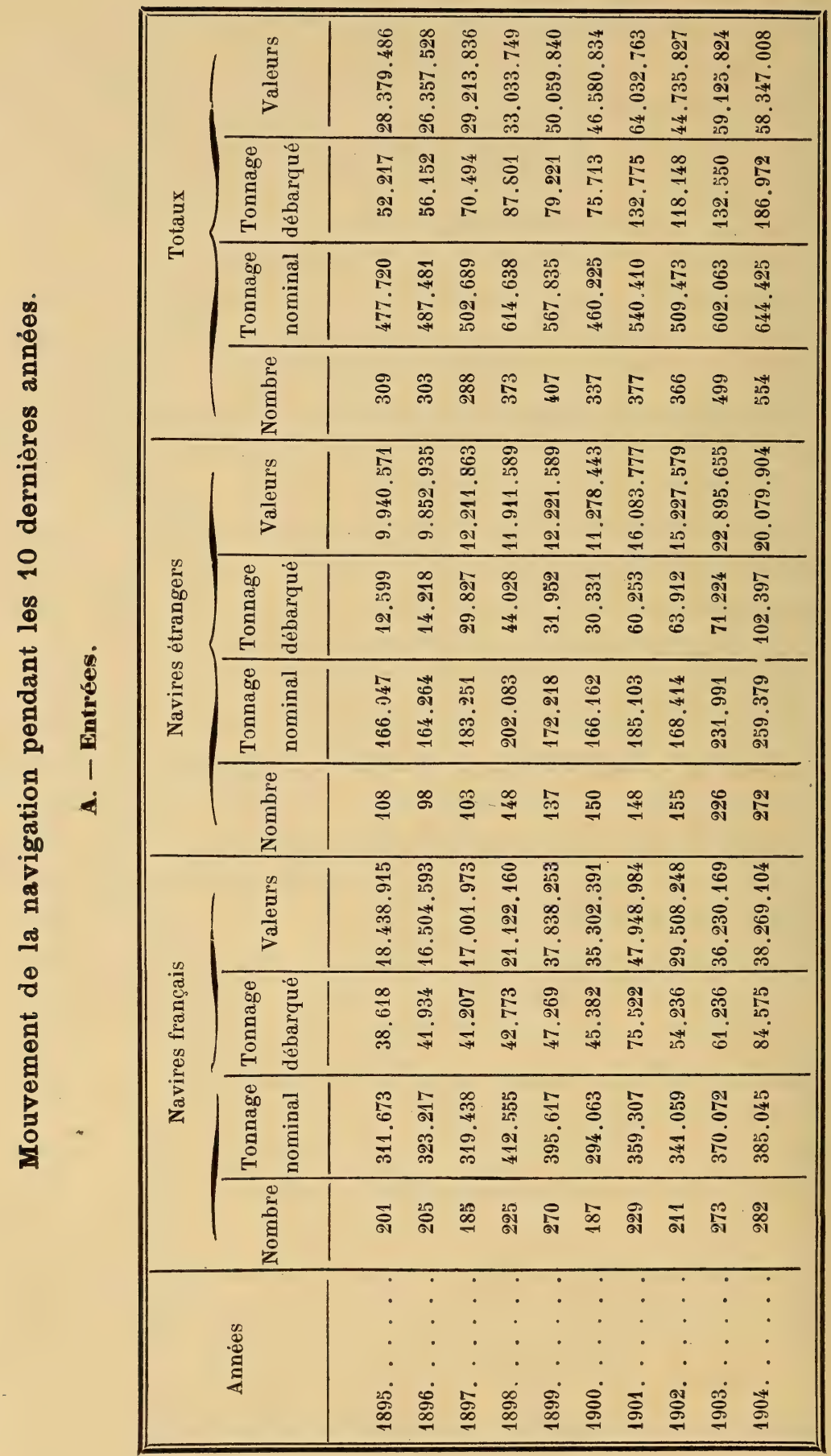




\begin{tabular}{|c|c|c|c|c|c|c|c|c|c|c|c|c|}
\hline \multirow{13}{*}{ 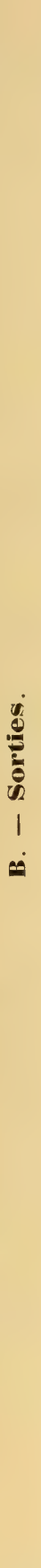 } & \multirow{4}{*}{$\stackrel{\Delta}{\Xi}$} & 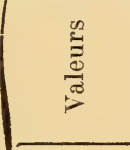 & 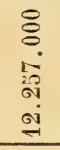 & 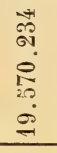 & $\begin{array}{l}\infty \\
\infty \\
20 \\
- \\
\dot{D} \\
\infty \\
\dot{\sigma} \\
\end{array}$ & 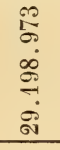 & 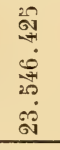 & 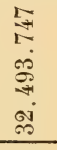 & 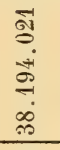 & 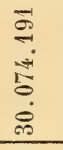 & 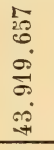 & 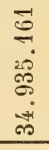 \\
\hline & & 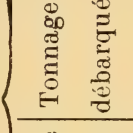 & $\begin{array}{l}a \\
\text { al } \\
\infty \\
0 \\
0\end{array}$ & $\underset{\infty}{\stackrel{+}{0}}$ & 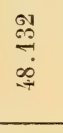 & $\begin{array}{l}\infty \\
\infty \\
\stackrel{0}{0} \\
\stackrel{-}{1}\end{array}$ & $\begin{array}{l}8 \\
2: 0 \\
\stackrel{8}{8}\end{array}$ & 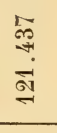 & 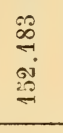 & $\begin{array}{l}\overrightarrow{5} \\
20 \\
20 \\
=\end{array}$ & 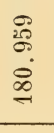 & $\begin{array}{l}\text { 今े } \\
20 \\
\text { ๙ิं } \\
\text { जิ }\end{array}$ \\
\hline & & 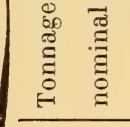 & 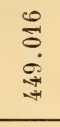 & 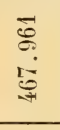 & 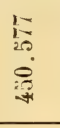 & $\begin{array}{l}\mathscr{0} \\
\stackrel{\circ}{0} \\
\stackrel{1}{1}\end{array}$ & 总 & \begin{tabular}{l}
20. \\
जิ \\
$\stackrel{0}{0}$ \\
\multirow{4}{*}{}
\end{tabular} & 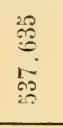 & 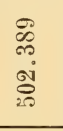 & $\begin{array}{l}\text { N } \\
\mathbb{N} \\
0 \\
0 \\
0 \\
20\end{array}$ & $\begin{array}{l}\overrightarrow{0} \\
\infty \\
\ddot{0}\end{array}$ \\
\hline & & 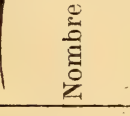 & के & $\stackrel{\infty}{\circ}$ & ๙ั & $\stackrel{\cong 0}{\circ}$ & 's & 㤐 & 囦 & लै & $\stackrel{+}{+\infty}$ & $\begin{array}{l}\infty \\
20 \\
20\end{array}$ \\
\hline & \multirow{4}{*}{ 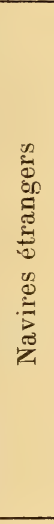 } & 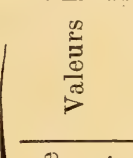 & $\begin{array}{l}\frac{61}{75} \\
\frac{12}{20} \\
0 \\
60\end{array}$ & $\begin{array}{l}0 \\
\infty \\
0 \\
0 \\
\infty \\
\dot{0}\end{array}$ & $\begin{array}{l}\stackrel{\text { In }}{\leftarrow} \\
\dot{0} \\
\stackrel{0}{1} \\
20\end{array}$ & $\begin{array}{l}\text { o } \\
0 \\
0 \\
\dot{0} \\
0 \\
0\end{array}$ & $\begin{array}{l}5 \\
\stackrel{5}{0} \\
0 \\
0 \\
9 \\
20\end{array}$ & $\begin{array}{l}0 \\
\mathscr{0} \\
\dot{0} \\
\text { बें } \\
20 \\
\infty\end{array}$ & 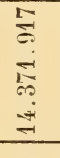 & 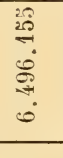 & 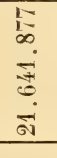 & 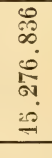 \\
\hline & & 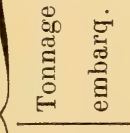 & 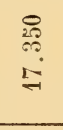 & 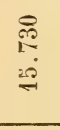 & 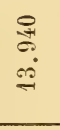 & 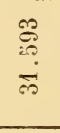 & $\stackrel{20}{-1}$ & $\underset{\substack{\infty \\
\infty}}{\stackrel{\infty}{\infty}}$ & $\begin{array}{l}\vec{*} \\
\stackrel{+}{*} \\
\dot{\infty}\end{array}$ & 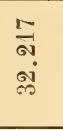 & $\underset{\infty}{\stackrel{\infty}{\infty}}$ & $\stackrel{\infty}{\frac{\infty}{20}}=$ \\
\hline & & 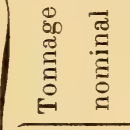 & $\stackrel{9}{\stackrel{2}{2}}$ & $\begin{array}{l}\mathscr{D} \\
\dot{0} \\
0 \\
\text { ơ } \\
20 \\
\end{array}$ & $\underset{\dot{0}}{\stackrel{5}{5}}$ & $\stackrel{\infty}{\stackrel{\infty}{*}}$ & $\begin{array}{l}\text { बำ } \\
\text { 든 }\end{array}$ & 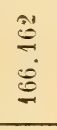 & $\begin{array}{l}\infty \\
\text { ol } \\
\infty \\
\infty \\
\infty \\
10 \\
-1\end{array}$ & $\begin{array}{l}\stackrel{0}{0} \\
0 \\
\stackrel{0}{0} \\
\stackrel{-}{0}\end{array}$ & 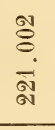 & $\begin{array}{l}0 \\
= \\
0 \\
20 \\
\text { ai }\end{array}$ \\
\hline & & $\begin{array}{l}0 \\
\text { है } \\
\text { हू } \\
\text { Z }\end{array}$ & 8 & $\stackrel{8}{\&}$ & 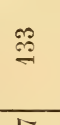 & $\stackrel{\infty}{\stackrel{1}{\sim}}$ & $\stackrel{22}{\stackrel{20}{2}}$ & 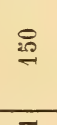 & \pm & $\stackrel{20}{2}$ & สิ & जั๊ \\
\hline & \multirow{4}{*}{ 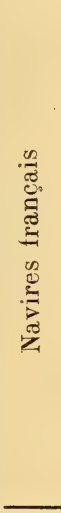 } & 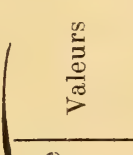 & $\begin{array}{l}\infty \\
\infty \\
2 \\
0 \\
\stackrel{8}{0} \\
0\end{array}$ & 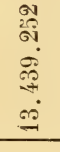 & 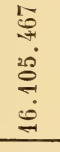 & 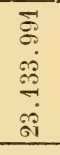 & 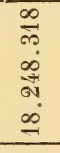 & 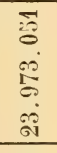 & 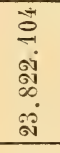 & 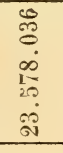 & 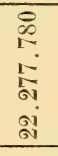 & $\begin{array}{l}20 \\
\text { of } \\
\text { o. } \\
0 \\
20 \\
20 \\
0 \\
0 \\
0\end{array}$ \\
\hline & & 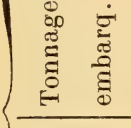 & Ğ & $\begin{array}{l}\text { హै } \\
\text { ज़ } \\
\text { มे }\end{array}$ & 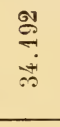 & $\begin{array}{l}20 \\
\underset{I}{2}\end{array}$ & $\begin{array}{l}\stackrel{8}{9} \\
\stackrel{9}{9} \\
\stackrel{9}{9}\end{array}$ & 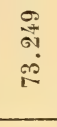 & $\stackrel{0}{i}$ & $\underset{\infty}{\stackrel{\vec{D}}{\vec{t}}}$ & $\begin{array}{l}0 \\
\infty \\
\text { के } \\
\text { gi }\end{array}$ & $\underset{\infty}{\stackrel{\infty}{\infty}}$ \\
\hline & & 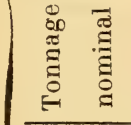 & $\begin{array}{l}= \\
\infty \\
0 \\
5 \\
0\end{array}$ & 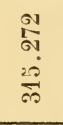 & $\begin{array}{l}1 \\
20.0 \\
\dot{0} \\
\text { जे }\end{array}$ & $\begin{array}{l}\infty \\
\stackrel{\infty}{*} \\
\infty \\
\stackrel{+}{+}\end{array}$ & 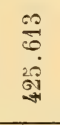 & 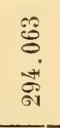 & 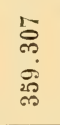 & $\begin{array}{l}\text { के } \\
\text { సँ } \\
\text { ஸे }\end{array}$ & 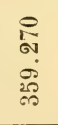 & $\begin{array}{l}\text { ब1 } \\
\infty \\
\infty \\
\infty \\
\infty \\
\infty\end{array}$ \\
\hline & & $\begin{array}{l}\text { हूँ } \\
\text { हूँ } \\
\text { ¿ } \\
\end{array}$ & $\underset{\sigma}{\stackrel{\sigma}{\sigma}}$ & $\stackrel{\infty}{\stackrel{一}{二}}$ & $\stackrel{\mathscr{\sigma}}{\stackrel{-}{9}}$ & बू & 导 & $\stackrel{\infty}{\infty}$ & สิ & ลิ & ชี & बิ \\
\hline & \multicolumn{2}{|r|}{ 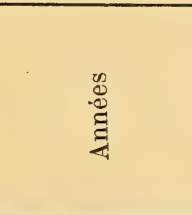 } & $\dot{2}$ & $\begin{array}{l}\dot{ } \\
\dot{0} \\
\dot{\mathscr{D}} \\
\stackrel{\infty}{=}\end{array}$ & $\begin{array}{c}\dot{ } \\
\dot{5} \\
\dot{\infty} \\
\stackrel{\infty}{=}\end{array}$ & $\begin{array}{c}\dot{ } \\
\dot{ } \\
\dot{0} \\
\dot{\infty} \\
\infty \\
\infty\end{array}$ & $\stackrel{\dot{D}}{\circ}$ & \&் & $\begin{array}{l}: \\
\dot{5} \\
\dot{5} \\
\dot{5}\end{array}$ & $\begin{array}{l}\text { : } \\
\text { : } \\
\text { 。 } \\
\stackrel{5}{\circ}\end{array}$ & : & $\begin{array}{l}: \\
\dot{\sigma} \\
\stackrel{+}{\circ}\end{array}$ \\
\hline
\end{tabular}

S. 


\section{DIAGRAMME}

du mouvement général de la navigation au long cours pendant les dix dernières années 1895-1904.

\section{Nombre de bateaux entrés}

\section{Légende :}

Bateaux français

Bateaux étrangers

Totaux des navires entrés

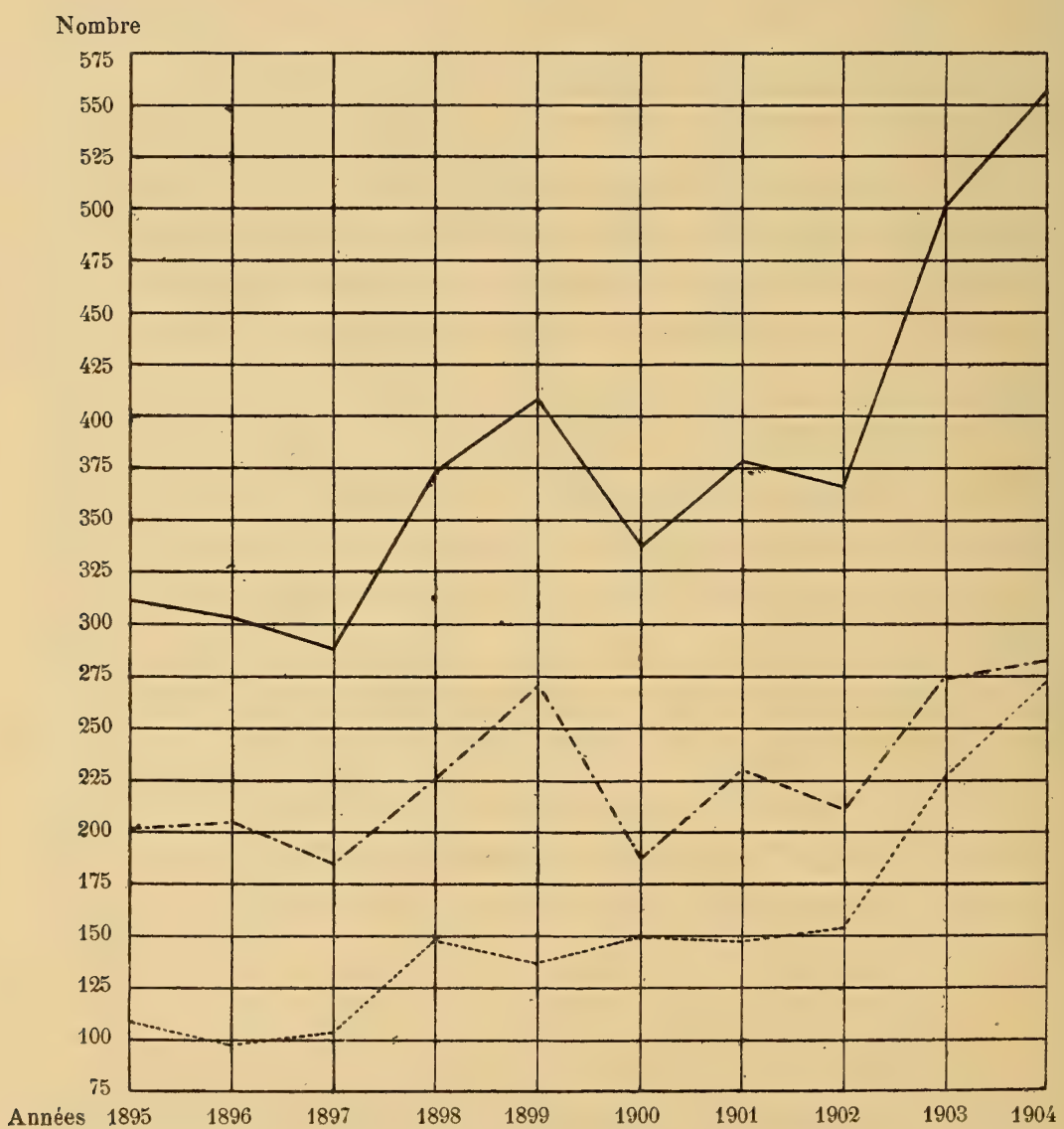




\section{DIAGRAMME}

du mouvement général de la navigation au long cours pendant les dix dernières années 1895̆-1904

\section{Nombre de bateaux sortis}

\section{Légende :}

Bateaux français

Bateaux étrangers

Total des navires sortis

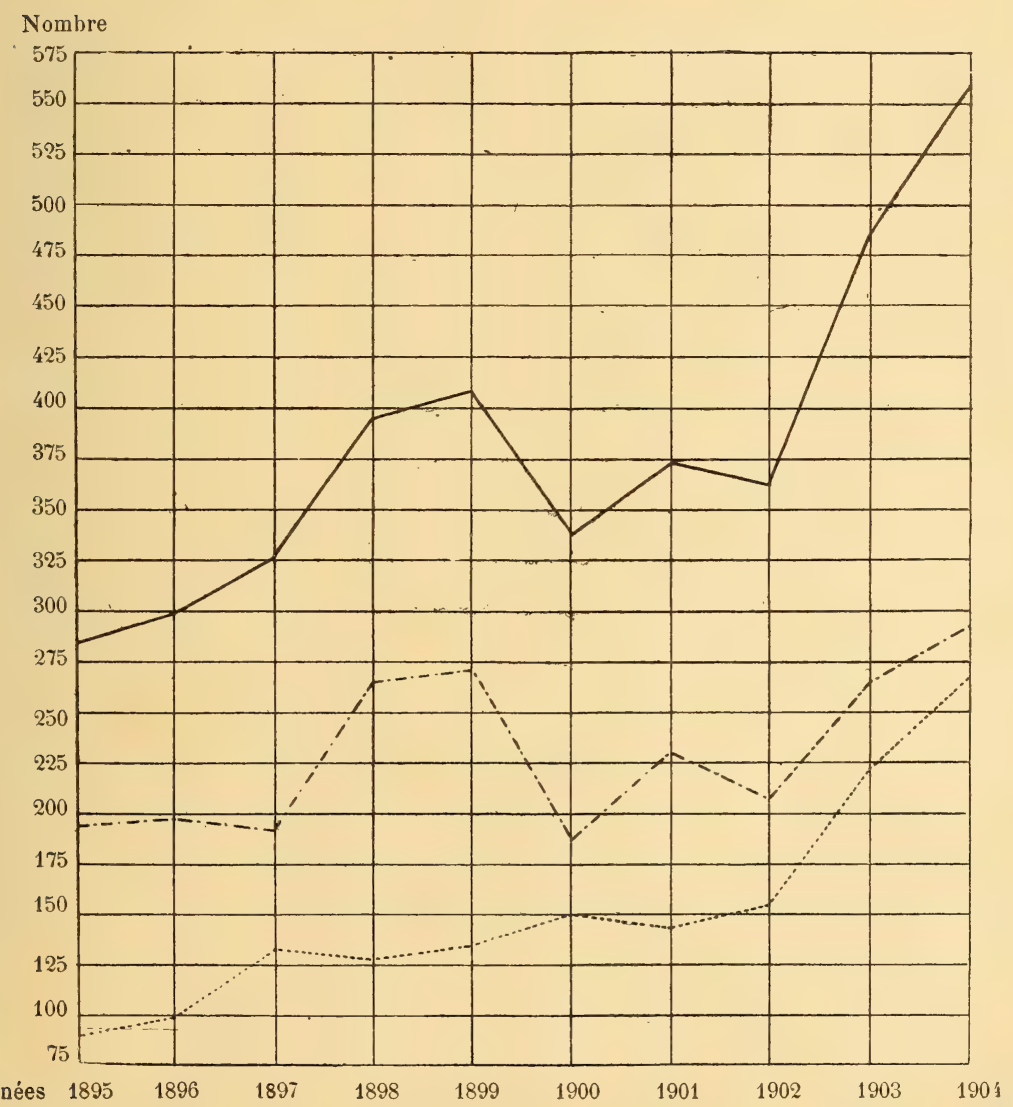




\section{DIAGRAMME}

du mouvement général de la navigation au long cours pendant les dix dernières années 1895-1904.

\section{Tonnages nominaux des navires entrés}

\section{Légende :}

Navires français

Navires étrangers

Total des tonnages nominaux

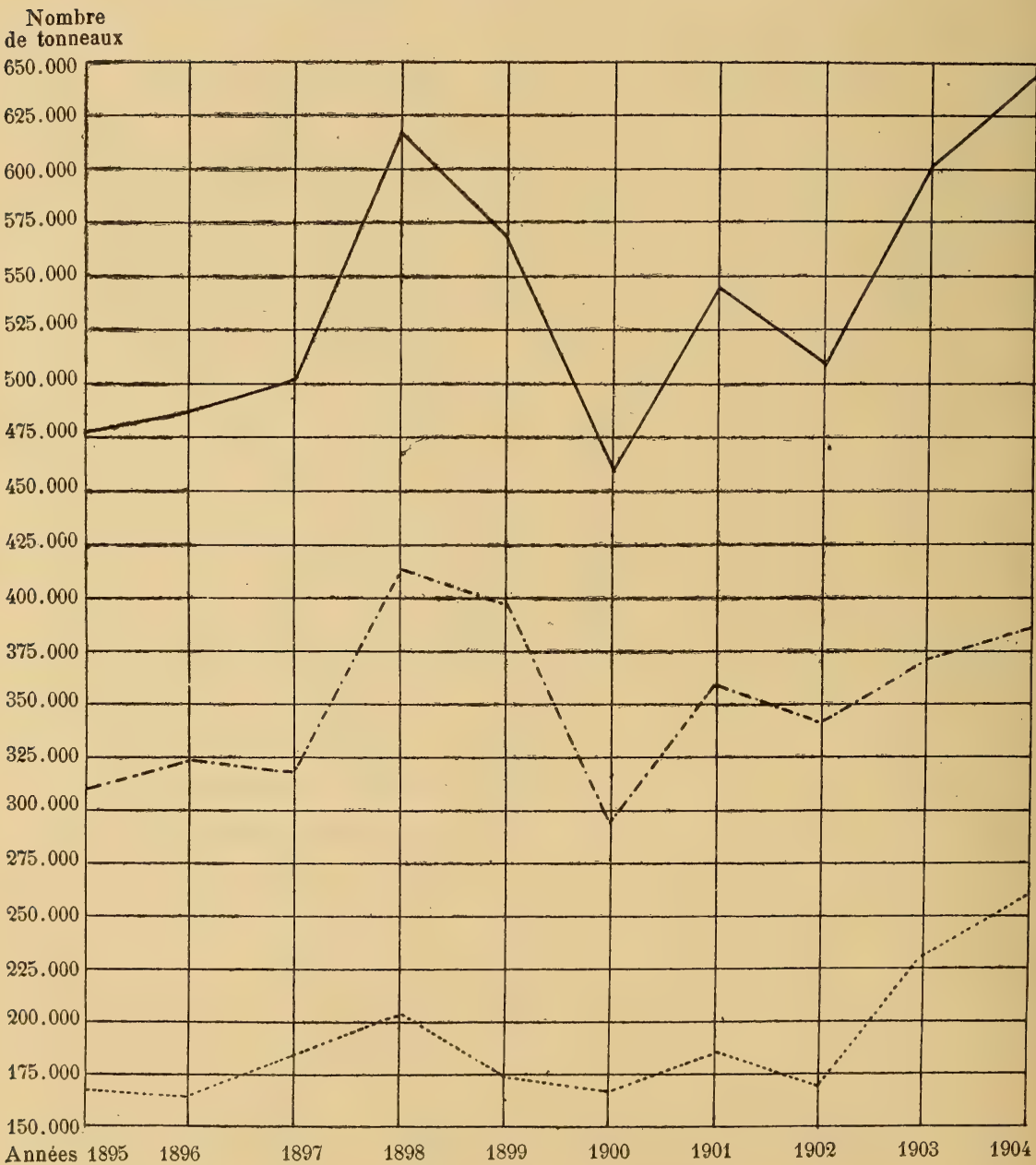




\section{COLONIE DU SÉNÉGAL}

\section{DIAGRAMME}

du mouvement général de la navigation au long cours pendant les dix dernières années 189\%-1904

\section{Tonnages nominaux des navires sortis}

Navires français

Navires étrangers

Total des tonnages nominaux

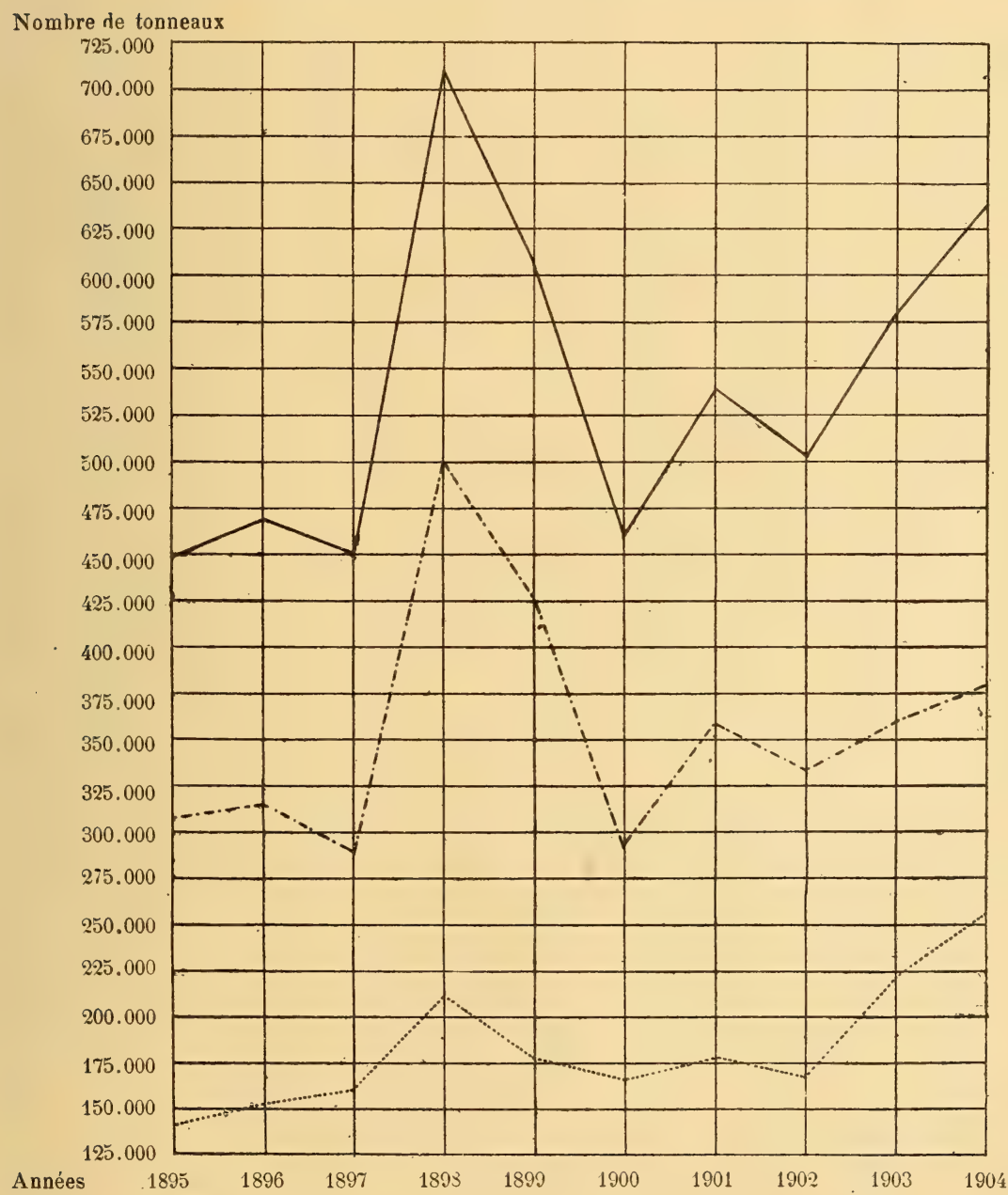




\section{DIAGRAMME}

du mouvement général de la navigation au long cours pęndant les dix dernières années 189\%-1904.

\section{Tonnages embarqués}

\section{Légende :}

Navires français

Navires étrangers

Total des tonnages embarqués

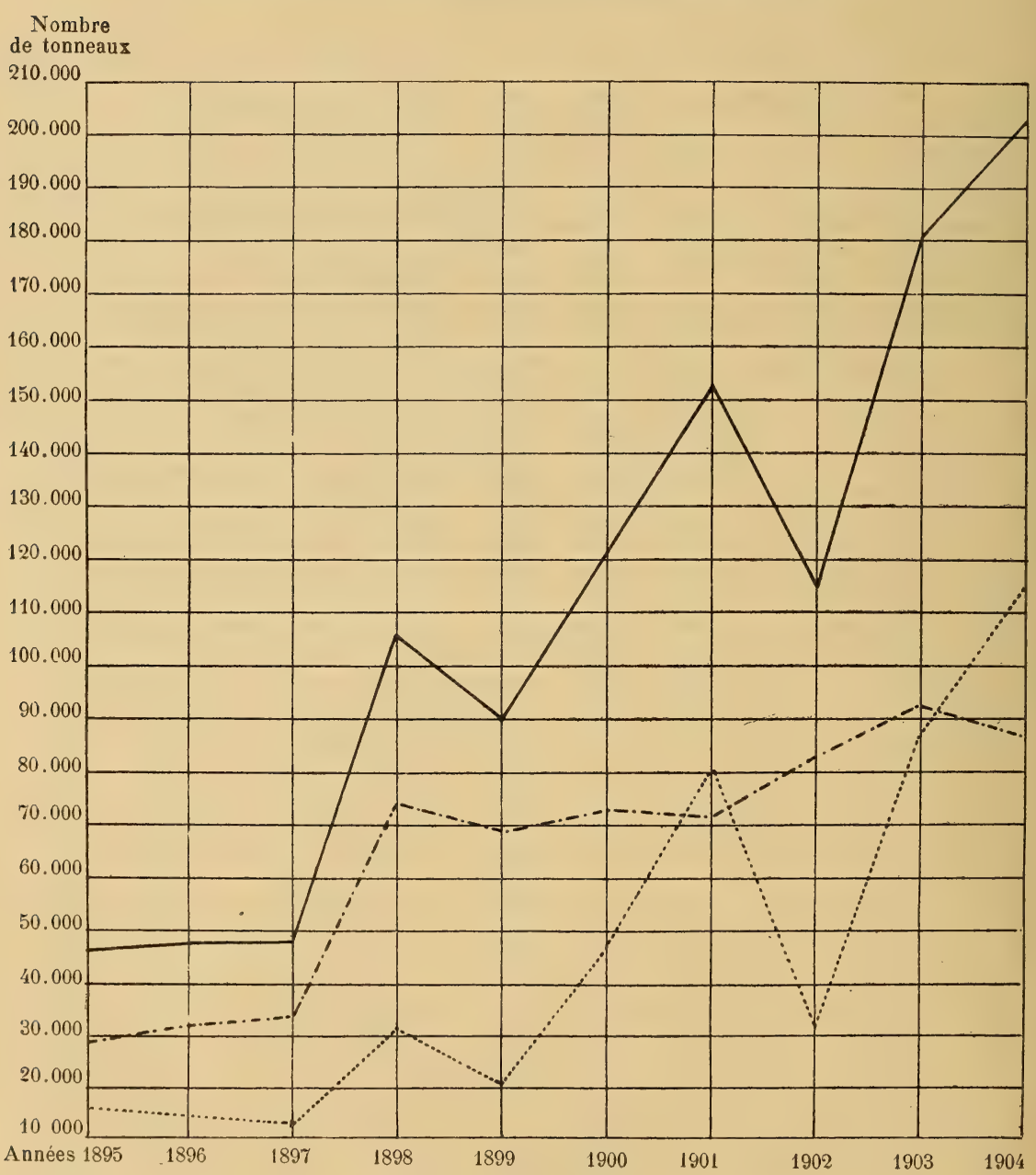




\section{DIAGRAMME}

du mouvement général de la navigation au long cours pendant les dix dernières années 189つ-1904

\section{Tonnages débarqués}

\section{Légende :}

\section{Navires français}

Navires étrangers

Total des tonnages débarqués

\section{Nombre de tonneaux}

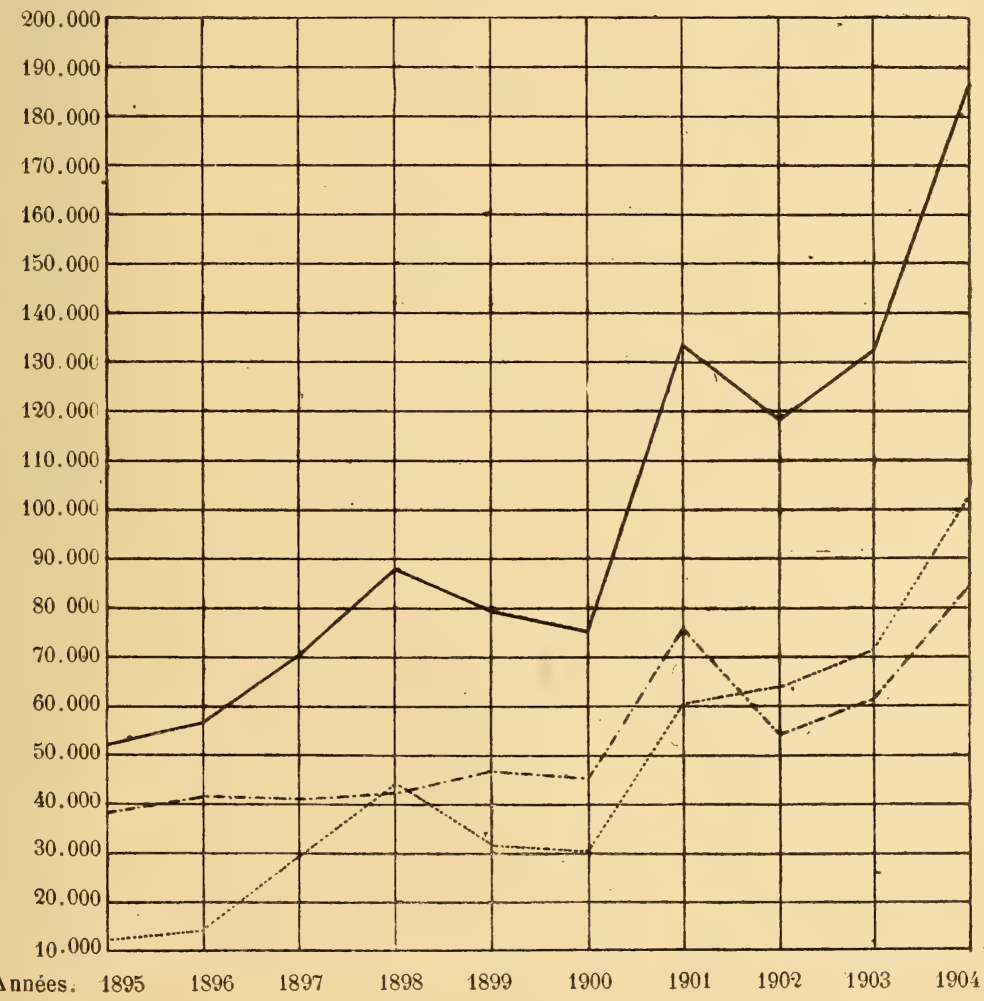




\section{DIAGRAMME}

du mouvement général de la navigation au long cours pendant les dix dernières années 1895-1904.

\section{Valeurs des chargements embarqués}

\section{Légende :}

Navires français

Navires étrangers

Valeurs totales des chargements embarqués

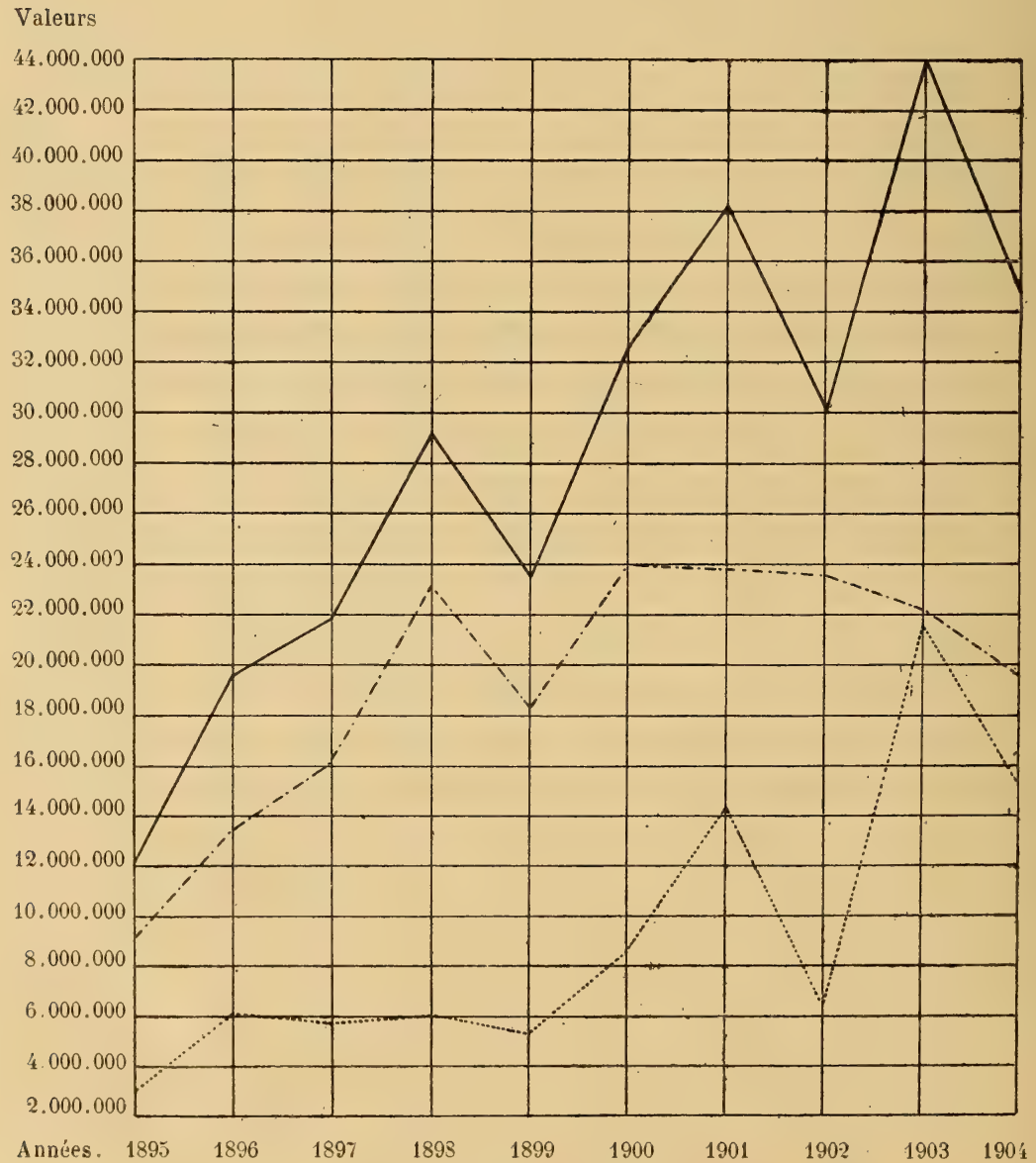




\section{DIAGRAMME}

du mouvement général de la navigation au long cours pendant les dix dernières années 1895-1904.

\section{Valeurs des chargements débarqués}

Navires français

\section{Légende :}

\section{Navires étrangers}

Valeurs totales des chargements débarqués

\section{Valeurs}

65.000 .000

62.500 .000

60.000 .000

57.500 .060

55.000 .000

52.500 .000

50000.000

47.000 .000

45.000000

42.500 .000

40:000.000

37.500 .000

35.000 .000

32.500 .000

30.000 .000

27.500 .000

25.000 .000

22.500 .000

20.000 .000

17.500 .000

15.000000

12.500 .000

10.000 .000

7.500 .000

5.000 .000

Années

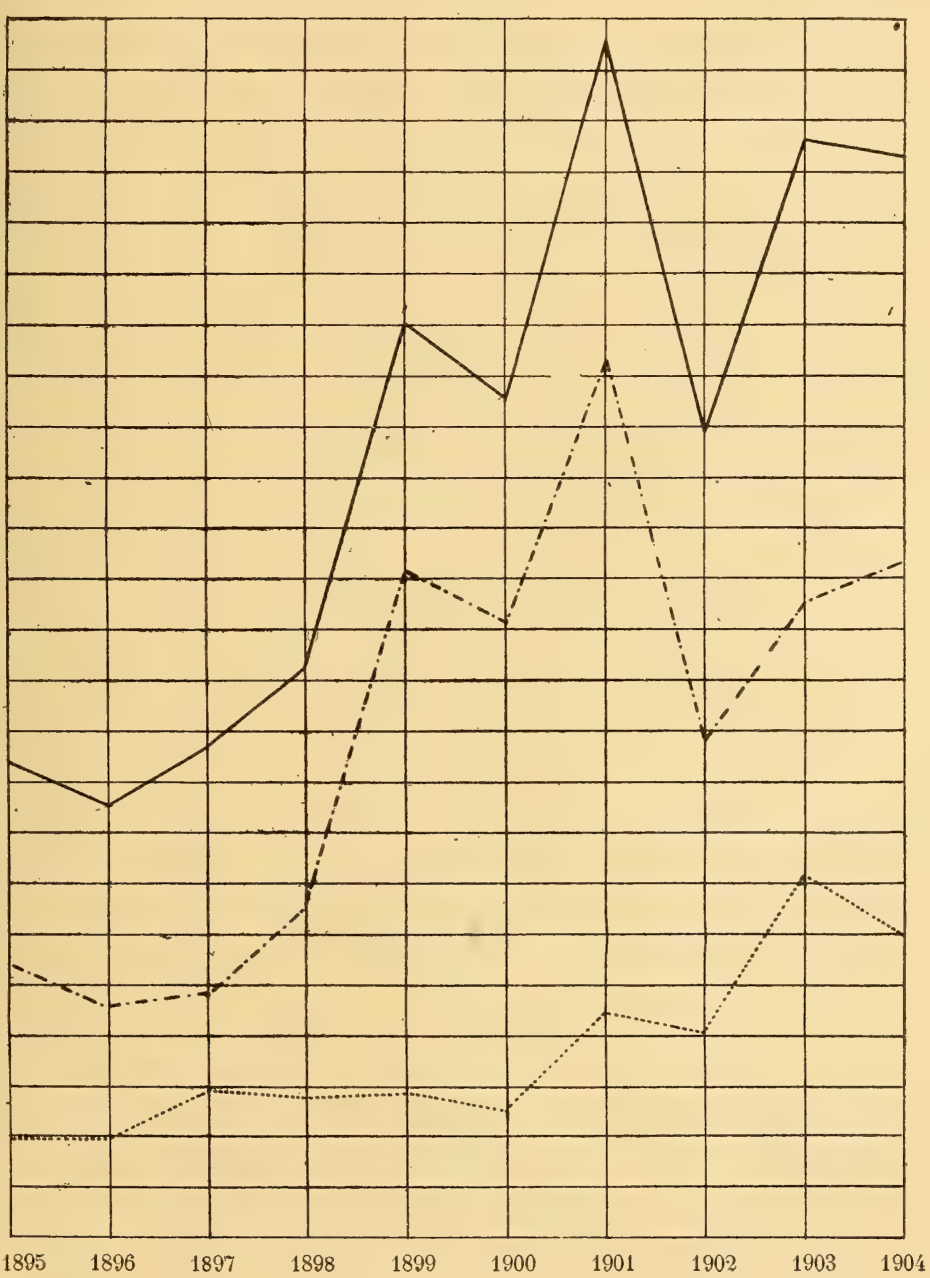


Pour compléter les renseignements ci-dessus, qui s'arrêtent à 1904, indiquons que le commerce si actif de 1905 que nous avons décrit, est, on peut le dire, presque entièrement effectué sous notre pavillon.

Dans le total de la navigation, le pavillon français tient toujours et de beaucoup la première place. Sur 329.000 tonnes embarquées ou débarquées à Dakar, 166.000 ont été transportées sous notre pavillon. Et ici encore - comme il a été fait pour l'examen du mouvement commercial - il faut tenir compte de ce fait que presque tout le charbon est forcément apporté par des navires étrangers, soit 70.000 tonnes. Si l'on fait abstraction de ce chiffre pour ne s'en tenir qu'aux marchandises la part du pavillon français est de $640 / 0$. Elle est comme on le voit beaucoup plus grande que dans la Métropole même où notre pavillon n'a représenté dans ces dernières années que $280 / 0$ du tonnage total. Une conclusion s'impose : Le port de Dakar est peut-être le port du monde où l'on voit le plus souvent flotter le pavillon francais.

Droits de navigation. - La navigation au Sénégal (navigation intérieure, cabotage intercolonial et grande navigation) est soumise à un certain nombre de droits dont il nous a paru intéressant de donner, ci-après, la nomenclature :

Droits de tonnage. - (Délibération du Conseil général du 28 juin, rendue exécutoire par arrêté du 20 novembre 1885 ).

Pour Saint-Louis, 2 fr. 50 par tonneau pour les chalands ou bâtiments pontés ; 1 fr. 23 pour ceux non pontés.

Pour le reste de la Colonie : 2 fr. 00 par tonneau pour les bàtiments de 10 tonnaux et au-dessous ; 1 fr. $2 \%$ par tomneau pour les bâtiments au-dessous de 10 tonneaux et jusqu'à 2 tonneaux. Battiments au-dessous de 2 tonneaux, exempts. Ce droit est annuel et payable d'avance. Il s'applique, dans toute la Colonie et dépendances, aux caboteurs immatriculés et aux navires étrangers faisant le cabotage.

Droits d'ancrage. - (Décrets des 10 juillet 1880 et 20 octobre 1885. Délibération du Conseil général du 8 janvier 1894) 50 centimes par tonneau pour les bàtiments français.

1 franc par tonneau pour les batiments étrangers (Ce droit est dû pour chaque voyage, par tous les navires de commerce, 
français ou étrangers, non inscrits comme caboteurs dans la Colonie).

Ce droit n'est payé qu'une seule fois par chaque voyage, quel que soit le nombre des escales du navire dans la Colonie et quoiqu ill ait touché dans des ports étrangers compris entre la Gambie et Sierra-Leone).

Les navires visés ci-dessous qui auraient payé le droit d'ancrage en Guinée française ne le paieront point une seconde fois au Sénégal et vice versa (Décision locale du 3 mars 1899).

Droits de francisation et de congé. - (Arrêtés des $\mathbf{2 2}$ janvier 1829, 30 juin 1833 et 22 février 18כ4).

Droits annuels de congé :

6 francs pour les bâtiments pontés ;

1 franc pour les bâtiments non pontés.

Francisation des bâtiments étrangers :

150 francs pour tout bàtiment étranger au-dessous de 30 tonneaux ;

5 francs par tonneaux de jauge pour les navires de 2 à 30 tonneaux.

Les bâtiments de 2 tonneaux et au-dessous sont exemptés.

Actes de francisation. - Les bàtiments de plus de 2 tonneaux jusqu'à 30 sont exemptés :

6 francs pour tout bâtiment de 31 à 100 tonneaux ;

18 francs pour tout bâiment de 101 à 200 tonneaux;

24 francs pour tout bâtiment de 201 a 300 tonneaux ;

Pour tout bàtiment de plus de 300 tonneaux, 6 francs en plus par 100 tonneaux.

Ces droits de francisation et de congé ne sont pas applicables aux embarcations faisant la navigation dans le fleuve Sénégal au-dessus de Saint-Louis (Arrêté du 30 novembre 1864).

Connaissements. -- Par décret du 28 mars 1899, les transports par mer pour le petit cabotage sont dispensés du timbre de connaissement.

III. Régime douanier. - Le régime douanier en vigueur au Sénégal résulte du décret du 14 avril 190 qui a fixé les droits à percevoir à l'entrée et à la sortie de l'Afrique occidentale. Ce 
décret maintient pour le Sénégal le régime différentiel appliqué depuis 1872. En voici les tarifs.

A. Tarif d'importation.

\begin{tabular}{|c|c|c|c|}
\hline \multirow{2}{*}{$\begin{array}{c}\text { Désignation } \\
\text { des } \\
\text { produits }\end{array}$} & \multirow{2}{*}{$\begin{array}{l}\text { Unités } \\
\text { sur } \\
\text { lesquelles } \\
\text { portent } \\
\text { les droits }\end{array}$} & $\begin{array}{c}\text { Situés en det } \\
\text { visés par } 1 \\
\text { du } 14\end{array}$ & $\begin{array}{l}\text { itoires } \\
\text { ors de la zône } \\
\text { convention } \\
\text { uin } 1898\end{array}$ \\
\hline & & $\begin{array}{c}\text { Droits } \\
\text { d'importation }\end{array}$ & \begin{tabular}{|ll} 
& Surtaxe \\
sur & les produits \\
étrangers
\end{tabular} \mid \\
\hline 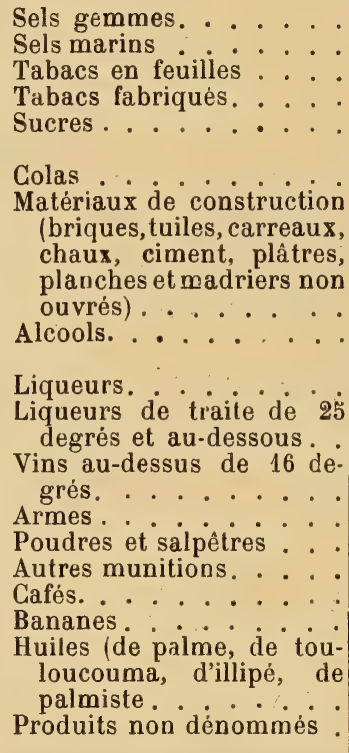 & $\begin{array}{l}\text { Hectolitre. } \\
\text { (Alcool pur) (2) } \\
\text { Hectolitı e. } \\
\text { Idem. } \\
\text { Idem. } \\
\text { Pièce. } \\
100 \mathrm{kilogr} . \\
\text { Idem. } \\
\text { Idem. } \\
\text { Idem. }\end{array}$ & $\begin{array}{c}5 \mathrm{p} .0 / 0 \\
160 » \\
11250 \\
60 " \\
\text { Régime de } \\
\text { l'alcool } \\
15 \mathrm{p} .0 / 0 \\
50 \% " \\
15 \mathrm{p} .0 / 0 \\
5 \mathrm{p} .0 / 0 \\
5 \mathrm{p} .0 / 0\end{array}$ & $\begin{array}{c}7 \mathrm{p} \cdot 0 / 0 \\
30, " \\
25 . \\
\\
15 \mathrm{p} .0 / 0 \\
\text { Régime de } \\
\text { l'alcool } \\
7 \mathrm{p} \cdot 0 / 0 \\
20.0 \\
7 \text { p. } 0 / 0 \\
7 \text { p. } 0 / 0 \\
7 \text { p. } 0 / 0\end{array}$ \\
\hline
\end{tabular}

Les droits ad valorem sont perçus d'après la valeur des produits au lieu d’importation. Cette valeur est déterminée par la mercuriale officielle, ou, à défaut, par le prix de facture augmenté de 25 p. 100.

Exemptions générales. - Sont exemptés de tous droits les produits suivants :

(1) Indépendamment des bases compensatrices applicables aux sucres originaires des pays qui accordent des primes à la production ou à l'exportation.

(2) Les-droits sur l'alcool vont être prochainement, en vertu de la Convention internationale de Bruxelles du 3 novembre 1906, portés au minimum de $200 \mathrm{fr}$. l'hectolitre d'alcool pur.

(3) V. plus loin au sujet des tissus dit « guinées » le décret du 10 mars 1906. 
Animaux vivants ;

Viandes fraîches ;

Poissons frais ;

Fruits frais;

Légumes frais ;

Pommes de terre;

Manioc et ignames;

Graines à ensemencer ;

Amandes de palme, sésame, piments frais et secs, riz en paille;

Machines et instruments agricoles ;

Houille ;

Livres ;

Instruments de précision ou scientifiques ;

Engrais ;

Armes, munitions, matériel de guerre et équipements militaires appartenant à l'Etat;

Vêtements d'uniforme et objets d'équipement des officiers et fonctionnaires ;

Effets des voyageurs lorsqu'ils portent des traces d'usage ;

Objets mobiliers portant des traces d'usage ;

Outils apportés par les ouvriers pour l'exercice de leur profession ;

Embarcations de tout tonnage ;

Caisses vides et futailles vides, montées ou démontées (1).

\section{B. - Tarif de sortie.}

Caoutchouc, 7 p. 100.

La valeur servant de base à cette perception est celle des produits au moment de l'exportation, valeur indiquée par la mercuriale officielle.

Première modification au décret du 14 avril 1906 en ce quı concerne le Sénégal.

Le régime des guinées. - Décret du 10 mars 1906.

La guinée est une variété de cotonnade teinte à l'indigo, dont

(1) Voir plus loin décret du 2 mai 1906. 
la fabrication longtemps localisée à Pondichéry ne date en Europe que d'une quarantaine d'années.

Les guinées de Pondicbéry furent introduites au Sénégal en 1742 par la Compagnie des Indes et elles y conquirent rapidement la faveur des indigènes et en particulier des Maures qui, en échange de leurs gommes, la préférèrent et l'exigèrent bientôt à l'exclusion de tout autre tissu. A dater de ce moment, la guinée remplit parmi ces populations l'office de monnaie d'échange et le rôle qu'elle joua ainsi dans le commerce de la gomme qui résuma longtemps tout le trafic du Sénégal, explique et justifie toute la faveur que sous des formes diverses : subventions, primes, détaxes, droits différentiels, la Métropole n'a cessé de témoigner à la fabrication de ces tissus.

Comme le montrent les chiffres suivants jusqu'en 1877 (1) l'industrie française, livrée à ses seules forces, se montra impuissante à lutter contre la concurrence étrangère.

\begin{tabular}{|c|c|c|c|c|}
\hline Années & & $\begin{array}{l}\text { Importations } \\
\text { de France }\end{array}$ & $\begin{array}{l}\text { Importations } \\
\text { des Colonies } \\
\text { françaises }\end{array}$ & $\begin{array}{l}\text { Importations } \\
\text { de l'Etranger }\end{array}$ \\
\hline - & & - & - & - \\
\hline 1866. & . . & . & 49.860 & 2.099 .780 \\
\hline 1867. & . . & ) & 43.350 & 2.807 .760 \\
\hline 1868. & . . & 92.030 & 18.115 & 2.587 .533 \\
\hline 1869. & . . & 3.592 & 65.671 & 3.151 .197 \\
\hline 1870. & .. & ) & 113.00马ٌ & 2.121 .960 \\
\hline 1871. & . . & ) & 43.259 & 2.373 .680 \\
\hline 1872. & . . & 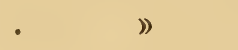 & 52.206 & 3.847 .260 \\
\hline 1873. & . . & $"$ & 15.081 & 1.853 .126 \\
\hline 1874. &.$\quad$. & $》$ & 41.378 & $805 ّ .731$ \\
\hline 1875. & .. & ") & 149.764 & 1.330.223 \\
\hline 1876. & $\cdot$. & ) & 178.356 & 2.680 .123 \\
\hline 1877. &.$\quad$. & 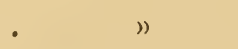 & 1.438 .374 & 2.071 .999 \\
\hline
\end{tabular}

C'est pourquoi le Grouvernement reconnaissant la nécessité de protéger les guinées nationales, établit, par un décret du

(1) De 1864 (Décret du 24 décembre) à 1877, les droits différentiels sur les marchandises étrangères furent abolis au Sénégal. 
19 juillet 1877, des droits protecteurs ( 0 fr. 08 de surtaxe par mètres sur les guinées d'origine étrangères).

Postérieurement deux décrets des $\mathbf{1 4}$ juin 1881 et 10 décembre 1890 ont maintenu les droits différentiels sur les tissus. D'après ces deux actes les guinées de toute provenance acquiltent au Sénégal un droit d'entrée de $0 \mathrm{fr}$. 025 par mètre, les guinées étrangères sont en outre frappées d'une surtaxe de 0,06 et paient donc 0,085 . Tous les tissus autres que les guinées sont soumis à leur importation au Sénégal à des taxes ad valorem ( $0 / 0$ pour les tissus de toute provenance avec surtaxe de $70 / 0$ pour ceux d'origine étrangère).

Or, le décret du 14 avril 1905 qui a fixé les droits à percevoir à l'entrée et à la sortie en Afrique occidentale, n'ayant pas fait une place particulière aux guinées, celles-ci tombent sous le régime commun des tissus, le décret de 190 ă ayant implicitement aboli - sans qu'il puisse y avoir un doute à cet égard - toutes dispositions antérieures contraires. Or les tissus rentrent, d'après la classification du décret, dans les produits non dénommés lesquels sont soumis à une taxe valorem de $50 / 0$ (avec une surtaxe de $70 / 0$ en ce qui concerne les tissus étrangers).

Ciette nouvelle taxation émut certaines Chambres de commerce qui faisaient remarquer — non raison d'ailleurs - que le nouveau régime diminuait la protection accordée aux guinées d'origine française de près de $500 / 0$.

En effet, sous le régime antérieur de droit spécifique de 0,06 par mètre, une pièce de guinée de 15 mètres acquirtait une surtaxe de . . . . . . . . . . . . . . . . . . 0,90

Avec le nouveau droit de 7 0/0, la même pièce de guinée mercurialisée à 7 francs paie une surtaxe de. $\frac{0,49}{0^{\mathrm{f}} 41}$

D'où un abaissement de protection de par pièce.

Il était à observer d'autre part que le régime institué par les décrets de 1881 et de 1890 avait permis à nos manufactures de l'Inde et de la Métropole de conserver sur le marché sénégalais une place prépondérante. Des statistiques officielles publiées par le Ministère des Colonies, il résulte que, en 1891 l'importation des guinées françaises originaires de l'Inde ou de la Métropole 
s'élevait à 2.102.293 francs tandis que les importations de guinées étrangères atteignaient $1.993,230$ francs, soit environ $450 / 0$ de l'ensemble. Sept années plus tard en 1898, cette proportion s'était modifiée à l'avantage de nos industries. Les importations de guinées françaises (489.602 pièces) arrivaient à $\mathbf{2 . 9 9 6 . 5 7 2 ~ f r . ~}$ contre 1.888.799 (251.840 pièces) pour les guinées étrangères, ces dernières ne représentaient plus que $3,650 / 0$ de l'importation totale. Enfin, les statistiques de 1903 accusent pour les guinées françaises $3.34^{n} .684$ francs contre 1.392 .183 francs pour celles originaires de l'étranger $(29,40 / 0)$. Ce qui revient, en résumé, à dire que, pendant la période qui s'étend de 1891 à 1903 , les importations de guinées françaises ont progressé de 1.200.000 francs tandis que les guinées étrangères diminuaient de 601.407 francs. L'écart entre les guinées françaises et les guinées étrangères qui était en 1891, de 109.000 est arrivé à 1.948.000 francs.

A cette thèse des industriels français, appuyée par des chiffres précis et qui tendait à démontrer la nécessité d'un régime spécialement protecteur en faveur des guinées introduites au Sénégal deux arguments principaux étaient opposés. Les guinées n'ont plus aujourd'hui et surtout - ce qui est incontestable n'auront plus dans un avenir prochain le rôle particulier qu'elles avaient autrefois, elles ne serviront bientôt plus de monnaie, car le commerce du troc ne tardera pas à disparaître complètement, si ce n'est même déjà un fait accompli.

D'autre part, et la Chambre de commerce de Saint-Louis insistait sur ce point, il est difficile de déterminer ce qu'on doit entendre par " guinée ". Il est impossible, ajoutait cette assemblée, de distinguer une guinée d'une autre cotonnade teinte en bleu indigo.

S’il est certain que les guinées sont appelées à diminuer d'importance au point de rue du troc, il n'en est pas moins exact cependant qu'actuellement encore leur commerce progresse : les importations de guinées entrent, dans l'introduction des tissus pour $68,70 / 0$ en $1899,770 / 0$ en 1903 , alors que les entrées de cotonnades autres sont restées presque stationnaires. Les tran- 
sactions auxquelles donnent lieu les guinées montent donc au Sénégal un régime spécial.

De plus, la Chambre de commerce de Saint-Louis commettait une erreur en avançant qu'aucun texte ne définissait ce qu'il fallait entendre par " guinées ". Le décret de 1877 nous parait en effet assez explicite sur ce point par la combinaison de ses deux premiers articles. "Seront seules considérées comme guinées de France ou de l'Inde Française les guinées portant les estampilles de la douane (a. 1). Ne seront admises à l'estampille que les guinées de France ou de l'Inde française ayant un poids déterminé et mesurant 16 mètres de longueur sur $0 \mathrm{~m}$. 8 de largeur. L'origine devra en être établie par une attestation du fabricant certifiée exacte en France par le maire de la commune et dans nos possessions de l'Inde par l'autorité locale » (a. 2).

Quoiqu'il en soit à la suite des réclamations pressantes de diverses Chambre du commerce et d'industriels français, le gouvernement général de l'Afrique occidentale française soumit, après avis du Conseil du gouvernement, au département des Colonies un projet de modification au décret du 14 avril 1905 ; projet qui, après examen du Conseil d'Etat, devint le décret du 10 mars $1906(1)$.

C'e décret se caractérise d'un mot: c'est le retour au statu quo ante (décrets des 14 juin 1881 et 2 décembre 1890), en ce qui concerne spécialement les guinées introduites dans la Colonie du Sénégal seulement. Les guinées sont à nouveau soumises au droit spécifique suivant : 0 fr. $020 ̈$ par mètre, avec surtaxe pour celle d'origine étrangère de 0 fr. 06 par mètre.

C'est par voie d'exception au tarif du décret du 14 avril 1905 que l'ancien régime a été de nouveau appliqué aux guinées importées au Sénégal.

On ne pouvait modifier le décret de 1905 indifféremment pour le Sénégal et pour la Guinée française. Dans cette dernière possession, il n'y avait en effet, aucun intérêt économique à changer la tarification ad valorem de 5 et $70 / 0$. Les imporiateurs avaient insisté pour qu'elle fut maintenue et les fabricants

(1) J. O. de la République française du 14 mars. 
ne demandaient aucune modification à cet égard. D'ailleurs, si la protection accordée à cette marchandise (surtaxe de $70 / 0$ sur les similaires étrangers avait été augmentée en Guinée française, il eut pu en résulter de graves inconvénients notamment le transfert du marché dans la Colonie anglaise voisine de SierraLeone.

Deuxième modification au décret du 14 avril 1905. Adjonction au tableau des exemptions générales à l'entrée et à la sortie. Décret du 2 mai 1906.

Le décret du 14 avril 1905 , avait compris parmi les exemptions les amandes de palme, le sésame, le riz en paille. Ces produits ne sont pas fréquemment importés dans nos Colonies qui les produisent elles-mêmes en abondance. Ils ne peuvent donc être utilisés pour la consommation et, d'autre part, il n'existe pas en Afrique occidentale française d'industries de transformation permettant de les mettre en œuvre. Ces importations, qui proviennent exclusivement des Colonies étrangères, sont destinées à être réexportées et elles n'empruntent les voies de nos possessions que pour bénéficier des facilités de réexpédition. Il s'agit donc en l'espèce d'un transitque, loin d'entraver, on doit chercher à encourager, puisqu il est susceptible de procurer à notre commerce maritime et à nos Colonies un supplément de trafic et d'activité.

Or, d'autres produits que ceux spécifiés au décret du 14 avril 1905 ont été récemment importés en Afrique occidentale française. C'est ainsi que des caoutchoucs bruts, de la gomme copal brute, des arachides, ont dû, en l'absence de disposition expresse du décret précité, acquitter des droits d'entrée.

C'est pour combler cette lacune qu'est intervenu après avis du Conseil d'Etat le décret du 2 mai 1906, spécifiant, en son article premier, que sont ajoutés à la liste des exemptions géné rales prévues au tarif d'importation du décret du 14 avril 190 Ð les produits suivants :

Caoutchoucs bruts; 
Gomme copal brute ;

Arachides.

Troisième modification au décret du 14 avril 1903 spéciale à la région de la Casamance. Décret du 31 janvier 1907.

Avant la promulgation du décret du 14 avril 1905, la Casamance était, pour des raisons diverses, l'objet d'un régime douanier particulier, consistant presque exclusivement en droits de sortie, alors qu’au Sénégal proprement dit les taxes établies étaient des droits à l'entrée.

Lorsqu'est intervenu ce décret qui, supprimant les tarifs spéciaux à chaque Colonie, a placé la Casamance dans une situation identique, au point de vue douanier à celle de nos autres établissements, on aurait pu penser que les deux colonies étrangères limitrophes : la Gambie anglaise et la Guinée portugaise établiraient des droits à l'entrée sinon identiques, du moins équivalents aux nôtres, ce qui aurait permis d'égaliser les conditions du commerce.

Il n'en a rien été, tout au moins en ce qui concerne la liuinée portugaise qui continue à appliquer des droits très inférieurs aux nôtres Cette situation a mis le commerce français dans une situation défavorable. En effet, les maisons nationales de la Casamance qui alimentaient la Guinée portugaise de divers articles ont été contraintes d'élever considérablement leurs prix de vente sur les articles qui autrefois entraient sinon en franchise tout au moins à un tarif peu élevé.

Cette considération majeure jointe à l'impossibilité d'établir pratiquement une surveillance douanière effective à la frontière et aux facilités particulières qu'offre la navigation du Rio Cacheo rendait nécessaire la réduction des tarifs de 1903 en ce qui concerne celle régie. Le décret du 31 janvier 1907 pris après avis du Conseil d'Etat spécifie par voie d'exception au tarif général qu'en Casamance les tabacs en feuilles acquittent seulement un droit de 00 francs, les colas étrangers 40 francs par 100 kilogs., les armes un droit de $50 / 0$ avec surtaxe de $70 / 0$ sur les armes étrangères, les poudres et salpêtres un droit de 20 francs les 
100 kilogs avec surtaxe de 10 francs et les autres munitions un droit de $50 / 0$ avec surtaxe de $\mathbf{7 0 / 0}$.

De cette façon nos commerçants pourront maintenir la situation qu'ils ont acquise en Casamance et lutter sur le pied d'égalité contre la concurrence étrangère.

\section{Chambres de Commerce.}

L'institution des chambres de commerce au Sénégal remonte à l'année 1820̈. Elle s'est manifestée à cette époque sous la forme d'un comité de commerce établi à Saint-Louis, par arrêté local du 7 novembre 1825 et se composant de cinq membres, un président et un vice-président. L'ordonnateur était de droit membre et président de l'assemblée. Le vice-président était choisi parmi les commissaires et nommé pour une année par le commandant et administrateur, sur une liste de trois candidats présentée par le comité. Parmi les autres membres, trois étaient pris parmi les négociants établis dans le pays et y faisant le commerce directement avec la France, au moins depuis cinq années ; deux parmi les traitants faisant le commerce de la rivière et des escales; enfin le septième membre parmi les capitaines de bâtiments armés au compte de négociants domiciliés en France.

La durée du mandal confié aux membres du comité était fixée à deux ans ; ils devaient être renouvelés par moitié chaque année.

Les attributions de ce comité étaient :

De donner son avis sur les questions qui lui seraient soumises par le commandant et administrateur ; de lui présenter des vues sur les moyens d'améliorer la situation du commerce ;

De déterminer le cours du change, des marchandises et denrées de toute espèce, des assurances, du fret ou nolis ;

De délivrer des parères sans que ce droit lui soit cependant attribué exclusivement;

De donner son avis sur les cas d'urgence ou sur les circonstances de force majeure où il deviendrait indispensable d'accor- 
der des permis de débarquement à la consommation pour des objets dont l'introduction n'est pas ordinairement permise ;

De surveiller l'exécution des travaux publics dont le commerce aurait fait les frais, en totalité ou en partie, et l'exécution des lois, ordonnances et arrêtris concernant la contrebande;

Enfin de tenir registre de tous les négociants ou marchands établis à Saint-Louis. A cet effet toutes personnes faisant des affaires commerciales devaient présenter leurs noms à cet enregistrement dans les six mois de leur résidence.

Le nombre des membres du comité fut porté de sept à douze par un arrêté du ら novembre 1827.

Un nouvel arrêté pris le 26 juin 1834 vint porter des modifications importantes dans l'organisation du comité de commerce. Le nombre des membres fut maintenu à 12 ainsi répartis : 4 négociants, 3 habitants notables faisant le commerce des escales, 3 marchands patentés, un capitaine au long cours et l'ordonnateur, président. Le comité, tel qu'il était alors constitué, fut dissous et l'on procéda à sa réorganisation, sur de nouvelles lois. La nomination des divers membres n'appartint plus au Gouvernement. Ils furent dorénavant élus par leurs classes respectives.

Le comité de commerce n'existait qu’à Saint-Louis. En 1834, sur une demande des commerasants de Gorée tendant à donner une certaine extension aux dispositions de l'art. 5 de l'arrêté du 19 novembre 1828, créant une commission des patentes dans cette île, le gouverneur de la colonie prit un arrêté le 15 septembre par lequel il supprimait la commission des patentes et établissait à Gorée une commission commerciale chargée de dresser les rôles des patentes et licences, conformément aux prescriptions de l'arrêté du 19 novembre 1828, et investie à peu de chose près des mêmes attributions que le comité de commerce du chef-lieu. Cette commission était composée du fonctionnaire chargé du service administratif, président; d'un négociant, de deux notables, de deux marchands et d'un capitaine au long cours, quand il s'en trouverait dans l'île. Comme pour l'assemblée de Saint-Louis, les membres étaient élus par leurs classes respectives: les négociants et les marchands par tous les négo- 
ciants et les marchands réunis, les notables par les notables de l'île.

Bientôt la nécessité se fit sentir de réunir en un seul corps les dispositions des divers arrêtés relatifs aux comités de commerce, d'en modifier quelques-unes et de les mettre en concordance avec la nouvelle organisation que l'ordonnance organique du 7 septembre venait de donner au gouvernement du Sénégal. Un arrêté du 27 décembre 1842 rapporta ceux des 7 novembre 1825, 5 octobre 1827, 26 juin et 5 septembre 1834 en condensant dans son corps leurs dispositions diverses. Certaines attributions précédemment dévolues à ces assemblées furent supprimées et conférées par la nouvelle législation au conseil général et au conseil d'arrondissement. La composition des assemblées reçut une légère modification : le capitaine au long cours compris dans la formation de la commission commerciale de Gorée fut supprimé, et celui qui entrait dans celle du comité de Saint-Louis remplacé par un subrécargue ou un capitaine des bâtiments armés au compte de négociants, domiciliés en France.

En 1854, le 7 août, un nouvel arrêté vint augmenter le comité de deux membres, l'un négociant, l'autre traitant; cet acte fixait en outre les conditions imposées aux traitants pour être admis à participer à l'élection des membres choisis dans leur classe, en même temps qu'il disposait que quatre membres choisis par le comité seraient appelés à émettre leur opinion devant le conseil d'administration de la colonie, sur toutes les questions qui lui seraient soumises par le comité de commerce. Trois mois après, le comité de commerce de Saint-Louis fut dissous par l'arrêté du 24 novembre 1854. La commission commerciale de Gorée, quoique continuant à subsister, cessa de fonctionner peu de temps après:

Les choses en demeurèrent là jusqu'en 1869, époque à laquelle on procéda à la reconstitution de ces assemblées, que l'on remplaça par des chambres de commerce, établies à Saint-Louis et à Gorée, et composées de sejt membres. L'arrêté du 29 décembre 1869, constitutif de ces assemblées, indique le mode d'élection des membres et la durée de leur mandat qui fut fixé à trois ans. Les chambres de commerce eurent la faculté de choisir dans 
leur sein leurs présidents et vice-présidents. Leurs attributions étaient purement facultatives. En 1877, un arrêté du 30 avril apporta quelques changements aux dispositions du texte constitutif de 1869 en ce qui concerne l'éligibilité des membres et le mode d'élection. Un autre arrêté du 31 mai 1878 porta à neuf le nombre des membres des chambres de commerce.

Rufisque, primitivement village sans importance, avait vu quelques commerçants s'établir sur sa plage et y ouvrir un commerce qui n'avait pas tardé à prendre de l'extension et qui nécessita, le 9 janvier 1883, l'institution d'une chambre de commerce à laquelle on rendait applicables les dispositions des arrêtés précités de 1869, 1877 et 1878.

Le décret du 17 juin 1887, promulgué dans la colonie le 17 octobre 1887, ayant érigé les sections de Gorée et de Dakar en deux communes distinctes, il fallut doter la nouvelle commune de Dakar d'une chambre de commerce. L'arrêté du 14 décembre 1887 porta institution de quatre chambres de commerce dans la colonie : à Saint-Louis, Dakar, Rufisque et Gorée. Ce texte ne fut qu'une refonte des dispositions des précédents arrêtés sur la matière; quelques-unes furent cependant modifiées ou complétées; le nombre des membres fut maintenu à neuf et la durée de leur mandat à 3 ans.

Enfin, l'arrêté actuellement en vigueur du 29 janvier 1892, modifié dans certaines de ses dispositions par celui du 27 février 1899, a donné aux chambres de commerce la constitution qu'elles ont aujourd'hui. Ce texte fixe à neuf le nombre des membres pour les chambres de Saint-Louis et de Rufisque, à sept pour celle de Dakar et à cinq pour celle de Gorée. Il a rendu applicables en partie à leur élection les principes en vigueur dans la métropole.

Tous les négociants et commerçants patentés, domiciliés dans la colonie, tous les fondés de pouvoirs généraux des maisons de commerce établies dans la colonie et dont les pouvoirs auront été déposés au greffe, sont inscrits sur la liste électorale, ainsi que les anciens membres de la chambre de commerce, les administrateurs des compagnies anonymes de commerce, de finance et d'industrie, les agents de change, les capitaines au 
long cours et les maitres de cabotag'e, ayant commandé des bâtiments pendant $\breve{b}$ ans et domiciliés depuis 2 ans dans le ressort de la chambre, et les traitants exercant pour leur compte le

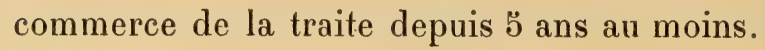

Les attributions des chambres de commerce continuent à être purement facultatives; elles présentent leurs vues sur les moyens d'accroître la prospérité de l'industrie et du commerce, sur les améliorations à introduire dans toutes les branches de la législation commerciale, sur l'exécution des travaux et l'organisation des services publics qui peuvent intéresser le commerce et l'industrie. Elles donnent, d'une façon générale, à l'administration les avis et les renseignements que celle-ci leur demande, notamment sur les créations de bourses et de charges d'ag'ent de change ou de courtiers, sur les tarifs et règlements des services de transport et autres établis à l'usage du commerce, sur les usages commerciaux, les tarifs et règlements de courtage maritime et de courtage en matière d'assurance de marchandises ou denrées, sur la création des tribunaux de commerce, sur les établissements de banque et autres institutions de crédit public, sur les projets de travaux publics locaux relatifs au commerce et à la navigation, sur les projets de règlement locaux concernant le commerce et l'industrie.

Les chambres de commerce ont en outre l'administration des établissements créés pour l'usage du commerce, comme les magasins de sauvetage, entrepôts, cours publics pour la propagation des connaissances commerciales et industrielles, si ces établissements ont été formés au moyen de contributions spéciales sur les commerçants.

Les chambres de commerce ont à leur disposition un budget spécial, alimenté soit au moyen de subvention fournie par le budget local, soit au moyen d'une contribution sur les patentes de leur circonscription. Cette contribution, qui ne doit pas dépasser le maximum de cinq centimes par franc, est votée annuellement par chacune des chumbres et autorisée par le conseil général. 


\section{Consulats.}

L'importance des échanges commerciaux qui s'effectuent au Sénégal et le nombre d'étrangers qui l'habitent ont amené diverses puissances étrangères à installer des agences consulaires dans notre colonie.

A Dakar, l'Angleterre possède un consulat général avec juridiction sur toutes nos possessions de la Côte occidentale d'Afrique, et un vice-consulat; la Norvège et le Portugal un consulat; la République Argentine et l'Urugay un vice-consulat. A Rufisque, l'Allemagne et l'Italie sont représentées par un consul et à Gorée, les Etats-Unis ont également installé une agence consulaire. 



\section{CONCLUSION}

La colonie du Sénégal, à laquelle nous sommes attachés, non seulement par le souvenir d'une conquête ancienne et glorieuse, mais encore par le lien d'intérêt qui unit toujours à la Métropole une colonie prospère, nous apparait ainsi parmi nos diverses possessions comme une de celles dont nous pouvons être le plus justement fiers.

Sans doute, dans l'organisation actuelle diverses réformes sont à apporter : l'unité administrative et financière, en premier lieu, lorsqu'elle sera un fait accompli, permettra la réalisation d'économies considérables par la fusion de nombreux services et facilitera singulièrement la tàche de l'organe de direction.

Malgré les efforts entrepris et que l'on a pu apprécier, il reste encore beaucoup à faire au point de vue de l'amélioration de la santé publique et en ce qui concerne la diffusion de l'enseignement parmi des populations dont beaucoup sont intelligentes et travailleuses.

Les indigènes ont compris toutes les ressources qu'ils pouvaient retirer de l'agriculture, mais d'immenses terres sont encore à cultiver et à féconder. Le mouvement commercial qui s'est accru d'une façon saisissante dans ces dernières années, ne peut manquer de se développer encore grâce à l'exécution d'un judicieux programme de travaux publics qui facilitera l'accès des ports et la navigation du fleuve. En outre, la construction du chemin de fer de Thiès à Kayes, devant faire de la colonie la voie naturelle de transit entre l'Océan et le centre africain, lui donnera une situation tout à fait privilégiée.

Un large champ est, en définitive, ouvert à toutes les activités, à tous les efforts, et si le passé du Sénégal peut être considéré avec une légitime fierté, l'avenir, de son côté, peut être envisagé avec infiniment d'espoir. 



\title{
TABLE DES MATIËRES
}

\author{
PREMIÉRE PARTIE
}

L'expansion coloniale française au Sénégal.

\section{CHAPITRE PREMIER}

LA PRISE de possession et L'OCCUPATION COTIÈRE

(1626-1848)

Premières expéditions au Sénégal, p. 3 ; Les Compagnies de commerce, p. 4 . . . . . . . . . . . . . .

La situation en 1814. Le colonel Smaltz, p. つ; Traité de Nguio (8 mai 1819), p. 8 ; Traités avec les chefs Maures, p. 11 ; Nouveau traité avec les Maures, p. 14 ; Ordonnance du 7 septembre 1840, p. 16 ; L'expansion en Casamance, p. 18 .

\section{CHAPITRE II}

LA FORMATION TERRTORIALE DU SÉNÉGAL

Faidherbe, p. 20 ; Guerre avec les Maures, p. 22 ; Traité avec les Braknas, p. 24 ; Guerre avec El Hadj Omar, p. 27 ; L'expansion française de 1862 à 1869 : le Toro, p. 28; Le Cayar, p. 28 ; Baol, Sine et province Sérère, p. 31 . .

\section{CHAPITRE III}

L'GUVRE DIPLOMATIQUE AU SÉNÉGAL

A. Délimitation franco-anglaise : La Gambie. La Convention du 27 mars 1857, p. 33 ; L'arrangement de 1889 , p. 34 ; L'accord du 8 avril 1904 , p. 35 . 
B. Arrangement franco-portugais: L'accord du 12 mai 1886 , p. 36 ; Mission Brosselard-Faidherbe 1888, p. 37; Les missions Payn, p. 37 ; Les missions Marchand, 1903-1906, p. 38

36 à 38

\section{DEUXIEME PARTIE}

\section{Les conditions de la vie sociale au Sénégal}

\section{CHAPITRE IV}

LE PAYS ET LES GRANDES RÉGIONS NATURELLES

A. Apercu géologique, p. 48 . . . . . . . . .

B. Les grandes régions naturelles, p. כొ0 ; Relief du sol : la côte subsaharienne, p. 50 ; Le Cayor et le Baol, p. 51 ; Région des Niayes, p. 53 ; La côte soudanienne, p. つ̋.

C. Hydrographie : Le Sénégal, p. 54; Les lacs et marigots, p. 5 ; Les rivières du Sud, p. 58 ; Le Saloum, p. 59 ; La Gambie, p. 59 ; La Casamance, p. 59

54 à 59

\section{CHAPITRE $\mathrm{V}$}

LES CONDITIONS DE LA VIE SOCIALE AU SÉNÉgal (Climat, FLORE, FAUNe)

A. Le Climat, p. 61

B. La Flore, p. 62 ; Les régions botaniques, p. 67 ; Principales espèces. p. 69 : a) Plantes fournissant des produits industriels, p. 69 ; b) Plantes alimentaires, p. 70 ; c) Plantes

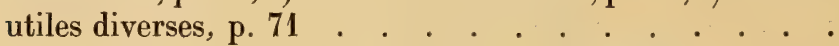

C. La Faune, p. 72 : a) Animaux domestiques, p. 73 ; b) Animaux sauvages, p. 74; Oiseaux, p. 76 ; Reptiles, p. 76 ; Poissons, p. 77 ; Invertébrés, p. 79 . . . . .

D. Produits du sous-sol, p. 83 . . . . . . . . .

\section{CHAPITRE VI}

LES POPULATIONS DU SÉNÉGaL

I. La population du Sénégal, p. 86 ; Répartition géographique des races, p. 87 ; Les Maures, p. 90 ; Les Peuhls, p. 91 ; Les Laobés, p. 91 ; Les Toucouleurs, p. 92 ; Les Mandingues, p. 92 ; Les Bambaras, p. 93 ; Les Sarakolés et les Khassonkés, p. 93 ; Les Ouolofs, p. 94 ; Les Sérères, p. 95 ; Les Diolas et les Balantes, p. 96 . . . . . . 
II. Progrès des indigènes : Influence de la colonisation française, p. 100 ; a) L'enseignement, p. 101 ; b) Progrès intellectuels, p. $104 ; c)$ Progrès matériels, p. 105 ; Habitation, p. 105; Vêtement, p. 106 ; Nourriture, p. 108 ; Hygiène, santé, p. $109 ; d)$ Progrès des exploitations indigènes, p. 110 ; Les industries indigènes, p. 111 .

\section{TROISIEME PARTIE}

\section{L'organisation de la colonie du Sénégal}

\section{CHAPITRE VII}

\section{ORgANisation POLITIQUE ET ADMINISTRATIVE}

I. Organisation politique, p. 121 ; Régime électoral, p. 121 ; a) Représentation au Parlement, p. 122 ; $b$ ) Conseil général, p. 122 ; Commission coloniale, p. 124; c) Organisation municipale : Communes de plein exercice, p. 12כ; Communes mixtes, p. 127 . . . . . . . . .

II. Organisation administrative. p. 131 ; Administration centrale de la colonie : Le Lieutenant-Gouverneur, p. 132; Le Conseil privé, p. 134; Le Conseil d'administration, p. 135 ; Le Conseil du contentieux administratif, p. 135 ; Le Secrétariat général, p. 135; Services divers, p. 136 ; Délégation du Gouvernement du Sénégal à Dakar, p. 136 ; Chefs d'administration et de service, p. 137 ; Organisation de l'administration régionale, p. 137 : Personnel de l'administration régionale, p. 137 ; Attributions des administrateurs, p. 138; L’indigénat, p. 138

\section{CHAPITRE VIII}

\section{ORGANISATION FINANCIÈRE}

I. Budgets. A. Le hudget colonial, p. 140; B. Le budget local, p. 141 ; Etablissement des budgets : a) Territoires d'administration directe, p. $141 ; b)$ Pays de Protectorat, p. 144 .

Examen des budgets : Section des dépenses : a) Territoires d'administration directe, p. 144 ; b) Pays de protectorat, p 147; Section des recettes : a) Territoires d'administration directe, p. 148 ; Pays de protectorat, p. 148 . . . . . . . . .

Les ressources et les impôts, p. 149; A. Territoires d'administration directe, p. $149: a$ ) Contributions 
directes et sur rôles, p. $150 ; b)$ Contributions indirectes et divers produits, p. 153. B. Pays de protectorat : a) Contributions directes et sur rôles, p. 159 ; b) Divers produits, p. 164 . . . . . . . . .

La situation financière et la caisse de réserve, p. 165

II. Services financiers, p. 166 ; Service de la trésorerie, p. 166 ; Contributions directes, p. 168 ; Enregistrement, timbre, domaines, p. 168.

166 à 168

\section{CHAPITRE IX}

\section{ORGANISATION JUDIGIAIRE}

I. Régime légal : La loi trançaise et la loi indigène, p. 169.

Origine de la législation au Sénégal, p. 169 ; La légis-

lation française au Sénégal, p. 169 ; Promulgation des lois et décrets, p. 170 ; Loi française et loi indigène, p. 171

II. Organisation judiciaire : Historique, p. 172 ; Organisation de la justice française et de la justice indigène, p. 175 ; A. La justice française, p. 176. B. La justice indigène, p. 182. G. La juridiction administrative, p. 183; Les auxiliaires de la justice, p. 183

172 à 183

\section{CHAPITRE $\mathbf{X}$}

\section{ORGANISATION MILITAIRE}

L'organisation militaire, p. 186 ; Recrutement, p. 187 ; Groupement des troupes, p. 187 ; Commandement, p. 188 ; Réserves, p. 189 ; Gaums, p 191 ; Composition des troupes au Sénégal, p. 192 . . . . . . . . . . . . .

Les dépenses militaires, p. 193 ; Administration des crédits militaires, p. 193 ; Affectation des crédits militaires, p. 194. Dakar point d'appui de la flotte, p. 195 . . . . . .

186 à 192

193 à 194

195

\section{CHAPITRE XI}

\section{ORGANISATION DES DIVERS SERVICES}

A. Service de la santé, p. 200; OEuvre sanitaire, p. 201; Comité supérieur d'hygiène et de salubrité publique, p. 203 ; Services municipaux d'hygiène, p. 204; Service d'assistance médicale indigène, p. 20 o ; Aides-médecins indigènes, p. 207 ; Etablissements hospitaliers, p. 211. 
B. Service des Travaux publics, p. $213: a$ ) Territoires d'administration directe, p. $214 ; b$ ) Pays de protectorat, p. 216 .

C. Service des Postes et Télégraphes, p. 217 ; Personnel du service des Postes et Télégraphes, p. 217

D. Imprimerie Officielle, p. 218 ; Personnel de l'imprimerie, p. 218 ; Publications officielles, p. 219.

E. Police et prisons, p. 219 ; Police, p. 219 ; Prisons, p. 220.

F. Services divers, p. $221: a)$ Service de l'enregistrement, des domaines, etc., p. 221 ; b) Service des contributions directes, p. 222 ; c) Service de l'agriculture, p. 222

G. Instruction publique, p. 223

H. Cultes, p. 224 .

\title{
QUATRIEME PARTIE
}

\section{La mise en valeur du Sénégal}

\author{
CHAPITRE XII \\ CONDITIONS DE LA PRODUCTION ET DU COMMERCE
}

A. Le régime des terres, p. $221: a)$ Du domaine : Domaine public, p. 231 ; Domaine privé, p. 234 ; Régime des concessions de terres, p. 234; Représentation en justice, p. 235 ; $b$ ) Régime des biens fonds : décret du 24 juillet 1906 , p. 236 ; c) Régime forestier, p. 244 ; Bois domaniaux, p. 244; Bois particuliers, p. 246 ; Revenus des droits des indigènes, p. 247 . . . . . . . . . .

B. Le régime de la main-d'œuvre et la population, p. 247 ; La main-d'œuvre locale, p. 248 ; Emigration, p. 248 ; Décrets des 17 juin 1895 et 12 janvier 1897 , p. 250 .

247 à 250

La population : recensement de 1904, p. 252 ; Progrès du peuplement français et européen au Sénégal, p. 255

221 à 247

218 à 219

219 à 220

221 à 222

223

224

C. Le crédit, p. 263 ; La monnaie, p. 263 ; La Banque de l'Afrique occidentale, p. 263.

\section{CHAPITRE XIII}

OUTILLAGE ÉCONOMIQUE

A. Voies fluviales et aménagement des ports. - Mission hydrographique du Sénégal, p. 283 ; Mission topographique, p. 285 ; Port de Saint-Louis, p. 285 ; Port de Dakar, 
p. 288 ; Mouvement du port de Dakar, p. 296; Port de Rufisque, p. 297 ; Utilisation du Sénégal, p. 297 ; Tarifs commerciaux entre Saint-Louis et Kayes, p. 297 . . . .

B. Chemins de fer : a) Chemin de fer de Dakar à SaintLouis, p. 298 ; - Historique de la construction, p. 298 ; Etat actuel de la ligne, p. 300 ; Exploitation technique et commerciale, p. 301 ; Tarifs, p. 302 ; Tableaux divers, p. 307 ; b) Chemin de fer de Thiès à Kayes, p. 318 . .

C. Travaux divers : a) Eclairage des côtes et rades, p. 323 ; b) Travaux d'assainissement : Assainissement de SaintLouis, p. 324 ; Assainissement de Dakar, p. 325 ; Assainissement de Rufisque, p. 325 ; $c$ ) Travaux divers : Pont Faidherbe, p. 326 ; Pont de Guet N'Dar, p. 328 ; $d$; Travaux projetés, p. 329 . . . . . . . . . . . .

D. Les communications postales et télégraphiques. Service postal maritime. p 330 ; Service postal intérieur, p. 330 ; Courriers piétons, p. 331 ; Services électriques, p. 334 ; Câbles sous-marins, p. 334

\section{CHAPITRE XIV}

\section{LES RÉSULTATS ÉCONOMIQUES}

A. Agriculture : Le mil, p. 336 ; L'arachide, p. 336 ; Le riz, p. 339 ; Le cotonnier, p. 342 ; Gomme, p. 344 ; Caoutchouc, p. 344 ; Huile de palme et palmiste, p. 344 ; Cocos coprah, p. 344 ; Huile, p. 344 ; Tannin,p. 345 ; Teintures, p. 345 ; Textiles, p. 345; Animaux domestiques, p. 345. . . .

B. L'industrie : Briques indigènes, p. 349 ; Pêcheries, p. 349 ; a) Pêche maritime, p. 349 ; Pêche fluviale, p. 351 ; Mines, p. 352 ; Circulaire du 1 er avril 1902, p. 356 ; Considérations générales, p. 356 ; Droit de priorité. Cas d'envoi par la poste, p. 359 ; Permis d'exploration, p. 359 ; Droit de priorité au sujet des permis de recherche et d'exploitation,

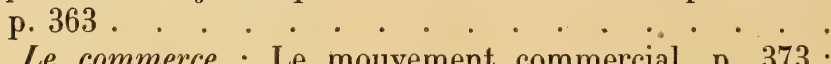

C. Le commerce : Le mouvement commercial, p. 373 ; Importations, p. 375 ; Exportations, p. 377 ; Commerce avec la France, p. 378 ; a) Principaux articles d'importation : Conserves de viandes de toutes sortes, p. 379 ; Farines, p. 379 ; Biscuits, p 380 ; Riz, p. 380 ; Noix de kola, p. 381 ; Sucres de toutes sortes, p. 381 ; Tabacs en feuilles, p. 381 ; Huiles comestibles de toutes sortes, p. 382 ; Bois de construction, p. 382 ; Vins de toutes sortes, p. 383 ; Boissons distillées, p. 383 ; Matériaux de construction, p. 384 ; Houille, p. 387 ; Fers de toutes sortes, p. 387 ; Sels marins, p 388 ; Parfumeries, p. 388 ; Savons, p. 388 ; 
Verroterie (grains), p. 388 ; Fils de coton, p. 389 ; Guinées, p. 389 ; Autres tissus de coton, p. 389 ; Vêtements et confections, p 391 ; Machines de toutes sortes. p. 391 ; Ouvrages en fonte et fer, p 392 ; Armes de toutes sortes, p. 392 ; Poudres à tirer, p. 392 ; Ouvrages en bois et Bimbeloterie, p. 392 ; b) Principaux produits d'exportation : Peaux brutes de bœufs, p. 393 ; Peaux d'oiseaux et plumes de parures, p. 394 ; Arachides, p. 394 ; Amandes de palme, p 395; Gommes, p. 395 ; Caoutchoucs, p. 395 ; Or de Galam, p. 396 ; Les centres commerciaux du Sénégal : Gorée, p. 434; Rufisque et voie ferrée, p. 43 ; Sine-Saloum, p. 438; Casamance, p. 439 ; Dakar, p. 442 ; Saint-Louis-le-Soudan, p. 444. Trafic avec la France et l'étranger, p. 446 ; Navigation, p. 447; Droits de navigation, p. 458; Droits de tonnage, p. 458; Droits d'ancrage, p. 458 ; Droits de francisation et de congé, p. 459; Actes de francisation, p. 459 ; Connaissements, p. 459; Exemptions générales, p. 460 ; Le régime des guinées, p. 461 ; Chambres de Commerce, p. 468; Consulats, p. 473 




\section{96 SI BR}


(3)

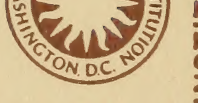

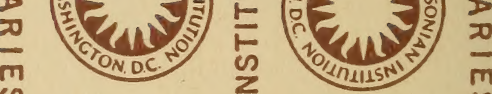

NIAN INSTITUTION NOIINIILSNI NHINOSHLIWS S SIYHYGI7 LIBRARIES
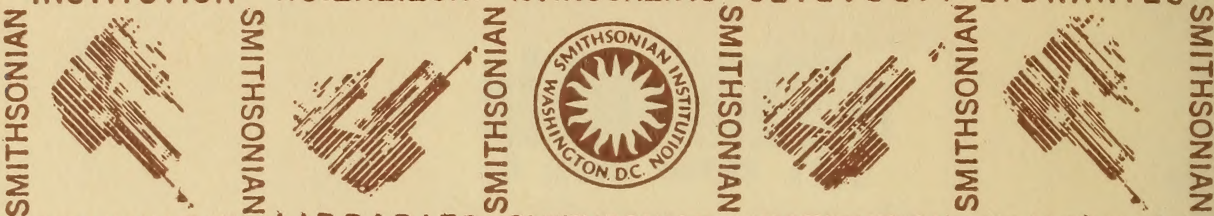

LIWS S3IV甘Y817 LIBRARIES SMITHSONIAN
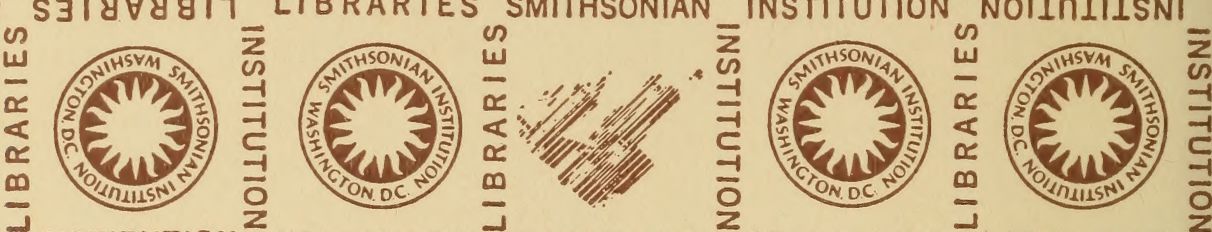

NIAN ${ }^{-1 N S T I T U T I O N}$
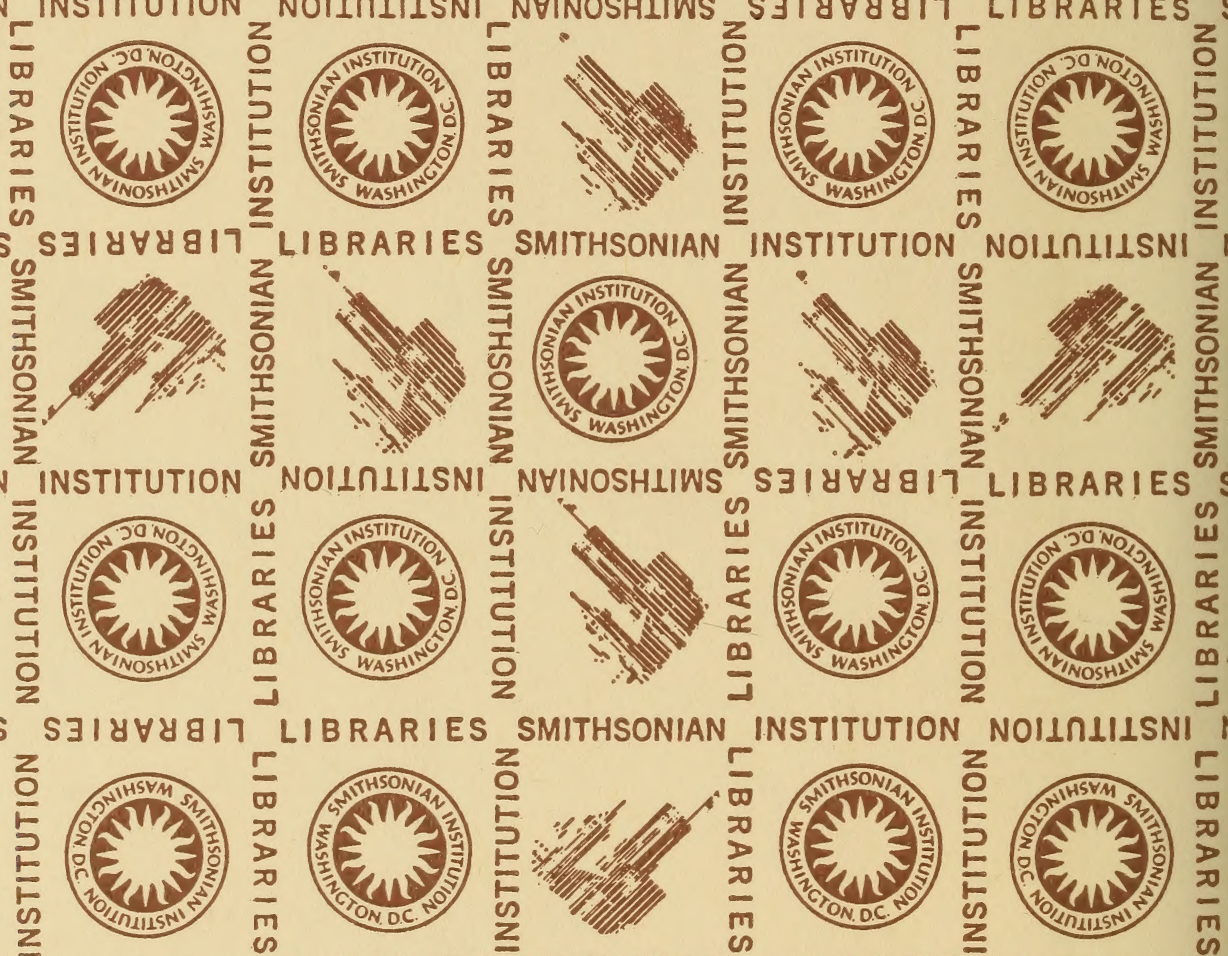

NIAN INSTITUTION
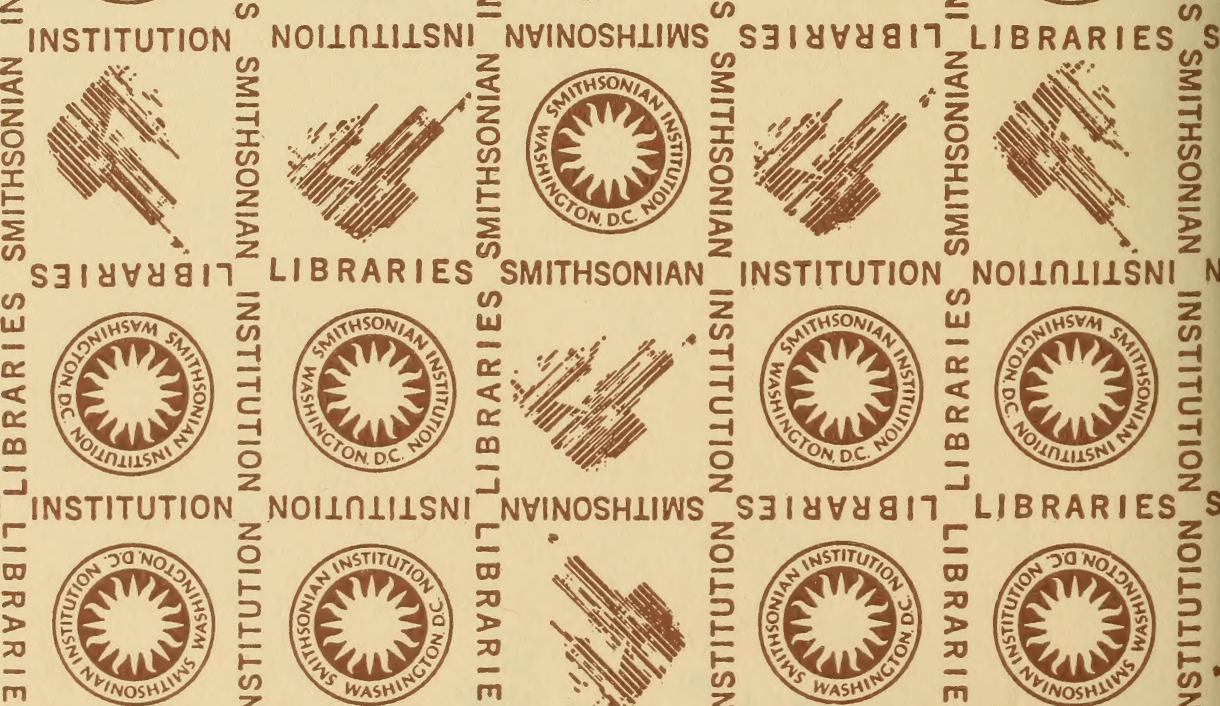
